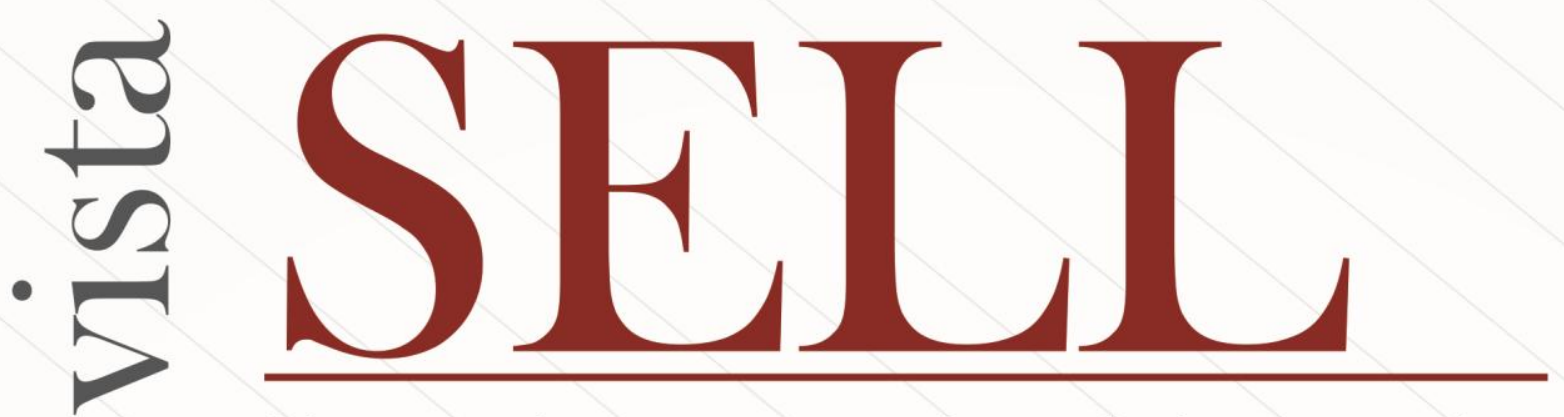

(4) Simpósio Internacional de Estudos Linguísticos e Literários da UFTM
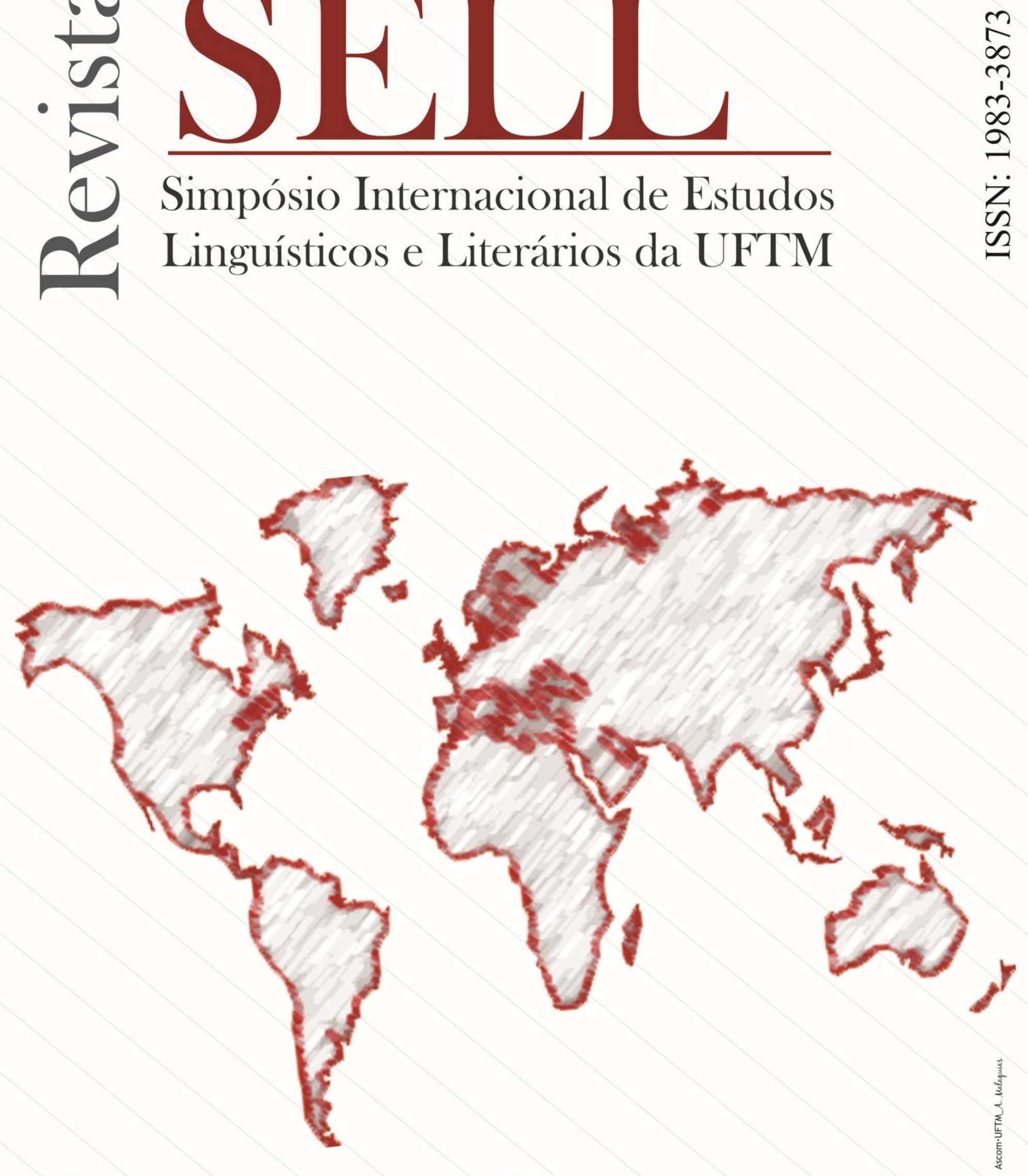

\title{
Línguas Estrangeiras e outras áreas
}




\section{SUMÁRIO}

APRESENTAÇÃO

.5

"FAMÍLIA RESTART": ANÁLISE DO DISCURSO MULTIMODAL DO MYSPACE OFICIAL DA BANDA

Ana Amélia Calazans da Rosa

OS PROCESSOS DE INTERPRETAÇÃO, ANÁLISE E COMPREENSÃO DE GÊNEROS TEXTUAIS POR ALUNOS COM DEFICIÊNCIA VISUAL: UMA REFLEXÃO EM SERVIÇO Ana Maria Pereira Dionísio

ENSINO DE LÍNGUA MEDIADO POR COMPUTADOR: DA EDUCAÇÃO INFANTIL AO ENSINO MÉDIO

Andréa C. Centeno Rodrigues da Cunha; Cláudia Almeida Rodrigues Murta 33

A IDENTIFICAÇÃO DE TÓPICOS NA CONVERSA CASUAL: UM ESTUDO BASEADO EM CORPORA SOBRE O DISCURSO NA MÍDIA

Barbara Malveira Orfano. 4

A RELEVÂNCIA DO RECURSO PEDAGÓGICO: MÚSICA NO ENSINO E APRENDIZAGEM DA LÍNGUA INGLESA

Domingos Caxingue Gonga 61

PERSPECTIVAS EDUCACIONAIS DAS TECNOLOGIAS EM CURSO ON-LINE E AS ABORDAGENS TEÓRICAS DO ENSINO A DISTÂNCIA: LINGUAGENS E ENSINO Eliamar Godoi .72

APRESENTAÇÃO ORAL NAS AULAS DE LÍNGUA ESPANHOLA - DESEMPENHO LINGUÍSTICO, FATORES AFETIVOS E AVALIAÇÃO DA ATIVIDADE

Elizandra Zeulli .92

EDMODO: INTEGRANDO O ESPAÇO CIBERNÉTICO À SALA DE AULA DE INGLÊS Estela Rodrigues do Vale 
ENSINO DE GÊNEROS TEXTUAIS NA UNIVERSIDADE: EXERCITANDO AS PRÁTICAS DISCURSIVAS DAS PROFISSÕES

Francisca da Rocha Barros Batista

O HUMOR NO CONTEXTO PEDAGÓGICO DE LÍNGUA ESTRANGEIRA: UMA ANÁLISE DISCURSIVA MODO DE ABORDAGEM DA COMICIDADE

Ilka de Oliveira Mota.... 134

PROJETO TELETANDEM BRASIL, AS COMUNIDADES VIRTUAIS, AS COMUNIDADES DISCURSIVAS E AS COMUNIDADES DE PRÁTICA: A CARACTERIZAÇÃO DOS INSTRUMENTOS DE PESQUISA

Jaqueline Moraes da Silva

VOZES ADVINDAS DO VALE: EXPERIÊNCIA TRANSDISCIPLINAR DE UMA PROFESSORA DE INGLÊS NO VALE DO JEQUITINHONHA

Kátia Honório do Nascimento 169

NOVAS TECNOLOGIAS E ENSINO DE LÍNGUAS: RELAÇÕES ENTRE O "DIZER" E O "FAZER" DE DOCUMENTOS GOVERNAMENTAIS DE REFERÊNCIA PARA O ENSINO DE LÍNGUAS

Lara Brenda campos Teixeira Kuhn 188

A RECONTEXTUALIZAÇÃO, A MULTIMODALIDADE E O HIBRIDISMO NA ABORDAGEM DOS GÊNEROS DO HUMOR Maria Aparecida Resende Ottoni 196

O PROCESSO TRADUTÓRIO NA PERSPECTIVA DA RETEXTUALIZAÇÃO E SUA ABORDAGEM NO ENSINO DE INGLÊS COMO LÍNGUA ESTRANGEIRA.

Mayelli Caldas de Castro 209

SISTEMA DE GÊNEROS EM INTERAÇÕES MEDIADAS POR COMPUTADOR Nathasa Rodrigues Pimentel .227 
CONHECIMENTO PRÉVIO, LEITURA E METACOGNIÇÃO: UM ESTUDO COMPARATIVO DE LIVROS DIDÁTICOS DE HISTÓRIA DO ENSINO MÉDIO

Patricia Ferreira Botelho 243

DIREITOS HUMANOS E AS SIGNIFICAÇÕES SOBRE A NOÇÃO DE DIREITO EM UMA COMUNIDADE DO ORKUT

Rafaella Elisa da Silva Santos

A CONSTITUIÇÃO DE SUJEITOS E SENTIDOS EM CONTEXTOS DE ENSINOAPRENDIZAGEM DE LÍNGUA INGLESA E SEUS REFLEXOS NA PROFISSIONALIZAÇÃO

Relma Lúcia Passos de Castro Mudo. .271

O PAPEL DO CURRÍCULO DO CURSO DE FORMAÇÃO DE PROFESSORES DE LÍNGUA INGLESA NAS CRENÇAS DOS LICENCIADOS DA UNIVERSIDADE DE PERNAMBUCO

Relma Lúcia Passos de Castro Mudo; Roberta Guimarães de Godoy e Vasconcelos ....289

O PAPEL DA AVALIAÇÃO POR PORTFÓLIOS NO PROCESSO DE ESCRITA E REESCRITA DE ALUNOS DE LÍNGUA INGLESA

Roberta Guimarães de Godoy e Vasconcelos. .303

LEITURA DE TEXTOS DE INFORMÁTICA E PRODUÇÃO DE UM GLOSSÁRIO DE VERBOS DE MOVIMENTO POLISSÊMICOS

Rosana Ferrareto Lourenço Rodrigues; Leonardo de Melo João 319

TRABALHANDO COM WIKI NAS AULAS DE INGLÊS DO ENSINO FUNDAMENTAL II

Viviane Cabral Bengezen 336

AS RELAÇÕES ENTRE TECNOLOGIAS E PRÁTICAS PEDAGÓGICAS: NECESSIDADE DE ENFRENTAMENTO DO SUJEITO PROFESSOR

Walleska Bernardino Silva 348 


\section{APRESENTAÇÃO}

A Revista do SELL da Universidade Federal do Triângulo Mineiro (UFTM), desde sua criação, em 2007, publica somente artigos decorrentes de trabalhos apresentados no SELL - SIMPÓSIO INTERNACIONAL DE ESTUDOS LINGUÍSTICOS E LITERÁRIOS anterior à publicação do volume da revista.

A terceira edição do SELL, que se realiza, sem falha, na sequência dos anos ímpares desde 2007, aconteceu nos dias 12, 13 e 14 de maio de 2011 e teve como tema CONHECIMENTOS EM DIÁLOGO: LINGUAGENS E ENSINO. Dessa forma, visamos à interação entre a área de Letras e Linguística e estudiosos de áreas afins, tais como a Comunicação, a Psicologia, a Educação, a História, a Fonoaudiologia etc. Durante o evento, conseguimos propiciar o debate, em alto nível, das questões relacionadas, na atualidade brasileira e internacional, à formação de professores e ao ensino de línguas e literaturas, dada a importância dessas disciplinas na formação básica dos educandos, essencial para o desempenho positivo no ensino superior.

Em relação às apresentações orais de trabalhos, no III SELL foram apresentadas 300 (trezentas) propostas de Comunicação Individual, 20 (vinte) de Comunicações Coordenadas (incluindo, cada uma, quatro trabalhos). Foram dessas apresentações que selecionamos, via pareceristas externos, 110 artigos para esta edição da Revista do SELL.

A terceira edição Revista do SELL está dividida em três números, apresentando os trabalhos por ordem alfabética do primeiro nome dos autores e contemplando as seguintes áreas:

Número I - Estudos Linguísticos

Número II - Estudos Literários

Número III - Estudos em Línguas Estrangeiras e outras áreas

Ressaltamos que os dados e conceitos contidos nos artigos, bem como a exatidão das referências, serão de inteira responsabilidade do(s) autor(es).

Agrademos a contribuição de todos. Foi por meio de suas contribuições acadêmicas que pudemos concretizar a publicação de mais uma edição da Revista do SELL.

Os Organizadores

Profa. Dra. Juliana Bertucci Barbosa

Prof. Dr. Carlos Francisco de Morais Profa. Ms. Elizandra Zeulli (Uberaba, Novembro de 2011) 


\title{
"FAMÍLIA RESTART": ANÁLISE DO DISCURSO MULTIMODAL DO MYSPACE OFICIAL DA BANDA
}

\section{"RESTART FAMILY": AN ANALYSIS OF THE MULTIMODAL DISCOURSE FROM THE BAND'S OFFICIAL MYSPACE HOME PAGE}

\author{
Ana Amélia Calazans da Rosa \\ (PG - UNICAMP) \\ amelia calazans@hotmail.com
}

\begin{abstract}
RESUMO: Cientes do fato de que as novas tecnologias, em especial a internet, têm propagado amplamente variados discursos e influenciado atitudes, principalmente entre os mais jovens, nosso trabalho escolheu a página inicial de uma banda de muito sucesso entre os adolescentes para pensar um pouco sobre o "comportamento" da linguagem em meio digital, estudando não apenas o discurso, mas os recursos utilizados para a propagação do mesmo. Primeiramente, um mapeamento da página foi feito utilizando os conceitos de clusters e superclusters de Baldry \& Thibault (2006). Em seguida, embasados em Lemke (2002) e Kress \& van Leeuwen (2001), apresentamos e refletimos os discursos materializados nos significados presentacionais, orientacionais e organizacionais de nosso objeto de estudo. A análise mostra que, o contexto multi e hipermodal é bastante propício para fins mercadológicos. A página analisada constitui-se em um espaço de afinidade em que há a criação de um ambiente de identificação que acolhe e oferta oportunidades para o jovem ser parte da "família Restart" por meio do consumo de seus produtos (roupas, acessórios, música, etc.). A reprodução desse discurso e os reflexos comportamentais causados pela banda e por seu apelo claramente multimodal é notado com facilidade na mídia.
\end{abstract}

PALAVRAS-CHAVE: Multimodalidade; Hipermodalidade; Linguagem; Meio Digital.

ABSTRACT: We are aware of the fact that the brand new techonologies, especially the internet, have been disseminating several kinds of discourses and influencing attitudes, mainly among the youth. In this paper, we chose the myspace home page of a famous Brazilian band in order to think about the language "behavior" in a digital media. We intend to study not only the diffused discourse, but also the means used to its spread. Firstly, a page mapping was done by using the clusters and superclusters concepts from Baldry \& Thibault (2006). Then, we present and discuss the discourses reified in the presentational, orientational and organizational meanings from our research object. The analysis shows that the multi and hypermodal context is largely propicious to marketing purposes. The home page is, clearly, an affinity space in which there is the creation of an identifying environment that offers oportunities to the teenager to be part of "Restart Family" by consuming the band's products (clothes, accessories, music, etc.). The discourse reproduction and the behavioral consequences caused by the band and by its multimodal plea are easily noticed at the media in general.

KEYWORDS: Multimodality; Hypermodality; Language; Digital Media. 


\section{Introdução}

Acesso é poder e o poder é a informação.

Qualquer palavra satisfaz.

A garota, o rapaz e a paz quem traz, tanto faz. O valor é temporário, o amor imaginário e a festa é um perjúrio.

(Fernando Anitelli e Danilo Souza)

A proposta deste trabalho é realizar uma análise dos elementos multimodais e dos discursos que compõem o site myspace de uma das bandas teen de maior sucesso no cenário nacional atual: Restart. Essa banda adotou um determinado código visual como sua marca, pautado principalmente na adoção de cores fortes e "chamativas" para estabelecer sua identidade entre o público - trata-se de uma nova tendência da música: o rock colorido. Os dados foram coletados em 22/10/2010 por meio de cópias digitalizadas da página inicial do site, ignorando a seção de comentários por questões de tempo e espaço para o desenvolvimento do trabalho. No dia 18/11/2010 o site lançou um novo layout, portanto, as imagens disponibilizadas aqui já não são mais acessíveis online.

Para iniciar nossa discussão, parece pertinente, primeiramente, estabelecer o que se entende por (multi) modalidade e discurso, duas palavras-chaves aqui. Modalidades são os modos (visual, verbal, tátil, etc.) de transmissão/construção de mensagens/sentidos dentro de uma materialidade textual. Podem ser também sistemas de representação (fala, escrita, gestos, cores, música) presentes numa determinada cultura, incluindo todas as suas possibilidades expressivas. Multimodalidade seria, portanto, a integração de modalidades no mesmo texto com fins de materializar os discursos ali veiculados. Neste artigo, entendemos discurso como os diferentes saberes que aparecem na produção e interpretação dos significados textuais, dando-lhes certos sentidos e excluindo outros (KRESS \& Van LEEUWEN, 2001). Para complementar, os autores ainda destacam que os discursos podem aparecer em diferentes modos de linguagem: "our point is that discursive action takes place in, and is articulated in, a multiplicity of practices and a multiplicity of modes, of which lived human social action is one" (KRESS \& Van LEEUWEN, 2001, p. 25).

Para a análise, o primeiro passo será a identificação dos superclusters e clusters presentes na página inicial do site. Tomaremos como pressuposto teórico as discussões de Baldry \& Thibault (2006). Mapear os superclusters e clusters auxiliará a mostrar como 
diferentes escalas do texto integram-se e constroem significados no decorrer da página inicial.

Em seguida, com embasamento em Lemke (2002) e Kress \& Van Leewen (2001), será discutida a construção de sentidos a partir dos recursos multimodais ali presentes. Pretende-se refletir sobre como diferentes modalidades se organizam de tal forma que novos sentidos (inexistentes quando as modalidades estão isoladas) são produzidos e, consequentemente, os significados são multiplicados. Nas práticas comunicativas reais é muito difícil conceber as modalidades separadamente. Além de serem dificilmente isoláveis, veremos que, principalmente em ambiente digital, as diferentes modalidades funcionam juntas para a produção de significados, pois, o sentido que é possível numa delas não é possível na outra, assim cada modalidade apresenta diferentes propiciações ${ }^{1}$ de acordo com sua natureza. Para realizar essa análise os conceitos de significados presentacionais, orientacionais e organizacionais de Lemke (2002) serão essenciais.

\section{Mapeamento dos clusters}

Este primeiro momento do trabalho será destinado à apresentação da organização da página inicial do site da banda Restart em superclusters e clusters, de acordo com Baldry \& Thibault (2006). Segundo os autores

"In our approach to multimodal text analysis and transcription, clusters are groupings of resources that form recognizable textual subunits that carry out specific functions within a specific text. Multimodal transcription typically serves to identify the components of each cluster and the function that each specific cluster plays within a text". (p. 11)

A seguir, os clusters e suas funções serão apresentados, contudo, reservaremos adiante um espaço próprio para discutir com mais profundidade os significados de acordo com os princípios de análise das funções semióticas em contextos hipermodais de Lemke (2002) e a produção de discurso por objetos multimodais (Kress \& Van Leewen, 2001).

Como a página é longa, a discussão será organizada por "partes", isto é, por lexias. Lexia é um termo de Roland Barthes, que aparece pela primeira vez na obra S/Z (1970). Podemos dizer que lexias são unidades significativas que pertencem a um texto mais abrangente. Quando estudamos hipertextos falamos em lexias no lugar de páginas ou

\footnotetext{
1 Trata-se do ato de tornar algo mais propício. Propiciações seriam as possibilidades de sentido ofertadas pelo objeto em determinado ambiente de comunicação. Por exemplo, as cores têm propiciações (abrem um leque de possíveis efeitos de sentido) que a comunicação verbal não tem ou não alcança, e vice-versa.
} 
parágrafos. Dessa forma, determinamos os limites de cada lexia para a organização desse trabalho e, a partir delas, classificaremos os clusters, como fizeram Baldry \& Thibault (2006).

Primeira lexia:

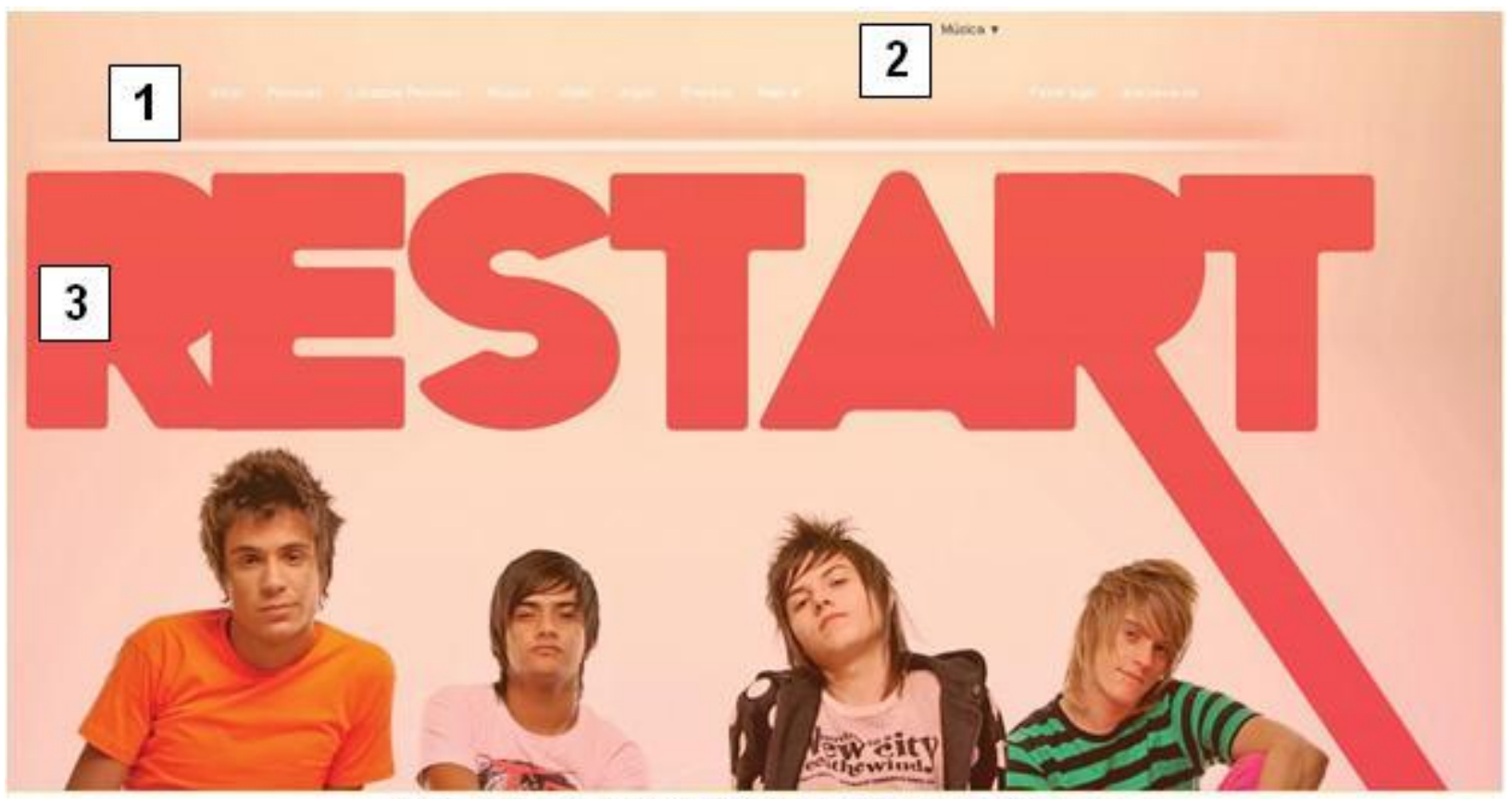

Fig. 1: Primeira lexia da página inicial do site.

Cluster 1: Início / Pessoas / Localizar pessoas / Música / Vídeo / Jogos / Eventos / Mais / Fazer Login / Inscreva-se: Este é um cluster com diversos elementos agrupados e que são ativados (ficam destacados) ao passar o mouse sobre eles, mas é preciso o clique para que o usuário seja direcionado para as outras páginas ali sugeridas. Esses clusters, na verdade, são padronizados pelo servidor no qual o site está hospedado, que é o myspace.com do grupo Microsoft (ao qual também pertencem o Hotmail e o MSN). Dessa forma, eles orientam o usuário para outros domínios que já não estão mais relacionados com a banda.

Cluster 2: Música: Aqui mostra a categoria a qual o site pertence de acordo com os critérios do myspace. Esse cluster pode ser modificado pelo usuário, ao clicar na seta uma série de categorias aparecem (Pessoas, Vídeo, Imagem, dentre outros). Entretanto, mudar a categoria não implicou em nenhuma modificação no site.

Cluster 3: Restart: Este é o maior cluster da página e funciona como a abertura do site. Bauldry \& Thibault (2006, p. 121) chamam esse tipo de cluster de "masthead", pois carrega todo o significado do site, o propósito pelo qual ele existe. Em português poderíamos chamar simplesmente de título. As fotografias dos integrantes da banda serão discutidas adiante. 
Segunda lexia:

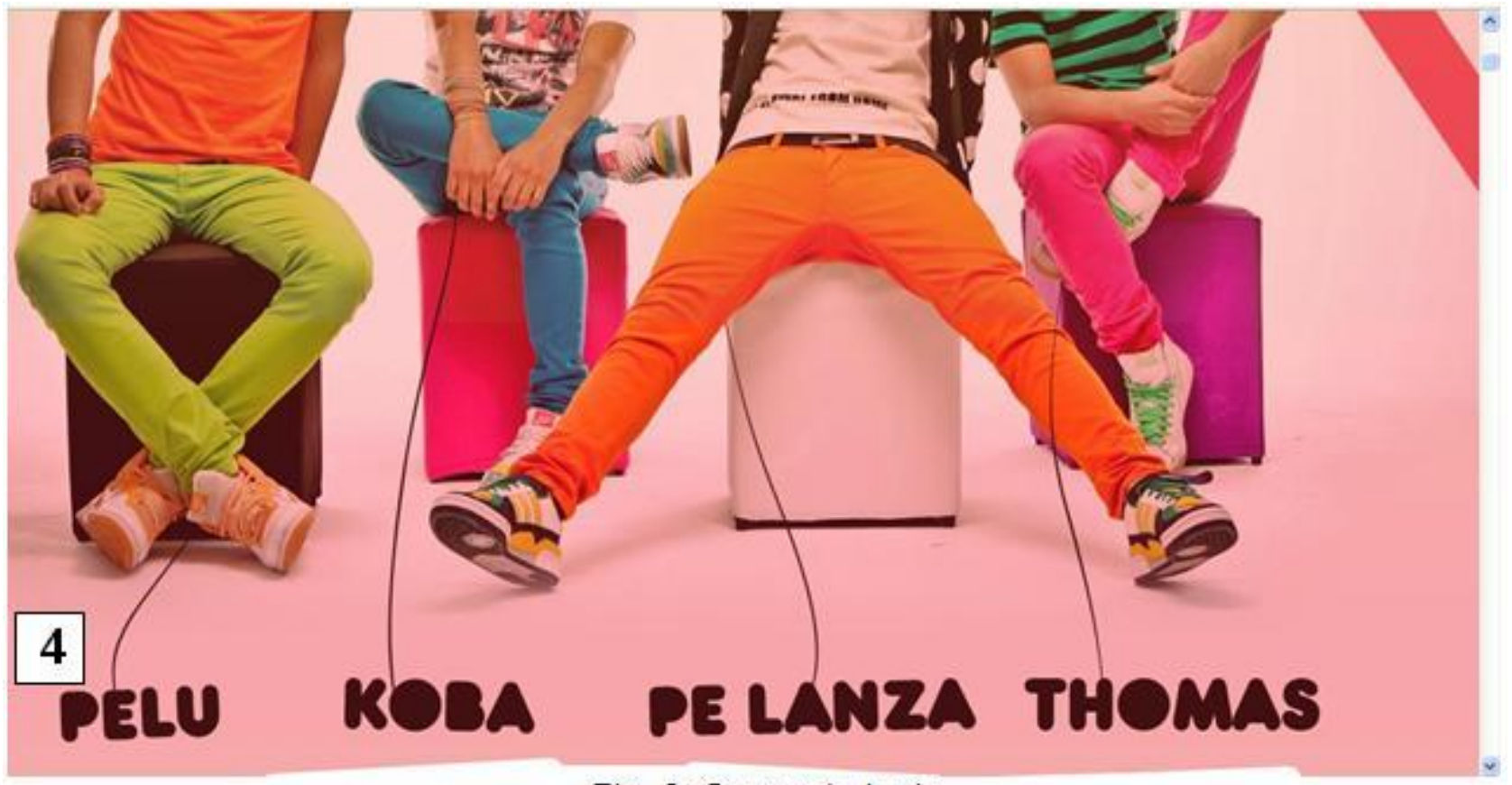

Fig. 2: Segunda lexia

Cluster 4: O quarto cluster corresponde aos nomes dos meninos integrantes da banda. Esses clusters não respondem nem a passagem do mouse, tampouco ao clique. Os nomes estão ligados por um fio a cada integrante, apontando quem é quem.

A terceira lexia é mais rica no que diz respeito aos recursos de linguagem escrita e apelo interpessoal.

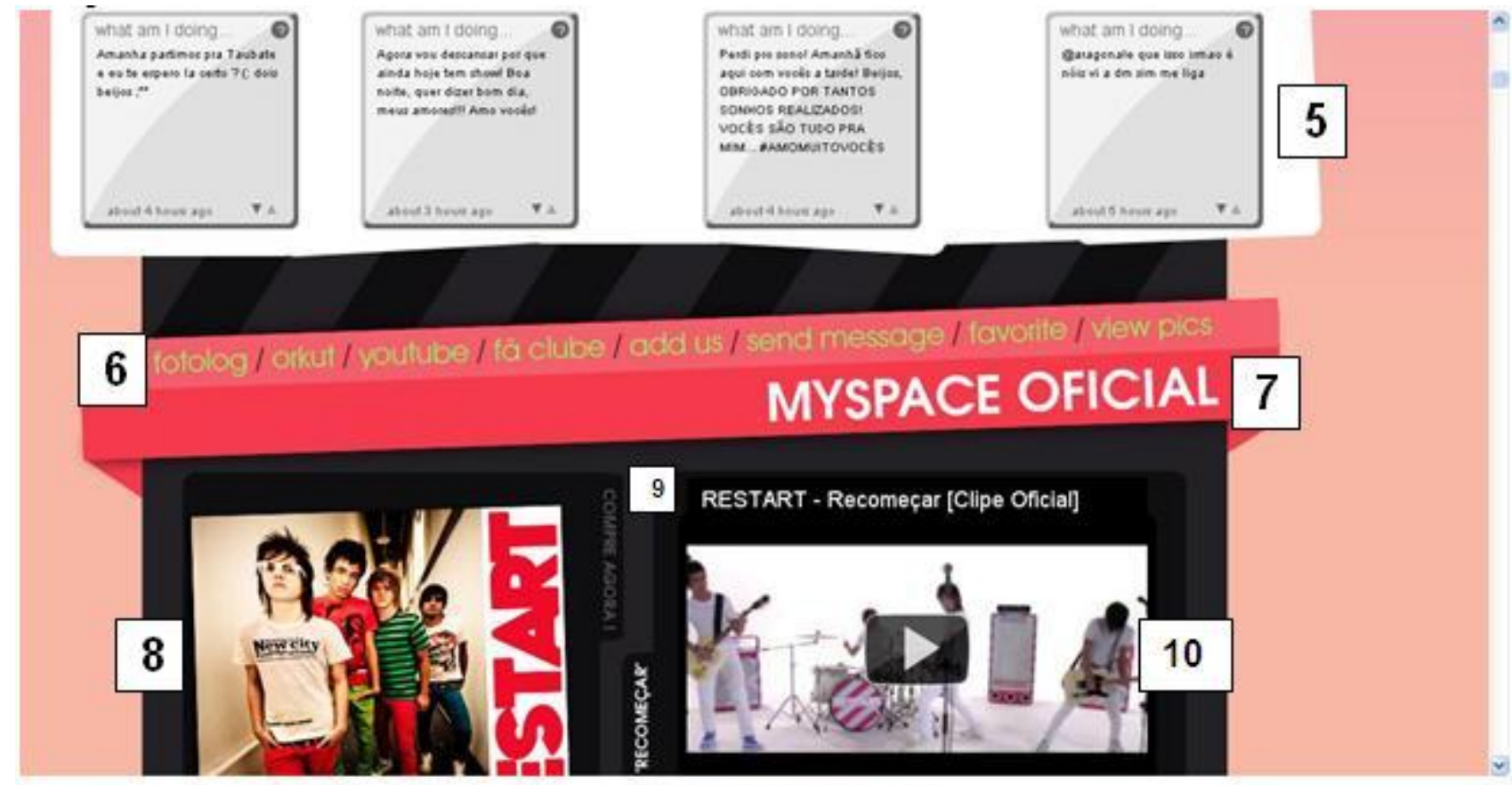

Fig. 3: Terceira lexia 
Cluster 5: what am I doing...: Este cluster contém quatro molduras que reproduzem a última mensagem deixada por cada um dos integrantes da banda em um site de relacionamento: o twitter.

Cluster 6: fotolog / Orkut / youtube / fã clube / add us / send message / favorite / view pics: aqui todos os elementos são ativados apenas com o clique do mouse. Cada um deles direciona o usuário para novas páginas. Diferentemente do cluster 1, aqui os links estão diretamente ligados à banda.

Cluster 7: Myspace Oficial: não responde à passagem do mouse nem ao clique, apenas indica o hospedeiro do site.

Cluster 8: Esse cluster é ativado com a passagem do mouse. Ao passar o cursor, o cluster fica mais escuro e a palavra "clique" aparece. O link desse cluster não abriu.

Cluster 9: Compre agora!: Inativo.

Cluster 10: Videoclipe de uma das músicas da banda, importado do site de vídeos youtube. Esse cluster tem pequenas reações à passagem do mouse (como realce da cor do símbolo "play"). Ao clicar no play, o vídeo é reproduzido ativando assim mais duas modalidades de linguagem: imagem em movimento e som.

Abaixo a quarta lexia. Aqui, para fins de praticidade, consideremos dois superclusters:

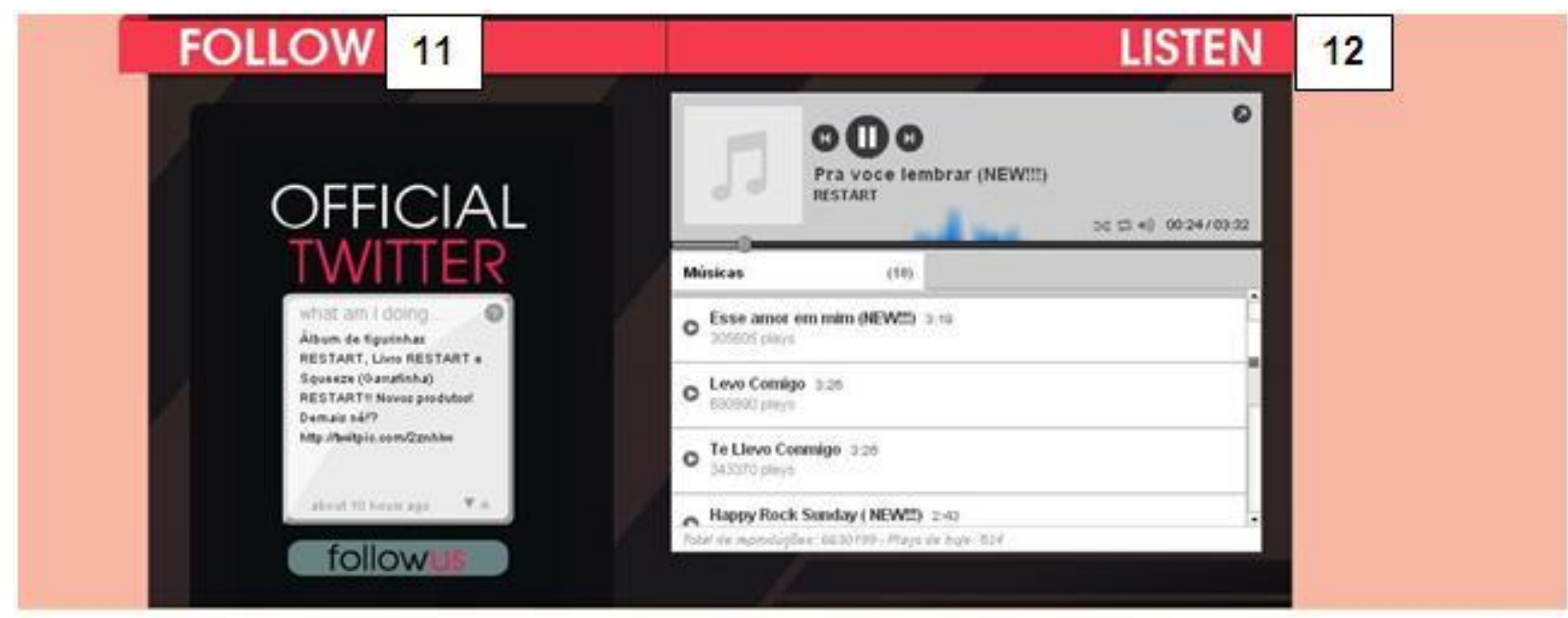

Fig. 4: Quarta lexia.

Supercluster 11: Follow: Aqui temos um supercluster porque se trata de um cluster mais complexo, com muitos elementos integrados e hierarquizados internamente dentro de uma mesma unidade funcional. A maior parte desse supercluster é inativa, a não ser pelo ícone "ponto de interrogação" (?) e pelas setinhas no canto direito, abaixo. O ponto de interrogação, quando se passa o mouse sobre ele, ativa uma breve descrição sobre o que 
é o twitter. As setinhas servem para ver os outros tweets (tweets anteriores) dos integrantes da banda.

Supercluster 12: Listen: Trata-se de uma interface de programa para execução de músicas. Ao passar o mouse alguns ícones são ativados, como o "reproduzir" e o "próximo". Há ainda, ícones bem pequenos, ao lado do marcador de tempo da música, que são alguns recursos próprios de programas para reproduzir músicas, como "modo aleatório de execução", "modo de repetição" e "volume”. Quando o mouse passa pelos nomes das músicas ali listadas, o cluster fica cinza e quando se clica na música para ativar a execução, o cluster no qual está o nome da música passa a ser o único cinza, enquanto os outros permanecem brancos. Mais uma vez tem-se a possibilidade de ativar um recurso modal adicional: o do som.

A quinta lexia repete alguns tipos de clusters já mencionados. Confira:

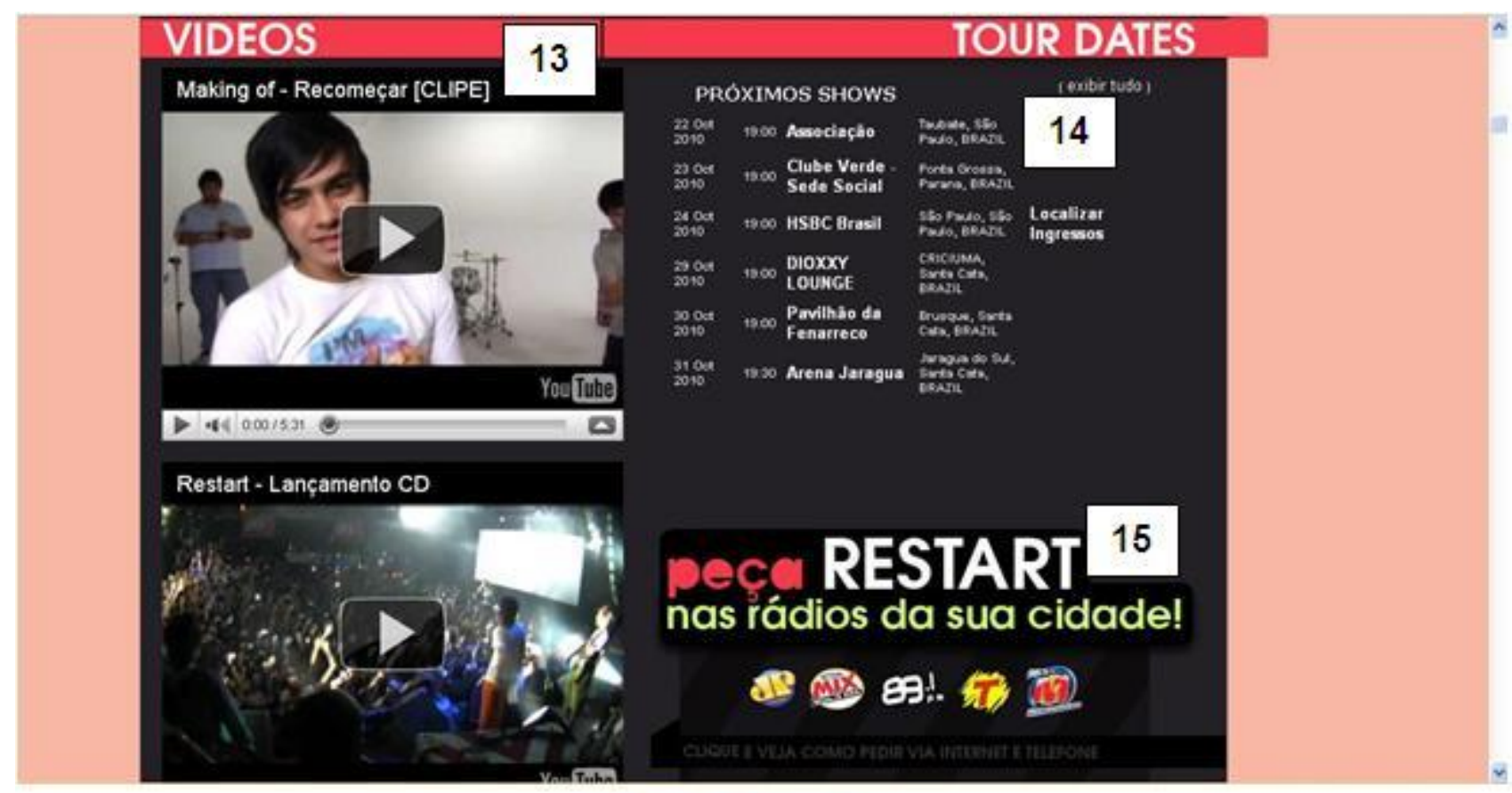

Fig. 5: Quinta lexia.

Cluster 13: Videos: Assim como o cluster 10, o cluster 13 é composto de dois vídeos importados do youtube que são ativados ao clicar no símbolo do play.

Cluster 14: Tour dates: Cluster que divulga os próximos shows da banda. Os nomes dos lugares onde serão realizados os shows são sublinhados quando o mouse passa por eles e quando se clica uma nova página abra com maiores detalhes sobre aquele show específico. O "exibir tudo" também recebe destaque com a passagem do mouse e também direciona o usuário para outra página, na qual os próximos shows do mês estão listados. 
Cluster 15: Peça Restart nas rádios de sua cidade: Esse cluster apresenta uma estratégia bastante clara e específica de marketing da banda. Ao clicar o usuário é direcionado para outra página contendo os nomes, telefones, e-mails e endereços das principais estações de rádio das principais cidades paulistas, como Campinas, Ribeirão Preto, São Paulo, dentre outras. É claro a forma como esse cluster trabalha para persuadir os fãs a empenharem-se para incluir as músicas da Restart nas emissoras de rádio mais famosas do estado e do país.

Finalmente, a sexta e última lexia mapeada:

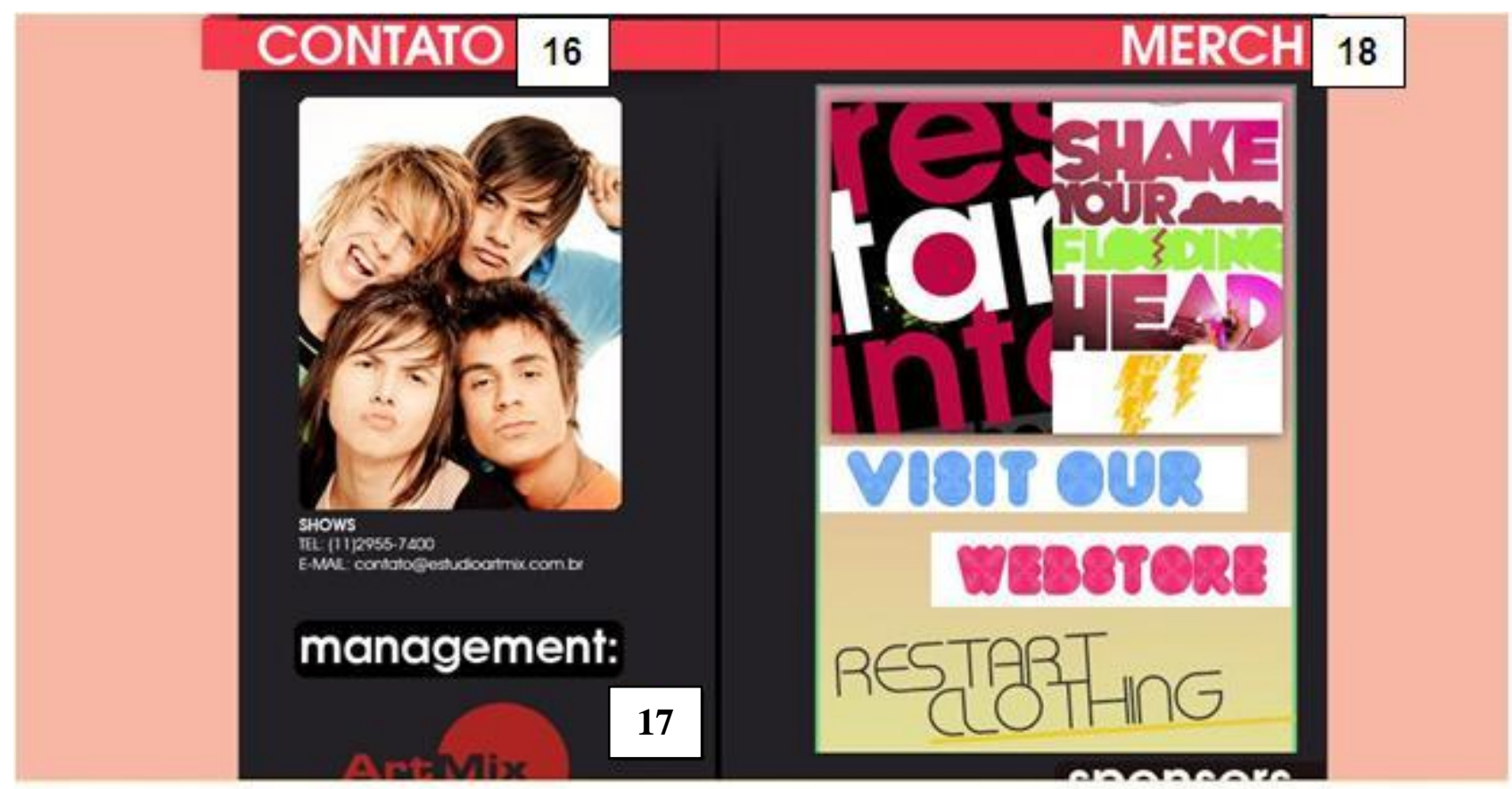

Fig. 6: Sexta lexia.

Cluster 16: Contato: A foto desse cluster é ativada pelo clique do mouse que abre o programa específico para envio de e-mail (no caso do Windows, por exemplo, o programa ativado é o Outlook) do computador do usuário, isto é, direciona o usuário para entrar em contato com a banda via endereço eletrônico, vale ressaltar de que se trata de um contato específico para contratação de show.

Cluster 17: Management: Aqui os clusters indicam a empresa que cuida dos negócios da banda. São clusters inativos.

Cluster 18: Merch: O "título" do cluster já anuncia: "merchandising". Ele é composto de elementos diferentes, com dizeres diferentes, contudo, em qualquer lugar que o usuário clique, ele será direcionado para uma página de vendas, na qual são vendidas peças de roupa e acessórios relacionados à banda. 


\section{O discurso colorido: construção de sentidos na hipermodalidade}

Segundo Lemke (2002), a interação de recursos multimodais, especialmente em hipertextos, multiplica o poder da comunicação. Baldry \& Thibault (2006) complementam tal afirmação:

The visual, spatial, auditory and linguistic features that contribute to the design of a home page and its meaning convey more than just information. They also contribute to its interpersonal appeal, to the evocation of affective responses, to the indexing of social values and to the creation of atmosphere. (p. 118-119)

Ao compreender o conceito de hipermodalidade como as novas interações entre palavra-image-som que geram novos significados em contexto de hipermídia (LEMKE, 2002) por meio de ações multiplicativas, e não apenas "somatórias", este trabalho analisará a seguir os diversos significados produzidos na página inicial do site da banda Restart já apresentada. Para isso, partir-se-á dos pressupostos de análise propostos por Lemke (2002). O autor propõe que a combinação multiplicativa dos recursos presentational, orientational e organizational das diferentes linguagens (semioses) do hipertexto demandam a necessidade de uma semântica específica para a análise multimodal do ambiente digital. Isso porque há inúmeras possibilidades de funcionamento da linguagem que são muito específicas no meio digital e não são possíveis em outros meios.

Apesar de este trabalho estar organizado em sessões separadas para lidar com os significados presentacionais, orientacionais e organizacionais, conforme Lemke (2002) alerta, os sentidos produzidos na hipermodalidade são de natureza multiplicativa, os significados emaranham-se e produzem novos significados que, quando separados, não existiriam mais. Por isso, é impossível falar dos significados presentacionais, orientacionais e organizacionais totalmente de forma separada. Nas discussões a seguir, mesmo quando estivermos discutindo os significados presentacionais, reservaremo-nos o direito de trazer os outros dois significados para a discussão todo momento em que acharmos conveniente e necessário.

Para iniciar a análise, alguns questionamentos devem ser feitos: que tipos de significados podem ser inferidos a partir das combinações de cores, linguagem escrita e imagens na página inicial do site da Restart? Quais são os possíveis efeitos desses significados na sociedade? 


\subsection{Significados presentacionais}

Os recursos presentacionais são aqueles que apresentam as circunstâncias dos elementos de significação e sua combinação naquele espaço e tempo. Tais circunstâncias constroem-se de acordo com o conteúdo ideacional dos textos, "what they say about processes, relations, events, participants, and circumstances" (LEMKE, 2002, p. 304).

A presença mais marcante do site da banda Restart, bem como em suas roupas, videoclipes e outras manifestações públicas é, sem dúvidas, a grande variedade de cores. A página inicial apresentada é bem marcada por cores leves e alegres, com predominância de tons de cor-de-rosa e lilás. Tais escolhas de apresentação podem significar que o público que se almeja atingir é o feminino e, sobretudo, jovem. O uso de cores variadas e, em sua maioria, quentes parece uma reação ao movimento "emo" que recentemente tomou conta da música e do comportamento adolescente. Até pouco tempo atrás, a moda teen era vestir-se de preto (ou cores escuras), usar acessórios também escuros (pulseiras, brincos, acessórios para cabelo, bolsas, "munhequeiras", todos na cor preta ou tons escuros em geral), deixar o cabelo na cor preta e com corte que cobrisse parte do rosto, e ouvir músicas melancólicas que tratassem de temas como infelicidade e revolta.

A banda Restart parece ser uma reação a essa moda "emo", ao trocar o estilo dark por uma explosão de cores. No site se vê isso claramente, não apenas pelas cores apresentadas na própria interface da página, mas também pelas cores das roupas dos integrantes da banda na foto de abertura do site. Dessa forma, o discurso muda de direção: não se trata mais de lamentar os problemas da vida, mas sim celebrar a alegria de viver e de ser jovem. As letras das músicas não serão objetos de estudo neste trabalho, mas, pode-se ver claramente pelos tweets divulgados no site (ver cluster 5 ) que o "amor" é o tema principal para estabelecer contato com os fãs. Ideias referentes a amor, sonhos e companhia, estar junto, são muito recorrentes e podem ser notados nos tweets e nos títulos das canções apresentadas ao usuário no supercluster 12.

Outro recurso presentacional é a foto principal da página. Apesar de todos estarem sentados e com expressão facial séria, os olhares e a inclinação das cabeças são diferentes. Dois meninos estão com o queixo erguido, demonstrando uma postura de segurança e autoconfiança. Os outros dois estão com seus rostos levemente voltados para baixo, e suas expressões estão menos "pomposas" e seus olhares parecem querer seduzir por meio de expressões mais meigas e delicadas. Aqui vale entrar no significado 
orientacional, os integrantes parecem estar orientando os fãs a falar com eles, seu olhar passa segurança para o outro, e não segurança de si mesmo como os primeiros. Dessa forma vemos um equilíbrio entre o ato de garantir a autoconfiança que atrai fãs e, ao mesmo tempo, proporcionar a abertura que os faz sentirem-se confortáveis na "companhia" da banda.

$\mathrm{Na}$ terceira lexia da página analisada nota-se a apresentação de um dos videoclipes da banda (ver cluster 10) e na quarta lexia são apresentadas algumas músicas com a possibilidade de ouvir por meio do próprio site, isto é, não é necessário fazer download e nem abrir uma nova janela. Esse ambiente virtual é, sem dúvidas, um ótimo veículo de divulgação do trabalho da banda. Apresentar possibilidades de ouvir a música ou ver o vídeo ali mesmo, sem precisar se deslocar, é essencial para conquistar mais fãs. Do ponto de vista orientacional, podemos chamar isso de oferta de serviços/informações. Em um ambiente hipermodal, tal como nosso objeto de estudo, alguns recursos extras são muito importantes na política de oferta do site como, por exemplo, os clusters que são ativados com a passagem do mouse, atraindo a atenção do usuário.

A sexta lexia apresenta (cluster 16) uma foto dos integrantes da banda para auxiliar na promoção da área de contatos para contratação. Ainda nessa parte, o cluster 18 apresenta um atalho que orienta o usuário para a página de vendas de produtos relacionados à banda. $A$ apresentação do banner é muito comum dada a dinâmica do site claramente voltada ao mercado. Cores de destaque e expressões em língua inglesa são utilizadas com o intuito de orientar os adolescentes a acessar a página.

Assim parece que 0 destaque principal no que tange os significados presentacionais é que um "grupo" e seus "componentes" são apresentados, e, em seguida, os atributos desse grupo: o que ele canta, veste, como se comporta, etc. Assim, temos um tipo de processo classificatório que diz quem pertence ao grupo e quem não pertence. Como podemos facilmente ver na mídia, uma nova tribo foi criada a partir desse novo discurso circulante.

\subsection{Significados orientacionais}

Os significados orientacionais indicam o que está acontecendo no evento comunicativo e qual posição seus participantes podem ter entre si e com o conteúdo presentacional. De acordo com Lemke (2002), esses significados orientam-nos para ações e sentimentos diante das práticas de linguagem em que estivermos inseridos. É 
também nos significados orientacionais que nos oferecem, ou demandam de nós, determinadas atitudes, pontos de vista e valores.

Logo na primeira lexia do site a orientação das cores é bastante evidente. Tons de rosa, culturalmente atribuídos ao sexo feminino, são oferecidos aos internautas e os orientam em direção a sentimentos nobres, como amor e afeição. De acordo com Kress \& Van Leewen (2001, p. 25), a cor também é uma modalidade de significação: "discourse, realised through the mode of colour, expresses and articulates knowledge of why a specific domain of social reality is organised the way it is (...)". Pode-se afirmar que a orientação das cores, e possivelmente dos olhares, é, especialmente, para meninas e meninos jovens, que se encontram na difícil e emotiva fase da adolescência, que a banda explora com notável sucesso. Ainda sobre a primeira lexia, vale a pena mencionar que os clusters 1 e 2 (que pertencem ao domínio do site hospedeiro) orientam o usuário a conhecer e utilizar ferramentas próprias do myspace, tais clusters apresentam e orientam sobre as possibilidades de qualquer um de nós ter o próprio myspace, seguindo a tendência da banda.

$\mathrm{Na}$ segunda lexia estudada, as cores das roupas chamam muito a atenção do usuário. Kress \& Van Leewen (2001) defendem que modalidades não linguísticas, como cores, por exemplo, podem ser capazes de realizar significados discursivos que a língua, por si mesma, não consegue: "the meaning-associations capable of being set up visually are simply not those which can be set up verbally" (p. 27). Ainda de acordo com Kress \& Van Leewen (2001), o significado orientacional das cores remete a experiências físicas e psicológicas não abstratas que, ousamos afirmar, fazem os adolescentes pertencerem a algum lugar, identificar-se com um modo de aparecer para a sociedade e até mesmo de deixar sua marca. O fato de milhares de fãs adotarem o mesmo estilo de roupa e acessórios mostra claramente como a orientação das cores e também dos modelos do vestuário dos meninos integrantes da banda tem grande influência sobre os adolescentes e inserem os mesmos em experiências novas, que podem ser linguísticas, visuais e até mesmo comportamentais. Claramente todos os recursos orientacionais que mencionamos são propositalmente criados não apenas para reforçar significados linguísticos, mas para produzir efeitos que a língua não alcança. Isso também fica evidente na definição da Restart: é chamada de banda colorida. O colorido tem diversas conotações, as quais nem sempre são possíveis de expressar verbalmente, ou seja, não é possível definir completamente por meio da língua o que esses meninos são e o querem dizer. Quando o recurso da cor é acionado como modalidade significativa há a possibilidade de criar sentidos que palavras não alcançariam. 
$\mathrm{Na}$ terceira lexia os clusters priorizam a modalidade linguística para a manifestação de significados orientacionais, isto é, eles usam recursos da língua (verbos no imperativo) para orientar o usuário a "comprar" a filosofia da banda. Os elementos dos clusters 8 (clique), 9 (compre), 10 (assista), 11 (follow), 12 (listen), 13 (assista - não verbal), 14 (vá - não verbal) e 15 (peça, clique e veja) são formas de induzir o usuário a participar da comunidade da banda. O cluster 11 (follow) remete a uma mensagem deixada no twitter por um dos integrantes (não revelado no site) incentivando a compra de produtos com tema da banda como álbum de figurinhas e squeeze (garrafa d'água). O cluster 12 (listen) também é uma ferramenta de venda, pois é como um tipo de "amostra grátis" das músicas que podem ser ouvidas no $C D$ da banda e/ou no show. E, nesse espaço os ícones são ativados apenas pela passagem do mouse, o que acarreta em maior destaque para o local. Aproveitando o gancho da amostra grátis das músicas, o usuário é orientado pelo cluster 14 (agenda de shows) a conhecer os locais dos próximos eventos que a banda participará. Finalmente, o cluster 15 (peça) orienta que os visitantes do site peçam as músicas da Restart nas emissoras de rádio mais famosas do estado de São Paulo e do país. Ao clicar no cluster, a pessoa é redirecionada a outra página que contém os endereços eletrônicos e telefones de estações como Jovem Pan e Transamérica.

O mesmo apelo de compra e venda está presente na última parte analisada da página inicial. Os clusters 16 e 18, respectivamente, fornecem os contatos para contratação da banda e orientam o usuário a visitar a página webstore, que vende artigos como roupas, pôsteres, adesivos e acessórios da "família Restart".

Pode-se notar claramente que o site é destinado a fomentar o consumo por meio do apelo ao entretenimento e sentimento de identificação, de pertencer a algum lugar. No dia que as imagens para análise neste trabalho foram coletadas não havia na página inicial nenhuma menção à expressão "família Restart", contudo, vale a pena destacar que tal expressão tem sido constantemente utilizada pelos integrantes da banda e também pelos fãs para se referirem ao grupo que, de certa forma, adota a filosofia das cores e da música da Restart. Trata-se de um modo de identificação, de localizar-se e sentir-se parte de algum lugar. Pode-se afirmar que a utilização constante dessa expressão associada a um modo específico de se vestir, de falar e de se comportar abre possibilidades para conquistar muitos adolescentes que buscam algum tipo de suporte para enfrentar todas as mudanças desse período da vida. Como dissemos anteriormente, os elementos presentacionais do site apontam para esse processo classificatório de estabelecer quem pertence e quem não pertence à família Restart. Ao mesmo tempo em que há 
classificação, ocorre um processo orientacional que funciona como uma espécie de convite ao leitor/consumidor para fazer parte do grupo.

Veja o exemplo de um tweet do integrante Thomas que coletamos na página da banda em 16/11/10, no qual o vocábulo "família" é utilizado²:

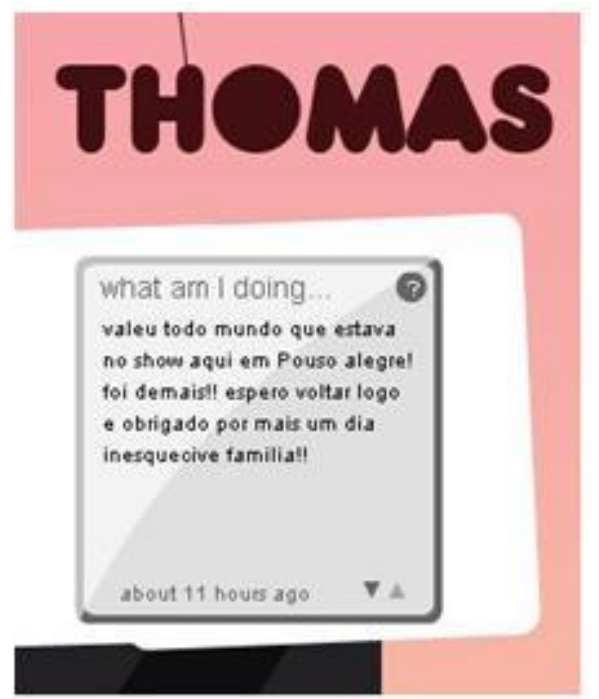

Fig. 7: Tweet atribuído a Thomas, integrante da banda. Acesso em: 16/11/10.

Antes de finalizar a discussão sobre os significados orientacionais da página analisada, é necessário voltar a atenção para os tweets que estavam disponibilizados na página no dia da coletas dos dados (ver cluster 5). Primeiramente, convém frisar que, sabe-se que as mensagens são tweets por três elementos básicos: (i) a frase introdutória "what am I doing..." que é um tipo de resposta à pergunta clássica do twitter que orienta os usuários do site ("what's happening?") e além disso a oração se repete nos quatro clusters; (ii) a presença de arrobas (@) necessárias para se dirigir a alguém no twitter e da marcação do tempo da mensagem ("about 5 hours ago") e (iii) o tamanho das mensagens, pois o twitter destaca-se por ser uma ferramenta na qual o usuário pode escrever mensagens de no máximo 140 caracteres por vez.

As três primeiras mensagens contêm características que aproximam o interlocutor, pois estão na segunda pessoa (do singular e do plural). Essa aproximação é orientacional no sentido que chama o usuário a se identificar com a mensagem, isto é, as palavras são direcionadas especialmente para ele (a). Além disso, são recados de cunho emocional, que fazem declarações e causam um efeito de valorização nos fãs, isto é, eles se sentem amados e valorizados por meio de enunciados como "amo vocês"; "eu te espero lá" e "vocês são tudo pra mim". Aqui já se pode notar mais uma das ferramentas de conquista

\footnotetext{
${ }^{2}$ Transcrição do tweet: "valeu todo mundo que estava no show aqui em Pouso alegre! foi demais!! espero voltar logo e obrigado por mais um dia inesquecível família!!".
} 
e manutenção de seguidores fiéis, o foco é o fã, o consumidor, é isso que garante o sucesso da banda, isto é, para consumir é preciso identificar-se com o produto. Todos os elementos multimodais aqui analisados apontam para a construção dessa identificação.

A página inicial da banda Restart também é um bom exemplo de orientação para individualização e valorização do "eu" sem excluir a importância do coletivo. Kress \& Van Leewen (2001) apontam que a mudança da organização social por classe, para a organização social por estilo de vida um fator de grande significado semiótico. A banda Restart, claramente, dissemina um estilo de ser, de agir e de consumir:

Semiotically the shift entails a distinct move towards (greater) individuation: that is, the self-definition of individuals through forms of consumption accompanied by an ideological current in which individuation is more intensely emphasised (KRESS \& VAN LEEWEN, 2001, p. 35).

$\mathrm{Na}$ realidade, a citação acima pode ser considerada de cunho mais geral, perpassando todas as metafunções (presentacional, orientacional e organizacional) e 0 perfil da banda como um todo.

\subsection{Significados organizacionais}

"Organizational meanings are largely instrumental and backgrounded" (LEMKE, 2002, p. 304). Isso significa afirmar que os significados organizacionais permitem que os outros dois atinjam maiores graus de complexidade e precisão. Os recursos de organização mostram-nos quais signos fazem parte de unidades maiores de significado. Tais unidades podem ser estruturais, que são imediatas no texto, e geralmente, contêm elementos diferenciados no que diz respeito à função.

Nas análises anteriores alguns princípios organizacionais já foram citados. O cluster 1 e o cluster 2 são itens-padrão em todas as webpages do myspace. O primeiro estabelece uma organização em cadeia de possíveis ações para participar/utilizar os serviços da rede social myspace. Todos os elementos (Início / Pessoas / Localizar pessoas / Música / Vídeo / Jogos / Eventos / Mais / Fazer Login / Inscreva-se) são clicáveis e se organizam em um cluster que não pertence ao domínio da publicidade da banda, mas ao domínio de publicidade do hospedeiro do site, o myspace.

O cluster 4 se organiza em quatro elementos que divulgam o nome ou apelido de cada integrante da banda. Os nomes/apelidos estão ligados aos respectivos meninos organizando quem é quem. No cluster 5 , há a organização das mensagens do twitter de 
cada integrante. Todas as molduras estão dentro do cluster e formam uma cadeia de mensagens com as mesmas características e dentro de uma organização que possibilita ao usuário saber que o conteúdo linguístico ali expresso está veiculado na página do twitter também. Ainda na terceira lexia, encontra-se o cluster 6 que organiza uma série de elementos com função de direcionar a pessoa interessada na banda a conhecer outros sites que divulgam o trabalho da Restart. Aqui a organização se dá por meio de diferentes domínios digitais nos quais se pode encontrar a banda (youtube, Orkut, fotolog) e domínios do próprio myspace que possibilitam estabelecer algum tipo de contato/vínculo com o site da banda (add us, send message, favorite).

Finalmente, o último recurso organizacional que será destacado é a organização dos clusters 8,10 e 12. O número 8 traz a foto da capa do CD da Restart; os clusters 10 e 12, que estão bem próximos do 8, trazem, respectivamente, um videoclipe da banda e algumas músicas do CD. Fica evidente que a organização é destinada à venda, pois os clusters 10 e 12 funcionam como "amostras gratuitas" do conteúdo do CD que, propositalmente, vem acompanhado do cluster com ênfase orientacional expressa no imperativo "Compre agora!".

\section{Considerações Finais}

Por uma questão de espaço e tempo, não foi possível explorar cada detalhe da página inicial da banda Restart. Contudo, este trabalho propôs-se a analisar as construções de significado mais expressivas encontradas nas relações multimodais que compõe o objeto de estudo.

Por meio de uma série de combinações de diferentes modalidades de significação (cor, olhar, som, linguagem verbal), a função que parece predominante do myspace da banda Restart é mercadológica. O contexto hipermodal para fins de mercado parece uma combinação de propriciações bem-sucedidas. Todas as modalidades apontam para uma valorização do sujeito que pertence àquele determinado grupo, isto é, os significados encontrados apontam para a ação de chamar o adolescente a participar daquele estilo de ser e de viver: o estilo do alegre, do colorido, dos sentimentos nobres, como o amor. A banda oferece um modo de subjetivação supostamente novo e original para os adolescentes: pertencer à família Restart. Para isso há um apelo para a individualização (cada membro da "família" é especial da sua maneira), ou seja, fazer o adolescente sentirse valorizado pelo que é e pelas escolhas que faz, como pertencer a essa tribo. Tanto o discurso verbal quanto o discurso visual da banda revelam-se de caráter persuasivo e 
acolhedor, o apelo ao emocional pode ser considerado o principal recurso de conquista. $\mathrm{O}$ apelo interpessoal é um reflexo do crescente mercado online. O site da Restart é mais um exemplo de cultura pop com ênfase no consumo. É preciso "vender" a filosofia da banda para os adolescentes, que são um público vulnerável e de fácil conquista.

Esse apelo mercadológico é realizado por meio da criação de um espaço de afinidade (GEE, 2004 apud DAVIES, 2006). O site é frequentado por adolescentes que compartilham um interesse: a banda Restart. Tal afinidade faz com que eles desenvolvam engajamento com o produto da banda (a música) e com os "acessórios", como roupas e cabelos. Tudo isso junto dá origem a um movimento de identidade e "agrupamento" nomeado pelos próprios integrantes da banda como "família", isto é, a aproximação e a identificação dos fãs com a Restart se fortalece a partir do momento que todos juntos mantêm (ou deveriam manter) relações de afeto como uma verdadeira instituição familiar.

O site pode ainda se considerado um espaço de afinidade porque os integrantes têm disponibilidade de interagir com o conteúdo do site e entre si por meio da postagem de comentários no "mural" (que não entrou na análise). Além disso, o acesso ao ambiente digital em questão remete os usuários a outros ambientes que também dizem respeito à banda, como o fotolog oficial, o canal do youtube e os twitters dos integrantes, ou seja, há incentivo para que os usuários se engajem em diversas práticas sociais e de linguagem cujo tema é a Restart e a afinidade que todos têm pela banda. Questões acerca da identidade adolescente construída e fortalecida nesses espaços de afinidade criados com intenção de exploração de situações de consumo e lucro merecem mais pesquisas, não apenas no campo da linguagem, mas das ciências sociais em geral.

Todas as discussões realizadas aqui têm importância ímpar para o professor que lida com alunos adolescentes todos os dias. É de muita valia conhecer os discursos que conquistam os adolescentes e, caso seja pertinente, trabalhar em sala de aula com esses discursos e essas linguagens que transmitem ideologias. Para isso é preciso saber como os discursos se constroem em diferentes modalidades e na sua combinação. Se um dos objetivos da escola é formar cidadãos conscientes, reflexivos e críticos, pode-se aproveitar o próprio discurso que os cerca e os conquista para trabalhar práticas de uso da linguagem e suas implicações sociais.

\section{Referências}

BALDRY, Anthony, THIBAULT, Paul J. Introduction: multimodal texts and genres. In: $\overline{\text { p. } 1-56 .}$ . Multimodal Transcription and Text Analysis. London: Equinox, 2006. Capítulo 1, 
BALDRY, Anthony, THIBAULT, Paul J. The web page. In: . Multimodal

Transcription and Text Analysis. London: Equinox, 2006. Capítulo 3, p. 103-164.

DAVIES, Julia. Affinities and Beyond! Developing ways of seeing in online spaces. In: Elearning and digital media. v. 3, n. 2, 2006. p.217-234.

KRESS, Gunther. \& VAN LEEUWEN, Theo. Discourse. In:

Multimodal discourse: the modes and the media of contemporary communication. London: Arnold, 2001. p. 2544.

LEMKE, Jay. L. Travels in hypermodality. In: Visual Communication, London, v.1, n.3, 2002. p. 299-325.

RESTART, Myspace oficial da banda. Disponível em:

<http://www.myspace.com/rockrestart>. Acesso em: 22 out. 2010. 


\author{
OS PROCESSOS DE INTERPRETAÇÃO, ANÁLISE E COMPREENSÃO DE GÊNEROS \\ TEXTUAIS POR ALUNOS COM DEFICIÊNCIA VISUAL: UMA REFLEXÃO EM \\ SERVIÇO
}

\title{
THE PROCESSES OF INTERPRETATION, ANALYSIS AND UNDERSTANDING OF TEXTUAL GENRES OF STUDENTS WITH VISUAL DISABILITIES: A REFLECTION IN SERVICE
}

\author{
Ana Maria Pereira Dionísio \\ anamariadionisio@yahoo.com.br \\ Instituto de Cegos do Brasil Central - Uberaba-MG
}

RESUMO: O objetivo deste artigo é apresentar algumas reflexões sobre a leitura, análise e interpretação de gêneros textuais de alunos com Deficiência Visual(Cego ou Baixa Visão/Visão Subnormal) . A pergunta que norteou nosso trabalho foi: Como desenvolver os processos de interpretação, análise e compreensão de textos de alunos cegos ou com baixa visão?. Baseamos nossas reflexões nas concepções de Vygotski sobre a deficiência visual, nas quais ele afirmava que o funcionamento psíquico das pessoas com deficiência visual obedece às mesmas leis que regem o das pessoas normais, diferindo apenas em sua organização. Assim, acreditamos que é necessário conhecer esta forma de organização do pensamento para que possamos direcionar o trabalho de interpretação, análise e compreensão de textos.

PALAVRAS-CHAVE: Deficiência Visual; compreensão de gêneros textuais; Vygotski.

ABSTRACT: The aim of this article is to present some reflections on the reading, analysis and interpretation of textual genres of students with Visual Disabilities (Blind or Low Vision/Subnormal Vision). The question that guided our work was: How to develop the processes of interpretation, analysis and understanding of texts of blind pupils or with low vision? We base our reflections in the conceptions of Vygotski on the visual disability, in which it affirmed that the psychic functioning of the people with visual deficiency obeys the same laws that prevail of the normal people, differing only in its organization. Thus, we believe that it is necessary to know this form of organization of the thought so that let us can direct the work of interpretation, analysis and understanding of texts.

KEYWORDS: Visual disabilities; textual genres; Vygotski.

\section{Introdução}

A escola é o espaço em que a diversidade se faz presente, mas nem sempre é encarada com equidade. O mote da inclusão traz em seu bojo a importância de considerar as diferenças e necessidades de acordo com as deficiências que os alunos 
têm. Isto significa considerar as dificuldades da criança na escola e as dificuldades da escola com as crianças.

A deficiência, seja de que natureza for, pode ocasionar dificuldades de aprendizagem que muitas vezes coloca o sujeito na contramão da história. Enquanto o todo avança, ele estagna e, muitas vezes, o fracasso destrói a esperança que até então habitava seu ser. Neste momento ele precisa de alguém que acredite que ele é capaz e 0 ajude a superar suas dificuldades de aprendizagem.

Ao investigar o que está por trás das dificuldades de aprendizagem e desenvolvimento de um sujeito, envereda-se pelo desconhecido que habita no outro. Desvendar o outro significa conhecer a si mesmo, pois investigando o seu sujeito de pesquisa em seus aspectos biopsicossociais depara-se com a natureza do outro e com a sua própria. Ambas humanas enquanto gênero, no entanto complexas porque se constituem de maneira ímpar.

Dentro desta perspectiva o presente trabalho tem por objetivo apresentar algumas reflexões sobre a leitura, análise e interpretação de gêneros textuais por alunos com Deficiência Visual(Cego ou Baixa Visão/Visão Subnormal). A pergunta que norteou nosso trabalho foi: Como desenvolver os processos de interpretação, análise e compreensão de textos de alunos cegos ou com baixa visão? Conforme observamos este, dentre outros, trata-se de um desafio para professor de Língua Portuguesa que recebe um aluno com Deficiência Visual em sala de aula.

Baseamos nossas reflexões nas concepções de Vygotski sobre a deficiência visual, nas quais ele afirmava que o funcionamento psíquico das pessoas com deficiência visual obedece às mesmas leis que regem 0 das pessoas normais, diferindo apenas em sua organização. Assim, acreditamos que é necessário conhecer esta forma de organização do pensamento para que possamos direcionar o trabalho de interpretação, análise e compreensão de textos.

Partindo do princípio de que todas as pessoas são capazes de aprender, que cada uma tem seu próprio ritmo e que o papel da educação é formá-las respeitando a diversidade e trabalhando a equidade, elaboramos algumas reflexões baseadas em nossa experiência com alunos com Deficiência Visual em nosso trabalho voluntário nas aulas de reforço no Instituto dos Cegos do Brasil Central em Uberaba, Minas Gerais. 


\section{A Deficiência Visual}

A pessoa com baixa visão ou visão subnormal apresenta uma redução na sua capacidade visual que interfere ou limita seu desempenho, mesmo após a correção de erros de refração comuns. Sendo que, a baixa visão pode ocorrer por traumatismos, doenças ou imperfeições no órgão ou no sistema visual. As pessoas com baixa visão podem ter baixa acuidade visual, dificuldade para enxergar de perto e/ou de longe, campo visual reduzido e problemas na visão de contraste.

Dependendo do grau da deficiência esta pessoa poderá ler em tinta utilizando-se de recursos ópticos como: lupas, lentes, telescópios e óculos especiais que ampliam a imagem na retina, melhoram a qualidade, o conforto e o desempenho visual. No entanto, a utilização desses recursos depende de orientação oftalmológica e de um trabalho de estimulação visual, além de orientação aos professores e à família.

Além desses recursos as pessoas com baixa visão poderão utilizar também os recursos não ópticos como: tipos ampliados (fontes acima de 18), circuito fechado de televisão (CCTV), softwares com ampliadores de tela e programas com síntese de voz.

A cegueira ocorre quando a visão varia de zero (ausência de percepção de luminosidade) a um décimo na escala optométrica de Snellen, ou quando o campo visual é reduzido a um ângulo menor que 20 graus. No caso das pessoas com cegueira, a escrita será realizada pelo sistema Braille e a leitura poderá ser pelo mesmo sistema, com a ajuda de um leitor ou por meio de programas de síntese de voz.

\section{A Deficiência Visual e a leitura de textos}

A deficiência visual priva a pessoa do mundo das imagens, sem as quais é necessário que outras rotas de compreensão do mundo sejam acessadas para que o desenvolvimento siga seu curso. O deficiente visual necessita de estímulos táteis e auditivos para se desenvolver, pois segundo Vygotski a criança com alguma deficiência não é uma criança que apresente um desenvolvimento menor que a normal, apenas se desenvolveu de outro modo. Em seu livro Obras Escogidas ele faz a seguinte colocação:

"Jamás obtendremos por el método de resta la psicologia de niño ciego , si la psicologia del vidente restamos la percepción visual el todo lo que está vinculado a ella. Exactamente del mismo modo, el niño sordo non es um niño normal menos el oído y el lenguaje. (...) Así como el niño em cada etapa del desarollo, em cada uma de su fases presenta uma peculliaridad cuantitativa, una estructura especifica del organismo y de La personalidad, 
de igual manera el niño deficiente present un tipo de desarollo cualitativamente distinto, peculiar(Vygotsky, 1997a, p.12)

Refletindo sobre esse desenvolvimento qualitativo e peculiar do deficiente visual, torna-se importante para os professores de Língua Portuguesa conhecer as necessidades e dificuldades de seu aluno com a deficiência visual. Saber como seu aluno aprende, para ajudá-lo a desenvolver rotas nas quais os processos mentais superiores como a atenção, percepção, memória, raciocínio, imaginação e a linguagem que auxiliam diretamente os trabalhos de leitura, análise e interpretação de textos faz parte do trabalho do professor.

O deficiente visual com baixa visão, dependendo do grau poderá usar dos recursos ópticos ou não ópticos para a leitura, já aquele com cegueira dependerá da audição e do tato para ler. Assim, será necessário que o professor esteja atento à essas questões e planeje seu trabalho levando em consideração as diferenças desse modo peculiar de desenvolvimento do deficiente visual. O que não significa que essas atividades devam ser mais fáceis que aquelas solicitadas para os demais alunos e sim adequadas à deficiência e o grau de conhecimento do aluno e que permitam que ele avance.

\section{O Contexto}

Minha primeira experiência com alunos com baixa visão (visão subnormal) foi em uma sala de $7^{\circ}$ ano do ensino regular de uma unidade escolar de uma rede particular da cidade de São Paulo. Recém concursada na rede me deparei com o Luiz, que usava óculos e conseguia ler com tipos ampliados. Naquele momento não sabia exatamente como lidar com a situação e a coordenação e a direção também não souberam me orientar. A única observação foi de que ele tinha muita dificuldade para aprender.

Para tentar entender qual era o problema de Luiz conversei com outros professores e uma das professoras mais antigas é que revelou a questão da baixa visão. Como não sabia do que se tratava busquei fazer um curso na Fundação Dorina Nowill sobre inclusão de alunos com Deficiência Visual no contexto escolar.

Após o curso tive condições de elaborar um plano de aula que permitisse atividades diferenciadas para que o Luiz pudesse avançar.

Ao me mudar da cidade de São Paulo para Uberaba desenvolvi um trabalho voluntário no Instituto de Cegos do Brasil Central no reforço escolar, onde a leitura, interpretação e análise de textos faziam parte da rotina. 
O Instituto de Cegos do Brasil Central é uma entidade filantrópica que tem por objetivos educacionais: promover a educação formal e informal do deficiente visual; através de oficinas Braille, recursos tecnológicos e metodologias inovadoras, para atender pessoas com cegueira, visão subnormal e surdocegueira. Por isso mantém em sua sede um leque de trabalhos especializados e voluntários, dentre os quais o reforço escolar.

\section{A leitura}

Para Kleiman (1992), a leitura é uma prática social que remete a outros textos e outras leituras. O que significa, que ao lermos um texto, seja ele qual for desvelamos todo o nosso sistema de valores, crenças e atitudes que vão refletir o grupo social ao qual pertencemos e no qual fomos criados.

Partindo deste princípio procurei entender o contexto no qual os alunos que comecei a atender estavam inseridos, quais eram os seus valores e o vínculo com a leitura.

O que percebi durante este trabalho é que não havia um vínculo com a leitura, pois para eles o que importava era ler para fazer as avaliações e as resenhas dos livros paradidáticos.

A leitura de um texto não proporcionava uma reflexão que remetesse a outros textos e tão pouco percebiam o que Schneuwly e Dolz(2004) chamam de "domínios sociais da comunicação", ou seja, qual a intenção e a estrutura do texto.

No Instituto de Cegos trabalhei com dois alunos, sendo que um era cego e outro com baixa visão.

\section{Victor (nome fictício)}

Ele era cego tinha 14 anos e era um aluno interno no instituto. Tinha família, mas esta vivia em outra cidade. Frequentava o $6^{\circ}$ ano (5 $5^{\text {a }}$ série) de uma escola particular em Uberaba.

Ele sabia ler e escrever no sistema Braille, no entanto a leitura para ele era imprescindível, pois era por meio dela que ele conseguia estudar para as provas e fazer as resenhas dos livros paradidáticos. Seu vínculo com a leitura era apenas com a finalidade de estudo. Sua rota era a audição, na qual elaborava as imagens, interpretava e compreendia o texto. 


\section{João (nome fictício)}

Aluno com baixa visão, 13 anos, interno no instituto. Não tinha pai nem mãe, mas tinha outros irmãos que estavam em outras instituições. Ele também estudava numa escola particular de Uberaba. João conseguia ler com tipos ampliados, mas precisava se posicionar bem próximo ao material de leitura, de tal forma que pudesse ler com o olho direito que tinha o maior resíduo de visão. Mesmo assim, em muitos momentos solicitou que lesse para ele. Seu vínculo com a leitura também era com a finalidade de estudo.

Durante a leitura os alunos prestavam muita atenção e sua concentração na sequência de ações dos textos também era muito boa. Um aspecto que considero importante é que se algo era incompreensível para mim, também o era para eles. Quando isso ocorria eles pediam para voltar, pois não haviam entendido.

O fato de verbalizar que eu também não havia compreendido o que estava escrito, porque o trecho do texto estava confuso, os deixava mais tranquilos por saber que 0 problema não estava neles.

Sentia-me bem fazendo aquele trabalho voluntário, porém apenas ler para eles sem aprofundar um conhecimento, por mínimo que fosse, não era suficiente, então iniciei um trabalho com gêneros textuais utilizando o material que eles precisavam estudar.

Não estabeleci metas para o trabalho, mas tinha como expectativa que a compreensão da função dos gêneros textuais melhorasse.

Considerando-se o gênero textual como um instrumento, que segundo Schneuwly e Dolz(2004), trata-se de um objeto socialmente elaborado e que determina, guia e diferencia a percepção de quem faz uso dele numa determinada situação, elaborei uma sequência de trabalho que permitisse a eles se apropriarem daquele texto e também de outros.

O trabalho tinha início com a exposição do gênero de texto a ser trabalhado, domínios sociais de comunicação, a linguagem e o vocabulário específico.

Consultando a bibliografia sobre gêneros textuais elaborei o quadro abaixo que foi adaptado do quadro existente no livro "Gêneros orais e escritos na escola". 


\begin{tabular}{|c|c|c|c|c|}
\hline $\begin{array}{c}\text { Domínios } \\
\text { sociais de } \\
\text { comunicação }\end{array}$ & $\begin{array}{c}\text { Capacidades } \\
\text { de linguagem } \\
\text { dominantes }\end{array}$ & Gêneros escritos & $\begin{array}{c}\text { Tempos } \\
\text { verbais }\end{array}$ & Pessoa \\
\hline $\begin{array}{c}\text { Transmissão e } \\
\text { construção de } \\
\text { saberes }\end{array}$ & Exposição & $\begin{array}{c}\text { Textos expositivos } \\
\text { ou explicativos } \\
\text { (Textos de livros } \\
\text { didáticos })\end{array}$ & $\begin{array}{c}\text { Infinitivo e } \\
\text { presente }\end{array}$ & $\begin{array}{c}3^{\underline{a}} \text { pessoa do } \\
\text { singular ou } \\
\text { plural }\end{array}$ \\
\hline $\begin{array}{c}\text { Cultura literária } \\
\text { ficcional }\end{array}$ & Narrativa & Narrativa de & Passado & 1ª ou 3 \\
& & aventuras & & singular ou \\
& & & & plural \\
\hline
\end{tabular}

Fonte: Quadro adaptado a partir do quadro presente em"Gêneros orais e escritos na escola" , pág.121. Bernard Schneuwly e Joaquim Dolz Editora Mercado das Letras, 2004

O quadro acima direcionava meu trabalho com os alunos e a exposição do seu conteúdo não era feita de maneira formal e sim permeava a leitura dos textos. A medida que lia chamava a atenção dos alunos para a estrutura do texto, a linguagem, os tempos verbais e a pessoa.

Foram utilizados dois gêneros de texto: os textos dos livros didáticos, que têm como capacidade de linguagem dominante o expor. E o gênero narrativa de aventura que tem como capacidade de linguagem dominante o narrar.

Durante a leitura, além do conteúdo fazia observações para eles a respeito das características dos textos, a linguagem e vocabulário. Quando terminávamos a leitura, solicitava que me dissessem o que compreenderam e solicitava que com que refletissem sobre a intenção que estava por trás daquele gênero.

Nas primeiras vezes este exercício de reflexão foi muito difícil para eles, porque a reflexão os obrigava a perceber o texto por outro ângulo, diferente do que eles estavam acostumados, que era a leitura pela leitura.

A medida que avançávamos no número de atendimentos percebia que eles desenvolviam um outro tipo de escuta, ou seja, ao ouvirem determinada sequência já relacionavam aos aspectos característicos do gênero.

Reconheciam o narrar e o expor, também relacionavam a outros textos lidos pelos professores em sala e que apresentavam as mesmas características.

Essa apropriação da linguagem, nesse caso específico do expor e do narrar, colaborou para uma melhora na compreensão, interpretação e análise de textos que surgiram posteriormente, tanto didáticos como paradidáticos. 


\section{As reflexões em serviço}

Assim, as reflexões que elaboramos durante este trabalho foram:

$\checkmark \quad$ A escuta pura e simples do conteúdo do texto não elevava o padrão de atenção, concentração, percepção e memória dos alunos.

$\checkmark \quad$ Estabelecer um parâmetro de leitura proporcionou um trabalho com um objetivo e maior aproveitamento por parte dos alunos, no que diz respeito à atenção, concentração, percepção e memória do conteúdo lido.

$\checkmark \quad O$ trabalho com a leitura focada em parâmetros pré-definidos fez com que a rota da audição fosse trabalhada, não com o objetivo da escuta pura e simples, mas direcionada para a compreensão, interpretação e análise.

\section{Considerações Finais}

As reflexões que elaboramos durante 0 trabalho apontam para a importância do conhecimento das possibilidades que o deficiente visual tem e que precisam ser exploradas.

Longe de ser um método para o trabalho de análise, interpretação e compreensão de gêneros textuais por deficientes visuais, o presente trabalho trata-se apenas de uma reflexão sobre esse aspecto. $\mathrm{Na}$ qual, buscamos explorar a rota da audição de maneira qualitativa com o objetivo de proporcionar uma reflexão sobre o conteúdo lido.

O estabelecimento de parâmetros para a leitura dos gêneros textuais colaborou de forma positiva para elevar o padrão da atenção, concentração, percepção e memória dos alunos.

Compreendemos o grande desafio do professor de Língua Portuguesa que recebe um aluno com Deficiência Visual em sala de aula. No entanto, retomando Vygotski, a criança com alguma deficiência não é uma criança que apresente um desenvolvimento menor que a normal, apenas se desenvolveu de outro modo.

Esse outro modo que as crianças com deficiência visual se desenvolvem precisa ser compreendido pelo professor, durante o trabalho de leitura, interpretação e análise de gêneros textuais. Porque todas as pessoas são capazes de aprender, cada uma tem seu próprio ritmo e o papel da educação é formá-las respeitando a diversidade e trabalhando a equidade. 


\section{Referências Bibliográficas}

KLEIMAN, Angela. Oficina de Leitura: Teoria e Prática. 10ª ed., Campinas, SP: Pontes, 2004.

SCHNEUWLY, Bernard. DOLZ, Joaquim. Gêneros orais e escritos na escola. Tradução e organização Roxane Rojo e Galís Sales Cordeiro - Campinas, SP: Mercado de Letras, 2004 - (Coleção as faces da Linguística Aplicada).

VYGOTSKI, Lev Seminovich. Fundamentos da Defectologia. Obras Escogidas. $2^{\mathrm{a}}$ ed. vol. V. Havana: Editorial Pueblo y Educación, 1997. 


\title{
ENSINO DE LÍNGUA MEDIADO POR COMPUTADOR: DA EDUCAÇÃO INFANTIL AO ENSINO MÉDIO
}

\section{TEACHING LANGUAGE MEDIATED BY COMPUTER: THE CHILDREN EDUCATION TO HIGH SCHOOL}

\author{
Andréa C. Centeno Rodrigues da Cunha \\ UFMG / Colégio Nossa Senhora das Dores - Uberaba-MG \\ andrea centeno cunha@yahoo.com.br \\ Cláudia Almeida Rodrigues Murta \\ UFMG / Colégio Atenas - Patrocínio-MG \\ claudia.murta@bol.com.br
}

RESUMO: No novo cenário que se apresenta na realidade social, o da intensificação do uso das tecnologias da informação e comunicação, o papel do professor, mais uma vez, se mostra fundamental para a promoção do letramento digital dos educandos. Neste sentido, metodologias de ensino que envolvam o uso das tecnologias da informação e comunicação são demandadas. O objetivo deste trabalho é relatar a experiência de ensino de língua portuguesa e estrangeira mediado por computador em escolas da rede particular de ensino nos anos iniciais e no ensino médio nas cidades de Patrocínio-MG e Uberaba-MG.

PALAVRAS-CHAVE: Ensino de línguas; computador; interação.

ABSTRACT: Within a new context which arises in social reality and is related to the growing use of information and communication technologies, the teacher's role, once again, becomes fundamental for the promotion of students' digital literacy. In this sense, teaching methodologies which involve the use of these information and communication technologies are demanded. The aim of this paper is to report the experience of the teachning of Portuguese and foreign language mediated by the computer in private schools both in the beginning years and in high school in the cities of Patrocínio-MG and Uberaba-MG.

KEYWORDS: Language teaching; computer; interaction.

\section{Introdução}

O momento histórico em que nos encontramos no qual o uso das tecnologias digitais e dos sistemas de informação permeiam as relações sociais, o letramento digital é premissa para inserção do cidadão nas práticas sociais. As grandes inovações tecnológicas ocorridas nas últimas décadas resultaram na inclusão dos computadores nas 
escolas modificando o cenário escolar, trazendo desafios para os professores que se veem diante de novas situações pedagógicas geradas pelo acesso à informação, à participação ativa do aluno no processo de ensino e aprendizagem.

Nesse novo cenário que se descortina, o papel do professor, mais uma vez, se mostra fundamental para estimular nos alunos a busca pelo letramento digital, orientandoos a utilizar o computador e, consequentemente, a internet, de maneira segura, crítica e autônoma, dentro ou fora da escola.

Este trabalho tem como objetivo relatar a experiência de ensino de língua portuguesa e estrangeira mediado por computador em escolas da rede particular de ensino nos anos iniciais e no ensino médio nas cidades de Patrocínio-MG e Uberaba-MG.

\section{Nova era, nova escola}

Grandes revoluções acompanharam a trajetória do homem provocando grandes mudanças sociais e culturais que, consequentemente, levaram ao surgimento de novos gêneros do discurso. A revolução da comunicação trouxe a Tecnologia da Informação e Comunicação (TIC) e a cultura digital propiciou o surgimento de novos gêneros textuais ou a evolução de gêneros antes restritos a determinadas esferas. A difusão da internet no cotidiano fez surgir segundo Lévy (1998, p. 28), "uma inteligência distribuída por toda parte, incessantemente valorizada, coordenada em tempo real, que resulta em uma mobilização efetiva das competências".

A escola como a instituição social responsável pela instrução formal dos indivíduos, especialmente pelo ensino da linguagem escrita, e, consequentemente, do letramento de seus alunos, também deve se responsabilizar pela formação digital de seus educandos, preparando-os para a interação com a cultura digital.

Para isso, deve estar aberta a novas metodologias de ensino que utilizem as tecnologias da informação e comunicação (TICs) para fins pedagógicos, visto que na vida social elas já são uma realidade.

Os profissionais da educação devem, portanto, estar preparados para a prática educativa utilizando novos recursos tecnológicos de maneira criativa e proficiente. Mas, não só isso, os professores devem letrar-se digitalmente antes de pensar em qualquer coisa. 


\section{O computador na sala de aula}

A ação do sujeito tratada frequentemente como prática ou práxis é o cerne do processo de ensino-aprendizagem. Mas, mais que isso, Vygotsky (1993) afirma que o meio social é determinante do desenvolvimento humano e isso acontece fundamentalmente pela aprendizagem da linguagem, que ocorre por imitação. Vygotsky concebe o homem como um ser histórico e produto de um conjunto de relações sociais, daí sua linha epistemológica ser denominada sócio-histórica. O estudioso considera que a consciência é engendrada no social, a partir das relações que os homens estabelecem entre si, por meio de uma atividade sígnica, portanto, pela mediação da linguagem.

É nas relações com o meio e com o outro (colegas e professor) mediadas pela linguagem que ocorrerá o desenvolvimento sóciocognitivo dos alunos. Na abordagem vygostskiana, o homem é visto como alguém que transforma e é transformado nas relações que acontecem em sua cultura. O homem é produto de trocas recíprocas, que se estabelecem durante toda sua vida, entre indivíduos e meio.

O professor vygotskiano é aquele que detendo mais experiência, funciona intervindo e mediando a relação do aluno com o conhecimento. O professor pode interferir no processo de aprendizagem do aluno e contribuir para a transmissão do conhecimento acumulado historicamente pela humanidade.

Outro aspecto importante no processo de ensino e aprendizagem tanto de Língua Materna quanto em L2 são as atividades lúdicas, visto que essas estimulam o desenvolvimento da fala e da escrita, propiciando aos alunos um ambiente de descontração. Para Vygotsky (1994, p. 103) "a aprendizagem e o desenvolvimento estão estritamente relacionados, sendo que as crianças se inter-relacionam com o meio objetal e social, internalizando o conhecimento advindo de um processo de construção".

Assim, de acordo com Teixeira (1995), o jogo é um fator didático de extrema importância; mais do que um passatempo, ele é indispensável para o processo de ensinoaprendizagem. A educação pelo jogo deve, portanto, ser a preocupação básica de todos os professores que têm intenção de motivar seus alunos ao aprendizado.

É possível observar, portanto, o quanto o lúdico desempenha um papel fundamental na educação. Levar esse lúdico para as telas do computador é um desafio para os profissionais conscientes de que a mentalidade das escolas engajadas com 0 processo de evolução crescente pelo qual estamos passando é um fato real. 
As noções da Linguística Ecológica também fundamentam uma proposta de ensino mediado por computador, já que é uma teoria que vê a linguagem como um sistema dinâmico, como atividade no mundo e nas relações entre os indivíduos, comunidade e mundo (VAN LIER, 2002 apud SOUZA, 2011).

Van Lier (2002 apud SOUZA, 2011) expõe quatro construtos básicos que sustentam a Linguística Ecológica, são eles:

1. A língua(gem) emerge de atividade semiótica;

2. A língua(gem) não surge de input que é processado, mas de affordances que vem a tona a partir de engajamento ativo e que permitem ação e interação adicional;

3. A língua(gem) não é transmitida de pessoa para pessoa por meio de monólogo ou diálogo, mas surge de processos indicativos que ocorrem em interações triádicas (para a Linguística Ecológica, o ambiente é parte constituinte das interações, sendo um terceiro interlocutor.)

4. A atividade linguística em contextos específicos pode ser analisada em termos de qualidade.

Paiva (2010) aponta para a importância do conceito de affordances utilizado pela perspectiva ecológica que pode ser de grande valia para esse projeto. O termo foi cunhado por Gibson (1986) explicado como o que o ambiente fornece ao animal (sujeito) tanto positiva quanto negativamente, implicando na complementaridade do animal (indivíduo) e do ambiente. O verbo afford, do inglês, pode ser traduzido como permitir-se, ter recursos, proporcionar, causar. Produzir affordances, na perspectiva do observador, faz referência ao processo de perceber objetos permeados de valoração. Van Lier (2004 apud SOUZA, 2011) pressupõe que o aprendiz ativo deve estabelecer relacionamento com e dentro do ambiente, em toda sua rica complexidade de fatores, interagindo em um espaço semiótico multidimensional.

O ensino de linguagem nessa proposta é um meio para que o aluno compreenda e insira-se no mundo por meio do domínio da Linguagem e das representações simbólicas. "Assim, na medida em que ele se torna mais competente nas diferentes linguagens, tornase mais capaz de conhecer o mundo" (VIEIRA, 2008 p. 449).

Novas tecnologias, ao se espalharem pela sociedade, levam a novas experiências e a novas formas de relação com o outro, com o conhecimento e com o processo de ensino. Conhecendo o percurso que a informação faz até se transformar em conhecimento, podemos desenvolver modelos de ensino-aprendizagem e de design instrucional que ajudem o aluno nos "processos de seleção, integração, armazenamento e 
recuperação da informação" o que a Filatro (2008, p. 72) trata como teoria da carga cognitiva.

Essa teoria aplica-se a todos os tipos de conteúdos, todos os tipos de mídias, e a todos os estudantes, visto que, ela tem como fim saber como se elabora as ferramentas de ensino - texto, imagens e áudio - e como aplicá-las a todo o conteúdo de ensino, bem como as plataformas de aprendizagem a distância, no intuito de potencializar a aprendizagem e desenvolver habilidades flexíveis através da criação e uso de recursos e ambientes de aprendizagem que estejam em sintonia com processo cognitivo humano.

De acordo com a Teoria da Carga Cognitiva (FILATRO, 2008), o aprendizado eletrônico deve propor atividades e exercícios práticos que requeiram dos alunos processar informações, em vez de simplesmente recuperar informações previamente fornecidas. Sob a luz do princípio da prática podemos dizer que o conjunto site/aplicativo permite ao aluno por em prática o conhecimento adquirido em sala de aula através da construção dos mais diferentes gêneros de texto, de acordo com o conteúdo estudado.

Assim, devemos criar atividades que levem os alunos a processar informações utilizando linguagem verbal e não-verbal, e não apenas um sistema semiótico, que não garante a capacidade de armazenamento na memória. Além disso, essa é uma forma mais prazerosa de aprendizagem.

O uso de ferramentas que propiciem novos significados exige profundas mudanças na forma de aprender, não sendo possível fazê-las apenas se espelhando no modelo educativo tradicional.

Atividades de ensino de língua mediadas por computador não é trocar o giz pelo mouse, é promover a autonomia do aluno, tornando-o construtor de seu conhecimento, instigando-o a buscar a informação, processá-la, analisá-la, criticá-la, para, enfim, apropriar-se dela de maneira consciente.

\section{Web 2.0 no ensino de línguas}

Antes de falarmos das ferramentas que propiciam a aprendizagem mediada pelo computador, é necessário esclarecer o conceito de web 2.0, visto que antes mesmo dos primeiros passos que tornariam a Web possível, Vannevar Bush (1945) já previa o que seria possibilitado pelo ambiente on-line, em sua idealização de um dispositivo, intitulado Memex, no qual poderíamos salvar toda nossa biblioteca, nossos registros, nossas comunicações, o que poderia ser consultado com rapidez e flexibilidade, suplementando 
assim a nossa memória. A primeira versão da Internet tornou-se uma realização duas décadas após tal projeção quando a ARPAnet, uma rede pertencente ao departamento de defesa dos Estados Unidos, foi colocada em funcionamento (TEELER; GRAY, 2000). Em 1990, Tim Berners Lee implementou a comunicação entre um cliente http e um servidor via Internet, passo que iniciou a popularização da rede que hoje conhecemos como Web.

Mesmo que não haja um consenso sobre esta questão, a academia, em geral, considera que após a implantação da Web, ela vem passando por diferentes fases que são denominadas gerações. A geração Web 1.0 caracteriza-se pela primeira fase da rede como um ambiente de conteúdo mais estático composto por aplicativos fechados, geralmente arquitetados por profissionais da área - webmasters. Desde 2004, uma nova geração de serviços e aplicações para a Internet entre em cena. A denominada Web 2.0 (O’REILLY, 2005) é vista como uma rede social, que permite aos usuários ao redor do mundo comunicarem-se, trocarem informações, arquivos de vídeos, imagens e sons. O'Reilly (2005) sublinha o fato de que Web 2.0 não se trata de algo novo, mas sim uma utilização da plataforma da Web e todo o seu potencial em uma perspectiva filosófica de criação e socialização de conteúdo e de conhecimento.

Em termos de linguagem de programação e de automatização da rede, BernersLee e Hendler (2001) antecipam a revolução tecnológica denominada por eles como Web Semântica, que posteriormente em um artigo do New York Times passa a ser considerada uma terceira geração da rede, Web 3.0 ou World Wide Database, termos empregados por John Markoff (2006).

Trata-se da organização inteligente do que está disponível na Web e da tendência para a convergência de várias tecnologias na mesma plataforma.

Várias são as ferramentas que podemos utilizar para promover a interação e a interatividade. A interação define, entre outras coisas, a existência de reciprocidade das ações de vários agentes. A interatividade traduz, mais particularmente, uma qualidade técnica das chamadas máquinas "inteligentes". Assim, podemos resumir afirmando que a interatividade é feita com a mediação de um meio tecnológico, uma máquina, um computador por exemplo. A interação, por sua vez, se torna muito mais ampla, podendo ser digital (interatividade), ser trocas e influências entre pessoas como em conversas, gestos, recados, discussões, etc.

Sob essa ótica, as relações educativas tornam-se pluridirecionadas e dinâmicas, possibilitando a todos os interessados interagir no próprio processo, rompendo com velhos modelos pedagógicos de comunicação unilateral que privilegia o emissor/professor onisciente e onipotente desconsiderando as peculiaridades do receptor/aluno, que deixa 
de apenas aceitar ou não a mensagem proposta pelo professor para tornar-se sujeito da própria educação em uma comunidade educacional interativa. Podemos ter dois tipos de sistemas de informática (Design Instrucional): reativos e interativos.

Os reativos seriam aqueles que deixam ao usuário a opção de reagir aos estímulos a partir de respostas pré-definidas, ou seja, as respostas que o usuário pode emitir são previamente selecionadas pelo sistema (ou pelo designer), restando a ele transitar pelo ambiente previamente programado, disparando as possíveis alternativas que o ambiente apresenta.

Já em sistemas interativos, os agentes envolvidos na comunicação podem interagir livremente. É basicamente a diferença entre preencher um questionário com alternativas fechadas e escrever uma redação.

Como Filatro (2008), acreditamos que em projetos mediados por computador a interação é pré-requisito, já que a primeira interação é com a máquina, além da interação com o outro: colegas e professores.

\section{Nossas experiências}

O relato que trazemos é acerca da inserção dos recursos da Web 2.0 no ensino de língua nas referidas escolas e níveis de ensino.

O site www.literaturanaweb.ning.com, desenvolvido pela professora Claudia Murta, em uma escola da rede particular de ensino da cidade de Patrocínio-MG. Trata-se de uma rede social criada dentro do ambiente online NING. É um ambiente agregador e veiculador das produções dos alunos. Ele é uma plataforma utilizada para complementar as atividades de sala de aula. Fomentar a aprendizagem da língua e literatura brasileiras mediante a produção de textos, literários e não-literários, que são veiculados na rede, promovendo a interação entre alunos e professor e entre alunos e seus pares. O público ao qual se destina essa proposta de ensino é o do Ensino Médio, já que a disciplina de Literatura encontra-se inserida na grade curricular desse nível escolar.

As ferramentas disponibilizadas na rede NING são utilizadas aproveitando o que os alunos fazem nas aulas, como vídeos que desenvolvem na disciplina, fotos de eventos da escola, etc., e ainda para fomentar as discussões em fóruns, cujos objetos são os temas literários. O objetivo do projeto é promover atividades utilizando o computador e criar um ambiente em que se possa veicular e articular os produtos dessa interação, compartilhando-os com a comunidade de alunos formada. 
De acordo com Filatro (2008) a teoria que melhor fundamentará esse tipo de trabalho é a Socioconstrutivista, já que o objetivo é justamente a colaboração e a interação entre os alunos. O modelo de aprendizado mais condizente é o colaborativo e o design instrucional contextualizado que utiliza os recursos da web 2.0 é o que atenderá às necessidades educativas, levando em conta que a dinamicidade do processo pode influenciar na sua mudança no decorrer das atividades.

A outra experiência compartilhada é o projeto Nice Class, cujo endereço é http://niceclass.webnode.com.br// desenvolvido pela professora Andrea Centeno numa escola da rede privada na cidade de Uberaba-MG. O objetivo do projeto é elaborar um site contendo atividades que apresentem os grupos de vocabulários básicos para as aulas de Língua Inglesa nos $1^{\underline{o}}$ e e $2^{\circ} \mathrm{s}$ anos do Ensino Fundamental, tais como: Greetings, Family Members, Colors, Fruits, Food \& Drink, Numbers $(0-10)$, Parts of the Body, Days of the Week, Months of the Year and Festivals (Easter \& Christmas).

A metodologia de ensino desenvolvida requer primeiramente que as aulas de L2 sejam feitas em sala de aula, a metodologia adotada segue a linha Montessoriana. Os alunos são reunidos em círculo e o professor apresenta o conteúdo a ser trabalhado utilizando materiais concretos, os quais os alunos têm total acesso para manusear, tais como: objetos reais (realia), flashcards, bexigas, massinha etc. O vocabulário é apresentado utilizando-se diversas estratégias e os alunos são convidados a interagir com seus colegas em L2. Nesse momento ainda não há nenhuma escrita, uma vez que as salas montessorianas do colégio utilizam o método fônico de alfabetização, o qual, nesse primeiro momento, acarretaria confusões desnecessárias aos alunos. Após todos terem conhecido o assunto, atividades recreativas e de produção criativa são proporcionadas. Nesse momento, os alunos têm acesso à parte escrita das palavras, porém a mesma não é enfatizada. Logo em seguida, em uma próxima aula, os alunos são convidados a praticarem os assuntos estudados na semana anterior, na sala de informática acessando o site criado para esse momento. Caso os alunos se sintam envolvidos e queiram praticar as atividades propostas pelo site em suas residências, será pedido para que os pais estejam juntos nesse processo, uma vez que é possível acessar o site diretamente, não sendo necessário passar pelo próprio site do colégio onde há um link para esse trabalho. O professor manterá um canal direto com pais e alunos através do link feedback proporcionado pelo site.

Assim sendo, temos como proposta adaptar as aulas de L2 em consonância com a computação, promovendo atividades virtuais que reforcem os vocábulos trabalhados. Através de um site, o aluno poderá praticar tais vocábulos no laboratório de informática do 
colégio, ou até mesmo em casa, com o auxílio dos pais. Essa interação será sempre acompanhada pelo professor/mediador, que, constantemente, checará no site o link feedback.

\section{Ferramentas utilizadas}

A seguir listamos uma série de ferramentas da web 2.0 e de outras gerações que utilizamos em nossas propostas. Os endereços elencados poderão servir de referência a demais profissionais da educação que queiram inserir em suas aulas os recursos do computador e da internet.

CRIAÇÃO DE BLOG

EduBlogs: http://edublogs.org

Blogger: http://www.blogger.com

Wordpress: http://wordpress.com/

Multiply: http://multiply.com/

VÍDEOS

Vixynet: (Converta arquivos do YouTube no formato FLV para AVI, MOV, dentre outros) http://vixy.net/

Yolango: http://www.yolango.com (Indicação da Prof ${ }^{a}$ Dra Vera Menezes)

Blip.tv: http://www.blip.tv/

Google video: http://video.google.com/

Eyespot (editor de vídeos online): http://eyespot.com/

Like television: http://tesla.liketelevision.com/

Pyro.tv: http://www.pyro.tv

SERVIÇOS DE PODCAST

Criação e hospedagem de Podcast: http://www.podomatic.com

CNN Podcasts http://www.cnn.com/services/podcasting/

Digital Podcast: http://www.digitalpodcast.com/

Newsweek Podcast: http://www.learnoutloud.com/Podcast-Directory/Social -

Podcast directory: http://www.podcastdirectory.com/

Podfeed: http://www.podfeed.net/

PLATAFORMAS WIKIS

Tiddyspot: http://tiddlyspot.com/

Wetpaint: http://www.wetpaint.com/

Wikia: http://www.wikia.com/wiki/Wikia 
Wikispaces: http://www.wikispaces.com

CRIAÇÃO DE HISTÓRIAS EM QUADRINHOS

http://www.makebeliefscomix.com// (indicação da Prof ${ }^{a}$ Dra. Vera Menezes)

http://www.stripcreator.com/

http://mashon.com/comics/

www.pixton.com

Estes são apenas algumas das infinidades de possibilidades que o computador e a internet podem trazer para o ensino de línguas. A cada dia novos aplicativos, ferramentas, softwares são criados e disponibilizados no universo virtual.

\section{Considerações finais}

A escola deve estar aberta para as novas modalidades de aprendizagem que podem ser mais democráticas e responsáveis pelo desenvolvimento da cidadania à medida que mais artefatos culturais são disponibilizados e veiculados na internet.

A condição de letrado digital é hoje uma premissa de integração social, especialmente no mundo do trabalho, e a promoção do letramento digital pode e deve ser mais uma das tarefas da escola.

A cultura digital pressupõe uma nova forma de aprendizagem que se caracteriza por ser mais dinâmica, participativa, descentralizada (da figura do professor) e pautada na independência, na autonomia, nas necessidades e nos interesses imediatos de cada um dos aprendizes que são usuários frequentes das tecnologias de comunicação digital e que ultrapassam os limites da sala de aula (XAVIER, s.d.).

\section{Referências}

BERNERS-LEE, T.; HENDLER, J. The semantic web. Mai. 2001. Disponível em: $<$ http://www.scientificamerican.com/author.cfm?id=582>.

FILATRO, A. Design Instrucional na prática. São Paulo: Pearson Prentice Hall, 2008. GIBSON, J. J. The theory of affordances. In: . The ecological approach to visual perception. New Jersey; London: Lawrence Erlbaum Associates, 1986. p. 127-143.

LÉVY, Pierre. A Inteligência Coletiva por uma antropologia do ciberespaço. São Paulo: Edições Loyola, 1998.

MARKOFF, J. Entrepreneurs See a Web Guided by Common Sense. In: The New York Times. Nov., 2006. Disponível em:

<http://www.nytimes.com/2006/11/12/business/12web.html>.

O'REILLEY, T. What is Web 2.0. set. 2005. Disponível em:

$<$ http://oreilly.com/web2/archive/what-is-web-20.html>.

PAIVA, V. L. M. O. Affordances beyond the classroom. (no prelo). 2010. Disponível em: $<$ http://www.veramenezes.com/beyond.pdf $>$. 
SOUZA, V. V. S. Uma textografia de ambientes virtuais de aprendizagem à luz do paradigma da complexidade. 2011. Tese (Doutorado em Linguística Aplicada) Universidade Federal de Minas Gerais, Belo Horizonte.

TEIXEIRA, C. E. J. A ludicidade na escola. São Paulo: Loyola, 1995.

VIEIRA, A. Formação de leitores de Literatura na escola brasileira: caminhadas e labirintos. Cadernos de Pesquisa. São Paulo: Fundação Carlos Chagas. v. 38, n. 134, maio/ago. 2008.

VYGOTSKY, L. S. A formação social da mente. São Paulo: Martins Fontes, 1994. . Pensamento e Linguagem. São Paulo: Martins Fontes, 1993.

XAVIER, A. C. dos S. Letramento digital e ensino. Disponível em: $<$ http://www.ufpe.br/nehte/artigos/Letramento\%20digital\%20e\%20ensino.pdf >. Acesso em: 10 jun. 2010. 


\title{
A IDENTIFICAÇÃO DE TÓPICOS NA CONVERSA CASUAL: UM ESTUDO BASEADO \\ EM CORPORA SOBRE O DISCURSO NA MÍDIA
}

\section{IDENTIFYING TOPICS IN CASUAL CONVERSATION: A CORPUS-BASED STUDY ON MEDIA DISCOURSE}

Barbara Malveira Orfano

bmalveira@yahoo.com.br

\begin{abstract}
RESUMO: Este estudo baseado em corpora objetiva revisar e investigar os principais tópicos apresentados no seriado da comédia Friends comparando com exemplos de converas espontaneas. Seguindo as observacoes feitas por Cutting (2000) este tranalho analisa e compara os topicos presentes no seriado Friends tendo o Santa Barbara Corpus of Spoken Language como corpusde referencia. Foram utilizadas, na análise, as seguintes ferramentas de análise de corpora eletrônicos: listas de palavras-chaves (keyword lists), listas de clusters (cluster lists) e linhas de concordancia (concordance lines). A pesquisa demonstra como os tópicos preferidos no seriado consequentemente influenciam o discurso no programa trazendo insights interessantes ao estudo de mídia baseado em corpora.
\end{abstract}

PALAVRAS-CHAVE: corpora; mídia; tópicos e palavras-chaves.

ABSTRACT: The aim of this research is to look at the topics found in the sitcom Friends, comparing some examples to casual conversation. According to Cutting (2000:27) topics need to be addressed following an interactive and pragmatic approach focusing on what speakers say about something that is being talked about. Following Cutting's (ibid.) observations to the study of topic this paper analysis and compare the topics found in the sitcom using the Santa Barbara Corpus of Spoken Language as a reference corpus. Following a thorough examination of key word lists and concordances lines the mainstream topics from both corpora are discussed. The results contribute to an ongoing discussion of how corpora research can contribute to media discourse studies.

KEYWORDS: corpora; media; topics and key words.

\section{Introduction}

According to Brown and Yule (1983:70) topic is one of the most frequently used but least explained terms in the analysis of discourse .This research sets out to investigate the role of the topics presented in the sitcom taking into consideration the fact that the sitcom is broadcast around the world, and thus has a broad participation framework represented by a 'global audience'. This analysis looks at the topics found in the sitcom, comparing some examples to casual conversation. First, drawing on Gardner's (1987) framework for the study of topic, we investigate how topics are developed in the sitcom. Secondly, we 
audit the types of topics found in the programme followed by examples from the Friends corpus and discussion. In this part of the analysis we follow Cutting's (2000) research on topic in order to identify and classify the topics in the sitcom. It is believed that both Gardner's (1987) and Cutting's (2000) work on topic will provide useful insights to the discussion of the linguistic features that determine the topics present in the sitcom. Drawing on the fact that the audience is also seen as part of the community of the show, the present article will also take into consideration the following issues:

i)shared knowledge: topics are usually conveyed from the pool of common knowledge of participants within a particular culture

ii) pragmatics: topics are negotiated and speakers speaking topically seek to make their contributions in accordance with what they think the other participants are talking about (Brown and Yule, 1983:89).

iii) audience: topics must be chosen taking into account the audience's interpretative schemata, and their expectations. The appropriate choice of topics contributes to the engagement of the audience within the participation framework of a particular show.

\section{Data and methodology}

This study comprises two corpora. The Friends corpus containing episodes from the sitcom Friends and a sub-corpus from the Santa Barbara Corpus of Spoken English (after here $S B C$ ). The Friends corpus is composed of fourteen episodes from the seventh season that were transcribed and stored for analysis and it has approximately 40,000. The Santa Barbara Corpus of Spoken Language has the same size of the main corpus and it has dialogues containing conversations among close friends that were carefully chosen in order to be representative and comparable to the main corpus.

At first, an observation from the key-word list pointed out the items that were indicating the possible relevant topics present in the sitcom. After this analysis, each scene was isolated and manually topics were classified. This topic classification confirmed that the results from the key- word list were indicating the most common topics in the sitcom and their importance in the overall narrative of the show. Following this observation in 
order to identify and characterize topics in Friends, we manually searched the data isolating the topics found in the sitcom.

\section{Definition of topic}

Before looking more specifically into the topics in Friends, we shall outline some definitions associated with the term topic. Many researchers have tried to pin down a definition of topic, but there are still many ongoing debates about what a topic is. Gardner (1987:129) emphasises that there are substantial problems in assigning the extent to which topic is crucial in the structuring of discourse. According to Gardner (ibid: 132.) native speakers seem to have an intuitive knowledge of topic as they usually summarise the topic of a conversation in a single sentence posing problems to a more systematic study of topics. However, O'Keeffe (2003) puts forward the idea that the 'notion of topic is both a process and product of generic activity within a given participation framework' (ibid: 111). The participation framework in Friends, due to the global nature of the show's audience, is very broad and this plays a crucial role in the topics chosen by scriptwriters in the sitcom.

Brown and Yule's (1983) definition of topic proposes a 'characterisation of topic that allows expressions and titles to be considered incorporating all reasonable judgments of what is being talked about' (ibid: 75). This definition is in line with Cutting (2000) who observes that a topic can be given a title that is an embedded question such as 'Why $X$ happened' or 'How to do $Y$ ' (ibid:27). Extract 1 gives an example of what a topic is following Cutting`s (2000) approach to topic.

Extract 1) Monica decides to make candies for her neighbours in order to get to know them.

Topic: Monica, Chandler and Joey are talking about the fact that they do not know their neighbours.

1 - <Chandler $>$ Hey. What are you guys doing.

2- < Joey> Hey.

3- $<$ Monica $>$ Making holiday candy for the neighbours.

4- <Chandler $>$ I'm sorry, who.

5- <Monica> I'm gonna hang this basket on the door and when the neighbours walk by they can all take a piece.

6 - <Chandler $>$ But we don't know the neighbours.

7-<Joey> I do. There's uh, let's see, guy with a moustache, smokes a lot lady, some kids I've seen, and a red-haired guy who does not like to be called rusty.

8- <Monica> See. This is exactly why I'm making this candy. We can learn their names and get to know our neighbours. 
In extract 1, Monica decides to make candies in order to get to know her neighbours. Joey's turn (line seven) supports Monica's claim that they do not know anyone living in the building as he cannot name any of their neighbours. In fact, they only know Rachel who shares the apartment with Joey. Thus, following the topic definition proposed by Cutting (ibid.), thus, we can say that the topic of the conversation in extract 1 is related to the following question: Why is Monica making candies for the neighbours? Before proceeding to the analysis we shall review some previous research on topics that are relevant to the present study.

\section{Theoretical Framework}

Before looking more specifically at the topics in the sitcom, we survey relevant research previously done in topics following a linguistic perspective. Gardner (1987: 129), examines the presence of elements of spoken discourse that are associated with topical talk and acknowledges the presence of six categories ${ }^{3}$ of topical development in spoken interaction (topic change, topic continuation, topic introduction, topic shift, topic recycling and topic reintroduction). After analysing the topics present in the sitcom, we see that all of the features of topic outlined by Gardner for casual conversation exist in Friends. This finding is in line with the fact that TV series, usually, apply some of the characteristics of casual conversation in the dialogues of the programmes in order to convey a sense of reality to the audience. This can also explain the presence of similar linguistic features in the sitcom and in the natural corpus used in this study.

In another study, Cutting (2000), when investigating markers of in-group membership, observed that topics played an important role in revealing linguistic indicators of group dynamics. Cutting (ibid.) observed topic shifts in conversations of a group of students doing a Master's course in Applied Linguistics. According to Cutting, the increase of topic shifts after the first term of the academic year stems from the fact that after one term students become closer to each other forming a solid group. Thus the increase of topic shifts evidenced in Cutting's (2000) study determines the prevalent characteristics of the language of a group.

O'Keeffe (2003) observes the notion of topics in a radio phone-in context and finds that in her data, topics are culturally relevant and transparent for the audience, conveying a further index of shared space and knowledge in which the audience reside. We

\footnotetext{
${ }^{3}$ All the definitions concerning Gardner's categories are taken from Gardner (1987: 138-139).
} 
speculate that the reverse will be the case in Friends. Because of the global nature of the programme, topics will be culturally generic and hence universally transparent.

Fahey (2005) looked at topics in two soap operas, one Irish and one Chilean and also observed that personal knowledge of participants plays an important role. She states that in soap operas, topics and the rules of conversation that apply to the characters of a soap opera are presented and developed taking into account the audience, who ultimately ratify the dialogues. There are many similarities between soap operas and sitcoms and the dialogues in Friends seem to be carefully selected taking into account the audience's expectations; this will be further investigated in the analysis section.

\section{Topics in the sitcom}

In the first part of the analysis, we take into account the totality of topics found in the sitcom corpus and we examine their nature. As previously mentioned, defining and categorising topics is not an easy procedure. However, the fact that scriptwriters predecide the main theme of each show and main and sub-topics are developed within scenes has helped in the categorisation of topics outlined here. Topics were searched for manually, taking into consideration first the theme of the episode, then the main topic of each scene and its sub-topics. All of the scripts from fourteen episodes in the corpus were read and classified under specific categories considering the definition of topic arrived at in the introduction. Figure 1 shows how topics are structured hierarchically:

Fig.1- Outline of topic structure in the sitcom:

Theme of episode: The one with Monica's thunder

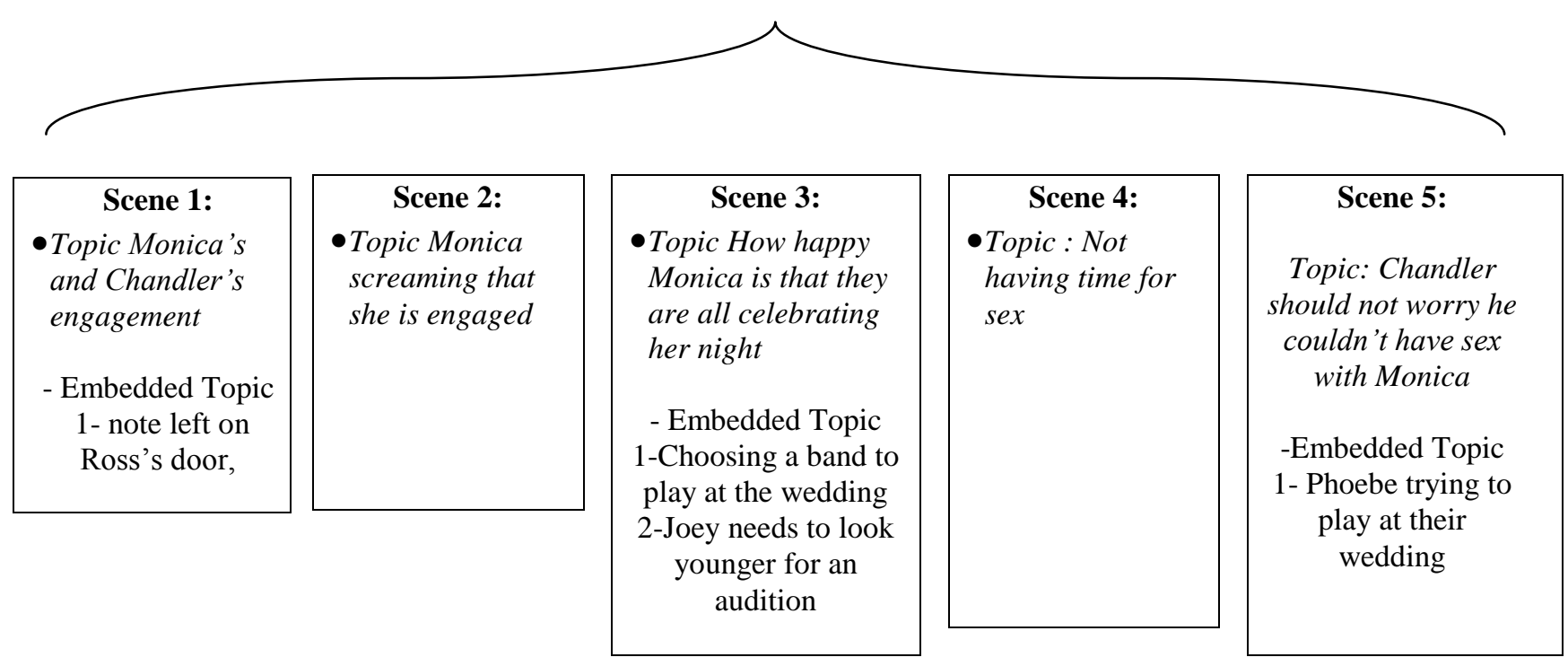


As can be seen from figure 1, topics in the sitcom are limited to the main topic of each episode. Topics and sub-topics are related to the main theme of a particular episode. The one with Monica's thunder is related to the fact that this night is supposed to be only about Monica and nothing else (see scene 3 from figure 1).

The sitcom corpus comprises fourteen episodes of the show and each show has a main topic as is illustrated by the title of each episode. This in itself self-defines topic at one level. The naming of the episode also means that viewers know what is going to be the main topic. To distinguish this overt topic from topics as they arise in the script, we will refer to this as the 'theme' of the episode. In parallel with the theme of the show, we find other sub-topics. They are important in the process of developing different storylines in the show in addition to the main theme. However, while identifying topics in the sitcom there were problems regarding the characterization of main topics and sub- topics. For example, some scenes appeared to have two main topics instead of only one, or in some cases finding the right category for a specific topic caused difficulties. Again, knowing the main theme of the episode and analysing each scene separately guided the classification of topics into main and sub- topics which also helped to identify the main themes in the sitcom as a whole.

Extract 2, gives an example of main topic and sub-topic in the sitcom.

\section{Extract 2}

Episode: The one with the truth about London

[Phoebe, Joey, Chandler, and Monica are returning from Central Perk.] Main topic: The fact that Monica had intended staying with Joey on the first night that she spent with Chandler (whom she subsequently forms a longterm relationship with).

Sub- topic: Phoebe's medicine side effects

1- <Phoebe $>$ I feel like my face is swelling. Is my face swelling.

2- <Monica> Phoebe, your face is fine. Come on, none of this stuff is going to happen to you. Stop being such a baby.

3- <Phoebe> Oh, interesting you should call me that. Now that I may never have one. Okay you guys, I got a little more written. Are you ready.

4- $<$ Chandler> Yeah. Okay.

5- <Joey> Oh. Okay. Ooh. Ooh. Okay, maybe l'll talk about London. You know when you two hooked up. Only, only I won't say hooked up. I'll say, began their beautiful journey

6- <Monica $>$ There you go.

7- < Joey $>$ By doing it.

8- $<$ Chandler $>$ Joe.

9- < Joey> Okay. All right. Umm, so uh, so how did it happen. Did your eyes meet across the room. And then the next thing you know you're in the bathtub together and she's feeding you strawberries.

10- <Chandler> Isn't that what happened with you and the bridesmaid.

11 - < Joey > Yeah. I call that London style. 
12- <Monica> No that is not what happened with us. Well, I was umm, I was really sad that night because this guy thought that I was Ross's mom. 13-<Joey> Oh.

14- <Monica> And then Chandler was, was really sweet and he consoled me. And well we drank too much+

15- < Joey> Yeah baby. Oh could you imagine if I sent that hooker up to the room like I was gonna. You two might've never gotten together. It's like it was in the stars.

16- <Phoebe> Yeah, it's totally meant to be. Tell him who you originally wanted to hook up with that night.

17- <Monica $>$ What.

18- $<$ Chandler $>$ What.

19- <Phoebe $>$ What.

20- $<$ Chandler $>$ Who did you originally want to hook up with.

21- <Monica> Okay, fine but please don't be upset. Okay. I was really depressed okay. And really drunk. I just wanted something stupid and meaningless. I just wanted just sex. So, when I went to your room that night I was actually looking for Joey.

22- <Joey> Yeah baby. No baby.

In Extract 2, for example, the scene starts with characters talking about Phoebe's medicine side effects (embedded topic) until Joey initiates the main topic of the scene and of the episode the fact that Monica had planned to stay with Joey and not Chandler. After this dialogue we have two more scenes in which this topic is readdressed.

One thing that is important in relation to topics in the sitcom is the fact that topics are already selected and designated to conversations by scriptwriters. This implies that topics are dealt with in the show taking into consideration its broad audience who are expected to interpret the dialogues in a pre-arranged way. By auditing the range of topics in Friends, it is possible to get a glimpse of what is seen as interesting, relevant and transparent to the audience of Friends. See table 1 for a breakdown of the frequency of the main topics.

Table 1- main topics in the Friends corpus.

\begin{tabular}{|l|l|}
\hline Mainstream Topics & Occurrences \\
\hline 1. Talking about relationships and sex & 37 \\
\hline 2. Talking about the workplace & 28 \\
\hline 3. Talking about non present people & 23 \\
\hline 4. Referring to leisure activities & 15 \\
\hline $\begin{array}{r}\text { 5. Referring to everyday objects like } \\
\text { photos and etc }\end{array}$ & 13 \\
\hline 6. Talking about age & 10 \\
\hline
\end{tabular}




\begin{tabular}{|c|l|}
\hline $\begin{array}{c}\text { 7. Talking about what is involved in } \\
\text { minding a child }\end{array}$ & 5 \\
\hline $\begin{array}{c}\text { 8. Talking about childhood memories } \\
\text { and objects }\end{array}$ & 4 \\
\hline 9. Referring to food & 3 \\
\hline 10. Referring to natural phenomenon & 1 \\
\hline
\end{tabular}

Relationships, the workplace and talking about non-present people, as can be seen in table 1, are major themes in the sitcom corpus. Nevertheless, some topics in Friends are bound to specific episodes, for example, the episode entitled: The one where they all turn thirty where the speakers' fear of getting old is discussed, but that does not mean that age is a recurring theme in the sitcom. In the next sections we look at the main topics in greater detail.

\section{Analysis}

\subsection{Relationship}

The topic relationship plays an important role in the sitcom, more specifically, dating, flirting and sex. This is also observed by Quaglio (2009), who calls attention to the limited range of subjects in Friends. One reason for that might be the fact that all characters belong to a close knit group. First, Monica and Rachel are childhood/school friends. Then, Chandler and Joey were roommates, Phoebe and Monica were also roommates in the past and second, Ross went to college with Chandler who ends up marrying Monica, Ross's sister. In addition Rachel and Ross were lovers and have a daughter together. All these facts can contribute to the emphasis on relationship themes present in the show. Another important reason is the fact that the target audience of the sitcom is young people, who are likely to favour topics relating to relationship themes. Extract 3 is an example from Friends.

\section{Extract 3)}

[Rachel enters Joey's apartment while he is teaching Chandler how to smile in pictures]

1- <Rachel> All right, will you, will you at least tell him how hollow and unsatisfying this dating tons of women thing is.

2- $<$ Joey $>$ What.

3- <Rachel> I just don't want him to meet anybody until I am over my crush. And I will get over it. It's-it's not like I love him, it's just physical. But I mean I 
get crushes like this all the time. I mean hell, I had a crush on you when I first met you.

4-<Joey> I know, Monica told me.

$5-<$ Chandler $>$ Did you have a crush on me, when you first met me.

6- $<$ Rachel $>$ Yeah. Sure.

The topic in this extract is Rachel's being attracted to her assistant. She is trying to hide her feelings, explaining that she gets 'crushes' on people all the time and ends up confessing that she had a crush on Joey and Chandler before.

A concordance line for the word love, for example, shows that speakers are constantly talking about relationships and how they feel about each other. Figure 2 is a concordance line for love in Friends.

Fig. 2- Concordance line for the word love in Friends

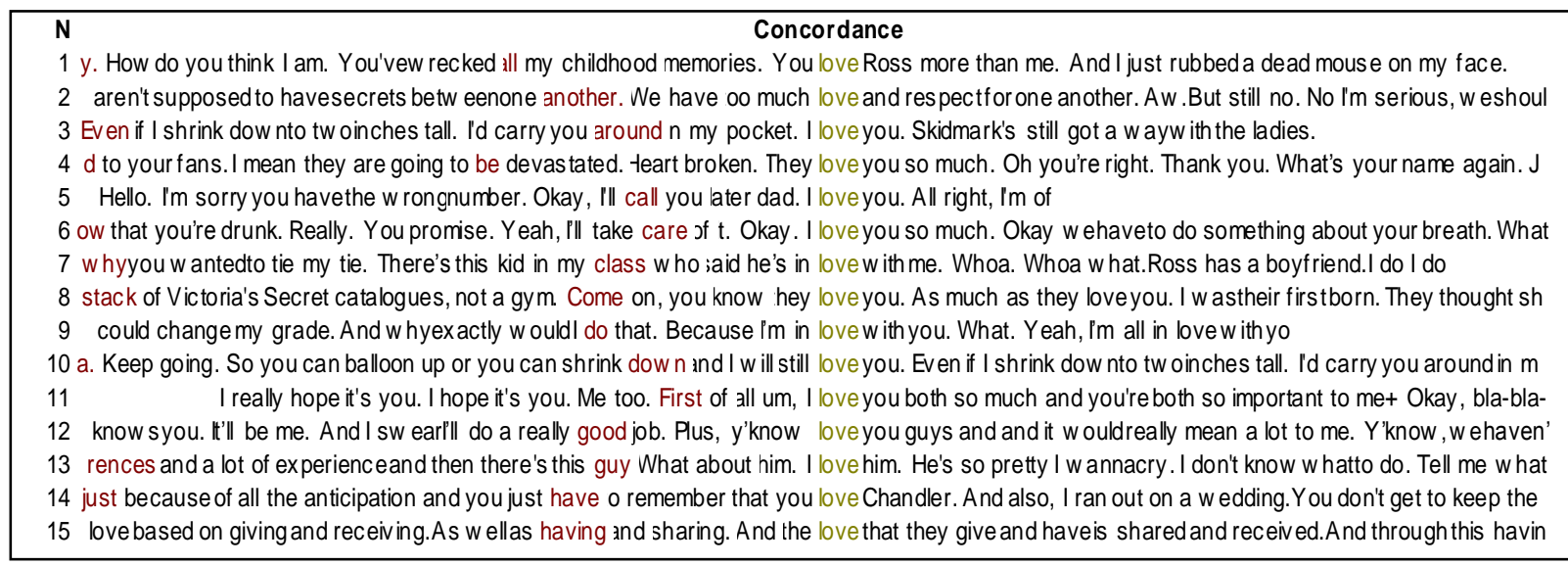

As we can see, in most of these instances, speakers use the word love to refer to their feelings for someone. For example, in line five from figure 2 above, Monica tells her father on the phone that she loves him: Okay, l'll call you later dad. I love you.

Using the log-likelihood function in Wordsmith Tools, a keyword analysis was carried out, using The Santa Barbara Corpus of Spoken Language as a reference corpus, and it was observed that the word love is an important word in Friends. The fact that love is unusually frequent in the sitcom when compared to the reference corpus confirms that the topic of relationships is an important one in the sitcom. Another important aspect about the word love is that the three word cluster frequency lists show that the expression I love you has a high frequency in the Friends corpus. Figure 3 is a sample of concordance lines for the expression I love you in the sitcom. 
Fig. 3- Concordance lines for the expression I love you in Friends

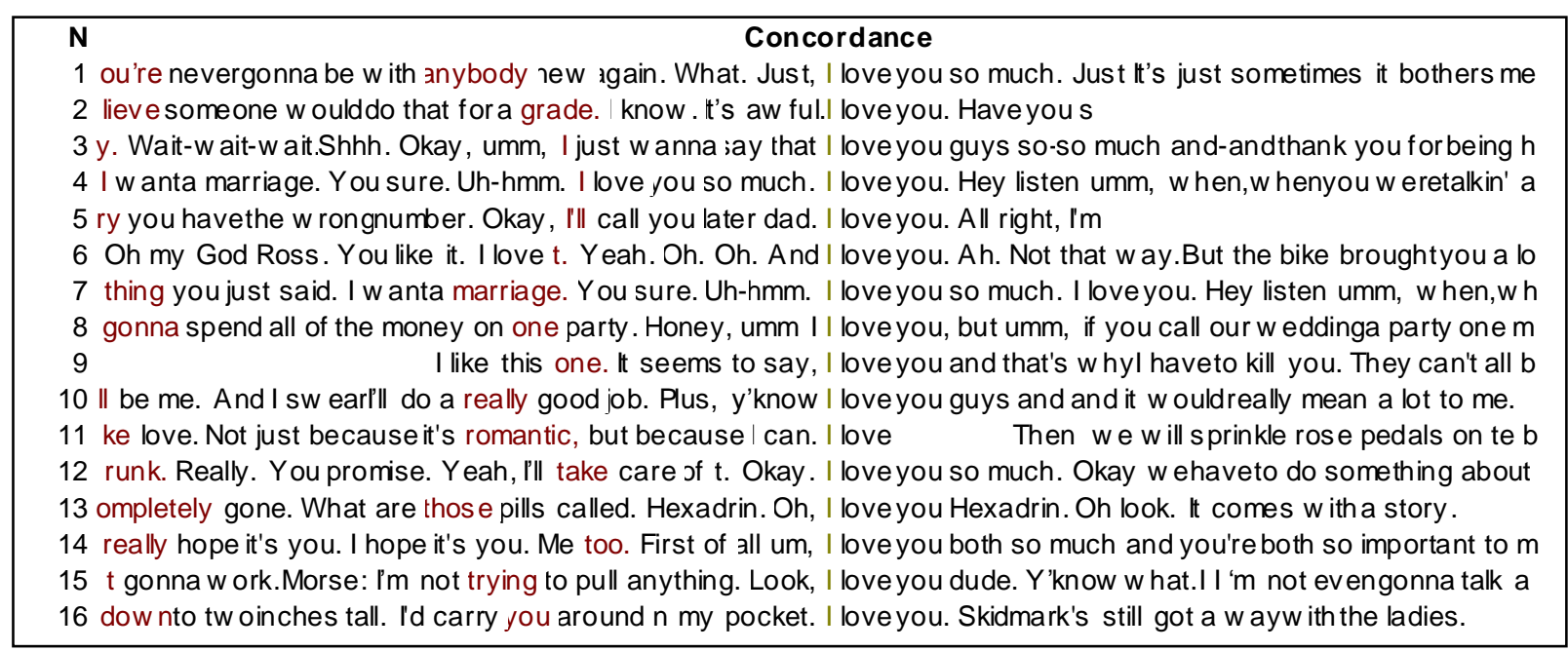

When comparing the frequency of I love you in the Santa Barbara Corpus it was observed that the expression is practically nonexistent in SBC. There is only one occurrence in SBC. This reinforces the claim that dating and flirting are at the heart of the programme.

\section{$6.2 \mathrm{Sex}$}

Another topic relevant in Friends is sex. Together with relationships, very often, sex accounts for many of the Friends dialogues. Sex is discussed subtly, in some examples, within the broad topic of relationships. In extract 4 Joey is trying to help Chandler with his sex life, but instead of using the word sex he uses a euphemism the expression the problems in the bedroom.

\section{Extract 4)}

[Context: Joey is asking his friends to stop talking about Chandler's sex life Main topic: Chandler's current sex problems]

1- < Joey> Oh my God. I cannot believe you guys are talking about this. The problems in the bedroom are between the man and the woman. All right. Now Chandler is doing the best he can.

$2-<$ Chandler $>$ I don't think that's what they were talking about Joe.

3- $<$ Phoebe $>$ What a great night, Chandler can't do it, these guys kissed

In another example Rachel also uses the word stuff instead of using sex when talking to Ross.

\section{Extract 5)}


[Context: Ross and Rachel talking about their relationship in the past

Main topic: Trying to find out something good about their past relationship]

1- <Rachel $>$ No, absolutely. you know like it was um

2- <Ross $>$ Surely you can think of something good.

3- $<$ Rachel> Yeah, just give me a minute. Oh well, yes, I can think of one good thing.

4- $<$ Ross $>$ What.

5- $<$ Rachel $>$ Well you uh, you were always really good at the uh the stuff.

$6-<$ Ross $>$ Yeah. I was good at the stuff huh.

As can be seen in the two extracts above it seems that making overt reference to sex is often avoided by speakers who instead prefer to use euphemisms as illustrated in table 2.

Table 2- Euphemism for the word sex in Friends (raw frequency):

\begin{tabular}{|l|l|l|}
\hline Word/expression & Frequency & Example \\
\hline Bed & 2 & $\begin{array}{l}\text { Well maybe she wouldn't have to be selfish } \\
\text { in bed if someone else knew where } \\
\text { everything was. }\end{array}$ \\
\hline Bedroom & 3 & $\begin{array}{l}\text { Yeah well, maybe she should've spent a } \\
\text { little less time decorating and a little more } \\
\text { time in the bedroom. }\end{array}$ \\
\hline To go to third base & 1 & $\begin{array}{l}\text { Remember, you went to third base with my } \\
\text { cousin Charlie. }\end{array}$ \\
\hline To sleep with & 1 & Why did you ever sleep with me? \\
\hline
\end{tabular}

The use of euphemism when referring to sex might be an indication that writers could be avoiding overusing or overtly using the word sex which can cause problems with censorship policies. Moreover, it is important to take into account the show's broad participation framework represented by its global audience. The show's scriptwriters have to find a way to make reference to topics that are appealing to the Friends target audience without being offensive. Therefore, talking about sex euphemistically allows scriptwriters to develop the theme of sex in a more subtle way.

\subsection{Workplace}


Speakers also talk about their work and in doing so they make reference to common tasks related to their jobs. Extract 6 is an example from Friends:

\section{Extract 6)}

[Context: Joey is explaining to Phoebe and Rachel that people from his job are upset with him because he refused to audition for a part in a TV show

Main topic: The fact that Joey does not have a job anymore]

1- < Joey> How could this happen to me. Yesterday I had two TV shows. Today, I got nothing.

2- $<$ Rachel $>$ Well wait a minute, what happened to Days of Our Lives.

3- < Joey > Uh, well they might be a little mad at me over there.

4- $<$ Phoebe $>$ What happened.

5- < Joey > Well maybe I got a little upset and maybe I told them where they could go.

6- <Rachel> Joey, why would you do that.

7- < Joey $>$ Because they wanted me to audition.

8- <Phoebe> You. An actor. That's madness.

In the previous extract Joey is telling Rachel and Phoebe what happened at his work. As he is an actor auditioning is part of his job and when he tells Rachel and Phoebe that he got upset when a director asked him to audition for a role in a soap opera Phoebe reacts ironically in line 8 . There are few examples in Friends where dialogues take place in the workplace.

Another important aspect observed is that when speakers in Friends talk about work they make reference to their co-workers which in some situations overlaps with the theme of talking about non-present people, but as they are referring to the work place when they do so, we may consider that the main topic is still about work. In extract 8 , Ross is talking about one of his students with Rachel and Joey. Previously, Ross, who is a lecturer, had spoken to his student about his grades and apparently the student is not able to concentrate because he is in love with Ross. In extract 7 Ross talks about his student with Joey and Rachel.

\section{Extract 7)}

[Context: Ross is telling his friends about his student falling in love with him

Main topic: the student might not be able to concentrate because he is attracted to Ross]

1- $<$ Ross $>$ The point is my natural charisma has made him fail his midterm.

2- <Rachel> Oh, see now I feel bad for the kid. I had a crush on a teacher once and it was so hard. You know you I couldn't concentrate and I blushed every time he looked at me. I mean come on, you remember what it's like to be 19 and in love.

3- <Ross > Yeah. I guess I can cut him some slack. 
4- $<$ Rachel $>$ Yeah.

$5-<$ Joey $>$ How do you get over that teacher.

One characteristic of this dialogue that enables us to classify it as a workplace topic is, for example, the use of words like fail and midterms which are very common for teachers.

\subsection{Non-present people}

Being a close knit group, speakers in Friends hardly ever talk about each other, when they do so; it is rarely in a pejorative way. When mentioning people they mainly talk about co-workers and family members. In addition, their talk has more the function of 'spreading news' about someone (Eggins and Slade, 1997:278). According to Eggins and Slade, talking about a third person with one or more people is an aspect of group cohesion and it also unifies a group, which is relevant in the sitcom data due to the nature of the main character's relationship. In extract 8 Rachel meets Ross in the hallway and starts talking about Monica's engagement but the topic shifts to the fact that she believes she will never get married.

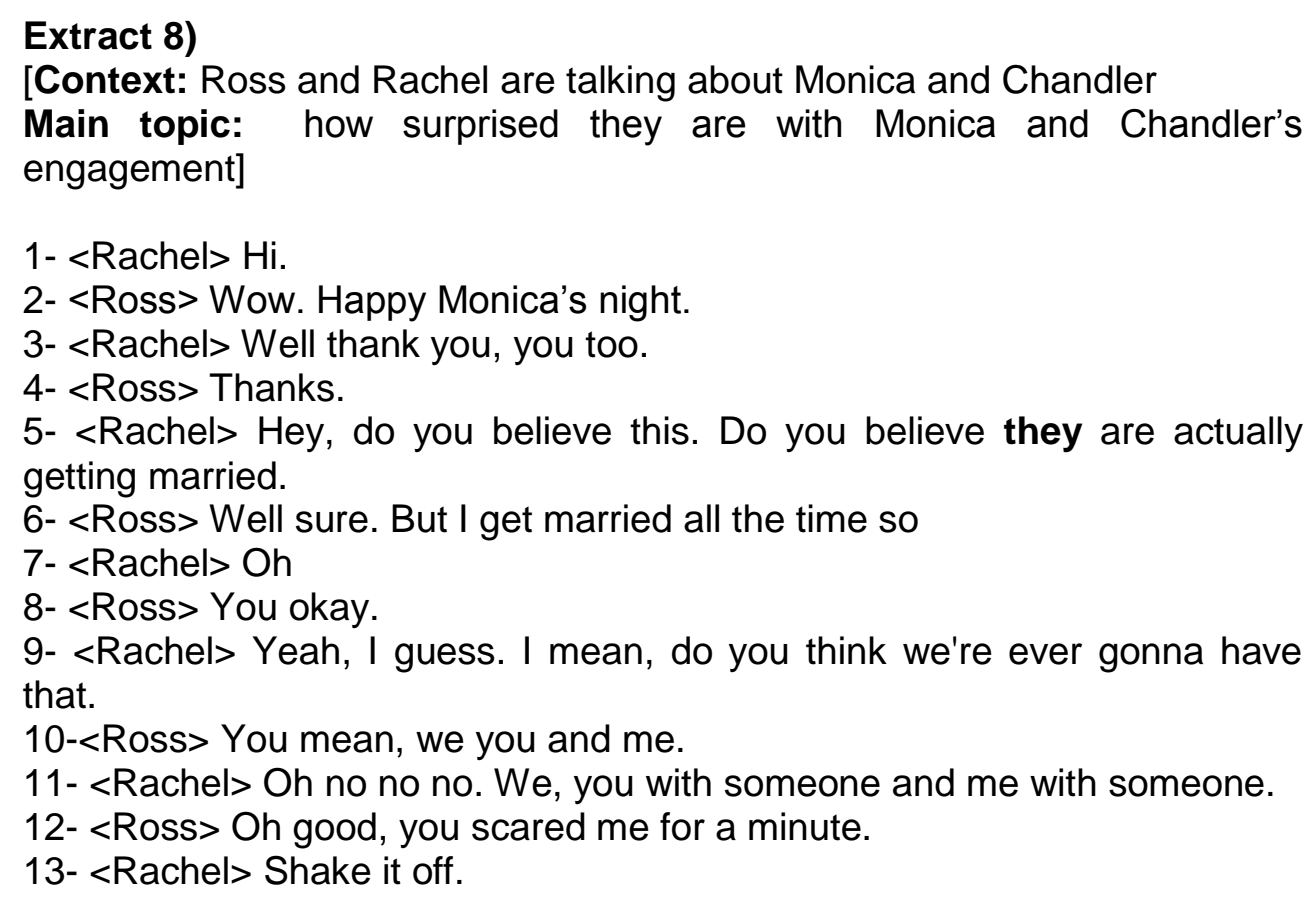

After the greeting stage lines (1-4), Rachel starts talking about Monica and Chandler (line 5) using the personal pronoun they. In the previous scene the group has agreed to go out to celebrate Monica and Chandler's engagement, something that the 
group would never expect to happen. An interesting aside in this dialogue is that Ross's answer to her question shifts the topic to her fear of being alone (lines 7-9) and their past relationship which is a recurrent topic in the sitcom (lines 10-13). Ross and Rachel's relationship causes a lot of anticipation for the show's audience and the scriptwriters seem to rely on the audience's accumulated shared knowledge about the previous events related to the couple. It is common to find references to their relationship in different dialogues.

When looking at the frequency of he, she and they in the two datasets we find that in Friends speakers talk less about non-present people than in the reference corpora (SBC), see table 3.

Table 3- Occurrence of he, she and they in the two corpora (per million words).

\begin{tabular}{|l|l|l|l|l|}
\hline Corpora & He & She & They & Total \\
\hline Friends & 3,725 & 3,175 & 3,200 & 10,100 \\
\hline SBC & 8,550 & 4,050 & 12,900 & 25,500 \\
\hline
\end{tabular}

The results in table 3 indicate that the reference corpora share more the characteristics of a unified group than the speakers in Friends. The higher frequency of the personal pronouns (he, she and they) in SBC ties in with Eggins and Slade's (1997:278) observations that talking about 'others' unifies a group of friends. Speakers in the sitcom do talk about non-present people; however, they do so significantly less (see table 3 ). In order to investigate this further, we looked at concordance lines to isolate the occurrences of he, she and they that were not referring to any of the main characters of the show (Rachel, Ross, Chandler, Joey, Monica and Phoebe) see table 4 below.

Table 4- Occurrence of he, she and they when referred to non-present people in the sitcom (per million words).

\begin{tabular}{|l|l|l|}
\hline Pronouns & Entire corpus & Non- present people \\
\hline $\mathrm{He}$ & 3,725 & 925 \\
\hline She & 3,175 & 725 \\
\hline They & 3,200 & 375 \\
\hline
\end{tabular}


According to table 4, in Friends speakers rarely talk about other people. When they talk about people they either talk about themselves or about each other. This might be an indication that narrowing down the range of people that the main characters refer to in the show might facilitate the comprehension for a 'global audience' that does not need to know a great number of characters. When new characters are introduced to the show they are usually referred to by their names followed by some kind of explanation as can be illustrated in extract 9 below.

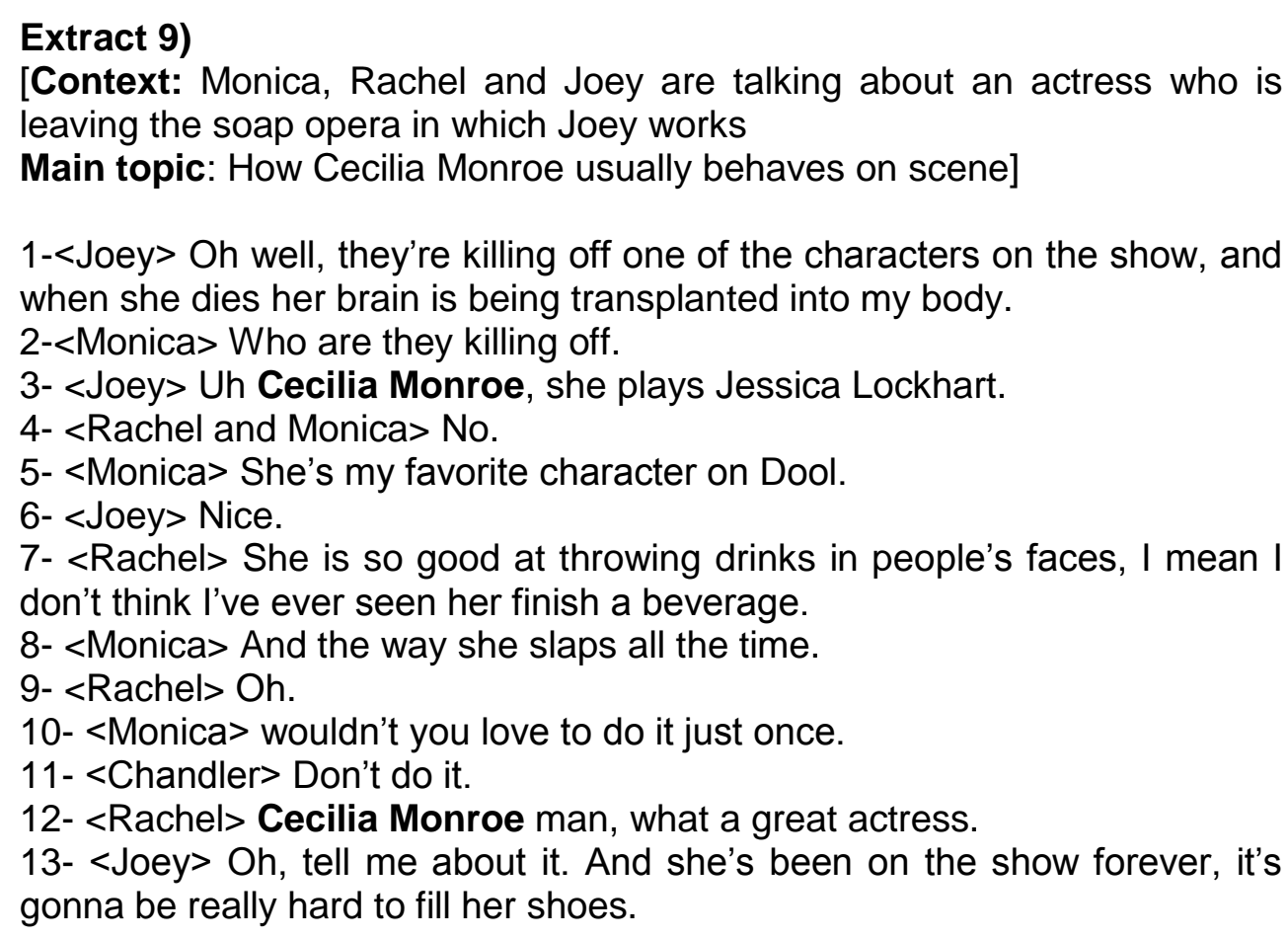

As can be seen in extract 9, Joey gives a kind of introduction to Cecilia Monroe before Rachel and Monica start talking about her. Viewers know she is an actress who works in the soap opera with Joey. In extract 10 from SBC speakers are also talking about someone who is not present in the conversation.

\section{Extract 10)}

[Context: Angela and Sam are talking about Ted

Main topic: the fact that Ted is very busy at the moment]

1- $<$ Angela $>$ how's Ted doing.

2 - $<$ Sam $>$ He's keeping very busy, he's on mostly uh evening hours,

3- $<$ Angela $>$ Mhm

4- $<$ Sam $>$ they're redoing the pharmacy there at Wal-Mart.

5- $<$ Angela $>$ Oh

6- $<$ Sam $>$ Enlarging it. He works uh six days next week, instead of five days, he only gets one day off.

7- $<$ Angela $>\mathrm{Hmm}$

8- $<$ Sam $>$ He's off today. 
9- $<$ Angela $>$ Mhm.

10- $<$ Sam $>$ and uh

11- $<$ Angela $>$ Well

12- < Sam> But he hasn't had day hours, he's been working evening hours and weekends.

In extract 10 from SBC it seems that the speakers know Ted very well. However, outsiders might not be able to establish the kind of relationship among Ted, Angela and Sam. It seems that in this example it is not necessary to give further information about who Ted is due to the fact that he is well known by the speakers. Examples like this are very common in casual conversation; however, in the sitcom when people mentioned are not present in the conversation they need to be introduced to the audience, in particular when these people are the topic of the conversation. Thus it can be said that the sitcom avoids mentioning people that do not belong to the group consisting of the six main characters in order to make the narrative easier for the audience to follow. When the topic of the conversation is related to non-present people, the first lines of the dialogue are dedicated to introducing the person to the audience, as seen in extract 10.

This section has surveyed the main topics of the sitcom. The examples illustrated that the main theme of the sitcom is relationships, followed by sex, workplace and talking about non-present people. It can be said that these topics are prevalent in the sitcom due to the show's audience interests. Scriptwriters take into consideration the show's target audience when writing and planning the dialogues of the episodes.

\section{Conclusion}

As mentioned earlier, the definition of topic is not a straightforward one. This research has proposed a notion of topic that acknowledges what is being said of what is being talked about (Cutting 2000). In addition, after analysing the Friends corpus, we believe in a notion of topic that contemplates speakers' commitment to a particular theme on the basis of participant's contributions to the dialogue as illustrated in extract 1 .

Evidence in support of Gardner's categories in the sitcom data shows that the Friends' pattern of topic generation is similar to that found in natural conversation. However, only relying on Gardner's (1987) topic framework, which is based on natural conversation is not sufficient and poses problems to the analysis of the topics in the sitcom. The dialogues in the sitcom are scripted and scriptwriters take into account their target audience's interpretative schemata when choosing the topics of the show. In addition, a crucial point in Friends is the fact that the sitcom has a broad participation 
framework represented by its 'global audience' around the world that consequently also influences the topics addressed in the show.

We concluded that in Friends speakers spend most of their time talking about flirting and dating, hence the mainstream topic relationships is very significant in the sitcom which may be in line with the viewing audience's preferences. Another topic that is common in Friends is talking about non- present people; but although they talk about workmates and family, they prefer to talk about themselves. They rarely refer to people that do not belong to their group. Conversely, both in SBC speakers talk about people that are not present in the conversation more often relying on their mutual knowledge about participants.

It is also important to highlight that, due to the nature of the topics chosen in the sitcom, one can say that the show avoids controversial themes such as politics, religion, personal opinions, etc. Overall the topics in Friends are very 'safe'; this might stem from the fact that the show needs to be able to 'travel' around the world and 'sensitive' topics could offend viewers and also hinder its broadcasting overseas.

In sum, the range of topics in Friends is an indication of what is seen as relevant to the show's target audience, bearing in mind that in the case of the sitcom this audience is represented by viewers around the world. In addition this characteristic seems to play a crucial role on the narrative of the show as can be seen in the prevalence of particular linguistic features present in the dialogues.

\section{Bibliographical references}

BROWN, G.; YULE, G. Discourse Analysis. Cambridge: Cambridge University Press, 1983.

CUTTING, J. Analysing the Language of Discourse Communities. Oxford: Elsevier Science, 2000..

EGGINS, S.; SLADE, S. Analysing Casual Conversation. London: Cassell, 1997.

FAHEY, M. A cross-cultural discourse and pragmatic analysis of two soap operas: Fair

City and Amores de Mercado compared: 2005. Tese (Doutorado em Linguistica Aplicada)

- Mary Immaculate College- University of Limerick, 2005.

GARDNER, R. The identification and role of topic in spoken interaction. Semiotica $65-1 / 2$, 1987

O'KEEFFE, A. Strangers on the line: a corpus-based lexico-grammatical analysis of radio phone-in. 2003. Tese (Doutorado em Linguistica Aplicada) - University of Limerick, 2003.

QUALIO, P. Television Dialogue: The sitcom Friends Vs. Natural Conversation. Amsterdam: John Benjamins, 2009. 


\title{
A RELEVÂNCIA DO RECURSO PEDAGÓGICO: MÚSICA NO ENSINO E APRENDIZAGEM DA LÍNGUA INGLESA
}

\author{
THE RELEVANCY OF TEACHING RESOURCE: MUSIC IN TEACHING AND LEARNING \\ OF ENGLISH
}

Domingos Caxingue Gonga ${ }^{4}$
dominguescg@hotmail.com

UENF

Duas culturas diferentes, duas formas diferenciadas de conceber conhecimento e organizar seus currículos de formação de professores. (FAZENDA, 1998.)

RESUMO: A música como forma de expressão cultural veicula valores estéticos, ideológicos, morais e religiosos. Ela possui, em seus conteúdos, as marcas do tempo e do lugar de sua criação. Ao mesmo tempo, representa um fator cultural importante por expressar a história, o idioma de um país/povo e ainda permite ao professor trabalhar as quatro habilidades da língua (compreensão, leitura, escrita e fala) com um vocabulário rico que oferece exemplos autênticos de coloquialismo e uma forma vasta de fonte de dados linguísticos contemporâneos. Quando escutamos músicas e tentamos repetir as palavras ditas pelo cantor (a), exercitamos nossa capacidade de pronunciarmos de forma correta os fonemas.

PALAVRAS-CHAVE: Música; Ensino-aprendizagem; Identidade; Língua Inglesa; interdisciplinaridade.

ABSTRACT: Music as a form of cultural expression indicates ideological, moral, religious and aesthetic values. They have in their contents, the marks of time and place of its creation. At the same time, representing an important cultural factor, by expressing the history, the language of a country/folk, and even allows the teacher to work the four language skills (reading comprehension, writing and speaking) with a rich vocabulary that offers authentic examples of colloquialism and a vast array of contemporary linguistics data source. Because when we listen to music and try to repeat the words spoken by the singer (he/she), we are exercising our ability to talk properly phonemes.

${ }^{4}$ Mestrando em Cognição e linguagem sob orientação do Dr. Sérgio Arruda pela - Universidade Estadual Norte fluminense - UENF. 
KEYWORDS: Music; teaching and learning; Identity; English; interdisciplinarity.

\section{Introdução:}

Ritmo e o alcance da mudança acontecem "à medida que áreas diferentes do globo são opostas em interconexão uma com as outras, ondas de transformação social atingem virtualmente toda a superfície da terra" - e a natureza das instituições modernas (In Hall, Ciddens 1990, p.6).

Esta pesquisa interessa-se pela aprendizagem da língua inglesa por meio da música, entendida como possibilidade de minimizar as barreiras que o discente encontra no aprendizado de uma língua estrangeira. Parte-se da premissa de que por meio deste recurso, o ensino da língua torna-se mais dinâmico, motivador e eficaz. Sendo assim, firma-se que a música muitas vezes é o reflexo de uma cultura, pois representa crenças, valores, hábitos, enfim, as tradições de um povo. A música ainda pode contar a história de uma nação e aproximar povos em torno de assuntos universais como: amor, mágoa, ódio, desesperança/esperança. A música está presente em todo o lugar e faz parte do universo da comunicação. Isso a torna uma ferramenta de comunicação de destaque. A relevância do recurso pedagógico música no ensino aprendizagem da língua inglesa em sala de aula pode ensinar, divertir, acalmar e unir os indivíduos. O uso deste aparato no ensino das línguas estrangeiras tem a conveniência de ser um importante elemento cultural e um excelente caminho para se estabelecer um paralelo entre cultura e o ensino de línguas, por isso, está cada vez mais presente nas escolas. A música ajuda na aquisição de um vocabulário cultural, ou seja, expressões populares que marcam a oralidade - gírias e pronúncias. A música colabora na aprendizagem de uma língua estrangeira, que pode ser trabalhada de modo a auxiliar o aprendiz no desenvolvimento de habilidades tais como: escrita, leitura, compreensão auditiva e oral. E assim consequentemente, tem-se o aumento da eficiência para se assimilar às normas gramaticais que regem este idioma (ou uma língua). O uso desse recurso no ensino e aprendizagem de língua estrangeira, não só estreita os laços entre o discente e o docente contribuindo para o desenvolvimento das habilidades acadêmico-cognitivas e outras como intrapessoal/interpessoal necessárias para a fluência oral, assim como outras relacionadas a aspectos da competência 
sociolinguística (CUMMINS, 1979). Para BRUNER (1986) e VYGOTSKY (1978), educação é um processo essencialmente cultural e social nos quais alunos e professores participam interagindo na construção de um conhecimento conjunto. Sendo assim, a utilização da música como recurso pedagógico diferencia-se dos métodos tradicionais, tornando os alunos mais produtivos, pois constitui uma quebra de rotina da aula tradicional, o que desperta o interesse e motivação dos estudantes a aprenderem. A música relaxa, diverte, emociona e proporciona um elo entre a linguagem e o mundo. Quando cantamos, adquirimos uma ótima capacidade de memorização, já que a maioria das pessoas consegue se lembrar de trechos de músicas aprendidas.

\section{Os sujeitos culturais}

Nosso mundo é um planeta unificado pelos quatro cantos do universo transformado por um "complexo processo e força de mudança, que, por conveniência, pode ser sintetizado sob termo "globalização" Anthony McGraw (1992)", esse processo, segundo Hall (2006), atua numa escala global que atravessa fronteiras nacionais, integrando e conectando comunidades e organizações em novas combinações de espaço- tempo, tornando o mundo, em realidade e experiência, mais interconectado. Este mundo unificado exige que busquemos cada vez mais construir uma educação interdisciplinar que não se retém somente na mútua troca das ideias, mas também na organização dos saberes e no ato de formar professores capazes de conduzirem com a busca da cientificidade disciplinar e com ela o surgimento de novas motivações epistemológicas, novas fronteiras existenciais (Fazenda, 2008.18). Motivações estas que buscam minimizar ou desconstruir as barreiras existentes entre o discente e o docente. Deste modo, objetivando a transdisciplinaridade, há a construção de uma fundamentação epistemológica tendo como finalidade argumentar em favor da unidade do conhecimento por ele denominado transdisciplinar. (idem)

Segundo Fazenda (2008), cada disciplina precisa ser analisada não apenas no lugar que ocupa ou ocuparia na grade, mas nos saberes que contempla, nos conceitos enunciados e no movimento que esses saberes engendram, próprios de seu lócus de cientificidade. Desta forma, essa cientificidade então ganha status de interdisciplinaridade no momento que obriga o professor a rever suas práticas e a redescobrir seus talentos, no âmbito em que ao movimento da disciplina seu próprio movimento foi incorporado. (idem) 
$\mathrm{Na}$ interdisciplinaridade escolar a perspectiva é educativa. Assim, os saberes escolares procedem de uma estruturação diferente dos pertencentes aos saberes constitutivos das ciências (In Fazenda Chervel, 1988; Sachot, 2001). Contudo, na interdisciplinaridade escolar, as noções, finalidades habilidades e técnicas visam favorecer, sobretudo o processo de aprendizagem, respeitando os saberes dos alunos e sua integração (Fazenda, 2008), sendo assim o uso do recurso-pedagógico música na arte de ensinar, dá ênfase a contatos com culturas diferentes por meio da aprendizagem das línguas estrangeiras. Há um conflito de culturas, que se justificam pelo sentimento de inexistência, de descrédito nacional que geralmente permeia o povo em desenvolvimento, outrora sujeitos à colonização predatória. Tal fato faz aflorar sentimentos que foram profundamente arraigados no passado colonial e continuam a sê-los no presente das indústrias culturais mundiais. Para contrapormo-nos a eles é importante que haja, no ensino das línguas estrangeiras,uma criticidade. Deve-se basear o ensino da língua nas histórias de cada povo, inclusive o nativo, e no relativismo cultural. Entende-se por relativismo cultural a veiculação de ideias de que todos os povos e países têm de suas próprias histórias e valores. Tal relativismo descarta a idéia da existência de países ou povos melhores ou piores que outros. (In Fazenda, Incanclini, 1983).

Como consequência, para sobrevivermos neste segundo dilúvio da informação na educação do século XXI, duas concepções são necessárias, segundo Lenoir (In Fazenda 2001). A primeira diz que a cientificidade aqui revelada deve estar em conformidade com a forma de pensar de uma cultura eminente francófona na qual o saber se legitima pela beleza da capacidade de abstração- saber/saber. Já a segunda parte da classe de ordenação social que se aproxima mais de uma cultura de língua inglesa na qual o sentido da prática - do para que serve - impõe-se como forma de inserção cultura essencial e básica - saber /fazer. (id in fazenda2008) por estarem mais ligadas às exigências sociais, políticas e econômicas.

Desde o início dos tempos, em conjunto com as grandes mudanças ocorridas na vida humana, nota-se que a mente, o caráter e a personalidade de um adolescente são formados na base sólida dos pais em conjunto como a escola. A escola em conjunto com os pais têm o papel de constituir os valores e formar um sujeito supranacional, preparado para um mercado de trabalho competitivo, com ritmos desenfreados.

Percebe-se então que o homem é constituído de fases que são chamadas de identidade. Assim sendo, tivemos o sujeito do lluminismo, que estava baseado numa concepção da pessoa humana como um indivíduo totalmente centrado, unificado, dotado das capacidades de razão, consciência e de ação, cujo "centro" consistia num núcleo 
interior que emergia pela primeira vez quando o sujeito nascia e quando ele se desenvolvia, ainda que permanecendo essencialmente o mesmo - contínuo ou "idêntico" a ele ao longo da existência do indivíduo. E o centro essencial do eu era a identidade de uma pessoa. Hall (2006)

O sujeito sociológico refletia a crescente complexidade do mundo moderno e a consciência deste núcleo interior do sujeito não era autônomo e auto-suficiente, mas formado na relação com "outra pessoas importantes para ele", que mediavam para o sujeito como valores, sentidos e símbolos culturais dos mundos que ele habitava (Hall, id). A identidade é formada na "interação" entre o eu e a sociedade. O sujeito não tem um núcleo ou uma essência interior que é o "eu real", mas este é formado e modificado num diálogo contínuo com os mundos culturais "exteriores" e as identidades que esses mundos oferecem (idem). A identidade na concepção sociológica preenche o espaço entre o "interior" e o "exterior" entre o mundo pessoal e o mundo público. A identidade, então, costura - ou para usar uma metáfora médica, "sutura" - o sujeito à estrutura. "Estabiliza tanto o sujeito à estrutura quanto aos mundos culturais que eles habitam, tornando ambos reciprocamente mais unificados e produzíveis". (id)

Como consequência, o sujeito pós-moderno é conceitualizado como não tendo uma identidade fixa, essencial ou permanente. A identidade torna-se uma "celebração móvel": formada e transformada continuamente em relação às formas pelas quais somos representados ou interpretados nos sistemas culturais que nos rodeiam (Hall, 1987).

Para Bakhtin (2003), a ideologia é um fato de consciência e que o aspecto exterior do signo é simplesmente um revestimento, um meio técnico de realizações do efeito interior, isto é, da compreensão. Um signo é um fenômeno do mundo exterior, sem signo não há ideologia, pois a ideologia é fruto da classe dominante.

\section{O ensino da língua inglesa no mundo tecnológico}

Entende-se que o advento das novas tecnologias da comunicação, viabilizaram a utilização da música como recurso pedagógico, diferenciando-se dos métodos tradicionais e assim tornando os alunos mais produtivos e interessados a atenderem aos objetivos dos docentes A música facilita a oralidade entre professor e aluno, pois permite uma quebra de rotina da aula tradicional, o que desperta 0 interesse e motivação dos estudantes a aprenderem. A música relaxa, diverte, emociona e proporciona um elo entre a linguagem e o mundo, entre o professor e o aluno, possibilitando a construção de um conhecimento coletivo. Quando cantamos, adquirimos uma ótima capacidade de 
memorização, já que a maioria das pessoas consegue se lembrar de trechos de músicas aprendidas. As canções como forma de expressão cultural, veiculam valores estéticos, ideológicos, morais e religiosos. As músicas possuem, em seus conteúdos, as marcas do tempo e do lugar da suas criações. Ao mesmo tempo, representam um fator cultural, importante por expressar a história, o folclore, o idioma de um país/povo, e ainda permitem ao professor trabalhar as quatro habilidades da língua - compreensão. leitura, escrita e fala - com um vocabulário rico que oferece exemplos autênticos de coloquialismo e uma forma vasta de fonte de dados linguísticos contemporâneos. A peça publicitária da escola de idiomas "IBEU", veiculado em 2010, ratifica a idéia da importância da utilização de novas metodologias no ensino da língua inglesa:

"A gente pode ensinar inglês assim; a gente fala e você repete e a gente fala de novo e você repete, mas a gente prefere acredita sabe em quê? Naquela banda Americana que você curte, e naquele artista inglês que você desenha pra caramba. Naquele filme que acabaram de lançar em Hollywood. Por que no IBEU, além do Livro do Professor, música também é aula."

Percebe-se que a visão interdisciplinar está dentro das práticas pedagógicas de variados cursos de inglês, ocorrendo troca mútua entre arte, desenho lúdico, cinema, atualidade e música - como um dos principais veículos para se alcançar o seu público alvo. É o que Fazenda $(2008,18)$ chama de interdisciplinaridade - a interação existente entre duas ou mais disciplinas. Verificamos que tal ação pode nos encaminhar da simples comunicação das ideias até a integração mútua dos conceitos-chaves da epistemologia, da terminologia, do procedimento, dos dados e da organização da pesquisa e do ensino, relacionando-os.

\section{A interdisciplinaridade}

Para que se possa entender a importância da interdisciplinaridade, faz-se necessária a definição de outros temas e idéias precedentes como a idéia de Multidisciplinaridade ou Pluridisciplinaridade - que é a justaposição de duas ou mais disciplinas, com objetivo múltiplo, sem relação entre elas, com certa cooperação mais sem coordenação de nível superior. Esta é uma estratégia pedagógica muitas vezes confundida com a interdisciplinaridade. Consiste de um trabalho constituído por duas ou mais disciplinas. Nela temos a escolha de um tema comum, onde cada professor contribui com o conhecimento especifico de sua área. 
Para Japiassu (1976), existe uma diferenciação entre os dois termos. A multidisciplinaridade, no sentido trabalhado por ele, trata-se de um sistema onde as disciplinas trabalham o mesmo tema, mas não há nenhuma cooperação entre elas, ou seja, o tema comum aparece como um meio para se chegar ao fim original da disciplina. Já a Pluridisciplinaridade traria a existência de cooperação entre as disciplinas, mas cada disciplina ainda estaria apegada ao seu fim original, sendo assim, o tema ainda aparece como um artifício da disciplina.

Segundo Japiassu, a interdisciplinaridade surge como uma necessidade imposta pelo surgimento cada vez maior de novas disciplinas. Assim, é necessário que haja pontes de ligação entre as disciplinas, já que elas se mostram muitas vezes dependentes umas das outras, tendo em alguns casos o mesmo objeto de estudo, variando somente em sua análise.

Fazenda (1996) define bem essa necessidade quando diz que "o que caracteriza a atitude interdisciplinar é a ousadia da busca, da pesquisa: é a transformação da insegurança num exercício do pensar, num construir". Maria Elisa Ferreira (1996) também reforça a idéia de atitude: "interdisciplinaridade é uma atitude, isto é, uma externalização de uma visão de mundo que, no caso, é holística".

O prefixo 'inter' dentre as diversas conotações que podemos lhes atribuir, tem o significado de 'troca', 'reciprocidade', e 'disciplina', de 'ensino', 'instrução', 'ciência'. Logo, a interdisciplinaridade pode ser compreendida como sendo a troca, de reciprocidade entre as disciplinas ou ciências, ou melhor, áreas do conhecimento. (FEREIRA in FAZENDA, 1993, pp. 21-22).

"Um olhar interdisciplinar sobre as práticas pedagógicas recuperam, segundo Fazenda (2001), a magia das práticas, as essências de seus movimentos". Para Atlet (2002), práticas pedagógicas são os atos singulares de um profissional da educação bem como os significados que este último lhe atribui. Para Bru (2002b), elas são entendidas como aquilo que faz o professor no seu estabelecimento de ensino em presença ou não dos alunos. Segundo Marcel (apud Bru e Talbot, 2001), a prática pedagógica comporta várias outras. Ela compreende, além da prática em classe com os alunos, os atos efetuados fora do tempo escolar frequentemente realizado na ausência deles, entre outros, as ações ligadas à planificação, aos encontros com colegas de trabalho e aos encontros com os pais.

Segundo Jean Piaget (in, Japiassu, 1976,55), a interdisciplinaridade deixa de ser um simples produto de ocasião para tornar-se a própria condição do progresso das pesquisas nas ciências humanas. 
Para Jiapiassu (1976), a interdisciplinaridade se define e se elabora por uma crítica das fronteiras das disciplinas, de sua compartimentação, proporcionando uma grande esperança de renovação e de mudança no domínio da metodologia das ciências humanas. O objetivo ideal a ser alcançado não é outro senão o de descobrir, nas ciências humanas, as leis estruturais de sua constituição.

JAPIASSUI, interdisciplinaridade também é um método que se elabora para responder a uma série de demandas:

a) há uma demanda ligada ao desenvolvimento da ciência: a interdisciplinaridade vem responder à necessidade de criar um fundamento ao surgimento de novas disciplinas;

b) há uma demanda ligada às reivindicações estudantis contra um saber fragmentado, artificialmente cortado, pois a realidade é necessariamente global e multidimensional: a interdisciplinaridade aparece como símbolo da "anti-ciência", do retorno ao vivido e às dimensões sócio históricas da ciência;

c) há uma demanda crescente por parte daqueles que sentem mais de perto a necessidade de uma formação profissional: a interdisciplinaridade responde à necessidade de formar profissionais que não sejam especialistas de uma só especialidade;

d) há uma demanda social crescente fazendo com que as universidades proponham novos temas de estudo que, por definição, não podem ser encerrados nos estreitos compartimentos das disciplinas existentes.

Quanto aos objetivos, os principais foram repertoriados por Clark Abt (7): despertar entre os estudantes e os professores um interesse pessoal pela aplicação de sua própria disciplina a outra; estabelecer um vínculo sempre mais estreito entre as matérias estudadas; abolir o trabalho maçante e por vezes "bitolante" que constitui a especialização em determinada disciplina; reorganizar o saber; estabelecer comunicações entre os especialistas; criar disciplinas e domínios novos de conhecimento, mais bem adaptados à realidade social; aperfeiçoar e reciclar os professores, reorientando-os, de sua formação especializada, a um estudo que vise à solução de problemas; reconhecer o caráter comum de certos problemas estruturais, etc.

\section{Pesquisa de campo}

Foi realizada, no ano de 2007, uma pesquisa junto aos alunos do $6^{\circ}$ ao $9^{\circ}$ ano do ensino fundamental do Colégio Adventista do Sétimo Dia da cidade de Campos dos 
Goytacazes/RJ. O efetivo ensino de inglês era dificultado por grupos que diziam não saber nada e pelos que não gostavam da disciplina e não tinham motivação.

Com o objetivo de motivar seus alunos, o professor procurou formular aulas cotextualizadas com a vida dos discentes. Observando-os, percebeu que adoravam levar para as aulas aparelhos de mp3 player e outros meios que reproduziam não somente som, mas também imagens. Alguns alunos chegaram a mostrar ao professor clipes de cantores famosos e trailer dos filmes, como Spelling Bee, que tinha marcado suas vidas e ainda estavam presentes em suas memórias.

Como estratégia de ensino, o professor passou a fazer uso de vídeos e notou os benefícios de tal experiência. Os alunos falavam, uns com os outros, sobre os vídeosn e começaram a cogitar a possibilidade de se realizar um Spelling Bee ou musical na escola. Em seguida, apresentaram clipes de Michael W. Smith um lendário músico e compositor gospel, com canções que ultrapassam o tempo, e outros, que naquele momento faziam a cabeça deles, tais como: Cris Brown, Rihanna, Miles Salles, Ne-yo, Link Park, Jonas Brothers e a febre do momento que era High School Music. O professor pôde perceber que haveria possibilidades reais de efetivar, tanto o Spelling Bee quanto o musical. A concretização desses eventos transformaria não só as práticas pedagógicas do docente, mas também mudaria as relações entre professor e alunos, transformando e melhorando o desempenho destes nas aulas, além de estreitar os laços entre a escola, a família e o professor.

A dificuldade estaria em escolher as músicas, pois a escola era uma instituição evangélica e nem todas as músicas poderiam ser tocadas lá. O professor pediu que eles trouxessem algumas músicas de seus gostos para que, em conjunto, escolhessem as melhores para serem trabalhadas nas aulas, sem mudar o planejamento escolar.

O trabalho foi realizado com as músicas selecionadas e também acontecia um Spelling Bee nos momentos finais da aula, trazendo extrema felicidade e realização pessoal ao docente. O sucesso dessa prática pedagógica provocou o desejo de se realizar um musical na escola com os alunos de $6^{\circ}$ a $9^{\circ}$ do ensino fundamental, o que foi decidido em conjunto e com o apoio da direção da instituição. Após a divulgação do evento, os alunos foram informados de que quem desejasse fazer parte dele, deveria fazer uma inscrição para viabilizar a participação.

Foram escolhidos, democratticamente, líderes para representar as turmas e para facilitar a realização do evento. Assim, o evento foi dividido em três grupos: o primeiro incumbia-se da arrumação do cenário, o segundo, da organização do evento e o outro, dos participantes - que iriam cantar, encenar ou tocar instrumentos. 
Motivados, os alunos convidaram amigos e pais, e diante da necessidade de se transferir o evento por motivos financeiros, os próprios disponibilizaram meios para que esse evento se concretizasse na data prevista.

Quase todos os alunos vieram vestidos a caráter de gala. $O$ evento teve como nome The First School Musical. A realização desse evento foi um sucesso para efetivação e consolidação das relações intrapessoal e interpessoal, entre alunos - alunos, e alunos com o professor. Houve, também, aproximação tanto dos pais com a escola, tanto da escola com os pais, criando uma relação de troca de saberes para melhor lidar com os seus filhos, além de permitir maior compreensão de atitudes dos discentes, provenientes da base educativa de seus lares.

O grande segredo para que esse evento fosse bem sucedido foi o planejamento dos seguintes itens:

a) a escolha das músicas da atualidade, ao gosto dos alunos;

b) a seleção das músicas a serem apresentadas e quais os alunos que teriam as vozes principais;

c) por último, a escolha dos instrumentistas principais, não excluindo os menos talentosos, facilitando o sucesso do evento.

\section{Considerações finais}

O sucesso em sala de aula se traduz na harmonia existente entre o profissional interdisciplinar preparado e a relação intrapessoal/interpessoal do professor com os seus alunos. A música é somente um recurso e depende de o docente saber usufruir dos benefícios deste. Se não bem utilizados, os benefícios existentes nele jamais serão vistos, como, por exemplo, harmonia, diversão, paz interna, relaxamento, prática dos tempos verbais, desenvolvimento da oralidade e da escrita etc. A resistência existente desaparecera por motivos de óbvios, que foi o planejamento da aula utilizando a música como motivação.

Conforme Jiapiassu (1976,53), falar das motivações do projeto interdisciplinar é reconhecer o conjunto das necessidades intelectuais e afetivas, bem como dos interesses que, de um modo ou de outro, puderam levar os pesquisadores a se engajarem no empreendimento interdisciplinar.

Compreendemos, portanto, a prática pedagógica como a prática profissional do professor antes, durante e depois da sua ação em classe com os alunos. Ela revela as competências, os invariantes de conduta, bem como os esforços de adaptação efetuados 
pelo profissional do ensino para responder aos desafios impostos pelas situações complexas em contexto de ensino-aprendizagem. Anderson Araújo-Oliveira (In Fazenda, 2008).

\section{Referências}

BAKHTIN, Mikhail. Marxismo e filosofia da linguagem. Tradução: Michel Lahud e Yara Frateschi Vieira, e com Colaboração de Lúcia Teixeira Wisnik, Carlos Henrique Chagas Cruz. São Paulo, Hucitec, 2004.

CALVET, Louis Jean. Sociolinguística. Tradução: Marcos Marcionílio. São Paulo, Parábola, 2002.

CASTELLS, M. A era da informação: Economia, Sociedade e Cultura: O poder da Identidade, Vol.II Fundação Calouste Gukbenkkian. Lisboa, 2003.

FAZENDA, Ivani(org.). O que é interdisciplinaridade? - São Paulo, Cortez, 2008.

JAPIASSU, Hilton. Interdisciplinaridade e patologia do saber - Rio de Janeiro, Imago editora Ltda. 1976.

MAGALHÃES, M; PAIVA, C.C. Estilos de identidade nas redes sociais de relacionamento. Culturas Midiáticas. In Revista de Pós-Graduação em Comunicação da Universidade Federal da Paraíba. Ano II, n. 02 - jul./ dez/ 2009

MCLUHAN, Marshall. Os meios de comunicação como extensões do homem. São Paulo: Cultrix, 1969.

MUSSALIN, Fernanda, BENTES, Anna Christina. Introdução à Linguística: Domínios e Fronteiras. São Paulo, Cortez, 2001.

MOITA Lopes, Luiz Paulo Da. Oficina de lingüística aplicada- a natureza social e educacional do processo de ensino/aprendizagem de línguas. - Campinas, SP: mercado de letras, 1996.

MAINGUENEAU, Dominique. Análise do texto de comunicação. Tradução: Cecilia P. de Sousa Silva e Décio Rocha. São Paulo, Cortez, 2002.

VERA, Lúcia Menezes de Oliveira e Paiva (Org.). Ensino de língua inglesa - reflexões e experiências. Pontes Editores, 1996.

HALL, Stuart. A identidade na cultura pós-modernidade. Tradução: Tomas Tadeu da Silva e Guacira Lopes louro - Rio de Janeiro, DP\&A, 2006.

HALL, Stuart (LIV, Sovik org.). Da Diáspora - identidade e Mediações Culturais. Tradução: Adelaine La Guardia Resende, Ana Carolina Escosteguy, Cláudia Álvares, Francisco Rudiger e Sayonara Amaral. Belo Horizonte, Editora UFMG 2009.

SAUSSURE, Ferdinand. Curso de Lingüística Geral. Tradução: Antônio Chelin, José Paes e Izodoro Blikstein. São Paulo, Clutrix Ltda., 1999/2000.

TERRA, Ernani. Linguagem, língua e fala. São Paulo, Scipione, 2002.

TSUDA, Yukio. (1994). The diffusion of English: Its impact on culture and communication. Keio Communication Review, 16, 49-61, 1994.

WEEDWOOD, Barbara. História Concisa da Lingüística. Tradução: Marcos Bagno-São Paulo: Parábola Editorial, 2002. 


\title{
PERSPECTIVAS EDUCACIONAIS DAS TECNOLOGIAS EM CURSO ON-LINE E AS ABORDAGENS TEÓRICAS DO ENSINO A DISTÂNCIA: LINGUAGENS E ENSINO
}

\author{
THE EDUCATIONAL PERSPECTIVE OF THE TECHNOLOGIES IN ON-LINE COURSES \\ AND THE THEORETICAL APPROACHES OF THE DISTANCE EDUCATION: \\ LANGUAGES AND TEACHING
}

\author{
Eliamar Godoi \\ PPGEL/FACED/ UFU ${ }^{5}$ \\ eliamar@cepae.ufu.br
}

\begin{abstract}
RESUMO: O objetivo desse trabalho é identificar e descrever as diferentes abordagens teóricas do ensino a distância e as perspectivas educacionais das tecnologias de um curso oferecido na modalidade on-line e seus reflexos na formação do professor. Partimos da hipótese de que as tecnologias como recurso didático auxiliam o aprendizado do aluno, influenciando o processo ensino-aprendizagem. Assim, como metodologia, foi adotada a pesquisa quantitativa e qualitativa de natureza exploratória. O ponto de partida teórico desse estudo assimila uma concepção de ensino baseada em metodologias de ensino adequadas para essa modalidade e na interação entre: o professor, o aluno, o conteúdo e as ferramentas digitais, tendo o Design Instrucional como elo, suporte e ambiente onde ocorre todo o processo de ensino e aprendizado. Sendo assim, se constitui como objeto de nossa pesquisa elementos como: ferramentas utilizadas ambiente on-line, design Instrucional, metodologias de ensino, modelos pedagógicos, além dos vários processos de interação. Procuramos, também, visibilizar, além das teorias, algumas concepções que permeiam o contexto do Ensino na modalidade a Distância como: Empirismo, Inatismo, Dialética. Como resultado parcial, percebemos que as insuficientes produções científicas em $\mathrm{EaD}$ pouco têm contribuído para o desenvolvimento de teorias nessa modalidade.
\end{abstract}

PALAVRAS-CHAVE: Ensino a Distância; Metodologias de ensino; Processo ensinoaprendizagem; Ambiente on-line; Ferramentas interativas

ABSTRACT: This study aims to identify and describe the different theoretical approaches of the distance education and the educational perspectives of educational technology course offered at a distance in the form on-line and their reflections on teacher training. Our hypothesis is that technology as a didactic resource helps student learning,

\footnotetext{
${ }^{5}$ Programa de Pós-Graduação em Estudos Linguísticos e Faculdade de Educação da Universidade Federal
} de Uberlândia 
influencing the teaching-learning process. Thus, the methodology adopted was the qualitative and quantitative research of an exploratory nature. The theoretical starting point of this study assimilates a conception of education based on teaching methodologies appropriate for this modality and interaction: the teacher, students, content and digital tools, and the Instructional Design as a link, support and environment where occurs throughout the process of teaching and learning. Thus, the object of our research are elements such as tools used online environment, Instructional design, teaching methodologies, pedagogical models, besides the various processes of interaction. We also seek to make visible, beyond the theories, some conceptions that underlie the context of the Distance Education in this mode in as: Empiricism, Innatism, Dialectic. As a partial result, we realize that insufficient scientific productions in distance education have contributed little to the development of theories in the discipline.

KEYWORDS: Distance Learning; teaching methodologies; teaching-learning process; Environment Online; Interactive tools

\section{De início}

O enfoque de nosso estudo recai sobre o uso de tecnologias voltado ao processo de ensino e de aprendizagem e busca promover uma reflexão sobre o fazer pedagógico de cursos oferecidos a distância. Por meio de uma discussão teórica, esse trabalho intenta fornecer ao interessado elementos que possam compor uma prática pedagógica mais consciente e que melhor atenda às necessidades dos alunos.

Nesse caso, esse estudo tem como objetivo problematizar em específico o processo de ensino, além de identificar e descrever as diferentes perspectivas educacionais em relação ao ensino disponibilizadas no modelo instrucional de um curso de extensão oferecido a Distância na modalidade on-line. Intentamos, também, elencar o levantamento das abordagens teóricas que fundamentam as ações no campo do ensino a distância.

Esperamos, nesse contexto, que com os resultados de nosso trabalho possamos fomentar a necessidade de construção de novos conhecimentos e de novas alternativas de ação da área de ensino nessa modalidade e seus reflexos no processo ensinoaprendizagem do aluno e na formação do professor.

Assim, esse estudo foi idealizado partindo do pressuposto de que todas as nossas ações devem apoiar-se no tripé pesquisa-ensino-prática. Essas ações devem envolver todos os elementos da comunidade educacional que compartilhem o mesmo interesse pela Educação de qualidade tais como: professores, alunos, coordenadores, técnicos e instituições.

Lembrando que nosso trabalho se insere no campo da Linguística com interface na Educação. Trata-se de uma pesquisa investigativa e descritiva de cunho interpretativista 
que percebe os dispositivos e ferramentas dos cursos on-line como constituintes de diferentes linguagens e como elementos que compõe a tecnologia educacional.

Para esse artigo apresentamos análises, fundamentações, além de uma contextualização de algumas ferramentas e dispositivos disponíveis em cursos on-line que surgem configurando as diferentes linguagens do processo de ensino.

Demonstramos também aspectos de uma confluência epistemológica que envolvem metodologias de ensino e os modelos pedagógicos apresentado em cursos online de modo geral abarcando o aspecto Ensino. Ao final, apresentamos nossas considerações esclarecendo sobre o processo de interação, o papel do professor e do aluno e a mediação do ensino (tutoria e docência).

A idéia da criação desse trabalho, surgiu da necessidade de se implementar um espaço de pesquisa, discussões e reflexões sócio-político-educacionais sobre a formação, a prática de ensino na modalidade a distância e os reflexos dessa modalidade na formação do professor e na aprendizagem do aluno para que fomentasse a construção de novos conhecimentos e de novas alternativas de ação da área de ensino.

Nesse contexto, pretendemos à luz de reflexões de alguns autores tais como: Maia e Mattar (2007); Pellanda, Schlünzen e Schlünzen Júnior (2005) esclarecer sobre alguns conceitos; em Ivan Domingues (1991); Oresti Preti (2002) entre outros, buscamos situar nossa pesquisa no campo de investigação epistemológica. Já para o campo de investigação teórica buscamos em: David Ausubel (1980), situar algumas de nossas questões no que se refere às formas de aprendizagem.

Com fins didáticos, para esse artigo, dividimos o processo da pesquisa em partes, quais foram: primeiramente, buscamos apoio teórico visando contextualizar e fundamentar nossas pesquisas em arcabouços teóricos que respaldaram nosso trabalho. Nessa parte, delineamos o papel do professor e do aluno no campo do ensino a distância, esclarecemos alguns conceitos e ainda

$\mathrm{Na}$ segunda parte, buscamos identificar, analisar e avaliar as interfaces e os dispositivos que compõem os ambientes virtuais de aprendizagem dos cursos analisados e como eles contribuem na formação do professor e na aprendizagem do aluno: as abordagens metodológicas e o modelo pedagógico, material didático, desenho instrucional e a disposição do conteúdo, a interação; e dispositivos como: chats, fóruns, sala de bate-papo, mensagens entre outros.

Para isso, partimos de uma avaliação quantitativa para uma qualitativa, amparados pela pesquisa interpretativa que se dará por meio da análise dos dados coletados no 
próprio ambiente do curso analisado, ou seja, nas situações ocorridas em ambientes reais de ensino e aprendizado em contextos virtuais.

Por último, são apresentadas as conclusões parciais de nosso trabalho, demonstrando os resultados de uma pesquisa apoiada no tripé: pesquisa-ensino-prática, cujas ações demonstraram a nossa preocupação com um trabalho que envolve certa totalidade abarcando nossa pretensão em contribuir para a formação de professores com perspectiva de atuação no ambiente digital e nosso desejo pela qualidade nos cursos oferecidos na modalidade on-line e sua influência no aprendizado do aluno.

A seguir, apresentamos os referenciais teóricos de nosso trabalho com propostas que fundamentam todas as ações no decorrer de nosso trabalho. Por motivos didáticos, nossa fundamentação tende a seguir a sequência disposta nos itens últimos ordenados nessa introdução.

\section{Fundamentação teórica: papel do professor e do aluno}

Como a área de educação a distancia ainda está em busca da formalização de uma base teórica, iniciamos nosso trabalho esclarecendo que na expressão 'Educação a Distância' (EAD) o termo Educação normalmente é substituído por Ensino, embora muitos estudiosos prefiram o primeiro termo, já que remete ao um conceito mais amplo que o de Ensino. Em nosso trabalho, nos permitimos adotar o termo Ensino, já que atuamos num campo mais específico de pesquisa que é investigar como ocorre o processo ensinoaprendizagem em cursos on-line, mas com um enfoque na área do Ensino.

Em relação ao conceito, segundo Maia e Mattar (2007, p. 06) "a Educação a Distância é uma modalidade de educação em que professores e alunos estão separados, é planejada por instituições e utiliza diversas tecnologias de comunicação". A partir desse conceito, podemos perceber que a modalidade a Distância se configura como um processo relevante para o desenvolvimento da educação que passa a usar das novas tecnologias para se configurar como evolução no que se refere ao ensino sistematizado. Essa modalidade tem-se atualizado no decorrer dos tempos e agregado muita pesquisa e uso de tecnologias. Ao obter ampla aceitação, o Ensino a distância requer estratégias diferenciadas para sua prática.

Nesse contexto teórico, para desenvolver esse trabalho, adotamos o conceito de Ensino a Distância como um meio que possibilita à comunicação, o ensino, a aprendizagem, o desenvolvimento de competências, habilidades e construção de conhecimento. Percebemo-la como um processo de socialização cujas ferramentas se 
configuram como dispositivos motivadores e como instrumentos pedagógicos dinâmicos que desencadeiam novas formas de pensar, construir conhecimento, novos modos de ensinar e de aprender amparados pela interação.

Assim, concebendo a linguagem como um lugar de ação e interação, buscamos uma ampliação do conceito de interação em que o diálogo ocorre de forma dialógica influenciando na experiência do dia a dia em campos de prática de ensino e de aprendizado o qual, no ambiente on-line, tende a ocorrer por meio da prática, ou seja, pelo aprendizado significativo (AUSUBEL, 1980).

É perceptível que o contexto do Ensino a distância prevê situações bem distintas das práticas de ensino convencional, pois tende a promover uma separação de questão espacial e temporal entre professor e aluno, requerendo um planejamento adequado à modalidade a distância, além de usar as novas tecnologias de comunicação.

Outro fator que favorece as práticas de ensino e aprendizado é que essa modalidade oferecida por meio das mídias interativas contribui para que o aluno construa o seu conhecimento de forma autônoma e significativa respeitando o tempo de desenvolvimento de cada participante. Nesse aspecto, é notória a evolução do ensino por meio dessa modalidade e mudanças se fazem indispensáveis.

Segundo Maia e Mattar (2007, p. 08) "o que mudou com as novas mídias é que os alunos e professores têm a possibilidade de interação e não apenas de recepção de conteúdos. Além disso, o aluno e o professor on-line aprendem a trabalhar com essas ferramentas". Esses autores chamam a atenção para uma proposta que valoriza um aprendizado significativo tanto para o professor em sua busca por capacitação profissional quanto para o aluno que aprende fazendo.

Tudo isso, num processo interativo que supera a barreira do espaço e do tempo favorecendo ao dialogismo e distribuindo responsabilidades. Nesse caso, o aluno deve assumir responsabilidade pelo seu aprendizado e o professor assumir o papel de mediador do conhecimento, além de criador de ambientes de aprendizado. Deve haver uma "apropriação" das tecnologias para que tanto o ensino quanto o aprendizado obtenha êxito, evolução e desenvolvimento, num processo de busca e construção do conhecimento por meio da interação.

No que se refere à apropriação das novas tecnologias como forma emancipatória, temos Pellanda, Schlünzen e Schlünzen Júnior (2005) que vêem a inclusão digital e a cultura das novas tecnologias como modelos potencializadores das qualidades dos seres humanos na busca pela autonomia na construção do aprendizado. 
Segundo esses autores, a implantação do Ensino a Distância depende de fatores que vão além da apropriação de tecnologias. São necessários investimentos mais direcionados e acertados principalmente na capacitação de muitos professores que ainda se vêem às margens do uso das tecnologias.

Assim, não basta o envio de máquinas 'potentes' para as escolas que sequer possuem locais adequados para recebê-las, mas carece estruturar, 'treinar', moldar a cultura tradicional, integrar e principalmente incluir o uso das mídias no contexto escolar amenizando a atual situação de exclusão digital.

Os autores acima, ainda esclarecem que a

exclusão digital não afeta somente os mais carentes do ponto de vista socioeconômico, mas os trabalhadores das empresas, os indivíduos com necessidades especiais, muitos alunos e educadores que ainda não têm a oportunidade de trabalhar com esses recursos tecnológicos. (PELLANDA; SCHLÜNZEN E SCHLÜNZEN JR., 2005, p. 17)

Esses autores apostam no engajamento de vários aspectos que tendem a contribuir para o desenvolvimento da Educação por meio do uso de todo o potencial que as tecnologias de informação e de comunicação e que o ensino a distância podem oferecer para a melhoria do processo ensino e aprendizagem favorecendo melhorias de vida para toda a sociedade.

Assim, eles apostam na apropriação das tecnologias como forma de promover as transformações necessárias na melhoria da qualidade de vida dessas pessoas e aumentar o acesso à formação profissional nos diversos níveis, inclusive à formação do professor.

Por outro lado, esses autores asseveram que para que essa apropriação ocorra, o acesso à tecnologia deve ser acompanhado de ações educacionais, prevendo a intencionalidade dos que ensinam ao assumir o papel de educador. Nesse contexto, ao professor é dada a função de criador de condições para que haja construção de conhecimento em relação aos aspectos técnicos e de conteúdo disciplinar que envolve os aprendizes em práticas comunitárias significativas. Aos alunos é dada a oportunidade de buscar soluções e aplicá-las na resolução de problemas em contextos próprios.

Para situar nossa pesquisa no campo de investigação epistemológica, esclarecemos que nossa pesquisa se encontra no campo das ciências humanas cujas bases se encontram sobre diferentes formas compondo a chamada Episteme moderna proposta por Ivan Domingues (1991). Segundo ele, atualmente são adotadas três 
estratégias discursivas que compõe a Base Epistemológica Moderna: a Essencialista, a Fenomenista e a Histórica.

Ao analisar características que compõe o ambiente on-line no que se refere à metodologias, modelos pedagógicos no campo da seleção e sistematização do conteúdo, pudemos observar certa confluência de concepções de ensino, de aprendizado, de docente e até de língua permeando todo o curso.

Sendo assim, ao observarmos as ações que compõe o ambiente do Ensino on-line ao se constituírem nesse emaranhado de concepções, pudemos fundamentar nosso estudo nas estratégias propostas por Ivan Domingues (1991), vislumbramos a possibilidade de enquadramentos para cada uma das estratégias que compõe da Episteme Moderna proposta por esse auto. Temos, nesse contexto, as estratégias:

- $\quad$ Essencialista - mais atenta ao modus essendi dos objetos - fundamentados por essa estratégia, nosso estudo busca pela origem, modo de produção e aplicação de cursos on-line e os tipos de métodos aplicados.

- $\quad$ Fenomenista - mais atenta ao modus operandi dos objetos - estudamos como ocorre o processo tanto de ensino quanto de aprendizado, como o aluno adquire conhecimento e o apreende e como os cursos são oferecidos.

- Histórica - mais atenta ao modus faciendi dos objetos - investigamos as possibilidades de aplicação do conhecimento e da formação adquiridos e mediados pelas tecnologias como: a formação do professor de EAD, descrição e avaliação das etapas de produção, aplicação e avaliação do curso.

Nesse caso, percebemos que a nossa pesquisa de cunho descritivainterpretativista se insere na Episteme moderna, já que percebe o objeto de estudo por diversos ângulos, tendo no Empirismo, no Inatismo e na Dialética as bases epistemológicas que mais influenciam o pensamento e a prática pedagógica na modernidade, sobretudo, no ensino a distância, de acordo com Oresti Preti, (2002).

Para Preti (2002) o Empirismo no Ensino a Distância se mostra na organização do trabalho pedagógico que é definida e controlada de cima para baixo: a instituição (Ministério da Educação e/ou secretarias de educação ou cursos particulares) decide o que fazer e como. Esse "modelo" organizacional é reproduzido pelas pessoas responsáveis pela produção do curso e principalmente pelo professor. Exemplo: cursos "e-learning", em cursos "mediados eletronicamente". 
Ainda segundo esse autor, a concepção empirista leva instituições a produzirem e utilizarem de uma forma "industrializada de ensino", oferecendo "pacotes instrucionais", fundamentados nas teorias comportamentalistas (neo-behavioristas e tecnicistas, de base estímulo-resposta, com materiais auto-instrucionais). Seu objetivo é treinar os cursistas (desenvolvendo habilidades técnicas) ou instruí-los (oferecendo um volume de informações).

Nesse caso, o estudante é considerado (no início do curso) a matéria-prima a ser trabalhada, "qualificada", o professor (muitas vezes substituído pelo "tutor") como o trabalhador numa linha de montagem seguindo as orientações recebidas (manuais, guias, monitoramentos), as tecnologias como as ferramentas, o currículo como o plano de modelagem e o aluno "educado" (ao final do curso).

Em relação ao Inatismo no Ensino a Distância, Preti (2002) critica que desenvolveu-se uma espécie de mito na "independência intelectual" do estudante, em sua capacidade auto-didática, em saber estudar sozinho não necessitando da presença de outrem. Divulga-se a crença de "quanto menos o cursista recorrer ao auxílio do professor ou do tutor, melhor". Isso significaria que o curso foi bem planejado e que o estudante confia em si mesmo, em suas capacidades. Por isso, a troca, o diálogo com o outro, o sentido de cooperação e construção coletiva não são estimulados. O individualismo é premiado!

E por último, segundo esse mesmo autor, a Dialética no Ensino a Distância demonstra que o professor - profissional dos profissionais, o especialista da aprendizagem - procura: garantir a evolução adequada da aprendizagem do aluno, propor modos de sustentar processos precários de aprendizagem; praticar, com cada aluno, na medida do possível um relacionamento individualizado, tendo em vista o bom desempenho; traduzir para o aprendiz a abrangência do desafio da aprendizagem, de estilo interdisciplinar e totalizante e manter diagnósticos sempre atualizados sobre a aprendizagem do aluno para sustentar o desempenho.

No contexto do Ensino a Distância, parafraseando Preti (2002), defendemos, com ele, que a aprendizagem e educação são processos "presenciais", e exigem o encontro, a troca, a co-operação, que podem ocorrer mesmo os sujeitos estando "a distância". E que a aprendizagem pode "transpor a distância temporal ou espacial" fazendo recursos às tecnologias unidirecionais como o livro, o telefone ou à tecnologia digital que é multidirecional (todos-todos), etc. eliminando a distância ou construindo interações diferentes daquelas presenciais. Mas, muito mais do que recorrendo à mediação 
tecnológica, é a relação humana, o encontro com o outro que possibilita ambiência de aprendizagem.

\subsection{O Ensino e as linguagens dos ambientes virtuais: o uso pedagógico da interação a distância}

O ensino encontra um campo profícuo nas múltiplas linguagens que compõe o contexto educacional no âmbito de ambientes virtuais. Sendo assim, temos Collins e Ferreira (2004) que apresentam trabalhos relacionados à aprendizagem e ao ensino de línguas, além de abordar o desenho e implementação de cursos, linguagem pedagógica e interação, ferramentas, ensino, aprendizagem e formação de professores de línguas.

Todos esses trabalhos são voltados para o contexto on-line. Dentre as abordagens acima propostas por Collins e Ferreira (2004) optamos por demonstrar discussões a respeito dos recursos técnicos e o uso pedagógico da interação a distância apresentadas por Braga (2004) pela relevância desses assuntos para o desenvolvimento de nosso estudo.

Nessa obra, Braga (2004), em seu artigo, discorre a respeito das vantagens pedagógicas do ensino mediado por computador e sobre o uso pedagógico da interação a distância mediada por computador.

Segundo essa autora o uso do computador como ferramenta de ensino oferece além da agilidade da comunicação a distância traz novas maneiras de organizar e veicular informação no ambiente virtual. Outra vantagem do uso desses recursos técnicos é a possibilidade de facilitar a construção do conhecimento favorecendo a aprendizagem independente, além de desenvolver o pensamento reflexivo.

No que se refere ao uso pedagógico da interação a distância, Braga (2004) esclarece que a participação ativa dos alunos na construção compartilhada do conhecimento tende a se expandir favorecidos pelo contexto a distância numa situação de ensino e aprendizagem via rede. Assim, deixa para trás todo um contexto de postura autoritária e centralizada do professor e/ou da instituição da situação presencial.

Braga (2004) acredita que mesmo havendo uma distância física entre professor e aluno, os avanços tecnológicos viabilizam a simultaneidade nas trocas interativas em que "no espaço da sala de aula virtual todos podem interagir com todos indiscriminadamente. 
Os textos escritos pelos alunos aparecem linearmente na tela, cabendo ao leitor/interlocutor a opção de ler, ou não ou mesmo responder ou não, às diferentes emissões (BRAGA, 2004, p. 161).

Essa situação apresentada por Braga (2004) demonstra que muitas das dificuldades de interação apresentadas no contexto presencial como competição pelo turno de fala, obrigatoriedade de silêncio, timidez, limites espaciais como a disposição das carteiras que limitam a comunicação restringindo-a apenas aos colegas que estejam mais próximos, imposições institucionais, do professor e do tempo, todos esses fatores são superados quando em ambiente virtual.

Nesse contexto, "o aluno não sofre a pressão de tempo imposta pela situação face a face e pode interagir como menor sanção social, já que a intermediação da tela pode dar a sensação de um maior distanciamento, um fator que pode diminuir a inibição" (BRAGA, 2004, p. 161).

Outro fator relevante exposto por essa autora é que a tela do computador funciona como neutralizadora das reações sociais que presencialmente transmitiriam censura e desagrado tanto por parte do aluno como por parte do professor. Trata-se da comunicação não verbal como expressões, olhares, posturas de corpo, tom de voz entre outras atitudes que demonstrariam repressão ou agressividade que num contexto virtual seriam neutralizados, oferecendo mais privacidade e liberdade para os envolvidos no processo a distância.

Braga (2004) defende que esse conjunto de fatores que viabiliza o ensino e o aprendizado a distância explica por que as interações pedagógicas via rede têm sido bastante valorizadas como uma alternativa que favorece a participação ativa do aluno.

Desse modo, essa autora elege como fonte de interação pedagógica mais valorizada algumas ferramentas como chat, fórum de discussão ou e-mail que acaba por se constituir como diferentes linguagens no processo de interação. Segundo Braga (2004, p.161) "essa participação amplia as possibilidades de construção de conhecimento, já que o aluno passa a contar com um apoio pedagógico diversificado, oferecido não só pelo professor, mas também pelos demais colegas da classe".

Nesses ambientes interativos o professor pode interagir com os alunos e ainda pode acompanhar todo o processo de desenvolvimento e de participação do aluno no curso. Pode propor atividades, avaliá-las, trocar informação dispondo de inúmeros tipos de linguagens que se combinam no ambiente virtual. 
Ambientes on-line refletem uma combinação de linguagens verbais e não verbais em que sons, imagens, gravuras, escrita, vídeos entre outras linguagens, se combinam com o objetivo de promover o ensino, a interação e motivar a busca pelo aprendizado.

Diante disso, em consonância com os pressupostos dessa autora, percebemos que todos esses aspectos mediados pelas novas tecnologias favorecem amplamente as mudanças de postura e metodologias tanto de ensino quanto de aprendizado.

Como nós, essa autora acredita que no contexto on-line os papeis se definem favorecidos pela mudança de postura dos envolvidos no contexto da educação. $\mathrm{Na}$ interação pedagógica, o professor assume a posição de orientador do processo de aprendizagem e o aluno a de colaborador e co-construtor do seu próprio conhecimento.

Em nosso trabalho, observamos as diversas formas de interação e a mudança de postura nos papeis de alunos e professores favorecida pelo contexto on-line de educação.

Em relação às interações virtuais encontramos em Marquesi, Silva Elias e Cabral (2008) respaldo para nosso estudo, pois essa obra enfoca questões teóricometodológicas da organização do ambiente virtual e do texto destinado ao ensino de Língua Portuguesa a distância, além de privilegiar os aspectos interacionais da aprendizagem colaborativa.

Nessa obra, os pesquisadores discutem, de modo geral, sobre a aplicação da tecnologia ao ensino e sobre os ambientes virtuais para o ensino e aprendizagem, além da interação em ambientes on-line e a escrita e a leitura em ambientes virtuais para ensino e aprendizagem.

Nesse contexto, nosso interesse recai sobre o trabalho de Cabral (2008) cujo artigo discorre a respeito da produção de material para cursos a distância. Nesse trabalho, Cabral (2008) discute problemas relacionados à produção de texto para cursos a distância em ambientes virtuais de aprendizagem. A autora discorre sobre estratégias textuais para a ampliação da informação e para a construção de relações.

Segundo essa autora essas estratégias textuais orientam a construção dos sentidos, indicando um percurso de leitura que funciona como estratégia argumentativa. Ela ainda discute as características da linguagem utilizada em ambientes virtuais, além das possibilidades que a tecnologia oferece para a organização textual dos conteúdos a serem veiculados em um curso a distância, oferecido na modalidade on-line.

Cabral (2008) se fundamenta na Linguística Textual e nos estudos sobre a linguagem na internet e mostra como um curso se organiza, como acontece a articulação dos conteúdos teóricos e como os elementos hipertextuais participam da construção da coerência do curso e traduzem uma orientação argumentativa. 
Lembrando sempre que a existência das inúmeras abordagens que coexistem simultaneamente, nos leva a considerar inúmeras possibilidades de usos das tecnologias também coexistindo simultaneamente, ora se integrando ora se completando.

Enfim, o processo de ensino e aprendizagem deve centrar-se na análise e na interpretação de situações, na busca de estratégias de solução, na análise e comparação entre diversas estratégias e abordagens, na discussão de diferentes pontos de vista e de diferentes métodos de solução. Até aqui, já pudemos inferir que não se pode considerar uma única abordagem em relação ao modo adequado de transmitir/construir conhecimento na modalidade de ensino a distância.

Torna-se necessário vislumbrar a pertinência de todas as situações, pois todas as tecnologias estão simultaneamente presentes em diferentes níveis e graus de desenvolvimento, no mesmo espaço geográfico. Cada situação de ensino requer uma aplicação distinta e específica de estratégias. Nesse contexto multicultural surge a necessidade de cogitar sempre novas possibilidades de ensino para se conseguir qualidade do aprendizado.

A seguir apresentaremos os aspectos metodológicos e nossa rota de investigação no sentido de delinearmos o processo de construção desse estudo.

\section{Procedimentos metodológicos}

Consideramos, o processo interativo em cursos on-line como pressuposto relevante para a construção do conhecimento e da autonomia na busca pelo ensino e pelo aprendizado. Para isso, em nosso estudo, foi feito um levantamento dos fundamentos teóricos que embasam o ensino a distância com suas devidas interfaces, além dos dispositivos necessários para se oferecer um curso de qualidade. Investigamos, nessa perspectiva, como ocorre a interação no ambiente on-line e ainda buscamos identificar as ferramentas que se mostraram mais produtivas para esse fim.

Tendo em vista os aspectos que compõe o Ensino a Distância, o processo ensinoaprendizagem configura-se como um aspecto significativo para os profissionais interessados em desvendar o papel da tecnologia na expansão da pesquisa sobre ensino a Distância.

Nesse contexto, este estudo situa-se na interface da Linguística Aplicada e da Educação, especificamente da Educação a Distância. Pretende-se com os resultados desse estudo contribuir para a formação de professores com perspectiva de atuação no ambiente digital de cursos oferecidos na modalidade on-line e ainda investigar como se 
constitui o processo de aprendizagem nesse ambiente com vistas a identificar e descrever as diferentes perspectivas educacionais das tecnologias de um curso oferecido a Distância na modalidade on-line e seus reflexos no processo ensino-aprendizagem do aluno e na formação do professor.

É desse modo que reflexões sobre experiências, pesquisa, docência na esfera do Ensino a Distância interessam não somente a profissionais que trabalham com as mídias educativas, mas a todos no campo educacional em que a relação ensino-aprendizagem ocorre, seja em situações semi-presenciais ou a distância, mediado por material impresso ou virtual.

O todo desse trabalho será desenvolvido por meio da pesquisa teórica em que serão tratados conceitos envolvendo o Ensino a Distância. Trata-se de um estudo que se pauta num trabalho de cunho descritivo e interpretativo. Por isso, a análise dos dados será feita de forma interpretativista e, metodologicamente, faremos uso de material bibliográfico de obras teórico - criticas da Linguística Aplicada e da Educação, apoiandonos em pesquisa quantitativa e qualitativa.

Assim, como ponto de partida desse estudo, foi feito um levantamento da base teórica descrevendo e indicando o estágio de desenvolvimento do tema em que serão analisadas obras recentes dos principais autores que tratam do assunto. Uma vez que, a análise, a montagem e aplicação de um curso em ambiente on-line com suas novas tecnologias podem demonstrar que pesquisa e ensino são atividades bastante interrelacionadas.

Nosso estudo sobre como ocorre o processo de ensino aprendizagem em ambientes on-line ainda envolveu o levantamento e descrição de dados sobre: os modos de instrução, a metodologia de ensino, os modelos pedagógicos de Ensino a Distância, os princípios que regem a atuação de atores participante do processo, as ferramentas digitais além da influência do uso das tecnologias na mediação do conhecimento entre várias outras ações. Nesse caso, os resultados advindos da pesquisa teórica se constituíram como primeira etapa de nosso trabalho.

Pudemos verificar que no processo de ensino e aprendizagem envolvendo Ensino a Distância em ambiente on-line, as ferramentas utilizadas, os modelos pedagógicos, além dos vários processos de interação, contribuem para a melhoria da qualidade de ensino nessa modalidade, além de enriquecer a formação acadêmica.

Assim, usar o meio digital para articular as diferentes dimensões da docência e da pesquisa foi uma das estratégias usadas para estimular nosso estudo, pois buscamos 
associar a tecnologia às metodologias pedagógicas observando se houve adaptações ou adequações para a configuração do ambiente virtual.

Nesse sentido, revemos os diferentes papeis que compõem o cenário do Ensino na modalidade a distância. Pois acreditamos, sobretudo, na importância do ensino mediado pelas novas tecnologias para o desenvolvimento da sociedade que busca um conhecimento a ser construído na prática e não adquirido de forma passiva.

A seguir, traremos a descrição do nosso objeto de estudo e discorreremos sobre a investigação, contextualização e o processo de coleta e análise dos dados.

\section{A coleta e descrição dos dados}

Para realizarmos nosso estudo relacionado às novas tecnologias nos processos de ensino e de aprendizagem, investigamos entre outros, um curso de extensão, oferecido na modalidade a distância em versão on-line oferecidos pela Universidade Federal local para professores da rede pública para diversas regiões do Brasil.

Trata-se do Curso de Extensão Professor e Surdez: cruzando caminhos, produzindo novos olhares que é um curso desenvolvido e promovido pela Universidade Federal de Uberlândia - UFU, através do CEPAE - Centro de Ensino, Pesquisa, Extensão e Atendimento em Educação Especial. Nesse contexto, este curso se constitui como resultado de uma parceria da UFU com a Secretaria de Educação Especial do Ministério da Educação e do Desporto - SEESP/MEC.

Esse curso busca promover uma reflexão sobre a problemática na educação dos surdos, apresentando discussões teóricas que forneçam aos participantes conhecimentos necessários para realização de uma prática pedagógica que melhor atenda às necessidades deste grupo de aprendizes, e, também, o ensino de um vocabulário básico da Libras via Web e DVS. É um curso voltado para a formação de docentes para que possam atuar no ensino favorecendo a aprendizagem de pessoas surdas.

Nesse caso, a avaliação se estendeu por meio da verificação do processo de ensino e de aprendizagem, seus mecanismos e ferramentas que foram acompanhados no decorrer no oferecimento de cada curso. Salientamos, no entanto, que nosso trabalho se pautou num comprometimento teórico cuja concepção de ensino e aprendizagem foi a que se construiu num contexto sócio-interativo sob uma concepção de linguagem que considera a linguagem como uma atividade, uma forma de ação e lugar de interação e que considera o estabelecimento de vínculos entre os participantes do diálogo no ambiente virtual. 
Nosso estudo abrangeu, também, reflexões sobre o uso das ferramentas disponíveis para o desenvolvimento do processo de ensino e aprendizagem nos meios de comunicação on-line que funcionaram como suporte à mediação pedagógica. Nesse contexto, fez-se relevante refletir sobre o uso das ferramentas e as formas de linguagem adequadas a fim de desenvolver o estudo sobre o processo educativo.

Analisamos, ainda, a função do tutor de apoio pedagógico tendo em vista a função específica de cada tutoria, investigamos quais as competências profissionais e tecnológicas do tutor nessa nova relação com o saber.

Da mesma forma, promovemos, também, um estudo sobre o Desenho Instrucional e seus princípios norteadores para a construção do conhecimento, além estudarmos sobre sua relação com a práxis e sobre sua influência na autonomia do aprendiz na busca pelo conhecimento e na prática do professor.

No que se refere à avaliação e acompanhamento da montagem e aplicação desse curso, nosso interesse recaiu, primeiramente, na possibilidade de avaliação e construção de ciência ao vislumbrar todo o processo. Verificamos, por meio da produção escrita do aluno, questionários diagnósticos aplicados pelo próprio curso, utilizando uma análise interpretativa, analisando se houve aprendizado e se esse conhecimento foi utilizado, de que forma e quais dimensões do ensino a distância mais contribuíram para a aquisição desse conhecimento.

Analisamos também de que forma as ferramentas interativas e metodológicas influenciaram na motivação e desempenho do aluno e se houve trocas de experiências, conhecimentos e idéias, além de aprendizagem colaborativa e interação entre: aluno/ferramentas, aluno/tutor, aluno/aluno e aluno/material didático.

A disponibilização de ferramentas e de formas de linguagens do curso propiciounos a possibilidade de investigar os aspectos técnicos e metodológicos que envolvem o processo de ensino e de aprendizagem do curso com vistas a identificar e descrever as diferentes perspectivas educacionais das tecnologias desse curso oferecido a Distância na modalidade on-line e seus reflexos no processo ensino-aprendizagem do aluno e na formação do professor.

Assim, fundamentados em pesquisa bibliográfica e no processo de produção, o acompanhamento desse curso se baseou na avaliação dessas dimensões educativas que envolveram o processo de formação, de ensino e aprendizagem na modalidade on-line. Isso a fim de verificar as influências dessas dimensões na prática de ensino a distância e quais delas realmente contribuíram para a autonomia do aprendizado no ambiente virtual e para a formação do professor. 
Acreditamos que os resultados de nossos estudos contribuirão para reformulação das práticas de ensino em ambientes on-line refletindo positivamente tanto no processo formativo e de capacitação do professor se constituindo em iniciativas que desenvolvam a autonomia do aluno na busca pelo conhecimento.

\section{Considerações e resultados parciais}

Como primeiro passo, buscamos apoio teórico visando contextualizar e fundamentar nossas pesquisas em arcabouços teóricos que respaldassem nosso trabalho. Nesse momento, percebemos que embora haja inúmeros trabalhos relacionados ao ensino mediado por novas tecnologias, ainda há certa carência de teorias que amparem as atividades executadas no ensino a distância.

Assim, já se tornou evidente que as insuficientes produções científicas em Ensino a Distância pouco têm contribuído para o desenvolvimento de teorias nessa modalidade, já que há certa escassez de estudos e de novas metodologias de ensino que contemplem o Ensino na modalidade a Distância.

Mesmo porque, trata-se de uma área em franca expansão que carece que professores pesquisem por concepções de ensino baseadas em metodologias de ensino adequadas para essa modalidade e desenvolvam mais estudos sobre interação entre: o professor, o aluno, o conteúdo e as ferramentas digitais e Design Instrucional. Isso porque é no espaço virtual onde ocorre todo o processo de ensino e aprendizagem

Como percebemos que todo curso se constitui como um ciclo de atividades dispostos no Desenho Instrucional, vislumbramos esse mecanismo como um fator indispensável atuando como espaço para criação de ambientes virtuais de aprendizagem. É nele que vários recursos são projetados para facilitar a interação entre professor, aluno, material didático e ainda disponibilizar o conteúdo, além de direcionar ações, leituras e atividades.

Nesse caso, é por meio do Desenho Instrucional que se cria e se desenvolve ambientes para expandir e melhorar a aprendizagem de determinadas informações em contextos virtuais, o que exige um processo de planejamento e execução voltado às necessidades dos aprendizes e baseado em princípios pedagógicos, mas respeitando as características estruturais do espaço disponibilizado pelo Design Instrucional. 
Por isso, investigamos, também, a disponibilidade e funcionamento de ferramentas, metodologia e conteúdo dispostos pelo Desenho. Observamos, sobretudo, que dispositivos e metodologias se combinaram no curso articulando teoria e prática. $\mathrm{O}$ conteúdo teve sua adequação à modalidade de ensino a distância, vislumbrando alternativas para o aprendizado significativo.

A importância dada ao papel do Desenho Instrucional para o desenvolvimento do processo de ensino e aprendizagem no ambiente do curso justificou um especial enfoque de nossa pesquisa nesse aspecto da modalidade a distância. Identificamos, assim, uma metodologia baseada na interação e na comunicação com o aluno.

Em todo momento do curso o professor se refere ao aluno chamando-o às atividades, tentando motivá-lo a seguir com o estudo e concluir as atividades. Ouve uma sequenciação didática do conteúdo especialmente pensada no perfil do aluno cursista (professores atuantes no ensino básico de sala regular).

Esse aspecto pôde ser vislumbrado na percepção de unidade demonstrada pelo curso, na disponibilidade e acessibilidade da página entre outros mecanismos do Desenho Instrucional que ainda nos instigam a continuar nosso estudo.

Nessa perspectiva, pudemos perceber que o curso analisado agrega em seu desenho inúmeras possibilidades de aprendizagem e se enquadra na chamada epistemologia moderna agregando abordagens empirista, inatista e dialética. Pode-se verificar que disposição dos ícones favorece o acesso rápido por parte do aluno que não precisa procurar muito para encontrar a informação e/ou atividade desejada.

É um curso que é fundamentado por abordagem empirista, pois, o estudante buscando à qualificação recebe instruções do tutor que substitui o professor e segue orientações prontas recebidas por meio dos dispositivos do curso de modo sequencial. As tecnologias são tidas como as ferramentas e o conteúdo sistematizado se torna o plano de modelagem do curso sendo disposto pelo desenho instrucional por meio do qual o aluno adquire a capacitação e aprende fazendo.

Por outro lado, o curso também agrega a características da abordagem inatista que privilegia a independência intelectual do cursista em sua capacidade auto-didática, em saber estudar sozinho não necessitando do auxílio do professor. Nesse caso, essa abordagem colaborou para reforçar a autonomia do aluno na busca pelo conhecimento, significando, de acordo com esses princípios, que o curso foi bem planejado e que o estudante foi valorizado em suas capacidades.

De outro modo, a troca, o diálogo com o outro, o sentido de cooperação e construção coletiva foram estimulados. $O$ individualismo foi premiado, mas a coletividade 
também. Essa característica do curso o inscreve também de abordagem dialética. Nesse caso, o seu formato busca garantir a evolução adequada da aprendizagem do aluno numa visão da formação continuada. O curso sustenta a aprendizagem e, por meio do tutor, tenta manter um relacionamento individualizado, tendo em vista o bom desempenho e o desafio da aprendizagem.

Trata-se de um curso de estilo interdisciplinar que envolve todo o processo de formação do professor de forma sistematizada e disposta pelo design instrucional de maneira acessível e de fácil manuseio. É relevante salientar que o curso oferece acesso também a pessoas com necessidades especiais como: cegos, surdos e pessoas com baixa visão. Ele disponibiliza recursos que favorecem a formação de todos no verdadeiro sentido da inclusão.

É por isso que o conteúdo desse curso de modalidade on-line, ou seja, um ensino por meio de atividades realizadas em ambientes virtuais tornou-se um elemento motivador para o aluno que associa o estudo mediado pelo computador ao lazer e ainda podendo realizar as atividades em horários que melhor Ihes convier. Dessa forma, além disso, o computador e suas tecnologias utilizados como recurso didático pode levar o aluno a um aprendizado significativo e prazeroso.

Nesse aspecto, consideramos aprendizado significativo uma aprendizagem que pressupõe o oferecimento ao aluno de informações relevantes que relacionadas aos conceitos já ou pré-existentes em sua estrutura cognitiva tendem a influenciar na aprendizagem e no significado atribuído aos novos conceitos aprendidos (AUSUBEL, 1980). Assim, buscamos rever as formas atuais de ensino já que a forma de ensino online se constitui bastante diferente do ensino na modalidade presencial e até mesmo diferente do ensino a distância por meio de material impresso.

Em outro contexto, como o ponto de partida teórico desse estudo assimila uma concepção de ensino baseada na interação e nossa hipótese inicial era de que o processo interativo em cursos on-line se constituía como pressuposto relevante para a construção do conhecimento e da autonomia na busca pelo ensino e pelo aprendizado.

Entretanto, ao analisar o número de acesso, de participação, grau e formas de interação por meio de ferramentas como chats, fóruns, diários entre outros, tivemos resultados não muito motivadores, já que a participação por esses mecanismos foi tímida e, muitas vezes, teve que ser forçada por meio de postagem de atividades avaliativas nesses dispositivos.

\section{Considerações finais}


Pudemos perceber que não basta disponibilizar as tecnologias para que as pessoas possam utilizá-las, mas proporcionar condições para que as ações possam ser realizadas tanto do que se refere ao ensino quanto ao aprendizado.

No processo ensino-aprendizagem, embora cada personagem tenha um papel específico, trocas de papel se mostram bastante comuns, já que ao ensinar o professor também aprende e o aluno ao aprender acaba por ensinar. Entretanto, constatamos que é papel do professor buscar pela formação de qualidade, criar alternativas de construção de conhecimento possibilitando caminhos para a autonomia da aprendizagem.

Pesquisamos também os modelos pedagógicos para Ensino a Distância que se inscrevem no material didático dispostos de forma instrucional no curso on-line. Evolvemos pesquisa sobre os elementos que os compõem, inclusive os elementos epistemológicos abordando: conceitos, metodologias, dispositivos e conteúdo dos modelos pedagógicos analisados. Faz-se mister um professor conhecer quais concepções envolvem sua prática e quais ferramentas pode disponibilizar para tornar sua aula mais criativa, envolvente e mais produtiva.

Nessa perspectiva, ainda defendemos um ensino o qual pressupõe: o diálogo, o trabalho em grupo, troca de experiências, intervenções, colaboração e ferramentas que interfiram de forma positiva na construção do conhecimento que acontece no ínterim de um processo denominado processo de ensino-aprendizagem.

Como o ensino on-line exige métodos didáticos e pedagógicos próprios, para 0 domínio do ensino na modalidade a distância e em ambiente virtual elegemos um ensino baseado na acessibilidade para a fonte do conhecimento, disponibilidade de conteúdo e simplicidade no manejo das ferramentas e na busca eletrônica de informações.

Já sabemos, no entanto, que a modalidade de ensino a distância influencia na formação do profissional docente, no processo ensino-aprendizagem e que a facilidade de manuseio, além da disposição clara e objetiva do conteúdo na página de acesso, a qualidade, bem como a velocidade da execução do programa tendem se constituir como fator bastante relevante para a motivação e busca autônoma do conhecimento por parte do aluno.

O ponto de partida teórico desse estudo assimilou, nesse aspecto, uma concepção de docência cujo ensino pode ser sistematizado, aplicado e pode também provocar o aprendizado mesmo se os aprendizes estiverem à distância. Isso porque as tecnologias utilizadas para o desenvolvimento do ensino a distância se constituem como um produto que foi produzido como um recurso didático e segue teorias pedagógicas que contemplam 
as necessidades pedagógicas dessa modalidade. As tecnologias dessa modalidade foram sim pensadas e desenvolvidas baseadas nas características e necessidades individuais e coletivas dos atores envolvidos no ensino a distância.

\section{Referência Bibliográfica}

AUSUBEL, David P.; NOVAK, Joseph D.; HANESIAN, H. Psicologia Educacional. Rio de Janeiro: Editora Interamericana, 1980. 625 p.

BECKER, Fernando. Modelos Pedagógicos e modelos epistemológicos. Educação e Realidade, Porto Alegre, 19(1), jan./jun. 1994, p. 89-96. Disponível em:

$<$ http://www.associacaosaolucas.org.br/educacao inclusiva 16.htm> Acesso em: 22 set. 2010.

BRAGA, Denise Bértoli. Linguagem pedagógica e materiais para aprendizagem independente de leitura na web. In: COLLINS, Heloisa; FERREIRA, Anise. (Org.). Relatos de experiência de ensino e aprendizagem de línguas na internet. Campinas: Mercado de letras, 2004. p. 157-184.

COLLINS, Heloisa; FERREIRA, Anise. (Org.). Relatos de experiência de ensino e aprendizagem de línguas na internet. Campinas: Mercado de letras, 2004. 336 p.

DOMINGUES, Ivan. O grau zero do conhecimento: o problema da fundamentação das ciências humanas. São Paulo: Edições Loyola, 1991. 379 p.

MAIA, Carmen; MATTAR, João. $A B C$ da EAD: a educação a distância hoje. São Paulo: Pearson Prentice Hall, 2007. 138p.

MARQUESI, Sueli Cristina; SILVA ELIAS, Vanda Maria da; CABRAL, Ana Lúcia Tinoco (Org.). Interações virtuais: perspectivas para o ensino de Língua Portuguesa a distância. São Carlos: Editora Claraluz, 2008. 208 p.

PELLANDA, Nize Maria Campos; SCHLÜNZEN, Elisa Tomoe Moriya; SCHLÜNZEN JÚNIOR, Klaus (Org.). Inclusão digital: tecendo redes afetivas/cognitivas. Rio de Janeiro: DP\&A editora, 2005. 376 p.

PRETI, Oreste. Bases epistemológicas e teorias em construção na Educação a Distância. Cuiabá, Liber Livro NEAD/UFMT, 2002. Disponível em:

<http://www.uab.ufmt.br/siteuab/images/artigos site uab/bases epistemologicas.pdf> Acesso em 29 jun. 2010.

SILVA, Lázara Cristina. Curso de extensão Professor e Surdez: cruzando caminhos, produzindo novos olhares. Disponível em: <http://www.cepae.ufu.br/> Acesso em: 10 mai. 2011. 


\section{APRESENTAÇÃO ORAL NAS AULAS DE LÍNGUA ESPANHOLA - DESEMPENHO LINGUíSTICO, FATORES AFETIVOS E AVALIAÇÃO DA ATIVIDADE}

\section{ORAL PRESENTATION IN SPANISH CLASSES - LINGUISTIC PERFORMANCE, AFFECTIVE FACTORS AND ASSESSMENT OF ACTIVITY}

Elizandra Zeulli (UFTM)

lizeulli@hotmail.com

RESUMO: Este trabalho ${ }^{6}$ tem por objetivo investigar as características da apresentação oral desenvolvida nas aulas de língua espanhola e verificar a atuação das alunas da platéia, da professora-pesquisadora e da apresentadora durante essas atividades; os aspectos afetivos revelados pelas alunas e a avaliação que fazem dessa atividade; e observar os problemas linguísticos revelados nas apresentações orais.

PALAVRAS-CHAVE: apresentação oral; aspectos afetivos; desempenho linguístico; língua espanhola.

ABSTRACT: This work aims at investigating the characteristics of oral presentations made in Spanish classes and verifying: how the students in the audience, the researcher-teacher and the presenter act during these activities; the affective aspects revealed by the students and the evaluation they make of such activities; as well as observing the linguistic problems revealed at the oral presentations.

KEYWORDS: oral presentation; affective aspects; linguistic performance; Spanish language.

\section{Introdução}

Esta pesquisa surgiu a partir de minha prática profissional como professora de língua estrangeira, ao observar as inquietações das alunas durante a realização de

${ }^{6}$ Este artigo é resultado da dissertação de Mestrado desenvolvida no Programa de Linguística Aplicada e Estudos da Linguagem(LAEL) da Pontifícia Universidade Católica de São Paulo, sob a orientação da Profa. Dra. Rosinda de Castro Guerra Ramos. 
atividades com foco na produção oral, pois aqueles alunos que tinham dificuldade ou que consideravam seu desempenho ruim se sentiam frustrados.

É nesse sentido que, nesta pesquisa, trabalhei com um grupo de alunas do último ano do curso de Licenciatura em Letras, com habilitação em Português e Espanhol, com a apresentação oral, uma atividade pedagógica que assume as características do speech, como será evidenciado no decorrer do trabalho. A utilização desse tipo de atividade se justifica por ser uma atividade na qual o aluno tem a possibilidade de produzir enunciados mais longos, ou seja, o aluno estará mais tempo exposto à língua; por ser considerada uma atividade comunicativa e por aproximar-se de contextos reais de fala de língua estrangeira.

Dessa forma, pretende-se verificar as características da apresentação oral desenvolvida nas aulas de língua espanhola; observar a atuação dos participantes da pesquisa (professora-pesquisadora e alunas); averiguar o desempenho linguístico e investigar os aspectos afetivos e a avaliação que as alunas fazem dessa atividade como atividade pedagógica.

\section{A arte de falar em público e o medo}

Segundo Polito (2000a:30) a arte de falar em público, nos dias atuais, ganhou um amplo espaço, pois não se limita aos religiosos, políticos e advogados; vários outros profissionais precisam se comunicar bem para enfrentar diversas situações.

A arte de falar em público, em especial para o espaço educativo, é uma ação que pode acarretar problemas de ordem afetiva, como por exemplo, o medo.

Conjuntamente com a necessidade de se falar em público, o medo daí proveniente aflige um grande número de pessoas. As causas e/ou justificativas são muitas, originárias de fatores como timidez, ansiedade, vergonha ou mesmo domínio insuficiente dos temas a serem apresentados.

Em uma perspectiva educacional, que é o foco deste trabalho, vários trabalhos foram desenvolvidos, como o de Morais (1992), Duarte (1988) e Penna (2000) abordando aspectos relacionados ao ensino de línguas estrangeiras a estudantes brasileiros.

Neste trabalho, outro fator a ser considerado é o perfil do participante: aluno adulto, que parece mais criterioso, exigente, por já ter vivência ou conhecimento maior da língua materna e se preocupar com sua imagem, com os julgamentos dos outros. Dessa forma, acredito que as atividades de apresentação oral, a preparação e a experiência de falar em público farão com que os problemas afetivos dos alunos possam ser atenuados. 


\section{A apresentação oral nas aulas de língua estrangeira}

Nas aulas de língua estrangeira, as atividades de aprendizagem de língua estrangeira (LE) e/ou segunda língua (L2) relacionadas à apresentação oral recebem nomes diferentes: discurso (speech), relatório oral (oral report), comunicação oral (oral communication), entre outros.

Alguns autores destacam pontos importantes da apresentação oral. Graham (1994), ao se referir a esse tipo de atividade, chamada por ele de speech, defende a necessidade de um preparo prévio para que a atividade seja bem-sucedida, além de uma escolha adequada do assunto e de uma prática prévia. Underhill (1987) e Ander-Egg \& Aguilar (1981) enfatizam a necessidade de que o tema seja escolhido pelo aluno. Para Murphy (1991) as atividades de apresentação oral são importantes para que o estudante tenha oportunidades de melhorar a fluência na comunicação. Underhill (1987) y Murphy (1991), ambos destacam que, nessas atividades, o aluno precisa preparar sua apresentação e fazer algumas notas, podendo utilizá-las como material de apoio. Além disso, deve poder fazer uso dos equipamentos eletrônicos que achar conveniente.

Um aspecto a ser observado em atividades dessa natureza é que o tipo de apresentação oral proposta para o contexto de ensino e aprendizagem de línguas assume um caráter monológico, ou seja, o aluno se prepara para a apresentação e fala por um período de tempo. Underhill (1987:47), por exemplo, propõe que o aluno fale entre 5 e 10 minutos e que responda às possíveis dúvidas da platéia depois da apresentação.

Percebe-se que, apesar dos nomes diferentes dados às atividades de apresentação oral, como discurso, comunicação oral, palestra, produção oral, relatório oral, entre outros, todas têm por objetivo o desenvolvimento da produção oral dos alunos. Além disso, focalizam produções com enunciados mais longos, ou seja, que propiciem maior tempo de exposição à língua, e se assemelhem a usos reais da língua estrangeira em questão.

Nesta pesquisa, adoto o nome de apresentação oral porque a atividade proposta reúne vários elementos citados pelos pesquisadores e porque, sobre ela, incidem as seguintes implicações que justificam sua escolha como atividade pedagógica: a necessária preparação, em especial, por ser realizada em forma de monólogo; a estipulação do tempo de fala do apresentador, que variou entre 5 e 20 minutos; leitura de textos; pesquisa; utilização de recursos audiovisuais; e a escolha do tema, pelo aluno. 
Essa atividade é uma autêntica atividade comunicativa porque dá voz ao aluno, possibilita a ele fazer uso da língua com um determinado propósito comunicativo.

\section{A abordagem comunicativa}

A abordagem comunicativa embasa teoricamente a atividade didática aqui escolhida, pois a apresentação oral está focada nos interesses e necessidades dos alunos e no desenvolvimento da produção oral em uma situação que parece se aproximar do uso real da língua. Ademais, dá oportunidade ao aluno de utilizar a língua dentro do contexto de sala de aula.

Scott (1981), Widdowson (1991) e Almeida Filho(1993) criticam as atividades próprias da visão estruturalista, com foco na forma. Os autores, pautados nos estudos da abordagem comunicativa, defendem que, para o aluno é mais importante saber usar a língua estrangeira, tanto no ambiente educativo como fora dele.

Outro aspecto importante sobre a abordagem comunicativa diz respeito aos papéis do aluno e do professor. Na abordagem comunicativa, segundo Nunan (1989: 80-81) o aluno deixa de ser passivo e de reproduzir o que o professor ensina, passa a ser ativo, a negociar significados e ter mais responsabilidade e autonomia sobre o seu processo de aprendizagem.

Já o papel do professor, segundo Breen \& Candlin (1980:99) é o de negociador dos significados e de facilitador da aprendizagem, deixando o lugar de centro do processo para ocupar o de co-participante no contexto de sala de aula.

Em suma, os autores resenhados propõem, através de teorias e conceitos, que o aprendiz tenha competência comunicativa para usar a língua estudada em vários contextos.

Canale \& Swain (1980:28-34) e Canale (1983:6-14) entendem que a competência comunicativa se compõe de quatro outras competências: gramatical, estratégica, sociolinguística e discursiva.

Segundo as autoras, a competência gramatical corresponde aos códigos linguísticos, como vocabulário, pronúncia, aspectos semânticos, formação de palavras, formação de sentenças, itens lexicais, morfológicos e de sintaxe. É o tipo de competência que enfatiza a acuidade e é de suma importância por ser um dos objetivos da abordagem comunicativa, não só a comunicação, mas uma comunicação expressa de modo eficaz e gramaticalmente correta. A competência estratégica, por sua vez, é definida por Canale (1983) como pertencente ao domínio de estratégias verbais e não-verbais de 
comunicação com o objetivo de ampliar a eficiência comunicativa, a aplicação da competência estratégica pode compensar uma falta, insuficiência, desconhecimento ou esquecimento.

Já a competência sociolinguística segundo Canale \& Swain (1980), está estreitamente relacionada ao contexto de produção do discurso. Ela requer entendimento do contexto social onde a língua é usada, adequação do discurso a diferentes contextos tendo em vista os participantes, o conhecimento do propósito da informação e das normas da interação.

Por fim, a competência discursiva, para Canale \& Swain (1980) e Canale (1983), consiste em reunir, combinar harmoniosamente formas e significados gramaticais para se ter um texto uniforme.

Com base no que foi exposto sobre a competência comunicativa, é possível afirmar que todas as outras competências que a compõem são importantes para o processo comunicativo e para o ensino de línguas de modo geral.

No entanto, neste trabalho, ênfase maior será dada à competência linguística do aluno devido à sua situação: aluno do quarto ano do curso de licenciatura em Letras e, portanto, futuro professor de língua espanhola.

\section{O brasileiro falando espanhol}

Não é difícil encontrar brasileiro que ache que o espanhol é uma língua fácil, tendo em vista a aparente semelhança com o português. Por serem línguas próximas, o senso comum construiu o discurso de que todo brasileiro é capaz de se comunicar em espanhol.

Quanto à proximidade entre as línguas alguns autores consideram que há vantagens e as desvantagens provocadas por essa proximidade.

Almeida Filho (1995:14) acredita que o alto grau de compreensibilidade entre as línguas próximas estimula o estudante a arriscar-se mais com mais segurança, fatores que podem favorecê-lo pela grande probabilidade de conseguir resultados mais satisfatórios na língua espanhola. Já Alcaraz (2005:197) acredita que essa proximidade pode dificultar a aprendizagem da língua.

Ferreira (1997:143) considera que a proximidade entre as línguas traz vantagens e desvantagens. Vantagem em um primeiro momento, pois o estudante de espanhol é considerado um falso principiante, já que ele traz consigo conhecimentos e habilidades que são comuns às duas línguas. Contraditoriamente, a aparente vantagem inicial da proximidade entre as línguas leva os estudantes a perceber mais facilmente as 
semelhanças do que as diferenças. Sem perceber as diferenças, o estudante produzirá o famoso "portunhol", termo utilizado para designar a produção de um falante de espanhol ou português tentando falar a outra língua.

De modo geral, todo brasileiro deve desconfiar dessa "aparente" vantagem inicial apresentada por alguns autores e se preocupar com o estudo da língua espanhola de forma séria e comprometida, em especial os estudantes de Licenciatura em Letras, que serão professores de Língua Espanhola.

Em suma, todas as questões discutidas acima, como facilidade, vantagens e "portunhol", partem do senso comum e são bastante usuais tratando-se do ensino de espanhol para estudantes brasileiros, mas, em pesquisas realizadas por alguns estudiosos da área, a visão é outra, pois, ao contrário do que defende o senso comum, discutem-se as dificuldades e os problemas encontrados por alunos brasileiros aprendizes de espanhol.

Ainda tratando da proximidade entre as línguas, outro conceito discutido por Selinker(1972), Kellerman (1978) e Cruz (2004) é o da transferência, que consiste na utilização de algum conhecimento linguístico de uma língua, a materna ou outra, na língua estrangeira que está sendo estudada.

Cabe ressaltar que, neste trabalho, adoto o conceito de transferência como uma forma de interpretar os erros gramaticais e de vocabulário ocorridos nos dados coletados junto às alunas participantes da pesquisa.

\section{Metodologia}

Esta pesquisa caracteriza-se como pesquisa-ação por apresentar as propriedades da pesquisa-ação propostas por Burns (2005), Crookes (1993), El Andaloussi (2004), Nunan (1992,1996), Nunes (2000) e Thiollent (2000), entre outros. A escolha metodológica justifica-se por várias razões, dentre elas, pelo trabalho apresentar um caráter reflexivo, por ter sido realizado pela professora-pesquisadora em sua sala de aula, pela negociação entre os participantes envolvidos e pelo desenvolvimento em uma situação prática, com o intuito de provocar uma melhora nas ações das participantes.

Quanto ao contexto e os participantes, esta pesquisa foi realizada em uma instituição particular de nível superior, situada no interior do estado de São Paulo. A coleta de dados foi realizada especificamente nos dois últimos semestres do curso de Licenciatura em Letras (português/espanhol) dessa Instituição. As participantes da pesquisa foram cinco alunas e a professora-pesquisadora. 
A atividade de apresentação oral foi utilizada pela professora-pesquisadora como uma atividade didática, com o objetivo de melhorar a produção oral das alunas. Foram realizadas por cada aluna quatro atividades de apresentação oral.

Para a coleta de dados foram utilizados vários instrumentos como: notas de campo, questionários, gravações em áudio, fichas de avaliação, uma conversa após a apresentação e uma entrevista oral guiada.

\section{Resultados}

Quanto à atividade de apresentação oral ficou claro para a professorapesquisadora e para as alunas que ela se caracteriza por ter duas fases: a da preparação e a da apresentação propriamente dita.

A fase da preparação corresponde à escolha dos temas e aos materiais utilizados como pesquisa. Evidenciou-se uma diversidade temática e que a apresentação que chama mais atenção da platéia é aquela de interesse não só da apresentadora, mas de interesse geral.

Quanto à fase da preparação, ficou claro para o grupo que, quanto mais a apresentadora se preparar para a atividade, mais segura se sentirá. As mudanças de comportamento das alunas verificadas nas últimas atividades de APO evidenciam que elas reconheceram a importância da preparação e do uso do esquema ou de notas na apresentação propriamente dita. Os resultados mostraram que o uso de esquema ou notas pelo apresentador, durante a apresentação, é bom, mas o uso dos textos utilizados na preparação não funciona, pois a apresentação acaba se tornando uma leitura.

As fases de preparação e a apresentação propriamente dita se configuraram de várias maneiras. Acredito que um dos motivos seja que a professora-pesquisadora apenas orientou sobre as formas de preparação e de apresentação, mas não ofereceu um exemplo de como fazer o esquema ou as notas. Portanto, penso que, para que uma apresentação oral possa ser mais organizada no grupo, é importante que o professor dê um exemplo, ensine a fazer notas ou esquemas. Como professora-pesquisadora, ao olhar os dados, constatei que, se os esquemas tivessem sido dados, as apresentações teriam sido mais organizadas.

Ainda sobre as várias maneiras como as apresentações ocorreram, posso dizer que elas podem estar relacionadas às características pessoais de cada aluna, mas essa é apenas uma inferência, pois não tenho dados suficientes para afirmá-la. 
Quanto à preparação e realização das atividades de APO, foram dadas apenas algumas orientações, porque o que se pretendia ao adotar essa atividade em sala de aula era, de modo geral, que o aluno tivesse oportunidade de praticar a língua espanhola em sala de aula, já que a maioria afirmava ter estudado mais gramáticas, nos anos anteriores, com poucas oportunidades de praticar a língua.

Os dados revelaram um aspecto que eu já imaginava; com a preparação e realização frequente dessas atividades, os aspectos afetivos podem ser atenuados.

Quanto às transferências, os dados revelaram que algumas são mais problemáticas para a comunicação, podendo provocar estranhamento e, consequentemente, a não compreensão da mensagem; outras são aparentemente mais simples, apenas um erro. Mas, neste trabalho, vale ressaltar a importância de usar a língua de acordo com as exigências do padrão culto e o papel social que as pessoas representam na sociedade. No caso das alunas participantes da pesquisa é problemático não usar a língua gramaticalmente correta, pois, para elas, não basta saber se comunicar; são pessoas que vão servir de "modelo" para seus alunos, portanto a transferência é um aspecto que mereceu reflexão, em especial pelo papel social que as participantes vão desempenhar.

\section{Considerações finais}

A principal contribuição advinda desse trabalho é a reflexão, pois este tipo de trabalho provoca reflexão tanto do aluno quanto do professor. As alunas perceberam a importância da atividade para o contexto de sala de aula, suas dificuldades e passaram a ocupar um papel central no processo de ensino- aprendizagem.

Contribuiu também para mostrar às alunas que a graduação não resolveu todos os seus problemas linguísticos e que significa apenas o término de uma etapa de um processo de aprendizagem, que deve ser continuado, que exige pesquisa, envolvimento, dedicação, responsabilidade e comprometimento.

Em relação às contribuições deste estudo, posso afirmar que colaborou para a minha formação tanto de professora quanto de pesquisadora. Depois de ter realizado esta pesquisa, percebo que como pesquisadora consigo enxergar os resultados com mais clareza. Como professora, questionei-me sobre meus procedimentos em sala de aula e verifiquei quais poderiam ser mais adequados e quais poderiam favorecer a aprendizagem do aluno. 


\section{Referências bibliográficas}

ALCARAZ, R. C. 2005. Do Português ao Espanhol: os Prós e os Contras da Proximidade. In: SEDICYAS, J. (Org.). O Ensino do Espanhol no Brasil: Passado, presente, futuro. Parábola.

ALMEIDA FILHO, J. C. P. 1993. Dimensões Comunicativas no Ensino de Línguas. Pontes.

1995. Uma Metodologia Específica para o Ensino de Línguas Próximas? In: ALMEIDA FILHO, J. C. P. (Org.) Português para Estrangeiros: Interface com o Espanhol. Pontes.

ANDER-EGG, E. \& AGUILAR, M .1981. Técnicas de Comunicación Oral. Cuadernos de Animación Socio -Cultural.

BARBIER, R. 2002. A Pesquisa-ação. Trad. L. Didio. Líber Livro.

BREEN, M. \& CANDLIN, C.1980. The Essentials of a Communicative Curriculum in Language Learning. Applied Linguistics, 1, p. 89-112.

CANALE, M. 1983. From Communicative Competence to Communicative Language Pedagogy. In: RICHARDS, J. C and SCHMIDT, R.W (Eds.) Language and Communication. Longman.

CANALE, M \& SWAIN, M. 1980. Theoretical Bases for the Communicative Approaches to Second Language Teaching and Testing. Applied Linguistics, 1, p. 1-47.

COHEN, L. \& MANION, L.1994. Research Methods in Education. Croom Helm.

CRUZ, M. L. O. B. 2004. Etapas de Interlengua Oral en Estudiantes Brasileños de Español. Asele.

DUARTE, V.C.L.1988. As Relações Interpessoais em Sala de Aula num Curso de Inglês na Universidade. Dissertação de Mestrado. LAEL, PUC-SP.

FERREIRA, I. A. 1997. Interface Português/ Espanhol .In: ALMEIDA FILHO, J.C.P.(Org). Parâmetros Atuais Para o Ensino de Português Língua Estrangeira. Pontes.

GOFFMAN, E. 1981. Forms of Talk. Basic Blackwell.

GRAHAM, J. 1994. Four Strategies to Improve the Speech of Adult Learners. TESOL JOURNAL, 3/3, p. 26-28.

HAGER, P. J.; CORBIN, N. C.; SCHEIBER, H. J. 1997. Designing \& Delivering Scientific, Technical, and Managerial Presentations. Paperback: Wiley-IEEE.

KELLERMAN, E. 1978. Giving Learners a Break: Native Language Institutions as Source of Predictions about Transferability. Working Papers on Bilingualism, 15. p.60-92

MORAIS, E. N. D.1992. Desconforto em Aulas de Língua Estrangeira: um Estudo em Dois Contextos de Aprendizagem. Dissertação de Mestrado. LAEL, PUC-SP

MURPHY, J. 1991. Oral Communication in Tesol: Integrating Speaking, Listening and Pronunciation. Tesol Quaterly, 25/1, p. 51-75.

NUNAN, D. 1989, Designing Tasks for the Communicative Classroom. Cambridge University Press.

PENNA, L. 2000. O Speech nas Aulas de Inglês: Reflexões do Aluno e Contribuições para o seu Desempenho. Dissertação de Mestrado. LAEL, PUC-SP.

POLITO, R. 2000a. Como Falar Corretamente e sem Inibições. Editora Saraiva.

Saraiva. 2000b. Assim é que se Fala: Como Organizar a Fala e Transmitir Idéias. Editora

SAVIGNON, S. J. 1983. Communicative Competence: Theory and Classroom Practice .Addison - Wesley Publishing Company.

SCOTT, R. 1981. Speaking. In: JOHNSON, K \& MORROW, K (Eds.). Communication in the Classroom. Longman.

SELINKER, L. 1972. Interlanguage. IRAL.

THIOLLENT, M. 2000. Metodologia da Pesquisa-ação. Cortez. 
UNDERHILL, N. 1987. Testing Spoken Language: a Handbook of Oral Testing

Techniques. Cambridge.

WIDDOWSON, H. G. 1991. O Ensino de Línguas para a Comunicação. Trad: J.C.P. Almeida Filho. Pontes.

\title{
EDMODO: INTEGRANDO O ESPAÇO CIBERNÉTICO À SALA DE AULA DE INGLÊS ${ }^{7}$ \\ EDMODO: INTEGRATING THE CYBER SPACE TO THE ESL CLASSROOM
}

\author{
Estela Rodrigues do Vale - ESEBA (UFU)
}

estela.r.v@gmail.com

\begin{abstract}
RESUMO: O presente trabalho propõe discutir como as novas tecnologias podem ser inseridas ao contexto de ensino de inglês (L2) de maneira simples, interativa e acessível, a fim de favorecer o desenvolvimento da competência comunicativa dos alunos. O mesmo apresenta também a plataforma virtual edmodo e discorre sobre suas funcionalidades e vantagens para os aprendizes, por proporcionar-Ihes um espaço cibernético amplamente favorável a um aprendizado colaborativo e co-construído. Além disso, sugere algumas ferramentas da Web 2.0 que podem servir como propulsoras de um ensino mais motivador para o desenvolvimento das quatro habilidades comunicativas: Listening, Reading, Speaking and Writing.
\end{abstract}

PALAVRAS-CHAVE: plataforma social on-line; aprendizes do mundo digital; ensino de inglês como L2.

ABSTRACT: This research aims at discussing how the new technologies can be inserted in the process of teaching English as a second language, in a simple, interactive and accessible way, in order to favor the development of the students' communicative competence. It also presents the virtual platform edmodo and discusses its functionality and advantages for the learners, for offering them a cyber space that is highly liable for a collaborative and co-constructive learning. Moreover, it suggests some web 2.0 tools that might serve as intensifiers of a more motivational learning and the development of the four communicative skills: listening, reading, speaking and writing.

KEYWORDS: online social platform; learners from the digital world; teaching English as a second language

\section{Introdução}

\footnotetext{
${ }^{7}$ Pesquisa orientada pela Professora Dra. Reinilde Dias, UFMG.
} 
Nos últimos anos as novas tecnologias têm sido divulgadas e amplamente aplicadas a todas as áreas do conhecimento, inclusive no âmbito do ensino de inglês como L2 (ARAUJO, 2007; DIAS, 2008; 2010; BELL, 2009). Existe, hoje, um público altamente "conectado", aprendizes que passam grande parte de seu tempo em frente a um computador, geralmente ligado à internet. Esses aprendizes da sala de aula contemporânea são chamados de nativos digitais (digital natives) por Prensky (2001), referindo-se àqueles que cresceram cercados por todos os aparatos da era digital (computadores, vídeo games, aparelhos de reprodução de mídias como MP4, câmeras digitais etc.), utilizando-os diariamente. Destarte, é fundamental que o uso de tais tecnologias seja integrado ao ensino, a fim de que possamos motivar cada vez mais esses nativos digitais a envolverem-se em um processo colaborativo de aprendizagem com o uso de recursos da era digital. Além disso, é essencial promover o letramento digital daqueles que ainda não têm acesso a essas tecnologias, bem como dos próprios professores que, em sua maioria, podem ser classificados como imigrantes digitais (digital immigrants) (PRENSKY, 2001).

As ferramentas da web 2.0 (blogs, wikis, redes sociais etc.) (O’REILLY, 2005) têm ampliado as possibilidades para interações síncronas e assíncronas entre alunos que acreditam na possibilidade de aprender juntos, colaborando para a co-construção do conhecimento (DIAS, 2008). Além do mais, este universo hipermidiático proporciona uma gama variada de formas de expressões (imagens, sons, vídeos etc.) que só têm a favorecer o aprendizado e a construção de significados e do conhecimento. Assim sendo, é imprescindível que o professor lance mão dessas ferramentas como sujeito ativo e colaborador no processo, de forma a favorecer a criação de experiências educativas significativas e relevantes para os aprendizes (ALMEIDA ${ }^{* * * *}$ ). O procedimento pedagógico mais adequado parece ser mesclar ambos, o espaço virtual e o presencial, para promover um ensino que seja próximo da realidade de muitos dos nossos aprendizes, incluindo também aqueles que ainda não tiveram a oportunidade de participar ativamente do espaço cibernético.

O presente trabalho propõe discutir de que maneira as novas tecnologias podem ser inseridas ao contexto de ensino de Inglês como L2 para favorecer o desenvolvimento da competência comunicativa dos alunos. Além disso, apresenta a plataforma virtual EDMODO (http://www.edmodo.com/) e discute sobre suas funcionalidades e vantagens. Sugere ainda algumas ferramentas da Web 2.0 que podem servir como propulsoras de um processo de ensino/aprendizagem colaborativo mais motivador para 0 
desenvolvimento das quatro habilidades comunicativas: Listening, Reading, Speaking and Writing.

\section{A ferramenta Edmodo}

O espaço cibernético tem favorecido o surgimento de formas de convivência e colaboração distintas ampliando o universo de possibilidades para a construção e troca de informações, opiniões, vivências e conhecimento, abrindo perspectivas inovadoras. Dias (2008) acrescenta que "a incorporação de tecnologias da web ao contexto educativo de ensino de inglês pode influenciar positivamente a interação aluno/informação", o que, segundo a autora, contribui para a criação de múltiplos caminhos de significação no processo de aprendizagem, retomando as teorias de Vgostsky (1978) sobre a importância da colaboração interativa durante o processo de desenvolvimento e aprendizagem, que ocorre entre aluno e professor, e aluno e colegas de sala (AGUIAR, 2009).

A plataforma edmodo foi criada com 0 intuito de oferecer, aos professores e estudantes de diversas partes do mundo, um espaço virtual no qual é possível explorar e beneficiar-se de praticamente toda e qualquer forma de expressão textual possível nos dias atuais (vídeos, imagens, sons, textos escritos etc.). Além disso, trata-se de uma ferramenta totalmente "compartilhável" entre seus usuários, dando-Ihes a autonomia de produzir textos escritos, inserir mídias diversas e links para qualquer outro site, comentar, sugerir, enfim, participar ativamente de uma comunidade cibernética cujo intuito final é aprender e praticar a língua-alvo de forma colaborativa e significativa. Além de ser altamente vantajosa para aprendizes, trata-se ainda de uma excelente ferramenta de compartilhamento para educadores de áreas e/ou instituições afins.

Tendo em mente as possibilidades e vantagens de se utilizar ferramentas virtuais em favor do processo colaborativo de ensino/aprendizagem, esta pesquisa emergiu da idéia de experimentar a plataforma educacional edmodo. A idéia surgiu a partir de uma experiência na qual os professores de uma escola de idiomas estavam utilizando esse instrumento para compartilhar materiais, experiências, sugestões e dúvidas entre si. Ao perceber os benefícios desse espaço virtual foi feito um experimento para utilizá-lo com alguns alunos (assim como já estavam fazendo outros professores da referida escola). Os resultados de tal experimento serão detalhados e analisados mais adiante

É importante ressaltar que a opção de utilizar a plataforma edmodo ao invés de outros ambientes educacionais já vigentes como as plataformas moodle e teleduc, por exemplo, foi feita levando em consideração o perfil dos participantes da pesquisa, e o 
público da escola na qual o projeto foi desenvolvido. Afinal, trata-se de um grupo de jovens classificados, em sua maioria, como nativos digitais e que já utilizam redes sociais como orkut e facebook. O ponto forte do ambiente edmodo em relação aos outros é sua semelhança visual a essas redes sociais, mais especificamente ao facebook. Portanto, ao trabalhar com uma ferramenta nova, porém familiar para os aprendizes, foi possível obter uma maior adesão de participantes às ações da pesquisa.

\section{Metodologia}

Uma vez diante da problemática de como utilizar recursos da web de forma a estimular e motivar uma aprendizagem colaborativa entre os aprendizes de língua inglesa como L2, ficou decidido que a pesquisa-ação seria o método mais adequado para a realização do trabalho proposto. Além do mais era necessário, de alguma forma, levantar hipóteses para transformar e melhorar a prática educativa docente. Afinal, acredita-se na premissa de que pesquisa e ação devem caminhar juntas de modo que os apontamentos levantados durante todo o processo levem o pesquisador a refletir sobre sua prática e promover ações que visem aprimorar o contexto no qual a pesquisa foi fundamentada.

Franco (2005) apresenta de forma detalhada e esclarecedora um histórico da pesquisa-ação como metodologia científica de pesquisa, e ainda propõe distinções entre três de suas formas. Sendo assim, a definição com a qual melhor identifica-se o presente trabalho, é o que a autora chama de "pesquisa-ação estratégica". Segundo ela, o diferencial dessa terminologia reside no fato de que "a transformação é previamente planejada, sem a participação dos sujeitos, e apenas o pesquisador acompanhará os efeitos e avaliará os resultados de sua aplicação". Apesar de os participantes desta pesquisa estarem intrinsecamente presentes em todo o processo desenvolvido, a parte analítica e avaliativa fica restrita aos pesquisadores.

Os participantes da referida pesquisa foram especificamente alunos de língua inglesa como segunda língua, e a mesma foi desenvolvida em um curso livre de idiomas no qual esses alunos estudam em uma turma regular, e têm aulas presenciais duas vezes por semana durante uma hora e vinte minutos. Trata-se de um grupo de pessoas de ambos os sexos, majoritariamente composto por digital natives, de idades variadas entre 14 e 40 anos, classificado como de nível intermediário de proficiência, e que utilizam como material didático o livro New English File - Intermediate (OXENDEN et.al, 1997). É 
válido mencionar que a referida escola dispõe de lousas interativas (e-boards) e acesso à internet em cada sala de aula, bem como um laboratório de informática disponível para os alunos, também conectado à web.

Os dados para a pesquisa foram coletados ao longo de um semestre letivo, com base nas interações realizadas no espaço virtual edmodo. Todo o material usado nesta pesquisa foi disponibilizado com a autorização dos participantes conforme carta de consentimento assinada por eles mesmos ou seus respectivos responsáveis legais.

Primeiramente, a fim de conhecer melhor a realidade digital na qual se inseriam os participantes do projeto, cada aluno do grupo foi questionado oralmente em sala de aula sobre a influência e presença do meio virtual em suas vidas. Aproximadamente noventa por cento do grupo confirmou a hipótese inicial de que utilizavam a internet pelo menos uma vez ao dia. Cada um com seu objetivo específico, mas, em geral, os interesses convergiam-se para os mesmos: checar e-mails, ler notícias, assistir vídeos, ouvir músicas, realizar pesquisas, divertir-se, informar-se, e alguns para trabalhar. Finalmente, diante de um grupo para o qual utilizar a internet como ferramenta educacional não parecia ser uma experiência inacessível, iniciou-se o projeto.

Antes de tudo, para utilizar a plataforma edmodo, é necessário criar uma espécie de conta no site www.edmodo.com. A fim de melhor detalhar o procedimento, foi criado um tutorial em forma de vídeo explicando passo a passo como proceder. Para acessá-lo, basta acessar o endereço eletrônico http://www.screenr.com/4OV.

Como alguns alunos já conheciam a plataforma, não foi preciso entrar em maiores detalhes sobre como inscrever-se. No entanto, é fundamental esclarecer os procedimentos para registrar-se no site, bem como os objetivos e as funcionalidades de utilizar o mesmo como uma ferramenta de suporte ao processo de ensino/aprendizagem. Em alguns casos, fez-se necessário criar contas juntamente com os participantes, uma vez que esses nunca haviam tido acesso ao referido site. Como a estrutura da escola permite, foi possível fazê-lo de forma interativa tendo a participação de toda a sala com o auxílio da lousa-interativa.

A partir do momento que os participantes da pesquisa estavam devidamente inscritos no referido grupo virtual, foi possível iniciar as interações cibernéticas com os mesmos. O primeiro contato foi feito de forma informal, assim como os contatos subsequentes, uma vez que o intuito era promover um ambiente descontraído, e, em seguida, Ihes foi pedido que escrevessem um comentário expressando suas opiniões sobre o seguinte tópico: "It's not so important to learn/speak English". É importante lembrar que todos os contatos com os participantes foram redigidos na língua-alvo, 
utilizando uma linguagem mais informal e até mesmo característica do espaço cibernético (ver figura 3.0). Em um espaço de tempo de aproximadamente 15 dias cinco participantes inseriram seus comentários sobre o tema, lembrando que trata-se de um grupo com 13 inscritos.

Os contatos ou posts subsequentes foram variados em sua forma e objetivo. Por exemplo, em alguns, foram postados vídeos específicos e pedido aos participantes que dessem suas opiniões sobre os mesmos. Em outros momentos, foram utilizados links de sites de atividades que se baseiam em vídeos ou arquivos de áudio para praticar a línguaalvo. Mais adiante, em outros posts foram colocados links de atividades de leitura, compreensão auditiva e até mesmo de ferramentas disponíveis na internet que possibilitam ao aluno expressar-se de forma oral e participar de discussões sobre um tópico específico. Noventa por cento dessas ferramentas foram editadas e criadas pela professora/pesquisadora, de modo a adaptá-las para seus objetivos diante do grupo. Em todos os posts ao menos um participante da pesquisa deixou sua opinião ou comentário.

O espaço virtual em destaque está repleto de posts sugeridos, colocados e comentados, de maneira interativa, pelos próprios participantes. Como não existem restrições de temas ou formas de mídias, os alunos postaram de diversas maneiras. Como exemplos é possível citar estes: um trabalho de faculdade que um participante quis compartilhar com seus colegas; vídeos de músicas que cada participante gosta e sugeriu para seus colegas e colaboradores de aprendizado; links com notícias de jornais internacionais; e até mesmo a fotografia tirada por um participante dentro do centro cirúrgico no momento em que sua filha nasceu. Sendo esse último um dos posts mais comentados até o momento.

É notório ressaltar que a plataforma em questão é um ambiente virtual colaborativo de aprendizagem que serve como uma sala de aula cibernética. Além disso, pode também proporcionar um espaço para que se possa "hospedar" (host) links para outros sites ou outras ferramentas da web2.0, que servem como fomentadoras de um ensino/aprendizagem mais descontraído, real e interativo. Portanto, para melhor aproveitar e ampliar as possibilidades oferecidas pela plataforma edmodo, é elementar lançar mão de algumas ferramentas gratuitas e de fácil acesso e utilização disponíveis na internet. Todas elas foram utilizadas ao longo desta pesquisa e beneficiaram amplamente este ambiente de aprendizagem virtual.

Como já é conhecida, a ferramenta youtube (http://www.youtube.com/) é um canal de divulgação de vídeos de diversas fontes e com variados propósitos, que foi utilizado de várias maneiras durante esta pesquisa: ora pela professora, postando vídeos distintos 
sobre os quais os participantes deveriam refletir e postar comentários; ora pelos próprios participantes a fim de compartilhar gostos musicais ou curiosidades sobre temas variados. Trata-se de uma ferramenta bastante prática e de fácil acesso, que oferece um acervo ilimitado de vídeos que podem servir a praticamente qualquer propósito desejado. Extremamente bem aceito e, em geral, familiar aos os participantes do projeto.

Outra ferramenta também bastante simples e acessível utilizada é chamada wallwisher (http://www.wallwisher.com/). Em linhas gerais trata-se de um grande painel virtual que pode ser criado por qualquer pessoa que queria ler as opiniões de outros sobre determinado tema por ela proposto. No caso desta pesquisa, a professora propôs um tema relevante para que seus alunos expressassem suas opiniões; criou um painel no site mencionado e postou o link no site edmodo. Em seguida os participantes puderam expressar suas opiniões, compartilhar vivências ou sugestões. Outro ponto forte dessa ferramenta é o fato de ela ser facilmente compartilhada com pessoas em qualquer parte do mundo, por exemplo, via twitter, e dessa maneira, os participantes tiveram acesso a opiniões e testemunhos de pessoas que escreveram de outros países, para citar alguns, Grécia, Espanha, Argentina e Alemanha. Isso ajudou a motivar os aprendizes a participarem desse processo colaborativo de aprendizagem, e os permitiu ampliar seus horizontes linguísticos e culturais.

Apesar de assemelhar-se ao youtube pelo fato de trabalhar essencialmente com base em vídeos, a ferramenta es/video (http://www.eslvideo.com/) permite ao professor/pesquisador criar quizzes ou questionários de múltipla escolha, baseados em qualquer vídeo disponível na web. O resultado final é uma atividade com perguntas e opções de respostas inseridas em um layout objetivo e atraente. Além disso, é possível que o participante tenha acesso ao resultado do quiz instantaneamente e visualize suas respostas e pontuação. Em geral os participantes apreciaram bastante o uso dessa ferramenta/atividade, pois trabalhar a língua alvo através de mídias visuais, no caso o vídeo, ainda está entre as maneiras preferidas dos aprendizes. Além do mais, trata-se de uma abordagem menos técnica e instrumental do ensino/aprendizagem de L2.

A ferramenta proprofs (http://www.proprofs.com/) talvez seja aquela com maior enfoque na língua propriamente dita, pois com ela é possível criar testes online sobre qualquer tema, tópico gramatical ou conteúdo programático. O diferencial, no entanto, reside no fato que é possível escolher dentre vários modelos de questões: múltipla escolha; discursivas; verdadeiro/falso; e de completar lacunas. Outro aspecto distinto é a possibilidade de inserir mídias variadas em cada questão de acordo com a necessidade, ou seja, no mesmo teste é possível exigir que o aluno responda à questões de múltipla 
escolha sobre um ponto gramatical ou temático, e também à questões discursivas nas quais devam opinar sobre um vídeo ou uma imagem inseridos na mesma. Além de todas essas possibilidades, ao final do teste o aluno recebe um relatório com seu desempenho descrito e um certificado com sua classificação e pontuação. Essa ferramenta foi utilizada principalmente às vésperas de provas na escola e serviu de apoio como um exercício de revisão para auxiliar os estudos de cada participante. Em geral o feedback por parte dos mesmos foi positivo, principalmente pelo fato de eles terem acesso às respostas e explicações instantaneamente, e por terem a opção de fazerem o teste de acordo com sua disponibilidade de horário.

Outra ferramenta bastante utilizada foi o glogster (http://www.glogster.com/) - não só prática e visualmente atraente, mas também extremamente favorável ao uso de uma gama midiática infindável. Basicamente é um enorme pôster no qual é possível inserir praticamente qualquer forma de linguagem, verbal e não verbal. Trata-se de uma ferramenta auto-explicativa e que poderia ser facilmente utilizada pelos próprios aprendizes para, por exemplo, criarem um pôster com suas coisas prediletas. No entanto, com esse grupo de participantes a ferramenta foi utilizada para inserir vídeos, imagens e links para sites diversos que pudessem auxiliá-los a melhor se prepararem para os exames escritos da escola. O resultado final foi a reunião de várias fontes de conhecimento que os pudessem auxiliar a refletir e praticar a língua alvo. Em todos depoimentos sobre o uso da ferramenta, os alunos mencionaram sua praticidade, 0 design diferenciado e sua enorme funcionalidade.

Finalmente uma ferramenta completamente distinta das outras já apresentadas neste artigo, o voicethread (http://www.voicethread.com/) permite que o aluno interaja, de maneira assíncrona, com seus colegas e ou professores, através de uma gravação de áudio e/ou vídeo de seu depoimento, ou para aqueles que não possuem os aparatos necessários como uma câmera ou microfone, é possível deixar seu comentário em forma de texto redigido. O interessante dessa ferramenta é a possibilidade de propiciar ao participante um momento para se expressar de formas diferentes daquelas que ele está habituado no ambiente cibernético. Em geral os aprendizes sentiram-se motivados a utilizar essa ferramenta, e ficaram mais a vontade para falar diante de uma câmera ou um microfone do que no ambiente da sala de aula diante de todos.

Com o auxílio das ferramentas descritas acima, foi possível estabelecer um espaço de aprendizagem totalmente inovador para a maioria dos participantes do projeto.

Ao final da pesquisa solicitamos que cada participante respondesse a um questionário reflexivo semi-aberto (veja anexo 1), com o intuito de elucidar questões 
relacionadas a quais ferramentas cada um utilizava antes da pesquisa e após a pesquisa. Além disso, através do mesmo questionário, foi solicitado aos participantes que refletissem sobre todo o processo do qual participaram para estabelecerem esse ambiente colaborativo de construção do conhecimento, e se a utilização do mesmo favoreceu, facilitou ou colaborou de alguma maneira para seu aprendizado.

Sete alunos identificaram-se e responderam prontamente ao questionário. Todos eles afirmaram utilizar a internet em seu dia a dia. Quanto ao uso de ferramentas para aprender inglês como L2, apenas dois participantes afirmaram utilizar algumas delas antes desta pesquisa. No entanto, quando perguntados sobre a utilização das mesmas ferramentas após a participação neste projeto, todos os alunos utilizam pelo menos duas ferramentas como suporte no processo de aprendizagem e disseram ter interesse em continuar utilizando a plataforma edmodo.

Quando questionados sobre suas experiências ao longo desta pesquisa, todos se posicionam de maneira positiva diante do uso dessas ferramentas como fontes de estudo, conhecimento e aprendizado colaborativo. Todas as respostas convergem em alguns aspectos, como por exemplo, no relato de uma aluna: "acredito que tenha adicionado e facilitado muito, sendo que é uma ferramenta interativa e divertida" 8 , e também de outros que afirmam: "percebi que era uma forma bem interessante de associar o aprendizado do inglês com a internet", e "com a utilização do espaço virtual, consigo uma interação com os outros estudantes e, principalmente, com a professora, o que proporciona um excelente ambiente de aprendizado e desenvolvimento". Outro aspecto recorrente nas reflexões foi a praticidade de poder acessar os conteúdos inseridos no espaço edmodo fora do espaço físico da sala de aula. Como por exemplo, no relato deste aluno: "(...)em momentos fora de sala de aula. Eu posso acessar nos finais de semana ou quando eu não tenho nada pra fazer(...)", e também na fala deste outro: "(...)pelo fato de dar a opção aos alunos de manter a comunicação em inglês de forma continuada, sem que o fim de cada aula acarrete, necessariamente, na interrupção dela”. Esses relatos comprovam que a criação de uma sala de aula virtual, na qual os alunos podem interagir de formas distintas entre si e com a professora, foi extremamente proveitosa e benéfica para 0 aprendizado deste grupo. É possível afirmar ainda que essa experiência ampliou os horizontes desses aprendizes em relação às possibilidades de se aprender, de maneira colaborativa, uma segunda língua (L2) em um ambiente descontraído, diferente e inovador para alguns.

${ }^{8}$ Informações escritas. Questionário preenchido durante a pesquisa. 


\section{Considerações Finais}

O presente trabalho iniciou-se com o intuito de oferecer aos seus participantes uma alternativa para aprenderem a aprender de maneira conjunta, construtiva e colaborativa, utilizando uma ferramenta simples, de fácil acesso, gratuita e extremamente funcional. Afinal, utilizando o edmodo esses alunos/participantes têm a possibilidade de interagirem entre si e interagirem com o conhecimento e a informação nas variadas formas em que se apresentam: imagens, sons, vídeo e textos escritos. Deste modo, construindo e compartilhando o aprendizado de uma maneira natural, significativa e integrada à sua realidade.

Apesar de tudo, ao longo da pesquisa houve alguns pontos negativos devem ser destacados. Primeiramente é válido lembrar que nem todos os alunos conseguem ou podem dedicar tempo e esforços para participar de um projeto que demande tempo e recursos tecnológicos, como um computador e acesso à internet. Portanto, o número de participantes ativos acaba sendo reduzido no percurso da pesquisa, como foi o caso deste projeto. Ao final dentre 14 alunos 8 participaram ativamente do processo proposto. De qualquer maneira é notável que esses participantes tiveram uma experiência única e que pôde ajudá-los a ampliar seus horizontes como aprendizes responsáveis pela própria aprendizagem e também pela aprendizagem de seus colegas, colaboradores, coaprendizes.

O espaço virtual que analisado nesta pesquisa ainda está em funcionamento e hoje é utilizado por seus participantes de forma extremamente livre e descontraída. Nele, eles postam o que acham interessante, divertido ou relevante compartilhar com seus colegas. Desde dúvidas sobre datas de provas até histórias pessoais sobre experiências vividas no final de semana, lembrando, tudo redigido na língua-alvo. Enfim, trata-se realmente de uma comunidade que une todos esses participantes em um universo cibernético que transcende o âmbito da sala de aula, mas ao mesmo tempo os une com um objetivo em comum: aprender colaborando.

\section{Referências Bibliográficas}

AGUIAR, Adriana Aparecida Souza. A produção textual em L2 no contexto universitário: possíveis contribuições do procedimento sequência didática. Disponível em <http://www.letras.ufmg.br/profs/reinildes/dados/arquivos/adriana.pdf>. Publicado em 2009. Acesso em 16 Abril, 2011

DIAS, R. A incorporação de tecnologias ao processo de ensino e aprendizagem de inglês 
como língua estrangeira. Belo Horizonte: PucMinas Virtual, 2002

DIAS, R. A integração das TICS ao ensino e aprendizagem de língua estrangeira e o aprender colaborativo on-line. Disponível em

http://www.letras.ufmg.br/profs/reinildes/publicacoes.asp?file=publicacoes. Publicado em

Revista Moara $n$ 30. Belém: UFPA - Programa de Mestrado, 2008. Acesso em: 16 Abril, 2011.

O'REILLY, T. What Is Web 2.0: design Patterns and Business Models for the Next

Generation of Software. Disponível em <http://www.oreillynet.com/lpt/a/6228>. Publicado em 2005. Acesso em: 16 Abril, 2011.

PRENSKY, M. Digital natives, digital immigrants. On the Horizon, 9(5), 1-6. Disponível em: http://www.marcprensky.com/writing/Prensky\%20\%20Digital\%20Natives,\%20Digital\%20I mmigrants\%20-\%20Part1.pdf. Acesso em 30 Set., 2010,

VYGOTSKY, L. S. A formação social da mente: o desenvolvimento dos processos psicológicos superiores. 5. Ed, São Paulo: Martins Fontes, 1996.

Anexos

\section{Anexo 1:}

\section{Questionário para a pesquisa : Edmodo: integrando o espaço cibernético à sala de}

\section{aula}

Leia atentamente cada questão abaixo, reflita e marque a opção que melhor se aplica à sua realidade. Lembramos que este questionário será utilizado apenas para fins de pesquisa. Obrigada pela sua participação.

\section{Qual o seu nome? * \\ Você utiliza a internet em seu dia-a-dia? *}

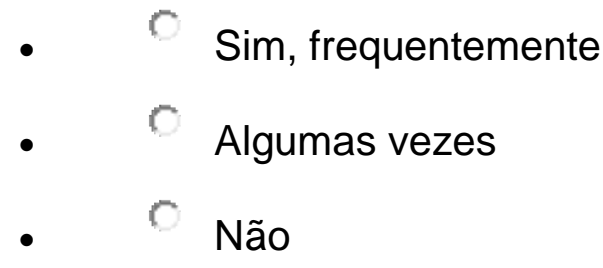

Quais dos recursos abaixo você utiliza com mais frequência? *
- $\quad\ulcorner$ e-mail
- $\quad$ e-groups
- $\quad\ulcorner$ redes sociais
- $\quad\ulcorner$ ferramentas de bate-papo (eg. msn, google talk, skype) 


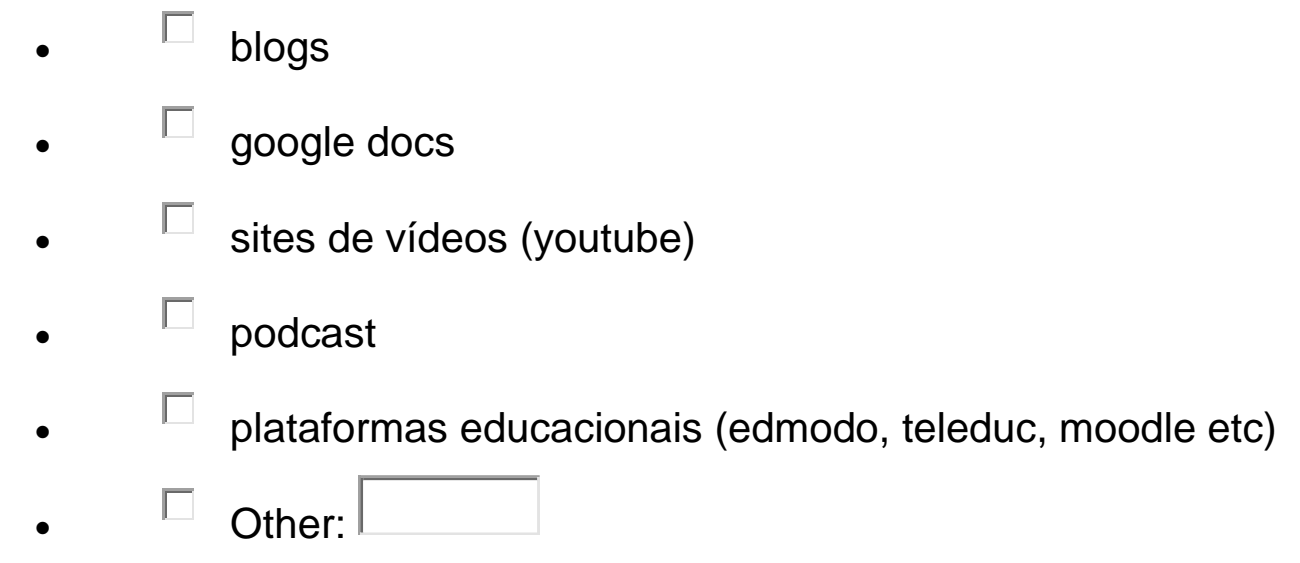

Antes de utilizar a ferramenta edmodo, você utilizava alguma das ferramentas abaixo para aprender e/ou praticar Inglês? Marque as opções que se aplicam. *

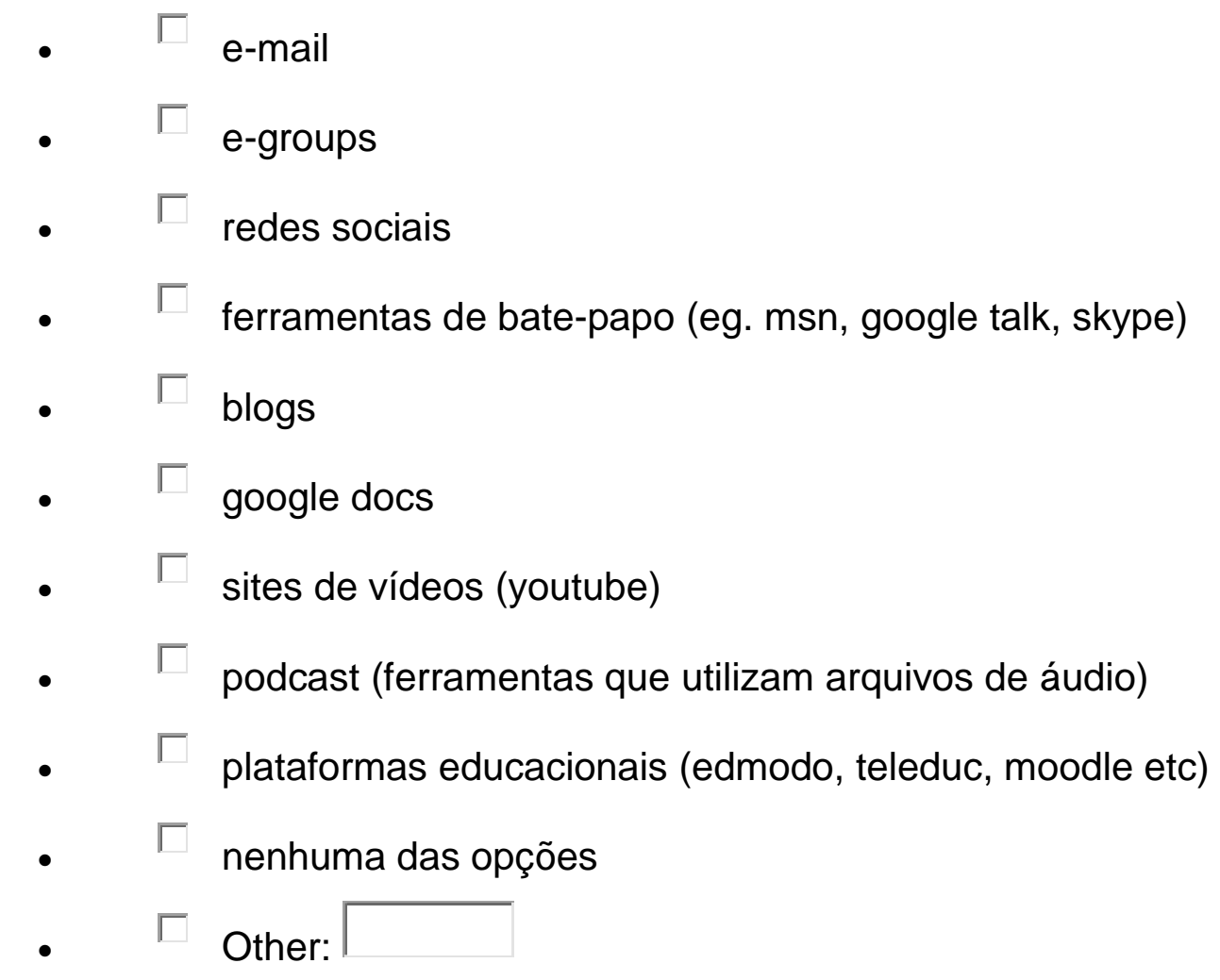

Após alguns meses utilizando a ferramenta edmodo, você utiliza alguma das ferramentas abaixo para aprender e/ou praticar Inglês? Marque as opções que se aplicam. *

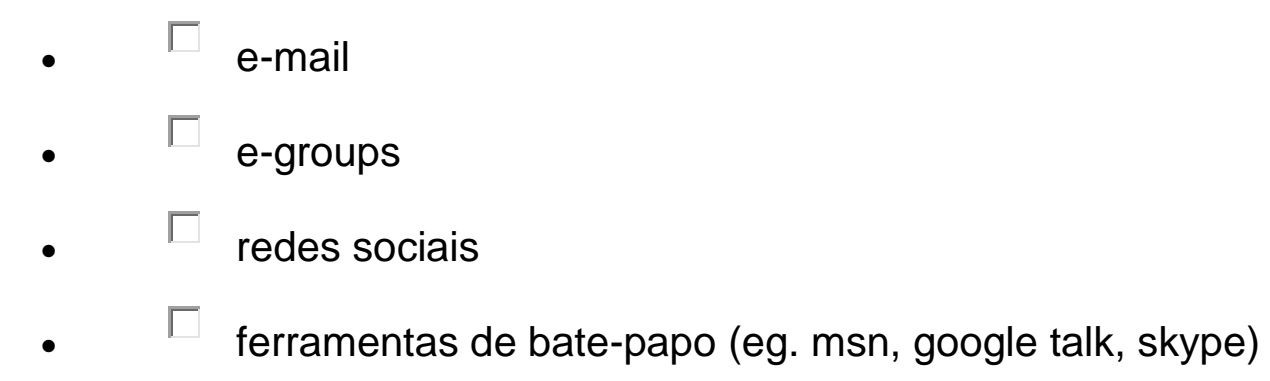




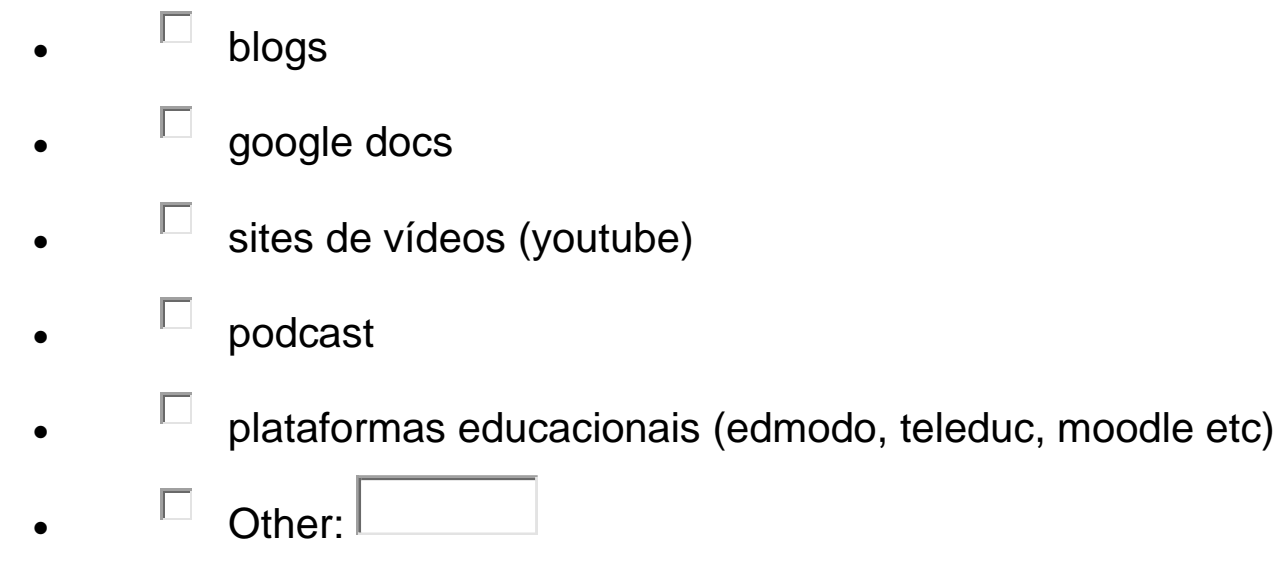

Você acredita que o uso dessas ferramentas, em especial o espaço virtual edmodo, possa ter colaborado para a sua aprendizagem? *

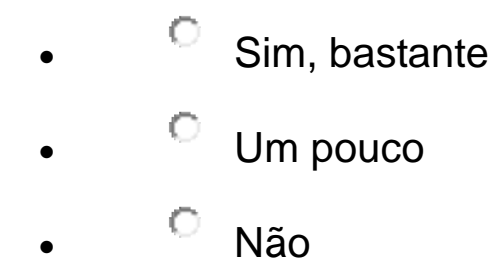

Você gostaría de continuar utilizando a ferramenta edmodo como tem feito após o término de seu curso presencial de inglês? *
- $\quad$ Sim
- $\quad$ Não

Escreva um pouco sobre sua experiência utilizando o espaço virtual edmodo. Você acredita que tenha tido um efeito positivo no processo de aprendizagem de inglês? Como? Por que? *

\section{Powered by Google Docs}

Disponível em:<https://spreadsheets.google.com/viewform?hl=en\&formkey=dGN5M0U5Sk5XekNRO TFOUIVzM0F6c2c6MQ\#gid=0> 


\section{Anexo 2:}

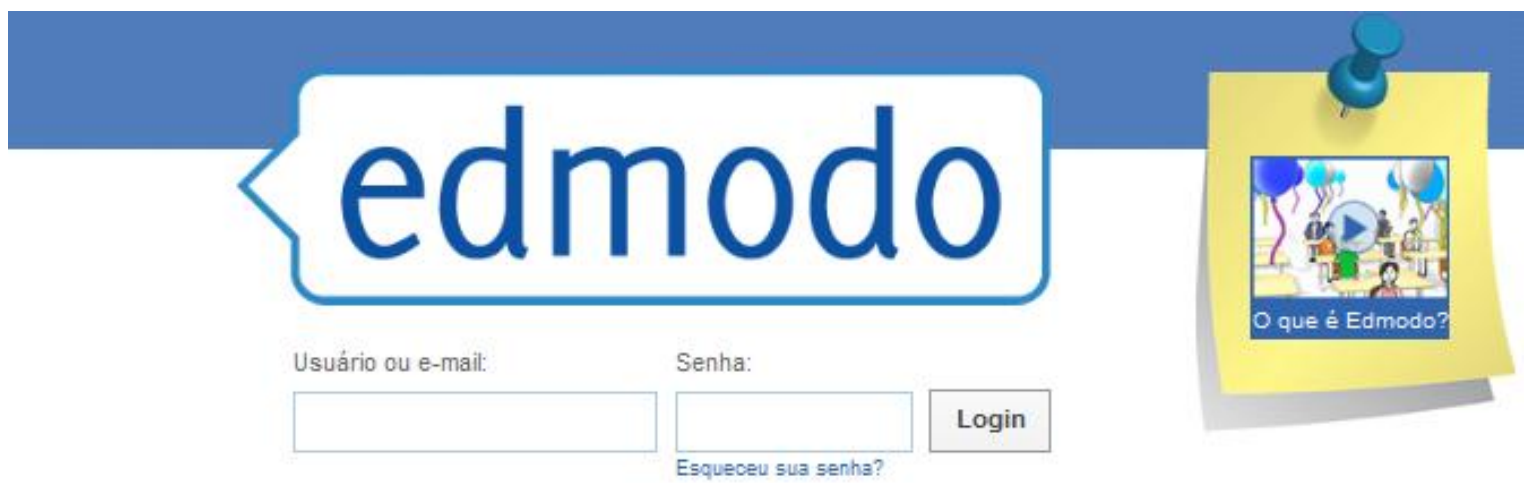

\section{Cadastre-se}
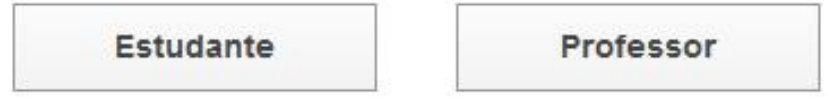

Cadastro para Pais (TRANSLATION NEEDED)
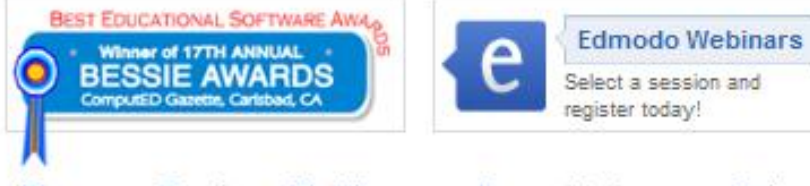

Blog Escolas e Distritos

Comunidades

Guia

(fig. 1.0: Página inicial da plataforma edmodo. Fonte: <www.edmodo.com> 


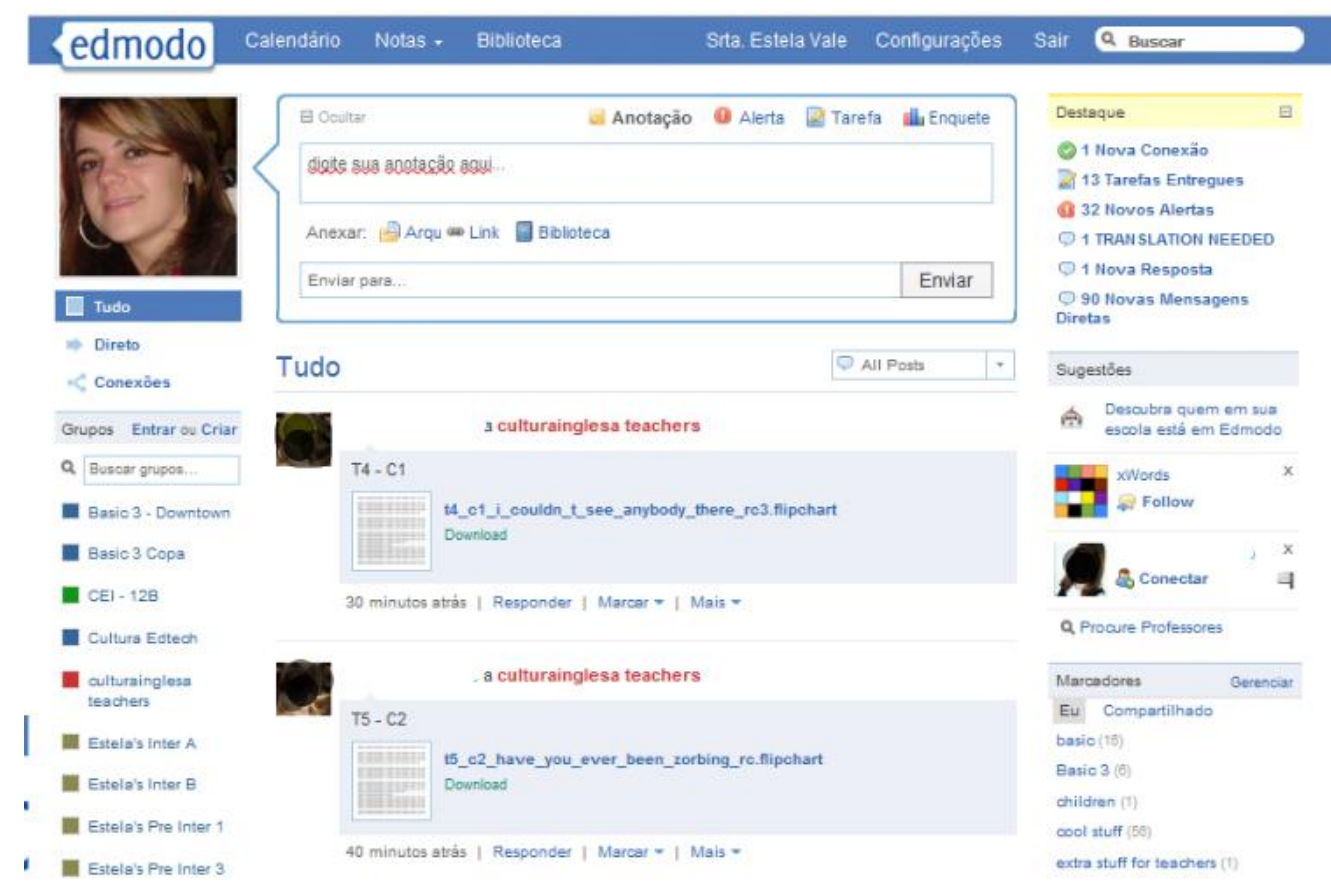

(fig. 2.0: Página pessoal da plataforma edmodo. Fonte: <www.edmodo.com/home> 
Hey XIDSt!! Weloome to our ONLINE GROUP on EDMODO... chill out, this is just a nicer way to study and have fun at the same time!!?

So, last olass I asked you to write your thoughta about this oomment: IT is NOT SO IMPORTANT TO LEARNUSPEAK ENGLISH.

Clayton, our new friend. send me a comment saying that ONE of the reasons Enplish is soopoooo important is the fact that "everybody in the businens world apteaks Engliah". What do you think about that? Do think he ia tlght? Now, is this the ONLY reason for which people study English nowadays?

Can't wait to read your thoughts.

TRMAGATIONNGEDEO

Sesc 1Q, 2011 | Fesponoer | Poenco | Marcar - | Mals-

Q Srta. Estela Vale - oh, take a lock at this article about the importance of learning English, maybe it could give v some ideas

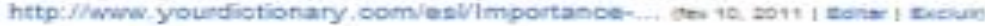
Q

u. - Hello gurys!l!

1 agree with Clayzon, English nowadays beosme a internacional language. We know all the countries have your own language but the English is the first option to learn around the world. Added to this I think everything we have learned we will use for something: perhaps today we think that we don't need a Engliah course, but in the future we will see how much important it is. Learn never is too much.

Kisses. :-)

000

D. - Hello Folk, english is a very important language

nowadays is quite impossible find a good work

if you don't apeak english very wel. In the company where 1 work, many e-mais are sending in

english because we ve pot foreings clients, so was created a peopram to teach english for everybody

speak english. So if a a little excample that How important is this language to

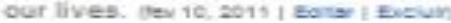

$$
\text { M. - Hi Guys!! : j }
$$

I Agree with everybody, Englah is very important to have a good work, but I read the text about the importance of learning English 1 agree with the writer despite of the dificulties, learning English teaches more than vocabulary, you can spesks your native tongue easier.

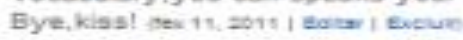

4. M. - In my opinion english is very important. If's heip if you want to travel another oountry. ia very important for get a good work. People al over the word speak englisht wou =4, 20ss i Edus i Evcum

1. O. - I disagreed with that comment, obviously. I guess afs. important to speak Englsh, because we need it if we want to survive at job market. After all this is the official languape of the work. Moreover I love it so much, It's a pleasure for me. I often spend the weekends studying or

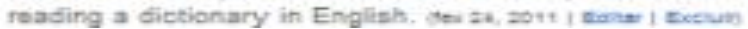

(fig. 3.0: Primeiro post na plataforma edmodo. Fonte: www.edmodo.com/home

O. a IA downtown

Hi guys! I've made this video for a college work. It's about myself, my pleasures and thoughts about lots of things. I hope you like it.

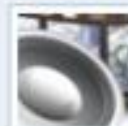

auto_retrato_ericdos.wmv

Downiogd

mar 15, 2011 | Responder | Público | Marcar * | Mais *

$\square$ Srta. Estela Vale - WOW, great way to tell us a bit about urselfi!l really liked the songs and the photos u chose to talk about ur lifellil Now, How about making something like that IN ENGLISH???!! You could use some websites that will make the video lighter/faster... like fotobabble, for instance....

looking forward to seeing the International version!!!!

See ya (mar 17, 2011 | Editar | Excluir)

(fig. 4.0: Post de participante na plataforma edmodo compartilhando um trabalho. Fonte: $<w w w . e d m o d o . c o m / h o m e>$ 
Ten oook as a hobby, women cook because they have to'

I agree with that, because since a long time ago the oely person who used to

cooked was the women, time went and men started to cook too. Many women

like to cook, but not all women like to do it. In my opinion men who like to cook.

cook better than women because when you do something with pleasura, you do

it better than someone who dont like to do it, and we can see it when we go to a

restaurant and see that the most cooks are men.

mar 3,2011 | Fesponder | Pcolliso | Marcar * | Mais *

1 B. a IA downtown

teacher this is my hw from page 7 speaking $c$

'Women worry more about theur diet than men'

I agree that women are more concerned with their heath than men. they are more concerned with the body, with feeding, with the aesthetics of her body. ja men are not very concerned, they will eat and drink without worrying about the body. exitom course, exceptions

mar 1.2011 | Resoonoer | Puolizo | Marcar * | Mais *

\section{M. a lA downtown}

Hi Teacherl! This are my excercise.

From page 7 , Speaking of

- Hen cook as a hobby, women cook because they have to

I diagree, because sometimes the man has to be the "women of the houce"

and some womens really Bce to cook not as an obligation but like a way to

relax. They cook to her famly in some birthday partys, in sundays with al the

family... Of course we can't put everybody in the same pocket, the true is tha:

we have a lot of styles of life defined by the habits.

Sorry if $\mathrm{Tm}$ a ittle late.

Kisses, :-).

Thusutionnasoso

(fig. 5.0: Post de participantes na plataforma edmodo compartilhando uma tarefa. Fonte:<www.edmodo.com/home>

\section{a IA downtown}

Hello everyone.

I have a sugestion to share with you. I'm putting here my MSN adress and would like talk with everybody in english. I don't know if you like, but, if yes, reply my post with your adress.

But reminder: Conversation only in correct english, right?

One think. I work a lot and didn't enter in MSN frequently, but if you can it's a good way to improve our english and vocabulary
C
Oliveira -
i@hotmail.com

abr 3,2011 | Responder | Público | Marcar * | Mais *

Srta. Estela Vale - Here is mine: $\quad$ 3@hotmail com

(abr $4,2^{n} 11$ | Fditar | Excluir)

Q 0. - I'd like to join it. Here is it: @hotmail.com

(abr 5, 2011 | Editar | Excluir)

9. M. - So nice, here is mine: $r \quad$ _ _-,@hotmail com

(abr 7, 2011| Editar | Excluir)

(fig. 5.0: Post de participantes na plataforma edmodo sugerindo o uso do MSN. Fonte: $<$ www.edmodo.com/home> 


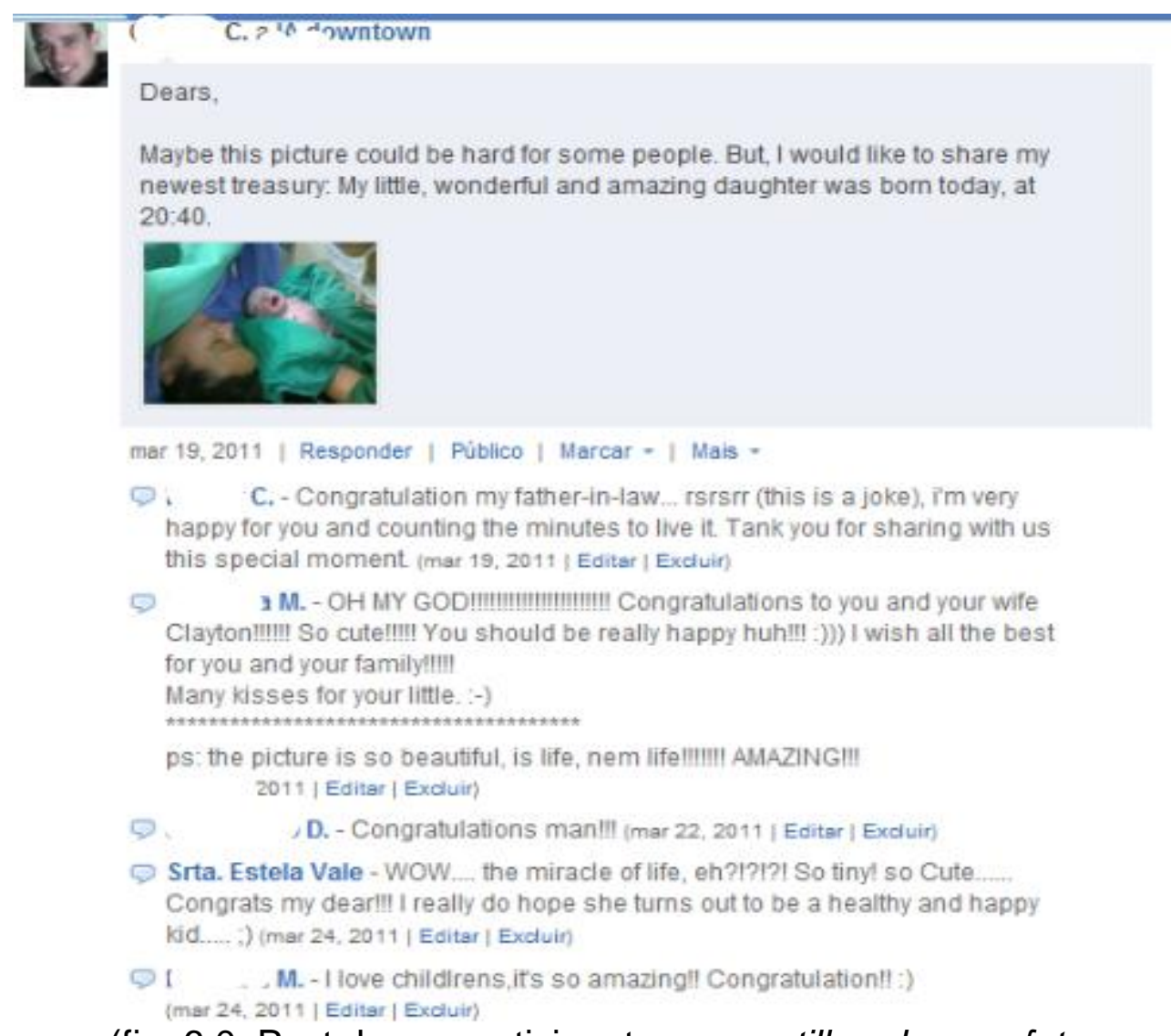

(fig. 6.0: Post de um participante compartilhando uma foto pessoal. Fonte:

www.edmodo.com/home

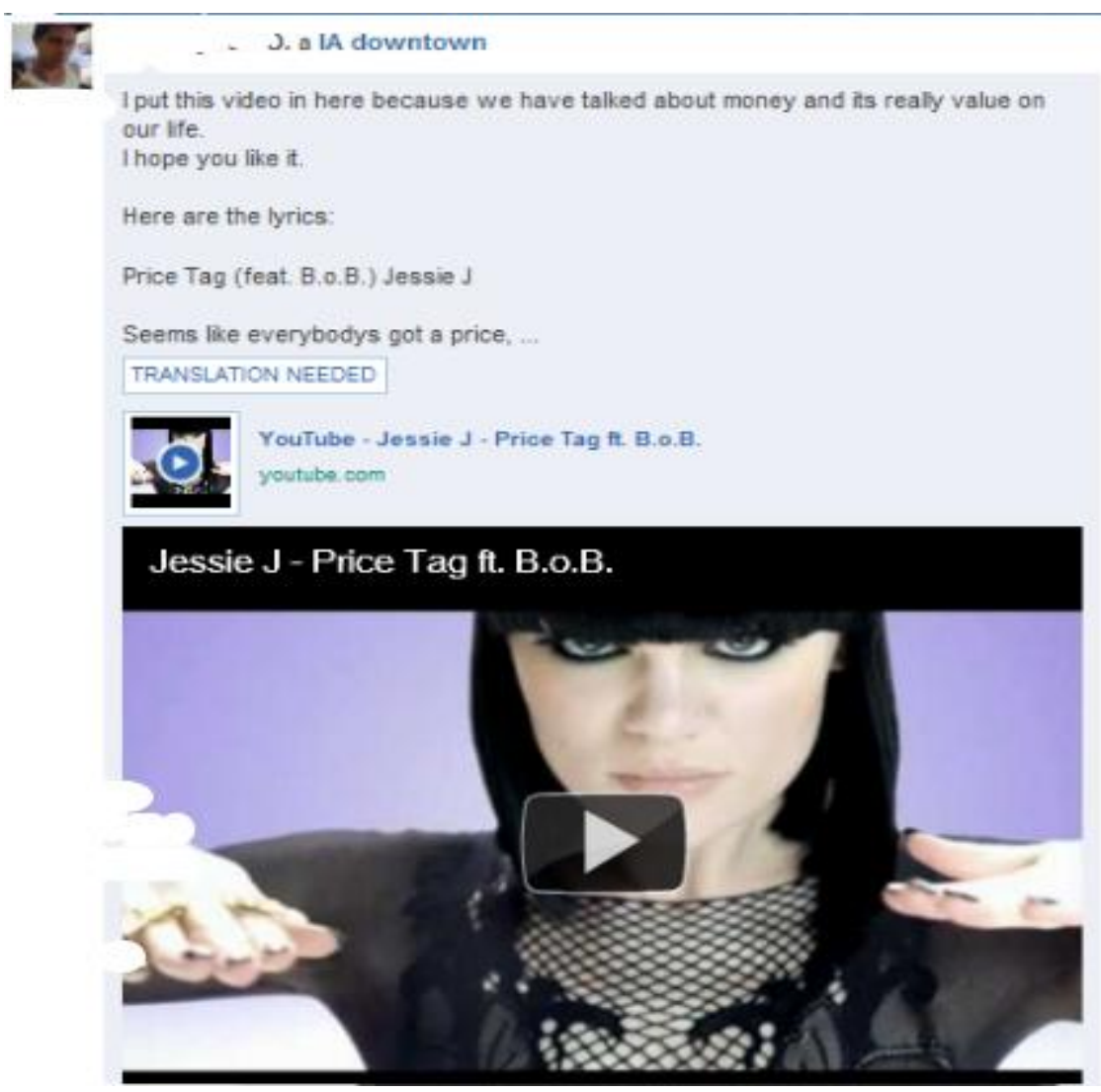

(fig. 6.0: Post de participante com um vídeo relacionado a tema discutido em sala. Fonte: $<w w w . e d m o d o . c o m / h o m e>$ 


\section{2. a IA downtown}

News in New York Times about the crime happened in Realengo today morning, at Rio de Janeiro city, were I was yesterday in a business trip.

Follow link: http://www.nytimes.com/2011/04/08/world/ameri..

Regards

abr 7,2011 | Resp \& Público | Marcar * | Mais *

S Srta. Estela Vale - OMG I!!! I didnt about this!!!! what a terrible piece of news!!!! (abr 7,2011| Editar | Excluir)

Q - M. - I saw this!!!!!!!!! It's was a terrible thing... How someone could do this wit., .....?!!! This guy don't have a heart.... (abr 7, 2011|Editar | Excluir)

(fig. 7.0: Post de participante com um link do New York Times. Noticia sobre o Brazil. Fonte: <ww.edmodo.com/home>

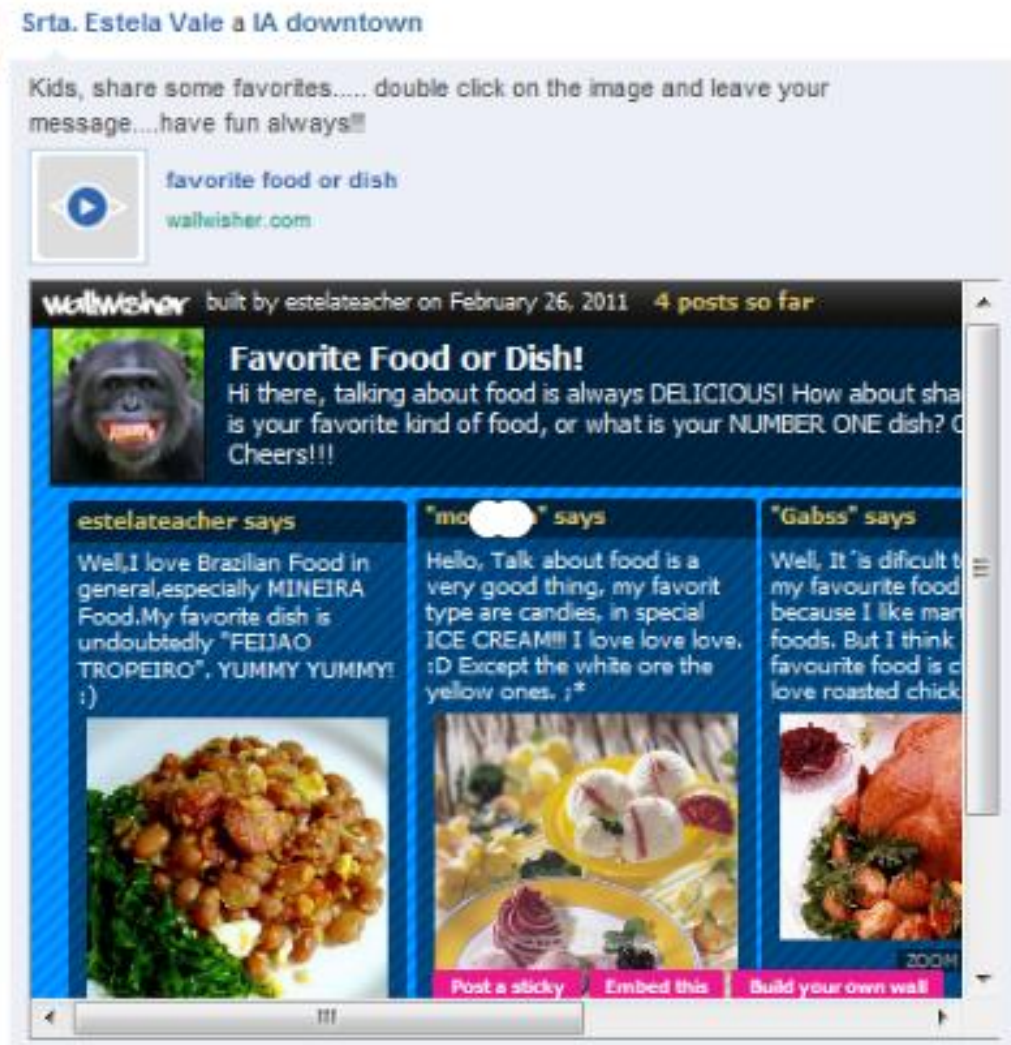

(fig. 7.0: Post da professora utilizando a ferramenta wallwisher . Fonte: $<w w w . e d m o d o . c o m / h o m e>$ 
Srta. Estela Vale a IA downtown

Hello dear ones,

This link if for an activity we're doing tonight, ok??

See ya

)
c
voicethread
c. gigcount.com

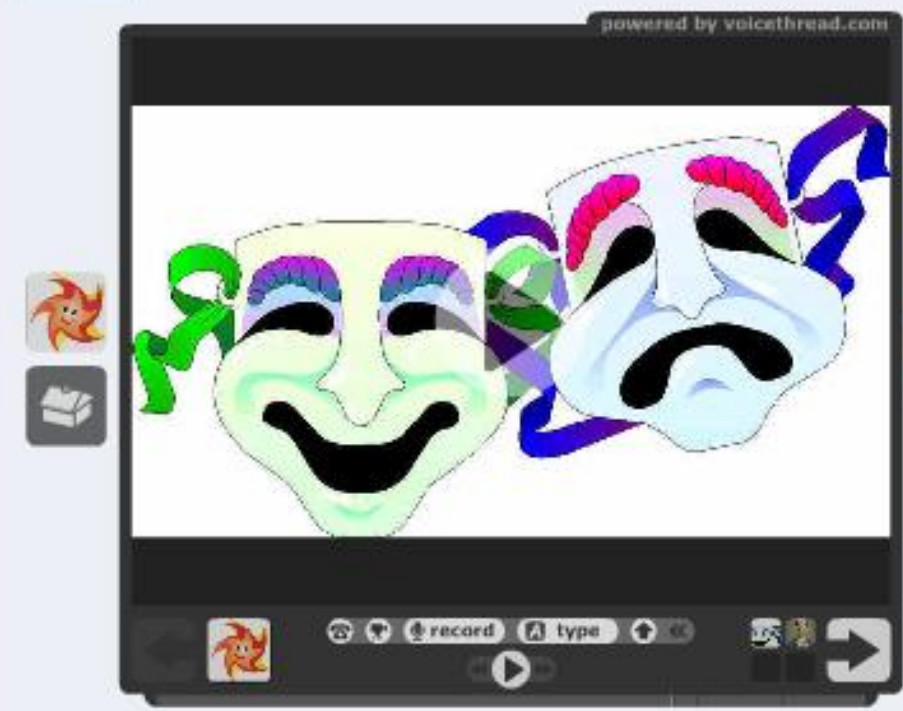

(fig. 7.0: Post da professora utilizando a ferramenta voicethread. Fonte: <www.edmodo.com/home> 
Srta. Estela Vale a Ih downtown

Hello dear students!!!

Here is a little gift to help you study this weekend!I!

Have a great one!

Dont forget to do your workbooks as wel, ok?1?!!

Sne yal!!

ㅇ

Intat A toviow glog

colgoounteom

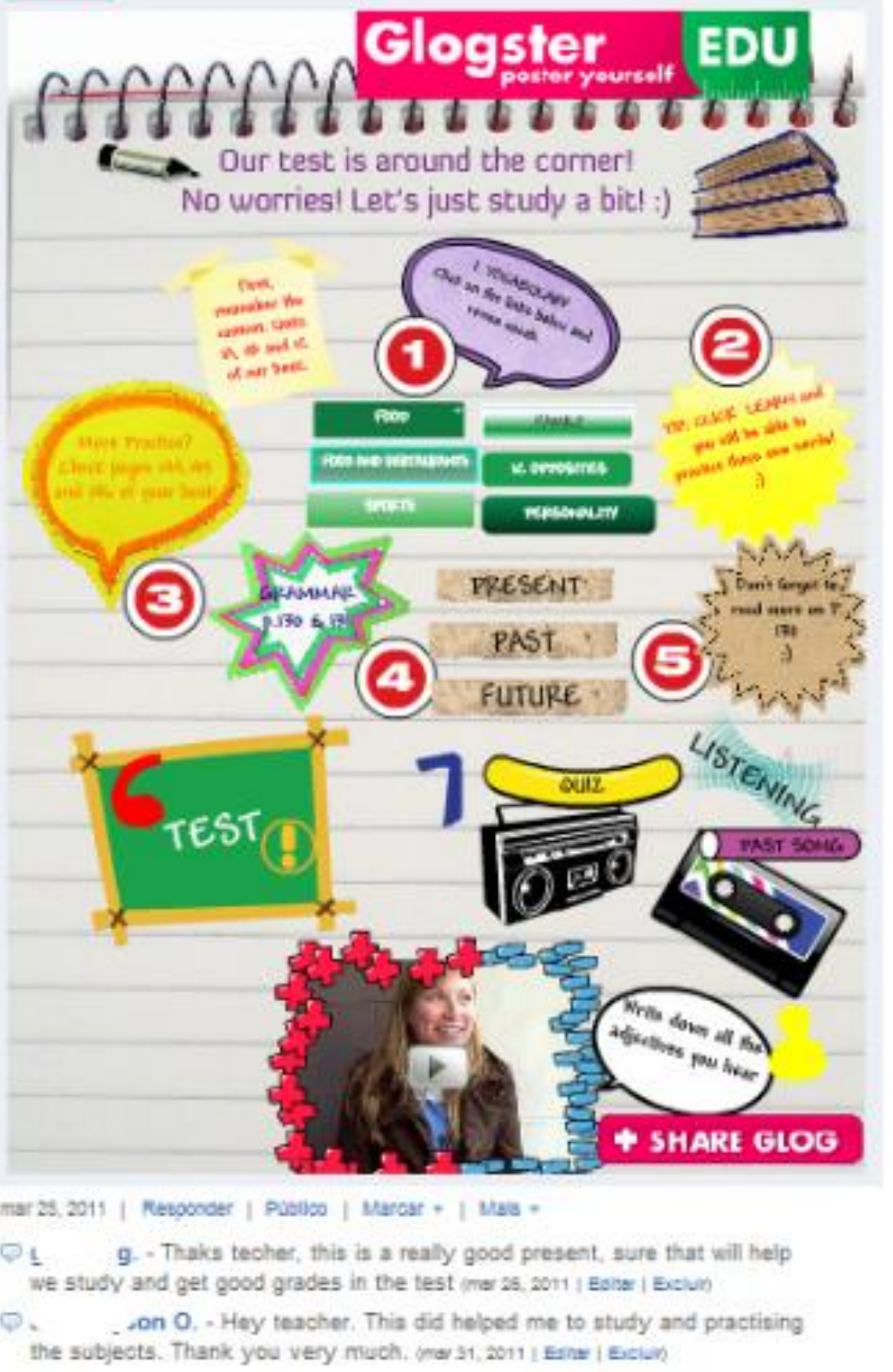

(fig. 7.0: Post da professora utilizando a ferramenta glogster. Fonte: $<$ www.edmodo.com/home> 


\title{
ENSINO DE GÊNEROS TEXTUAIS NA UNIVERSIDADE: EXERCITANDO AS PRÁTICAS DISCURSIVAS DAS PROFISSÕES
}

\section{TEACHING OF TEXTUAL GENRE AT THE UNIVERSITY: EXERCISING THE DISCURSIVE PRACTICES OF THE PROFESSIONS}

\author{
Francisca da Rocha Barros Batista ${ }^{9}$ \\ fran2.barros@gmail.com
}

\begin{abstract}
RESUMO: Este trabalho destaca a importância de a universidade possibilitar aos alunos dos cursos de graduação contato com os gêneros textuais utilizados na interação entre os participantes da comunidade discursiva da qual esses alunos participarão. Os estudos sobre gêneros textuais, hoje, no que tange ao ensino, dedicam-se mais ao ensino fundamental e ao ensino médio. Na universidade, geralmente, esses estudos direcionamse para a análise de gêneros acadêmicos, e não ao ensino de gêneros mais específicos de cada curso. Esse fato, aliado ao resultado de uma pesquisa de extensão que apontou a relevância de o gestor ter intimidade com determinados gêneros para atingir os objetivos relacionados a sua função, despertou nosso interesse por pesquisar a opinião dos estudiosos de gêneros textuais sobre esse tema. Desse modo, partimos da congruência do pensamento de autores como Bazerman, Bathia, Bronckart, Marcuschi, Miller e Swales, e estabelecemos um diálogo no qual os conceitos de gêneros textuais, de comunidades discursivas e de propósitos comunicativos embasam a defesa sobre a necessidade de os professores disponibilizarem, nos cursos de graduação, os gêneros textuais próprios de cada curso, dando condições para que os alunos sejam aceitos e tenham ascensão na comunidade discursiva de sua profissão.
\end{abstract}

PALAVRAS-CHAVE: Gêneros textuais; Comunidades Discursivas; Ensino; Universidade.

ABSTRACT: This work detaches the importance of the university to make possible to students of the degree courses contact with textual genres used in the interaction among the participants of the discourse community from which they will participate. The studies on textual genres, today, applying to the teaching, have devoted more to the fundamental and medium education. In the university, generally, those studies are addressed to the analysis of academic genres, and not to the teaching of more specific genres of each graduate course. This fact, allied to the result of an extension research that pointed the relevance of the manager to have intimacy with certain genres to reach the goals related to his function, called our interest in researching the views of specialists in textual genres on this theme. Thus, we started from the congruence of the authors' thought as Bazerman, Bathia, Bronckart, Marcuschi, Miller and Swales, and it was established a dialogue in which the concepts of textual genres, of discourse communities and of communicative purposes base the defense about the need of the teachers work, in the degree courses, the own textual genres of each course, giving conditions for students to be accepted and have ascension in the discourse community of their profession.

${ }^{9}$ Doutoranda do PGLETRAS/ UFPE 
KEYWORDS: Genre; Discourse Communities;Teaching; University.

\section{Introdução}

O estudo dos gêneros textuais, balizado pela visão sociointeracionista da linguagem, embora tenha se desenvolvido recentemente, desperta hoje interesse das mais diversas áreas do conhecimento, isto é, os gêneros textuais norteiam as reflexões, as pesquisas, enfim, a prática de profissionais dos mais diversos campos do saber, fazendo com que esse campo de análise, no dizer de Bhatia (2009), assuma uma relevância nunca esperada. Reforça essa surpresa com a popularização dos estudos de gêneros a indagação de Candlin (1993, apud Bathia, 2009, p. 159):

O que há com o termo e com a área de estudos que ele representa, para que atraia tanta atenção? O que lhe permite agrupar sob o mesmo abrigo terminológico críticos literários, retóricos, sociólogos, cientistas cognitivistas, especialistas em tradução automática, linguistas computacionais e analistas do discurso, especialistas em inglês para fins específicos e professores de língua? O que é isso que nos permite reunir sob o mesmo rótulo publicitários, especialistas em comunicação comercial e defensores do Inglês Simplificado?

Se observarmos os estudos contemporâneos desenvolvidos nas ciências humanas e sociais, constataremos que o foco na atividade das pessoas nas práticas discursivas, mediadas pela linguagem, constitui o núcleo desses estudos. Pode-se apontar como uma das justificativas para o despertar desse interesse a compreensão que se tem da relevância de se estudar a vida social a partir das redes de práticas que se constroem com o desenvolvimento da ação humana.

Reforça esse pensamento a defesa de Machado (2001), ao responder a críticos que consideram fora de moda falar sobre gêneros. Para a autora, as grandes mudanças do processo de comunicação e a diversidade oriunda das transformações de formas discursivas e de meio parecem afirmar justamente o contrário. Mesmo que o momento se caracterize por formas de comunicação inacabadas e anárquicas, é necessário, pelo menos, que tentemos compreender essa suposta desorganização.

Esses estudiosos consideram gênero textual como evento recorrente de comunicação em que uma determinada atividade humana, envolvendo papéis e relações sociais, é mediada pela linguagem (Bakhtin, 2003). Nesse sentido, Bronckart (2008, p.103), afirma que "a apropriação dos gêneros é um mecanismo fundamental de socialização, de inserção prática nas atividades comunicativas humanas", o que é salientado por Marchuschi (2005), ao afirmar que dominarmos um gênero textual equivale 
a uma forma de realização linguística de objetivos específicos, em contextos sociais particulares. Se observarmos alguma atividade humana ou uma esfera social, perceberemos, inclusive, como se organizam valores e como as pessoas os utilizam.

Assim, se concordamos com a afirmação de Hendges (2001) de que é necessário investigar os gêneros textuais utilizados na interação entre os participantes de uma determinada esfera para compreendermos como se efetivam as atividades comunicativas que nela se efetivam, a importância de se conhecer melhor a maneira como as práticas sociais e discursivas dos diversos meios sociais se concretizam em gêneros de textos parece-nos indiscutível.

Enriquece esse pensamento a opinião de Marcuschi (2006, p. 23) ao ressaltar a relevância e a necessidade dos estudos sobre gêneros textuais, afirmando que estes existem desde que existe linguagem, e que vêm "essencialmente envoltos em linguagem". Salienta ainda que esses estudos constituem-se uma fecunda área interdisciplinar com atenção especial para o uso da língua e para as atividades socioculturais.

No momento em que alguém que frequenta uma determinada esfera social ou uma comunidade discursiva começa a produzir gêneros específicos daquele grupo, "começará a pensar de maneira ativa, produzindo enunciados pertencentes àquela forma de vida..." (BAZERMAN, 2005, p.102)., Para reforçarmos essa ideia, inspirada na definição Wittgensteiniana de "linguagem-em-uso" como uma forma de vida, expomos a opinião de alguns estudiosos da área sobre a necessidade de os professores dos cursos de graduação atentarem para a importância de disponibilizarem para seus alunos gêneros textuais próprios do espaço discursivo que estes ocuparão no campo profissional.

O interesse por esse tema cresceu após o resultado de uma pesquisa desenvolvida no Programa de Apoio à Pesquisa - ProAGRUPAR, do Instituto Federal de educação, Ciência e Tecnologia do Piauí - IFPI, que objetivou mapear os gêneros textuais utilizados pelos gestores de pessoas de uma empresa de Teresina-PI. $\mathrm{O}$ fato de a gerente de Recursos Humanos entrevistada apontar a intimidade que ela tem com os gêneros textuais utilizados nessa comunidade como um dos fatores responsáveis pela liderança que exerce junto aos colaboradores da empresa e por sua ascensão na empresa, nos motivou a visitar a literatura da área a fim de descobrirmos como estes se posicionam a respeito e de adquirirmos embasamento teórico para pesquisas futuras.

Assim, iniciamos com esta seção, na qual apresentamos nosso objetivo e a justificativa deste trabalho, bem como uma rápida contextualização do tema; a seguir, apresentamos os conceitos de gêneros textuais, comunidades discursivas e propósitos 
comunicativos; na seção seguinte, discutimos a importância da abordagem do discurso das profissões no contexto universitário; por fim, apresentamos as considerações finais.

\section{Gêneros textuais, comunidades discursivas e propósitos comunicativos}

Nesta seção, objetivando contextualizar nossas discussões, apresentamos conceitos de gêneros textuais ${ }^{10}$, de comunidades discursivas e de propósitos comunicativos, defendidos e adotados por vários pesquisadores da área.

Todas as atividades humanas estão relacionadas à utilização da linguagem, e esse uso efetiva-se em forma de enunciados (orais e escritos) concretos e únicos, relativamente estáveis "proferidos" pelos membros de uma ou outra esfera da atividade humana, denominados de gêneros do discurso (BAKHTIN, 2003). Dessa forma, o autor vincula a constituição dos gêneros à atividade humana, relacionando a opção por um gênero ou por outro a uma forma de inserção social e de execução de propósitos comunicativos intencionais.

Daí a pertinência da posição de Marcuschi (2006, p. 103) ao defender uma concepção de gêneros textuais como entidades dinâmicas, ou seja, como "formas culturais e cognitivas de ação social corporificadas de modo particular na linguagem", isto é, faz-se necessário que a concepção de gênero adotada nos estudos não seja a de modelos acabados nem de estruturas inflexíveis. Com pensamento semelhante, Miller (2009) defende uma compreensão de gênero alicerçada na prática retórica, nas convenções de discursos que uma sociedade institui como forma de "agir junto". Esse entendimento decorre do fato de que "os gêneros mudam, evoluem e se deterioram; o número de gêneros correntes em qualquer sociedade é indefinido e depende da complexidade e variedade da sociedade" (MILLER, 2009, p.41). Assim, para a autora, uma definição retórica de gênero para ser válida precisa ser centrada na ação que é utilizada para sua realização, e não na substância ou na forma. Gêneros são "ações retóricas tipificadas fundadas em situações recorrentes". (MILLER, 2009, p.34).

E é nessa ideia que Bazerman se fundamenta ao afirmar que, para termos uma compreensão mais profunda sobre gêneros, precisamos concebê-los como "fenômenos de reconhecimento psicossocial que são parte de processos de atividades socialmente organizadas" (BAZERMAN, 2005, p.31). Assim, gêneros são fatos sociais, são o que as pessoas reconhecem como gêneros em qualquer momento do tempo. Os gêneros

\footnotetext{
${ }^{10}$ Não faremos distinção entre gêneros textuais, gêneros discursivos ou gêneros do discurso, por não acharmos necessário para o nosso objetivo. Adotaremos a terminologia gêneros textuais ou apenas gêneros, com exceção das citações nas quais respeitaremos a terminologia usada pelo autor.
} 
surgem nos processos sociais nos quais as pessoas tentam compreender umas às outras, de forma a coordenar atividades e compartilhar significados, objetivando atingir propósitos práticos.

Ressalta-se, porém, que essa posição dos autores não significa a negação dos aspectos formais do gênero, mas uma crítica ao ensino de gêneros que privilegia a forma em detrimento da ação social que o gênero concretiza.

Para explicar como os gêneros se configuram e se encaixam em organizações, papéis e atividades mais abrangentes, Bazerman (2005) propõe alguns conceitos que se sobrepõem, quais sejam: conjunto de gêneros, sistema de gêneros e sistema de atividades, sendo que cada um envolve um aspecto diferente dessa representação.

O autor define conjunto de gêneros como sendo um ajuntamento de textos de mesma natureza que uma pessoa num determinado papel produz. Portanto, para identificar boa parte do trabalho de um profissional, uma boa estratégia é mapear todos os gêneros que um profissional precisa produzir (na forma escrita ou oral).

Os diversos conjuntos de gêneros usados por pessoas que trabalham juntas de uma forma organizada, e também as relações padronizadas que se formam na produção, circulação e utilização de tais documentos constituem o sistema de gêneros. Dessa forma, o sistema de gêneros apreende as sequências regulares com que um gênero segue outro gênero, dentro de um fluxo comunicativo característico de um grupo de pessoas. Já o sistema de atividades é um frame que organiza o trabalho, a atenção e o que as pessoas de um dado campo profissional realizam.

Portanto, analisar o conjunto de gêneros permite perceber a extensão e a variedade da produção escrita exigida por certo papel, bem como determinar 0 conhecimento de gênero e as habilidades de escrita essenciais para alguém executar esse trabalho. Investigar o sistema de gêneros proporciona a compreensão das interações práticas, funcionais e sequenciais de documentos. Por fim, considerar o sistema de atividades possibilita o entendimento de todo o trabalho realizado pelo sistema e de que maneira os textos auxiliam as pessoas a realizarem atividades, em vez de focalizar os textos como fins em si mesmos.

Swales (2009) corrobora esse pensamento ao enfatizar que o conhecimento do texto em si não é determinante para que alguém redija no contexto acadêmico. $O$ autor baseia-se na visão de autores como Miller, apresentada anteriormente, cuja proposta é de que se perceba no gênero não a forma discursiva, mas sim a ação social realizada pelo gênero. Desse modo, achamos importante recorrer ao conceito de gênero defendido por esse autor, qual seja: 
Um gênero compreende uma classe de eventos comunicativos, cujos exemplares compartilham os mesmos propósitos comunicativos. Esses propósitos são reconhecidos pelos membros mais experientes da comunidade discursiva original e constituem a razão do gênero. (SWALES, 1990, p.58).

A esse respeito Bonini (2001) defende que a partir do momento em que se conceitua comunidade discursiva como uma contraparte do conceito de gênero textual, concebe-se gênero como elemento da comunicação de uma comunidade discursiva, 0 qual a caracteriza, ao mesmo tempo em que é caracterizado por ela. Baseando-se no conceito de Swales (1990), esse autor afirma que um gênero textual revela os modos de interação próprios de uma comunidade discursiva, pois representa eventos comunicativos a partir dos objetivos compartilhados entre os seus membros. As maneiras como um gênero se concretiza decorrem de como é convencionalizado dentro da comunidade discursiva, ao adquirir função, posicionamento e uma forma característica.

Desse modo, a comunidade discursiva pode ser definida como um grupo de indivíduos que atuam comunicativamente a partir de um tópico de referência, ou de um conjunto restrito deles, mediante os mesmos objetivos e uma linguagem comum estruturada nessa atividade. Para alguém fazer parte de uma comunidade discursiva e de ascender em sua estrutura hierárquica de participação, é necessário conhecer esse padrão linguístico particular (estilo, léxico, gêneros textuais etc.). Salientamos que não apenas o conhecimento desse padrão linguístico é importante para esse fim, saber identificar que gêneros são mais adequados para atingir determinados propósitos comunicativos é determinante para o sucesso das interações sociais.

Vale observar, entretanto, que o conceito de comunidade discursiva ocupa o centro de discussões de vários estudiosos da área que consideram reducionista o conceito proposto por Swales.

Embora reconheça esse conceito como um instrumento bastante produtivo nos estudos sobre gêneros, Bonini (2002) declara que os critérios utilizados para definir comunidade discursiva não contemplam um grande número de gêneros textuais, dentre os quais os gêneros de comunicação de massa e os gêneros cotidianos. Soma-se a esse pensamento a observação de Marcuschi (2005) sobre o fato de, em diversos contextos da internet, como os chats, os membros serem, em sua maioria, anônimos, e as interações passageiras e superficiais, mesmo que os participantes possuam interesses e práticas semelhantes. 
Bazerman também se posiciona a respeito. Para ele, o argumento de Swales (1990) sobre os gêneros escritos dependerem de propósitos comunicativos modelos pertencentes a comunidades textuais de discursos, e o posicionamento de Berkenkotter \& Huckin (1995) que definem a propriedade dos gêneros por uma comunidade discursiva como um aspecto relevante, afirma que, mesmo reconhecendo o valor das ideias do primeiro e comungando das proposições explicativas dos últimos, adota outro critério para descrever o embasamento de gênero na atividade social. Acredita "que as noções estruturalistas de comunidades de discurso são inadequadas para caracterizar o caráter complexo, emergente, multiforme, conflituoso e heterogêneo do intercâmbio e dos grupos humanos". (BAZERMAN, 2007, p.177). O interesse do autor dirige-se para as diversas caracterizações dos grupos e dos locais dentro dos quais os discursos circulam e para os modos de atividades recorrentes e emergentes, concretizados através dos enunciados e materializados em gêneros.

Swales (2009), tentando responder às críticas direcionadas ao seu conceito de comunidade discursiva, primeiramente, declara ter sido facilmente seduzido por esse conceito. Acrescenta que talvez "tenha feito causa comum, com boa vontade demasiada, com aqueles que possuem seus próprios motivos para conceber as comunidades discursivas como grupos reais e estáveis de pessoas com posições consensuais" (SWALES ,2009, p.204). É possível inferir que o autor não concorda totalmente com as críticas, tanto que cita nomes de intelectuais, como Kuhn, Rorty, Latour e Woolgar, salientando que estes precisam de um consenso social para que possam construir uma descrição social dos fatos científicos. Continuando seus argumentos, o autor salienta que seja qual for a verdade, a aceitabilidade é uma construção social por excelência, portanto, carece, no mínimo, de uma percepção de ordem. Para Swales, existem razões para que se mantenha o controle sobre a comunidade discursiva, principalmente, quando concebida como veículo de controle para a produção e administração dos gêneros.

Apesar desse posicionamento, Swales reconhece a existência de questionamentos e de incertezas muito fortes, e que a "verdadeira" comunidade discursiva pode ser mais rara e "esotérica" do que ele imaginava. Reconhece, ainda, que seus critérios anteriores para a definição de uma comunidade discursiva também não sobreviveram ao tempo.

Desse modo, o autor modifica os critérios ${ }^{11}$ (com exceção do segundo) de uma comunidade discursiva, estabelecidos por ele em 1990.

\footnotetext{
${ }^{11}$ Não apresentamos os critérios anteriores por não acharmos necessários para o momento, uma vez que estes já foram modificados pelo próprio autor.
} 
1) possui um conjunto perceptível de objetivos. Esses objetivos podem ser formulados pública e explicitamente e também podem ser, no todo ou em parte, aceitos pelos membros; podem ser consensuais; ou podem ser distintos, mas relacionados (velha e nova guardas; pesquisadores e clínicas, como na recém-unida Associação Americana de Psicologia).

2) Possui mecanismos de intercomunicação entre seus membros.

3) Usa mecanismos de participação para uma série de propósitos: para prover o incremento da informação e do feedback; para canalizar a inovação; para manter os sistemas de crenças e de valores da comunidade; e para aumentar seu espaço profissional.

4) Utiliza uma seleção crescente de gêneros para alcançar seu conjunto de objetivos e para praticar seus mecanismos participativos. Eles frequentemente formam conjuntos ou séries (Bazerman).

5) Já adquiriu e ainda continua buscando uma terminologia específica.

6) Possui uma estrutura hierárquica explícita ou implícita que orienta os processos de admissão e de progresso dentro dela. (SWALES, 2009, p. 207).

Percebemos, nessa nova abordagem, um "afrouxamento" das amarras do conceito de comunidade discursiva. Esse fato fica perceptível quando o autor utiliza como exemplo a própria associação local (Audubon ${ }^{12}$ ) da qual ele participa. Essa comunidade, segundo o autor, possui mecanismos de participação, testa suas formas e canais de comunicação, possui uma hierarquia informal de heróis locais e recém-admitidos questionáveis. E mais ainda quando ele afirma: "há muito mais fluidez e contingência no sistema do que aquilo que eu quis reconhecer". (SWALES, 2009, p.218).

Ainda sobre esse assunto, o autor destaca o papel do conceito de comunidade discursiva como um mecanismo de ajuda para o ingresso, sobrevivência e progressos de novatos como comunicadores em suas áreas particulares.

Independentemente de divergências conceituais ou analíticas a respeito de comunidade discursiva, o certo é que há consenso entre estudiosos da relevância do domínio dos gêneros para que o participante de uma determinada esfera não seja excluído ou permaneça no anonimato.

\section{O discurso das profissões na Universidade}

A proliferação de "novos gêneros", resultante dos avanços tecnológicos e da velocidade da comunicação caracterizam o início do século XXI. Esse novo contexto, marcado por mudanças culturais, provoca mudanças nas concepções dos educadores, pesquisadores e profissionais em geral, comprometidos com o estudo da linguagem, concebida como processo de interação entre sujeitos sócio-historicamente situados.

\footnotetext{
12 "N.T.: Associações ornitológicas cuja denominação faz referência a John James Audubon (1785-1851), ornitólogo e pintor americano nascido no Haiti. (...)". (SWALES, 1990, p. 208).
} 
Assim, para esses estudiosos é necessário que se priorize, no trabalho em sala de aula, o estudo de gêneros textuais a fim de que o educando aprenda a lidar com essa diversidade de gêneros textuais, para que tenha condições de engajar-se no discurso da contemporaneidade, e, consequentemente, de agir de forma adequada em situações diversas. É preciso, todavia, que entendamos que, mais do que a variedade, a escolha desses gêneros e a maneira como estes são explorados fazem-se mais significantes ainda, principalmente, porque, nessa visão sociointeracionista da linguagem, o homem tem seus comportamentos, seus relacionamentos, seus conhecimentos, enfim, sua própria identidade determinada pelos gêneros que circulam em seu meio social, que ele produz e consome. Portanto, o trabalho com gêneros deve ultrapassar o estudo das regularidades típicas de cada gênero, deve explorar também as ocorrências nas esferas sociais onde eles são utilizados.

Bazerman (2007), preocupado com a importância de se promover o engajamento dos alunos com as ferramentas essenciais para a compreensão, avaliação e participação nos sistemas de atividade social maiores nos quais os textos assumem significados e vida, ressalta a necessidade de a educação letrada atender tanto as habilidades formais de codificação e decodificação dos gêneros quanto os processos individuais da construção de sentido. Para o autor,

\begin{abstract}
"alguns desses sistemas textualmente mediados são menos familiares e acessíveis. Entretanto, eles se tornam particularmente importantes na educação secundária e superior, quando os alunos estão sendo introduzidos em mundos mais amplos de possibilidades como também em mundos mais focalizados de atividade profissional, disciplinar e outras atividades altamente especializadas com seus gêneros característicos,vocabulários, discursos e padrões de circulação e uso de documentos. ( BAZERMAN, 2007, p. 196-197)
\end{abstract}

Percebe-se na fala de Bazerman o destaque para a necessidade de o aluno ter contato com gêneros com os quais precisa lidar em situações particulares, isto é, para a necessidade de a escola promover oportunidade para que o aluno se familiarize com as características dos gêneros que, no futuro, farão parte de suas atividades. Ou seja, à medida que o aluno é inserido em um grau mais elevado de educação, por exemplo, no ensino superior, é necessário que a universidade promova o contato desse aluno com os gêneros com os quais ele precisará lidar no exercício de sua profissão.

Seguindo o mesmo raciocínio, Araújo (2009), defendendo o trabalho com o gênero resenha com alunos de graduação, ressalta a relevância da promoção de conhecimentos sobre esse gênero e outros gêneros para que o aluno tenha fundamento necessário para 
que se posicione de forma crítica ao engajar-se nas práticas sociais. Nesse caso específico, a autora salienta a importância de o professor orientar o aluno sobre a maneira como as resenhas são expressas linguisticamente e como os significados são construídos no texto.

Segundo Devitt (2009), o trabalho com gêneros textuais na escola, especialmente com os escritos, exige que os professores preocupem-se com os gêneros que os alunos precisam aprender, ou seja, com os gêneros que eles compartilharão com seus pares. Essa prática requer compromisso também com a maneira como os discentes vão aprender, pois é imprescindível que eles atentem para as estruturas que os gêneros representam e como esses gêneros servem ao grupo social, enfim, descubram que ideologia eles reproduzem. Esse posicionamento vai ao encontro da perspectiva de gênero defendida por Miller (2009), que, segundo a autora, tem importância não somente para a teoria e a crítica, mas também para a educação retórica, haja vista que:

aquilo que aprendemos e quando aprendemos um gênero não é apenas um padrão de formas ou mesmo um método de realizar nossos próprios fins. Mais importante, aprendemos, quais fins podemos alcançar: aprendemos que podemos elogiar, apresentar desculpas, recomendar uma pessoa para outra, assumir um papel oficial, explicar o progresso na realização de metas.Aprendemos a entender melhor as situações em que nos encontramos e as situações potenciais para o fracasso e o sucesso ao agir juntamente. Como uma ação significante e recorrente, um gênero incorpora um aspecto de racionalidade cultural. (...); para os alunos, os gêneros servem de chave para entender como participar das ações de uma comunidade. (MILLER, 2009, p. 44).

Miller ainda chama a atenção para o efeito que a noção sobre gênero pode acarretar na estrutura de um currículo, ou seja, como o entendimento de gênero como ação social pode interferir numa disciplina de escrita (por exemplo, no $1^{\circ}$ ano de faculdade dos EUA). Esse fato reduz o que poderia ser uma prática para alcançar objetivos sociais a uma mera arte de construção de textos que se adaptem a certas exigências formais.

É importante lembrarmos que, independentemente do lugar, o ensino de gêneros textuais dissociado da concepção de gênero como ação social não instrumentalizará o aluno de condições adequadas para agir dentro de comunidades específicas. Para Bazerman (2005) a abordagem sociointeracional de gêneros é fundamental para o ensino de gêneros, e essa tem início a partir do conhecimento que os professores e os alunos têm do mundo e da vida e une a prática e o ensino diretamente à construção de sentido e ao uso de coisas úteis na vida cotidiana. 
Dando prosseguimento a essa ideia, Bazerman (2006) defende que a retórica de um campo não pode ser dissociada de sua epistemologia, de sua história e de sua teoria, uma vez que aquela está preparada dentro de um mundo concebido e à procura de objetivos finais e imediatos. Desse modo, quanto mais o membro de uma comunidade compreende as pressuposições e os objetivos fundamentais de sua esfera, maior sua capacidade de avaliar se os hábitos retóricos que traz para uma determinada tarefa são adequados e eficazes.

Fica evidente, então, que o aluno de graduação, independentemente do curso, necessita ter acesso à variedade de gêneros com os quais irá lidar na comunidade discursiva à qual pertencerá. Conforme Bazerman (2006), quando os alunos já definiram suas carreiras ou têm ideias, mesmo que vagas, das vidas que gostariam de levar, essas metas podem despertar interesses por vários tipos de leituras que contribuam para a construção de esquemas de conhecimentos que acreditam ser significativos para sua formação profissional. $O$ autor salienta que os alunos sentir-se-ão atraídos por qualquer leitura pertencente ao modo de vida que eles almejam. Isto é, se o educando percebe que há conexão entre o texto e alguma atividade na qual esteja envolvido, ou entre o texto e algum assunto sobre o qual seu interesse está direcionado, o trabalho com esse texto, sem dúvida, será significativo. Portanto, caso os alunos imaginem-se futuros engenheiros, advogados, contadores, gestores de pessoas, dentre outras profissões, o gosto pelo estilo de vida desses profissionais também será antecipado.

Desse modo, adotar uma prática comprometida com os discursos das profissões constitui um meio de auxiliar o desenvolvimento dos alunos como membros atuantes, reflexivos e questionadores de suas comunidades, como bem demonstra a fala de Bazerman:

\footnotetext{
E estudar o discurso disciplinar pode significar olhar para as disciplinas e profissões que rejeitamos como alunos de graduação (...) Se vamos criar uma sociedade humanitária para o próximo século, são precisamente as palavras das disciplinas e das profissões que teremos que manter por perto. (BAZERMAN, 2006, pág.113).
}

Essa postura poderá imbuir os alunos de agência, e esse poder individual permitirá a esses futuros profissionais pressionarem as práticas disciplinares paras as quais foram treinados, pois a capacidade de desvendarem as aparências do discurso fará com que estes questionem quais as estruturas, padrões e retóricas comunicativas capacitarão mais adequadamente os seus campos, a fim de que estes alcancem seus objetivos. Portanto, não podemos conceber o ensino de gêneros textuais dissociado das 
ações e das intenções que eles realizam, e mais: não podemos negar aos alunos dos cursos de graduação o acesso aos gêneros pertencentes à comunidade discursiva da qual estes farão parte no exercício profissional, sob pena de contribuirmos para que eles sejam alijados do processo de ascensão em sua esfera.

\section{Considerações finais}

O diálogo entre os vários autores aqui apresentados mostra-nos que é comum entre eles a defesa de que o reconhecimento e o uso adequado de gêneros textuais pertencentes a uma determinada comunidade discursiva são de suma importância para a eficiência das relações entre os membros dessa esfera, bem como para o sucesso profissional de seus componentes.

Como sabemos, a cada dia mais, as revistas especializadas das mais diversas áreas profissionais divulgam a preocupação das empresas com o perfil do profissional a ser contratado. $E$ dentre às exigências elencadas, a intimidade com a língua materna sempre aparece em destaque. Esse fato ilustra a importância da competência discursiva para que os futuros profissionais tornem-se membros "ativos", "reativos" e pró-ativos" (BAZERMAN, 2006, p. 113) da comunidade discursiva a qual ele pertencerá. E essa competência discursiva só pode ser adquirida através das atividades de linguagem, orais e escritas, na interação verbal dos indivíduos através dos gêneros textuais. Como muitos gêneros, diferentemente dos gêneros do cotidiano, precisam ser aprendidos, a universidade, no caso especial de nossa discussão, deve responsabilizar-se pelo ensino dos gêneros necessários à atuação dos profissionais.

Portanto, a importância de um trabalho adequado com gêneros textuais nos cursos de Graduação é indiscutível se comungamos da idéia de que práticas dessa natureza podem representar possibilidades para que 0 aluno prepare-se efetivamente para enfrentar os desafios impostos pela sua comunidade, pois, segundo Bazerman (2006), para participar de uma comunidade, você necessita aprender o que fazer, como deve agir, o que é aceitável e quais as possíveis punições para os possíveis deslizes. Dessa forma, o cidadão terá condições de ser aceito dentro da estrutura social que se lhe apresente e terá voz para reivindicar seus projetos, particularmente se estes são concebidos e realizados dentro das exigências da comunidade.

\section{Referências}


BAKHTIN, Mikhail. Os Gêneros do Discurso. In: Estética da Criação Verbal. São Paulo: Martins Fontes, 2003. ( p. 261-306).

BAZERMAN, Charles. Gêneros textuais, tipificação e interação. Dionísio, Ângela Paiva \& Hoffnagel, Judith C. (Orgs.) São Paulo: Cortez, 2005.

Escrita, Gênero e Interação Social Dionísio, Ângela Paiva \& Hoffnagel, Judith C.

(Orgs.). São Paulo: Cortez, 2007.

. Gênero, Agência e Escrita. . Dionísio, Ângela Paiva \& Hoffnagel, Judith C.

(Orgs.). São Paulo: Cortez, 2006.

BHATIA, Vijay K. A análise de gêneros hoje. In: Bezerra, B. Gomes, BIASI RODRIGUES,

Bernadete e CAVALCANTE, M. Magalhães (orgs.). Gêneros e seqüências textuais.

Recife: Edupe, 2009.

BONINI, Adair. O conhecimento de jornalistas sobre gêneros textuais: um estudo introdutório. In: Linguagem em (dis)curso on line , v. 2, n. 1, 2001. . Ensino de Gêneros Textuais: A questão das escolhas teóricas metodológicas.

Trabalhos em Lingüística Aplicada, n. 37, p. 7-23, 2001.

Gêneros Textuais e Cognição: um estudo sobre a organização cognitiva da

identidade dos textos. Florianópolis: Insular, 2002.

BRONCKART, Jean Paul. Atividade de Linguagem, Textos e Discurso: Por um

Interacionismo Sociodiscursivo. São Paulo: EDUC, 1999.

DEVIT, E. J. Os tópicos e os desafios no estudo de Gênero. In: Encontro Acadêmico:

Gênero na Lingüística e na Literatura. Recife: PGLETRAS ( PROCAD - NF), UFPE;

PPGLE (PROCAD-NF), UFCG, 2009.

HEMAIS, Bárbara e BIASI-RODRIGUES, Bernadete. A Proposta Sócio-Retórica de John

M. Swales Para o Estudo de Gêneros Textuais. In: MEURER, J.L; BONINI, Adair;

MOTTA-ROTH, Desirée (Orgs). Gêneros, Teorias, Métodos, Debates. São Paulo:

Parábola, 2005.

HENDGES, G. R. 2001. Novos contextos, novos gêneros: a revisão da seção de literatura

em artigos acadêmicos eletrônicos. Dissertação (mestrado em Lingüística) - UFSM,

Santa Maria.

MARCUSCHI, Luiz Antônio. Da fala para a escrita: atividades de retextualização. São

Paulo: Cortez, 2001.

Gêneros textuais: configuração, dinamicidade e circulação. In: Acir Mário

Karwoski et al.(Orgs.). Gêneros Textuais: Reflexões e Ensino. Rio de Janeiro: Lucerna, 2006.

. Gêneros textuais emergentes no contexto da tecnologia digital. In:

MARCHUSCHI, Luiz Antonio e XAVIER, Antonio Carlos (orgs). Hipertexto e Gêneros

Digitais. Rio de Janeiro: Lucerna, 2005a.

. Gêneros Textuais: definição e funcionalidade. In: DIONÍSIO, Ângela Paiva;

MACHADO, Ana Rachel: BEZERRA, Maria Auxiliadora (orgs). Gêneros Textuais \&

Ensino. 4a Ed. Rio de Janeiro: Lucerna, 2005b.

MILLER, Carolyn R. Estudos Sobre Gênero textual, Agência e Tecnologia. Dionísio, Ângela Paiva \& Hoffnagel, Judith C. (Orgs.) Recife: Ed. Universitária da UFPE, 2009. 


\title{
O HUMOR NO CONTEXTO PEDAGÓGICO DE LÍNGUA ESTRANGEIRA: UMA ANÁLISE DISCURSIVA DO MODO DE ABORDAGEM DA COMICIDADE
}

\author{
THE HUMOR IN THE PEDAGOGICAL CONTEXT OF FOREIGN LANGUAGE: A \\ DISCURSIVE ANALYSIS ABOUT THE WAY HOW COMICITY IS APPROACHED
}

\author{
Ilka de Oliveira Mota \\ Universidade Federal de Rondônia (UNIR) \\ ilka.mota@unir.br
}

\begin{abstract}
RESUMO: Ancorados na Análise de Discurso, na interface com a psicanálise freudiana, este artigo tem por objetivo apresentar alguns resultados de nossa pesquisa de doutoramento. Em síntese, analisamos o modo como Livros Didáticos (LD doravante) de Inglês abordam o campo da comicidade. Há uma forte tendência de os LDs apagarem os efeitos de humor e suas condicoes de produção. Isto acontece pelo modo de sua abordagem. Baseados em uma concepção formal de língua, a abordagem adotada tende a eliminar a piada, a ambiguidade, o duplo sentido, resultando no apagamento dos aspectos culturais e discursivos constitutivos do campo da comicidade, o que traz sérias implicações para o ensino-aprendizagem de inglês e para a constituição da subjetividade, a saber: a) o apagamento da criatividade, imaginação e prazer; b) a ausência do componente lúdico, o apagamento dos aspectos polticos que atravessam o campo da comicidade. Tal apagamento reforça de que o humor é uma mera brincadeira que nao demanda um exercício intelectual. Nossa posicao é que a comicidade implica relações sociais, históricas e culturais, ou seja, há implicações subjetivas e histórico-sociais na produção do prazer e da poeticidade cômica, o que a torna um elemento importante para o ensino de inglês.
\end{abstract}

PALAVRAS-CHAVE: Comicidade; Ensino de Inglês; Discurso didático-pedagógico.

Abstract: Anchored in Discourse Analysis, in the interface with the Freud's Psychoanalyze, this paper aims to present some results of our research. In brief, we analyze the way how some handbooks of English as a foreign language (FL) approach the field of comicity. There is a strong tendency the handbooks erase the effects of humor and their conditions of production. This happens because of the approaching adopted. Based on a formal conception of language, the approach tends to eliminate the joke, ambiguity, double meaning, resulting in the erasure of the cultural and discursive aspects which constitute the field of comicity. It brings serious implications for the English learning and teaching and the constitution of the subject's identity: a) the erasure of creativity, imagination and pleasure; $b$ ) the absence of the pleasure component, $c$ ) the erasure of the political aspects which span the field of comicity. That erasure reinforces humor is a simple play which does not demand an intellectual exercise. Our position is that comicity entails social, 
historical and cultural relations, that is, there are subjective and social-historical relations entailed in the production of the pleasure and of the comics poeticity, what makes it an important element for the teaching-learning of English.

KEYWORDS: Comicity; English Teaching; didactic-pedagogic discourse.

\section{Introdução}

O trabalho que apresento neste $3^{\circ}$. SELL estabelece um forte diálogo com algumas das reflexões que produzi em minha tese de doutorado defendida em meados de agosto de 2010, no Instituto de Estudos da Linguagem (IEL), na Unicamp, e que agora tenho o imenso prazer de poder compartilhá-las e problematizá-las com nossos colegas professores, pesquisadores e amantes da língua(gem) que aqui se encontram. De modo a situar o leitor, a proposta fundamental que norteou nosso estudo foi compreender os modos de abordagem do campo da comicidade por LDs de inglês como LE produzidos por autores brasileiros, que constituem a educação básica. Noutras palavras, inclinamos nosso olhar no(s) modo(s) de abordagem da comicidade pelos LDs pesquisados ${ }^{13}$. Com base em práticas didático-pedagógicas, principalmente, justapostas à quadrinhos de humor, foi possível estudar o funcionamento do campo da comicidade no contexto didático-pedagógico. Este estudo possibilitou-nos depreender as representações construídas para o inglês, para os usuários (alunos e professores) dos LDs de inglês pesquisados e, o mais contundente a nosso ver, para o humor, no sentido que Freud (1905) dá ao termo ${ }^{14}$.

Tentaremos, neste texto, responder as seguintes perguntas: Como o campo da comicidade é abordado? Quais as representações imaginárias que se pode depreende dessa abordagem? As práticas didátíco-pedagógicas com base nos quadrinhos contemplam os efeitos de comicidade? Com base no tipo de abordagem da comicidade, que consequências é possível prever para a constituição da subjetividade (identidade) do aluno, do professor e sobretudo para o processo de ensino-aprendizagem?

Começaremos delineando as características principais do lugar teórico-metodológico a partir do qual enunciamos. Em seguida, objetivamos trazer para a reflexão o(s) modo(s) de funcionamento do campo da comicidade. Para isso, apoiar-nos-emos na Análise de Discurso e nos estudos produzidos por Freud (1905).

\footnotetext{
${ }^{13}$ Para um maior aprofundamento das reflexões produzidas sobre os modos de abordagem da comicidade por LDs de inglês, ler a tese de doutorado de MOTA, 2010 (cf. bibliografia).

${ }^{14}$ Esta questão será trabalhada mais adiante.
} 


\section{A(s) especificidade(s) do aporte teórico-metodológico}

Gostaríamos de situar o interlocutor para a especificidade que marca a posição a partir da qual enunciamos. É possível dizer, apoiados no aparato teórico-metodológico da Análise de Discurso, que a língua não é uma estrutura fechada nela mesma justamente porque "a língua não é um ritual sem falhas", citando Pêcheux (1988). Enquanto elemento fundamental para a constituição da subjetividade e para a construção dos processos identificatórios e de significação (dos sentidos), a língua é lugar de jogo, de contradição, de embate, de (des)identificação. Isso significa que ela traz em seu bojo um real que não se submete aos enquadramentos formais da língua lógica. "Por isso", afirma Ferreira (2000, p. 16) " [o real da língua] se apresenta atravessado por falhas, furos e fissuras, que se evidenciam pela existência de jogos de palavras, do absurdo, dos lapsos, enfim, das brincadeiras com a língua".

Esse modo de existência da língua implica em sua não transparência, fechamento e objetividade. A língua não é transparente nem os sentidos estão prontos a priori. A língua é, isto sim, capaz de jogo, de poesia, e é por isso mesmo que os sentidos são volantes, deslizantes, escorregadios. Esta é a condição própria da língua e, por conseguinte, dos sentidos.

Todavia, é preciso dizer que, ao mesmo tempo que a língua é lugar de jogo, é também passível de determinação, de fechamento (ainda que imaginário), uma vez que toda formação social apresenta, em sua constituição, formas de controle dos sentidos e, logo, da interpretação, que são, de nossa perspectiva, historicamente determinadas. Os instrumentos linguísticos tais como Gramáticas, Enciclopédias, Dicionários, Livros Didáticos são lugares que tendem a funcionar como procedimentos de controle dos sentidos, corroborando, deste modo, para um mundo semanticamente normal, parafraseando Pêcheux ${ }^{15}$.

Ao lado da noção de língua, há outra igualmente importante, qual seja: a noção de sujeito. Discursivamente, "o sujeito diz, pensa que sabe o que diz, mas não tem acesso ou controle sobre o modo pelo qual os sentidos se constituem nele" (ORLANDI, 1999, p. 32). Trabalhamos, pois, com uma noção de sujeito que se diferencia da noção psicológica de sujeito empiricamente coincidente consigo mesmo. Perpassado pela linguagem e pela história, sob o modo do imaginário, o sujeito tem acesso somente a parte do que diz, o

\footnotetext{
${ }^{15}$ Esta questão será trabalhada na próxima seção.
} 
que significa, em outros termos, que ele tem apenas ilusão de dominar e controlar os sentidos que produz. Como afirma Orlandi (1999, p. 49),

ele [o sujeito] é materialmente dividido desde sua constituição: ele é sujeito à língua e à história, pois para se constituir, para (se) produzir sentidos ele é afetado por elas. Ele é assim determinado, pois se não sofrer os efeitos do simbólico, ou seja, se ele não se submeter à lingua e à história, ele não se constitui, ele não fala, não produz sentidos.

Quando o sujeito fala (enuncia), o faz a partir de posições no discurso. Mas, vale dizer, assumir esta ou aquela posicao não se dá de modo consciente, isto é, o sujeito não tem acesso aos sentidos que produz nem às posições discursivas assumidas ${ }^{16}$ nos processos de interlocução pelos quais é enredado.

Passemos, agora, a uma breve descrição de algumas das especificidades que caracterizam o Livro Didático (LD doravante) em geral e, na sequência, o LD de inglês como LE, que é objeto de nosso interesse.

\section{O Livro Didático (de inglês) sob o viés discursivo}

Concebemos o LD como um objeto discursivo constituído historicamente. Tomá-lo como parte constitutiva da história significa considerá-lo como um objeto simbólico em movimento, isto é, como parte de uma história em que sujeito e sentidos se constroem ao mesmo tempo.

Embora seja um objeto simbólico em movimento, no plano do imaginário ${ }^{17}$, os LDs comparecem como um produto que está sempre aí em sua evidência, com seu formato, seu conteúdo, sua maneira de recortar, organizar e apresentar o "saber". Ao lado desse modo de significação, eles são comumente representados como "lugar do saber definido, pronto, acabado, correto", (SOUZA, 1999, p. 27), talvez seja essa a razão pela qual, por muito tempo, ele tenha sido concebido como "fonte última" e, em alguns casos, "única" de referência. Pelo seu modo de configurar (recortar, formatar, organizar, etc.) o conhecimento, isto é, os conteúdos didático-pedagógicos legitimados institucionalmente pela Escola e pela sociedade em geral, o LD vem, ao longo da história, se apresentando, segundo Ramos (2009, p. 176), como uma "forma conveniente de apresentar o material

\footnotetext{
${ }^{16}$ Isso explica porque há sujeitos que dizem pertencer à extrema esquerda, quando, na verdade, têm suas falas (e, por que não dizer, posturas, comportamentos) fortemente marcadas pelo discurso da direita.

17 Compreendemos o imaginário como espaço de organização dos sentidos. Por isso, ele faz necessariamente parte do funcionamento da linguagem. De acordo com Orlandi (1999, p. 42), "[ele] assenta-se no modo como as relações sociais se inscrevem na história e são regidas, em uma sociedade como a nossa, por relações de poder".
} 
para os alunos", uma vez que ele dá a impressão de garantia de "consistência e continuidade a um curso; dá aos alunos um senso de sistema, coesão e progresso, e ajuda os professores a preparar suas aulas".

Tais sentidos construídos historicamente sobre o LD estão diretamente relacionados ao estatuto do autor de LD em nossa sociedade. Além de representar um lugar de autoridade no imaginário social, autoridade esta garantida pelo conhecimento que detém ou que é suposto que detenha - daí a ideia de entidade todo-poderosa ${ }^{18}$-, o autor de LD é significado como aquele que tem "competência" de selecionar, recortar, formatar e hierarquizar os conteúdos com "clareza didática". Segundo Souza (1999), a imagem historicamente construída sobre o autor do LD é aquela que o configura não somente como responsável pelo que "diz" no livro, como também e principalmente pelo "conteúdo que ele seleciona; pela forma de organização do conteúdo selecionado e pela forma de apresentação desse conteúdo, a sua competência enquanto autor é, geralmente, medida pelo caráter de clareza didática, avaliada em termos da linguagem utilizada" (idem, p. 29).

Por tudo isso, é possível afirmar que o LD não é um objeto transparente, evidente, a-histórico. Ele é parte de um contexto mais amplo, isto é, parte constitutiva de um processo histórico-social, ideológico. Assim, enquanto legitimador de um saber linguístico e metalinguístico, o LD, assim como outros instrumentos linguísticos que circulam em nossa sociedade, tem sua história, conforme afirma Auroux (1992, p. 11): "Todo conhecimento é uma realidade histórica, sendo que seu modo de existência real não é a atemporalidade ideal da ordem lógica do desfraldamento do verdadeiro, mas a temporalidade ramificada da constituição cotidiana do saber."

Para melhor situar o leitor, o surgimento de diferentes tecnologias da linguagem e a explosão do discurso midiático no final da década de 80 e início da 90, produziram - e ainda têm produzido - efeitos importantes na sociedade, resultando em transformações significativas no contexto escolar. No que diz respeito aos LDs de inglês como LE produzidos nas últimas décadas (80 e 90 principalmente), eles tiveram influência da mídia, provocando, com isso, uma grande mexida nos modos de se conceber 0 conhecimento. Isso pode ser notado não somente por meio da observação de sua configuração, ilustração, como também, e principalmente, pelos tipos de textos selecionados. Os textos quadrinizados como, por exemplo, as tirinhas, passaram a não mais significar pejorativamente; eles passaram a fazer parte da realidade escolar. Mas, é

\footnotetext{
${ }^{18} \mathrm{O}$ conhecimento que o autor detém ou que é suposto que detenha está relacionado a um campo de saberes já legitimado institucional e socialmente.
} 
preciso dizer que, ao serem transferidos para o âmbito escolar, os quadrinhos e outros tipos textuais passaram a estabelecer relações diferentes com os sentidos, com a leitura, com o olhar. Isso acontece porque, discursivamente, o lugar de circulação dos objetos (qualquer objeto) demanda sentido. Por isso, o fato de os quadrinhos circularem em um LD de inglês e/ou em um livro de humor não é indiferente ao processo de significação nem aos modos de subjetivação do sujeito, mais precisamente aos modos de sua inscrição no processo de leitura.

A seguir, temos por objetivo discorrer, resumidamente, sobre a especificidade do texto quadrinizado.

\section{Especificidade do texto quadrinizado}

Em linhas sucintas, o texto quadrinizado traz um tipo de textualização que demanda um novo modo de olhar, ler. Predominantemente verbo-visual, o texto quadrinizado, sob a influência do cinema, vem instaurar uma nova sintaxe. Como o próprio nome indica, o quadrinho, tipo de texto produzido sob o recurso da quadrinização, isto é, sob a justaposição de quadros sequenciais, é fruto de um novo contexto sóciohistórico e ideológico em que o icônico ganha força. Enquanto possibilidade expressiva, ele surge no final do século XIX, graças à era midiática. Caracterizado, predominantemente, pelos planos verbal e não-verbal, o quadrinho vem provocar um verdadeiro deslocamento no modo de ler, subvertendo a ideia hegemônica de texto como um conjunto de palavras organizadas. Neste tipo de texto, não há um predomínio de um plano sobre o outro, isto é, um plano (o visual) não está subordinado a outro (verbal). Ambos os planos funcionam igualmente, produzindo efeitos no processo de leitura. Como resultado desse funcionamento, o olhar pressuposto para a prática de leitura do quadrinho teve, necessariamente, de passar por um processo de "aprendizagem", isto é, o olhar passou a ter que "aprender" a ler os quadrinhos, a sua sintaxe, como aconteceu, igualmente, com a arte cinematográfica.

Desse modo, a arte quadrinizada pode ser considerada uma forma bastante complexa de materialidade simbólica, na qual se entrecruzam linguagens de diferentes naturezas: palavras, palavras iconizadas, sons - é o caso das palavras onomatopaicas, isto é, aquelas que imitam o som dos signos que representam -, (efeito de) movimento, espaços, imagem (gestual) etc.

\section{A comicidade como cenário do desejo e do poder}


Distanciamo-nos da concepção de humor como um objeto já-dado, transparente e mero instrumento para relaxar os ânimos. Para falar sobre o humor, apoiamo-nos nos estudos elaborados por Freud (1905) e na Análise de Discurso.

Freud, em seu célebre estudo "O chiste e sua relação com o inconsciente" (1905) afirma que o humor consiste numa "técnica". Para ele, o que garante humor não é o conteúdo de uma piada ou chiste, mas seu modo de elaboração.

$\mathrm{O}$ autor distingue três grandes subclasses da comicidade: o chiste, o cômico e o humor. Como veremos mais adiante, embora cada uma dessas formas apresente suas peculiaridades, "a produção e a fruição do prazer" é um traço comum "dessas formações psíquicas carregadas de comicidade" (KUPERMANN, 2003, p. 39). Basicamente, o campo da comicidade constitui-se como um conjunto de processos psíquicos associados à liberação de prazer. Esse prazer, que ajuda a confrontar as pressões sobre o psiquismo, é vigiado a todo instante pelo pensamento racional e por inibições sociais. Vale aqui a abertura de um parêntese.

O campo da comicidade em geral tem relação forte com a libido e outras tendências primitivas, básicas, do ser. Sendo o sujeito um ser desejante, é verdade que ele deseja, inconscientemente, a perpetuação do momento de prazer. Porém, sabemos, uma vez imerso no mundo do simbólico, há castração, isto é, esse mundo simbólico impede o prazer sem limites. E é nesse duplo que a comicidade se instaura, ou seja, entre as restrições sociais que a entrada no simbólico impõe e o desejo (de obter prazer) constitutivo do sujeito de linguagem. É justamente por visar à liberação do prazer e das restrições sociais que o campo da comicidade está em uma relação conflituosa, tensa, com a civilização, com o social, com a lei.

Acrescente-se, a comicidade põe em jogo questões fortes envolvendo a relação do sujeito com os sentidos e o mundo. Segundo Pêcheux e Gadet (2004), o humor (aqui o termo significa todo o campo da comicidade) e a poesia não são o "domingo do pensamento [...] mas pertencem aos meios fundamentais de que dispõe a inteligência política e teórica..." Estes autores (2004: 94) não apenas sustentam que a língua é capaz de humor e de poesia, como defendem, citando Brecht, que é "difícil aderir ao Grande Método (a dialética) quando não se tem humor": a história, com suas contradições, requer uma posição humorada, aberta ao equívoco e ao disparate.

Referindo-se a Freud, Eagleton (1993: 192) observa que o prazer, o lúdico, o sonho, o mito, cenas, símbolos, fantasias, representações [entre os quais se pode incluir a comicidade] "deixam de ser concebidos como questões acessórias, adornos estéticos 
às coisas importantes da vida, e passam a ocupar a própria raiz da existência humana". Isso porque Freud considera a arte em um contínuo com os processos libidinais que atravessam a vida cotidiana.

Enquanto uma prática de linguagem, o campo da comicidade, do qual deriva o chiste, o cômico e o humor, conforme a distinção estabelecida por Freud (1905), se manifesta, em sua maioria, na relação conjunta entre a materialidade linguística e imagética. Recorrendo a recursos expressivos constitutivos da própria estrutura significante do sistema linguístico (tais como duplicidade de efeitos discursivos, ironia, ambiguidade, equívoco, trocadilhos, jogos de palavras, entre outros), e do sistema imagético (desenho, caricatura, palavras iconizadas, palavras onomatopaicas), o campo da comicidade atesta, pois, o caráter oscilante da língua(gem), desestabilizando-a das estruturações lógico-matemáticas a que ela, muitas vezes, é submetida (FERREIRA, 2000).

A subclasse do chiste [Witz] inclui as piadas e os jogos verbais que produzem comicidade. Entre os inúmeros exemplos dados por Freud, um dos mais emblemáticos é o que retirou do livro Estampas de Viagem, do poeta Heinrich Heine. Narrando a ocasião em que esteve com um milionário, o agente de loteria e pedicuro Hirsch-Hyacinth diz: "ele me tratou como a um dos seus, totalmente familionário [Familionär] ${ }^{19 "}$ (FREUD, 1905: 18). O chiste apresenta dois conteúdos: um conteúdo manifesto, correspondente à formulação "familionário", condensação das palavras "familiar" [Familiär] e "milionário" [Millionär], e um conteúdo latente, não-dito, que, em outro contexto, poderia ser formulado nos seguintes termos: "ele me tratou como a um dos seus, de modo inteiramente familiar, ou seja, como o faz um milionário", ou ainda: "A condescendência de um homem rico sempre tem algo de incômodo para quem a experimenta" (1905: 19). O modo condensado caracteriza a técnica do chiste. Por meio da "fusão" dos fonemas comuns às duas palavras, o locutor constrói uma expressão alusiva e sintética, chistosa. A princípio, "familionário" pode provocar desconcerto, parecendo uma formação lexical defeituosa e enigmática, mas, em seguida, com a "iluminação", isto é, com o entendimento da palavra, produz-se o prazer e o riso como não aconteceria se a formulação fosse outra (1905: 145). Existe uma crítica à forma como o milionário trata os mais pobres, mas o que importa no chiste é a forma condensada pela qual ele a faz, o que lhe dá um caráter transgressivo e cômico.

\footnotetext{
${ }^{19}$ Todas as citações de Freud (1989) são traduções nossas.
} 
Na subclasse do cômico intervêm basicamente dois elementos: o ego e o objeto (uma pessoa ou não) em que se descobre a comicidade.

Indagando sobre a natureza dessa forma de comicidade, Freud se pergunta por que rimos do palhaço. Para ele, rimos por causa do seu gasto excessivo de movimentos. Ele observa, porém, que esse tipo de comicidade não se produz apenas artificialmente, mas no curso da vida cotidiana, de modo não deliberado. Cita como exemplos o excesso de gasto da criança que põe a língua fora da boca quando está aprendendo a escrever e os adultos que nos parecem cômicos por movimentos concomitantes ou por movimentos expressivos exagerados. O prazer aqui é produzido pela superioridade que sentimos em relação ao outro, ao percebermos que seu gasto corporal é maior do que o anímico (ou psíquico), se comparado ao que teríamos para realizar a mesma ação. Porém, se o contrário se dá, isto é, se o gasto psíquico ou corporal da pessoa observada é menor do que o que teríamos para executar a ação, então, passamos a admirá-la. O prazer cômico e o efeito que o torna discernível, o riso, surgiriam de uma diferença de gasto sem aplicação, suscetível, pois, de uma descarga de prazer. Nas palavras de Kupermann (2003: 40), "no cômico, o prazer deriva de uma economia na despesa com o investimento em alguma representação que se mostra supérflua".

Um bom exemplo do cômico é dado por Saliba (2002). Para o autor, o cômico nasce de uma percepção do contrário, como na história da velha de Pirandello que, já decrépita, cobre-se de maquiagem, veste-se como uma moça e pinta os cabelos. Ao se perceber que aquela senhora é o oposto do que uma respeitável senhora deveria ser, produz-se o riso, que nasce da ruptura das expectativas, mas, sobretudo, do sentimento de superioridade. A percepção do contrário, porém, pode transformar-se num "sentimento do contrário" - quando aquele que ri procura entender as razões pelas quais a velha se mascara na ilusão de reconquistar a juventude perdida; neste passo, a velha da anedota não está mais distante do sujeito que percebe, porque este último pensa que também poderia estar no lugar da velha - seu riso se mistura com a compreensão piedosa e se transforma num sorriso. É aqui que Pirandello começa a diferenciar o cômico do humor, tal como observa Saliba (idem: 24).

Vale lembrar que esse sentido de cômico vai ao encontro de uma afirmação de Aristóteles (1998), na Poética, de que a comédia pinta os homens piores dos que eles são, colocando em evidência, bem à semelhança de uma lente de aumento, os seus defeitos físicos e morais ${ }^{20}$. Boa parte desses aspectos do universo cômico é produzida,

\footnotetext{
${ }^{20}$ Além da caricatura, faz parte do cômico a imitação, a paródia e todas as técnicas de tornar o(s) outro(s) rebaixado(s). Vale dizer que boa parte desses aspectos do universo cômico é produzida sem que,
} 
sem que, necessariamente, se utilizem palavras: é a caracterização (pelo traço, como no caso dos QHs, pelo gesto ou pela palavra) que exagera os defeitos do outro, ou que os parodia, tornando-o risível, como na caricatura a seguir:

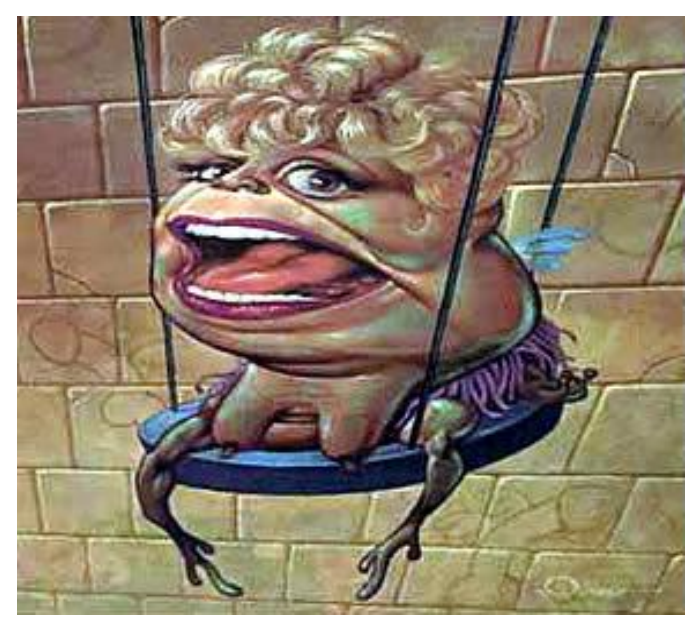

Note-se que ela também tem aspecto chistoso, pois condensa a imagem da atriz Dercy Gonçalves (que exibia os seios quando velha) e a letra de uma das músicas cantadas por ela: "A perereca da vizinha tá presa na gaiola".

Finalmente, o humor, ao contrário do cômico, se caracteriza por surgir diante da adversidade: o prazer humorístico se produz com afetos que normalmente nos seriam penosos. Freud dá como exemplo a frase que diz a si mesmo, no caminho para o patíbulo, o réu condenado à morte na segunda-feira: "Vá, comece bem a semana!". Tratase de humor de patíbulo ou Galgenhumor, "humor negro". O discurso do réu economiza ${ }^{21}$ um afeto doloroso em proveito do prazer humorístico, o que faz com que Freud veja nele um mecanismo defensivo - e de resistência política, diríamos - do sujeito. $O$ humor desestabiliza e desconstrói os sentidos da adversidade, aqui, a própria morte. É possível ver ai um certo heroísmo, isto é, essa coragem de fazer rir, ao desafiar a morte, triunfa sobre ela. Trata-se de uma tomada de posição: ao invés de se colocar na posição de vítima - que seria o esperado - ou, no dizer de Kehl (2002) "numa situação em que seriam esperadas lágrimas", o sujeito afronta a morte, atitude dionisíaca por excelência. Neste sentido, o humor representa o triunfo da subjetividade diante das vicissitudes e dos

necessariamente, se utilize palavras: é a caracterização (pelo traço, como no caso dos quadrinhos, pelo gesto ou pela palavra) que exagera os defeitos do outro, ou que o parodia, tornando-o risível.

${ }_{21}$ Freud conclui que em todos esses diferentes tipos de comicidade o prazer advém de uma economia. No caso do chiste, há uma economia de gasto de inibição (o chiste escapa à vigilância racional). No cômico, temos um gasto de representação economizado, porque, simultaneamente ou em rápida sucessão, comparamos dois gastos diferentes. Já o humor economiza um gasto de sentimento. Essas modalidades recuperam o prazer que se perde com o desenvolvimento das atividades anímicas. As crianças não têm necessidade de recorrer ao chiste, ao cômico e ao humor para obter prazer: sua subjetividade exige um gasto mínimo (FREUD, 1905, p. 223). 
desastres, correspondendo a uma postura ideológica rebelde, não resignada; é a declaração da invulnerabilidade do sujeito ao mundo. É por conta dessa sua capacidade de rir de si mesmo, "bem distante do "nada me pode acontecer" (KUPERMANN, 2003: 123), que Freud (1989) considera o humor como a manifestação psíquica mais elevada do campo da comicidade (ibid.: 216), uma vez que, como declara Kehl (2002: 180), "a possibilidade de modificar a relação do homem com seu sofrimento é o que confere ao humor uma dignidade que o chiste, voltado somente para a produção de um efeito prazeroso, não tem".

\section{Resultados da análise discursiva sobre os modos de abordagem da comicidade por LDs de inglês como LE.}

Da grande diversidade de recortes que constituem nosso corpus de pesquisa, traremos apenas dois que são representativos do modo de abordagem do campo da comicidade encontrada no LDs de inglês pesquisados.

O quadrinho, a seguir, inicia a unidade e tem por objetivo principal introduzir a forma futura dos verbos. Observe:

Recorte 1:

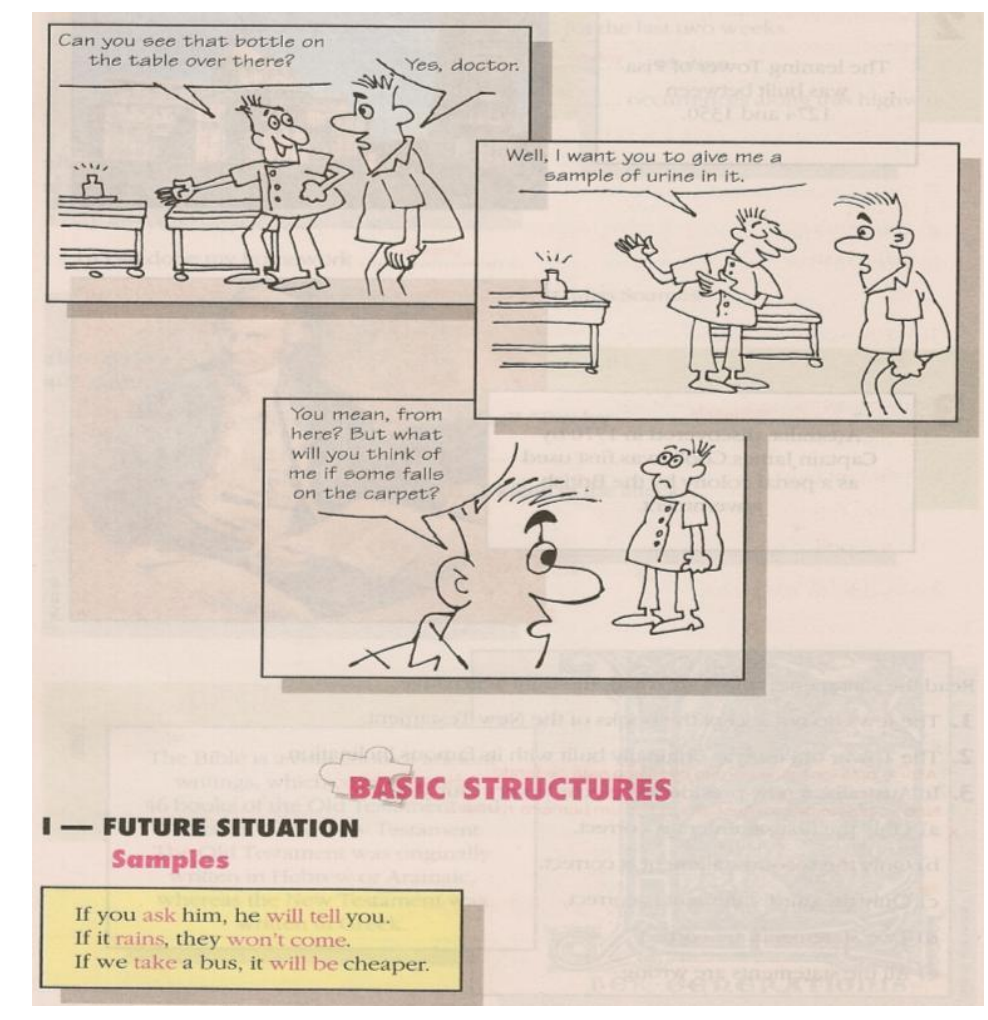

Este quadrinho perde a sua função de provocar efeitos de sentido, como o riso, por exemplo, para ser apenas lugar de reconhecimento de unidades e estruturas linguísticas, 
como é possível observar no recorte acima, que introduz o futuro após a inserção do quadrinho.

Embora o campo da comicidade se movimente dentro de um universo que subverte, por vezes, o mundo semanticamente normatizado, estabilizado, no espaço didático-pedagógico, por sua vez, ele parece passar por um tipo de "terapêutica da linguagem", parafraseando Pêcheux (1994 [1982]), que tende a fixar sentidos ou, mais exatamente em nosso caso, a tirar deles a sua espessura material, a sua forma lúdica e a duplicidade de efeitos discursivos.

Temos, então, de um lado, a representação da comicidade como lugar de descontração - o fato de os QHs serem introduzidos logo no início de cada unidade tem por objetivo despertar o interesse do aluno para o conteúdo a ser ensinado - e, de outro, uma concepção normativa (lógica) de língua, que corrobora para um ensino centrado na forma. Como resultado, os efeitos de comicidade ficam amarrados aos limites de uma visão normativa de língua. Assim, por conta dessa abordagem, perde-se a possibilidade da fruição do prazer cômico e do deslocamento das posições subjetivas do leitor (aluno e professor). Em função dessa visada lógico-formalista e, por que não dizer utilitarista, proíbe-se que o sujeito experimente outros sentidos e, ainda e o mais importante a nosso ver, que extraia o prazer que o campo da comicidade permite instaurar.

É pertinente ressaltar que todos os QHs que compõem as unidades do LD pesquisado foram produzidos exclusivamente para ele, isto é, não se trata de textos que têm livre circulação na sociedade. No caso em questão, trata-se de textos produzidos para o livro, cuja finalidade é unicamente ensinar - ensinar a língua como código. Portanto, a essa comicidade feita para fins estritamente didático-pedagógicos estamos chamando de comicidade pedagógica. Tudo parece funcionar ao modo de uma "encomenda": o artista produz sua arte de acordo com o conteúdo programático estabelecido pelo livro. Disso resulta, ao que tudo indica, uma comicidade forçada. Assim, embora o texto pertença ao campo da comicidade, ele serve só e unicamente para atender a uma abordagem que prima exclusivamente pelo ensino da língua como forma, como código. Dito de outro modo, embora introduza o gênero discursivo "quadrinhos" tipo de texto considerado inovador, divertido, criativo, etc., a inserção do campo da comicidade no LD é tão somente identificar os fatos linguageiros presentes nos QHs que serão introduzidos, estudados. Produz-se a impressão de que o livro e o ensino são inovadores, divertidos, modernos, mas a sua abordagem, como vimos, nos recortes analisados, é pautada no formalismo, na mera identificação (localização) de estruturas linguísticas. 
Convém dizer que esse modo de funcionamento da comicidade é regular em todos os LDs pesquisados. Assim, é possível dizer que, embora tragam em suas páginas um tipo de texto considerado inovador, criativo e divertido, em respeito às recomendações dos PCNs, a sua postura assume um caráter estritamente linguístico, o que aponta para um caráter utilitarista. Em síntese, os QHs estão a serviço tão somente de:

a) ensinar aspectos linguísticos que os LDs julgam importantes, aspectos estes desvinculados de seu contexto de produção,

b) treinar o aluno para interpretar texto, atividade esta que se reduz a uma mera busca de informações no quadrinho (o que, quem, quando, onde, por que?), o que resulta, a nosso ver, na descaracterização do texto quadrinizado cômico, e, finalmente,

c) levar o aluno a identificar, nos quadrinhos, o tema introduzido na unidade. Como os resultados da análise empreendida puderam mostrar, a espessura material dos aspectos linguísticos não é trabalhada, explorada, resultando no apagamento de efeitos cômicos e, consequentemente, na proibição da fruição na leitura.

Sem querer dar receita de como trabalhar QHs no contexto linguístico escolar, entendemos que, sendo a comicidade um fato linguageiro que diz respeito ao sujeito, à sua subjetividade - ao mesmo tempo em que é um fato linguístico-cultural que traz em seu bojo questões de ordem existencial, política e sócio-histórica - faz-se necessária uma abordagem que foque nas especificidades dos QHs, de sua linguagem, bem como dos aspectos verbo-visuais que corroboram para a produção de efeitos de comicidade.

$\mathrm{O}$ QH, a seguir, de autoria de Walt Disney, foi extraído de um LD de inglês de ensino fundamental. Diferentemente do anterior, o quadrinho a seguir é considerado um texto autêntico. Nele podemos vislumbrar um diálogo entre Margarida e Pato Donald. Observemos:

Recorte 2:

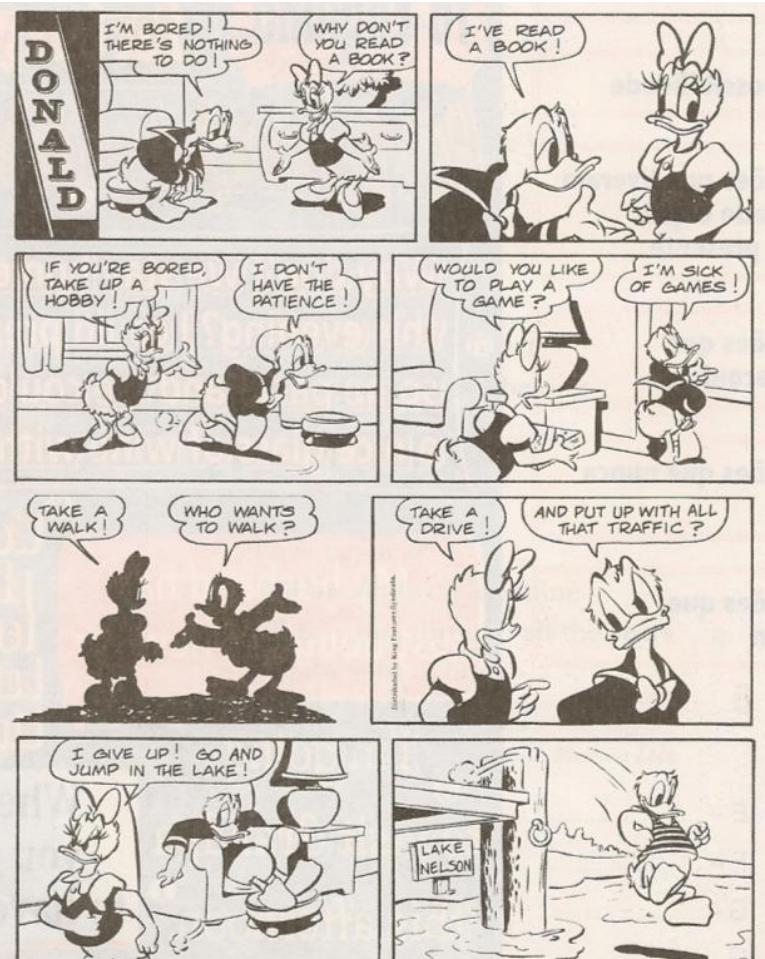


Este QH traz uma pequena narrativa, cujo efeito de comicidade está na formulação ambígua "Go and jump in the lake!", enunciada por Margarida depois de dizer "I give up". $\mathrm{Na}$ verdade, ela quis dizer "vá e se mate", "vá e se suicide", mas Donald interpretou literalmente. Ele tomou a última formulação de Margarida como uma das diversas sugestões de lazer que ela tinha aconselhado. De todas as sugestões de lazer existentes em nosso mundo semanticamente normal elencadas por Margarida, a atitude de Donald que resulta da equivocidade de sentidos "suicídio" e "mergulho" - soa cômica, na medida em que há um exagero, um excesso de gasto na atitude de "mergulhar no lago" se comparada com as possibilidades de lazer apontadas por Margarida.

A "escolha" em mergulhar no lago foi motivada por conta de sua natureza: sendo um pato, não era de se estranhar que "escolhesse" o lago em detrimento de um livro ou um jogo, por exemplo ${ }^{22}$.

Abaixo, segue uma prática didático-pedagógica produzida com base no quadrinho acima. $\mathrm{Na}$ atividade a, o aluno deve completar o quadro que está dividido da seguinte forma: no lado esquerdo, "Sugestões de Margarida", e no lado direito, "Justificativas de Donald".

Recorte 3:

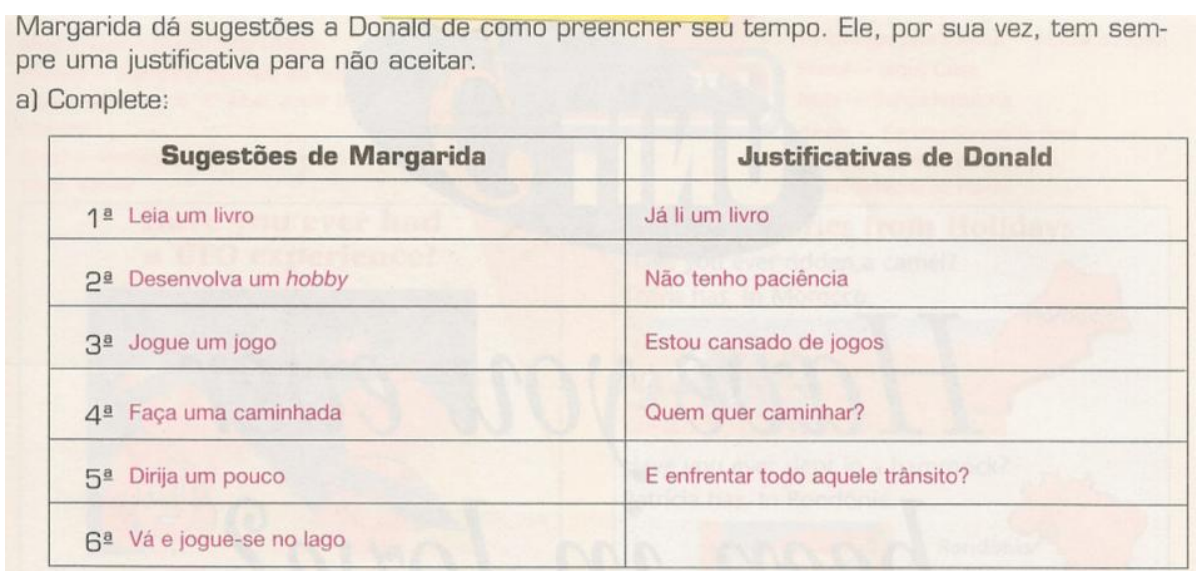

b) Que sugestão Donald finalmente aceita?

Donald aceita a sugestão de pular no lago

\begin{abstract}
${ }^{22}$ A formulação "Go and jump into the lake" foi significada por Donald como mais uma sugestão de lazer, mas, como já dissemos, tal formulação oferece lugar à interpretação. Donald e Margarida, cada um em sua posição de sujeito, interpretam-na diferentemente. Para Donald, "jump into the lake" é tomada, literalmente, o que produz a impressão de ser mais uma possibilidade de lazer. Por sua vez, tal enunciado dito por Margarida significa "se mate então".
\end{abstract}


Identificamos, nesta prática didático-pedagógica, que o propósito do livro é tão somente fazer com que o aluno traduza o texto literalmente. Trata-se de atividades didático-pedagógicas ( $a$ e b) ligadas à prática de um ritual que determina para os sujeitos escolares papéis preestabelecidos. O aluno fica encarregado de traduzir a tira para realizar a tarefa proposta, que, no caso, consiste em completar o quadro proposto pelo LD.

Embora a atividade $\mathbf{b}$ seja em forma de pergunta, observamos o mesmo gesto presente na atividade $\mathbf{a}$, qual seja, o aluno é colocado na posição de traduzir o quadrinho (o final dele) literalmente, sem a sua referência à dimensão enunciativa. Mais precisamente, o aluno deve responder à questão "Que sugestão Donald finalmente aceita?", questão esta, a nosso ver, conteudista, uma vez que requer do aluno tão somente a resposta (tradução literal): "Donald aceita a sugestão de pular no lago", tal como aparece no Livro do Professor. Trata-se de uma pergunta que não problematiza as interpretações colocadas em jogo pelas posições que os personagens assumem na cena discursiva. Assim sendo, o jogo, a ironia, a contradição presentes no quadrinho se perdem, se esvaziam, se esfacelam por conta do gesto normatizador da pergunta. Disso resulta, consequentemente, a proibição (silenciosa) da fruição (prazer cômico) na leitura.

\section{Considerações finais}

Embora os textos pertencentes ao campo da comicidade sejam lugar de jogo de sentidos, de trabalho da língua(gem), de funcionamento de diferentes discursividades, o modo de abordagem encontradas nos LDs de inglês investigados, cerceia o trabalho de interpretação, de movência dos sentidos e do sujeito. Ler um texto pertencente ao campo da comicidade é sempre um processo complexo, que exige exercício intelectual. Como se trata de um texto artístico verbo-visual que faz parte da sociedade em que vivemos e se constitui como um lugar de resistência, de liberdade, de estética do pensamento, faz-se necessário outro tipo de abordagem.

Acreditamos que o modo de abordagem da comicidade deve transcender o objetivo de mero reconhecimento (localização) de verbos, estruturas linguísticas, temas e vocabulário. É preciso, pois, mudar as condições de produção já sedimentadas de leitura na escola, o que é possível por meio de uma mudança de concepção de língua, de texto e de ensino-aprendizagem de uma língua. Em síntese, urge um tipo de abordagem que 
permita vislumbrar o funcionamento do texto, da língua, a fim de o sujeito vislumbrar e experimentar o movimento de sentido.

Entendemos que o tipo de abordagem que encontramos nos LDs pesquisados pode ter implicações sérias no ensino-aprendizado de inglês como LE, dado o papel relevante que o LD de língua estrangeira adquire na constituição da identidade de professores e alunos (PERUCHI e CORACINI, 2003). Observamos, pelo menos, três consequências, principalmente para o aluno, de uma abordagem dos QHs pautada na leitura monossêmica e na língua enquanto código e conjunto de regras gramaticais. A primeira delas é o apagamento da criatividade, da imaginação, do prazer. A segunda, intimamente relacionada à primeira, é a total ausência do componente lúdico e, portanto, do prazer (cômico), do envolvimento que toda aprendizagem (entendida como aquela que atravessa o corpo e o transforma) deve pressupor. Finalmente, a terceira diz respeito ao apagamento do aspecto político da comicidade.

O modo de ler QHs, instaurado pelos LDs investigados, é, assim, regulado por procedimentos de controle da interpretação (dos sentidos) que se materializam, em grande parte, em formas enunciativas - como é caso das PDPs justapostas aos QHs que mergulham o aluno num espaço lógico-pragmático que tende a desambiguizar os sentidos, normatizando-os; mas também de impotência, de impossibilidade de produzir e experimentar sentidos de outro modo.

Acreditamos que, para que haja historicização de sentidos, efeito e prazer cômico, para que o ensino de inglês por meio de QHs constitua uma experiência mobilizadora de questões linguístico-culturais e identitárias, é preciso uma mudança de posição: pensar a língua em seu funcionamento, ou seja, na sua relação constitutiva com a história (sóciocultural) para produzir sentido, e não como uma estrutura que funciona por si mesma, exterior ao sujeito. Só assim, o humor ${ }^{23}$ não seria concebido como um mero momento de divertimento que não requer um exercício intelectual ou, simplesmente, concebido como lugar de reconhecimento, de estruturas da língua, mas como elemento fundamental para a constituição da subjetividade, dos sentidos, possibilitando o estranhamento, 0 deslocamento de posições subjetivas e a criatividade.

\section{Referências bibliográficas}

\footnotetext{
23 "Humor" está sendo empregado aqui para significar o amplo e complexo campo da comicidade (FREUD, 1905).
} 
ARISTÓTELES. Poética: tradução, prefácio, introdução, comentário e apêndices de Eudoro de Sousa. Trad. Eudoro de Sousa. 5 ed. Imprensa Nacional, Casa da Moeda, 1998.

ARROJO, R. (1992). "Compreender X interpretar e a questão da tradução". In: Rosemary Rojo (org.). O Signo Desconstruído. Implicações para a tradução, a leitura e o ensino. Campinas, SP. Editora Pontes, p. 67-70.

AUROUX, S. (1992). A Revolução Tecnológica da Gramatização. Campinas, SP: Editora da Unicamp.

EAGLETON, T. (1993). A ideologia da estética. Rio de Janeiro, RJ: Jorge Zahar Ed. FREUD, S. (1905). El Chiste e su Relación con lo Inconciente. In: Obras Completas, volumen 8. Traducción directa del alemán de José L. Etcheverry. Buenos Aires:

Amorrortu. $2^{\mathrm{a}}$ ed., $1^{\mathrm{a}}$ reimpressão, 1989.

FELISBINO, A. (2001). A des-contrução dos sentidos e a formação do humor em Jô Soares. Revista Linguagem em (Dis)curso, volume 1, número 2, jan/jun.

FERREIRA, M. C. L. (2000). Da ambigüidade ao equívoco: a resistência da língua nos limites da sintaxe e do discurso. Porto Alegre: Editora da Universidade do Rio Grande do Sul.

FOLKIS, G. M. B. (2004). Análise do discurso humorístico: as relações marido e mulher nas piadas de casamento. Tese de doutorado. Campinas: IEL/Unicamp.

FREUD, S. (1908). Escritores criativos e devaneios. In: Obras Completas, volume 9. Rio de Janeiro, RJ: Editora Imago. ${ }^{\text {a }}$ Ed., 1976.

KEHL, M. R. (2002). Sobre Ética e Psicanálise. São Paulo, SP: Companhia das Letras. 1ạ. reimpressão.

KUPERMANN, D. (2003). Ousar rir. Humor, criação e psicanálise. Rio de Janeiro, RJ: Civilização Brasileira.

MOTA, I. M. A comicidade no contexto linguístico escolar: quadrinhos de humor em livros didáticos de inglês como língua estrangeira. Tese de doutorado. Campinas: IEL/Unicamp. ORLANDI, E. (1999). Análise de discurso - princípios e procedimentos. Campinas, SP: Editora Pontes.

PERUCHI, I. e CORACINI, M. J. F. R. (2003). "O discurso da cultura e a questão da identidade em livros didáticos de francês como língua estrangeira". In: Maria José R. Coracini. Identidade e Discurso. Campinas, SP: Editora da Unicamp; Chapecó: Argos Editora Universitária, p. 363-385.

SALIBA, E. T. (2002). Raízes do Riso: A representação humorística na história brasileira da Belle Époque aos primeiros tempos do rádio. São Paulo, SP: Editora Companhia das Letras.

SOUZA, D. M. (1999). "Autoridade, Autoria e Livro Didático". In Maria José Rodrigues Faria Coracini (org.). Interpretação, Autoria e Legitimação do Livro Didático. 1ํㅡ. Ed. Campinas, SP: Pontes, p. 27-31.

\section{Livros didáticos de inglês como LE selecionados para a presente pesquisa}

JELIN, I. English - A High School Coursebook. São Paulo, SP: FTD.

MARQUES, A. (1999). Password - special edition. São Paulo, SP: Editora Ática.

SIQUEIRA, R da S. N. Magic Reading, Book 4. 1 edição. São Paulo, SP: Editora Saraiva. SIQUEIRA, V. Lellis e PELLIZZON, E. L. Enjoy it - An English course. Volume 1. São Paulo: Atual Editora, 1995. 


\title{
PROJETO TELETANDEM BRASIL, AS COMUNIDADES VIRTUAIS, AS COMUNIDADES DISCURSIVAS E AS COMUNIDADES DE PRÁTICA: A CARACTERIZAÇÃO DOS INSTRUMENTOS DE PESQUISA.
}

\section{TELETANDEM BRAZIL PROJECT, THE VIRTUAL COMMUNITIES, \\ THE DISCOURSE COMMUNITIES AND THE COMMUNITIES OF PRACTICE: THE CHARACTERIZATION OF RESEARCH INSTRUMENTS}

\author{
Jaqueline Moraes da Silva ${ }^{24}$
}

jaquemoraes net@hotmail.com

\begin{abstract}
RESUMO: Este trabalho tem como objetivo apresentar a caracterização dos instrumentos de pesquisa utilizados em um projeto de mestrado em andamento e a relação destes com os critérios para o estabelecimento de uma comunidade virtual (LÉVY, 1999) que compartilha características comuns à noção de comunidade discursiva (SWALES, 1990; 1992) e à noção de comunidade de prática (WENGER, 1998).
\end{abstract}

PALAVRAS-CHAVE: gêneros; comunidade virtual; modo de aprendizagem in-tandem.

ABSTRACT: This paper aims to present the characterization of research instruments used in a master's degree project in progress and their relation to the criteria for establishing a virtual community (LÉVY, 1999), that shares common characteristics with the notion of discourse community (SWALES, 1990; 1992) and with the notion of community of practice (WENGER, 1998).

KEYWORDS: genres; virtual community; in-tandem learning.

\section{Introdução}

${ }^{24}$ Mestranda do PPG Estudos Linguísticos do campus UNESP-IBILCE. Orientadora: Prof ${ }^{\text {a }}$ Dra Solange Aranha. Apoio: (FAPESP/Processo: 2010/2010/02381-3) 
A escolha dos instrumentos para a coleta de dados em uma pesquisa é fundamental para o seu bom andamento e para se obter, ao final, resultados satisfatórios. Em meio à variedade dos instrumentos de pesquisa, destacam-se o questionário e a entrevista.

Segundo Günther (2003), há três maneiras de se compreender o comportamento humano no contexto das ciências sociais empíricas: i) observar o comportamento no âmbito real; ii) criar situações artificiais; observar o comportamento mediante tarefas definidas para essas situações e iii) perguntar às pessoas sobre o que fazem ou pensam. Entre as maneiras descritas, encontra-se o instrumento questionário, definido como um conjunto de perguntas sobre um determinado tópico que não testa a habilidade do respondente, mas pode manifestar sua opinião, seus interesses, aspectos de personalidade, dados biográficos e entre outros. (GUNTHER, 2003)

A entrevista, por sua vez, permite aos pesquisadores obter informações: dados objetivos e/ou subjetivos. Sobre a elaboração das questões que irão compor a entrevista, os autores salientam que o pesquisador deve ter cuidado para não elaborar perguntas descabidas, arbitrárias, ambíguas, deslocadas ou tendenciosas. As perguntas devem ser feitas levando em conta uma determinada sequência de, conduzindo a entrevista com certo sentido lógico, compatível ao objetivo da pesquisa. (BONI \& QUARESMA, 2005).

Com base na discussão anterior, neste artigo, apresentaremos a caracterização dos instrumentos de pesquisa utilizados, um questionário e uma entrevista, e a relação direta destes com os critérios para o estabelecimento de uma comunidade virtual (LÉVY, 1998) que compartilha características comuns às noções de comunidade discursiva (SWALES, 1992) e de comunidade de prática (WENGER, 1998). Cabe salientar que este trabalho é um recorte de um projeto de mestrado em andamento que investiga a pertinência da aplicação do conceito de comunidade virtual (LEVY, 1998; 1999), da noção de comunidade discursiva (SWALES, 1990; 1992) e do conceito de comunidade de prática (WENGER, 1998) aos interagentes do Projeto Teletandem Brasil: Língua Estrangeira para Todos.

\section{Fundamentação teórica}

\subsection{O Projeto Teletandem Brasil}

A proliferação das novas tecnologias nos meios educacionais obriga a redefinição da função dos docentes e de novos modos de acesso aos conhecimentos. A utilização 
dessas novas tecnologias, como o computador, no processo de ensino/ aprendizagem, podem contribuir para relaxar a relação dual entre professor e aluno. (LÉVY, 1999).

Em meio a este contexto inovador se insere o projeto Teletandem Brasil: Línguas Estrangeiras para todos. Desenvolvido por um grupo de docentes da Universidade Estadual Paulista, atuantes nas áreas de Linguística Aplicada, Educação e Em meio a este contexto inovador se insere o projeto Teletandem Brasil: Línguas Estrangeiras para todos. Desenvolvido por um grupo de docentes da Universidade Estadual Paulista, atuantes nas áreas de Linguística Aplicada, Educação e Computação, e pesquisadorescolaboradores de universidades estrangeiras, coordenado pelo docente João Antonio Telles professor doutor do campus de Assis e apoiado financeiramente pela FAPESP (Processo 2006/03204-2), o projeto tem como objetivos principais vincular a pesquisa acadêmica da universidade a ações sócio-pedagógicas na área de ensino de línguas estrangeiras e aplicar uma nova ação pedagógica de aprendizagem de línguas à distância. Segundo Pierre Lévy "[...] a distinção entre ensino "presencial" e ensino "à distância" será cada vez menos pertinente, já que o uso das redes de telecomunicações e dos suportes multimídia interativos vem sendo progressivamente integrada às formas mais clássicas de ensino. A aprendizagem à distância foi durante muito tempo o "estepe" do ensino; em breve irá tornar-se, senão a norma, ao menos a ponta de lança." (p.170).

O projeto ainda pretende investigar a efetivação do aplicativo MSN Messenger como ferramenta e meio de aprendizagem de línguas estrangeiras in-tandem à distância, já que este aplicativo dispõe de recursos de vídeo e de som, o que possibilita a interação oral e escrita em língua estrangeira, e também destacar a importância da interação no processo de aprendizagem entre os pares participantes, ressaltando o papel essencial do professor-mediador e gerenciador nesta nova didática de ensino de LE. É importante salientar que os participantes se comportam como professores alunos conforme a ordem das línguas ensinadas. Além disso, há um processo de troca entre eles como reflexões a respeito do conteúdo, da forma, do léxico dependendo do interesse dos envolvidos, o que comprova que não se trata de um simples "bate-papo". Outro ponto destacável do Teletandem Brasil se refere aos aspectos orais, já que o modo de aprendizagem proposto possibilita o desenvolvimento de tais habilidades - produção e compreensão oral - que não são enfatizadas e praticadas no ensino de uma LE nas salas de aula. Além disso, a aplicação do projeto pode ser realizada em diversos contextos sociais, possibilitando à população carente a oportunidade de aprender e entrar em contato com uma LE, muitas vezes restrita a algumas classes sociais. 
Desse modo, observa-se a ação pedagógica inovadora do Teletandem que se torna interessante e atrativa para os jovens por utilizar o aplicativo MSN Messenger e eficiente na medida em que privilegia a interação, a troca de papéis (professor-aluno, aluno-professor), negando a relação assimétrica presente na maioria das salas de aula de ensino de LE e enfatizando o papel do professor-mediador, o que favorece a aprendizagem e promove a educação de qualidade, a qual deve ser almejada por todos sempre.

\subsection{0 conceito de gênero}

A concepção de gênero adotado neste trabalho é calcada na perspectiva sóciorretórica (SWALES 1990; 1992). Os gêneros podem ser entendidos, de uma maneira geral, como práticas sócio-históricas inseridas em um contexto comunicativo.

De acordo com Swales (1990; 1992), os gêneros são sócio-historicamente construídos e não somente objetos textuais mais ou menos semelhantes. São eventos codificados inseridos em processos sociais comunicativos compartilhados pelas comunidades em que ocorrem e reconhecidos por seus membros como legítimos.

Bhatia (1993, apud ARANHA, 1996), partindo do conceito de Swales (1990; 1992), sugere, também, que o gênero é um evento comunicativo caracterizado por um conjunto de propósitos comunicativos compartilhados e identificados pelos membros da comunidade na qual os gêneros se inserem.

Bazerman (2006) considerando o gênero como uma categoria sociopsicológica, afirma que gênero não é simplesmente uma categoria linguística definida pelo arranjo estruturado de traços textuais. É uma categoria sociopsicológica que usamos para reconhecer e construir ações tipificadas dentro de situações tipificadas. "É uma maneira de criar ordem num mundo simbólico sempre fluido". (BAZERMAN, 2006, p.60)

De acordo com Swales (1990; 1992), o conceito de gênero abrange:

1) Os eventos comunicativos, nos quais a língua desempenha papel significativo e indispensável. Nesse caso, um evento comunicativo compreende o discurso e seus participantes, o papel desse discurso e seu ambiente de produção e recepção, incluindo suas associações históricas e culturais; 
2) Os propósitos comunicativos compartilhados pelos membros da comunidade discursiva, dos quais os gêneros são um veículo para atingir determinados objetivos;

3) A variação dos gêneros, ou seja, expressões diversas circundadas pela estrutura retórica prevista;

4) O sistema (inerente ao gênero) que estabelece limitações às contribuições linguístico/discursivas disponíveis em função do conteúdo do texto, do posicionamento do autor e da forma textual compartilhada pelos seus pares. Desse modo, uma vez estabelecidos os propósitos do gênero por parte dos membros da comunidade discursiva, haverá um conjunto de convenções características e, em alguns casos, limitadoras. Essas convenções são dinâmicas, isto é, elas se modificam ao longo do tempo, mas, mesmo assim, continuam a exercer influências dependendo do momento histórico;

5) A nomenclatura usada pela comunidade discursiva, que é responsável por dar nomes a classes de eventos comunicativos que os membros da comunidade discursiva reconhecem como exercendo ação retórica recorrente.

Além disso, é importante destacar que um gênero apresenta uma relação direta com o estabelecimento de uma comunidade discursiva a qual pode ser compreendida como um conjunto de indivíduos que compartilha as mesmas atividades profissionais ou recreacionais e tem objetivos comuns e, portanto, compartilha um conjunto comum de significados, (ARANHA, 1996). Logo, percebe-se que os membros pertencentes a uma comunidade discursiva são responsáveis pela elaboração do gênero e este é também responsável pelo estabelecimento de uma comunidade discursiva. Nota-se, portanto, uma relação de dependência.

\subsection{Comunidade discursiva}

De acordo com a definição de 1990 de John Swales, uma CD é, de um modo idealizado, vista como um conjunto de indivíduos com objetivos em comum, formalmente expressos ou não, e mecanismos de intercomunicação, usados primeiramente para fornecer informação e feedback a seus membros. Esses mecanismos seriam variáveis, podendo, às vezes, nem existir. Uma comunidade discursiva possui também um léxico específico - uma terminologia da área - que restringe e adéqua os textos compartilhados por seus membros e ainda dificulta seu acesso por não-membros que desconhecem tal terminologia. (ARANHA, 1996) A CD, segundo Swales (1990, p. 10) é um dos elementoschave para a realização do propósito comunicativo. Segundo Aranha (1996) existe um processo de "auto-alimentação" entre a comunidade discursiva e a existência de gêneros. A comunidade desenvolve os gêneros, e a existência de gêneros configura grupos sociais 
como comunidades discursivas por compartilharem propósitos comunicativos efetivados por meio dos gêneros pertinentes a ela.

Este modelo proposto por Swales em 1990 recebeu muitas críticas. A definição proposta sugeria que o conceito pudesse ser verificado no mundo real, como se o grupo pudesse ser delimitado como grupos reais e estáveis de participantes sempre em consenso (ARANHA, 1996). O próprio autor questiona posteriormente (SWALES, 2004) se uma CD é de verdade um construto social (concreta) ou uma ilusão que serve para generalizações sobre o mundo (abstrata). Ele admite que a comunidade de Genre Analysis (1990) parece utópica, além de não levar em conta as tensões geralmente presentes em toda comunidade. Ainda assim, ele diz que o conceito serviu para validar grupos já existentes apesar de não fornecer meios de analisar o processo de formação de tais grupos. (cf. HEMAIS E BIASI-RODRIGUES, 2005). Assim, devido ás críticas ao modelo de 1990, Swales (1992) reformula os critérios que havia proposto, que passam a ser:

1) Uma $C D$ tem um conjunto de objetivos identificáveis. Eles podem ser pública e explicitamente formulados e ampla ou parcialmente aprovados pelos membros; eles podem ser consensuais; podem ser separados, mas com pontos de contato, fronteiras em comum. (O autor passa a levar em conta a forma de estabelecimento dos objetivos entre os membros da comunidade).

2) Uma CD tem mecanismos de intercomunicação entre seus membros; este critério permanece inalterado, visto que sem mecanismos de intercomunicação não há comunidade.

3) Uma CD usa desses mecanismos participatórios para uma variedade de propósitos: para aumentar o desempenho da informação e do feedback; para propiciar inovações; para manter o sistema de crenças e valores da comunidade e para aumentar seu espaço profissional.

4) Uma CD utiliza uma seleção de mecanismos participatórios; eles geralmente formam conjuntos ou séries. ( Swales passa a considerar a evolução dos gêneros dentro da comunidade).

5) Uma CD tem e busca constantemente terminologia específica própria. Destaca-se o fato de a terminologia específica não estar determinada e acabada, mas sempre em desenvolvimento.

6) Uma $C D$ tem uma estrutura hierárquica explícita ou implícita que gerencia o processo de entrada e ascensão dentro da CD. (ARANHA, 1996).

Swales conclui que uma $C D$ possui práticas e princípios com base linguística, retórica, metodológica e ética; essa visão enfoca os textos a partir de princípios retóricos, permite um exame das mudanças nas comunidades, as quais são instáveis, desorganizadas ou mal definidas, sendo esse um ponto favorável para sua manutenção. Há ainda a possibilidade de haver divergências, falta de união e até preconceito entre os membros. (SWALES, 1998).

\subsection{Comunidade virtual}


De acordo com Pierre Lévy (1999), uma comunidade virtual se estabelece a partir de afinidades de interesses, de conhecimentos, sobre projetos mútuos, em um processo de cooperação ou de troca, independentemente das proximidades geográficas e das filiações institucionais. A regra básica é a reciprocidade. Todos ensinam a todos e todos aprendem com todos. Ainda segundo Lévy (1996), os membros de uma comunidade virtual se "virtualizam", tornam-se "não presentes", não há contato físico, se desterritorializando. Não apresentam um lugar de referência. Uma CV pode estar presente em toda parte onde seus membros móveis se encontram. Assim, Lévy conclui que a virtualização reinventa uma cultura nômade.

Hagel (1999, apud SAMPAIO-RALHA, 2005, p.3) postula que as comunidades virtuais podem ser de "interesses pessoais, demográficas e geográficas e comunidade de negócios entre empresas (business to business)". Rojo (1995 apud SAMPAIO-RALHA, 2005, p.3) enumera os benefícios de se participar de comunidades virtuais, são eles: travar contato com idéias correntes, lançamentos e eventos no campo de estudo; ter a oportunidade de obter rapidamente respostas de qualidade; conseguir materiais de valor, ou ponteiros para estes materiais; aprender sobre o meio em si; adquirir o sentimento de fazer parte de uma comunidade de interesse; ter a oportunidade de expressar idéias e sentimentos; ter a oportunidade de intensificar contatos com pessoas e compartilhando interesses similares.

De acordo com Palacios (1998) os elementos que caracterizariam a comunidade são: o sentimento de pertencimento, a permanência, a ligação entre o sentimento de comunidade, caráter corporativo e emergência de um projeto comum, e a existência de formas próprias de comunicação. Segundo Palácios (1998), o sentimento de pertencimento, ou "pertença", seria a noção de que o indivíduo é parte do todo, coopera para uma finalidade comum com os demais membros (caráter corporativo, sentimento de comunidade e projeto comum).

As comunidades virtuais desenvolvem uma forte moral social, um conjunto de regras que regem suas relações, mais conhecido como "netiqueta" (PIERRE LÉVY, 1999). Essas regras de conduta emergem naturalmente e têm o intuito de maximizar o diálogo e proteger os usuários de ofensas e atrasos na comunicação. Assim, se algum usuário negligencia a "netiqueta" os próprios participantes se encarregam de censurar o procedimento. Antes de participar de uma comunidade, os novatos devem estudar como os participantes se comportam e como é o fluxo de informações (PIERRE LÉVY, 1999). 
Para se comunicar é essencial que se domine o gênero em questão, que se leve em conta o contexto da situação. Ainda segundo o autor, "as comunidades virtuais exploram novas formas de opiniões públicas", já que as comunidades virtuais oferecem um campo amplo para debate coletivo, mais aberto e mais participativo, (p.129). É importante ressaltar que as regras que regulam as interações devem ser construídas na coletividade (SAMPAIO-RALHA, 2005).

No que diz respeito à emergência das comunidades virtuais, Rheingold (1993) defende que a diminuição das possibilidades de encontros reais nas cidades motivou 0 surgimento e o crescimento de comunidades virtuais. E ainda ressalta que as relações online não excluem as emoções, a responsabilidade individual, a opinião pública e o julgamento, e não substituem, simplesmente, os encontros físicos; na verdade, podem ser entendidas como um complemento ou adicional destes.

Simon (2000) quando se refere à prática de comunidades em rede, afirmando que basicamente todas as atividades na rede se desenvolvem em torno de alguma comunidade virtual.

Sendo assim, pode-se compreender que as comunidades virtuais seriam baseadas em proximidade intelectual e emocional ao invés de mera proximidade física. Os participantes reconhecem-se parte de um grupo e responsáveis pela manutenção de suas relações. $O$ indivíduo escolhe, elege qual comunidade quer fazer parte, sendo a principal motivação o seu interesse particular em um ou mais assuntos em que percebe uma identificação e encontra pessoas com quem possa compartilhar idéias e promover discussões. A interação mútua e relação recíproca, que ocorrem entre as pessoas mediadas pelo computador, são fundamentais para o estabelecimento e consolidação de comunidades virtuais (PRIMO, 1998). Nesse aspecto, torna-se importante esclarecer que é o interesse em comum partilhado que transmite à comunidade o sentimento de pertencimento.

\subsection{Comunidade de prática}

Além dos conceitos de Comunidade Discursiva e Comunidade Virtual, tendo em vista as características dos interagentes do Projeto Teletandem Brasil, consideramos oportuno discutir ainda nesta pesquisa o conceito de Comunidade de Prática (doravante, $\mathrm{CP})$.

De acordo com Vassalo (2008), “o clima” da prática de teletandem realizada no laboratório do campus da UNESP em Assis se assemelha muito ao de uma comunidade 
de prática no que diz respeito ao comprometimento em um processo de aprendizagem coletivo num domínio compartilhado de esforço humano (Wenger 2006).

A concepção de Comunidade de Prática (CoP) adotada neste trabalho está calcada na definição sugerida por Wenger (1998; 2006): uma comunidade de prática é formada por pessoas que se comprometem em um processo de aprendizagem coletivo num domínio compartilhado de esforço humano, como um grupo de artistas buscando novas formas de expressão, um grupo de engenheiros trabalhando em um problema parecido, um grupo de estudantes definindo suas identidades na escola, entre outros. O termo foi primeiramente usado pela teoria da aprendizagem, de acordo com Wenger (1998), mas o número de aplicações atual engloba praticamente todas as áreas de conhecimento, como a área de negócios, design organizacional, governo, educação, associações profissionais, projetos de desenvolvimento e vida cívica. A Internet, segundo Wenger (1998), foi responsável pela expansão do alcance de nossas interações além das limitações geográficas das comunidades tradicionais. E o constante aumento do fluxo de informação expande as possibilidades de comunidades e pede novos tipos de comunidades baseadas em práticas compartilhadas.

As vantagens da definição de CP, segundo Wenger (2006) são enumeradas como segue:

1) Comunidades de prática possibilitam que os membros assumam responsabilidade coletiva pelo gerenciamento do conhecimento que precisam, reconhecendo que, dada a estrutura própria, estão na melhor posição para tanto.

2) Comunidades entre membros criam uma ligação direta entre aprendizado e desempenho, porque as mesmas pessoas participam das comunidades de prática e de equipes e unidades de negócios.

3) Membros podem se valer dos aspectos tácitos e dinâmicos da criação e compartilhamento de conhecimento, assim como de aspectos mais explícitos.

4) Comunidades não são limitadas por estruturas formais, elas criam ligações entre pessoas por meio de fronteiras organizacionais e geográficas. (WENGER, 2006, p. 4 minha tradução)

Desse modo, o autor postula que uma CoP é, resumidamente, um grupo de pessoas que compartilham interesses ou paixões por algo e procuram maneiras de aperfeiçoar o que fazem e aprendem por meio de interações regulares. Mais que comunidades de "aprendizes", a Comunidade de Prática (CoP) pode ser uma "comunidade que aprende", pois são compostas por pessoas que têm compromisso de agregar as melhores práticas. (WENGER, 1998). Além disso, o autor sugere que uma 
comunidade de prática pode ser grande ou pequena, local ou global, pode interagir face a face ou apenas pela internet, pode ser formal ou informal.

Wenger (2006) ressalta que nem toda comunidade pode ser considerada uma comunidade de prática. Para uma comunidade ser caracterizada como uma CoP é preciso que esta apresente três características essenciais:

1) O domínio (the domain): o comprometimento com o domínio, e, portanto, uma competência compartilhada que distingue os membros de outros indivíduos.

2) A comunidade (the community): Ao buscarem o interesse em seus domínios, os membros engajam-se em discussões e atividades comunitárias, ajudam-se uns aos outros, compartilham informação, interagem e aprendem juntos.

3) A prática (the practice): A CoP não é meramente um grupo de pessoas que compartilham o interesse por certo tipo de filmes, por exemplo. Membros são praticantes que desenvolvem certo repertório de recursos experiências, histórias, ferramentas, modos de lidar com problemas recorrentes. Basicamente, deve haver o compartilhamento de uma prática, o que leva tempo e interação constante. O desenvolvimento de uma CoP pode ser mais ou menos consciente. Por exemplo, um grupo de engenheiros que coleta e documenta truques e lições aprendidas em uma base de dados é uma CoP do mesmo modo como um grupo de enfermeiras que almoçam juntas em um hospital tem em suas discussões a maior fonte de conhecimento em cuidar de pacientes. Em ambos os casos temos, no decorrer de suas conversas, um conjunto de histórias e casos que se tornou um repertório compartilhado para a prática do grupo.

O referido autor destaca que as novas tecnologias, como a Internet, têm possibilitado a expansão de nossas interações, as quais antes eram limitadas nas comunidades tradicionais por razões geográficas. Deste modo, o constante aumento do fluxo de informação possibilita o surgimento de comunidades baseadas em práticas compartilhadas.

\section{Procedimentos Metodológicos}

\subsection{A escolha e a caracterização dos instrumentos de pesquisa}

Para o desenvolvimento desta pesquisa, partimos da hipótese de que os interagentes do TTB compartilham características comuns à noção de CV, à noção de CD e à noção de CP.

Primeiramente, com o objetivo de definir os critérios para a busca de parâmetros para o estabelecimento da comunidade virtual, que compartilha características comuns à noção de comunidade discursiva proposta por Swales (1992) e à noção de comunidade 
de prática (WENGER, 1998), foi elaborado um questionário virtual com 14 perguntas semi-abertas, por meio da ferramenta online Google docs e uma entrevista composta por 10 perguntas, sendo 6 específicas e 4 gerais.

Tanto o questionário como a entrevista foram escritos nas línguas portuguesa e inglesa, e submetidos aos interagentes brasileiros e norte-americanos. Cabe ressaltar que a ferramenta Google docs permite a elaboração de um questionário virtual. Este foi enviado por e-mail a todos participantes e ainda foi impresso, aplicado e coletado pessoalmente no laboratório de teletandem da UNESP de São José do Rio Preto e no laboratório de teletandem da UNESP de Assis.

Já a entrevista foi realizada, presencialmente, com participantes brasileiros e americanos. Foram entrevistadas apenas as parcerias do campus da UNESP de Assis, uma vez que as parcerias do laboratório deste campus eram mais antigas e constantes, o que, a nosso ver, poderiam nos fornecer dados mais precisos e qualitativos, tendo em vista que a entrevista foi elaborada com o propósito de coletar dados qualitativos. Quanto aos participantes americanos, estes foram entrevistados pela orientadora Prof ${ }^{a} \mathrm{Dr}^{\mathrm{a}}$ Solange Aranha na Utah Valley University, onde realizava Pós-Doutorado.

Cabe ressaltar que as perguntas que compõem tanto o questionário como as entrevista foram elaboradas tendo em vista os critérios para o estabelecimento de uma comunidade virtual (LÉVY; 1999). Tais instrumentos podem ser visualizados abaixo:

\section{Questionário:}

1. Gostaríamos de saber qual(is) o(s) seu(s) propósito(s) em participar das interações em tandem. Para isso, escolha a(s) opção (ões) que melhor represente seu(s) objetivo(s):

\section{Aprender/aperfeiçoar a L2 123}

Conhecer a cultura do estrangeiro 123

Participar de pesquisas acadêmicas 123

Outro (especifique)

2. Como é a sua relação com o seu interagente? 

a) Muito ruim
b) Ruim
c) Regular
d) Boa
e) Muito boa

3.Nas suas interações há reciprocidade/troca de conhecimentos?
a) $\operatorname{Sim}$
b) Não

4. Se você respondeu SIM na pergunta anterior, justifique:

5. Avalie a relevância de sua participação nas interações:

1
2
3
4
5

6. Avalie o grau de importância de sua participação no Projeto Teletandem Brasil:

1

2

3

4

5

7. As interações entre você e seu parceiro ocorrem exclusivamente por meio do computador?
a) $\operatorname{Sim}$
b) Não 
8. Se você respondeu NÃO na pergunta anterior, justifique:

9.Nas interações você e seu parceiro construíram alguma regra ou fizeram alguma exigência que deva ser respeitada?
a) $\mathrm{Sim}$
b) Não

10. Se você respondeu SIM na pergunta anterior, justifique:

11.Você e seu parceiro já infringiram alguma regra que deveria ser respeitada?
a) $\operatorname{Sim}$
b) Não (pule a próxima pergunta)

12. Se você respondeu SIM na pergunta anterior, justifique:

13. Durante as interações você e seu parceiro utilizam emoticons?
a) $\operatorname{Sim}$
b) Não ( não continue)

14. Qual número abaixo representa o grau de frequência de utilização dos emoticons? 


\section{Perguntas Gerais:}

1) Qual o seu objetivo em participar do Projeto Teletandem Brasil?

2) Com qual frequência ocorrem as interações? Vocês se encontram fora do horário da aula? Se sim, com qual frequência? Se não, há razão específica?

3) Quais os tipos de conhecimentos são trocados?

4) Quais são as regras seguidas entre você e seu parceiro?

\section{Perguntas Específicas:}

1) O que você aprendeu na interação de hoje e o que ensinou para o seu parceiro?

2) Sobre o que conversaram? Quem sugeriu o assunto?

3) Quais foram os pontos positivos e negativos da interação de hoje?

4) Liste os pontos positivos desde o começo das interações.

5) Liste os pontos negativos desde o começo das interações.

6) Você tem interação sempre com o mesmo parceiro?

\subsection{Os critérios para a elaboração}

O primeiro instrumento desenvolvido foi o questionário virtual. Ao se elaborar um questionário, o pesquisador deve considerar: a) o contexto social da aplicação do instrumento; b) a estrutura lógica do instrumento na organização de seus elementos e c) os elementos constituintes do instrumento, como questões e itens. É preciso destacar que o pesquisador não tem poder sobre o respondente, e será preciso convencê-lo de que a pesquisa vale à pena. (GUNTHER, 2003)

Com relação ao segundo instrumento de pesquisa elaborado, a entrevista, de acordo com (BONI \& QUARESMA, 2005), esta é definida por Haguette (1997:86) como 
um processo de interação social entre duas pessoas na qual uma delas, o entrevistador, tem por objetivo a obtenção de informações por parte do outro, o entrevistado.

Como já explicitado, a entrevista foi elaborada com o intuito de coletar dados qualitativos, logo, a perguntas escolhidas tinham como objetivo complementar os dados do questionário, isto é, clarear e especificar algumas considerações que pudessem estar confusas, obscuras ou incompletas.

Levando em consideração as discussões anteriores, é relevante mencionar que os instrumentos de pesquisa foram elaborados tendo em vista os seguintes critérios para a verificação da formação de uma CV (LÉVY, 1999):

1. Uma comunidade virtual se estabelece a partir de afinidades de interesses, de conhecimentos, sobre projetos mútuos; (LÉVY, 999)

2. As interações entre seus membros são realizadas tendo como base um processo de cooperação ou de troca (reciprocidade), (feedback). (LÉVY, 1999)

3. Os membros de uma comunidade virtual são "não presentes", desterritorizados; (LÉVY, 1996; 1999)

4. As comunidades virtuais desenvolvem um conjunto de regras, coletivamente, que regem suas relações ("netiqueta"); (LÉVY, 1999)

5. Os membros de uma comunidade virtual compartilham um léxico específico. (Baseado no quinto critério postulado por Swales $(1990 ; 1992)$ para a definição de uma CD)

\subsection{Os instrumentos de pesquisas e a relação com a comunidade virtual}

Como já mencionado, os instrumentos de pesquisa foram elaborados de acordo com os critérios para a verificação da formação de uma CV (LÉVY, 1999), uma vez que o objetivo do projeto de pesquisa em andamento é verificar se os participantes do projeto Teletandem Brasil configuram uma comunidade virtual (LEVY, 1999) que compartilha características comuns à noção de comunidade discursiva (SWALES, 1990; 1992) e ao conceito de comunidade de prática (WENGER, 1998).

A primeira pergunta do questionário foi elaborada tendo em vista o primeiro critério para a verificação da formação de uma CV (LÉVY, 1999): uma comunidade virtual se estabelece a partir de afinidades de interesses, de conhecimentos, sobre projetos mútuos.

As questões 2, 3,4, 5 e 6 vão ao encontro do segundo critério para o estabelecimento de uma CV (LÉVY, 1999): As interações entre seus membros são realizadas tendo como base um processo de cooperação ou de troca (reciprocidade), (feedback), provocando um sentimento de pertencimento; (PALACIOS, 1998). Acredita-se que as respostas às perguntas 2 e 3 poderão indicar como se chega à construção do 
conhecimento nas interações, se há processos de cooperação ou não. As respostas das perguntas 4 e 5 informarão o grau de pertencimento/comprometimento dos interagentes no projeto TTB.

A sétima e oitava pergunta vai ao encontro do terceiro critério para 0 estabelecimento de uma CV: os membros de uma comunidade virtual são "nãopresentes", desterritorizados, têm como ambiente comum o meio virtual. (LÉVY, 1999)

As perguntas 9, 10,11 e 12 vão ao encontro do quarto critério para o estabelecimento de uma CV: As comunidades virtuais desenvolvem um conjunto de regras, coletivamente, que regem suas relações ("netiqueta"). (LÉVY, 999)

As perguntas 13 e 14 dizem respeito ao quinto critério para o estabelecimento de uma CV (LÉVY, 1999): Os membros de uma comunidade virtual compartilham um léxico específico. (Baseado no quinto critério postulado por Swales (1990; 1992) para a definição de uma CD). Acredita-se que os emoticons sejam elementos característicos do léxico das interações virtuais.

Com relação à entrevista, a primeira pergunta geral vai ao encontro do primeiro critério para o estabelecimento de uma CV: uma comunidade virtual se estabelece a partir de afinidades de interesses, de conhecimentos, sobre projetos mútuos. (LÉVY, 1999). Acredita-se que as respostas a esta pergunta possa validar ou refutar as dados apontados pelo questionário.

A segunda pergunta geral diz respeito à frequência das interações, o que vai ao encontro do conceito de comunidade, uma vez que o conceito pressupõe o contato frequente de seus membros, uma prática constante. (WENGER, 1998)

As perguntas gerais 3 e 4 têm como objetivo especificar os tipos de regras, condutas e troca de conhecimentos entre os parceiros, o que vai ao encontro do $4^{\circ}$ critério para o estabelecimento de uma CV: "As interações entre seus membros são realizadas tendo como base um processo de cooperação ou de troca (reciprocidade)"; "As comunidades virtuais desenvolvem um conjunto de regras, coletivamente, que regem suas relações (“ netiqueta”)". (LÉVY, 1999)

As perguntas específicas dizem respeito à interação realizada no dia da entrevista. O propósito era investigar a qualidade da interação do dia e verificar se os princípios de objetivo comum, troca/reciprocidade, construção de conhecimento, frequência e comprometimento estavam presentes na interação, uma vez que tais princípios são fundamentais na configuração de uma CV.

\section{Considerações Finais}


Este trabalho buscou apresentar a caracterização dos instrumentos de pesquisa utilizados em um projeto de mestrado em andamento, que tem como objetivo verificar se os participantes do projeto Teletandem Brasil configuram uma comunidade virtual (LÉVY, 1999) que compartilha características comuns a noção de comunidade discursiva ( SWALES, 1990; 1992) e à noção de comunidade de prática (WENGER, 1998).

Na seção 1, foi apresentada a fundamentação teórica, na qual foram abordados os objetivos do projeto Teletandem Brasil, o conceito de gênero, as concepções de comunidade virtual, comunidade discursiva e comunidade de prática. Na seção 2, foram apresentados os procedimentos metodológicos do referido projeto de mestrado, assim com a caracterização dos instrumentos de pesquisa, o critério de escolha e, ainda, a relação destes com o conceito de comunidade virtual.

Por fim, na seção 4, foram apresentadas as considerações finais a respeito do artigo em questão e, na seção 5 , as referências bibliográficas.

\section{Referências Bibliográficas}

ARANHA, S. A argumentação nas introduções de trabalhos científicos da área de Química. 1996. Dissertação (Mestrado em Linguística Aplicada ao Ensino de Línguas) Pontifícia Universidade Católica de São Paulo, São Paulo, 1996 Contribuições para a introdução acadêmica. 2004. Tese (Doutorado em Lingüística e Língua Portuguesa) Universidade Estadual Paulista - Campus de Araraquara, 2004.

BAZERMAN, C. Gêneros, agência e escrita / Tradução e adaptação de Judith Chanbliss Hoffnagel: - São Paulo: Cortez, 2006.

BAZERMAN, C. Gêneros textuais, tipificação e interação / Tradução e adaptação de Judith Chanbliss Hoffnagel: revisão técnica Ana Regina Vieira... [et. al.]. 2. ed. São Paulo: Cortez, 2006.

BONI, V.; QUARESMA, S. J. Aprendendo a entrevistar: como fazer entrevistas em Ciências Sociais. Em Tese, Florianópolis, v. 2, n. 1, p.68-80, jan.-jul., 2005.

GUNTHER, H. Como Elaborar um Questionário (Série: Planejamento de Pesquisa nas Ciências Sociais, № 01). Brasília, DF: UnB, 2003.

HEMAIS, B.; BIASI-RODRIGUES, B. A proposta sócio-retorica de John M. Swales para o estudo de gêneros textuais. In: MEURER, J. L.; BONINI, A.; MOTTA-ROTH, D. (org). Gênero: teorias, métodos, debates. São Paulo: Parábola Editorial, 2005, p. 108-129. LÉVY, P. A máquina universo: criação, cognição e cultura informática / Pierre Lévy; trad. Bruno Charles Magne, - Porto Alegre: Artmed, 1998.

LÉVY, P. Cyberculture / Tradução de Carlos Irineu da Costa São Paulo: Ed. 34, 1999.

PALACIOS, M. Cotidiano e Sociabilidade no Cyberespaço: Apontamentos para

Discussão. Arquivo capturado em 19 de novembro 1998. Disponível em:

$\mathrm{http}: / / \mathrm{facom} / \mathrm{ufba} / \mathrm{br} / \mathrm{pesq} / \mathrm{cyber} /$ palacios/cotidiano.html

PRIMO, A. F. T. Interação Mútua e Interação Reativa: uma proposta de estudo. In:

Congresso da Sociedade Brasileira de Estudos interdisciplinares em Comunicação, 21, 1998, Recife. Anais... Recife: UFPE, 1998. Disponível em:

<http://usr.psico.ufrgs.br/ aprimo/pb/espiralpb.htm>. Acesso em: 7 Fev. 2009, às 19:40 
RHEINGOLD, H. "The Virtual Community: Homesteading at the Electronic Frontier 1993". [on-line] Arquivo capturado em 16 de dezembro de 2008. Disponível em:

http://www.rheingold.com/vc/book/.

SAMPAIO-RALHA J.L.F. Comunidades Virtuais: Definições, origens e aplicações, 2006.

Disponível em <http://www.rau-tu.unicamp.br/nourau/ ead/document/?down=79.Acesso em 12 de Agosto, 2009.

SIMON, I. "O Impacto das redes: estudos de Informação e Comunicação (EdIC)". Arquivo capturado em 20 de dezembro de 2000. Disponível em:

http://www.usp.br/iea/infocom.html

SWALES, J. Genre analysis: English in academic and research settings. Cambridge:

Cambridge University Press, 1990.

SWALES, J. Other floors, other voices: a textography of a small university building.

Mahwah, NJ: Lawrence Erlbaum, 1998.

SWALES, J. Rethinking genre: Another look at discourse community effects. Trabalho apresentado no colóquio 'Rethinking Genre'. Carleton University, Ottawa, 1992 TELLES, J. A.; VASSALLO, Maria Luisa. Foreign language learning in-tandem: Teletandem as an alternative proposal in CALLT. The Especialist, v. 27, 2006. VASSALLO, Maria Luisa; O Laboratório de Teletandem de Assis: Questões de Organização e Gerenciamento. Teletandem News, 2008. Disponível em <http://www.teletandembrasil.org/site/docs/Newsletter_Ano_III_n_3.pdf.> Acesso em: 28 jul. 2009.

WENGER, E. Communities of Practice: A Brief Introduction. 2006. Disponível em: $<$ http://www.ewenger.com/theory/> Acesso em: 10 ago. 2009.

WENGER, E.. Communities of Practice - learning, meaning and identity. Cambridge: Cambridge University Press, (1998). Disponível em: <http://www.google.com/books?id=heBZpgYUKdAC\&pg=PT1\&dq=Wenger, + E.+1998/> Acesso em: 18 ago. 2009. 


\title{
VOZES ADVINDAS DO VALE: EXPERIÊNCIA TRANSDISCIPLINAR DE UMA PROFESSORA DE INGLÊS NO VALE DO JEQUITINHONHA
}

\section{VOICES FROM THE VALLEY: AN ENGLISH TEACHER'S TRANSDISCIPLINARY EXPERIENCE IN JEQUITINHONHA}

\author{
Kátia Honório do Nascimento \\ Universidade Federal dos Vales do Jequitinhonha e Mucuri \\ katiahonorio@yahoo.com.br
}

RESUMO: Um diálogo interdisciplinar entre áreas de conhecimento vem sendo defendido por diversos teóricos da Linguística Aplicada (Moita Lopes, 2006; Pennycook, 2006; Signorini e Cavalcanti, 1998). Uma das vias seria o percurso transdisciplinar de investigação visando o desemaranhar dos fios discursivos das ideologias a que estão sujeitos os professores. Ao analisar os textos oficiais das políticas educacionais pretendese refletir sobre como possuem implicações decisivas sobre o magistério. $O$ relato de experiência se baseia em uma situação singular de docência no Vale do Jequitinhonha/MG e evidencia a imposição de um discurso político, centralizado nas altas esferas de poder e, imposto, faz dos professores instrumentos eficientes de execução e propagação de diretrizes políticas. Esta vivência possibilitou verificar como o imaginário de seus professores-alunos estava impregnado de um discurso ideológico determinado e pronto que os faziam porta-vozes das políticas voltadas à manutenção da educação como produtora de mão-de-obra a ser (in)gerida pelo mercado de trabalho. Tal fato leva a professora da disciplina a pensar sobre a centralidade do assunto e a propor aos alunos uma reflexão crítica sobre a proletarização do trabalho docente e a condução de um magistério mais engajado e mais politizado como resistência às relações de dominação e de poder. 
PALAVRAS-CHAVE: discurso; ensino/aprendizagem de línguas; Estudos Críticos do Discurso; relato de experiência.

ABSTRACT: An interdisciplinary dialogue within areas of knowledge has been endorsed by several theorists from Applied Linguistics (Moita Lopes, 2006; Pennycook, 2006; Signorini e Cavalcanti, 1998). One of the ways for this dialogue would be through transdisciplinarity and through an investigative work; this work aims to understand the ideological and political discourse that teachers are exposed. The article intents to exhibit how the official documents have implications to education. This report is based on a unique teacher's experience in Vale do Jequitinhonha/MG, and it demonstrates the imposition of a political discourse, centered in the international arena. When it is imposed to teachers, it makes them effective instruments of execution and implementation of the international project to educational reforms. This experience shows how the teachers' discourse contained the ideological discourse and the defense of the politics that turns education as an area which produces workers to the labor market. This fact made the teacher thought about the centrality of this subject and then proposed to students a critical thought about how they are being changed to technicians and how they could be more critical and have a political attitude against the power and dominance relations.

KEYWORDS: discourse; language teaching/learning; Critical Discourse Studies; experience report.

\section{Introdução}

"Todo conhecimento é político". (Pennycook, 2001:43 apud Moita Lopes, 2006)

O diálogo interdisciplinar entre áreas de conhecimento vem sendo defendido por diversos teóricos da Linguística Aplicada (LA) nos últimos tempos (Moita Lopes, 2006; Pennycook, 2006; Signorini e Cavalcanti, 1998; dentre outros). Essa proposta perpassa por uma conjunção de campos teóricos como os da LA, das Ciências Sociais e das Humanidades (Moita Lopes, 2006). Tais áreas favorecem, no caso específico desse relato, um entendimento sobre o sujeito e os discursos ideológicos das políticas e reformas internacionais para a educação. De mais a mais, propicia a análise das discursividades constantes nos documentos oficiais voltados para o magistério.

Moita Lopes (2006) alude a esse diálogo como de natureza interdisciplinar/transdisciplinar de produção de conhecimento que vinga-se com a interação e os empréstimos entre as disciplinas. Por uma interface entre as zonas fronteiriças dessas disciplinas, os estudos de investigação em LA têm "um outro modo de produzir conhecimento" (Moita Lopes, 1998, p. 113; Signorini, 1998).

Nesse viés, o presente artigo trata do relato de uma experiência docente de cunho transdisciplinar no Vale do Jequitinhonha/MG. A professora lecionou a disciplina Estrutura 
e Funcionamento do Ensino Médio em um curso de Pedagogia em uma instituição privada de ensino superior. A experiência foi possível graças à sua formação acadêmica e profissional em ciências gerenciais e contábeis, o que sempre a levou a leituras em áreas diferentes de sua práxis atual, a saber, o ensino de língua inglesa.

A professora busca com este artigo fazer com que essa prática pedagógica vivida "ao ser narrada deixe de ser um acontecimento isolado ou do acaso" (Miccoli, 2010, p. 29) e torne-se um "processo reflexivo de narrativa que (grifo meu) oferece a oportunidade de ampliar o sentido dessa experiência e de definir ações para mudar e transformar seu sentido original bem como aquele que a vivenciou" (Miccoli, 2010, p. 29). Pretende-se, ao produzir este artigo, compartilhar uma experiência individual e torná-la coletiva (Machado, 2007), além de voltar um olhar para tópicos inerentes ao magistério e à compreensão dos discursos criados que orientam fazeres pedagógicos e que mantêm o quadro da ordem das coisas inalterado.

Por essa vivência pôde-se colaborar para que os alunos da disciplina ${ }^{25}$ percebessem como o jogo discursivo implícito nos textos oficiais já fundamentava sua própria prática docente e já tinha obtido sua adesão. A intenção foi fomentar nesses professores uma consciência política para que criticassem a ordem das coisas (Gramsci, 1978 apud Uyeno, 2009). Nessas premissas, objetivou-se tornar mais elucidativas algumas questões concernentes aos vários aspectos enfrentados que sugeriam algum tipo de manipulação discursiva em favor da reestruturação produtiva e econômica que já se mostrava, por si só, emblemática quanto às suas implicações para o magistério. Tencionava-se, de igual modo, refletir sobre essa pedagogia, tendo em mente que, "toda experiência revela algo importante para aquele que a relata" (Miccoli, 2010, p. 29).

\section{De Buscas pela Via Transdisciplinar: o fio condutor para reflexões em experiências pedagógicas}

Signorini e Cavalcanti (1998) discutem sobre a transdisciplinaridade mencionando como tal abordagem permite explorar os fenômenos investigados por outros prismas conceituais, tendo em vista uma maior compreensão sobre os problemas do mundo real e das práticas sociais dos sujeitos. Signorini (1998, p. 100) alega que a LA tem se mostrado por uma imbricação com algumas zonas fronteiriças de conhecimento ao tratar de uma interface com "a Psicologia, a Sociologia, a Antropologia, a Pedagogia, a Psicanálise" etc.

${ }^{25}$ Os sujeitos desse relato eram alunos que já possuíam experiência como professores no ensino fundamental. Por isso o fato de serem aqui tratados como "professores-alunos". 
A "transdisciplinaridade é um modo de investigação que envolve uma forma de produção de conhecimento que corta várias disciplinas" (Moita Lopes, 1998, p. 122), e sua junção a esses (e a outros) campos teóricos corrobora trabalhos de pesquisa e de reflexão por uma perspectiva mais aprofundada.

A transdisciplinaridade reorganiza as áreas do saber e cria uma relação de sentidos que possibilita capturar a realidade dos sujeitos com todas as suas implicações sociais e político-ideológicas. A transdisciplinaridade trata da produção de conhecimentos para a resolução de problemas em contextos específicos, tendo "uma orientação para a prática social ou para a ação" (Moita Lopes, 1998, p. 118). Tal prática gera conhecimentos que são úteis para os participantes do mundo social, os quais são importantes atores sociais e não somente sujeitos-objetos, passivos de investigação e de análise. Pela via transdisciplinar, a "teoria informa à prática e a prática informa à teoria" (Moita Lopes, 1998, p. 119) com o objetivo de tornar o conhecimento produzido, aplicado. Outro ponto diz da consideração de sujeitos para a pesquisa que estejam fora do ambiente acadêmico como, por exemplo, "as faculdades, as escolas e os institutos não-universitários" (Moita Lopes, 1998, p. 120), caso deste relato.

Ademais, o trabalho transdisciplinar exprime uma preocupação pelos estudos "das pessoas em ação no mundo" (Moita Lopes, 1998, p. 123), o que se traduz em uma via de responsabilidade social, visto que, nas investigações se procura um contexto de aplicação para os fenômenos estudados e "um retorno de seus resultados para a prática social" (Moita Lopes, 1998, p. 124). Um fator adicional refere-se às análises de natureza interpretativa, baseadas na afirmativa de que o "que é específico no mundo social é o fato de os significados que o caracterizam serem construídos pelo ser humano, que interpreta e re-interpreta o mundo a sua volta, fazendo, assim, com que não haja uma realidade única, mas várias realidades" (Moita Lopes, 1998, p. 125).

Celani (1998) destaca que a transdisciplinaridade remete-se a alteração na percepção do pesquisador e no seu engajamento com a coletividade, o que implica em tomar para si uma atitude mediadora de mudanças. Faure (1992 apud Celani, 1998, p. 133) declara que o pesquisador transdisciplinar é "um nômade, um rei sem reino", por isso de sua inquietude e de seu envolvimento com áreas outras. Moita Lopes (2006, p. 96) afirma que "é preciso sair do campo da linguagem propriamente dito: ler sociologia, geografia, história, antropologia, psicologia cultural e social etc." e, desse modo, deve aproximar-se "de áreas que focalizem o social, o político e a história. Essa é, aliás, uma condição para que a LA possa falar à vida contemporânea". Esse envolvimento o 
sensibiliza em favor das peculiaridades da "mistura que tece o mundo" social (Signorini, 1998, p. 101) e a vida social dos sujeitos.

Devido à experiência com a referida disciplina, a professora buscou conduzir seu trabalho de modo que pudesse trazer para a discussão sua formação anterior à Linguística Aplicada. Pela via transdisciplinar consegue produzir conhecimento e instigar uma reflexão crítica para o fenômeno. Com a disciplina pôde aplacar sentimentos contraditórios que sempre a fizeram se sentir híbrida e deslocada de seu próprio eixo como linguista aplicada. A sensação vivida sempre a fazia pensar em como já a inquietava certos fenômenos na área da Educação e da própria La que necessitava do auxílio de outras áreas para serem mais bem entendidos e analisados. A busca pelo trabalho transdisciplinar ajudou-a a conciliar essa inquietude e o fato de se sentir "nômade" e "um rei sem reino" em sua própria área de atuação.

\section{Da Experiência Transdisciplinar no Vale do Jequitinhonha: os Estudos Críticos do Discurso e a Pedagogia Crítica}

Nesse viés, o presente relato objetiva construir uma reflexão sob um panorama transdisciplinar e crítico. A intenção aqui é promover a discussão da prática educacional e da temática sob um aspecto mais abrangente que a da investigação meramente linguística, tradicionalmente conduzida em LA. Ao mesmo tempo, a alusão a outras áreas, como a Pedagogia Crítica, os Estudos Críticos do Discurso (ECD) ${ }^{26}$ e a Educação, justifica-se pela expansão e enriquecimento de perspectivas para a discussão depreendida, pois permite o debate sobre questões inerentes à docência e às reformas internacionais com suas propostas curriculares. Essas questões interferem e influenciam o fazer pedagógico e possuem implicações decisivas sobre o magistério. Também conduzem a certos discursos e atitudes adotados pelo professorado que deveriam supor mais reflexão, posto que envolvem diretamente o magistério.

A proposição baseia-se nos ECD e na pedagogia crítica. O primeiro traz subsídios para a discussão, pois proporciona uma descrição qualitativa dos fenômenos por determinadas abordagens. Os ECD não são essencialmente um método de análise do discurso; na verdade, utilizam-se de diferentes métodos que são essenciais aos objetivos da pesquisa, à natureza dos dados estudados, aos interesses e à qualificação do

\footnotetext{
${ }^{26}$ Ver definição mais completa sobre os Estudos Críticos do Discurso no livro de Van Dijk intitulado Discurso e poder (2008a), referenciado no final deste artigo.
} 
pesquisador (Van Dijk, 2008a, p. 11), lançando mão de recursos para a análise, tais como:

"Análise gramatical (fonológica, sintática, lexical, semântica); análise pragmática dos atos de fala e dos atos comunicativos; análise retórica; análise estilística; análise de estruturas específicas (gênero etc.): narrativa, argumentação, notícias jornalísticas, livros didáticos etc.; análise conversacional da fala em interação; análise semiótica de sons, imagens e outras propriedades multimodais do discurso e da interação" (Van Dijk, 2008a, p. 11).

De acordo com Van Dijk (2008a), os ECD concordam com os interesses dos grupos sociais pesquisados e concorrem para o empoderamento dos mesmos no tocante ao domínio e à maior clareza do discurso a eles dirigido. Para tanto, os ECD admitem a análise das estruturas da fala e da escrita através da análise das metáforas, dos itens lexicais, dos pronomes, dos tópicos frasais, dos eufemismos e, ainda, dos recursos semióticos usados como, por exemplo, um ângulo de câmera, uma imagem etc., que podem mostrar várias outras nuanças.

\begin{abstract}
"Essas propriedades podem incluir, de um lado, uma entonação especial, as propriedades visuais e sonoras (cor, tipografia, configurações de imagens, música), as estruturas sintáticas (tais como ativas e passivas), a seleção lexical, a semântica de pressuposições ou as descrições de pessoas, as figuras retóricas ou as estruturas argumentativas e, do outro lado, a seleção de atos de fala específicos, os movimentos de polidez ou as estratégias conversacionais" (Van Dijk, 2008a, p. 14).
\end{abstract}

Já a Pedagogia Crítica diz que todo ensino e aprendizagem deve se pautar pela aquisição de competências amparadas em bases críticas e políticas e não somente em competências linguísticas. A pedagogia crítica consiste em refletir sobre as relações sociais e materiais presentes entre a educação e a sociedade e constitui uma análise crítica que revela os meios pelos quais a priemira está subordinada a estruturas de poder (McLaren, 1999). Também, orienta alunos e professores para que tenham condições de divisar sua própria realidade e criticar o sistema político vigente.

Utilizando-se dos subsídios dessas áreas, isto é, dos ECD e da Pedagogia Crítica, pôde-se analisar o uso da linguagem nos textos oficiais quando sua retórica se volta para a educação como apropriação e manutenção de poder e "domínio de algumas pessoas sobre as outras" (Fairclough, 1989, p. 01 apud Pennycook, 1998, p. 43). Nesse ínterim, para fins de análise e compreensão pensou-se a linguagem vinculada a uma discussão política e crítica. "Como linguistas aplicados, precisamos não só nos percebermos como 
intelectuais situados em lugares sociais, culturais e históricos bem específicos, mas também precisamos compreender que o conhecimento que produzimos é sempre vinculado a interesses" (Pennycook, 1998, p. 46). Por esses motivos, conduzir um trabalho de análise sob esses pressupostos reforça 0 debate sobre questões que subjazem ao magistério. Relacionada ao fazer docente, a linguagem pode traduzir um domínio ideologizante de consciência de outrem que torna-se importante percebê-la em detrimento às políticas educacionais atuais.

Para proceder a discussão em sala de aula e a posterior análise da linguagem do discurso oficial contida nos documentos escolhidos, procurou-se analisar as metáforas e as figuras retóricas utilizadas e o chamamento enfático destes textos à adesão ao projeto político das reformas educacionais.

\section{De Discursos e de Verdades: a memória discursiva dos professores refletida em seu interdiscurso}

O presente relato se baseia em uma situação singular de docência no Vale do Jequitinhonha, permitindo à professora a discussão de tópicos que considerava importantes para gerar reflexões críticas para o magistério. Esta prática de ensino propiciou pensar a linguagem por uma visão politizada e crítica ao tratar do discurso empregado nos textos para as políticas para a educação e de como tal discurso era absorvido por seus alunos.

Ainda procurou-se apreender como a própria fala desses professores-alunos era "atravessada por fragmentos dispersos de outros discursos (interdiscurso)" (Coracini, 2007, p. 209). Fragmentos estes compostos de múltiplas vozes que impregnavam suas memórias discursivas. Foi possível notar, no seu dizer, um fio de interdiscurso, inconscientemente adotado e já tomado como um regime de verdade que passou a ser verdadeiro e a ser defendido como a única via para o desenvolvimento dos alunos como pessoas humanas e integrais, aptas ao mercado de trabalho.

Esse interdiscurso e suas vozes provenientes das políticas públicas, torna-se consoante ao que Foucault (1996) entende como regimes de verdade. Dentre essas verdades, percebe-se a voz de um tipo de discurso que faz do magistério instrumento ideologizante das reformas educacionais e dos professores seus porta-vozes. Esse processo reflete-se no imaginário dos professores e gera sua naturalização, fazendo com que esse discurso outro passasse a ter "um valor de verdade" e ganhasse "status de 
necessidade" (Coracini, 2007, p. 210). Sendo necessário, na visão de Foucault (1996), torna-se aceito como verdadeiro e, assim, controla, persuade e regula sem, contudo, impor-se como obrigatório. E, logo, constitui-se "um batalhão móvel de metáforas, metonímias [...] que são enfeitadas e, que, após longo uso, parecem a um povo sólidas, canônicas e obrigatórias" (Nietzsche, 1966, p. 46 apud Eckert-Hoff, 2008, p. 50). Desta feita, os professores legitimam um discurso que, não necessariamente, é seu.

Geralmente, os professores são reportados como aqueles responsáveis "pelo sucesso ou fracasso de seus alunos, o que alimenta o imaginário idealizado de que o professor é missionário, a serviço de outros" (Coracini, 2007, p. 243). Além desse caráter missionário, congregam uma "elite simbólica" (Van Dijk, 2008a) que tem como função desempenhar um "papel essencial de dar sustentação ao aparato ideológico que permite o exercício e a manutenção do poder em nossas modernas sociedades [...]" (Van Dijk, 2008a, p. 46). Essa elite simbólica, representada por professores, jornalistas, economistas, acadêmicos, escritores etc., se apropriam de um capital simbólico (como discutido por Bordieu e Passeron, 1977 apud Van Dijk, 2008a, p. 45) e influem a agenda de discussão pública, os editoriais de jornais e as revistas, isto é, influenciam o padrão de conhecimento de uma dada sociedade (Van Dijk, 2008a). Ao mesmo tempo, tem acesso aos discursos públicos e, de certa forma, controlam a reprodução discursiva na sociedade ao intermediarem as relações sócio-discursivas entre aqueles que detêm o poder e a população em geral (Van Dijk, 2008a).

Os indivíduos, sempre controlados pelo discurso e não totalmente livres para falarem ou escreverem o que querem, pois existem leis, normas e códigos a serem seguidos, sofrem com o controle difuso de mentes que é sutil, persuasivo, manipulativo e doutrinário. Este controle delineia "opiniões, atitudes, ideologias", "conhecimento, valores" pelo discurso (Van Dijk, 2008a, p.20). Nesse ínterim, a educação cumpre um papel crucial por seu poder simbólico de influenciar mentes e doutrinar consoante as ideologias de grupos dominantes. Consequentemente, não leva os alunos a serem críticos no tocante à realidade à sua volta. Van Dijk (2008a) assinala que, na maioria das vezes, os envolvidos não notam as nuanças desse tipo de influência.

Como parte dessa elite simbólica, os professores apóiam o discurso ideológico dominante e não se dão conta que argumentam em prol de sua manutenção e de sua afirmação. Essa "forma de influência pode ser muito mais difusa, complexa, global, contraditória, sistemática e quase não percebida por todos os envolvidos" (Van Dijk, 2008a, p. 21-22). Normalmente, os professores estão convencidos da validade do que 
ensinam e, por vezes, persuadem, seduzem, doutrinam e manipulam mentes sem se aperceberem da afiliação a que estão se ligando (Van Dijk, 2008a).

Tal observância se faz fundamentada nos princípios da pedagogia crítica e dos ECD com objetivos voltados à condução de um magistério engajado. Van Dijk (2008b) afirma que ao lado do discurso político e midiático, o discurso da educação e da pesquisa, em termos ideológicos, é o mais influente na sociedade. Por esse motivo, a análise e a discussão sobre esse universo procedem, pois este, muitas vezes, reproduz a ideologia oficial. Por assim dizer, os itens lexicais e as metáforas contidas no uso linguístico e nos eventos e gêneros discursivos, por exemplo, precisam ser analisados para se entender o modo de dominação e influência ideológica por que passa a educação e os professores.

\section{De Lapidações e de Discursos: as novas exigências estruturais para a educação}

Transformações nas últimas décadas, nas esferas econômica, política e sóciocultural das nações vêm sendo delineadas por um processo de reorganização do sistema capitalista que se faz a partir da internacionalização do capital e da sua reestruturação produtiva. Essa conjuntura, primordialmente tecnológica, permite aos conglomerados empresariais ampliarem sua influência nos setores da economia e da política, suplantando, inclusive, os Estados-nações (Bruno, 1997). Esta estrutura de poder possui articulações nos centros de decisão internacionais, tais como, o Banco Mundial, o FMI, o BID e os governos das potências mundiais (Bruno, 1997, p. 22-23).

Há alguns anos atrás, o Estado se encarregava da organização e do comando da economia quanto às condições gerais de produção e de controle social (Bruno, 1997). Atualmente, as grandes empresas tomam para si essa função; sobretudo a de selecionar no mercado o tipo de mão-de-obra desejável, prescindindo-se de um significativo exército de reserva com qualificações específicas ${ }^{27}$. Soma-se que o cenário mundial tem sido

${ }^{27}$ Entende-se aqui qualificação como a capacidade de realizar tarefas condizentes com as exigências do novo padrão tecnológico e da nova forma de organização do trabalho. As competências requeridas aludem a uma maior qualificação da classe trabalhadora que passa por um deslocamento do foco de exploração do seu componente físico (muscular) para o intelectual para exercer seu trabalho. De acordo com Bruno (1996), esse é o elemento fundamental da nova reestruturação do trabalho e do capital. Nesse contexto, determinadas habilidades são requeridas como, os traços de educabilidade, de adaptabilidade, de multifuncionalidade, a capacidade de aprender a aprender, as habilidades relacionais e técnicas como, por exemplo, a "facilidade de comunicação, de compreensão de textos, de raciocínio abstrato" etc. (Bruno, 1996, p. 92-93). 
alterado de maneira acentuada pelos efeitos da globalização, principalmente para os indivíduos que se vêem diante de uma lógica de mercado que fragmenta o trabalho e precariza a classe trabalhadora ${ }^{28}$.

"É cada vez mais a capacidade de pensar do trabalhador que se busca explorar. E não é qualquer forma de pensar, por isso, trata-se de disciplinar a estrutura psíquica dos trabalhadores, para que seu raciocínio desenvolva-se primordialmente, consoante a 'cultura organizacional' da empresa e, sua subjetividade opere no sentido de envolvê-lo com os objetivos da organização" (Bruno, 1997, p. 39).

\section{A década de 90 foi emblemática nesse sentido. As reformas educacionais vieram} no bojo das mudanças no âmbito produtivo designadas aos países da América Latina e Caribe $^{29}$. Nesse momento, as escolas passaram a ser vinculadas ao mercado. Tais mudanças as levaram a ter um papel fundamental nesse novo paradigma produtivo

${ }^{28}$ Bruno (1996, p. 113-118) expõe essa nova lógica como uma reestruturação interna pela qual vem passando a classe trabalhadora: novos regimes de trabalho, novas formas de contratação chamadas flexíveis, precarização do trabalho, subcontratação, rebaixamento salarial e intensa exploração da maisvalia relativa. Além disso, há a formação de segmentos no interior da força de trabalho que estão sujeitos aos mecanismos de desvalorização e de exploração de sua capacidade de trabalho; o que, segundo a autora, a fragmenta e dificulta suas formas de luta e resistência. Os segmentos formados no seio da força de trabalho são: a) Os trabalhadores com qualificações complexas e estratégicas que têm relativa segurança no emprego, boas perspectivas de promoção e de aprimoramento profissional e direitos previdenciários. Atendem às expectativas de serem adaptáveis, multifuncionais e geograficamente móveis; b) Os trabalhadores em regime de tempo integral, com habilidades e atributos facilmente encontráveis no mercado, sendo menos especializados. Caracterizam-se por menor acesso a oportunidade de carreira, alta taxa de rotatividade e insegurança no emprego; c) Os trabalhadores com qualificações pouco valorizadas no mercado, em regime de tempo parcial, eventuais, com contratos de trabalho por tempo determinado, subcontratados, que têm ainda menos segurança de emprego que as outras categorias citadas. Geralmente, inserem-se na economia paralela quando desempregados e, d) Os desempregados (Bruno, 1996, p. 114-122).

${ }^{29}$ Os objetivos das reformas na década de 1990 perpassavam a situar a educação e o conhecimento no centro das estratégias de desenvolvimento mundiais. Buscou-se iniciar uma nova etapa de desenvolvimento educacional com mudanças na gestão escolar, com sua descentralização e ênfase na qualidade e na equidade. Queria-se melhorar os níveis de qualidade de aprendizado com a adoção de sistemas nacionais de avaliação, com o desenvolvimento de programas compensatórios de discriminação positiva e com a reforma curricular e a autonomia das escolas com um currículo adaptado às suas características. Ao longo das décadas de 80 e subsequentes, os ministros da educação dos países da América Latina e Caribe são convocados pela Unesco para realizarem os Promedlacs (Comitês Intergovernamentais do Projeto Principal de Educação na América Latina e Caribe). Os objetivos desses comitês referem-se a assegurar a escolarização das crianças em idade escolar, a oferecer uma educação mínima de 8 a 10 anos e a eliminar 0 analfabetismo antes do fim do século XX; pretendia-se também desenvolver e ampliar a educação dos adultos, melhorar a qualidade e a eficiência da educação através de reformas e princípios de equidade, de políticas educacionais inclusivas e de financiamento. Em 1990, acontece a Conferência Mundial de Educação para Todos em Jomtien/Tailândia, onde os organismos internacionais envolvidos (a Unesco, a Unicef, o Banco Mundial ,o PNUD, o BID e vários países e várias outras agências internacionais) reúnemse para discutir a reorientação do crédito internacional para as políticas educacionais com o intuito de melhorar a aprendizagem. Em 1993, ocorre a 24a - Reunião da Cepal, em Santiago/Chile com a convocação dos ministros da economia dos países envolvidos com o objetivo de colocar a educação no cerne das estratégias do desenvolvimento. Acreditava-se que certos fatores seriam o mecanismo para 0 desenvolvimento e para o crescimento econômico, como o investimento em educação e o crescimento sustentável. Cria-se que a educação era a única política pública capaz de responder às necessidades de desenvolvimento expressas no crescimento econômico e na integração social dessas nações (Casassus, 2001). 
(Maués, 2009), pois passam a formar indivíduos capazes de gestar as novas tecnologias. As escolas começaram a funcionar como uma das esferas de produção da capacidade de trabalho ${ }^{30}$ e a preparar os alunos para o mercado. A "lógica da aprendizagem muda das disciplinas para as competências, enquanto saber fazer" ("savoir-faire") (Maués, 2009, p. 291), isto é, muda para uma formação flexível e polivalente, adaptável às novas exigências. Essa tendência das escolas é denominada por Maués (2009, p. 304) de "pedagogia das competências" que alega que esta é uma maneira de conduzir os alunos a serem como indivíduos autômatos que respondem "às exigências mercantilistas, mas que não desenvolveram as capacidades críticas [...] como uma forma de emancipação". As escolas tornam-se, então, agências de preparação e de inserção eficientes no mundo produtivo; e esta "parece ser uma demanda a ser feita às escolas" (Maués, 2009, p. 287).

\begin{abstract}
"Como a esfera da produção passa a exigir competências superiores, associadas ao pensamento mais abstrato, à realização simultânea de tarefas múltiplas, à capacidade de tomar decisões e de solucionar problemas, à capacidade de trabalhar em equipe, ao desenvolvimento do pensamento divergente e crítico, a formação não pode se limitar a competências restritas ou aos desempenhos previstos nos antigos objetivos comportamentais. Os princípios do construtivismo e da perspectiva crítica são então associados a princípios eficientistas e a princípios do progressivismo como forma de projetar a formação de competências mais complexas, mas ainda assim marcadas pela formação de desempenhos" (Lopes, 2002, p. 394).
\end{abstract}

Todavia, estes não deveriam ser os objetivos das escolas. Segundo Paro (1999), as escolas ao gerarem a grande massa de trabalhadores para o mundo produtivo, colocam de lado sua função formativa; não preparam seus alunos para a crítica ao trabalho alienado, tampouco para questionarem as condições de exploração de trabalho e a ordem vigente (Paro, 1999).

\title{
6. Das chances reais de ganhar a aposta na borboleta: a voz dos discursos oficiais
}

Durante a disciplina, analisaram-se as recomendações pertinentes aos textos destinados ao ensino médio e à educação de modo geral; avaliou-se a tônica do discurso contida nas Leis de Diretrizes e Bases da Educação Nacional - Lei oㅜ 9.394/96, nos Parâmetros Curriculares Nacionais para o Ensino Médio - os PCNs, no Relatório da Comissão Internacional sobre a Educação no Século XXI para a UNESCO -

\footnotetext{
${ }^{30}$ As escolas, na visão de Bruno (1996; 1997) figuram-se numa das esferas de produção da capacidade de trabalho ao lado da família e do meio social.
} 
especialmente o texto intitulado Os Quatro Pilares da Educação ${ }^{31}$, de Jacques Delors e no Parecer CEB no 15/98. Os textos evidenciam a importância da educação na nova conjuntura e apontam seu papel nesse contexto; ainda, instigam a adesão dos professores na educabilidade de seus alunos e no auxílio à aquisição de habilidades relacionais e técnicas desejáveis para o trabalho, suscitando sua participação no projeto da pedagogia das competências (Bruno, 2006; Maués, 2009).

De acordo com Van Dijk (2008a, p.33), "a maioria das nossas ideologias são formadas discursivamente" e, por isso, fez-se necessário analisar os textos oficiais para que fosse possível verificar qual o tom do seu discurso político. Seu papel persuasivo fica evidente, pois atrai os professores para a empreitada de se lançarem ao novo projeto que se configura para a educação. Os textos buscam, dessa maneira, o sancionamento dos professores e sua adesão para a legitimação do discurso político como verdade (Foucault, 1996).

No corpo do texto da LDB verifica-se a orientação para a educação escolar vinculada ao mundo do trabalho e à prática social (artigo $1^{\circ}$, $\S 2^{\circ}$ ). O pleno desenvolvimento dos educandos, o seu preparo para o exercício da cidadania e a sua qualificação para o trabalho são mencionados no artigo $2^{\circ}$. 0 artigo $22^{\circ}$ assegura aos educandos uma formação comum, indispensável para que progridam no trabalho. $\mathrm{O}$ artigo $27^{\circ}$ estabelece que os conteúdos curriculares devam, de igual modo, orientar para o trabalho. No texto da LDB, o ensino médio trata da preparação para o trabalho e da adaptação flexível dos alunos às novas condições de ocupação; além de tocar no domínio dos princípios científicos e tecnológicos da produção moderna.

Os PCNs analisados em sala formam a carta de intenções do governo para o ensino médio e possuem um discurso híbrido ao citar às diretrizes curriculares para a educação e ao recomendar, simultaneamente, a inserção no mundo produtivo (Lopes, 2002), citando, inclusive, a revolução informática. Lopes (2002) salienta que os PCNS têm embutido, assim, um discurso que se quer instrucional e regulativo, pois funciona dentro de um território de influências sobre a produção do conhecimento e das práticas escolares como todo discurso oficial geralmente opera.

"O discurso pedagógico oficial formado pelos documentos oficiais é capaz de regular a produção, distribuição, reprodução, inter-relação e mudança dos textos pedagógicos legítimos, suas relações sociais de transmissão e

${ }^{31}$ Os quatro pilares da educação foram definidos neste relatório da UNESCO em 1996 e esteve sob a coordenação de Jacques Delors. A inclusão do texto na discussão em sala de aula deveu-se ao fato do Parecer $15 / 98$ conter a base teórica deste relatório. 
aquisição e a organização de seus contextos, redefinindo as finalidades educacionais da escolarização" (Lopes, 2002, p. 388).

No caso em questão, o texto dos PCNs é lido e interpretado nas escolas e ressignificado para o contexto atual. Este documento possui uma "série de mecanismos de difusão, simbólicos e materiais" (Lopes, 2002, p. 390) com o intuito de criar uma retórica discursiva favorável à sua implementação e de submeter a educação ao mundo produtivo. Logo, transforma os professores em executores de políticas públicas; já os alunos leva-os a atitudes em que se "auto-regulam e mobilizam seus conhecimentos de acordo com as performances solicitadas pelo mercado de trabalho" (Lopes, 2002, p. 394).

\begin{abstract}
"Pensar um novo currículo para o Ensino Médio coloca em presença estes dois fatores: as mudanças estruturais que decorrem da chamada "revolução do conhecimento", alterando o modo de organização do trabalho e as relações sociais; e a expansão crescente da rede pública, que deverá atender a padrões de qualidade que se coadunem com as exigências desta sociedade" (PCNs - ensino médio, 2000, p.6). (Grifos meus).
\end{abstract}

"O novo paradigma emana da compreensão de que, cada vez mais, as competências desejáveis ao pleno desenvolvimento humano aproximamse das necessárias à inserção no processo produtivo. Segundo Tedesco, aceitar tal perspectiva otimista seria admitir que vivemos "uma circunstância histórica inédita, na qual as capacidades para o desenvolvimento produtivo seriam idênticas para o papel do cidadão e para o desenvolvimento social". Ou seja, admitindo tal correspondência entre as competências exigidas para o exercício da cidadania e para as atividades produtivas, recoloca-se o papel da educação como elemento de desenvolvimento social" (PCNs - ensino médio, 2000, p. 11). (Grifos meus).

Percebe-se pela retórica do texto que se trata das competências requeridas do trabalhador, no caso específico dos alunos, para sua inserção no mercado produtivo, itens reafirmados tanto nos PCNS para o ensino médio quanto na LDB. Os quatro alicerces citados referem-se aos quatro pilares da educação apresentados no texto do Relatório para a UNESCO da Comissão Internacional sobre Educação para o Século XXI, coordenada por Jacques Delors, destacado adiante.

"É importante destacar, tendo em vista tais reflexões, as consideracões oriundas da Comissão Internacional sobre Educacão para o século XXI, incorporadas nas determinações da Lei no 9.394/96: a) a educação deve cumprir um triplo papel: econômico, científico e cultural; b) a educação deve ser estruturada em quatro alicerces: aprender a conhecer, aprender a fazer, aprender a viver e aprender a ser" (PCNs - ensino médio, 2000, p. 14). (Grifos meus) 
Os Quatro Pilares da Educação, propostos por Delors (2003), destacam os princípios de aprender a conhecer, aprender a fazer, aprender a viver juntos e aprender a ser. Aprender a conhecer significa dotar os educandos de uma cultura geral, contribuindo para a sua formação humana. Aprender a fazer conjuga a qualificação profissional com a participação em tarefas e em atividades que estimulem tomadas de decisão e a organização de eventos, criando competências para que se tornem aptos a enfrentar desafios e a trabalhar em equipe. Aprender a viver juntos refere-se à capacidade de compreender o outro, de criar respeito mútuo e de realizar projetos comuns; o que os instrumentaliza a gerir conflitos e a respeitar os valores do pluralismo e da diferença. Aprender a ser desenvolve suas personalidades e suas capacidades de autonomia, de discernimento e de responsabilidade pessoal e social perante sua comunidade e a sociedade.

Ao longo do Parecer 15/98, evidencia-se uma preocupação com a formação geral dos educandos e a sua formação para o trabalho, ou seja, com suas habilidades em se adequarem às exigências tecnológicas e produtivas. O texto inicia-se aludindo à inquietação presente na sociedade em relação ao ensino médio. Declara que o Parecer foi fruto de uma consulta a variadas fontes e conselheiros, sendo, portanto, de cunho democrático. Para isso, aponta a participação de instituições educacionais e produtivas no debate como, as universidades, o Fórum dos Conselhos Estaduais de Educação e o SENAI, demonstrando, assim, o amplo foro de discussão em que a elaboração do documento esteve envolvida. Também delineia diretrizes para que as escolas se adaptem às novas formas de organização do trabalho e a urgência de preparação dos educandos para esta nova demanda; isto se coaduna ao que Villarta-Neder (2009, p. 257-258) indica: “o significante 'Diretrizes' sugere de que lugar o documento enuncia. $\mathrm{O}$ das normas a serem seguidas".

De acordo com o Parecer o quadro da situação de desigualdades sociais e de atraso do país pode ser superado pela via educacional quando esta favorecer a inserção mais qualificada de seus alunos ao mercado. No transcurso do texto faz-se uma convocação aos agentes educacionais e afirma-se o dever imperativo destes contribuírem para tal projeto, mesmo diante de condições precárias de trabalho docente. Aqui divisa-se a imagem vocacional e missionária que sempre se destinou ao magistério (Chamon, 2005). Como reforço a esse discurso que convoca ao sacrifício e à participação, o Parecer ressalta três itens essenciais para que a prática pedagógica esteja coerente com as demandas que se fazem: a estética da sensibilidade, a política da igualdade e a ética 
da identidade, itens que também constam no Relatório da Reunião da Educação para o Século XXI da UNESCO e nas bases dos Quatro Pilares da Educação de Delors.

"O esforço doutrinário se justifica porque a superação desse estado crônico de carências requer clareza de finalidades, conjugação de esforços e boa vontade para superar conflitos, que só a comunhão de valores pode propiciar" (Parecer 15/98). (Grifos meus).

A estética da sensibilidade estimula a criatividade e a afetividade e valoriza a leveza, a delicadeza e a sutileza, contrariamente ao período produtivo em que eram exigidas habilidades manuais para operar maquinários. A política da igualdade significa 0 "reconhecimento dos direitos humanos e o exercício dos direitos e deveres da cidadania, como fundamento da preparação do educando para a vida civil" (Parecer 15/98). A ética da identidade se faz pelo reconhecimento e respeito pelo outro.

O Parecer usa a metáfora da borboleta para referir-se à aposta incisiva que os professores têm que fazer relativo a seus alunos como potenciais humanos: "Ignorando que será uma borboleta que pode ser devorada pelo pássaro antes de descobrir-se transformada. O mundo vive um momento em que muitos apostam no pássaro. educador não tem escolha: aposta na borboleta ou não é educador". Este, segundo o Parecer, é o papel da educação como mediadora para a aquisição de conhecimentos e competências por parte dos educandos para o mundo do trabalho.

"Não é por acaso que essas mesmas competências estão entre as mais valorizadas pelas novas formas de producão pós-industrial que se instalam nas economias contemporâneas. Essa é a esperança e a promessa que o novo humanismo traz para a educação, em especial a média: a possibilidade de integrar a formação para o trabalho num projeto mais ambicioso de desenvolvimento da pessoa humana. Uma chance real, talvez pela primeira vez na história, de ganhar a aposta na borboleta" (Parecer 15/98). (Grifos meus).

\section{Das Vozes Advindas do Vale: o fio discursivo dos professores-alunos nas teias do discurso político para a educação}

A experiência no Vale do Jequitinhonha instigou a professora a procurar compreender como "as imagens que foram instituídas, historicamente, acerca do professor permanecem na memória discursiva desse sujeito e têm efeitos de poder" sobre seu próprio discurso (Eckert-Hoff, 2008, p. 93). As origens históricas do magistério e sua visão como atividade mais vocacional que profissional (Chamon, 2005) mostrou-se central 
para a percepção dos professores-alunos em relação aos discursos oficiais e a apropriação de sua retórica. Assim, a professora da disciplina reflete sobre a centralidade do assunto e sobre a adoção de um magistério mais engajado e mais politizado.

Durante a condução da disciplina, os professores-alunos apresentaram um discurso caracterizado pelo sentimento de doação ao magistério, demonstrando como o concebem como vocacional. Além disso, expuseram em suas falas um fio discursivo (Eckert-Hoff, 2008) impregnado de vozes provenientes do discurso político internacional regido pela nova ordem mundial que, conforme visto, combina-se às novas exigências para a classe trabalhadora e para a educação (Bruno, 1996). Desse modo, pôde-se distinguir certa afiliação ideológica que, como afirma Eckert-Hoff (2003, p. 291), é constituída "por palavras já-ditas" por outrem e por palavras não-ditas pelos professoresalunos, já que repetem discursos de outras vozes que trazem, inconscientemente, como se fossem suas. Configura-se, assim, o apagamento das vozes dos professores pelos textos oficiais, já que se apresentam modelares "para que os professores assumam tais concepções" (Villarta-Neder, 2009, p. 253) como verdade e passem a adotar tal retórica em defesa da promoção do projeto de reforma que se apresenta.

\footnotetext{
"Aparentemente, o Parecer parte do pressuposto de que as suas premissas e as do professor são as mesmas e que se resumem numa única. Entretanto, num mecanismo também de silêncio constitutivo do interdiscurso, esse silêncio, por ausência, entremeia-se com o silêncio por excesso do dizer impositivo do discurso institucional, legal" (Villarta-Neder, 2009, p. 259-260).
}

Na formação de seu imaginário, os professores-alunos viam-se como participantes de um projeto ambicioso e maior de formação de indivíduos "lapidados" como pessoas humanas e munidos de qualidades e competências valorizadas pelas economias contemporâneas. Entendiam a educação como importante nessa nova conjuntura, não visualizando como era evidente e recorrente em suas falas a centralidade das políticas das reformas educacionais.

A experiência evidenciou a imposição de um discurso político centralizado nas altas esferas de poder, que faz dos professores instrumentos eficazes e eficientes de execução e propagação do mesmo. Possibilitou igualmente verificar como o imaginário desses professores-alunos estava impregnado de ideologias (pré-)determinadas e prontas que os faziam porta-vozes de políticas voltadas à manutenção da educação como produtora de mão-de-obra a ser (in)gerida pelo mercado de trabalho. 


\section{Conclusão}

A experiência de docência no Vale do Jequitinhonha inseriu a professora em uma outra discursividade que não fosse somente aquela do ensino da língua inglesa, sua formação atual. Pensa-se que nenhum trabalho é desconectado das histórias de vida dos sujeitos (Silva, 2001). Dessa forma, sua primeira formação acadêmica foi essencial para dar-Ihe uma visão mais crítica do contexto político e econômico que envolvia (e envolve) o magistério. A possibilidade de lecionar a disciplina a permitiu discutir assuntos que vinha a tempos refletindo e estudando. A experiência também auxiliou na sua formação como profissional crítica e responsável, uma vez que pôde suscitar uma discussão pela via transdisciplinar e contribuir para a formação de outros profissionais da educação.

Sua intenção foi suscitar uma abordagem reflexiva para a disciplina de modo a cooperar para a conscientização dos professores-alunos sobre o jogo discursivo implícito no discurso dos textos políticos para a educação. Buscou-se explicitar a "ordem do discurso" (Foucault, 1996) nesses textos que propiciava um matiz de verdade aos mesmos. Ao mesmo tempo, tentou-se salientar como a retórica adotada por esses textos os levava a aderirem ao projeto político gestado para as reformas educacionais em vistas a servirem às demandas do capital.

Outro ponto considerável foi discutir o papel contra-hegemônico que os professores poderiam se dispor e sobre sua resistência ao projeto político-ideológico de reprodução de poder, de reprodução das classes dominantes e dominadas e de manutenção da ordem das coisas (Gramsci, 1978 apud Uyeno, 2009). A análise dos textos políticos se colocou como uma perspectiva reflexiva para os professores-alunos e evidenciou "o sequestro de seus papéis de intelectuais, o que reflete a alienação pela divisão social do trabalho, reduzindo-os a meros executores de tarefas que Ihes foram pré-determinadas" (Uyeno, 2009, p. 100).

A adesão inconteste às políticas educacionais revelou que as vozes docentes advindas do Vale reproduziam e referendavam o discurso político para a educação, visto que o entendiam como diretrizes a serem seguidas sem, contudo, adotarem uma postura crítica. Pela disciplina ministrada, entendem como a retórica discursiva dos textos oficiais já fazia parte de sua própria retórica e como já estavam trabalhando em prol de sua implementação e aceitação dentro das escolas. Na verdade, enxergavam os textos como documentos que determinavam procedimentos a serem seguidos e, isto conferia a eles o status de transmissores das ideologias políticas das reformas produtivas. 
"No jogo do interdiscurso, há uma voz que parece ser participativa, democrática, uma voz que propõe uma avaliação compartilhada, 'transparente' para os sujeitos envolvidos"; porém, "instaura um lugar discursivo de onde não se concebe uma participação efetiva, mas uma obediência a princípios previamente estabelecidos" (Villarta-Neder, 2009, p. 257).

Dessa maneira, a professora acredita que a vivência de ensino/aprendizagem no Jequitinhonha exprimiu uma conscientização crítica e reflexiva por parte dos professoresalunos derivando uma nova visão de mundo e um novo posicionamento político. $\mathrm{Na}$ acepção da professora, a discussão foi crucial para mostrá-los sua "responsabilidade social" e a importância de serem "conscientes do seu próprio discurso (e de qualquer ação pública)" (Van Dijk, 2008a, p. 34).

A região do Vale do Jequitinhonha é considerada uma das mais pobres de Minas Gerais e figura-se numa das mais estagnadas econômica e socialmente. Nessa região predominam os mecanismos de mais-valia absoluta, com a intensificação de trabalhos simples, sem maiores qualificações dos trabalhadores. Além disso, há uma falta histórica de interesse pela região como pólo industrial que não gera desenvolvimento para as populações locais. O que indica uma estagnação da produtividade e da tecnologia e o agravamento da exploração de trabalho, fatores bastante preocupantes. A inserção precoce de crianças e jovens adolescentes no processo produtivo, afastando-os da formação escolar direciona-os a constituírem mais tarde o exército de reserva desqualificado para o mercado de trabalho e para o subemprego, conformando, mais uma vez, a região a um círculo vicioso de estagnação que revitaliza o grande bolsão de miséria já existente e o acirramento da exploração do trabalho pela mais-valia absoluta.

Além dessas considerações, pensa-se ser de grande valia incrementar discussões e reflexões no contexto de ensino das línguas estrangeiras para se incentivar uma prática docente mais politizada e mais crítica, complementando-se ao ensino de práticas linguísticas e de ensino de línguas.

"Praticar a reflexão constitui um passo fundamental para que o profissional não seja um mero operário a desempenhar seu ofício, mas, sim, o responsável pelo seu saber, resultante do seu pensar. Formar o professor de maneira reflexiva possibilitaria seu envolvimento no conhecimento e desenvolvimento de teorias de ensino e na compreensão de sua prática, bem como promoveria uma base para avaliações, tomadas de decisões e transformações" (Villarta-Neder, 2009, p. 158).

\section{Referências bibliográficas}


BRASIL. Lei 9.394, de 20 de dezembro de 1996. Estabelece as Diretrizes e Bases da Educação Nacional. Diário Oficial da União. Brasília, DF, 23 dez. 1996.

. Ministério da Educação. Secretaria de Educação Média e Tecnológica.

Parâmetros curriculares nacionais: ensino médio. Brasília: MEC/SEMTEC, 2000.

BRASIL/CNE/CEB. Parecer no 15 de 01/06/98. Diretrizes Curriculares Nacionais para o

Ensino Médio. Relatora: Guiomar Namo de Mello.

BRUNO, L. Educação, qualificação e desenvolvimento econômico. In: Bruno, L. (Org.). Educação e Trabalho no Capitalismo Contemporâneo: leituras selecionadas. São Paulo: Atlas, 1996. p. 91-123.

. Poder e administração no capitalismo contemporâneo. In: OLIVEIRA, D. A. (Org.). Gestão democrática da educação: desafios contemporâneos. Petrópolis, RJ: Vozes, 1997. p. 15-45.

CASASSUS, J. A Reforma Educacional na América Latina no Contexto de Globalização. In: Cadernos de pesquisa, n. 114, novembro/2001, p. 07-28, São Paulo: Fundação Carlos, Chagas.

CELANI, M. A. A. Transdisciplinaridade na Lingüística Aplicada no Brasil. In: SIGNORINI, I.; CAVALCANTI, M. C. (Orgs.) Lingüística aplicada e transdisciplinaridade: questões e perspectivas. Campinas, SP: Mercado de Letras, 1998. p. 129-142.

CHAMON, M. Trajetória de feminização do magistério: ambigüidades e conflitos. Belo Horizonte: Autêntica; FCH-FUMEC, 2005. 179p.

CORACINI, M. J. A celebração do outro: arquivo, memória e identidade: línguas (materna e estrangeira), plurilingüismo e tradução. Campinas, SP: Mercado de Letras, 2007. 247p.

DELORS, J. Educação: um tesouro a descobrir. $2^{2}$ ed. São Paulo: Cortez Editora; Brasília, DF: MEC/UNESCO, 2003. p. 89-102.

ECKERT-HOFF, B. M. A denegação como possibilidade de "captura" do não-um no tecido do dizer. In: Coracini, M. J. (Org.). Identidade \& discurso: (des)construindo subjetividades. Campinas, SP: Editora da Unicamp; Chapecó, SC: Argos Editora Universitária, 2003. p. 285-302.

Escrituras de si e identidade: o sujeito-professor em formação. Campinas, SP: Mercado de Letras, 2008. 152p.

FOUCAULT, M. A Ordem do Discurso. São Paulo: Edições Loyola, 1996.

LOPES, A. C. Os parâmetros curriculares nacionais para o ensino médio e a submissão ao mundo produtivo: o caso do conceito de contextualização. In: Revista Educ. Soc., Campinas, SP, vol. 23, n. 80, setembro/2002, p. 386-400.

MACHADO, A. M. N. Do modelo ao estilo: possibilidades de autoria em contextos acadêmico-centíficos. In: KALIL, E. (Org.). Trilhas da escrita: autoria, leitura e ensino. São Paulo: Cortez, 2007. p. 171-207.

MAUÉS, O. C. O papel da escola na construção dos saberes e os limites da noção de competências. In: FERREIRA, E. B.; OLIVEIRA, D. A. (Orgs.). Crise da escola e políticas educativas. Belo Horizonte: Autêntica, 2009. p. 287-307.

McLAREN, P. Uma pedagogia da possibilidade: reflexões sobre a política educacional de Paulo Freire. In memoriam Paulo Freire. In: FREIRE, A. M. A. A pedagogia da libertação em Paulo Freire. São Paulo: UNESP, 1999. p. 179-196.

MICCOLLI, L. Ensino e aprendizagem de inglês: experiências, desafios e possibilidades. Col. Novas Perspectivas em Lingüística Aplicada. vol. 2. Campinas: Pontes Editores, 2010. 280p.

MOITA LOPES, L. P. Por uma lingüística aplicada INdisciplinar. (Org.). São Paulo: Parábola Editorial, 2006. 279p.

A transdisciplinaridade é possível em Lingüística Aplicada?. In: SIGNORINI, I.; CAVALCANTI, M. C. (Orgs.) Lingüística aplicada e transdisciplinaridade: questões e perspectivas. Campinas, SP: Mercado de Letras, 1998. p. 113-128. 
PARO, V. H. Parem de preparar para o trabalho!!! Reflexões acerca dos efeitos do neoliberalismo sobre a gestão escolar e sobre o papel da escola básica. In: FERRETI, C. J. et al. Trabalho, formação e currículo: para onde vai a escola. São Paulo: Xamã, 1999. p. 101-120.

PENNYCOOK, A. A Lingüística Aplicada dos anos 90: em defesa de uma abordagem crítica. In: SIGNORINI, I.; CAVALCANTI, M. C. (Orgs.) Lingüística aplicada e transdisciplinaridade: questões e perspectivas. Campinas, SP: Mercado de Letras, 1998. p. 23-49.

. Uma lingüística aplicada transgressiva. In: MOITA LOPES, L. P. da. (Org.). Por uma lingüística aplicada INdisciplinar. São Paulo: Parábola Editorial, 2006. p. 67-83.

SIGNORINI, I. Do residual ao múltiplo e ao complexo: o objeto da pesquisa em Lingüística Aplicada. In: SIGNORINI, I.; CAVALCANTI, M. C. (Orgs.) Lingüística aplicada e transdisciplinaridade: questões e perspectivas. Campinas, SP: Mercado de Letras, 1998. p. 99-110.

SIGNORINI, I.; CAVALCANTI, M. C. (Orgs.) Lingüística aplicada e transdisciplinaridade: questões e perspectivas. Campinas, SP: Mercado de Letras, 1998. p. 99-110.

SILVA, A. F. G da. Pedagogia como currículo da práxis. In: FREIRE, A. M. A. (Org.). A pedagogia da libertação em Paulo Freire. São Paulo: UNESP, 2001. p. 33-38.

UYENO, E. Y. O letramento do professor e a transformação em Gramsci e Foucault. In: BERTOLDO, E. S. (Org.). Ensino e aprendizagem de línguas e a formação do professor: perspectivas discursivas. São Carlos, SP: Claraluz, 2009. p. 91-105.

VAN DIJK, T. A. Discurso e poder. São Paulo: Contexto, 2008a. 285p. (Org.). Racismo e discurso na América Latina. São Paulo: Contexto, 2008b.

383p.

VILLARTA-NEDER, M. A. Advinha como vou te avaliar: silêncios no discurso oficial sobre avaliação. In: BERTOLDO, E. S. (Org.). Ensino e aprendizagem de línguas e a formação do professor: perspectivas discursivas. São Carlos, SP: Claraluz, 2009. p. 247-263.

NOVAS TECNOLOGIAS E ENSINO DE LÍNGUAS: RELAÇÕES ENTRE O "DIZER" E O "FAZER" DE DOCUMENTOS GOVERNAMENTAIS DE REFERÊNCIA PARA O ENSINO DE LÍNGUAS

NEW TECHNOLOGIES AND TEACHING LANGUAGES: THE RELATIONSHIPS BETWEEN THE "SAID" AND THE "DONE" OF THE GOVERNMENTAL DOCUMENTS FOR TEACHING LANGUAGE

Lara Brenda Campos Teixeira Kuhn (UFU)

larakuhn@ymail.com

RESUMO: Com este artigo pretendo problematizar o "dizer e o fazer" de documentos de referência para o ensino de línguas e suas relações com o modelo pedagógico do curso de língua francesa on-line Reflets-Brésil, presente no site FrancoClic. O site surgiu de uma parceria entre o MEC e a Embaixada da França, para atender pessoas interessadas no ensino e aprendizagem da língua francesa. Para tanto, discuto as concepções de língua, ensino, aprendizagem e a utilização das novas tecnologias do curso Reflets-Brésil. $\mathrm{Na}$ sequência, relaciono as concepções subjacentes ao modelo pedagógico do curso (fazer) aos princípios dos PCN de línguas estrangeiras e do Quadro Europeu Comum de Referência para o Ensino de Línguas (dizer). Minhas principais críticas recaem sobre 
algumas incoerências entre a incorporação das TIC como inovação das técnicas de educação. E, ainda, sobre o contra-senso existente entre o "dito" sobre o ensino e aprendizagem de línguas, em documentos governamentais de referência para o ensino de línguas e, o que está sendo "feito" em cursos de línguas on-line. Em relação ao curso Reflets-Brésil e os "dizeres" dos documentos dos países envolvidos em sua elaboração, percebo que existe uma dissonância quanto aos propósitos apresentados por eles e o curso.

PALAVRAS-CHAVE: PCN; Quadro Europeu Comum de Referência; Novas Tecnologias.

ABSTRACT: I intend to discuss the "said and done" of the language teaching reference documents and their relationship to the pedagogical model of the Reflets-Brésil, French language online course. My main criticism is on some inconsistencies between the incorporation of News Technologies as an innovation of educational techniques. And yet, on the nonsense that exists between "said" about languages learning in reference governmental documents and what is being "done" in language courses online. About the Reflets- Brésil course and "said" of the language teaching reference documents of the countries involved in its drafting, I comprehend that there is a dissonance on the purposes and the documents submitted by the course.

KEYWORDS: PCN; Common European Framework of Reference; New Technologies.

\section{Introdução}

O site FrancoClic é um veículo de divulgação da Língua Francesa, criado por meio de uma parceria entre o Ministério da Educação (MEC) e a Embaixada da França no Brasil. Segundo a descrição, na página inicial, é "destinado particularmente aos alunos e professores interessados na aprendizagem e no ensino da língua francesa e das culturas francófonas". É um site composto por um curso de autoaprendizagem: Reflets-Brésil; por módulos de utilização em sala de aula: Br@nché!; módulos de especialidade agrícola: Agriscola e de descoberta: le monde francophone d'un clic, como representados na Figura 1. 


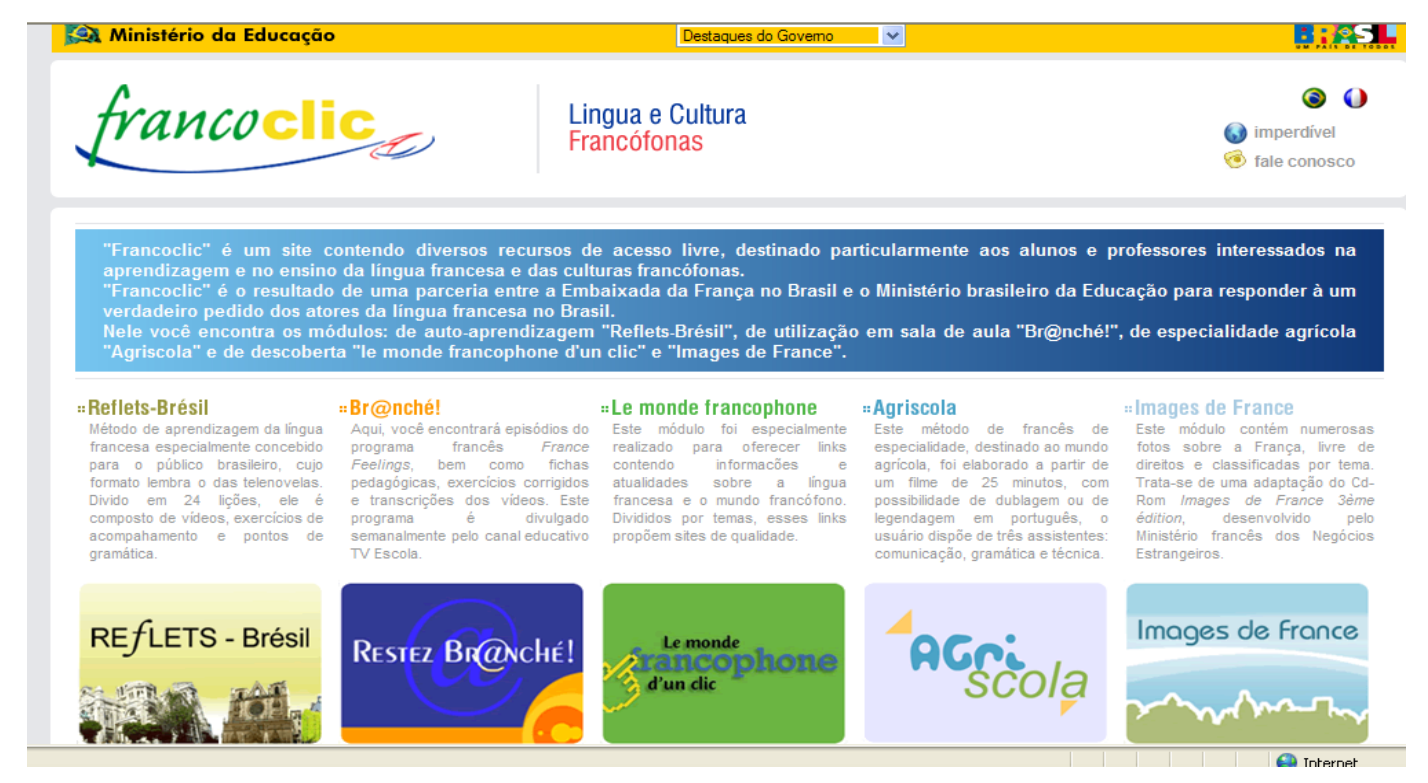

Figura 1: Tela inicial do site FrancoClic

O foco deste artigo é o curso Reflets-Brésil que se divide em vinte e quatro lições, acompanhadas de vídeos cujo formato lembra o de telenovelas. Por se tratar de um curso de autoaprendizagem, não há uma duração determinada, sendo o aprendiz quem define como estudar as lições, de acordo com suas preferências. Os espaços interativos permitem consulta a links que servem de suportes pedagógicos, tais como dicionários e gramáticas. As línguas francesa e portuguesa mediam a comunicação. É um curso livre e gratuito, sendo necessário para sua realização apenas conectar-se à internet e acessar o site do curso.

É certo que a iniciativa de se criar um curso de línguas on-line como o RefletsBrésil vai ao encontro dos objetivos da Secretaria de Educação a Distância do Brasil (SEED), que tem por objetivo atuar "como um agente de inovação tecnológica nos processos de ensino e aprendizagem, fomentando a incorporação das tecnologias de informação e comunicação (TIC) e das técnicas de educação a distância aos métodos didático-pedagógicos" (BRASIL, 2006). No entanto, minhas críticas recaem sobre algumas incoerências sobre a incorporação das TIC como inovação das técnicas de educação. E, ainda, sobre o contra-senso existente entre o "dito" sobre o ensino e aprendizagem de línguas, em documentos governamentais de referência para o ensino de línguas, e o que foi "feito", ou seja, o encontrei no curso.

Tanto os PCN de Línguas Estrangeiras quanto o Quadro Europeu Comum de Referência para as Línguas - Aprendizagem, Ensino, Avaliação ${ }^{32}$ (QECR) são 
documentos, que trazem uma nova concepção de ensino e aprendizagem de línguas estrangeiras. São referenciais de ensino e aprendizagem que prezam pela língua como um instrumento de comunicação, uma comunicação para vida, que leva em conta vários aspectos relacionados ao ato comunicativo. Dão o devido valor ao ensino normativo da língua, porém não o encerram à prescrição de regras e a manipulação de comportamentos.

Os PCN de Línguas Estrangeiras afirmam que o objetivo de se conhecer e usar uma língua estrangeira é fazer dela um instrumento de acesso a informações e outras culturas (BRASIL, 2000). Isso quer dizer que o ensino de línguas estrangeiras não deve restringir-se à prescrição de modelos gramaticais, nem destacar a norma culta e a modalidade escrita da língua (BRASIL, 2010, p. 28). Discute, ainda, que o desenvolvimento da competência gramatical não é suficiente para que o aprendiz entenda e se faça entendido, ela é uma das competências entre tantas outras importantes competências necessárias no ato comunicativo. Além da capacidade de compor frases, é preciso saber adequar os enunciados ao contexto de produção.

\section{As relações entre o curso Reflets-Brésil e os documentos governamentais}

Mesmo todos os recursos técnicos, informáticos e metodológicos do curso estando voltados para uma apresentação agradável de aspectos culturais, interação entre as personagens e entre os apresentadores do curso, nele o aprendiz não tem espaço para criar, agir e conceber uma realidade que o proporcione uma formação mais abrangente e, ao mesmo, tempo sólida como sugerido pelos PCN de Línguas Estrangeiras (BRASIL, 2001, p.26).

Os recursos audiovisuais são utilizados para apresentar ao aprendiz (objetivando, também, envolvê-lo com o tema estudado) um cenário, ou seja, um contexto de comunicação. A Figura 2 demonstra este aspecto, durante o vídeo do episódio. Nele pessoas encenam situações que poderiam ser comuns ao cotidiano do aprendiz. No entanto, uma das falhas recai sobre a mera exposição, o aprendiz não tem a oportunidade de colocar em prática o que lhe é exposto, pois as únicas atividades que compõem as

\footnotetext{
32 "O Quadro Europeu Comum de Referência (QECR) fornece uma base comum para a elaboração de programas de línguas, linhas de orientação curriculares, exames, manuais, etc., na Europa. Descreve exaustivamente aquilo que os aprendentes de uma língua têm de aprender para serem capazes de comunicar nessa língua e quais os conhecimentos e capacidades que têm de desenvolver para serem eficazes na sua actuação. A descrição abrange também o contexto cultural dessa mesma língua. O QECR define, ainda, os níveis de proficiência que permitem medir os progressos dos aprendentes em todas as etapas da aprendizagem e ao longo da vida" (CONSELHO DA EUROPA, 2001. p.19).
} 
lições requerem que ele demonstre a quantidade de aspectos linguísticos que fora capaz de assimilar, como demonstrado na Figura 3.

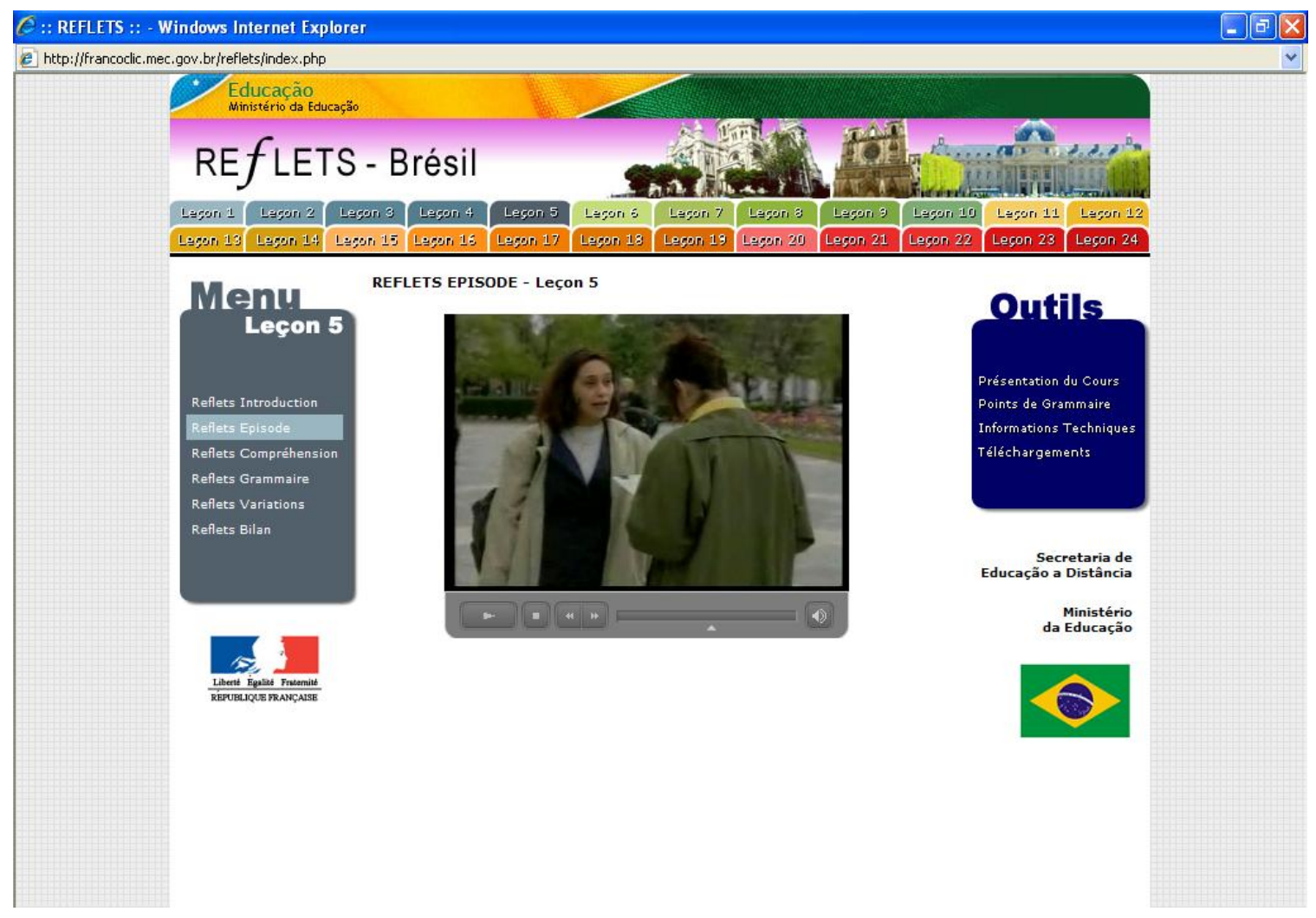

Figura 2: Trecho do vídeo do Reflets-Episóde

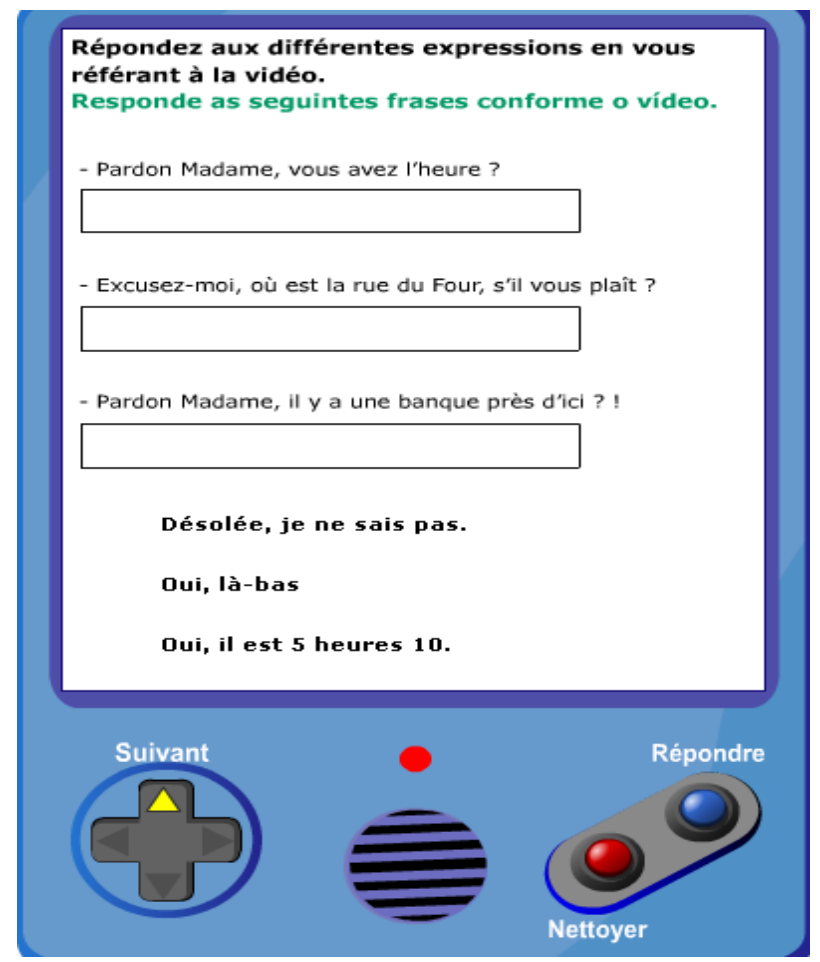

Figura 3: Atividade do Reflets-Episóde 
Outro aspecto importante, sobre o papel dos órgãos governamentais, para 0 modelo didático do curso Reflets-Brésil são as competências e habilidades delineadas pelos PCN a serem atingidas nos cursos de línguas (BRASIL, 2000, p.29).

Em síntese elas são sete:

1- Saber distinguir entre as variantes linguísticas;

2- Escolher o registro adequado à situação na qual se processa a comunicação;

3- Escolher o vocábulo que melhor reflita a ideia que se pretenda comunicar;

4- Compreender de que forma determinada expressão ser interpretada em função de aspectos culturais e/ou sociais;

5- Compreender em que medida os enunciados refletem a forma de ser, pensar, agir e sentir de quem os produz;

6- Utilizar os mecanismos de coerência e coesão na produção de Língua Estrangeira (oral e/ou escrita).

7- Utilizar as estratégias verbais e não verbais para compensar as falhas na comunicação, para favorecer a efetiva comunicação e alcançar o efeito pretendido.

Percebo que, mesmo havendo a predominância das concepções estruturalista de língua, de ensino e aprendizagem, o curso aproxima-se de algumas das almejadas habilidades e competências do documento, mas falha naquelas que requerem interação e produção, como as descritas pelos números 6 e 7 .

Em relação ao Quadro Europeu Comum de Referência para as Línguas Aprendizagem, Ensino, Avaliação, entre tantos aspectos, chama-me a atenção a visão de aprendiz no documento:

O aprendente da língua torna-se plurilingue e desenvolve a interculturalidade. As competências linguísticas e culturais respeitantes a uma língua são alteradas pelo conhecimento de outra e contribuem para uma consciencialização, uma capacidade e uma competência de realização interculturais. Permitem, ao indivíduo, o desenvolvimento de uma personalidade mais rica e complexa, uma maior capacidade de aprendizagem linguística e também uma maior abertura a novas experiências culturais (CONSELHO DA EUROPA, 2001, p.73). ${ }^{33}$

Trata-se de uma visão de aprendiz sob a concepção sóciointeracionista de ensino e aprendizagem de língua, em que aprender uma língua constitui-se um processo de construção de conhecimentos, fundado nas experiências advindas da interação (VYGOTSKY, 2001). No entanto, esta concepção não é aplicada ao curso, que é todo

${ }^{33}$ Citação idêntica ao original que se trata de uma versão do Português europeu. 
desenhado sem nenhuma interação entre pares. Existe no curso a intenção de aproximar o aprendiz aos aspectos culturais da França, como por exemplo, as encenações que contam com gravações na capital parisiense; a abertura das lições, que são marcadas com cenas do cotidiano francês; os apresentadores possuem "atitudes" parecidas com a de jovens franceses. Porém, tudo é apresentado passivamente ao aprendiz, ele não tem espaço, nem pares para compartilhar suas impressões.

Há, ainda, no documento europeu menção a atividades para o desenvolvimento de estratégias comunicativas que não requerem a interação, o que poderia justificar essa falta no curso Reflets-Brésil.

[...] quando o discurso é gravado ou transmitido, ou quando os textos são expedidos ou publicados, os que produzem estão separados dos que recebem, podem não se conhecer, ou pode nem sequer ter a possibilidade de responder. Nestes casos, o acontecimento linguístico pode ser entendido como dizer, escrever, ouvir ou ler um texto. Na maioria dos casos, o utilizador como falante ou escrivente produz o seu próprio texto para exprimir os seus próprios significados. Noutros, actua como um canal de comunicação (muitas vezes, mas não necessariamente, em línguas diferentes) entre duas ou mais pessoas que, por qualquer razão, não podem comunicar directamente. Este processo, a mediação, pode ser ou não interactivo (CONSELHO DA EUROPA, 2000, p.89).

No entanto, mesmo o documento destacando alguns traços de situações em que o aprendiz pode desenvolver estratégias comunicativas sem interação, o que pode vir ocorrer no curso Reflets-Brésil, não creio que esteja de acordo com as concepções de língua, ensino e aprendizagem subjacentes ao modelo pedagógico do curso. A meu ver, o cerne do QREC é a língua como um instrumento de comunicação sóciocultural. Mesmo que o aprendiz depare-se com atividades, por meio das quais ele não necessite de interação, para o desenvolvimento de estratégias comunicativas, ele precisa ter espaço para criação, o que não ocorre durante o curso Reflets-Brésil.

\section{Considerações}

Assim, o que percebi em relação ao Reflets-Brésil e os documentos PCN e QREC, é que existe certa dissonância quanto aos propósitos apresentados pelos documentos e o curso. Tanto as Tecnologias de Informação e Comunicação, como as atuais diretrizes para o ensino de línguas reclamam novos paradigmas educacionais, portanto é papel fundamental do Estado se comprometer em colocar em prática recursos que auxiliarão 
aprendizes a desenvolver suas competências comunicativas, também em cursos de línguas on-line.

Num mundo cada vez mais tecnológico, onde se requer a inclusão dos cidadãos, é responsabilidade do Estado prover com a melhor qualidade possível, o acesso a uma educação digital que de fato melhore e amplie capacidades e potencialidades do seu povo. Assim como nas palavras de Behar (2006) em relação aos novos paradigmas educacionais:

Será preciso dar foco à construção, à capacitação, à aprendizagem, a educação aberta e à distância, na gestão do conhecimento. Assim, conceitos como construção do conhecimento, autonomia, autoria, interação, construção de um espaço heterárquico, de cooperação, respeito mútuo, solidariedade; centrado na atividade do aprendiz, identificação e solução de problemas passam a ser os alicerces deste novo modelo que está emergindo (Behar 2006. p. 11).

Modelo esse que não deve fundamentar-se na manipulação de comportamentos e falta de espaços para produção. Cursos on-line como o Reflets-Brésil são instrumentos que podem ser utilizados como forma de contribuição para a educação linguística, no entanto creio na importância de mais pesquisas, esforços e comprometimento com a educação on-line para que, cursos como este instigue o desenvolvimento de capacidades comunicativas dos aprendizes, envolvendo todas as dimensões implicadas no processo, principalmente a interação.

\section{Referências}

BEHAR, P. A. (org.) Modelos Pedagógicos em Educação a Distância. Porto Alegre:

Artmed, 2009. 316 p.

BRASIL, Secretaria de Educação a Distância. Disponível em:

$<$ http://portal.mec.gov.br/index.php?option=com content\&view=article\&id=289\&ltemid=82 2>. Acesso em: 17 maio 2009.

. Parâmetros Curriculares Nacionais Ensino Médio. Disponível em:

<portal.mec.gov.br/seb/arquivos/pdf/blegais.pdf>. Acesso em: 24 jul. 2009.

CONSELHO DA EUROPA, Quadro europeu comum de referência para as línguas:

aprendizagem, ensino e avaliação. Disponível em: <http://www.dgidc.min-

edu.pt/recursos/Lists/Repositrio\%20Recursos2/Attachments/724/Quadro Europeu total.p df $>$. Acesso: 11 em jan. 2008.

VYGOTSKY, L. S. Pensamento e linguagem. São Paulo: Martins Fontes, 1993. 236 p. 


\title{
A RECONTEXTUALIZAÇÃO, A MULTIMODALIDADE E O HIBRIDISMO NA ABORDAGEM DOS GÊNEROS DO HUMOR
}

\section{THE RECONTEXTUALIZATION, MULTIMODALITY AND HYBRIDISM IN APPROACHING OF HUMOR GENRES}

\author{
Maria Aparecida Resende Ottoni (UFU) \\ cidottoni@gmail.com
}

RESUMO: Com o objetivo de contribuir para o debate sobre gêneros, apresento uma discussão de algumas questões que têm sido identificadas como fundamentais na abordagem dos gêneros, especialmente dos humorísticos, e que cada vez mais têm merecido a atenção de diferentes estudiosos/as. Neste artigo, focalizo o papel da recontextualização, da multimodalidade e do hibridismo na constituição desses gêneros.

PALAVRAS-CHAVE: recontextualização; multimodalidade; hibridismo; gêneros do humor. 
ABSTRACT: Aiming at to contribute for the debate on genres, I present a discussion of some subjects that have been identified as fundamental in the approach of the genres, especially of the humorous ones, and that more and more have deserved the attention of different researchers. In this article, I focus the importance of the recontextualization, multimodality and hybridism in the constitution of genres of humor.

KEYWORDS: recontextualization; multimodality; hybridism; genres of humor.

\section{Considerações iniciais}

Com o advento da televisão e, mais tarde, da internet, houve um crescimento considerável na produção do humor e uma mudança na forma dessa produção, do consumo e distribuição dos gêneros do humor (GHs). Consequentemente, houve também uma transformação nesses gêneros e o surgimento de novos gêneros, o que está relacionado a mudanças discursivas mais amplas no seio da sociedade contemporânea e a mudanças nas práticas sociais.

Nesse contexto de transformações, considero que é preciso que se discutam algumas questões fundamentais envolvidas na constituição dos GHs - não só deles -, tais como: a recontextualização, a multimodalidade e o hibridismo. Assim, neste artigo, apresento uma discussão introdutória dessas questões importantes para a abordagem dos gêneros.

Com isso, objetivo contribuir para o debate sobre o tema e apontar alguns aspectos que ainda precisam ser mais investigados com relação aos gêneros, especialmente dos humorísticos.

Este trabalho é oriundo de reflexões realizadas durante a produção de minha pesquisa de doutorado, desenvolvida no Ensino Fundamental em uma escola pública e voltada para a leitura crítica dos GHs. Essa pesquisa teve como principais bases teóricas os pressupostos da Análise de Discurso Crítica (FAIRCLOUGH, 2003; FAIRCLOUGH, 2001; CHOULIARAKI \& FAIRCLOUGH, 1999) e da Linguística Sistêmico-Funcional (HALLIDAY, 1978, 1989 E 1994; HALLIDAY \& MATTHIESSEN, 2004; BUTT et al., 2000).

\section{Diferentes questões envolvidas na abordagem dos gêneros do humor}

De acordo com Fairclough (2003), uma forma pela qual os gêneros diferem uns dos outros é quanto às tecnologias de comunicação para as quais eles são especializados, e um fator na mudança dos gêneros são os desenvolvimentos nessas tecnologias. Tais 
desenvolvimentos são acompanhados pelo desenvolvimento de novos gêneros, como, por exemplo, os 'formatos' na web, trazendo juntos gêneros que são tomados de outras tecnologias, como as entrevistas televisivas jornalísticas transformadas em gênero do humor em diferentes sites, e gêneros que têm se desenvolvido como parte da mudança tecnológica, como o e-mail. Isso, como já dito, está relacionado a transformações nas práticas sociais.

Fairclough considera que essas transformações são tanto manifestas nas mudanças no sistema de gêneros ${ }^{34}$ quanto em parte provocadas por tais mudanças.

Como Bakhtin teoriza, as limitações para a constituição dos gêneros são históricas e sociais e, como categorias históricas, eles são sujeitos a um processo de transformação contínua e sua estabilidade relativa é constantemente ameaçada por forças que atuam sobre as coerções genéricas. Essa visão de Bakhtin é básica ao estudo dos gêneros discursivos. Para ele, os estudiosos da linguagem deveriam sempre se preocupar com a construção de sentidos em relação a outros sentidos. Tudo isso está relacionado a questões importantes como: a recontextualização, a intermedialidade, a multimodalidade, a intertextualidade, a interdiscursividade e o hibridismo.

A recontextualização é um conceito desenvolvido na sociologia da educação (BERNSTEIN, 1996), que pode ser frutiferamente operacionalizado dentro da análise de discurso e texto (FAIRCLOUGH, 2003). Ela diz respeito à apropriação de elementos de uma prática social dentro de uma outra, colocando a primeira dentro do contexto da última e a transformando de formas particulares no processo (BERNSTEIN, op. cit.; CHOULIARAKI \& FAIRCLOUGH, 1999). Esse conceito significa, então, "o deslocamento, a apropriação, a relocação e o estabelecimento de relações com outros discursos em um contexto institucional particular" (MAGALHÃES, 2005, p. 235).

Pode-se dizer que a recontextualização e a intertextualidade imbricam-se, pois envolvem deslocamento, apropriação e relocação de materiais de um contexto para outro.

Fairclough (op. cit.), na sua abordagem do significado representacional, incorpora uma visão mais ampla da representação dos eventos sociais como recontextualização, segundo a qual ao se representar um evento social, entende-se que ele é incorporado ao contexto de um outro evento social, recontextualizando-o. Ele explica que campos sociais, redes de práticas sociais e gêneros particulares, como elementos de tais redes, têm

\footnotetext{
${ }^{34}$ Para Fairclough (2001, p. 161), o sistema de gêneros que é adotado em uma sociedade particular, em um tempo particular, determina em que combinações e configurações os tipos de atividade, estilo e discurso ocorrem. Ao se referir ao sistema de gêneros, o autor aplica o princípio da primazia das ordens de discurso: "uma sociedade - ou uma instituição particular ou domínio dentro dela - tem uma configuração particular de gêneros em relações particulares uns com os outros, constituindo um sistema. $E$, é claro, a configuração e o sistema estão abertos à mudança." (idem, p. 162).
} 
associados a eles 'princípios recontextualizadores' específicos (BERNSTEIN, op. cit.) e que a esses princípios subjazem diferenças entre os modos como um evento social particular é representado em diferentes campos, redes de práticas sociais e gêneros. De acordo com tais princípios recontextualizadores, os elementos dos eventos sociais são seletivamente 'filtrados'.

Em outras palavras, as escolhas para a representação de um evento e de atores sociais são feitas em função do campo social em que se situa o/a produtor/a da representação, do gênero produzido e das redes de práticas em que ele se situa. Isso significa que em um gênero humorístico, por exemplo, a representação de um evento social e de atores sociais não se dá da mesma forma que em um telejornal. O propósito de cada gênero influencia na seleção dos elementos e no modo como a representação se dá.

No que diz respeito aos gêneros humorísticos, essencialmente mediados ${ }^{35}$, observo que com o surgimento da internet tem havido, em grande escala, uma recontextualização de gêneros do humor existentes na oralidade, ou impressos em revistas, livros e gibis, ou veiculados pela televisão, bem como a recontextualização de gêneros outros, não-humorísticos, pelos sites de humor e pela televisão. Esse é o caso, por exemplo, das piadas antes só contadas oralmente e ou impressas em livros, revistas humorísticas e gibis, e agora veiculadas em sites de humor; das entrevistas produzidas nesses sites, como "Tobby entrevista" do sítio eletrônico www.charges.com.br ${ }^{36}$, que incorporam o gênero entrevista de programas televisivos de auditório; e dos esquetes do programa Casseta e Planeta, Urgente!, que trazem o gênero novela para a composição do programa de humor, satirizando principalmente as novelas da Rede Globo exibidas às 21 horas.

Nesse processo de recontextualização e em função de uma série de mudanças socioculturais, surgiram transformações nos gêneros já existentes e também nos enquadramentos desses gêneros. Navegando-se pelos diferentes sites humorísticos, pode-se perceber como são diversas as classificações para os gêneros do humor e como diferentes textos são agrupados sob a mesma designação. Para se ter uma idéia disso, veja parte da lista apresentada em três sites de humor:

\section{Humor Tadela}

\section{Charges.com.br Cia do Humor}

\footnotetext{
${ }^{35}$ A (inter)ação mediada é 'ação a distância', ação envolvendo participantes que estão distantes um do outro no espaço e/ou tempo e que depende de alguma tecnologia de comunicação.

${ }^{36}$ Charges.com.br é um site brasileiro de humor. Ele foi fundado por Maurício Ricardo Quirino, em 2000.
} 


\begin{tabular}{|c|c|c|c|}
\hline Animações & Molly & Home & Cúmulos \\
Charadas & Novelas & Arquivo de & Frases para \\
Charada & Piadas & Charges & carros \\
Animada & Piada & Cartões Virtuais & Pegadinhas \\
Charges & Animada & Charges-Okê & Provérbios \\
Charge & Quadrinhos & Cine Charges & A piada do mês \\
animada & Sátiras & Gifs de Futebol & Piada Visual \\
Classificados & Testes & Músicas & Piada Animada \\
Fotomontagens & Tiras & Mini-Sites & Quadrinhos \\
Horóscopo & Vestibular & Os Seminovos & Piadas \\
Imagens & Vídeos & Piada do Dia & \\
Jornal HT & & Top Charges & \\
\hline
\end{tabular}

Quadro 1: Lista com parte das opções oferecidas por três sites de humor

Como se pode ver, o leque de opções é diverso. São apresentados, por exemplo, três tipos de piadas: piadas, piada animada e piada visual; três tipos de charges: charges, charge animada, charges-okê. Por meio do acesso aos links referentes a cada item da lista, pode-se ver que aquilo que é denominado como animações, em um site, é, em outro, piada animada. Da mesma forma, o que em um site é considerado como uma fotomontagem equivale ao que, em outro, é uma piada visual; o que é novelas, em um, é cine charges em outro; o que é charge animada em um, é charge-okê em outro.

Certamente, essas classificações presentes nos sites são questionáveis. Como considerar, por exemplo, que animações é um gênero? $\mathrm{E}$ imagens, vídeos? Particularmente não concordo com tais classificações e entendo que alguns nomes que aparecem nas listas dos sites de humor podem ser entendidos como gênero, mas muitos não constituem um gênero.

Considerando que a preocupação dos responsáveis pelas classificações nos sites não é o gênero e considerando a importância dos estudos voltados para a abordagem dos diferentes gêneros que circulam na sociedade, julgo que o material ilustrado no quadro 1 constitui um interessante aspecto que ainda precisa ser investigado.

Além dessa questão da diversidade classificatória, nota-se, nos sites, que textos com características estruturais distintas, muitas vezes, são enquadrados sob o mesmo rótulo, como acontece com muitas piadas ${ }^{37}$. Nota-se ainda que muito do que antes não se considerava piada passou a ser apresentado como tal. É o caso das piadas visuais ${ }^{38}$. Veja um exemplo:

\footnotetext{
${ }^{37}$ Sobre isso, ver dissertação de Muniz (2004).

${ }^{38}$ Ver discussão sobre o gênero piada visual em Ottoni (2007).
} 


\section{$\left(\mathrm{PV}^{39}\right)$ Controle remoto humano}

\section{COMO SERIAM OS CONTROLES REMOTOS PARA SERES HUMANOS}
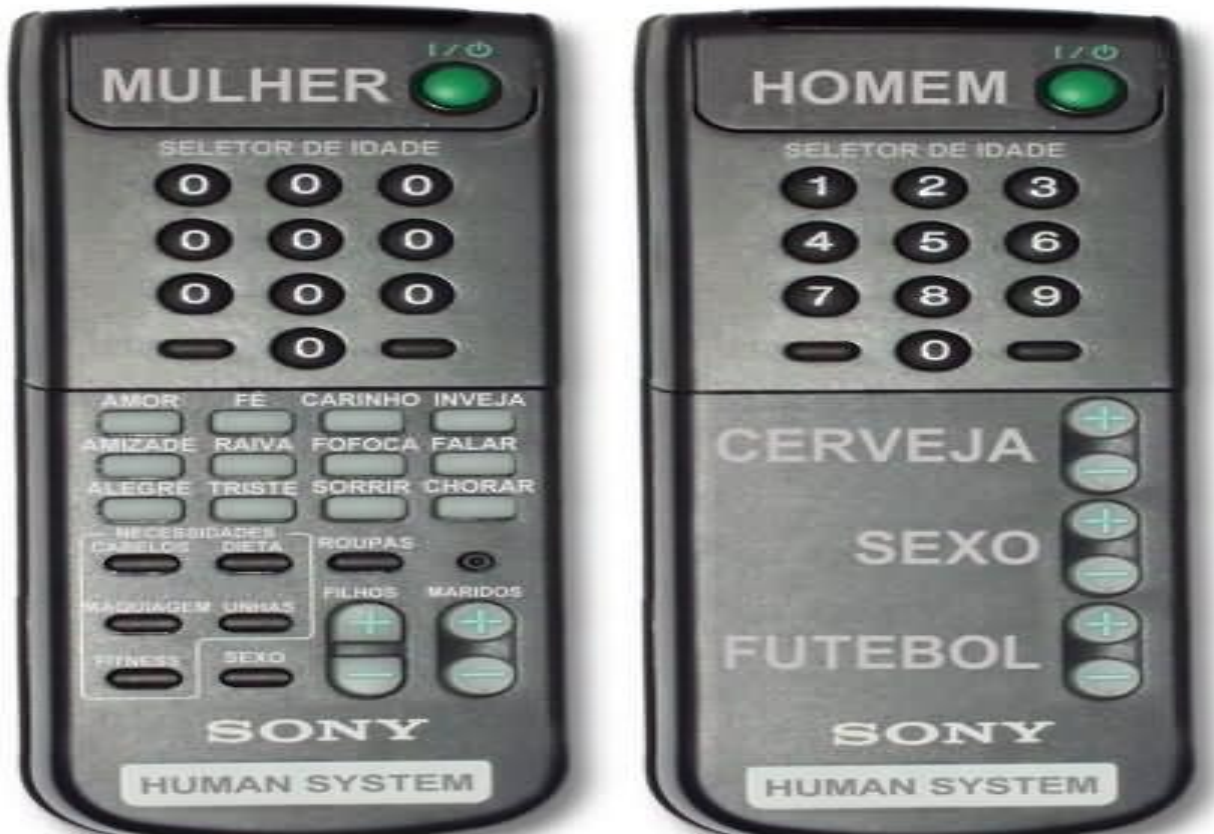

Categoria: Piadas Visuais

Autor: OraPois - O Site da diversão - (2004-01-23 09:48:38)

E é caso também de muitos outros textos que, mesmo não tendo os elementos estruturais obrigatórios do gênero piada ${ }^{40}$, são classificados como piadas em alguns sites, como este texto:

\section{(P) ORAÇÃO DA CPI}

Adauto Marin Molck/ Cosmo on line

SENHOR,

FAZEI-ME UM INSTRUMENTO DE VOSSA REELEIÇÃO...

ONDE HOUVER GORJETA, QUE EU LEVE UM MILHÃO,

EM CADA ENDEREÇO,

QUE VENÇA O MEU PREÇO,
QUANDO TOCAR O SINO, ME MANDE O GENOÍNO

SE MEXEREM NO MEU, QUE VENHA O DIRCEU

SE A PROPOSTA FOR CHULA, ME CHAME O LULA

ONDE HOUVER JABÁ, QUE NÃO ME ATRAPALHE O BABÁ,

\footnotetext{
${ }^{39}$ Os gêneros do humor são identificados pelas suas iniciais. $\mathrm{O}$ GH piada visual é identificado como PV; piada, como P; charge, como $\mathrm{CH}$; charge animada, como CHA.

${ }^{40}$ Sobre as descrições do gênero piada, ver Ottoni (2007).
} 
ONDE HOUVER MUTRETA,

QUE EU MOSTRE A MALETA,

ONDE HOUVER ÓCIO,

QUE EU FECHE O NEGÓCIO.

ONDE HOUVER PROPINA, QUE NÃO ME DEIXEM NA ESQUINA,

ONDE HOUVER ESQUEMA, QUE O PALOCCI NÃO TREMA.
ONDE HOUVER PRAZO

QUE EU RECEBA À VISTA.
Ó MESTRE,

FAZEI COM QUE EU CONTINUE

HONRANDO,

A CONFIANÇA DO SEU CHEQUE EM

BRANCO,

NEGOCIANDO E NO PLANALTO

TRANSITANDO

SEM SUJAR MEU COLARINHO BRANCO.

POIS É DANDO, QUE SE RECEBE, É SÓ NEGANDO QUE SE É PERDOADO POIS ENQUANTO O POVO SOFRE, NÓIS METE A MÃO NO COFRE...

PT SAUDAÇÕES. AMÉM. ALELUIA !!!

Publicada em 25/07/2005 no site <www.cosmo.com/br.humor> e acessada em 29 jul. 2005.

Percebe-se que as formas simbólicas ${ }^{41}$ veiculadas nos media são desencaixadas de seus contextos originais e recontextualizadas em diversos outros contextos, para aí serem interpretadas por uma pluralidade de atores sociais que têm acesso a esses bens simbólicos. E, mais do que interpretar essas formas simbólicas, esses sujeitos "as incorporam na própria compreensão que têm de si mesmos e dos outros, as usam como veículos para reflexão e auto-reflexão" (THOMPSON, p. 45).

Sobre essa recontextualização e influência na vida dos sujeitos, também nos fala Fairclough (2003, p. 4):

um gênero da mídia tal como jornais televisivos recontextualiza e transforma outras práticas sociais, tais como política e governo, e é, por sua vez, recontextualizado nos textos e interações de diferentes práticas, incluindo, crucialmente, a vida diária, em que contribui para a moldagem de como nós vivemos e dos significados que damos a nossas vidas (SILVERSTONE, 1999).

\footnotetext{
41 "As formas simbólicas envolvem um amplo espectro de ações e falas, imagens e textos verbais, que são produzidos por sujeitos e reconhecidos por eles e outros como construtos significativos" (THOMPSON, 1995, p. 79).
} 
No caso dos gêneros do humor, é marcante a recontextualização de materiais simbólicos oriundos dos media - uma das fontes principais de 'inspiração' dos humoristas -; fato registrado por produtores desses gêneros e por jornalistas ${ }^{42}$.

No que diz respeito especificamente à recontextualização de notícias, observa-se que ela se dá, geralmente, numa perspectiva crítica nos GHs. Tome-se como exemplo a charge lida e interpretada com alunos/as de $7^{\circ}$ ano ${ }^{43}$ no trabalho de campo, na qual se critica a compra de um novo avião pelo presidente da república em um momento em que se afirma que não há verbas para recuperar as estradas brasileiras:

$(\mathrm{CH})$ :

\section{7/01/2005 chargista Cláudio}

\section{blog de humor}

\section{Edição extraordinária}

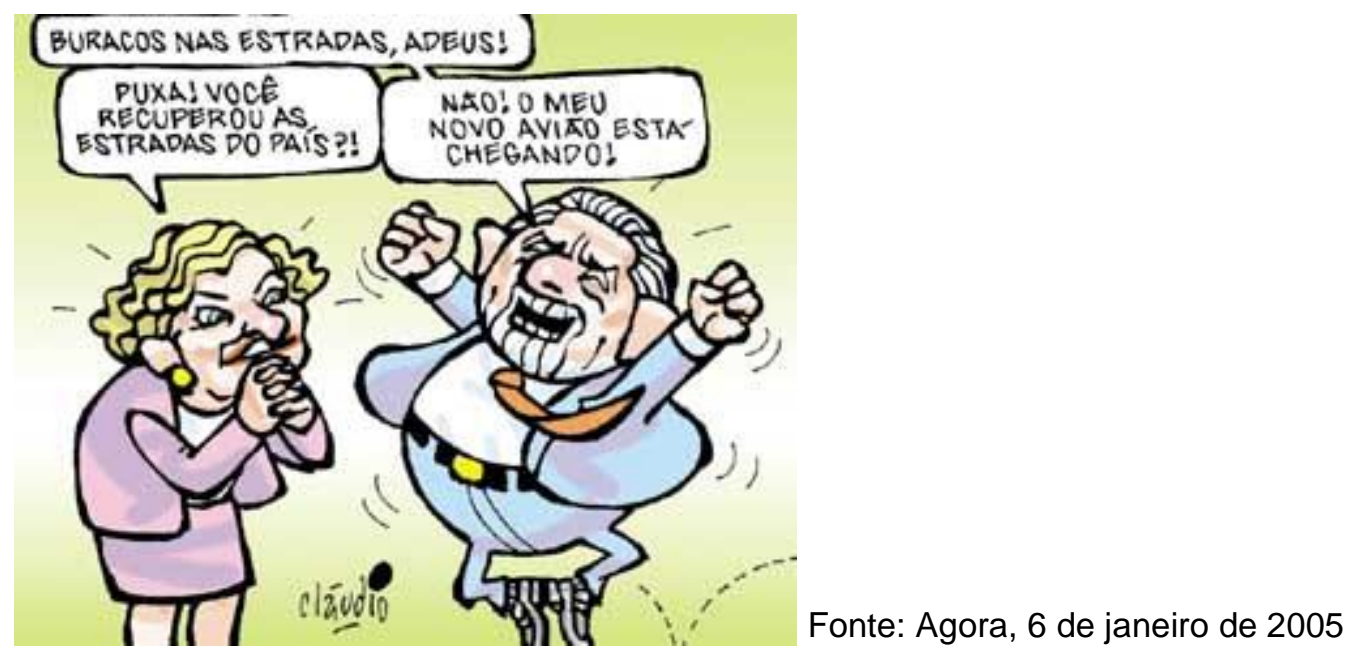

42 Sobre isso, veja bate-papo com o jornalista e cartunista Maurício Ricardo em http://tc.batepapo.uol.com.br/convidados/arquivo/frames.jhtm?url=http://bp.tc.uol.com.br/convidados/ arquivo/quadhumor/ult1757u50.jhtm).

${ }^{43} \mathrm{Em}$ função de como o ensino é estruturado na escola onde a pesquisa foi desenvolvida, 070 ano corresponde à antiga $7^{\underline{a}}$. série e não à antiga 6ª . série, como na maioria das escolas. 
O autor traz para esta charge o que, na época, era veiculado em diferentes meios de comunicação acerca da contradição existente entre uma situação de falta de verbas para reparos nas estradas brasileiras que se encontravam em péssimas condições e uma situação de mau uso e desperdício do dinheiro público em benefício do presidente, como no trecho, a seguir, de uma reportagem de Antonio Raimundo da Silveira publicada no Jornal da Mídia, em 12/04/04:

O superluxuoso avião que o governo federal comprou para transportar o presidente Luís Inácio Lula da Silva em suas viagens internacionais (...) é vendido ao preço de aproximadamente 35 milhões de dólares (...).O interessante é que o governo garante não ter condições de investir em infra-estrutura (rodovias, transportes, geração de energia, etc) -- de que o País tanto necessita -- por absoluta falta de recursos, mas na hora de comprar o superluxuoso jato o dinheiro apareceu. (SILVEIRA, 2004).

O autor da charge estabelece um intertexto com os textos que veiculavam nos media sobre o fato e apresenta um crítica à atitude de descaso do presidente em relação à necessidade de recuperação das estradas brasileiras.

Um outro exemplo que se pode apresentar é a charge animada, veiculada no site www.charges.com.br, na seção charges-okê, intitulada "Lula canta 'Enquanto houver sol'”, também lida e interpretada em conjunto com alunos/as de $7^{\circ}$ ano, cujos quadros iniciais ${ }^{44}$ são:

$(\mathrm{CHA})$ :

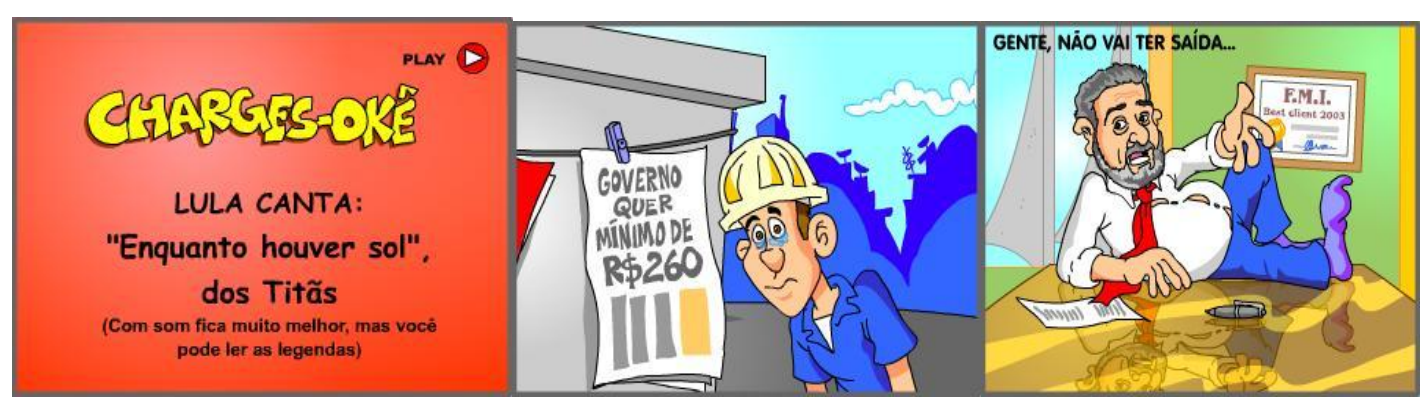

Esta charge foi produzida em 26/04/04, quando muito se discutia sobre o aumento do salário mínimo. Os media ressaltavam o impasse entre a equipe econômica do governo Lula e os ministros de outras áreas, bem como enfatizavam a oposição entre o que Lula dizia em campanha e o que na época fazia ou poderia fazer. Nela, percebe-se

\footnotetext{
${ }^{44}$ Como para cada movimento é produzido um quadro diferente, essa charge é composta por 969 quadros no total. Para leitura dos principais quadros dessa charge e da análise feita, ver Ottoni (2007).
} 
uma crítica tanto ao valor aumentado pelo governo como à postura de Lula enquanto presidente.

Pode-se dizer que os textos verbal e visual dessas duas charges ( $\mathrm{CH}$ e CHA) são baseados no que muitos media disseram sobre as questões focalizadas e no que 0 próprio presidente possa ter dito em entrevistas, o que representa um movimento de apropriação, transformação e colonização de discursos e gêneros na constituição de gêneros do humor. Nesse movimento, sem dúvida, os elementos selecionados e a forma de representação dos eventos e dos atores, nas charges, diferem da seleção e representação em outros gêneros, veiculados em outros media, como televisão, jornal, rádio.

A recontextualização crítica de materiais simbólicos veiculados nos media vem ao encontro da afirmação de Thompson (1995) sobre a recepção de produtos da mídia como uma atividade criativa. Os indivíduos trabalham o material simbólico a que têm acesso e o usam de acordo com seus propósitos, com os propósitos do gênero a ser produzido, com o meio em que será distribuído e com os seus consumidores. Como Thompson (op. cit: p. 45) observa, "as mensagens podem ser retransmitidas para outros contextos de recepção e transformadas através de um processo continuo de repetição, reinterpretação, comentário, riso e crítica". E, dessa forma, outros textos são produzidos, resultado da distribuição de um texto anterior (ou de outros textos) por outras tantas práticas discursivas e, conforme afirma Bernstein (1996, p. 184), "qualquer discurso recontextualizado torna-se um significador para alguma outra coisa que ele próprio"45.

O discurso de Lula, por exemplo, e as notícias veiculadas sobre a compra de um novo avião associadas às notícias sobre as péssimas condições das estradas brasileiras, assim como as notícias sobre o aumento do salário mínimo, ao serem recontextualizados nas charges não animada $(\mathrm{CH})$ e animada $(\mathrm{CHA})$, respectivamente, atuam como elemento de significação para outro/s discurso/s e de composição para outros gêneros.

Tudo isso está conectado à idéia de interdiscursividade que, em linhas gerais, refere-se à constituição de um texto a partir de discursos e gêneros diversos (MAGALHÃES, 2001), isto é, uma forma de hibridização discursiva e genérica (FAIRCLOUGH, 2003, p. 34, 66), o que nos remete à idéia de colonização discursiva e genérica. Esta representa "a recontextualização e transformação de práticas discursivas/sociais" (FAIRCLOUGH, op. cit.: p. 34) em outras práticas.

\footnotetext{
45 Tradução minha de "any recontextualized discourse becomes a signifier for something other than itself".
} 
É sabido que a interdiscursividade é característica dos gêneros discursivos, os quais incorporam outros gêneros e sentidos de outros discursos. Como destaca Magalhães (2005, p. 238-9),

Um aspecto fundamental dos gêneros discursivos é sua mobilidade e tendência à mudança em processos interdiscursivos, o que é um aspecto subestimado em alguns debates (...). Esse aspecto, que foi destacado por M. Bakhtin (trad. 1997), é uma contribuição da obra de N. Fairclough (trad. 2001, 2003), que aponta a transformação dos gêneros discursivos contemporâneos sob a influência dos processos sociais de desencaixe das práticas operacionalizado pelo capitalismo globalizado.

Essa mobilidade e tendência à mudança envolvem também questões relacionadas à intermedialidade - termo cunhado em 1965 por Dick Higgins.

A intermedialidade, de acordo com Lehtonen (2001), é "intertextualidade que transgride os limites dos media". Isso significa que não se restringe a um único meio (medium) ou domínio - o de textos -, mas acontece entre vários media.

Em seu livro "Gênero, agência e escrita", Bazerman, ao tratar da distância ou alcance intertextual nos gêneros, também faz referência ao termo "intermidialidade". Para este autor, "podemos perceber a intermidialidade, quando o meio ou referência se movem de uma mídia para outra, tal como quando uma conversa, um filme ou uma música é mencionado em um texto escrito" (BAZERMAN, 2006, p. 97).

Conforme Lehtonen (op. cit.), a mediatização, a comodificação, a globalização e a digitalização provocam uma intensificação da intermedialização. Segundo o autor, por meio desses processos, a cultura pós-moderna está se tornando crescentemente intermedial; "a centralização da indústria cultural e a comodificação da cultura têm resultado no fato de que os mesmos textos e personagens circulam em diferentes media" (idem, p. 78).

Assim, os mesmos personagens que circulam, por exemplo, em novelas e em programas como o Big Brother Brasil, circulam em programas de auditório, e, ainda, de forma satirizada, em programas de humor televisivo, em charges animadas e não animadas na internet. Da mesma forma, na televisão, em jornais e na internet circulam gêneros do humor cujo personagem principal é Lula e cujos discursos são muito similares em conteúdo. A charge $1(\mathrm{CH})$ é uma mostra disso, pois ela foi publicada no jornal Agora e veiculada em um blog de humor, estabelecendo uma intertextualidade que transcende os limites dos media (Lehtonen, op. cit.). Isso significa que o estudo da intermedialidade está também ligado à expansão do estudo do hibridismo na cultura pós-moderna, o qual é 
"inerente a todos os usos sociais da linguagem" (CHOULIARAKI \& FAIRCLOUGH, 1999, p. 13).

Um outro conceito importante no tratamento dos GHs, o qual é associado por Lehtonem à intermedialidade, é a multimodalidade. De acordo com Kress e van Leeuwen (2001, p. 20), a multimodalidade diz respeito ao "uso de vários modos semióticos no design de um produto semiótico ou evento, junto com formas particulares em que esses modos são combinados".

Percebe-se que os textos diversos (não só os humorísticos) que circulam na sociedade contemporânea, cada vez mais, estão repletos de ilustrações coloridas, layout e tipografia sofisticados. Enfim, passou-se a usar uma variedade de modos semióticos (não mais só e principalmente o verbal) para a produção de sentidos nos textos, o que deu origem a textos multimodais (KRESS, 1996; KRESS \& VAN LEEUWEN, 1996, 2001).

Cada vez mais se evidencia uma tendência à apreciação multimodal da construção de sentido e essa tendência, segundo ledema (2003), gira, em termos gerais, em torno de duas questões. Primeiro, o descentramento da linguagem verbal como produção de sentido preferida; e, segundo, a re-visitação e não-distinção dos limites tradicionais entre os papéis alocados para o verbal, para a imagem, para o layout de uma página, para o design de documentos etc. Essa indistinção das fronteiras entre as diferentes dimensões semióticas de representação tem sido ligada a mudanças em nossa paisagem semiótica, que está se tornando mais e mais povoada por complexas práticas discursivas sociais e culturais.

Observa-se que os gêneros do humor atualmente, em sua maioria, são multimodais, ou seja, são constituídos pelos modos verbal, gráfico-visual, sonoro, e ainda dispõem de animação em muitos casos.

Nas charges $\mathrm{CH}$ e $\mathrm{CHA}$, todos os recursos utilizados contribuem, em conjunto, para a representação crítica dos fatos e dos atores sociais e para a construção do sentido humorístico. $\mathrm{Na} \mathrm{CHA}$, por exemplo, a representação imagética de Lula (posição - deitado sobre a mesa -, combinação de cores da roupa - camisa branca, apertada, gravata vermelha, calça azul royal, meia lilás) juntamente com o texto verbal presente na charge, além de configurar uma crítica a Lula, também constitui um recurso para produção do humor, uma vez que vai de encontro ao comportamento que é culturalmente avaliado como 'próprio' ou 'ético' para um sujeito que ocupa a posição de presidente da república.

Assim, opera uma inversão do que é característico das sociedades pós-modernas: a "esteticização das identidades públicas" (FAIRCLOUGH, 2003) como um recurso para a construção da crítica e do humor. 


\section{Considerações finais}

Como se pôde ver, algumas mudanças estão ocorrendo na produção, distribuição e consumo dos GHs em decorrência de mudanças tecnológicas e culturais. Esse processo de transformações tem envolvido questões importantes, as quais se entrelaçam e jogam luz ao tratamento desses gêneros. Gêneros antes só veiculados por meio da oralidade e outros, só por meio impresso, hoje são distribuídos e consumidos por meio eletrônico.

Nesse processo de recontextualização e de intermedialidade, o hibridismo, a interdiscursividade e a intertextualidade são marcantes na configuração dos GHs. E, nesse processo, observa-se que, cada vez mais, os gêneros do humor multimodais ocupam espaço maior na sociedade em relação aos estritamente verbais.

A breve abordagem dessas diferentes questões apresentada neste artigo mostra que elas se imbricam de modo que o tratamento de uma acaba por levar ao de outra; atuando todas, de uma forma ou de outra, na constituição dos gêneros do humor - mas não só - e dos sentidos produzidos a partir desses gêneros. Também mostra que há muito ainda a ser investigado acerca das mudanças que vêm ocorrendo na produção, distribuição e consumo dos gêneros humorísticos e não humorísticos.

\section{Referências}

BAKHTIN, M. Estética da criação verbal. Trad. Maria E. G. G. Pereira. 3 ed. São Paulo: Martins Fontes, 2000.

BAZERMAN, C. Gênero, agência e escrita. Org. Judith C. Hoffnagel e Angela P. Dionísio. Trad. e adaptação de Judith C. Hoffnagel. São Paulo: Cortez, 2006.

BERNSTEIN, B. A estruturação do discurso pedagógico: classe, códigos e controle. Trad. T. T. Silva e L. F. G. Pereira. Petrópolis: Vozes, 1996.

BUTT, D. et al. Using functional grammar: an explorer's guide. 2 ed. Sídney: NCELTR, 2000.

CHOULIARAKI, L. \& FAIRCLOUGH, N. Discourse in late modernity: rethinking critical discourse analysis. Edinburgo: Edinburgh University Press, 1999.

FAIRCLOUGH, N. Analysing discourse: textual analysis for social research. Londres e Nova York: Routledge, 2003.

Discurso e mudança social. Coord. trad., revisão e pref. à ed. bras. de Izabel Magalhães. Brasília: Editora Universidade de Brasília, 2001.

HALLIDAY, M. A. K. An introduction to functional grammar. 2 ed. Londres, Melbourne, Auckland: Edward Arnold, 1994.

Part A. In: HALLIDAY, M.A.K. \& HASAN, R. Language, context, and text: aspects of language in a social-semiotic perspective. 2 ed. Oxford: Oxford University Press, 1989. p. 1-49.

Language as social semiotic: the social interpretation of language and meaning. Londres, Nova York, Melbourne, Auckland: Edward Arnold, 1978. 
HALLIDAY, M. A. K. \& MATTHIESSEN, C.M.I.M.. An Introduction to Functional Grammar. 3 ed. Londres: Edward Arnold, 2004.

IEDEMA, R. Multimodality, resemiotization: extending the analysis of discourse as multisemiotic practice. Visual Communication. Londres, Thousand Oaks, CA e Nova Delhi: Sage Publications. Vol. 2(1), p. 29-57, 2003.

KRESS, G. Multimodal texts and critical discourse analysis. In: PEDRO, E. R. (ed.). Discourse analysis. Proceedings of the first international conference on discourse analysis. Portugal: Edições Colibri: APL, 1996: 367-386.

KRESS, G \& VAN LEEUWEN, T. Multimodal discourse: the modes and media of contemporary communication. Londres: Arnold Publisher; Nova York: Oxford University Press, 2001.

1996. . Reading images: the grammar of visual design. Londres; Nova York: Routledge,

LEHTONEN, M. On No Man's Land. Theses on Intermediality. Nordicom Review, vol. 22, n. 1, p. 71-83, 2001. Disponível emhttp://www.nordicom.gu.se/common/publ pdf/28 lehtonen.pdf. Acesso em abril, 2006.

MAGALHÃES, I. Análise do discurso publicitário. Revista da ABRALIN, vol 4, n. 1 e 2, p. 231-260, dez. 2005.

. Prefácio a FAIRCLOUGH, N. Discurso e mudança social. Brasília: Editora Universidade de Brasília, 2001. pp. 11-14.

MUNIZ, K. da S. PIADAS: Conceituação, Constituição e Práticas - um estudo de um gênero. Campinas, 2004. Dissertação. (Mestrado em Linguística), IEL, UNICAMP, 2004. OTTONI, M. A. R. Os gêneros do humor no ensino da língua portuguesa: uma abordagem discursiva crítica, 2007. Tese (Doutorado em Linguística), UnB, 2007.

SILVEIRA, A. R. da. Avião novo de Lula é igual aos dos bilionários sheiks árabes. Jornal da Mídia. Segunda feira, 12 de abril de 2004. Disponível em

http://www.jornaldamidia.com.br/noticias/2004/04/Papo_Afiado_N/12-Aviao_novo_de_Lula e_igual_aos.shtml. Acesso em novembro de 2004.

$\bar{T}$ HOMPSON, J. B. Ideologia e cultura moderna: teoria social crítica na era dos meios de comunicação de massa. Petrópolis: Vozes, 1995.

\title{
O PROCESSO TRADUTÓRIO NA PERSPECTIVA DA RETEXTUALIZAÇÃO E SUA ABORDAGEM NO ENSINO DE INGLÊS COMO LÍNGUA ESTRANGEIRA
}

\section{THE TRANSLATION PROCESS IN THE PERSPECTIVE OF RETEXTUALIZATION AND ITS APPROACH IN TEACHING ENGLISH AS A FOREIGN LANGUAGE}

\author{
Mayelli Caldas de Castro - IFES \\ mayellicastro@yahoo.com.br
}

RESUMO: Esta pesquisa tem como objetivo geral fazer uma reflexão sobre o ato tradutório considerado como Retextualização. A partir dessa busca, concretizar-se-á o 
que é considerado o objetivo central deste trabalho: analisar a pertinência da abordagem desses textos traduzidos e a implicação que a tradução pode exercer sobre o entendimento do texto na sala de aula de língua inglesa e em relação ao público alvo que, nesta pesquisa, serão os estudantes de língua inglesa do Ensino Médio.

Esta é uma abordagem da atividade tradutória que utiliza elementos da Linguística Textual, já que não se traduzem palavras isoladas, e, sim, textos. Então, trata-se de uma análise textual, com suas fases de produção e, consequentemente, de co-produção. Para essa análise procurou-se a abordagem de um conjunto de textos com finalidades didáticas que originalmente estão escritos em inglês e traduzidos para o português brasileiro. No entanto, para esta exposição usar-se-á um desses exemplos. Desse modo, a intenção principal é investigar os mecanismos textuais que construirão o sentido do texto em inglês e no texto traduzido para depois propor uma forma de utilização dos textos analisados em uma sala de aula de inglês como língua estrangeira do Ensino Médio.

PALAVRAS-CHAVE: Ensino de língua estrangeira e Tradução; textualidade; retextualização.

ABSTRACT: This research aims mainly to reflect on the translation act as one of Retextualization. We will therefore discuss the activity of translation as a text (re)production, that is to say, a production of a new/same text that has as its source a different language. We will also attempt to identify and examine how the factors of textuality contribute to the translation process. By doing so, we hope to fulfill our main objective, which is: to analyze the relevance of the use of these translated texts in the English class and the importance of this approach in facilitating the comprehension of a text by the target readers, secondary students studying English as a foreign language. This translation approach relies on elements from textual linguistics because we cannot translate single words but texts. Thus, this is about text analysis, with its phases of production and, consequently, of co-production. In order to perform this analysis, a number of didactic texts, originally written in English and translated into Brazilian Portuguese, was selected. However, for this paper, we have selected one of these texts as a sample. The main intention here is to investigate and to highlight which factors of textuality determine the choices made by the translator and how the choice of vocabulary can interfere in the function performed by these factors, so as to therefore better understand implications in teaching English as a foreign language.

KEYWORDS: foreign language teaching and translation; textuality; retextualization.

Este trabalho consiste em fazer uma reflexão da Tradução à luz da perspectiva da

"Retextualização" proposta por Neuza Gonçalves Travaglia (2003). Esse termo foi empregado por Travaglia, em 1993, para fazer referência à tradução interlingual (de uma língua para outra). O termo foi empregado por Costa (1992), que também trata a questão da Tradução sob o aspecto da retextualização, porém sua abordagem é referente a textos literários e, consequentemente, as análises se voltam para esse lado. Mas o termo foi empregado em trabalhos com procedimentos diferentes como: a refacção ou reescrita, como o fazem Raquel S. Fiad e Maria Laura Mayrink-Sabinson (1991) e Maria Bernadete Abaurre et al. (1995), que observam aspectos relativos às mudanças de um texto no seu 
interior, isto é, reescrevendo o mesmo texto; e observa-se também a transformação de textos orais em textos escritos, segundo a concepção de Marcuschi (2001).

Marcuschi, em pé de página (2001, p.45), explica que a expressão retextualização foi empregada por Neuza Travaglia (1993) em sua tese de doutorado sobre a tradução de uma língua para outra. O autor, então, apropria-se do termo, utilizando-o para explicar a "tradução" realizada de uma modalidade linguística para outra, embora permanecendo em uma mesma língua. Neste trabalho, a retextualização é tomada em seu primeiro sentido, proposto por Travaglia, que reflete a atividade tradutória numa perspectiva textual, ou seja, propõe uma reflexão da Tradução enquanto trabalho com o texto, realidade existente em uma determinada língua, que passará a existir como texto em outra língua. Nessa proposta, a tradução, como produção textual, considera que todos os fatores linguísticos e extra-linguísticos da textualidade co-existem e se articulam nos diversos planos, tanto no universo da língua de partida como no da língua de chegada.

A hipótese básica defendida por Travaglia é de que a produção original é uma textualização, uma 'mise en texte' e a produção da tradução é uma retextualização, produção de um novo/mesmo texto em uma língua diferente daquela em que foi originariamente concebido. A Tradução, vista sob esse ângulo, considera que o texto não pode ser só produto, mas também processo, já que só existe pelo processo de composição e de leitura.

A retextualização é uma prática que envolve a passagem de um texto para outro. Ocorre, nessa prática, uma atividade cognitiva denominada compreensão. Sendo assim, para se dizer de outro modo, em outra modalidade, ou em outra língua e em outro gênero, o que foi dito ou escrito por alguém, deve-se compreender o que esse alguém disse ou quis dizer.

Dessa forma, faz-se aqui uma busca de pistas linguísticas que atestam as escolhas do tradutor, e não somente de pistas linguísticas, mas também uma busca dos elementos textuais, do conhecimento de mundo, conhecimentos partilhados, informatividade, focalização, inferência, relevância, fatores pragmáticos, situacionalidade, intertextualidade, intencionalidade e aceitabilidade, ou seja, essa busca é embasada nos critérios de textualidade propostos por Beaugrande \& Dressler (1981), bem como os critérios pragmáticos. Isso faz com que se torne um trabalho extremamente rico, que considera fatores de ordem sócio-histórico-ideológico-cultural e linguístico. Tal característica é de grande relevância, já que traduzir não pressupõe apenas o domínio do sistema da língua. 
Tendo essas justificativas em vista, direi que, como objetivo geral, este trabalho propõe uma reflexão do ato tradutório considerado como Retextualização, baseado na hipótese defendida por Neuza Gonçalves Travaglia (2003), utilizando para isso fontes textuais e investigando o processo do ato tradutório através de uma tradução feita e comparada ao texto de partida. Também é pretendido discutir a atividade de traduzir enquanto (re)produção textual, ou seja, produção de um novo/mesmo texto que se originou de uma língua diferente, bem como analisar as fases do processo tradutório em relação às fases do processo de produção textual e, mais especificamente em relação às operações realizadas na produção de um texto original; isto é, a partir da construção de sentidos. Enfim, vou apontar como objetivo-chave desta pesquisa reconhecer e examinar os fatores (mecanismos) de textualidade que contribuíram para o processo ${ }^{46}$ de tradução, apontando quanto esses fatores influenciaram as escolhas do tradutor (incluindo os de ordem linguística e extra-linguística) e, consequentemente, qual a implicância que poderá haver a partir dessas escolhas para o entendimento do texto por parte do leitor alvo que, nesta pesquisa, será o estudante de língua inglesa do Ensino Médio. Dessa forma, analisaremos, também, a pertinência da abordagem do texto analisado para o Ensino de Língua Inglesa para esse público, ou seja, a forma como a tradução foi utilizada nesse caso.

\section{A Linguística Textual e a Tradução}

Este trabalho consiste em fazer uma reflexão sobre a Tradução à luz da perspectiva da Retextualização. Sendo assim, trata-se de uma proposta teórica sobre a Tradução utilizando elementos da Linguística Textual. Isso porque, como afirma Adam (2008, p.321), "a unidade não é a palavra, mas o texto [...]. Assim, uma tradução é apenas um momento de um texto em movimento. Ela é, inclusive, a imagem de que ele nunca acaba. Ela não poderia imobilizá-lo". Ao fazer essa afirmação, Jean-Michel Adam assegura ao texto seu caráter interativo e reforça também a teoria de que a tradução só pode ser analisada enquanto processo de produção textual e, assim, vai ao encontro do que defende Marcuschi sobre o material linguístico a ser analisado:

Todos nós sabemos que a comunicação linguística (e a produção discursiva em geral) não se dá em unidades isoladas, tais como fonemas, morfemas ou palavras soltas, mas sim em unidades maiores, ou seja, por

\footnotetext{
${ }^{46}$ A palavra "processo" referida aqui faz menção à qual perspectiva pretendemos olhar a tradução - como processo de leitura e de produção textual . Portanto, a Tradução vista sob esse prisma só poderá ocorrer enquanto processo de leitura, interpretação e produção textual, por isso chama-se "processo tradutório".
} 
textos. E os textos são, a rigor, o único material linguístico observável. (2008, p.71)

Se a tradução é um "texto em movimento", como afirma Adam, ela está sempre sendo reconstruída à medida que se façam novas interpretações. Assim, pode-se afirmar que se trata de um ato de comunicação. Parafraseando Marcuschi, torna-se indispensável aqui sua noção de texto que "pode ser tido como um tecido estruturado, uma entidade significativa, uma entidade de comunicação e um artefato sócio-histórico" (2008, p.72). Para esse autor, o texto é uma 'reconstrução do mundo e não uma simples refração ou reflexo'. Parece-nos interessante essa passagem de Marcuschi, pois ela atinge também a Tradução (vista numa abordagem textual). Seria ousado (no entanto apropriado) defender que a afirmação também se enquadraria nessa reflexão sobre a tradução, já que o tradutor, por intermédio de seu texto, reordena e reconstrói o mundo na medida em que faz suas escolhas para formar outra unidade de sentido (outro texto) com a substância de conteúdo do texto anterior.

Marcuschi afirma que a LT (Linguística Textual) faz distinção entre sentido e conteúdo e não tem como objetivo uma análise de conteúdo, já que isso, segundo ele, é objeto de estudo de outras disciplinas. "O conteúdo é aquilo que se diz, ou se descreve ou se designa no mundo, mas o sentido é um efeito produzido pelo fato de se dizer de uma outra forma esse conteúdo" (MARCUSCHI, 2008, p.74). Então, o sentido é um efeito do funcionamento da língua quando os falantes estão situados em contextos sócio-históricos e produzem textos em condições específicas.

Assim, na tradução procura-se manter o conteúdo, porém o sentido vai depender dos aspectos cognitivos, pois é a partir deles que o produtor/tradutor vai interpretar e, consequentemente, reconstruir o mundo à sua maneira, e depois vai (re)escrever esse mesmo conteúdo fazendo uso de estratégias e escolhas que vão determinar o efeito de sentido que ele pretende, a fim de situar seu texto em um outro contexto sócio-histórico.

Visando apenas o conteúdo, a tradução seria tida como uma atividade 'totalmente' dependente do texto original. Mas com o advento das novas teorias, em especial o surgimento da Linguística Textual, e também das Análises Cognitivas que buscam estudar e explicar o sentido, e ainda o da Pragmática, podemos refletir sobre a Tradução como uma atividade independente, pois é a construção de sentido, tendo em vista seu funcionamento e seu efeito em determinada comunidade, que vai determinar as escolhas feitas pelo tradutor. 
Sendo assim, torna-se necessário ter em mente a noção de texto e de seus constituintes de textualidade. Beaugrande (1981, p.10) postula a noção de que "texto é um evento comunicativo em que convergem ações linguísticas, sociais e cognitivas". Vale dizer que o texto ativa estratégias, expectativas, conhecimentos linguísticos e nãolinguísticos.

Cabe ainda uma citação de Koch que irá reforçar tudo o que foi defendido aqui sobre o uso dessa corrente da Linguística moderna para refletir sobre a Tradução:

A Linguística Textual toma, pois, como objeto particular de investigação não mais a palavra ou a frase isolada, mas o texto, considerado a unidade básica de manifestação da linguagem, visto que o homem se comunica por meio de textos e que existem diversos fenômenos linguísticos que só podem ser explicados no interior do texto. O texto é muito mais que a simples soma das frases (e palavras) que o compõem: a diferença entre frase e texto não é meramente de ordem quantitativa; é, sim, de ordem qualitativa. Assim, passou-se a pesquisar o que faz com que um texto seja um texto, isto é, quais os elementos ou fatores responsáveis pela textualidade. Conforme se disse acima, Beaugrande \& Dressler (1981) apresentam um elenco de tais fatores, em número de sete: coesão, coerência, informatividade, situacionalidade, intertextualidade, intencionalidade e aceitabilidade. (KOCH, 2004, p.11)

É interessante ressaltar que a Linguística Textual constitui um ramo ainda considerado novo da Linguística, o qual começou a se desenvolver na Europa, na década de 60. Ampliou o seu objeto de análise, ultrapassando a palavra e a frase, focando-se no texto, isso porque, depois de observadas várias lacunas ${ }^{47}$, se concluiu que muitos fatores só podiam ser devidamente explicados se analisarem o texto e o seu contexto. Passam, então, a figurar nos estudos da Linguística Textual o sujeito e a situação de comunicação, excluídos das pesquisas sobre a linguagem, pela perspectiva da linguística estrutural que compreendia a língua como sistema e como código, com função puramente mecânica.

A Linguística Textual evoluiu principalmente no que tange à conceituação de texto, inserindo os conceitos de sentido e interlocução. Costa Val (2004, p.113), tratando de texto verbal, assim o conceitua: "Falando apenas de texto verbal, pode-se definir texto, hoje, como qualquer produção linguística, falada ou escrita, de qualquer tamanho, que possa fazer sentido numa situação de comunicação humana, isto é, numa situação de interlocução".

${ }^{47}$ Das gramáticas de frase no tratamento de fenômenos tais como a correferência, a pronominalização, a seleção dos artigos, a ordem das palavras no enunciado, a relação tópico-comentário, a entonação, as relações entre sentenças não ligadas por conjunções, entre outros. 
Para Costa Val, assim como para outros estudiosos da Linguística Textual, o sentido não está no texto, não é dado pelo texto, mas é produzido durante a interação, pelos interlocutores, locutor e alocutário, a cada acontecimento de uso da língua, ou seja, a cada interpretação.

A tradução é, pois, um texto retextualizado, na medida em que faz sentido e se constitui como uma produção linguística escrita, construído numa situação de comunicação humana. Portanto, a moderna Linguística Textual é ciência apta a descrever e analisar os acontecimentos linguísticos e os fenômenos deles decorrentes, sendo a Tradução um desses fenômenos.

Em suma, se a tradução é produção textual, devem-se levar em conta os mesmos elementos como determinantes dessa produção, isto é, se o texto original ativa tais elementos, a tradução (novo texto) deve também ativá-los. Travaglia afirma que "o ato de traduzir tem que levar em conta não apenas os elementos linguísticos em si, mas como eles funcionam discursivamente dentro de um texto" (2003, p.142).

No que concerne à produção, um texto, enquanto unidade comunicativa, obedece a um conjunto de critérios de textualização, já que, segundo Koch (1984, p.21-22) "todo texto caracteriza-se pela textualidade, rede de relações que fazem com que um texto seja texto (e não simples somatória de frases) revelando uma conexão entre as intenções, as idéias e as unidades linguísticas que o compõem [...]".

A concepção da Tradução como Retextualização acrescenta ao estudo do processo tradutório os instrumentos de reflexão da linguística textual, bem como alguns componentes pragmáticos, proporcionando uma releitura da própria tradução enquanto teoria e enquanto prática.

Assim, a tradução dentro de um funcionamento discursivo leva em consideração não só o texto como objeto materializado, mas também a situação imediata de produção, a situação como contexto sócio-histórico e ideológico mais amplo, o sujeito.

Em sua abordagem de Retextualização, Travaglia baseou-se principalmente na leitura dos critérios de textualidade de Beaugrande e Dressler feita por Koch e Travaglia (1995 [1989]). A autora defende que as etapas da tradução vão ser semelhantes às etapas da produção de um texto:

O que acontece na tradução é, desta forma, algo semelhante ao processo de produção de qualquer texto: o tradutor constrói o sentido a partir de um texto original; o sentido assim construído por ele transforma-se na sua intenção comunicativa; em seguida o tradutor planeja globalmente a tradução do texto levando em conta os elementos constitutivos da textualidade e buscando além disso estabelecer a coerência entre o 
original e a tradução e por fim realiza da fase por assim dizer concreta, palpável da retextualização, da "remise en text", utilizando-se dos elementos que lhe oferece a língua com a qual está trabalhando. Traduzir supõe assim uma representação dos processos de produção de textos. (TRAVAGLIA, 2003, p.68)

Assim como o fez Travaglia, também tomamos como base os critérios de textualidade propostos por Beaugrande e Dressler (1981), porém acrescentando fatores de textualidade embasados por Halliday e Hasan (1989), considerando também leitura feita por Koch e Travaglia (1995 [1989]), e, ainda, como base complementar, usaremos alguns aspectos da Pragmática, como a noção de contexto.

Travaglia defende que, partindo da textualidade (que para ela são características que juntas definem o texto), pode-se começar uma reflexão sobre o ato tradutório que possa se aplicar a todos os textos. Assim, o tradutor recoloca em texto numa outra língua a reconstrução de um sentido que faz a partir de uma textualização anterior.

Em sua hipótese, ela afirma que:

Ao traduzir (retextualizar em outra língua), o tradutor deve antes de mais nada ter em mente deixar abertos os caminhos da interpretação, embora, naturalmente sua tradução reflita sua própria interpretação e espelhe 0 sentido que para ele é, por assim dizer, o mais importante no original. (2003, p.40)

Logo no início de sua obra, essa autora ressalta a prioridade que se deve dar ao "texto", isto é, ao tratamento que se dá a ele. Ela defende isso afirmando que "a produção linguística de um falante aparece sempre sob a forma de texto e não sob a forma de fragmentos esparsos e isolados" (TRAVAGLIA, 2003, p.15). Existe em seu trabalho uma preocupação em definir o que é texto e discurso para deixar bem clara a noção de tradução a que se propõe.

$\mathrm{Na}$ verdade, Travaglia começa o livro com discussões de algumas concepções de discurso e texto porque, segundo ela, é a noção de discurso que lhe servirá de contraponto à noção de texto - já que é nessa última em que ela parece querer se concentrar para a abordagem textual da tradução que quer empreender.

Assim, torna-se necessário entendermos a concepção de texto de sua obra:

O texto é considerado como unidade geradora de sentidos, arranjo de marcadores, lugar dialógico onde a língua representa a mais importante condição de base da atividade humana chamada linguagem. (2003, p. 10) 
Assim sua hipótese se baseia em uma definição de texto e textualidade que considera que o texto "é o lugar onde se manifestam as operações de construção e reconstrução dos sentidos; é a manifestação efetiva dos discursos" (2003, p.20).

Para ela, o fato mesmo de traduzir, de tornar um objeto linguístico produzido em um idioma, para tornar possível sua recepção em um outro idioma, já pressupõe que o tradutor o considere de certa forma como um texto e, para isso, o tradutor terá que adotar, de forma explícita ou não, critérios definidores de textualidade. Em sua pesquisa, tais critérios serão os propostos por Beaugrande \& Dressler (1981), segundo leitura feita por Koch e Luis Carlos Travaglia (1989). E é assim, definindo o texto pela relação de textualidade com os fatores textuais supracitados, que essa estudiosa chega à sua hipótese de que a Tradução deve ser encarada como Retextualização, pois "o texto para o tradutor apresenta os mesmos 'ingredientes' do texto lido pelo [...] leitor comum". (TRAVAGLIA, 2003, p. 22)

Em sua hipótese, a Tradução focalizada como Retextualização é a composição de um novo/mesmo texto que, por sua vez, terá também funcionamento discursivo. As marcas linguísticas do novo texto serão colocadas dentro de uma situação comunicativa concreta e gerarão efeitos de sentidos para os leitores da língua para qual o texto foi traduzido. Então, para ela, todos os fatores de textualidade são importantes, e não somente o código linguístico de partida e o de chegada.

Desse modo, ela afirma que, "dentro do espaço linguístico, com os recursos expressivos disponíveis, são produzidos os discursos” (2003, p.17). Então, defende também que não poderá haver separação rígida e muito menos oposição entre o lado linguístico e o lado discursivo do processo de comunicação. Assim:

É impossível, na atividade comunicativa, se colocar de um lado a língua apenas como sistema estanque, distinto, e de outro lado os usuários, sujeitos da comunicação e as condições de produção/recepção, isto é, as condições de utilização. (TRAVAGLIA, 2003, p.17)

E no que diz respeito ao discurso, Travaglia afirma que "uma língua (português, francês, alemão) é, existe, discursivamente e o discurso é, realiza-se linguisticamente; não há como opor ou separar tais realidades" (2003, p.17, grifo da autora).

Além de afirmar que os discursos não só funcionam com os recursos expressivos de uma língua, mas os colocam em funcionamento, na medida em que modificam, alargando ou, às vezes, reduzindo seu potencial significativo. Essa passagem deixa transparecer os ideais de Meschonnic e sua influência quando ele fala que a tradução tem 
a ver com as transformações das relações interculturais, e isso envolve "esse entrecruzamento de campos que um discurso envolve”, já que, ao pensar em 'discurso', pensa-se em história, cultura, e ideologias que um discurso acarreta.

Neuza G. Travaglia também declara sobre os discursos;

Eles são também resultantes de atividades comunicativas que acontecem sempre dentro de determinadas condições de produção/recepção, mas no decurso do "acontecimento discursivo" tais condições podem ser alteradas, podem evoluir; por esta razão estas não devem ser consideradas apenas como cenários fixos e imutáveis. (2003, p.19)

Dentro de toda essa concepção de discurso, retomemos o conceito de texto citado e pensemos nele como a "unidade geradora de sentidos", a qual propôs Travaglia, e nos voltemos para o sujeito nessa atividade de gerar sentidos. O que temos são novamente sujeitos atuantes nesse processo que vão agir e modificar os sentidos interagindo sempre com e sobre o outro. Em sua abordagem sobre discurso, fica explícita também a forma como ela vê o sujeito. A afirmação supracitada é totalmente viável para entendermos as "marcas das escolhas" feitas pelo tradutor e realizadas no decorrer do processo de composição textual.

Sendo assim, a Tradução como Retextualização vai passar pelas mesmas etapas desse processo (pois se trata da construção de um novo texto) e que, segundo a autora, a parte de composição textual termina na fase de revisão para o produtor, ao passo que o processo textual propriamente dito continua na fase da leitura (de recepção), da construção do sentido pelo leitor.

Nesse momento, ela considera que outros "sujeitos textuais" entrarão e trabalharão a partir do texto "formado e acabado", para comporem seu sentido (TRAVAGLIA, 2003. p.112). Se pensarmos na tradução de textos escritos, veremos que o processo se concretiza como produto e, no caso, a leitura é que é o processo. O leitor busca esquemas internalizados para produzir sentidos no texto traduzido, ou seja, ele retextualiza.

Em suma, em sua obra os discursos são considerados não como objetos materiais, delimitáveis, mas como forma de funcionamento da linguagem resultantes da acumulação mais ou menos organizada e coerente de atividades comunicativas realizadas em determinados tipos de situação de comunicação, em condições sócio-históricas determinadas e com a utilização de recursos linguísticos disponíveis aos sujeitos dos eventos comunicativos. 
Nessa concepção, fica entendido que os falantes (sujeitos) atuam e agem sobre a língua interagindo com ela e sobre ela. Dessa forma, se o sujeito é fruto da relação entre a linguagem e história, para Travaglia a língua é a mais importante condição de base da linguagem como atividade humana.

Travaglia defende que a língua possui um caráter estável (que nos permite aprender e ensinar uma língua e que permite a tradução de textos) e instável (caracterizado pela 'modulação', a possibilidade de escolha por parte dos falantes) da linguagem enquanto atividade, o que acarreta, segundo ela, o dinamismo da língua enquanto produto/processo sempre em andamento.

Sendo a obra de Travaglia (2003) de base teórico-metodológica para a pesquisa sobre Tradução que é proposta aqui, fica evidente que a Tradução como Retextualização realça a entidade TEXTO na atividade tradutória, mostrando que a tradução é produto, mas também processo. A autora pretende, com essa hipótese, uma abordagem mais abrangente, já que é aplicável a todos os tipos de textos, pois, segundo ela, "o fenômeno retextualização se dá independentemente do tipo de texto" (2003, p.191).

Então, na obra em questão, são explicitados muitos dos itens que estão no estabelecimento da textualidade de uma sequência linguística, os quais devem ser considerados pelo tradutor ao retextualizar.

Torna-se, portanto, um trabalho em uma perspectiva textual que chama a atenção para várias questões pertinentes ao processo tradutório, tais como: diferentes modos de conceber a tradução (já que ela faz esse percurso), seus processos e possibilidades; a concepção de texto e discurso e como os fatores e princípios envolvidos afetam a atividade de tradução/retextualização; o estilo e a aplicabilidade da teoria proposta.

Tendo em vista essas concepções, proporemos a análise de um texto o qual fora traduzido do inglês para o português e publicado em um livro didático de inglês para o Ensino Médio. Curiosamente, a obra em questão traz, no manual do professor, todos os textos traduzidos em português. Sendo assim, somente os professores têm acesso a essas traduções. O texto utilizado para esta análise se encontra em anexo.

\section{Discussão e análise}


Dada a popularização da Internet nos dias atuais, fica evidente que os alunos, certamente, sentir-se-ão familiarizados com o assunto e provavelmente terão muito que comentar e discutir sobre esse tema.

Considerando todo o entorno semiótico, vemos que o aparato visual pode ser considerado bem atrativo para os jovens atualmente. Já no título é possível ter, por meio da palavra-chave "blog", a noção do que se trata o texto e essa é, sem dúvida, uma temática bem atual e de interesse dos adolescentes.

Sendo assim, o texto em inglês pode ter uma boa aceitabilidade, e não somente por causa do tema, mas também devido ao fato de que ele contém termos da informática que são conhecidos pelos adolescentes e utilizados por eles em inglês, como exemplo: blog, Weblogs, Weblinks, Web site, high-tech, Internet, Net. Os estudantes provavelmente se sentirão familiarizados com esses termos e, assim, poderão sentir-se mais confiantes em relação ao restante do texto.

Obviamente que, para uma compreensão satisfatória desse texto, é necessário certo nível de "conhecimento partilhado", para que o grupo de estudantes possa interagir e, dessa maneira, "aceitar" o texto, fazendo com que a comunicação tenha êxito. $\mathrm{Na}$ verdade, essa característica - a de que é necessário certo conhecimento partilhado para que haja uma boa interação - é inerente a qualquer texto, visto ser esse conhecimento que vai determinar a medida do interesse por parte do leitor-alvo.

No entanto, também é observado o uso de construções lexicais que podem causar estranheza por serem expressões idiomáticas, por exemplo: “clown around”, "mutual back-scratch society", "curmudgeon", "ankle-biter". Como expressões idiomáticas do inglês, elas demandam procedimentos específicos de tradução, quer seja interlinguais, quer seja intralinguais, para uma melhor interação com o texto. Esse é um exemplo de como a tradução se encaixaria no trabalho com esse texto em sala de aula de língua inglesa.

A autora Stella Tagnin preconiza que "é imprescindível o domínio de expressões idiomáticas e convencionais da linguagem cotidiana", isso porque "são elas, em boa medida, os 'lubrificantes' da interação social, garantindo uma comunicação mais ágil e eficaz" (1989, p. 7). Dessa maneira, entendemos que as expressões acima mereciam um trabalho mais específico com retextualizações para assegurar a comunicação.

De fato, a tradução de expressões idiomáticas está diretamente ligada ao pragmatismo da língua e é preciso reconhecer os aspectos particulares de cada comunidade de fala para qual se traduz algum texto. 
No entanto, observamos que há uma expressão idiomática que foi devidamente trabalhada no texto traduzido, trata-se da descrição de "Weblogging's 'A list"' traduzida como "lista A' de Weblogs" - que imediatamente vem acompanhada de sua explicação no texto, ou seja, uma retextualização intralingual. Essa pode ser considerada uma informação nova, porque nem todos podem ter esse conhecimento prévio, daí o texto pode ser considerado mais interessante ainda, já que o grau de previsibilidade diminuiria.

Porém, temos novamente que considerar que é necessário um bom grau de conhecimento partilhado para que haja a interação com esse assunto. Uma pessoa que não use o computador ou que nunca tenha ouvido falar sobre blogs, por exemplo, teria extrema dificuldade em compreender o texto, pois para essa pessoa esse conhecimento não faria sentido.

Todavia, o texto se apresenta coerente e também coeso, e isso por se situar bem no universo estudantil. Com isso, pensamos que ele terá um elevado grau de aceitabilidade. Em relação aos mecanismos textuais pragmáticos e também aos cotextuais (coesão e coerência), entende-se que o texto traduzido apresenta os mesmo aspectos, isso graças à temática, que pode ser considerada universal, e também, devido ao gênero dissertativo.

No texto traduzido o título foi retextualizado tal qual: "Vivendo na blog-osfera". É interessante observar o uso da palavra em inglês "osphere", constituindo um neologismo provavelmente relacionado à "atmosphere" ou "Stratosphere". Acreditamos que o sentido pretendido seja algo como "era", "tempos". Na verdade o uso do neologismo em inglês funciona tão bem quanto sua tradução literal para o português, causando assim o mesmo efeito de sentido.

Observa-se também que os termos citados antes (blog, web, net, etc.), como pertencentes à era digital, não foram retextualizados para o português, o que é perfeitamente entendido, visto que se constituem de neologismos da linguagem universal da Internet.

Há também um aspecto que é interessante observar na tradução, a ordem vocabular, já que em inglês as palavras são dispostas em determinada ordem e, quando passadas para o português, devem ser "ajustadas" para que se mantenha no texto a harmonia coesiva. Esse é o caso que se observa na tradução do extrato: "an easy-tomaintain journal-like personal Web Site [...]" por "um site pessoal da Web - fácil de manter e parecido com um diário [...]". Essa ordem na tradução foi bem aplicada, tendo em vista a preocupação com a estética bem como a estruturação adequada da frase do texto em português. 
Outra observação sobre neologismos pode ser feita em relação ao uso da expressão "Avatars", que é utilizada em inglês e também não possui uma tradução imediata em português. De acordo com a linguagem digital, pode ser entendido como a representação gráfica de uma divindade hindu. Na verdade, o estudante/leitor e o professor/leitor terão que ter conhecimento partilhado suficiente para dar conta dessas novas terminologias digitais que parecem surgir a cada instante, ou seja, aqueles pertencentes a esse grupo (essa osfera) provavelmente compartilharão desse conhecimento, o que é extremamente necessário para um entendimento completo do texto e para que haja a construção de sentidos desejável, o que estabelecerá a coerência e garantirá a situacionalidade do texto, bem como sua aceitabilidade.

Todavia, analisando a tradução de alguns termos, temos duas traduções interessantes para as palavras "publishers" e "blogger". A primeira (publisher) foi traduzida literalmente por seu correlato "editores". Porém, essa tradução poderá ser um pouco inapropriada, visto que uma possibilidade seria "autores instantâneos", já que eles estariam atuando como autores e não como editores em seus blogs. Em inglês o verbo "publish" tanto pode significar "publicar" como também "editar", porém em português esses verbos não funcionam igualmente - sendo autor quem escreve e publica, e editor quem revisa e/ou editora um texto. Deixando na tradução a palavra "editor", o próprio professor, se não souber essa diferença, poderá transmitir a informação de forma equivocada para seus alunos (considerando que o professor irá utilizar o texto traduzido como ferramenta de informação para a discussão em sala de aula).

Também, tem-se o neologismo "blogger", que permaneceu em inglês na retextualização, o que causou espanto, visto que em português existe um neologismo para esse termo (blogueiro). Então, por que o tradutor preferiu o termo em inglês? Se o livro utiliza a tradução como instrumento para o professor, por que não utilizá-lo em relação a essa palavra? Pode ser que o tradutor desconhecesse o termo em português, esse seria um conhecimento prévio do qual ele não se valeu.

Para finalizar, uma observação sobre o uso de uma expressão em francês que muito chama atenção: "Du jour". Essa expressão estrangeira não recebeu nenhuma nota explicativa e no texto em português ela foi diretamente traduzida por "do momento". Seria interessante utilizar novamente a tradução nesse caso com a exposição de uma nota ilustrativa para esse neologismo.

Enfim, nesse texto a tradução parece ter "seguido os passos" do texto original. Isso pode ser devido ao fato de ser um texto repleto de terminologias novas do mundo digital 
muito utilizadas pelos estudantes, e porque se adequa bem ao grupo pretendido, já que ele representa bem a realidade da juventude atual (da era digital)

\section{O Ensino de Língua Inglesa no Ensino Médio e a Retextualização}

Travaglia (2003), no final de sua obra, propõe uma reflexão sobre "Retextualização e Ensino". Em sua abordagem, a autora considera essa utilização sob dois aspectos: "o ensino da tradução propriamente dita, e o ensino de uma segunda língua com a utilização da tradução" (p. 179). Para essa pesquisadora, o ensino de Tradução é um "trabalho com o texto enquanto um todo".

No entanto, o que mais nos interessa neste trabalho é o segundo aspecto de "retextualização e ensino", isto é, o ensino de uma língua estrangeira via tradução ou o uso desta como recurso auxiliar. Preferencialmente se visará aqui ao uso como recurso auxiliar, haja vista que nossa intenção não é desenvolver nenhum método de ensino baseado na tradução. O nosso objetivo é avaliar o uso de textos traduzidos como ferramenta para o aprendizado de língua inglesa no Ensino Médio.

Há uma reflexão da professora Neuza G. Travaglia que é muito relevante a essa nossa proposta:

No que se refere ao ensino de línguas estrangeiras com a utilização da tradução é importante insistir no fato de que o estudante sempre "traduz". A prática mostra que é impossível impedir o aluno de "traduzir", de comparar, de aproximar o idioma materno do estrangeiro que está aprendendo, uma vez que já domina a língua materna, "pensa" nela e toda a sua vida está nomeada, qualificada, enfim, estruturada nela. Assim, ao invés de ter a tradução como "inimiga" do ensino de língua estrangeira, podemos fazer dela uma "aliada". (2003, p. 182)

Parece que Travaglia "traduziu" bem o que ocorre com os estudantes de línguas estrangeiras. Não é justo querer que eles simplesmente adquiram uma segunda língua em detrimento da materna. Essa não é proposta dos PCNs em relação ao Ensino Médio, é justamente o contrário, ou seja, tem que haver uma valorização da língua materna, e a abordagem do inglês nas escolas pode e deve contribuir para isso.

A tradução, como preconizou Travaglia, pode ser encarada como "aliada", se for utilizada com criatividade e apreço pelos professores. A autora acredita que "se a comunicação só se faz por textos, pela textualização, o ensino de uma segunda língua será mais lógico e até mais natural com a utilização da retextualização" (2003, p. 182). 
O que Travaglia (2003, p. 183) propõe como prática no ensino tanto de tradução como de uma língua estrangeira deve levar em conta:

a) a capacidade do aluno de controlar fatores que afetam o traduzir enquanto retextualização, buscando na segunda língua recursos capazes de produzir efeitos de sentido semelhantes aos que os recursos utilizados na língua de origem produzem em textos dados em dadas situações de comunicação; ou seja, buscar elementos da segunda língua que enquanto marcas, contenham pistas e instruções relacionais e de sentido, capazes de levar à consecução da intenção comunicativa desejada;

b) a competência comunicativa do aluno na segunda língua, quer dizer, sua capacidade de usar de forma eficiente e adequada os diversos recursos (linguísticos ou não) em diferentes situações de interação comunicativa, para a produção de efeitos de sentido pretendidos;

c) que o processo comunicativo (a tradução em especial) é algo dinâmico, onde o sentido se constrói à medida que vai evoluindo e que cada texto é único e irrepetível. Assim o aluno deverá ser capaz de superar dificuldades e impasses que só a opção de leitura aceita e assumida explica e resolve.

Percebe-se que a abordagem de Travaglia constitui-se numa visão não normativa, complementada com profundas reflexões a partir de uma visão realista de pesquisadora e professora. Nesse sentido, consideramos de especial interesse a ideia dessa autora (2003, p. 183) de que "[...] o processo comunicativo e a tradução em especial é algo dinâmico, onde o sentido se constrói à medida que vai evoluindo e que cada texto é único e irrepetível [...]", dado, é claro, seu posicionamento na Linguística Textual e sua visão da tradução como Retextualização.

A pesquisadora demonstra também que, ao acreditar que a intenção comunicativa é dinâmica e é construída à medida que o autor vai compondo seu texto, então o sentido também é reconstruído a cada leitura de cada indivíduo, mostrando, assim, que sua visão da comunicação humana e do processo de tradução é complexa e sistêmica.

Alguns autores enfatizam essa preocupação em interagir a Tradução com o ensino de uma maneira geral, como é o caso de Alison Cook-Sather (2006), em sua obra "Education is Translation", que traz uma redefinição radical das promessas e possibilidades dessa relação ensino/aprendizado. $O$ autor preconiza que a educação pode ser entendida como um processo de tradução por intermédio do qual o aprendiz desempenha ambos os papéis de tradutor e de sujeito de sua própria tradução. Percebese nessa obra a influência de campos como a Antropologia, Literatura, Psicologia, Estudos da Tradução e Teorias da Educação. É uma proposta diferente da de Travaglia, porém é um exemplo de um estudo que explora várias experiências educacionais e proporciona reflexões necessárias com o objetivo de desenvolver estratégias de 
ensino/aprendizado, tanto para o professor como para o aluno. Essa é uma visão diferente, no entanto, inovadora sobre tradução.

Uma pesquisadora que se destaca nos estudos de "Tradução e Ensino de Língua Estrangeira" é Lillian DePaula, que acredita que "longe de inibir a aprendizagem de uma língua estrangeira, a prática da tradução pode proporcionar uma maior compreensão das semelhanças e diferenças entre duas línguas, levando o aprendiz a realizar uma leitura mais aguçada das línguas em contato" (2005, p.57).

Para DePaula o pouco uso que se faz da tradução em sala de aula se constitui em um uso equivocado. Esse sentimento é percebido na passagem abaixo:

Enquanto o uso da tradução desponta em relevância nas áreas de estudos literários e culturais, na área pedagógica e no ensino de língua estrangeira, no entanto, ainda não é suficientemente considerada. Para uma grande legião de professores, a tradução é prática para ser rigorosamente evitada ou da qual se abusa para avaliar, punir ou simplesmente fazer que aconteça uma aula, com o professor passando um texto de nenhuma relevância, solicitando uma tradução e, sem mais ou menos discussão, despedindo-se até a próxima aula, quando a tradução nem sequer será retomada. (2005, p. 61)

A visão de DePaula é extremamente realista no que concerne ao ensino de língua inglesa, especialmente em escolas da rede pública de Ensino Médio, que preconizam o ensino de textos.

Portanto, como mostrado no texto analisado neste trabalho, acreditamos que o uso da tradução no aprendizado de língua inglesa no Ensino Médio pode ser considerado uma rica estratégia para que os estudantes tenham a oportunidade de avaliar e discutir as diferentes enunciações que serão produzidas em diferentes contextos de situação e cultural. Entendendo melhor essas diferenças, os estudantes poderão se familiarizar mais com a língua inglesa, elevando assim o grau de aceitabilidade em relação aos textos propostos.

Apesar de tímidas propostas de atividades que utilizam a tradução, observamos que existem estudiosos no contexto pedagógico (professores, autores, e até estudantes) que sentem a necessidade de uma abordagem da tradução no ensino da língua estrangeira, talvez por se sentirem mais confiantes. Esses pesquisadores enxergam na tradução a possibilidade de agregar valores ao ensino de uma língua estrangeira. 


\section{Referências Bibliográficas}

ABAURRE, Maria Bernadete M.; FIAD, Raquel Salk; SABINSON, Maria Laura T.M. \& GERALDI, João Wanderley. Considerações sobre a utilização de um paradigma indiciário na análise de refacção textual. Trabalhos em Linguística Aplicada. 1995. 25: 1-25. ADAM, Jean-Michel. A Lingüística Textual: introdução à análise textual dos discursos. Revisão técnica, Luis Passeggi, João Gomes da Silva Neto. Vários tradutores. São Paulo: Cortez, 2008.

BEAUGRANDE, R.de \& DRESSLER, W. Introduction to Text Linguistics. London: Longman, 1981.

COOK-SATHER, Alison. Education is Translation: a metaphor for change in learning and teaching. Philadelphia: University of Pennsylvania Press. 2006.

COSTA, W.C. The translated text as re-textualisation. In: M. Coulthard (Ed.) Ilha do Desterro: studies in translation / Estudos de tradução. Florianópolis: Editora da UFSC (1992a).

COSTA VAL, M. da G. Texto, Textualidade e Textualização. In: CECCANTINI, J. L. Tápias; PEREIRA, Rony F.; ZANCHETTA JR, Juvenal. Pedagogia Cidadã: cadernos de formação: Língua Portuguesa. Vol. 1. São Paulo: UNESP, Pró-Reitoria de Graduação, 2004, p. 113-128.

DePAULA. Lillian V. Franklin. Uma Pedagogia da Tradução. In Tradução e Comunicação. São Paulo, n. 14, p. 57-65, 2005.

FIAD, Raquel Salk \& MAYRINK-SABINSON, Maria Laura T. A escrita como trabalho. In: MARTINS, Maria H. (org.). Questões de Linguagem. São Paulo, Contexto, 1991, PP. 5463.

HALLIDAY, M.A.K., \& HASAN, Ruqaiya. Language, Context, and text: aspects of language in a social-semiotic perspective. Oxford University Press, 1985. . Cohesion in English. London: Longman, 1976.

$\overline{\mathrm{KOCH}}$, Ingedore G. Villaça. Argumentação e linguagem. São Paulo: Cortez, 1984. A Coesão Textual. 19 ed. - São Paulo: Contexto, 2004.

MARCUSCHI, L. A. Da fala para a escrita: atividades de retextualização. São Paulo: Cortez, 2001. Produção Textual, análise de gêneros e compreensão. São Paulo: Parábola Editorial, 2008, 296 p.

TRAVAGLIA, Neuza Gonçalves. Tradução Retextualização: a tradução numa perspectiva textual. São Paulo: EDUFU, 2003, 239 p.

\section{Bibliografia de Apoio}

Longman Dictionary of Contemporary English: the living dictionary. Longman: Pearson Education. 2004.

Orientações curriculares para o Ensino Médio. Linguagens, Códigos e suas Tecnologias.

Brasília: Ministério da Educação, Secretaria de Educação Básica. 2008.

Oxford Escolar para Estudantes Brasileiros de Inglês. Oxford: Oxford University Press,1999. 


\section{Anexo}

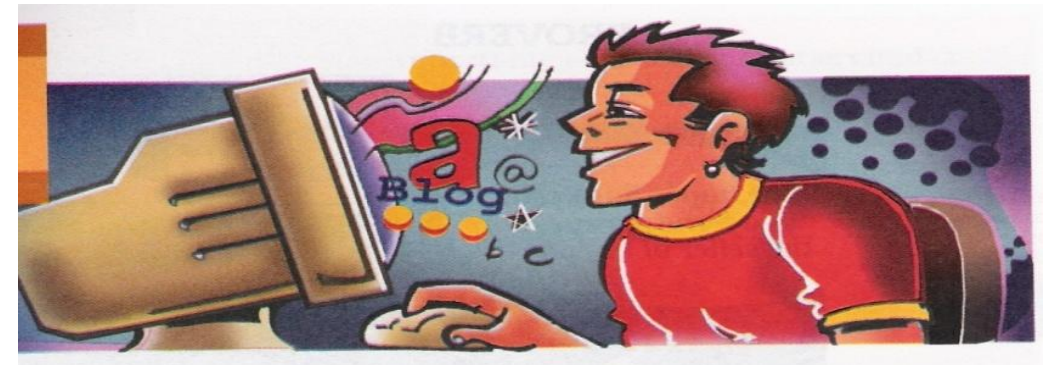

Living in the blog-osphere

Welcome to the world of a half million (and counting) Weblogs, where anyone can instantly publish his passions and favorite Weblinks. And the fun has just begun.

Zack was an insecure kid who clowned around in high school and felt that no one really liked him. About a year ago he started a Weblog, or blog - an easy-to-maintain journal-like personal Web site where he could express his feelings and share his songs, poems and artwork with his classmates. "I thought that people would like me if they truly knew me," explains Zack, now 18. As the journal became well known in the school, Zack saw the As the journal became "well known in the hoped for: "My friends found me."

Zack, with 28 readers a day, isn't part of Weblogging's "A list," an intricate mutual back-scratch society that includes clever curmudgeons, high-tech avatars and angry ankle-biters who ferociously snipe at traditional media. He is, however, a truer representative of the blogging boom that's making people into instant publishers, newshounds and public diarists - and helping the Internet make good on some of its heady promises of persona] empowerment.

Indeed, with a new blogger joining the crowd every 40 seconds, Weblogs are officially the explosion du jour on the Net. Most estimate the current number at a half a million Weblogs in the so-called Blog-osphere (the name given to the collective alternate universe consisting of all active Weblogs).

(Newsweek, Aug. 26, 2002, p. 42

LIBERATO, 2004, p.44

\section{Segue abaixo a tradução desse texto publicada na parte do manual do professor:}

\section{Vivendo na blog-osfera}

Bem-vindo ao mundo de meio milhão (e que continua crescendo) de Weblogs, onde qualquer um pode publicar instantaneamente suas paixões e Weblinks favoritos. E a diversão está apenas começando.

Zack era uma criança insegura que fazia palhaçadas no colégio onde cursava o Ensino Médio e sentia que ninguém gostava dele de verdade. Cerca de um ano atrás, ele começou um Weblog, ou blogum site pessoal na Web - fácil de manter e parecido com um diário no qual ele podia expressar seus sentimentos e compartilhar suas músicas, poemas e trabalhos de arte com seus colegas. "Eu pensava que as pessoas gostariam de mim se elas realmente me conhecessem", explica Zack, agora com 18 anos. À medida que o diário se tornava bem conhecido na escola, Zack viu a mudança que esperava: "Meus amigos me encontraram".

Zack, com 28 leitores por dia, não faz parte da "lista A" de Weblogs, uma intrincada sociedade composta de pessoas que se ajudam mutuamente de forma interesseira, que inclui bárbaros espertalhões, avatars da alta tecnologia e criancinhas furiosas que atacam ferozmente a mídia tradicional.

No entanto, ele é um representante mais verdadeiro da explosão dos blogs que está transformando as pessoas em editores instantâneos, caçadores de notícias e escritores públicos de diários - e ajudando a Internet a cumprir uma de suas promessas principais de motivação pessoal.

Além disso, com um novo blogger (escritor de blog) juntando-se à multidão a cada 40 segundos, os Weblogs são oficialmente a explosão do momento na Net. Muitos estimam o número atual em meio milhão de Weblogs na chamada Blog-osfera (o nome dado ao universo alternativo coletivo composto de todos os weblogs ativos). 


\title{
SISTEMA DE GÊNEROS EM INTERAÇÕES MEDIADAS POR COMPUTADOR
}

\author{
GENRE SYSTEM IN COMPUTER-MEADIATED INTERACTIONS
}

\author{
Nathasa Rodrigues Pimentel \\ $\mathrm{UNESP}^{48}$ \\ nathasa.nina@gmail.com
}

\begin{abstract}
RESUMO: Esta pesquisa tem como objeto de estudo as atividades desenvolvidas durante as sessões de Teletandem, e seu respectivo sistema de gêneros entre pares interagentes distintos. O Projeto Teletandem Brasil: línguas estrangeiras para todos visa facilitar a interação de falantes nativos de diversos países na a troca de conhecimentos linguísticos e culturais através do processo de colaboração online. Para isso, o projeto utiliza ferramentas tecnológicas (Skype, MSN Messesnger, Oovoo) para colocar falantes nativos de diferentes partes do globo em contato, cada um ensinando sua língua e aprendendo a do outro de maneira colaborativa. A diretriz teórica utilizada na realização deste trabalho é a perspectiva sócioretórica de gênero em Swales (1990) e Bazerman (2005). O corpus da pesquisa é composto por: i) gravações de áudio e vídeo das interações de duas duplas interagentes de português/inglês; ii) todas as produções textuais desenvolvidas pelos interagentes brasileiros no período em que as interações eram realizadas. A realização desta pesquisa buscou: levantar as atividades que permeiam as interações de Teletandem, e a sequência de eventos em que os textos são produzidos, e identificar o sistema de gêneros presente na realização das interações de Teletandem.
\end{abstract}

PALAVRAS-CHAVE: gênero; sistema de gêneros; sistema de atividades; Teletandem

ABSTRACT: This research aims to study the activities developed during the sessions of Teletandem, and its respective genre between distinct interacting pairs. The Teletandem Brazil Project: foreign languages for all aims to facilitate the interaction of native speakers from different countries, to exchange language skills and cultural through the process of online collaboration. For this, the project uses technology tools (Skype, MSN Messesnger, Oovoo) to put native speakers from different parts of the globe in contact, each teaching their language and learning from each other in a collaborative manner. The theoretical guideline used in this study is the socio-rhetoric of genre in Swales (1990) and Bazerman (2005). The research corpus is composed by: i) audio and video recordings of interactions of two pairs of interacting Portuguese / English; ii) all textual production developed by Brazilians interacting in the period in which the interactions were carried out. This research aimed: to raise the activities that mediate interactions of Teletandem, and the sequence of events in which texts are produced, and identify the genre system in carrying out this Teletandem interactions.

KEYWORDS: genre; system of genre; system of activities; Teletandem

\footnotetext{
${ }^{48}$ Mestranda - Universidade Estadual Paulista Júlio de Mesquita Filho/São José do Rio Preto
} 


\section{INTRODUÇÃO}

Esta pesquisa tem como objeto de estudo o sistema de gêneros das atividades realizadas durante as interações do Projeto Teletandem Brasil "Línguas Estrangeiras para Todos". O sistema de gêneros é uma definição utilizada por Bazerman (2005) que abarca os gêneros utilizados por indivíduos envolvidos na realização de uma tarefa.

O estudo do sistema de gêneros, aqui realizado, é direcionado teoricamente a partir de trabalhos desenvolvidos "dentro do campo da sócio-retórica", envolvendo principalmente os estudos de Swales (1990) e Bazerman (2005).

Os estudos desenvolvidos por Swales (1990) e Bazerman (2005) relacionados a gêneros têm trazido à tona questões que o enfatizam como uma realização social, envolvendo ciclos de textos e atividades que organizam, articulam e configuram sua estrutura. Nesse sentido, Bazerman (2005) afirma que em sequência de eventos sociais, uma quantidade significativa de textos é produzida por meio de uma série de atividades, as quais conduzem a um sistema organizado e de fácil compreensão para a comunidade em que textos específicos são produzidos. Os textos produzidos na sequência de eventos "se acomodam em conjuntos de gêneros dentro de sistemas de gêneros, os quais fazem parte dos sistemas de atividades humanas" (p. 22).

O corpus desse estudo compõe-se de interações de dois pares nativos falantes de inglês e português, e também de diários, e-mails e redações dos interagentes brasileiros. As interações gravadas no Laboratório de Teletandem da Universidade Estadual Paulista Júlio de Mesquita Filho - UNESP, Campus de São José do Rio Preto - São Paulo, foram registradas em áudio e vídeo, ao todo dezesseis arquivos, oito de cada dupla, gravadas de março a maio de 2011.

Com o desenvolvimento desta pesquisa buscou-se alcançar os seguintes objetivos: verificar quais são as atividades que permeiam as interações de Teletandem, e a sequência de eventos em que os textos são produzidos; investigar a organização e articulação das atividades realizadas durante uma interação de Teletandem, as quais conduzem os interagentes à produção de textos; e observar as condições de produção e recepção de textos produzidos pelos interagentes durante a realização das conversas. 


\section{METODOLOGIA}

Dados os objetivos de pesquisa, será utilizada no desenvolvimento das atividades uma metodologia de pesquisa qualitativa, através de um estudo de caso descritivo. $O$ estudo de caso descritivo é, segundo Leffa (2006), "um tipo de pesquisa qualitativa, com ênfase maior na exploração e descrição detalhada de um determinado evento ou situação". O estudo de caso é uma estratégia metodológica que consiste na abordagem de situações específicas dentro de um contexto. Tal estratégia de pesquisa será utilizada para investigar e analisar detalhadamente a organização das tarefas desenvolvidas pelos sujeitos, nos instrumentos e procedimentos envolvidos nas sessões de Teletandem.

No decorrer da coleta de dados foram gravadas as interações de duas duplas participantes do Projeto Teletandem Brasil: "Línguas Estrangeiras para Todos" na UNESP - Universidade Estadual Paulista "Júlio de Mesquita Filho". Cada dupla era composta por falantes nativos de português e inglês. Além das gravações em áudio e vídeo foram coletados os e-mails trocados entre os parceiros, os diários das interações feitos pelos participantes brasileiros e ainda as redações produzidas e enviadas ao parceiro Norte Americano para correções gramaticais.

Em seguida à coleta de dados foi realizado um mapeamento das atividades realizadas pelos interagentes para identificação da sequência de ações. Mapear a sequência ações permitiu identificar regularidades em ações sócio-retóricas relativas à produção, circulação e uso dos gêneros pelos participantes, gêneros esses que compõem o sistema de gêneros do Projeto do Teletandem Brasil.

\section{FUNDAMENTAÇÃO TEÓRICA}

No campo de estudos linguísticos há a preocupação de se compreender as várias práticas de leitura, escrita e oralidade como realizações comunicativas nas diversas comunidades sociais. Entender como essas práticas comunicativas circulam na sociedade ajuda na compreensão de como a sociedade e os indivíduos que nela vivem se organizam para a realização de tarefas.

Os indivíduos são os responsáveis pela organização de textos para a realização de atividades no meio em que vivem, e por ajustes desses textos para se adaptarem melhor às novas necessidades que surgem no dia a dia. Os textos são realizados através das manifestações enunciativas verbais humanas da língua, desenvolvidos no coletivo 
linguístico (MARCUSCHI, 2006). A linguagem materializada por meio de textos, orais ou escritos, diz respeito ao fruto da realização da comunicação organizada em sociedade.

A concretização da atividade comunicativa compartilhada por indivíduos de uma sociedade ocorre em uma sequência de eventos comunicativos. Swales (1990) apresenta que os eventos comunicativos são as situações cotidianas de comunicação motivadas por interesses individuais ou coletivos, relacionadas às questões pessoais, profissionais, acadêmicas etc., compreendidos não somente no discurso e nos participantes, mas no desempenho exercido por esse discurso e pelo contexto de interação, que levam as pessoas à realização de um objetivo comunicativo dentro da comunidade.

Os gêneros fazem parte dos eventos comunicativos compartilhados por indivíduos de uma sociedade (Swales, 1990). Os gêneros são historicamente construídos e apresentam características funcionais e organizacionais que refletem as situações contextuais de sentido no ambiente em que são utilizados.

\subsection{AS CONCEPÇÕES DE GÊNERO}

De acordo com Swales (1990), as comunidades discursivas são capazes de desenvolver gêneros e um léxico próprio para a comunidade que seja útil para a realização de seus objetivos. As comunidades discursivas dizem respeito a determinados grupos que retêm um conhecimento de prática razoável dos gêneros que utilizam em situações cotidianas pessoais e profissionais. Os membros de uma comunidade discursiva são capazes de identificar e compartilhar propósitos comunicativos dentro das ocorrências linguísticas estabelecidas em seu grupo.

Hemais e Biase- Rodrigues (2005) destacam no trabalho de Swales (1990) que o conceito de comunidade discursiva está relacionado ao ensino de produção textual, na realização de uma atividade social, por comunidades que utilizam o discurso em suas interações. A comunidade discursiva mostra então os conceitos convencionais estabelecidos em seu meio, que são repassados a novos membros, e é caracterizada por seu conjunto de objetivos em comum, por mecanismos de comunicação entre os participantes da comunidade, pela função e troca de informações na comunicação dentro da comunidade, pela capacidade de desenvolver e aperfeiçoar o próprio conjunto de gêneros, e pelo léxico com significado específico na comunidade.

Os gêneros fazem parte do propósito comunicativo em uma comunidade discursiva. A comunidade discursiva diz respeito aos usuários de gêneros que compartilham o mesmo objetivo, mantendo uma comunicação com mecanismos próprios 
que efetivem a interação e a troca de informações entre seus membros. Tais membros têm a capacidade de adaptar o léxico utilizado em seu meio para desenvolver uma interação que sirva aos propósitos comunicativos do grupo para alcançar seus objetivos comunicativos.

Swales (1990) explica que para entender e interpretar um texto qualquer é necessário entender o contexto em que ele foi produzido e as ações que o geraram. A postura do autor em relação ao gênero reúne diversos conceitos, vista que é construída a partir dos resultados obtidos de estudos compostos por vários campos de estudos: folclóricos, literários, linguísticos e retóricos. (ARANHA, 2004).

Hemais e Biase-Rodrigues (2005) trazem que no estudo desenvolvido por Swales (1990), no campo folclórico "os gêneros teriam um valor sociocultural na medida em que atendem às necessidades sociais e espirituais dos grupos sociais (p. 111). Ao do que ocorre no campo folclórico, no campo literário "há a preocupação em mostrar como as convenções são quebradas por autores que, assim, estabelecem um significado próprio e a originalidade de sua obra" (HEMAIS e BIASI-RODRIGUES, 2005, p. 111). Assim, há destaque para a não-estabilidade da forma do gênero, mostrando que não há forma fixa nem regulamentos que não possam ser inovados. Essa visão literária relacionada ao conceito de gênero mostra que os gêneros passam por um processo de evolução e mudança, acompanhando as necessidades humanas.

No campo linguístico, o gênero é pensado nos conhecimentos sistêmicos e etnográficos, expressando a forma de ação na linguagem, deixando à mostra os comportamentos verbais expressos pelas comunidades. Dessa maneira, no campo linguístico "o gênero se faz através do discurso e por isso a análise de estruturas discursivas se integra na abordagem dos estudos de gêneros" (HEMAIS e BIASIRODRIGUES, 2005, p. 112). No campo da retórica, Hemais e Biasi-Rodrigues (2005) afirmam que Swales (1990) "entende que um texto que ilustra um tipo de discurso é categorizado de acordo com o elemento que recebe maior destaque no processo comunicativo" (p. 112). Partindo dessa afirmação é possível destacar que os elementos do discurso revelam nos textos características expressivas, persuasivas, literárias e referenciais, além de levarem em conta o contexto do discurso, o qual revela as finalidades do texto para uma determinada comunidade.

Dessa forma Swales (1990) postula que

Um gênero compreende uma classe de eventos comunicativos, cujos membros compartilham os mesmos propósitos comunicativos. Tais propósitos são reconhecidos pelos membros especialistas da comunidade 
discursiva de origem e, portanto, constituem o conjunto de razões (rationale) para o gênero. Essas razões moldam a estrutura esquemática do discurso e influenciam e impõem limites à escolha de conteúdo e de estilo. O propósito comunicativo é o critério privilegiado que faz com que o escopo do gênero se mantenha relacionado estreitamente com uma determinada ação retórica compatível com o gênero. Além do propósito, os exemplares do gênero demonstram padrões semelhantes, mas com variações em termos de estrutura, estilo, conteúdo e público-alvo. Se forem realizadas todas as expectativas em relação àquilo que é altamente provável para o gênero, o exemplar será visto pela comunidade discursiva original como um protótipo. Os gêneros têm nomes que são herdados e produzidos pelas comunidades discursivas e importados por outras comunidades. Esses nomes constituem uma comunicação etnográfica valiosa, porém tipicamente precisam de validação adicional (SWALES, 1990 , p. 58). ${ }^{49}$

Nessa concepção de Swales (1990) supõe-se que a estrutura retórica do gênero seja passível de ser reconhecida. O termo gênero, segundo o autor, se refere a entidades dinâmicas, que podem sofrer transformações de acordo com as condições sociais e históricas em que são produzidos para atender às finalidades diversas de uma determinada comunidade. Dessa forma, o gênero para Swales (1990) é uma classe de eventos comunicativos, caracterizado pela realização da linguagem verbal e constituído pelo discurso, pelas pessoas envolvidas no discurso, pelo objetivo e contexto de produção e recepção do discurso.

Bazerman (2005) entende que os atos de fala se realizam em formas de textos padronizados, ou como o autor chama, gêneros, os quais mantêm relação com outras formas textuais que se realizam em ocorrências a que estejam relacionadas. $O$ autor afirma que todo enunciado congrega atos de fala e que os textos são parte da maneira como as pessoas desenvolvem as atividades em sociedade. Dessa forma, quando estão juntos, "os vários tipos de textos se acomodam em conjuntos de gêneros dentro de sistemas de gêneros, os quais fazem parte dos sistemas de atividades humanas" (p. 22).

Bazerman (2005) propõe que os textos são mediadores da presença dos indivíduos no mundo, e que os textos comportam as atividades desenvolvidas pelos participantes na mediação interativa entre escritor, texto e leitor. Os textos estão assim ligados a fatos sociais, e em uma sequência de eventos quaisquer, muitos textos são produzidos, seguidos de inúmeros fatos sociais realizados por indivíduos pertencentes a um ciclo de atividades. Dessa maneira, o autor salienta que os gêneros textuais unificam e organizam as práticas sociais.

${ }^{49}$ Tradução de Biasi-Rodrigues, Hemais e Araújo (2009) 
O primeiro conceito teórico referente à acomodação dos vários tipos de textos apresentado por Bazerman (2005), conjuntos de gêneros, diz respeito à coletânea de textos que um indivíduo inserido em uma determinada atividade produz para a realização de um objetivo. Esse conceito está relacionado à produção de cada um, aos de gêneros que cada pessoa desenvolve para realizar ações individualmente. $O$ conjunto de gêneros está associado a situações de produção de textos específicos, e que fazem parte de uma sequência para o cumprimento de uma determinada tarefa no processo interacional, em que uma pessoa utiliza um número finito de "gêneros de textos" para realizar um trabalho.

Os gêneros contidos no conjunto de gêneros possuem uma ligação intertextual entre si e com outros conjuntos de gêneros, ou seja, cada gênero faz referência implícita ou explícita a outro dentro de um sistema, na relação de organização coletiva de produção de documentos. Isso é chamado por Bazerman (2005) de sistema de gêneros, em que a realização de um trabalho coletivo ocorre onde pessoas se unem e utilizam vários tipos de gêneros na realização de uma ou mais tarefas quaisquer. Um sistema de gêneros envolve a sequência de um gênero em outro no processo de andamento comunicativo típico em um grupo de indivíduos na produção e circulação padronizada de documentos.

Para Bazerman (2007),

Um sistema de gêneros é constituído de vários conjuntos de pessoas trabalhando juntas numa maneira organizada mais as relações padronizadas de produção, fluxo e usos desses documentos. Assim, um sistema de gêneros captura as seqüências regulares de como um gênero segue outro nos fluxos comunicativos típicos de um grupo de pessoas. (BAZERMAN, 2007, p. 173)

Durante o processo de produção dos gêneros, são realizadas atividades que organizam os textos, ou seja, o que o autor define como o sistema de atividades. Bazerman (2007), subsidiado por discussões de Russell (1997b) afirma que o sistema de atividades especifica "as noções subjacentes à situação e à atividade que ligam participantes e textos juntos num sistema de gênero". Assim, os gêneros são considerados como instrumentos responsáveis pela mediação das "atividades regularizadas do sistema".

Tais atividades englobam o sistema de gêneros, e no caso da produção escrita há a necessidade de organizar essas situações, por meio de regras gerais de adequação e correção, uma vez que cada área requer um sistema de atividades a ser seguido para a realização de uma tarefa. Para Bazerman (2005) "levar em consideração o sistema de 
atividades junto com o sistema de gêneros é focalizar o que as pessoas fazem e como os textos ajudam as pessoas a fazê-lo em vez de focalizar os textos em si mesmo" (p. 34).

Assim, um sistema de atividades seria as ações realizadas dentro de ordens comunicativas, com estratégias que convenham a determinado grupo para atingir determinados objetivos. Um sistema de atividade é uma entidade heterogênea, composta por inúmeros elementos e regras responsáveis pela realização de um determinado gênero. O sistema de atividade está locado na realização do gênero.

Ao entrar no conceito de gênero, Marcuschi (2008) afirma que o gênero é uma prática social com "modelos correspondentes a formas sociais reconhecíveis nas situações de comunicação em que ocorrem" (p. 84). O conceito de gênero está ligado às atividades discursivas desenvolvidas em o que o autor chama "etapas esquematizantes". Tais etapas esquematizantes são desenvolvidas de acordo com a exigência da configuração do gênero escolhido, o roteiro para desenvolver esquemas que funcionem discursivamente para a finalidade estabelecida. Assim, o gênero é constituído a partir da necessidade de um grupo específico para se organizar e realizar determinadas tarefas. $\mathrm{O}$ autor diz ainda que

Gênero textual refere os textos materializados em situações comunicativas recorrentes. Os gêneros textuais são os textos que encontramos em nossa vida diária e que apresentam padrões sociocomunicativos característicos definidos por composições funcionais, objetos enunciativos e estilos concretamente realizados na integração de forças históricas, sociais, institucionais e técnicas. (MARCUSCHI, 2008, p. 155)

Essa concepção de gênero se afasta um pouco da de Swales (1990) e Bazerman (2005) no que diz respeito ao fato de os gêneros serem entidades dinâmicas que podem sofrer alterações dependendo da necessidade de adaptação do gênero para uma determinada comunidade.

Bonini (2004) explicita que para Swales (1990) o gênero é considerado um tipo de texto característico, no qual o foco se concentra nas atividades interativas que compreendem os eventos comunicativos relacionados ao propósito comunicativo de uma determinada comunidade. E em Marcuschi (2002), Bonini (2004) traz que os gêneros são considerados realizações culturais, sociais e históricas produzidos a partir de práticas sociais específicas.

O ponto de contato das teorias sobre gênero de Swales (1990), Bazerman (2005) e também Marcuschi $(2002 ; 2008)$, está na questão em que se refere que a linguagem é uma atividade realizada em sociedade e desenvolvida por processos interativos (ações), 
os quais necessitam de compreensão e da construção de um sentido para que haja a comunicação. Em outras palavras, a linguagem é uma atividade interativa, cognitiva, e uma forma de ação realizada por membros de uma sociedade. Nos três autores, percebese que os gêneros fazem parte do nosso cotidiano, e possuem características comuns, e diferentes que lhes são atribuídas de acordo com a necessidade da realização comunicativa social.

$\mathrm{Na}$ sociedade atual o surgimento de novas tecnologias e da cultura eletrônica proporciona o aparecimento de gêneros emergentes na mídia digital, e também a necessidade de adaptação de gêneros para atender às especificidades das condições desse novo processo tecnológico interativo.

\subsection{GÊNEROS E AS NOVAS TECNOLOGIAS}

As novas tecnologias têm derrubado as fronteiras ao redor dos campos de conhecimentos e aberto espaço para o surgimento de novos gêneros textuais. Xavier (2005) discorre sobre a importância de a sociedade aprender a conviver com os novos meios digitais de circulação de textos, uma vez que eles estão cada vez mais acessíveis à população. O autor fala em uma nova ordem mundial, a "Tecnocracia", que está relacionada diretamente à globalização no contexto econômico e à "informação digital" que circula no meio tecnológico. Isso é chamado por Xavier (2005) de "(hiper) textualizar", ou seja, uma nova maneira de decifrar o mundo por meio de instrumentos tecnológicos, responsáveis pela mediação das relações entre as pessoas inseridas na "Sociedade de Informação".

Pierre Lévy (1996) afirma que o meio virtual "afeta hoje não apenas a informação e a comunicação, mas também os corpos, o funcionamento econômico, os quadros coletivos da sensibilidade ou o exercício da inteligência" (p. 11). Com base nisso, pode-se perceber que a tecnologia eletrônica e a mídia virtual, que fazem parte dos novos meios de comunicação, possibilitam a ampliação e diversificação do acesso das pessoas a processos interativos, seja através do intercâmbio de ideias, ou da discussão destas, sobre os mais diversos assuntos com diferentes pessoas ao redor do globo em tempo real.

Marcuschi (2003) traz que o surgimento das novas tecnologias proporcionou a adaptação de gêneros para atender demandas surgidas nesse espaço intermediário gerado pela linguagem hipertextual. Essa Comunicação Mediada por Computador (doravante CMC) possibilita um processo de troca de conhecimentos de forma mais ágil, 
e favorece o "surgimento" de novas formas de gêneros. O e-mail (correio eletrônico) e o chat (bate-papo virtual) são dois exemplos de gêneros virtuais com características próprias, mas que emergem de gêneros primários.

De acordo com o Dicionário de gêneros textuais (COSTA, 2008, p. 88), o gênero email é caracterizado como um "bate-papo virtual, chat, correio eletrônico, mensagem, torpedo", ou seja, uma mensagem eletrônica escrita, com características linguísticas próprias, mas que emergiu do gênero carta, que apresenta características como remetente, data e destinatário.

O gênero chat (COSTA, 2008, p. 56) se apresenta como

bate-papo virtual, conversa, conversação informal teclada em tempo real através da Internet, portanto virtual. Caracteriza-se como uma escrita abreviada, sincopada, parecida com a escrita escolar inicial. Os usuários de Internet usam um código discursivo complexo (alfabético, semiótico, logográfico) em que simultaneamente, misturam alfabeto tradicional, caretinhas, scripts, etc. para "conversar" teclando, portanto escrevendo. Usam abreviações, síncopes e outros recursos (alongamentos, caixa alta, etc.). Trata-se de um novo código discursivo e cultural, espontaneamente construído, que se caracteriza como um conjunto de recursos icônicos, semióticos, logográficos, tipográficos e telemáticos. (p. 56)

Há a situação de troca de mensagens instantâneas no chat. Os chats seriam, no ponto de vista de Araújo (2005), uma "transmutação" do diálogo realizado no dia-a-dia para o meio virtual. Tal posição pode ser revisada, uma vez que nem todos os usuários de chats utilizam uma linguagem coloquial durante a conversa. Há tipos de chats, como as salas de aula virtuais, em que os participantes tendem a se comportar de maneira semelhante a se estivessem em uma aula presencial, portanto, fazem uso da linguagem padrão de norma culta.

É necessário se considerar os aspectos linguísticos presentes em cada situação comunicativa. Conforme Cavalari (2007), o ambiente virtual é um "canal que facilita e restringe nossa habilidade de comunicação de maneiras que são fundamentalmente diferentes daquelas encontradas em outras situações semióticas". O processo de materialização da língua falada em escrita por meio de chats, por exemplo, seria uma transmutação do diálogo do suporte da fala para o ambiente na web (chat).

\section{APRENDIZAGEM EM TANDEM}

Atividades em tandem são, de acordo com Macaire (2004, apud TELLES, 2006, p. 7), atividades desenvolvidas em pares que se encontram em uma "necessidade de troca". 
No processo de aprendizagem de línguas in-tandem há o envolvimento de pares falantes nativos de línguas diferentes, os quais trabalham de forma colaborativa para aprender a língua do outro. Assim, cada um dos interagentes é aprendiz da língua de seu parceiro tutor do parceiro, em um processo de troca de conhecimentos e experiências, o que proporciona ao par interagente uma maior autonomia no processo de aquisição de uma língua estrangeira.

$\mathrm{Na}$ definição de Brammerts (2002) o "objetivo da comunicação em tandem é a aprendizagem", isso, de acordo com o autor, partindo-se do princípio que um dos interagentes visa aprimorar seus conhecimentos e aptidões, e o outro parceiro compartilha desse princípio de ajudar e aprender. No processo de compartilhamento de conhecimentos linguísticos, os aprendentes fazem uso das duas línguas. Assim, aprendem com um parceiro nativo da língua alvo, o qual faz correções que julga pertinente durante as interações.

Os parceiros que interagem em um processo tandem são beneficiados por uma comunicação autêntica. A comunicação em circunstância autêntica proporciona aos parceiros a argumentação sobre qualquer assunto, levando em conta os valores, a personalidade e as necessidades do outro na conversa, além de contar com um tempo e dedicação maior na comunicação.

Brammerts (2002) afirma que

Em cada diálogo tandem, as circunstâncias da vida, as experiências e os conhecimentos do parceiro transformam-se no tema quase natural da conversa; ambos querem falar de si e ficar a saber mais sobre o outro. As informações, os pontos de vista e a atitude de cada um podem ajudar a compreender melhor o seu background cultural, de forma a reagirem mais adequadamente neste contexto. (p. 17).

Dessa maneira, é possível destacar que um aspecto particular da aprendizagem em tandem é que os parceiros podem aprender mais que somente a língua do outro, podem se beneficiar das particularidades da vida de cada um, trocando experiências profissionais e pessoais, o que os ajudará na melhora da capacidade comunicativa específica.

Outra vantagem da comunicação em tandem, segundo Brammerts (2002), é a quebra do obstáculo da inibição. Os parceiros se sentem mais seguros entre eles do que junto a um grupo maior. Essa experiência de troca entre os aprendentes no tandem gera um intercâmbio de conhecimentos, onde cada um se esforça para auxiliar o parceiro a adquirir as informações necessárias acerca da língua alvo. $O$ autor complementa que, caso não haja a preocupação com as necessidades do outro, em uma interação tandem, 
não há uma relação proveitosa para a dupla, gerando desinteresse por uma das partes ou ambas.

O aprendente no tandem é responsável por sua própria aprendizagem, levando em consideração que é ele quem deve fornecer feedback para o parceiro acerca de suas dificuldades. A colaboração do parceiro é fundamental para ensinar, e ajudar ao outro a formular estratégias próprias de aprendizagem que o levem a realização de seus objetivos nas interações Tandem.

Para ser considerada uma sessão tandem, a interação deve obedecer a dois princípios: reciprocidade e autonomia. De acordo com Little (2002) a autonomia tange no ponto em que os aprendentes são responsáveis pelo condicionamento de sua própria aprendizagem; e a reciprocidade se baseia no compromisso assumido por ambos interagentes de gerenciar sua própria aprendizagem e a do parceiro. Autonomia e reciprocidade regem como será desenvolvida a sessão tandem, visto que, os parceiros têm que decidir (autonomia) e concordar (reciprocidade) o tempo todo nas decisões.

\subsection{Teletandem}

A partir do conceito de tandem e tandem face a face, foi desenvolvida por Telles (2006) a modalidade Teletandem, cuja proposta tem por intuito diminuir as barreiras geográficas entre as pessoas que desejam aprender uma língua estrangeira, ou mesmo aperfeiçoar seus conhecimentos. Essa modalidade de aprendizagem consegue unir o tandem presencial com o tandem eletrônico, uma vez que os interagentes podem se ver mesmo a distância e utilizar de aplicativos tecnológicos para interagir em tempo real.

O Teletandem permite aos interagentes se comunicarem por imagem (com recursos de teleconferências, como a webcam), voz e por escrita, através do MSN Messenger, Skype, Oovoo, assim, proporciona oportunidade para pessoas no mundo inteiro terem contato com outras línguas e culturas de maneira interativa.

\subsection{O Projeto Teletandem Brasil - "línguas estrangeiras para todos"}

O projeto Teletandem Brasil é desenvolvido por pesquisadores da UNESP Universidade Estadual Paulista "Júlio de Mesquita Filho" juntamente com pesquisadorescolaboradores de universidades da França, Itália e Estados Unidos. Tal projeto tem por objetivos principais (Telles, 2006, p. 3): 
- Unir a pesquisa acadêmica da universidade a ações sóciopedagógicas interventivas na área de educação de línguas estrangeiras;

- $\quad$ Estudar, aplicar e divulgar a aprendizagem de línguas estrangeiras in-tandem a distância por meio de uma ação pedagógica inovadora, como o teletandem, na área de educação de línguas estrangeiras.

A Internet e as novas tecnologias têm aberto um vasto leque de oportunidades para o campo de ensino/aprendizagem de línguas. A velocidade de informações facilita, e muito, a comunicação entre as pessoas de qualquer parte do globo terrestre. O Projeto Teletandem Brasil faz uso dessas ferramentas para colocar falantes nativos em contato, para que cada falante ensine sua língua e aprenda a o do outro.

O projeto Teletandem Brasil permite que falantes de português interajam com falantes nativos de outras línguas por meio de escrita e fala, quebrando as barreiras geográficas que separam os interagentes. Os interagentes se valem dos princípios da aprendizagem tandem de autonomia e reciprocidade, e têm total liberdade, entre si, para escolher temas de conversas e para fazerem intervenções de correção quando acham necessário, o que proporciona aos pares uma aprendizagem mais dinâmica que contempla as atividades textuais interativas tanto na comunicação oral quanto na escrita.

Na proposta de Telles (2006), uma interação de Teletandem dura em média duas horas, onde uma hora é gasta com cada língua dos participantes. Em cada fase de conversa há o tempo para conversação sobre qualquer assunto (30 minutos), onde o parceiro-professor anota os desvios de fala; intervenção/correção (20 minutos), nesse espaço de tempo o parceiro-professor irá corrigir de maneira objetiva e simples os desvios de língua escrita e falada; e avaliação da interação do dia (10 minutos), onde o parceiroprofessor analisa os pontos positivos e negativos da sessão.

\section{APRESENTAÇÃO E ANÁLISE DOS DADOS}

Os dados utilizados neste trabalho foram extraídos de um corpus de 14 (quatorze) interações gravadas em áudio e vídeo entre duas duplas participantes do Projeto Teletandem Brasil: "Línguas Estrangeiras para Todos", via Skype. As duplas eram formadas por John ${ }^{50}$ e Marcela, e Emily e Paula. John e Emily são aprendizes de português como língua estrangeira, e Marcela e Paula, aprendizes de inglês como língua estrangeira. Os parceiros interagiram por 3 (três) meses, de março a maio de 2011, e a coleta de dados foi realizada neste mesmo período. A coleta de dados conta ainda, além

\footnotetext{
${ }^{50}$ Os nomes dos interagentes foram trocados para preservar o sigilo de suas identidades.
} 
das gravações, com os e-mails trocados pelas duplas durante todo o processo de ensino/aprendizagem, com os diários e as redações produzidas pelos parceiros brasileiros.

O coordenador responsável pela formação de novas parcerias é quem coloca os alunos interessados em participar do projeto Teletandem em contato através de e-mails. $A$ partir daí, os próprios parceiros em potencial começam a se organizar para darem início às interações. Acertados horário e tema, os parceiros passam à interação, ou diálogos, seguindo as orientações pré-estabelecidas pelo Teletandem. Durante as interações é escolhido o tema para a redação, escrita na língua alvo, a qual será enviada ao parceiro para correções. Ainda durante as interações, o uso do chat é bastante comum para sanar dúvidas acerca da escrita de uma palavra que não é compreendida pelo parceiro, além de ser utilizado para envio de links que decidam ser relevante à interação.

O diário é escrito pelas participantes brasileiras para fixar os temas discutidos durante as interações. Com eles, é possível fazer uma revisão do que foi relevante no dia e das expectativas relativas à aprendizagem, além de registrar as impressões pessoais sobre as conversas.

O trecho a segui demonstra as impressões de Paula:

After that, I remembered that on John's writing, he used the Portuguese word "contemplarão" in a wrong context. I guessed he would like to say the word in the sense of "surveillance", so, in order to solute my doubt, I asked him if "contemplarão" had the sense of "surveillance", but, as I said the last word in a wrong way (wrong pronunciation), he was not getting what I meant. During this time, he tried to guess what I wanted to say, saying "service" and other words with similar pronunciation, then he realized I wanted to say "surveillance" and said it in the right way, so I could get the right pronunciation and he learnt "contemplarão" was in a wrong context on his writing. In that case, "vigiarão" was more suitable.

Trata-se de um relato pessoal de Paula acerca de um momento em que ela e o parceiro John tiveram dificuldade de comunicação. No dia desta interação, Paula e John fazem uso do chat na tentativa de esclarecer o tempo verbal da redação enviada pelo parceiro Norte Americano. O chat é utilizado para reforçar alguma palavra ou expressão que não esteja clara. Poucas vezes o chat foi utilizado pelas duplas, e infelizmente esses dados não foram coletados em arquivos de textos, porém, as gravações de áudio e vídeo permitiram apreender que o gênero chat é utilizado na interação dos participantes.

O e-mail serve de mecanismo para agendamento de horários e escolha de temas, além de ser usado para envio de comentários sobre os textos produzidos pelos parceiros. 
O propósito comunicativo do e-mail, especificamente neste caso, é apresentação do tema das redações e o envio de temas para os próximos encontros.

A atenção nas gravações se direciona aos fragmentos em que os interagentes retomam assuntos mencionados nos textos e nos e-mails trocados fora do momento das interações, por estes demonstrarem as atividades desenvolvidas por eles na organização e realização do trabalho, as quais compõem o sistema de atividades.

A elaboração de diários sobre atividades mediadas por computador oferece uma noção sobre as impressões dos participantes, é uma ferramenta que possibilita identificar as dificuldades e os anseios dos participantes em relação a todo processo de ensino/aprendizagem.

O chat e o e-mail são gêneros específicos de comunidades discursivas ligadas ao uso da internet. Não são específicos do Teletandem, mas juntamente ao diário e às redações formam um sistema de gêneros presente no contexto Teletandem.

\section{CONSIDERAÇÕES FINAIS}

O diário, o e-mail, o chat, as redações, e os próprios diálogos constituem o sistema de gêneros das interações do Teletandem, visto que são os textos produzidos e utilizados de maneira organizada pelos participantes, e a relação se torna padronizada porque é recorrente nas duas duplas. Cada um destes textos é parte da realização de Teletandem, eles se inter-relacionam, ou seja, o e-mail é utilizado para enviar propostas de temas. Os temas são discutidos nas interações e as redações são elaboradas a partir do tema definido por e-mail e discutido na interação, e o chat é parte da interação no que se refere à resposta eficaz de escrita de palavras ou frases que não foram compreendidas, ou até mesmo para envio de endereço de páginas que sejam relevantes para a interação. Esses textos organizam as etapas das interações de Teletandem, o que condiz com a proposta de Bazerman (2005, p. 32) em que surgem "relações padronizadas que se estabelecem na produção, circulação e uso desses documentos".

Analisar o sistema de gêneros permitiu uma compreensão das relações práticas, de funcionamento e sequência dos documentos utilizados pelos interagentes de Teletandem. Por meio dessa compreensão foi possível constatar como os textos produzidos no processo das interações estão situados dentro de um sistema. A análise do sistema de atividade permitiu uma compreensão mais ampla de como são organizadas as sessões de Teletandem. Um gênero segue o outro em uma sequência de atividades, e 
essas atividades organizam o sistema de gêneros com os participantes e os textos, os quais são recorrentes no processo de ensino/aprendizagem de línguas no Teletandem.

\section{Referências bibliográficas}

ARANHA, S. Contribuições para a introdução acadêmica. 2004. Tese (Doutorado em Lingüística e Língua Portuguesa) - Universidade Estadual Paulista, Campus de Araraquara, 2004.

ARAÚJO, J. C. R. A conversa na web: o estudo da transmutação em um gênero textual. In: Hipertextos e gêneros digitais: novas formas de construção de sentido. L. A. Marcuschi, A. C. Xavier (orgs.) 2. ed. Rio de Janeiro: Lucerna, 2005, p. 91-109. BAZERMAN, C. Gêneros textuais, tipificação e interação. Org. por Angela P. Dionísio e Judith C. Hoffnagel. São Paulo: Cortez, 2005.

. Escrita, gênero e interação social. Org. por Angela P. Dionísio e Judith C.

Hoffnagel. São Paulo: Cortez, 2007.

BIASI-RODRIGUES, B., HEMAIS, B. A proposta sócio-retórica de John M. Swales para o estudo de gêneros textuais. In: MEURER, J. L.; BONINI, A. MOTTA-ROTH, D.

(orgs.).Gêneros: teorias, métodos e debates. São Paulo: Parábola Editorial, 2005. p. 108129.

BRAMMERTS, Helmut et al. Aprendizagem autónoma de línguas em tandem: desenvolvimento de um conceito. In: DELILLE, Karl Heinz; CHICHORRO, Adelaide. Aprendizagem autónoma de línguas em tandem. Lisboa: Edições Colibri, 2002. p. 15-26. CAVALARI. S. M. S. A linguagem do chat no ambiente teletandem: evidências da heterogeneidade da escrita. Artigo submetido à Revista Delta em 2007.

COSTA, Sérgio Roberto. Dicionário de gêneros. Belo Horizonte: Autêntica Editora, 2008. LEFFA, Vilson J. (Org.). Aprendizagem de línguas mediada por computador. In: LEFFA, Vilson J. Pesquisa em Linguística Aplicada: Temas e Métodos. Pelotas: Educat, 2006. Cap. 1, p. 5-30.

LÉVY, Pierre. O que é o virtual? Trad. Paulo Neves. São Paulo: Brasiliense, 1996.

LITTLE, David. Aprendizagem de línguas em tandem e autonomia do aprendente. In: DELILLE, Karl Heinz; CHICHORRO, Adelaide. Aprendizagem autónoma de línguas em tandem. Lisboa: Edições Colibri, 2002. p. 27-36.

MARCUSCHI, L. A. Gêneros textuais: definição e funcionalidade. In: DIONÍSIO, A. P.; MACHADO, A. R.; BEZERRA, M. A. (Orgs.). Gêneros textuais \& ensino. Rio de Janeiro: Lucerna, 2003. p. 19-36.

Gêneros textuais: configuração, dinamicidade e circulação. In: KARWOSKI, A. M.; GAYDECZKA, B.; BRITO, K, S. (Orgs.). Gêneros textuais: reflexões e ensino. 2.ed. Rio de Janeiro: Lucerna, 2006. p. 23-36. Produção textual, análise de gêneros e compreensão. São Paulo: Parábola Editorial, 2008.

SWALES, J. M. Genre analysis: English in academic and research settings. New York: Cambridge University Press, 1990.

TELLES, J. A. Projeto Teletandem Brasil: Línguas estrangeiras para todos - Ensinando e aprendendo línguas estrangeiras in-tandem via MSN Messenger. Faculdade de Ciências e Letras de Assis - UNESP, 2006.

XAVIER, A. C. Leitura, texto e hipertexto. In: Hipertextos e gêneros digitais: novas formas de construção de sentido. L. A. Marcuschi, A. C. Xavier (orgs.) 2. ed. Rio de Janeiro: Lucerna, 2005, p. 170-180. 


\title{
CONHECIMENTO PRÉVIO, LEITURA E METACOGNIÇÃO: UM ESTUDO COMPARATIVO DE LIVROS DIDÁTICOS DE HISTÓRIA DO ENSINO MÉDIO
}

\author{
CONHECIMENTO PRÉVIO, LEITURA E METACOGNIÇÃO: UM ESTUDO \\ COMPARATIVO DE LIVROS DIDÁTICOS DE HISTÓRIA DO ENSINO MÉDIO
}

\author{
Patricia Ferreira Botelho ${ }^{51}$ \\ pattyfb@yahoo.com.br
}

\begin{abstract}
RESUMO: Este trabalho analisa os aspectos relacionados à organização e execução das atividades de leitura em livros didáticos (LD) de História do Ensino Médio (EM). Tecemos avaliações sobre esses LD, pensados na formação do aluno como leitor. Como aporte teórico, utilizamos os pressupostos dos estudos em metacognição, que fornecem importantes estratégias para explorar as habilidades cognitivas dos alunos-leitores e para discutir a estrutura dos LD e a metodologia empregada nas atividades de leitura. Pressupomos o uso consciente do conhecimento prévio (CP) do aluno como uma estratégia metacognitiva, de modo a influenciar e aprimorar a leitura como atividade cognitiva. Como aparato metodológico, realizamos um estudo que avaliou a elaboração das atividades de leitura de um LD utilizado no EM de uma escola pública brasileira comparando-as às novas perguntas que formulamos sobre o mesmo texto, para um teste de leitura em turmas do Ensino Médio. Essas novas perguntas tomaram como base o quadro teórico que representa os conceitos de monitoramento e controle articulados aos três estágios de aprendizagem (NELSON \& NARENS, 1994). Esse teste ressalta a importância das habilidades metacognitivas nas atividades de leitura, porque, conforme nossa pressuposição, leva em consideração o CP dos alunos sobre o assunto abordado nas aulas e o ajuda a explorar esse assunto.
\end{abstract}

PALAVRAS-CHAVE: Ensino de leitura, metacognição, conhecimento prévio, livros didáticos.

ABSTRACT: This paper focuses the organization and accomplishment of reading activities in History High School textbooks. We will evaluate these textbooks considering the student as a reader. As a theoretical approach, we will take the concepts related to metacognition, which offer important strategies, in order to explore the cognitive abilities of the readers-students, and to discuss the structure of the textbooks and the methodology of

${ }^{51}$ Doutoranda do Programa de Pós-Graduação em Letras, área de Língua Portuguesa na Universidade Federal do Rio de Janeiro (UFRJ). 
reading activities. We advocate that the conscious use of students' previous knowledge is a metacognitive strategy, which influences and improves reading as a cognitive activity. As a methodology, we evaluated the elaboration of the reading activities of a textbook used in a brazilian public high school; we compared these activities to the new ones formulated by us over the same text and proposed to high school classes. These new questions were based on the theoretical framework which represents the concepts of monitoring and control, articulated to the three stages of learning (NELSON \& NARENS, 1994). That test highlights the importance of metacognitive abilities in reading activities, due to the fact that, according to our assumption, it takes into account students' previous knowledge about the theme discussed in class, and helps the students in exploring this theme.

WORDKEYS: literacy teaching, metacognition, previous knowledge, textbooks.

\section{Introdução}

Em geral, entende-se que a tarefa do livro didático (LD) é promover atividades que auxiliem o aluno no desenvolvimento da leitura, fazendo uso de seu conhecimento prévio na construção de significados. Entretanto, esse fazer não tem sido propiciado nesses materiais, o que permite a este estudo fazer uma avaliação sobre o desenvolvimento da leitura no ambiente escolar e verificar meios de repensar essa atividade, utilizando-se conceitos e estratégias relacionados aos estudos em metacognição.

O presente trabalho resulta das reflexões da dissertação de Botelho (2010) que ressaltou alguns problemas relacionados à metodologia de elaboração dos exercícios de leitura, enfatizando que os materiais didáticos deveriam estimular o desenvolvimento dessas atividades por meio de estratégias metacognitivas nos estágios de aquisição, retenção e recuperação de informações para o estudo das atividades de leitura em LDs.

O presente estudo traz como enfoque a atividade de leitura no ambiente escolar, levando em conta aspectos do LD no acesso aos textos. Apesar de pensarmos a leitura como uma atividade fundamental para a construção do conhecimento dos alunos e que permeia o cotidiano escolar, no ensino de leitura em História nos deparamos com a seguinte questão: o ensino de leitura em História está diretamente ligado à compreensão dos processos de permanências e mudanças na construção da sociedade e do homem, com a articulação de conceitos temporais como o passado e o presente. Para tanto, esse tipo de material precisa favorecer ao aluno meios de utilizar seu conhecimento prévio em interação com os dados textuais para que haja, efetivamente, construção de significados em leitura. Entretanto, a análise de Botelho (2010) apresenta uma questão problemática na metodologia de organização das atividades de leitura: perguntas que exploram apenas a reprodução de conteúdos, conduzindo os alunos ao movimento de cópia e colagem de informações, ou seja, uma leitura no nível linear (APPLEGATE, 2002). 
Vale dizer que uma razão norteadora deste trabalho é a necessidade de se apresentar conceitos relativos aos estudos em metacognição, relacionando essa área aos processos de aprendizagem, sobretudo em leitura. Partindo-se desse objetivo inicial, este trabalho também pretende verificar as estratégias empregadas na realização dos exercícios de leitura no LD, de modo a revelar em que medida esses materiais aprimoram a qualidade da leitura dos alunos. Além disso, tecemos avaliações sobre esses LD, pensados em relação à formação do aluno como leitor.

Mediante a apresentação desse objeto de estudo, serão discutidos brevemente os conceitos que serão profundamente relevantes para o encaminhamento deste trabalho, em vias de fornecer material teórico necessário a discussões relacionadas à leitura em livros didáticos.

Em seguida, será apresentado como aparato metodológico um estudo que avaliou a elaboração das atividades de leitura do LD de História (MOTA \& BRAICK, 2005), comparando-as às novas perguntas que formulamos sobre o mesmo texto, para um teste de leitura em turmas do Ensino Médio. Para tanto, essas novas perguntas tomaram como base o quadro teórico que apresenta os movimentos metacognitivos de monitoramento e controle articulados a três estágios de leitura, desenvolvido por Nelson e Narens (1994). No encerramento desse trabalho, será apresentada uma apreciação sobre as análises feitas para este trabalho.

\section{Apresentação do objeto de estudo}

Pode-se afirmar que a leitura é uma atividade fundamental para a construção do conhecimento dos alunos e para sua formação como cidadãos. Na escola, o desenvolvimento dessa atividade pode proporcionar ao aluno a aquisição de uma competência investigativa, por meio da percepção das estratégias expressivas que a língua materna apresenta para o enriquecimento do material a ser lido. A leitura possibilita, também, a apropriação dos recursos que a Língua Portuguesa dispõe no desenvolvimento dessa atividade, permitindo ao aluno não somente compreender a língua em si, mas, principalmente, saber avaliar criticamente e perceber a leitura como fonte para o alcance de diferentes informações, pontos de vista e contextos sócio-históricos.

O livro didático é um material utilizado largamente no espaço escolar porque contém informações consideradas essenciais para o desenvolvimento do ensino, como textos que visam apresentar conteúdos sobre determinado assunto e exercícios que pretendem retomar o que foi abordado em uma dada seção. No ambiente escolar, esse 
material é considerado de suma importância, pois se acredita que através dele pode-se empreender um contato entre o conteúdo a ser ministrado nas aulas e o seu leitor, ou seja, o aluno.

Mediante esse estado de coisas no ambiente escolar, faz-se necessário o desenvolvimento de trabalhos que apresentem esses problemas que envolvem a prática educativa e promovam tanto a reflexão como também propostas que permitam contornálos. A análise dos materiais didáticos de História permite perceber que a leitura dessa disciplina é norteada pela descrição e articulação dos fatos em termos dos processos de permanências e mudanças para a compreensão dos textos. Porém, é possível notar que as atividades de leitura desses materiais não conduzem o olhar do aluno para a relação estabelecida pelos fatos apresentados nos textos, em vias de explorar a relação passadopresente e as mudanças sofridas devido aos fatos históricos descritos. Para fundamentar toda a discussão suscitada pelo estudo desse material didático e dos testes aplicados, vale apresentar algumas questões teóricas relevantes a este estudo.

\section{Pressupostos teóricos}

A capacidade de refletir acerca dos nossos próprios pensamentos e comportamentos é tida, por muitos estudiosos como o constructo principal que nos distingue como seres humanos. Sabe-se, também, que tanto a autorreflexão como o conhecimento pessoal constituem a base da consciência humana (METCALFE \& SHIMAMURA, 1994, p. xi). Nossas ações cognitivas são passíveis de observação, análise e avaliação, sobretudo no que concerne aos processos de aprendizagem. Monitoramos nossa postura social; organizamos nosso pensamento e nossos estudos, adequando-os aos nossos objetivos; reestruturamos nosso comportamento, de acordo com a exigência de cada ambiente etc. Este autoconhecimento, ou seja, essa administração que uma pessoa promove acerca de sua cognição é denominada metacognição. Ao fazer uso da metacognição, o sujeito torna-se um administrador de seus próprios modos de pensar e das estratégias que emprega para resolver problemas, buscando identificar meios de aprimorar esse fazer. E essa administração dos processos cognitivos tem sido uma importante ferramenta a ser desenvolvida no ambiente escolar, sobretudo em exercícios de leitura que possam orientar o olhar dos alunos e ajudar na seleção de estratégias que favoreçam a articulação de informações para construção de significados. Essas questões ressaltam a necessidade de nos debruçarmos sobre aparatos teóricos que configurem 
essas estratégias metacognitivas, como foi desenvolvido pelo quadro teórico desenvolvido por Nelson \& Narens (1990; 1994).

\subsection{Monitoramento e controle}

Nelson \& Narens (1990) pensavam em uma dupla articulação em vias de ampliar os estudos em metacognição e desenvolveram uma estrutura de conhecimento que permitiu entender a metacognição como a capacidade humana de gerenciar e de autorregular a cognição, e os dois diferentes processos que a constituem são essenciais à composição do fluxo de informação: o monitoramento e o controle, definidos abaixo:

- O monitoramento metacognitivo relaciona-se à postulação de hipóteses sobre o trabalho cognitivo, como os julgamentos que são feitos acerca da facilidade ou dificuldade no aprendizado de dada informação em três momentos que envolvem a leitura, a saber, antes, durante e depois. Trata também do nível de confiança que se desenvolve na busca por uma informação, com a recuperação ou o retorno a um dado e até com a tarefa de retrospecção.

- $\quad$ O controle metacognitivo volta-se para a definição de objetivos que propiciem a aprendizagem ou o conhecimento cognitivo também em três momentos - antes, durante e depois da leitura.

Através das informações obtidas por meio do monitoramento, pode-se afirmar que o controle metacognitivo seleciona as estratégias que viabilizam o aprendizado, o que nos permite postular que conceptualizamos as informações em dois planos (SINHA, 1999; TOMASELLO \& RAKOCZY, 2003; GERHARDT, 2010), em que se processam os movimentos metacognitivos do controle e do monitoramento, como se pode verificar na figura 1:
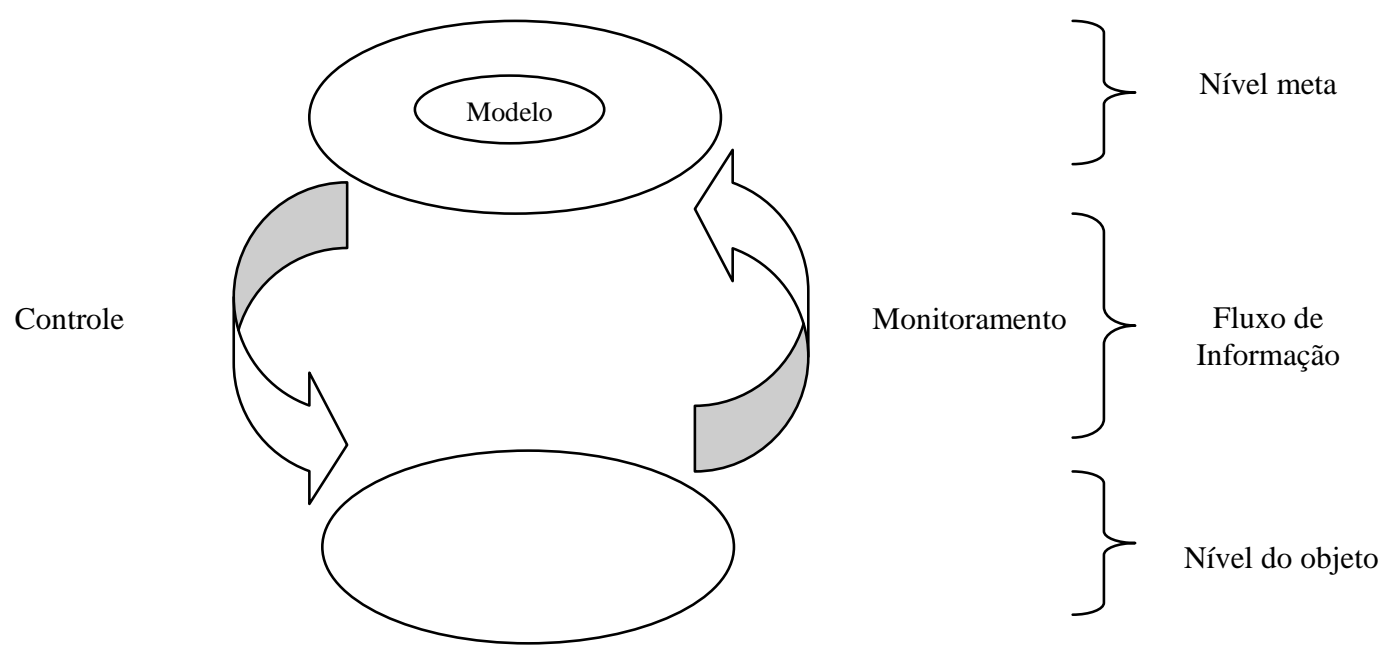

Figura 1. Esquema para os movimentos de monitoramento e controle (NELSON \& NARENS, 1994, p.11). 
A relação estabelecida entre os movimentos de controle e monitoramento é definida em termos da direção do fluxo de informações entre o nível do objeto e o nível meta, em que se validam as reflexões obtidas através do nível do objeto. Essa validação decorrente da cognição em dois planos constitui o reconhecimento de que o processo cognitivo empreendido em função de uma dada tarefa, como a escolar, foi efetivado, permitindo a conceptualização desse fazer e automatizando-o, uma vez que se reconhece essa tarefa como um processo válido cognitivamente.

Como toda atividade humana é conceptualizada em dois planos e isso envolve diversos níveis de experiência, desde tarefas simples do cotidiano até tarefas intelectuais complexas, uma atividade didática voltada para o conhecimento metacognitivo pode ser mais bem sucedida. Promover a reflexão acerca desses dois níveis de experiência é promover, portanto, a metacognição, conscientizando o aprendiz sobre o funcionamento de sua cognição em atividades escolares, propiciando melhoria em sua aprendizagem e no seu desenvolvimento em dadas tarefas, pois ao mesmo tempo em que uma atividade escolar, por exemplo, se processa, podemos validá-la por meio da auto-avaliação, da definição de objetivos e da seleção de estratégias para dar continuidade a essa ação.

Percebe-se que a conscientização das estratégias metacognitivas utilizadas para ler, ou aprender uma dada atividade, auxilia no processo de compreensão, por permitir ao aprendiz a administração das estratégias e dos objetivos empregados na efetivação de tarefas dessa natureza. Diante disso, vale dizer que se deve privilegiar o conhecimento de duas estruturas fundamentais ao processo de construção dos significados em leitura, a saber: o conhecimento prévio do aluno e o contexto sócio-histórico em que se aplica o material a ser lido. $O$ desenvolvimento da atividade de leitura requer 0 uso das habilidades metacognitivas no acesso a esse conhecimento prévio e sua associação às informações lidas, o que é claramente aplicável ao ensino de leitura em História, que requer estratégias de leitura desse tipo. Essa administração, em termos metacognitivos, se efetiva através de uma leitura estratégica e de objetivos para a percepção do que deve ser lido, auxiliando o leitor no acesso ao $\mathrm{CP}$ e na aquisição das informações novas que são oferecidas no fluxo da leitura do livro didático para construir um corpo de conhecimentos sobre um dado assunto.

De modo a apresentar uma maneira de pensar os livros didáticos de História sob a orientação dos estudos em metacognição, este trabalho recorre à estrutura de organização da aprendizagem de Nelson \& Narens (1994) - figura 2-, que funciona como uma sistematização das etapas das estratégias empregadas no fluxo da aprendizagem de uma dada atividade. A observação dessa estrutura, aplicando-a à leitura de livros 
didáticos, auxilia na percepção dos dois grandes componentes da metacognição - o monitoramento e o controle, já comentados - e o seu funcionamento no percurso decorrido pelos estágios da memória. Cabe, então, a partir das postulações desses autores, fazer um recorte desses conceitos, aplicando-os a este estudo e relacionando-os ao ensino de leitura em livros didáticos em História.

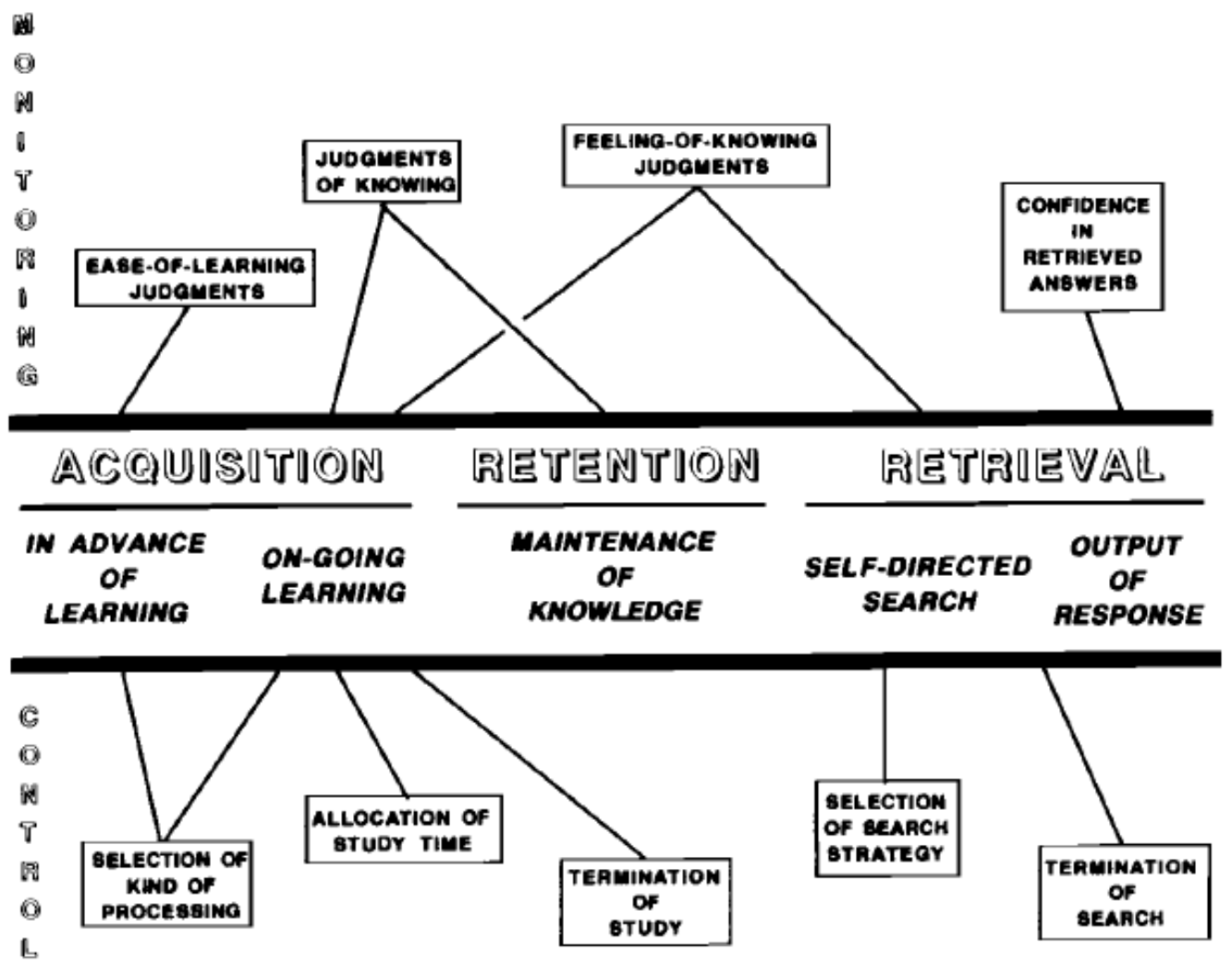

Figura 2: Metamemory Framework - Nelson \& Narens, 1994, p. 129.

O esquema contido na estrutura apresentada por Nelson \& Narens mostra como o monitoramento e o controle funcionam nas etapas de aquisição, retenção e recuperação de informações (respectivamente, acquisition, retention e retrieval, tradução nossa) e tal esquema é cabível à percepção do nível de aprendizagem dos alunos em uma dada atividade escolar. 
Vale, para este estudo, destacar as estratégias que envolvem as três grandes etapas de aprendizagem, em particular ao que interessa ao ensino de leitura em termos de monitoramento e controle metacognitivos:

- O primeiro estágio, de aquisição, mostra o controle metacognitivo orientando estratégias de seleção e análise do material ou texto com que o aprendiz terá contato visando ao avanço do estudo (in advance of learning). Ainda nesse estágio, o monitoramento metacognitivo recruta dados do objeto de estudo para checagem das estratégias utilizadas e avaliação do sucesso ou das falhas no fluxo da aprendizagem (on-going learning), detectando a eficácia ou a necessidade de mudança das estratégias para contato ou leitura do objeto de estudo.

- No estágio de retenção das informações, as estratégias empregadas no estágio inicial se mantêm devido à sua natureza de propiciar a administração da coleta e manutenção do aprendizado (maintenance of knowledge) do objeto de estudo em questão.

- O estágio final, de recuperação dos dados, pode ser representado pela aplicação de atividades de fixação e verificação da aprendizagem. Por um lado, o emprego do controle metacognitivo auxilia o aprendiz na seleção de estratégias eficazes ao autodirecionamento (self-directed search) para execução das tarefas requeridas nessa etapa. Por outro lado, o monitoramento metacognitivo auxilia o aprendiz a recrutar do objeto de estudo dados produtivos às respostas requeridas (output of response) e à avaliação da aprendizagem, produzindo a autoconfiança para o bom desenvolvimento dos estudos ou da leitura.

A discussão sobre esses estágios de aprendizagem leva-nos a repensar uma metodologia de estudos em leitura, sobretudo dos LDs de História, objeto de estudo deste trabalho. Pensamos que orientar o olhar dos alunos em todas as etapas de aprendizagem em leitura seja um meio relevante de explorar o $\mathrm{CP}$ deles em vias de articulá-lo às informações recrutadas em leitura, para explorar essa atividade escolar com qualidade, ensinando-o a desenvolver estratégias que o ajudem a administrar esse fazer. Para tanto, segue a metodologia desenvolvida para o estudo de leitura em LDs de História e toda a apreciação resultante da aplicação de um teste desenvolvido para verificação dessa metodologia fundamentada nos pressupostos teóricos da metacognição.

\section{Metodologia e análise do livro didático}

A metodologia de aprendizagem escolar que orienta o teste baseia-se no quadro teórico de Nelson e Narens (1994), com o emprego de estratégias metacognitivas nos três 
momentos que envolvem a atividade de leitura. No primeiro momento, denominado préleitura, as perguntas ativam o CP do aluno e propõem hipóteses e objetivos de leitura; no segundo momento, denominado monitoramento do fluxo da leitura, as questões avaliam as estratégias empregadas para a manutenção da aprendizagem e a alteração, ou não, de suas hipóteses; no terceiro momento, chamado pós-leitura, as questões avaliam o volume de CP por eles acessado para a leitura e a compreensão do texto.

Esse teste foi confeccionado com base no livro didático de História utilizado regularmente pela rede estadual de ensino (MOTA \& BRAICK, 2005). O conteúdo programático que fundamentou a montagem do teste foi $\mathbf{O}$ Renascimento Cultural e Científico. O teste foi aplicado em duas turmas do $1^{\circ}$ ano do Ensino Médio, divididas conforme a confecção do teste que seria aplicado. Uma turma, denominada "controle", utilizava o livro didático e respondeu às perguntas por esse formuladas. Nessa turma, 28 alunos participaram do teste. A outra turma, denominada "teste", respondeu às perguntas do material formulado com base no LD, uma espécie de apostila composta pelos textos do LD e a inserção de novas perguntas. Nessa turma, 26 alunos participaram do teste. Esse material foi desenvolvido de acordo com a proposta de estudos de Nelson \& Narens (1994), com perguntas de pré-leitura, alocadas antes da leitura do capítulo estudado; perguntas de monitoramento do fluxo da leitura, localizadas no interior do texto, após uma seção ou no fim de outra; e perguntas pós-leitura, localizadas no fim do capítulo.

\section{Análise dos dados}

O teste do grupo controle, e que participaram 28 alunos, foi constituído pelas perguntas do próprio LD na seção de pós-leitura, no fim do capítulo. A aplicação do questionário composto pelas perguntas formuladas pelo LD na seção denominada "Atividades", que encerra a leitura do capítulo lido, permite visualizar questões metodológicas e didáticas que podem ser discutidas com base nas respostas compostas pelos alunos.

Grande parte das respostas dos alunos a esse questionário foi composta pela cópia das informações lidas no texto factual que antecede o questionário. Justifica-se esse movimento feito pelos alunos pelo fato de o questionário ser composto, em sua maioria, por perguntas que apenas exigem o movimento de "cópia e colagem" das informações do texto lido. Isso constitui em falha grave na formulação desse LD, porque mostra que o material não favoreceu uma nível de leitura além do linear (APPLEGATE, 
2002), o que gera problemas em termos da construção de significados, que deveria ser propiciada pela atividade de leitura.

Esse tipo de comportamento cognitivo, de cópia e colagem de informações, foi apresentado por 24 alunos, que responderam conforme os modelos seguintes:

(1a) Conceitue Renascimento:

Aluno 2: Foi um movimento, uma reivindicação das capacidades do homem, um novo despertar da consciência de si próprio e do universo.

Aluno 3: Foi uma reivindicação das capacidades do homem, um novo despertar da consciência de si próprio e do universo.

Aluno 11: Foi um movimento, uma reivindicação das capacidades do homem, um movimento que se alastrou pela Europa e durou mais de dois séculos.

O teste também permitiu evidenciar a presença de perguntas que não favorecem a articulação entre o conteúdo lido no LD e o CP do aluno. Ou o aluno faz cópia e colagem de algo que foi lido ou diz que não entende como responder à pergunta:

Questão (5a) Explique as razões do ambiente urbano ser mais propício para o desenvolvimento da arte e da cultura.

18 alunos: "Por uma questão de lucro" ou "Os diversos desenvolvimentos econômicos dessas cidades faziam com que fossem mais próprios.

Aluno 2 e 20: Não consigo entender a relação.

Aluno 5: "Desenvolvimento da cidade vantagem comercial pela posição geográfica e os mecenas que contratavam os serviços".

Esse tipo de questão não apresenta objetivos claros para desenvolver a leitura, que corresponderia ao movimento de controle metacognitivo, e pode conduzir o aluno a produzir inferências que não têm relações com o material lido, comprometendo a qualidade dessa leitura.

O teste do grupo controle também apresenta perguntas baseadas em nomenclaturas, que não exploram o saber dos alunos e desenvolvem uma visão linear do estudo de História, que não articula as relações históricas passado-presente e não pensa em todo o processo de mudanças históricas $\mathrm{Na}$ questão (6a), 24 alunos evidenciaram isso: 
Questão (6a) Explique o sentido do termo Revolução Científica:

12 Alunos: Uma transformação profunda na pesquisa e na ciência.

Aluno 6: Foi o estudo do homem.

Aluno 7: Uma revolução baseada na ciência para criar, por exemplo, remédios, tecnologia etc.

Aluno 11: Foi um movimento, uma reivindicação das capacidades do homem, um movimento que se alastrou pela Europa e durou mais de dois séculos.

Vale ressaltar que esse tipo de questão reitera um ensino tradicionalista, que não favorece o recorte de dados do texto para a articulação entre as concepções de passado e presente, pensados no tempo do aluno em termos de processo de transformação histórica da sociedade.

O teste do grupo controle evidencia o que tem ocorrido de forma corrente no ensino de leitura, com adoção de LDs que apresentam atividades de leitura que não fornecem estratégias favorecedoras à construção de significados pelo aluno enquanto lê. Essas questões focam a dissecação do conteúdo e não fornecem aos alunos meios de serem agentes do próprio saber, em que fariam uso do CP articulado aos dados apreendidos pela leitura do LD para construir novos significados, o que seria, na verdade, efetivamente ler com qualidade.

O material desenvolvido pelo grupo teste foi composto por três partes: a pré-leitura, o monitoramento do fluxo da leitura e a pós-leitura, seguindo a estrutura de aprendizagem desenvolvida por Nelson \& Narens (1994).

Em relação à pré-leitura, vale comentar os resultados das questões 1 e 2, para compreender em que medida essa etapa será favorecedora ao desenvolvimento da leitura. Sobre a questão 1: "Explique em breves palavras se, no mundo em que vivemos hoje, você consegue perceber algum movimento cultural e científico que busque mudanças e transformações", podemos afirmar que a proposta de formulação de hipóteses foi alcançada por 9 alunos, com acesso ao conhecimento prévio, preparando-os para a leitura posterior. Modelos de resposta:

Aluno 24: "O que eu acho que busca mudanças e transformações são os projetos sociais que tentam tirar crianças da criminalidade".

Aluno 26: "Existem vários eventos culturais, projetos para ajudar pessoas de baixas rendas ou pessoas que já cometeram algum delito a não cometerem isso de novo ou melhorarem de vida". 
Ainda no momento da pré-leitura, podemos afirmar que na questão 2 ( $O$ que você imagina que tenha sido o Renascimento cultural e científico que iniciou no século XII?) os alunos também lançaram hipóteses coerentes sobre o conteúdo que seria lido no texto posterior naquele capítulo, como os modelos de resposta a seguir:

11 alunos destacaram grandes transformações ocorridas no período: "Foi uma grande mudança no modo de pensar, e comportar e agir nas pessoas, um processo que mudou a história e a cabeça de muita gente".

Alunos 1, 5, 8: "Foi um movimento que propos uma nova relação entre o homem e Deus".

Vale lembrar que a seção dedicada à pré-leitura, estágio de aquisição de informações, deve ser explorada, em termos metacognitivos, em busca do avanço do estudo, em que o aluno pode selecionar e administrar objetivamente os dados necessários ao início da atividade de leitura. Portanto, uma atividade de pré-leitura composta por esses requisitos destacados no quadro de Nelson \& Narens se mostraria satisfatória por favorecer esse primeiro contato do leitor com os dados necessários à aprendizagem.

As perguntas de monitoramento do fluxo da leitura têm como objetivo a manutenção da aprendizagem, retomando o conteúdo estudado/lido pelo aluno no LD. Movimento de cópia e colagem de informações, só que atrelado a questões que favorecem o acesso ao CP dos alunos.

Nessa etapa da leitura, podemos destacar que na questão 1 (Qual foi a contribuição dos humanistas para a difusão do Renascimento e que influência isso gerou nos dias atuais?), o objetivo foi alcançado pelos alunos, que retomaram as informações imediatamente lidas pelos alunos, para fazer uso dessa informação para articular significados em leitura nas questões posteriores, conforme o modelo:

Alunos 15: "O homem tinha interesse em captar o universo e descobrir o lado oculto do seu cotidiano e mentalidade. Transformações ocorridas na Europa".

Sobre a questão 4 (Qual importância que o movimento científico no Renascimento trouxe para nossos dias?), vale ressaltar que o objetivo de leitura foi alcançado. Os alunos conseguiram recuperar as informações recentemente lidas com reflexão sobre os 
processos de passado-presente. Essa articulação foi possível devido ao acesso ao CP, articulado ao conteúdo lido, como mostram os modelos de respostas seguintes:

Aluno 6: "Trouxe vantagens comerciais, universidades, mostrou que as pessoas podem ter pensamentos diferentes".

Aluno 11: "É que atualmente a ciência é muito importante e sempre vai contra a religião essa é a importância".

Aluno 19: "Várias vantagens tecnológicas como carro, moto, internet, telefone celular".

As perguntas de monitoramento do fluxo da leitura caracterizaram-se pela solicitação de resumos, descrição dos fatos ocorridos no passado e reprodução de causas e consequências relacionadas a esses fatos. Essa atividade é, geralmente, marcada por perguntas de cópia e colagem de informações, em que os alunos são avaliados pela capacidade de reproduzir as ideias apresentadas pelo texto factual, integrando esse tipo de informação ao CP que eles já possuem. Essa atividade, segundo a estrutura de análise de Nelson \& Narens, está relacionada à etapa de retenção de informações.

$\mathrm{Na}$ seção de pós-leitura do teste, o objetivo foi a avaliação do volume de CP acessado pelos alunos e articulado ao conteúdo do LD para a leitura e a compreensão do texto, com o fim de notar a construção de novos significados.

$\mathrm{Na}$ questão 1 (É possível avaliar os fatos sociais, históricos e científicos do Renascimento sob a perspectiva do homem atual? Por quê?), foi possível notar que grande parte das respostas dos alunos evidenciaram a articulação passado-presente, com acesso tanto ao CP dos alunos, com informações relativas ao seu domínio de experiência, como também ao conteúdo lido no LD, como mostram os modelos a seguir:

Aluno 7: "Sim, porque no renascimento aconteceu coisa que servem de apoio para nós até hoje..."

Aluno 23: "Sim. Porque com os pensamentos dos renascentistas nós podemos ter uma referência para alguns pensamentos atuais."

Aluno 18: "Não. Pois antes acreditavam que o sol girava em torno da Terra e hoje sabemos que é a terra e outros planetas que giram em torno do Sol graças aos novos aparelhos." 
Aluno 26: "Não, por que foram em épocas diferentes com pessoas geitos e fatos diferentes hoje em dia é tudo mais desenvolvido tanto em economia quanto em formas de pensar.

A questão 2 ( $\mathrm{O}$ Renascimento foi um movimento que propôs uma nova relação entre o homem e Deus. Que visão o homem tem da figura de Deus nos dias atuais?) revelou dois tipos de comportamento cognitivo nas respostas: 12 alunos não conseguiram empreender a articulação entre os processos de passado-presente, com acesso somente ao $\mathrm{CP}$ e outros 12 alunos articularam esses processos, acessando ao $\mathrm{CP}$ e ao conteúdo lido no LD:

- Respostas que apenas utilizaram o CP, sem articulação entre passado-presente com base no texto lido (12 alunos):

Aluno 3: "O homem de hoje pensa que Deus é o único modo de Salvação e que ele é o rei de todos."

Aluno 10: "Deus é o centro de tudo, é o superior"

Aluno 21: "O homem de hoje pensa que Deus é o único modo de salvação e que ele é o Rei de todos."

- Atingiram o objetivo proposto na questão, com articulação passado-presente (12 alunos):

Aluno 9: "No passado eles levavam deus ao centro de qualquer outra coisa. Hoje em dia não é tanto como eles faziam antigamente."

Aluno 17: "Para algumas pessoas nos dias atuais Deus é o criador (para a maior parte das pessoas), mas existem também pessoas que acreditam que Deus não existe e que o homem é o criador."

No fim da seção de pós-leitura, a questão 3 (apresentada abaixo) permitiu notar que o CP foi empregado por 10 alunos, por meio da articulação dos conceitos de passado-presente e ciência-religião utilizados no texto do LD, e não somente com a reprodução de conteúdos lidos no texto, como nos modelos de respostas seguintes:

Questão 3: O Renascimento propiciou mudanças na sociedade em relação ao conhecimento científico, que apresentou novas teorias e descobertas geradoras de avanços na área científica. 

a) Como as pessoas no período do Renascimento se comportaram diante das descobertas científicas?
b) É possível identificar esse comportamento hoje em dia?

Modelos de respostas:

Aluno 2: a) "Eles ficaram assustados, porque os geocentristas defendiam a ideia que o sol girava em torno da terra e os heliocentristas defendiam que a Terra girava em torno do Sol." b) "Sim. Porque ainda não há pesquisas científicas que comprovam quem gira em torno de quem."

Aluno 12: a) As pessoas ficaram surpresas e curiosas com as descobertas científcas que aconteceu naquele período. b) Sim. Porque mesmos as pessoas estando acustumadas com algumas descobertas, continuam ficando curiosas para saber como é, como foi feito. Aluno 17: a) As pessoas ficavam surpresas e até um pouco perdidas com as mudanças. b) Sim. Porque existem avanços que nós achamos absurdos e também ficamos perdidos (confusos) por eles estarem acontecendo muito rápido.

Aluno 23: a) Elas começaram a descobrir suas capacidades de pensarem. b) Sim. As pessoas que descobrem métodos de facilitar sua vida.

Com base no estudo apresentado, é possível afirmar que a atividade de pós-leitura apresenta questões que favorecem o aluno na articulação entre o que é requerido pelas perguntas, o conteúdo lido no texto e o conhecimento prévio dos alunos, em vias de auxiliar na construção da relação passado-presente e das mudanças sofridas devido aos fatos descritos. Esse tipo de atividade, no período pós-leitura, pode ser associado à etapa de recuperação das informações, apontada pelo quadro de Nelson \& Narens (1994), devido à sua característica de atividade voltada para a fixação dos dados e verificação da aprendizagem. Embora essas perguntas também induzam o aluno à cópia e colagem de informações do texto factual, elas são complementadas por questionamentos que valorizam a integração entre os dados fornecidos pelo capítulo e a situação social contemporânea ao aluno, suscitando o acesso a seu conhecimento de mundo para empregá-lo na construção de sentidos em leitura.

\section{Considerações finais}

Estabelecendo uma análise sob o aspecto metacognitivo, esse estudo ressalta a relevância dos três estágios de aprendizagem em leitura, em vias de revelar que alguns 
materiais didáticos que não apresentam esse tipo de estrutura, com perguntas que explorem a formulação de hipóteses e apresentam objetivos de letura, não favorecem a de significados em leitura.

As atividades de leitura nos livros didáticos em geral, como mostrou o teste do grupo controle, se caracterizam como atividades de leitura em nível literal, e não exploram as ações de monitoramento e controle metacognitivos. Em relação ao monitoramento, podemos afirmar as atividades não explora o conhecimento prévio do leitor na introdução do capítulo, tampouco o oferece questões suscitadoras de hipóteses sobre as motivações dos fatos históricos ou sobre o desfecho de dado conflito ou revolta popular, por exemplo. Em relação ao controle, a atividade não determina objetivos claros para essa leitura, orientando o olhar do aluno para a seleção de conteúdos relevantes que foram lidos e para a articulação desses dados ao seu CP.

As atividades do grupo teste evidenciaram que as três etapas de leitura orientadas por perguntas que exploram o monitoramento e controle metacognitivo são um procedimento metodológico favorecedor ao desenvolvimento de uma leitura de qualidade. Diante de questões suscitadoras de hipóteses empregáveis na construção de significados em leitura e de questões que oferecem objetivos claros ao exercício da leitura - mesmo com a apreensão de dados lidos - viabiliza-se ao aluno o emprego de seu CP articulado aos saberes envolvidos nas relações de passado-presente e de movimentospermanências no estudo do LD de História. Essa metodologia de estudo em leitura favorece ao aluno perceber essas articulações, bem como não considera o texto como um produto acabado, porque o aluno se torna agente do saber à medida em que não reproduz conteúdos, mas emprega o próprio saber em articulação com o que foi lido no texto, construindo significados e realizando efetivamente o ato de ler.

\section{Referências bibliográficas}

APPLEGATE, M. D.; QUINN, K. B.; APPLEGATE, A. J. (2002). Levels of thinking required by comprehension questions in informal reading inventories. Reading Teacher, 56 (2), 174-180.

BOTELHO, P. F. Textos factuais e problematizantes em livros didáticos de história: leitura e metacognição. 2010. Dissertação de Mestrado em Letras Vernáculas (Língua Portuguesa). Rio de Janeiro: UFRJ/FL.

GERHARDT, A. F. L. M.; VARGAS, D. S. A pesquisa em cognição e as atividades escolares de leitura. Trabalhos em Linguística Aplicada (UNICAMP), v. 49, pp. 145-166, 2010.

MOTA, M. B. \& BRAICK, P. R. (2005) História - Das Cavernas ao Terceiro Milênio - Vol. 1. São Paulo: Moderna, $1^{\mathrm{a}} \mathrm{Ed}$. 
NELSON, T. O. \& NARENS, L. (1994). Why investigate metacognition? In: METCALFE, J. \& SHIMAMURA, A. P. (eds.), Metacognition: knowing about knowing, pp. $1-25$.

Cambridge, MA: MIT Press.

METCALFE, Janet. \& SHIMAMURA, Arthur P. (1994). Preface In: METCALFE, J. \&

SHIMAMURA, A. P. (eds.), Metacognition: knowing about knowing, pp. xi-xiii. Cambridge, MA: MIT Press.

NELSON, T. O. \& NARENS, L. (1990). Metamemory: a theoretical framework and new findings. In: BOWER, G. (ed.), The psychology of learning and motivation: advances in research and theory, Volume 26, pp. 125 - 173. New York: Academic Press.

SINHA, C. (1999). Situated Selves: learning to be a learner. In: Joan Bliss, Roger Sãljõ and Paul Light (Eds.) Learning Sites: Social and Technological Resources for Learning. Oxford, Pergamon, p. 32-48.

TOMASELLO, M. \& RAKOCZY, H. (2003). What makes human cognition unique? From individual to shared to collective intentionality. Mind \& Language, vol. 18 No. 2. p. 121-147.

\title{
DIREITOS HUMANOS E AS SIGNIFICAÇÕES SOBRE A NOÇÃO DE DIREITO EM UMA COMUNIDADE DO ORKUT ${ }^{52}$
}

\section{HUMAN RIGHTS AND THE MEANINGS ON THE NOTION OF RIGHT IN AN ORKUT COMMUNITY}

\author{
Rafaella Elisa da Silva Santos ${ }^{53}$ \\ rafynha@folha.com.br
}

RESUMO: Vemos, na contemporaneidade, a emergência de discursos sobre direitos humanos (DH), em uma tentativa de entender quais são as necessidades fundamentais do homem e, com isso, estabelecer uma definição objetiva para os $\mathrm{DH}$, almejando a sua universalização, através de documentos internacionais, como a Declaração Universal dos Direitos Humanos, apesar das diferenças culturais entre os povos, o que influi nas significações sobre a temática no atual contexto histórico. Todavia, essas discussões não foram ainda capazes de efetivar tais direitos. Baseado nesse contexto, temos por finalidade, nesse artigo, compreender os sentidos sobre direitos humanos emergidos por cidadãos comuns, através de um dos elementos que compõem o sintagma - o direito -, por entendermos que as significações acerca desse componente configuram-se como redes onde os sujeitos filiarão seus sentidos sobre direitos humanos. Assim, objetiva-se, a partir da noção de efeito de sentido, da Análise do Discurso, discutir as significações sobre o objeto da ciência jurídica em discursos emergidos na comunidade do Orkut Direitos humanos para humanos direitos. Essa discussão possibilita compreender uma das bases discursivas que legitimam o sentido que norteia a comunidade do Orkut direitos humanos devem ser atribuídos a humanos direitos.

\footnotetext{
52 Parte de dissertação desenvolvida no Programa de Pós-Graduação em Estudo de Linguagens - PPGEL, da Universidade do Estado da Bahia - UNEB, sob orientação do Prof. Dr. Gilberto Nazareno Telles Sobral.

${ }^{53}$ Instituto Federal Baiano de Educação, Ciência e Tecnologia - IFBAIANO.

Universidade do Estado da Bahia - UNEB.
} 
PALAVRAS-CHAVE: Direitos humanos; Direito; Orkut; Análise do Discurso; Efeitos de Sentido.

ABSTRACT: One notes, nowadays, the emergence of discourses on human rights, as an attempt to understand what the fundamental needs of man are and, thereby, to establish an objective definition for human rights, which aims at its universalization through international documents. The Universal Declaration of Human Rights, despite the cultural differences between peoples, is influencing the meanings on the topic in the current historical context. However, those discussions have not been able to materialize such rights. Based on this context, it is our purpose to understand the meanings of human rights, from one of the elements of the phrase - the right -, because we think that the meanings of this component are characterized as networks in which people express their feelings/beliefs on human rights. Thus, our objective is to discuss the meanings about the object of legal science, from the notion of meaning effects in Discourse Analysis, in the Orkut community entitled Direitos humanos para humanos direitos. This discussion allows the understanding of the discursive foundations that legitimize the premise that guides the Orkut community - human rights must be assigned to human beings who behave appropriately.

KEYWORDS: Human Rights; Right; Orkut; Discourse Analysis; Meaning Effects. 1. CONSIDERAÇÕES INICIAIS

O debate sobre direitos humanos (DH) é muito polêmico, bem como a análise de discursos acerca dessa temática, devido à sua conceituação. Responder a pergunta $O$ que são direitos humanos é palmilhar um terreno repleto de minas e que, segundo Bobbio (2004) não oferece respostas concludentes, definições nítidas, surgindo apenas considerações tautológicas, ou seja, aquelas que indicam serem os direitos humanos aqueles destinados para os homens, o que, em verdade, não define nada, afinal toda a jurisprudência é construída pelo e para o homem em sociedade. Ampliam-se, assim, as possibilidades interpretativas de quem discute a temática, já que implica considerar, de imediato, ainda que se deseje a imparcialidade, como pretende a ciência jurídica, um juízo de valor do emissor.

Entretanto, os direitos humanos, por vezes, são pensados como direitos privativos a determinados grupos sociais, sendo vinculados a sentidos que estabelecem 0 comportamento do indivíduo em sociedade como critério que define aqueles que deles podem usufruir, norteando as significações de algumas comunidades virtuais sobre Direitos Humanos do site de relacionamentos Orkut, uma rede social que funciona por meio da interação entre os usuários, com o objetivo de conectar as pessoas e "tornar a [...] vida social (dos usuários) e a de seus amigos mais ativa e estimulante" ${ }^{\prime 4}$. O Orkut é pensado, conforme Eisenberg e Lyra (2006), como uma continuidade da vida urbana do

54 Extraído do tópico Sobre o Orkut, no referido site de relacionamentos. Disponível em: [http://www.orkut.com/Aout.aspx] Acesso em 14 jul 2008. 
indivíduo, espaço público em que ele exerce plenamente a sua cidadania, configurando, portanto, a rede social, em uma cidade virtual. A comunidade "Direitos humanos para humanos direitos" foi a selecionada para análise por ser a maior do site de relacionamentos Orkut a apresentar tal significação, ou seja, de que os direitos humanos só devem ser atribuídos a sujeitos que seguem a legislação em vigor.

A diversidade semântica se dá, sobretudo, por conta dos elementos que compõem o sintagma que nomeia esse campo. Tanto a palavra "direito" quanto "humano" apresentam variadas acepções, o que compromete o estabelecimento de um sentido único e estável para o sintagma, se é que isso é possível, mas sabe-se ser desejado tanto pelos juristas quanto pelos internautas. Neste artigo, objetivamos levantar os sentidos atribuídos pelos sujeitos da comunidade do Orkut à noção de direito, que parecem estar afinados a duas correntes, a saber: aquela que entende o direito de forma genérica e abstrata, apresentando como função básica a busca do sujeito enquanto indivíduo, pela justiça, ainda que "com as próprias mãos", afinal para os orkuteiros, "temos sim o direito de nos defender e protegermos nós mesmos os nossos direitos e os das pessoas queridas" ${ }^{55}$; ou ainda àquela que concebe o direito, primeiramente, a partir dos postulados constituídos pela ciência jurídica, pois ela deve ser a base das discussões sobre direitos humanos, sobretudo porque "antes de tudo, devemos conceituar a liberdade individual” ${ }^{256}$.

Ressaltamos a não pretensão em esgotar o conceito, devido à sua complexidade $\mathrm{e}$ por não se configurar como objetivo deste artigo a apresentação de um conceito bem definido e refinado, mas um brevíssimo mapeamento dos sentidos que emergem sobre a temática na comunidade estudada, alinhando-os ao que é discutido pelos cientistas do direito, através dos postulados teóricos da Análise do Discurso (AD).

\section{DIREITOS HUMANOS: MAS O QUE É O DIREITO?}

Antes de adentrarmos nas discussões acerca das significações sobre a noção de direito na comunidade do Orkut é necessário entendermos como a Análise do Discurso trabalha a constituição dos sentidos. É importante entendermos que a linguagem não é concebida sob os moldes da perspectiva saussuriana, que a compreende como sendo multiforme e heteróclita e a língua como "um produto social da faculdade da linguagem e

\footnotetext{
${ }^{55}$ Extraído do tópico "Morte estupenda de um estuprador", da comunidade do Orkut "Direitos humanos para humanos direitos".

${ }^{56}$ Extraído do tópico "Aborto!", da comunidade do Orkut "Direitos humanos para humanos direitos".
} 
um conjunto de convenções necessárias, adotadas pelo corpo social para permitir o exercício dessa faculdade nos indivíduos" (SAUSSURE, 2006, p. 17). Saussure (2006) entende que a língua é um fato social, mas não a relaciona com importantes elementos do processo comunicativo - a materialidade histórica e a ideologia, vitais para a teoria do discurso. A lingua(gem), para a $A D$, é a materialidade dos discursos. Ela não nega a concepção saussuriana, que vê a língua enquanto estrutura, mas a amplia, inserindo-a efetivamente na perspectiva da interação social. Desta forma, o caráter da linguagem é "ao mesmo tempo formal e atravessado por entradas subjetivas e sociais" (BRANDÃO, 2004, p. 10), sendo compreendida enquanto discurso, ou seja, efeito de sentido entre interlocutores, quer dizer, "o sentido não está (alocado) em lugar nenhum, mas se produz nas relações" (ORLANDI, 2007, p. 20), ou seja, o sentido não pode ser pensado sob o viés da imanência.

O discurso, então, é uma entidade abstrata e a língua, sua base material, palco da manifestação da ideologia. Ele, portanto, "materializa o contato entre o ideológico e o linguístico e manifesta a existência de materialidade linguística no interior da ideologia" (ORLANDI, 2007, p. 22), representando os efeitos da ideologia e suas contradições na língua.

Assim, os sentidos não se situam no nível da literalidade, deslocando-se entre a paráfrase (repetição do mesmo) e a polissemia (o diferente, o plural), emergindo devido aos processos ideológicos, caracterizando a linguagem como fenômeno nãotransparente. O processo de produção semântica é a assunção, pelo sujeito, de uma posição ideológica, em um dado contexto histórico, como se esse fora único e verdadeiro. Devemos entender, então, que uma das funções da ideologia é estreitar as possibilidades semânticas do sujeito, o que nos remete ao seu conservadorismo. Dessa forma, nem todos os sentidos sobre a noção de direito são possíveis para os sujeitos do Orkut.

Não há consenso sobre o que vem a ser direito na comunidade virtual. A palavra 'direito' pode assumir sentidos variados, ora constituindo-se apenas como um conjunto de normas (o ordenamento jurídico), ora como um ramo científico ou ainda como uma faculdade do indivíduo, ou seja, o sujeito com direito a. Todavia, as significações do Orkut reiteram a constituição do indivíduo enquanto um sujeito jurídico e é esse lugar que os sujeitos do Orkut defendem em seus discursos.

Na comunidade do Orkut, nota-se a coexistência de significações sobre a noção de direito que correspondem a fases da história do conceito na ciência jurídica. Desta forma, os sentidos transitam basicamente entre dois momentos históricos, a saber: a Antiguidade Clássica e a Idade Média, sendo o núcleo semântico mais relevante na constituição de 
seus sentidos. Assim, o direito é compreendido como sendo da ordem do sagrado, ora como direcionador da ação do indivíduo, tal qual em Roma, onde era concebido como exercício de atividade pautada na ética, ação com prudência (daí a palavra jurisprudência), com equilíbrio nos atos de julgar; ora com base no Cristianismo e suas crenças no livre-arbítrio do homem, na configuração e execução de seus direitos, sempre pautados na vontade de Deus e no divino enquanto salvação.

Chama-nos atenção, no tocante ao sentido proveniente da Antiguidade Clássica, a influência de documentos bem remotos. O Código de Hamurabi, por exemplo, datado do século 18 a.C. e que abarca diversas áreas do viver em sociedade, como o comércio, o trabalho, a propriedade e, principalmente, o que ainda permeia o imaginário dos sujeitos dos séculos XX-XXI - a Lex Talionis, na qual o delito era penalizado conforme a sua natureza - parece ser o elemento que norteia com mais frequência o entendimento sobre direitos humanos, sobretudo porque grande parte das discussões na comunidade circundam o direito à vida, o que leva os sujeitos do Orkut a adotarem como meta a penalidade por morte como solução para o problema da criminalidade no mundo. Relembramos que o código babilônico ficou conhecido principalmente pela imputação dessa modalidade penal para quase todos os delitos, desde simples casos de sortilégio sem provas aos de roubo e assassinato.

Outro aspecto de destaque na configuração da noção de direito é a constante recorrência ao argumento de civilização. Assim, o Brasil, país ainda pouco civilizado, na visão de alguns dos internautas, não teria condições de adotar os direitos humanos. Nesse aspecto, dois elementos têm relevância: a emergência de sentidos oriundos do discurso do Brasil enquanto colônia, terra inferior e selvagem, povoada por bárbaros, e o intercruzamento com a história bíblica, afinal há uma gradação no aparecimento dos diversos profetas, até a chegada do rei dos reis, Jesus Cristo, profeta maior, cada um adequado para cada estágio da evolução da humanidade. Civilizado parece, então, ter conexão maior com o conceito de cidadania, ou seja, é aquela nação que respeita os direitos e deveres de seus habitantes.

\section{Ralph}

\section{OLHO POR OLHO DENTE POR DENTE SIM !!!!!}

\section{DIREITOS HUMANOS FUNCIONA EM PAISES C I V I L I Z A D O S !!!}

Extraído do tópico "Morte estupenda de um estuprador", da comunidade do Orkut "Direitos Humanos para humanos direitos". 
Temos, na comunidade, duas importantes filiações ideológicas que norteiam a constituição dos sentidos: posicionamentos que indicam ser o direito uma virtude moral ou elementos que derivam do aparelho judicial, emergindo, tais posições, algumas vezes isoladamente, outras em comunhão. André ${ }^{57}$, por exemplo, demonstra, ao debater a relação direitos $X$ ser humano, o cotejo entre moralidade e penalidade, estabelecendo que o sujeito infrator seja um ser amoral e, por isso, a pena deve ser pensada sem referência aos direitos humanos, apesar de, em alguns momentos, enunciar não ser defensor da pena de morte. É relevante observar que na maioria dos posicionamentos levantados, a moralidade não se caracteriza por ser um elemento social e sim da natureza do indivíduo, inerente a ele ao nascer. Dessa forma, não compõem o mesmo campo de significações de teorias que apontam as condições sociais e psicológicas do sujeito na infância como motivadoras da prática de delitos e, por isso, sentidos que indicam a possibilidade de "correção" do sujeito infrator no sistema prisional, por ser o seu desvio de cunho bio-éticomoral, como demonstrado no discurso de André, abaixo, datado de 07.05.2006.

Nesse sentido, a humanização da pena não é sentido assumido pelos sujeitos da comunidade virtual e é tomada como elemento incentivador da criminalidade, evidenciado nas falas de Pluto, de 12.09.2009 e de André, de 22.05.2006, trazendo novamente ao seio da discussão sobre direitos humanos a relação interdiscursiva com os sentidos presentes no Código de Hamurabi, demonstrando também como a idéia de ser humano impacta a conceituação de direito. A possibilidade de penas alternativas é sentido que não perpassa os sujeitos do Orkut, sendo bastante criticada na comunidade, principalmente porque há a filiação com sentidos que possibilitam a defesa das penas de privação perpétua de liberdade e de morte.

\section{André}

Meu Deus!

Principios éticos e morais ve aprende quando recebe o peito da mãe para mamar...

independentemente de vc nascer numa ilha deserta ou nas hipóteses que vc mencionou, o sentimento de respeito ao próximo nasce incrustado no ser humano. Vc vulnerará esse sentimento por livre e espontânea vontade, não por culpa de um ser coletivo e sem face.

Extraído do tópico "Cuidado!", da comunidade do Orkut "Direitos Humanos para humanos direitos". 
O entendimento de direito como elemento moral, baseado, por vezes, na tradição, influência do posicionamento romano sobre a temática, filia o membro da comunidade à ideia de que o direito é indicação de como se deve atuar em sociedade, ou seja, como uma norma, uma regra de conduta. Daí a afirmação de que a experiência jurídica é normativa.

O direito enquanto instrumento comportamental é o sentido basilar que constrói a comunidade do Orkut "Direitos Humanos para Humanos Direitos", mesmo quando os sentidos expressos na comunidade tendem a se filiar à ideia de inerência dos direitos humanos: "se os direitos são para os humanos, todo ser humano merece ter direitos. Vocês querem tirar os direitos de quem não se comportou como deveria" ${ }^{58}$. Assim, os sujeitos acreditam que os direitos humanos devem atender às demandas da sociedade e, por isso, nem todos devem ter acesso a eles.

Todavia, as demandas sociais são compreendidas de maneira diferenciada a depender de como o indivíduo concebe o ser humano, ou seja, a partir de suas filiações ideológicas. Podemos afirmar que a correção dos comportamentos é, por vezes, pensada a partir da eliminação dos indivíduos que praticam atos condenados pela sociedade, afinal, segundo recomendação dos internautas, "quando um membro gangrena, ele é amputado... Então se um membro da sociedade não se reabilita, acabem com ele, pois assim como um membro gangrenado, se ele nao for cortado, posteriormente o corpo (Brazil) podera morrer de infecção" 59, evidenciando, inclusive, o entendimento de sociedade enquanto um corpo biológico. Caso o sujeito seja pensado como um ente social, suas atitudes, boas ou más, são entendidas como consequências da sociedade que o forjou, passando a ser, a sociedade, a grande culpada por esses delitos e, por isso, ela deve ser o maior alvo de transformação. Desta forma, "a solução para a criminalidade são políticas sociais e não o endurecimento da pena" 60 .

\footnotetext{
${ }^{58}$ Extraído do tópico "Cuidado!", da comunidade do Orkut "Direitos humanos para humanos direitos".

59 Extraído do tópico "Seletividade do sistema penal", da comunidade do Orkut "Direitos humanos para humanos direitos".

${ }^{60}$ Extraído do tópico "Seletividade do sistema penal", da comunidade do Orkut "Direitos humanos para humanos direitos".
} 
Essa diversidade no modo de conceber o direito dificulta o estabelecimento, na comunidade do Orkut, de um limite claro entre essa noção e a de moral. Como os dois sentidos concorrem igualmente, na comunidade, para compor a noção de direito, podemos afirmar que entre eles estabelece-se uma relação sinonímica. Um aspecto que ratifica a natureza sinonímica da relação entre moral e direito na comunidade é o fato de ela não atender, no Orkut, à distinção estabelecida, sobretudo por jusnaturalistas, conforme Bobbio (2001), a partir do binômio bem/mal, onde a moral é concebida como obrigatoriedade positiva (fazer o bem a outrem) e o direito enquanto obrigatoriedade negativa (não fazer o mal a outrem). Com isso, a ação relativa à moral passa a ser o comando e ao direito, a proibição. Na comunidade do Orkut, ocorre a utilização desse binômio apenas para caracterizar as pessoas, definindo-as como merecedoras ou não dos direitos humanos, conforme sua conduta, embora nem sempre tal atitude seja legitimada no seio do tópico. O direito não é construído como obrigatoriedade e sim apenas como benefício, uma faculdade concernente a humanos direitos, ou seja, os humanos propriamente ditos. Há, todavia, menções, nas discussões, sobre fazer o bem ao próximo, uma influência do discurso cristão, a ser discutido na seção subsequente.

\section{Victor-San...}

Nós, direitistas cometemos um grave equivoco ao observar a sociedade composta de pessoas más e pessoas boas, tudo como se fossem números naturais.

05/08/06 xtraído do tópico "Seletividade do sistema penal", da comunidade do Orkut "Direitos Humanos para humanos direitos".

O direito é significado não apenas como norma de conduta, o que gera essa confusão com a moral, mas também normas de estrutura ou de competências, que estabelecem "as condições e os procedimentos através dos quais emanam normas de conduta válidas" (BOBBIO, 1995, p. 33), a exemplo de quem tem competência para legislar ou aplicar punições. Os direitos humanos, na comunidade do ciberespaço, podem, então, ser caracterizados também como normas de competência, sentido perceptível em discussões, no Orkut, a respeito da "justiça feita com as próprias mãos". Nesse caso, compreende-se a legitimidade de aplicação penal como atribuição de qualquer indivíduo lesado por outrem, haja vista que aquele que é legitimado, no ordenamento oficial, para fazer justiça, ou seja, o Estado, não consegue atender às expectativas dos membros da sociedade, por causa da impunidade, compreendida por eles não apenas como a não aplicação de pena prevista em lei, mas também como ineficácia da legislação penal em vigor.

\section{$000^{\prime \prime} V_{i}^{-1000}$}

\section{Fernando}

A familia matou pq fez justiça com as próprias mãos.

Eu faria o mesmo se fosse com um dos meus!

Infelizmente não temos justiça no Brasil,salvo para os criminosos.

Certamente a familia vai ser punida, afinal direitos humanos é exclusivo para vagabundos,porém até agora nada

aconteceu para nenhum membro da familia da menina, graças à Deus!

Extraído do tópico "Morte estupenda de um estuprador", da comunidade do Orkut "Direitos Humanos para humanos 
Apesar disso, os sentidos assumidos pelos sujeitos da comunidade virtual perpassam a discussão sobre a universalização dos direitos humanos. Quanto a isso, cabe ressaltar que, na comunidade analisada, as barreiras nacionais não são consideradas nem positiva nem negativamente quando, ao mostrarem-se contrários aos Direitos Humanos, pelo menos na maneira como a temática é aplicada no Brasil, os membros não utilizem, na maioria das vezes, a nação como o problema, mas os comportamentos. Apesar de os usuários citarem a legislação, sobretudo ao discutir a penalidade de morte, o argumento principal é a natureza do indivíduo envolvido e não o Estado. Parece-nos, então, que a problemática gira em torno do sujeito receptor do direito e não do direito em si, afinal o nome da comunidade é Direitos Humanos para Humanos Direitos, não ocorrendo alusão contrária aos direitos e sim, a um tipo particular de ser humano, ou seja, à universalização integral desses direitos, apesar de a comunidade descrever-se utilizando o preâmbulo da Declaração Universal dos Direitos Humanos, demonstrando a sua aceitação, ainda que parcial.

Se os direitos são para humanos,todo ser humano merece ter direitos.Vocês querem tirar os direitos de quem não "se comportou como deveria".

Extraído do tópico “Cuidado!”, da comunidade do Orkut “Direitos Humanos para humanos direitos”.

Frente a tal aceitação e, observando a necessidade do Estado para efetivar os Direitos Humanos, ainda que percebamos, no Orkut, a importância da sociedade civil na promoção e efetivação dos Direitos Humanos e também por meio de significações que legitimam a independência do sujeito em relação ao Estado na resolução de suas inquietações jurídicas, como "fazer justiça com as próprias mãos", ainda que, para isso, sofra sanções/coações do aparelho estatal, notamos que os orkuteiros reconhecem que o Estado deve defender e/ou aperfeiçoar a tutela dos $\mathrm{DH}$, tanto em número de direitos quanto em qualidade, no interior do território nacional, como na educação, saúde, moradia e lazer, direitos presentes nos artigos 24 e 25 da Declaração Universal, dialogando com a história desses direitos, que foram paulatinamente desenvolvidos, apresentando três fases, definidas a partir dos direitos principais defendidos: direito à liberdade (limitação do poder DO Estado); direitos políticos (liberdade NO Estado); direitos sociais (liberdade ATRAVÉS do Estado). Dentre esses, os direitos sociais são os mais lembrados na 
comunidade, indicando que os membros acreditam no Estado como conferidor de bemestar social. Reitera-se que, quanto aos direitos em si, os assuntos preferenciais são aqueles relativos ao cerceamento da vida, como pena de morte e aborto.

Anjinho

02/08/06

De dois em dois anos, a população é ouvida e tem como manifestar os seus anseios, e o quadro político está como está!!! Não existirá democracia enquanto não forem democratizados a educação, a saúde, a moradia, o lazer etc!!! Extraído do tópico "Seletividade do sistema penal", da comunidade do Orkut "Direitos humanos para humanos direitos".

Victor-San...

08/08/06

Não é sábio derrubar o governo, mas devemos aproveitar a democracia nos dada com pouca luta e usá-la para forcar o Estado bara melhor administrar a nacão.

Extraído do tópico "Seletividade do sistema penal", da comunidade do Orkut "Direitos humanos para humanos direitos".

Com vistas ao pluralismo jurídico e entendendo o direito como discurso, não se pode pensá-lo fora da ordem social, da coletividade e da sociedade organizada enquanto unidade. Temos, então, os princípios que norteiam a concepção de direito como instituição, ou seja, oriundo de uma sociedade ordenada e organizada nem sempre pelo Estado. Todavia, tal ideia pode levar à supressão da figura do indivíduo devido ao entendimento de que o direito não existe para atender suas vontades particulares, e sim para ordenar a sociedade, a instituição. São sentidos como esses com os quais os sujeitos do Orkut entram em conflito, pois eles entendem que o Estado e o direito devem existir para organizar e promover o gozo de suas vontades individuais. É a ideologia da supremacia do indivíduo.

Como os desejos do indivíduo não podem conflitar com aqueles do grupo social dominante na sociedade, ou seja, os humanos direitos, os sujeitos do Orkut constantemente necessitam reafirmar as suas filiações ideológicas, reiterando, ainda que indiretamente e com algumas ressalvas (como a defesa de oferta de segunda chance ao infrator e trabalho para auto-sustento em regime prisional), a importância da pena de morte no país, pois o sujeito delinquente é uma doença da sociedade e, como tal, deve ser banido. Comparado a um câncer, na afirmação de que o próprio organismo gera a doença, em uma tentativa de metaforizar a culpa da sociedade na formação de um bandido, o crime e, por conseguinte, o criminoso, embora nesse tópico sejam salientadas questões sociais e a prisão como modalidade punitiva possível, se reformulada, deve ser retirado do corpo social, como o seio de uma mulher acometida por câncer de mama. Assim, a coletividade (bem comportada) é concebida como ente superior ao indivíduo que a compõe. 
É doloroso desejar o fim de uma vida, financiar um assassinato, mutilar a parte podre da sociedade mesmo sabendo que essa não é a cura.

Extraído do tópico "Seletividade do sistema penal", da comunidade do Orkut "Direitos humanos para humanos direitos".

Assim, na comunidade do Orkut, embora haja defensores dos direitos humanos e, com isso, valorizem mais o indivíduo frente à sociedade, sua visão ainda está atrelada ao sentido de coletividade como um ser superior e não como um somatório de individualidades. O indivíduo ainda não é visto como parte de uma sociedade que, para funcionar bem, precisa que todos os seus membros sejam tratados como iguais, independente do seu comportamento, principalmente porque valoração comportamental é cultural e, portanto, histórica, varia conforme o tempo. O sujeito, então, ainda é concebido, no Orkut, sob o véu de sua atuação na sociedade e, por isso, o direito passa a ser mérito.

\section{CONSIDERAÇÕES FINAIS}

Chega-se à conclusão de que o direito é uma norma jurídica institucionalizada que tem o poder de obrigar os membros do grupo que o gerou a seguir determinados comportamentos. Isso implica que, no caso do Orkut, as regras tacitamente expressas pelo moderador - figura responsável pelo controle das discussões no Orkut - devem ser cumpridas por terem força de lei. Esse conjunto de leis e regulamentos a que comumente chamamos direito recebe, no interior da jurisprudência, a designação de proposições prescritivas e o direito, portanto, concebido como imperativos que atribuem obrigações e direitos subjetivos (obriga/permite o sujeito a FAZER ou NÃO FAZER algo), além de ser coercitivo.

Ao iniciarmos este artigo colocamos a importância de se discutir o conceito de direito. Ao obtermos resposta, ficamos tentados a encaixar tal discussão na categoria dos Direitos Humanos. Para caracterizar uma norma como jurídica deve-se aplicar o princípio da coercibilidade, ou seja, possibilidade de coagir os indivíduos, haja vista que, segundo Bobbio (1995, p. 26), "jurídica é a norma seguida da convicção ou crença na sua obrigatoriedade". A partir desse entendimento e pensando na comunidade analisada 
nesta dissertação, é possível afirmar que os Direitos Humanos não são qualificados enquanto norma jurídica, sendo, então, entendidos enquanto normas morais.

Ademais, cremos que os Direitos Humanos não se constituem enquanto categoria unitária. No Orkut, eles não são vistos interligados: ou se discute o direito à vida ou se debate a pena de morte, mas sem relação entre eles. Reiteramos que os temas preferenciais na comunidade analisada estão voltados ao Direito Penal (por causa da discussão sobre pena de morte).

Os Direitos Humanos, na verdade, são intenções de como agir com o outro e, por isso, Bobbio (2004) acredita ser mais adequado o uso do termo exigências. Entendemos ser essa a melhor palavra para definir a expressão na comunidade do Orkut analisada: Direitos Humanos entendidos enquanto exigências morais para intervenção jurídica e estatal a fim de resguardar o indivíduo que segue as regras jurídicas e morais préestabelecidas na sociedade.

\section{Referências}

BOBBIO, Norberto. Teoria do ordenamento jurídico. 6.ed. Brasília: Editora UNB, 1995. . A era dos direitos. Rio de Janeiro: Elsevier, 2004.

BRANDÃO, Helena Nagamine. Introdução à análise do discurso. 2. ed. Campinas:

EdUNICAMP, 2004.

EISENBERG, José; LYRA, Diogo. A invasão brasileira do Orkut. Revista Ciência Hoje. Vol. 38. n. $.226,2006$.

ORLANDI, Eni. As formas do silêncio: no movimento dos sentidos. 6.ed. Campinas:

Editora da Unicamp, 2007.

SAUSSURE, Ferdinand de. Curso de Linguística Geral. 27.ed. São Paulo: Cultrix, 2006. 


\title{
A CONSTITUIÇÃO DE SUJEITOS E SENTIDOS EM CONTEXTOS DE ENSINO- APRENDIZAGEM DE LÍNGUA INGLESA E SEUS REFLEXOS NA PROFISSIONALIZAÇÃO ${ }^{61}$
}

\section{SUBJECTS AND SENSES CONSTITUTION IN CONTEXTS OF ENGLISH LANGUAGE TEACHING LEARNING AND ITS REFLEXS IN PROFISSIONALISATION}

\author{
Relma Lúcia Passos de Castro Mudo ${ }^{62}$ \\ relmacastro@gmail.com
}

RESUMO: O presente artigo tem como objetivo investigar a importância do domínio da Língua Inglesa e seus efeitos de sentido na prática profissional junto aos alunos e professores de idiomas dos cursos de Secretariado Executivo e Comércio Exterior da FACAPE no mercado de trabalho no que se refere ao processo de comunicação, seja falado ou escrito. O marco teórico centra-se nos pressupostos da Análise de Discurso, de orientação francesa, que refletem sobre os elementos que movimentam as relações entre

${ }^{61}$ Este artigo é um recorte da minha Dissertação de Mestrado em Letras pela UFPB, orientada pelo Professor Dr. José Wanderley Alves de Souza.

${ }^{62}$ Faculdade de Ciências Aplicadas e Sociais de Petrolina - FACAPE 
discurso, cultura, história, sujeito e sentido, como também preconiza um quadro teórico que os alie à Língua Inglesa e à aprendizagem, a fim de que indiquem como o idioma tem influenciado na inclusão ou exclusão profissional dos sujeitos envolvidos. $O$ resultado apreendido propõe, para os alunos, contribuições para uma reflexão crítica dos problemas abordados. Assim, ao compreenderem melhor a dinâmica da sociedade em que vivem, poderão perceber-se como elementos ativos de força política e capacidade de transformar e, até mesmo, viabilizar mudanças estruturais que apontem para um modelo mais justo de sociedade.

PALAVRAS-CHAVE: Discurso; Ensino-aprendizagem da Língua Inglesa; Sujeito; Sentido.

ABSTRACT: The present article has as objective to investigate the importance of English Language domain in Secretariado Executivo and Comércio Exterior courses at FACAPE in the work market in reference to communication process, spoken or written one. The theoretic guide is centered in Discourse Analysis presupposes, of French orientation, that reflects about the elements which moves the relations among discourse, culture, history, subject and sense, and also it recommends a theoretic board which align them to the English language and the learning, for indicating how the idiom has influenced in the professional inclusion and exclusion of the involved subjects. The caught result proposes, to the students, contributions to a critical reflection of the mentioned problems. So, by understanding better the society dynamism where they live, could notice themselves as life elements of political force and transforming capacity, and also make structured changes which point to a fairer society.

KEYWORDS: Discourse; English Language teaching learning; Subject; Sense.

\section{Introdução}

Partindo do pressuposto de que aprender uma língua estrangeira não é apenas desenvolver competências linguísticas, mas desenvolver o saber, relacionando-o ao dia a dia e à profissionalização, como também que, para que se possa utilizá-la como instrumento de trabalho, é preciso ter um conhecimento mais aprofundado de suas estruturas, vocabulário e boa desenvoltura oral e escrita, é que nos propusemos a investigar, pelo viés da Análise do Discurso de linha francesa, a importância do domínio da Língua Inglesa e seus reflexos na prática profissional, bem como averiguar até que ponto o idioma tem influenciado para a inclusão ou exclusão dos alunos dos cursos de Secretariado Executivo e Comércio Exterior da Faculdade de Ciências Aplicadas e Sociais de Petrolina - FACAPE no mercado de trabalho no que se refere ao processo de comunicação, seja falado ou escrito.

A escolha do corpus discursivo está relacionada à nossa prática de sala de aula. Tal iniciativa surgiu a partir de visitas realizadas às empresas da cidade pelos alunos da disciplina Língua Inglesa IV do curso de Secretariado Executivo da FACAPE, que tinham 
como objetivo fazer um contraponto entre a teoria vivenciada pela disciplina em sala de aula e a prática profissional, os quais revelavam facilidades e dificuldades de ascensão na empresa em função do domínio e do não domínio do idioma, seja falado ou escrito.

A Faculdade de Ciências Aplicadas e Sociais de Petrolina - FACAPE foi escolhida para a nossa pesquisa por ser uma faculdade de médio porte na região, uma vez que atende um grande número de alunos distribuídos em oito cursos: Administração de Empresas, Ciências Contábeis, Ciência da Computação, Secretariado Executivo, Economia, Turismo, Comércio Exterior e Direito.

Participaram da pesquisa cinco alunos, escolhidos aleatoriamente, dos cursos de Secretariado Executivo e Comércio Exterior - ingressantes e concluintes, três professores da FACAPE que lecionam a disciplina Língua Inglesa - sendo dois substitutos e um efetivo, e um representante de uma empresa local de Exportação. A opção pelos números acima citados remete ao fato de haver, nessa amostra, um quantitativo de depoimentos que contemplam a pesquisa proposta.

O processo de busca e análises dos dados foram realizados de forma qualitativa e descritiva, tendo como referência os objetivos dessa pesquisa, levando em conta as subjetividades dos sujeitos envolvidos na investigação e o contexto social no qual estão inseridos, realizando operações de sínteses descritivas que tem como referencial as teorias abordadas a fim de buscar os elementos que constituem os sujeitos e os sentidos no contexto da profissionalização.

O resultado da nossa pesquisa não pretende ser absoluto, mas propõe um (re)olhar sobre a questão do ensino-aprendizagem da Língua Inglesa e sua prática profissional. Para tanto, colocamos olhares discursivos, que propõem um (re)pensar sobre a função do ensino-aprendizagem da Língua Inglesa, uma vez que a mesma constitui Sujeitos e Sentidos e se articula com outros campos do saber, da história, do imaginário e da ideologia. Com isso, esperamos que o resultado deste trabalho possa contribuir para uma maior reflexão sobre o processo de ensinar e de aprender uma Língua estrangeira e que professores e alunos questionem e reconstruam suas práticas profissionais, recuperando os vazios teóricos, propondo superações e reconstruindo o conhecimento linguístico.

\section{Ideologia, sujeito e sentido: um breve olhar discursivo em contextos de ensino- aprendizagem de língua inglesa}


Nas palavras de Chauí (2006), o termo Ideologia surge pela primeira vez em 1801 no livro de Destutt de Tracy, que pretendia elaborar uma ciência da gênese das idéias, onde seus seguidores eram chamados por Napoleão Bonaparte de "ideólogos" no sentido de deformadores da realidade. A autora diz que Karl Marx conservou o significado napoleônico do termo e desenvolveu uma teoria da ideologia concebendo-a como uma forma de falsa consciência cuja origem histórica ocorre com a emergência da divisão entre trabalho intelectual e manual cujas transformações constituem o solo real da história real. É a partir deste momento que surge a ideologia, derivada de agentes sociais concretos, ou seja, dos intelectuais, resultado da luta de classes. Após Marx e Engels, outros pensadores abordaram a temática da ideologia, onde alguns mantiveram a concepção original de Marx e outros, como sinônimo de "visão de mundo".

Segundo Althusser (2007), a ideologia é materializada nas práticas das instituições e o discurso, como prática social, é a "ideologia materializada". No discurso, a ideologia possui uma dimensão que relaciona as marcas deixadas no texto com as suas condições de produção, e que se insere na formação ideológica; essa dimensão tanto pode transformar como reproduzir as relações de dominação. Assim, a ideologia é constitutiva dos atos de dizer, se define como o mecanismo que naturaliza sentidos para o sujeito, tornando-os evidentes, óbvios e naturais.

Pelo viés da Análise do Discurso, o sujeito é atravessado tanto pela ideologia como pelo inconsciente, o que produz um sujeito descentrado, ideológico, atravessado por uma memória do dizer. Vale destacar que a memória discursiva difere da memória da psicologia, uma vez que a primeira diz respeito à existência histórica do enunciado e a segunda às informações adquiridas ao longo do tempo. Dessa forma, o sujeito do discurso é caracterizado por Pêcheux como uma Forma Sujeito. Pêcheux (1995) diz que Forma Sujeito caracteriza-se como realizando a incorporação, dissimulação dos elementos do interdiscurso, ou seja, a unidade (imaginária) do sujeito, sua identidade presente, passado, futuro. O sujeito, ao usar o seu discurso, além de marcar seu lugar social e temporal, também vem marcado por formações discursivas, uma vez que, por meio delas, temos a constituição do sentido e a identificação do sujeito. É por meio dessas formações discursivas que se pode reconhecer, nos discursos, o cruzamento de vários outros discursos e, ao mesmo tempo, a dominância de um deles. É, também, nesses espaços discursivos que se processam o que chamamos de "assujeitamento", ou seja, o condicionamento do sujeito à ideologia e ao inconsciente.

$\mathrm{Na}$ visão de Orlandi (2007), todo dizer, na realidade, encontra-se na confluência dos dois eixos: o da memória (constituição) e o da atualidade (formulação) e que é desse 
jogo que tiram seus sentidos. Ressalta, ainda, que é preciso não confundir interdiscurso com intertexto uma vez que ambos mobilizam o que denominamos relação de sentido. Para ela, o interdiscurso é da ordem do saber discursivo, memória afetada pelo esquecimento, ao longo do dizer, já o intertexto restringe-se às relações de um texto com outros textos. Segundo Orlandi:

Sujeito e sentido se constituem, ao mesmo tempo, na articulação da língua com a história, em que entram o imaginário e a ideologia. Se, na psicanálise, temos a afirmação de que o inconsciente é estruturado como linguagem, na Análise do Discurso considera-se que o discurso materializa a ideologia, constituindo-se no lugar teórico em que se pode observar a relação da língua com a ideologia. (ORLANDI, 2002, p.66)

Nesse sentido, o sentido é constituído pela interação entre os sujeitos, visto que é regulado socialmente, de maneira que uma mesma expressão ou gestos podem produzir sentidos diferentes, a depender de quem enuncia e/ou da posição que o sujeito ocupa, uma vez que o sentido não se depreende da materialidade discursiva, mas de uma série de relações a serem estabelecidas entre o enunciado, o enunciador e o contexto que envolve a enunciação. Em função disso, deve ser visto de forma contextualizada como um acontecimento, uma vez que gera interpretação, constrói uma vontade de verdade e produz um recorte da realidade sócio-histórica-ideológica quando se põe algo em evidência. Por outro lado, no momento em que essa realidade não é abordada na sua totalidade, é, apenas, compreendida por partes, o que significa admitir que o discurso também é, muitas vezes, elaborado por lacunas, por aquilo que ele não diz, pelos aspectos sobre os quais silencia ou apaga e, consequentemente a isso, a ideologia vai funcionar como reprodutora das relações de produção.

Essas reflexões sobre o sujeito e a aprendizagem de línguas nos levam a problematizar a questão da identidade. Para tanto, Coracini (2003) ressalta que, quando se fala de busca da identidade, pretende-se encontrar características capazes de definir o indivíduo ou o grupo social por aquilo que ele tem de diferente com relação aos demais indivíduos. No entanto, o domínio do idioma não é comum a todos os sujeitos. Sobre o assunto Coracini (2003, p. 151), considera que:

Embora o desejo identitário do sujeito procure a todo o preço a sua individualidade, esse desejo, recalcado, depara-se com a presença do outro, ou melhor dizendo, de outros: todos aqueles que, de uma maneira ou de outra, tiveram e têm participação na sua formação, através de atitudes, textos (orais ou escritos), memória discursiva (valores, estereótipos, que são herdados...). São esses fragmentos que Bakhtin 
(1929/1978) denomina polifonia, pluralidade de vozes constitutivas da linguagem e do sujeito.

A identidade é vista como um processo, em movimento e o ensino-aprendizagem de uma língua estrangeira como um processo complexo, uma vez que o discurso é construído por alguém que fala, por um enunciado que se pretende legítimo, abafando outras vozes. Essa enunciação, que se faz como independente do objeto e de suas condições de existência manifesta a exterioridade ou relato do objeto segundo um modelo discursivo marcado pela seleção, inclusão ou exclusão de fatos.

A democratização do acesso e o conhecimento de uma língua estrangeira está, também, intrinsecamente ligada ao tema da diversidade cultural, que vem adquirindo crescente importância atualmente. Em torno da mesma, estão presentes: ideologias, tradições, conceitos políticos e sociais, que podem influenciar de forma positiva ou negativa indivíduos de outras nações, dependendo da forma que esses se posicionem diante das informações que Ihes são apresentadas. Essas características culturais estão embutidas nos relacionamentos históricos de poder e autoridade, que garantem o status social, profissional, político e pedagógico dos sujeitos envolvidos. Santos (2004) comenta que as preocupações com a cultura surgiram associadas tanto ao progresso da sociedade e do conhecimento quanto das novas formas de dominação. $O$ autor também afirma que existe relação entre linguagem e cultura e que isso pode justificar um idioma ser usado como forma de dominação de uma cultura sobre outra.

A Língua Inglesa, de um ponto de vista discursivo, não pode apenas representar algo já dado, sendo parte de uma construção social que rompe com a ilusão de naturalidade entre os limites do linguístico e os do extralinguístico. Trata-se de uma transdisciplinaridade com um foco específico sobre a relação entre o mundo social e a linguagem. É nesse contexto que Orlandi (2007, p.60) destaca que "os sentidos e os sujeitos se constituem em processos em que há transferências, jogos simbólicos dos quais não temos o controle e nos quais o equívoco - o trabalho da ideologia e do inconsciente - estão largamente presentes". Podemos, pois, afirmar que o indivíduo tem a necessidade de, pelo uso da linguagem, entender e ser entendido, uma vez que, no momento em que um sujeito aprende um novo idioma, abre-se um caminho de diferenças sócio-histórico-culturais onde cada um tem seus valores, e, por conseguinte, sua linguagem e sua forma de expressão.

Ao entrar em contato com a língua inglesa, o sujeito-aluno inscreve-se em uma nova discursividade, o que provoca deslocamentos na sua subjetividade $e$, 
consequentemente, apropria-se uma nova interpretação do mundo em que vive. É possível afirmar, também, que língua, cultura e história são cacos de um mesmo vitral, cujos matizes revelam que o domínio sobre línguas estrangeiras representa mais do que uma simples habilidade linguística: representa aptidão multicultural, bem como versatilidade de estruturar o pensamento por diferentes vias e de interpretar realidades sob diferentes óticas.

Nessa perspectiva, entendemos, então, que, à medida que as vozes dos sujeitos entram em contato com outras vozes, nas situações de comunicação de que participam, esses futuros profissionais constroem e reconstroem seus conhecimentos, suas concepções sobre a natureza social da linguagem e da aprendizagem e, em última análise, constroem e reconstroem a si próprios como profissionais.

\section{A constituição dos sujeitos e sentidos: o que revelam os discursos}

As sequências analisadas é um recorte dos depoimentos dos sujeitos envolvidos. Para isso, foram feitas perguntas abertas aos entrevistados, para que respondessem por escrito. É importante ressaltar que, acreditamos que os pressupostos teóricos bem como alguns aspectos colocados nesta amostragem significam apenas uma pequena abordagem, em meio a tantas mais, que poderiam ser elencadas como contribuições que a Análise do Discurso nos oferece ao ensino-aprendizagem da Língua Inglesa. Em função disso, ao verificarmos a constituição dos sujeitos e dos sentidos nos dizeres analisados, gostaríamos de destacar o caráter de incompletude de nosso discurso. Vejamos o que dizem:

\subsection{Sujeito-aluno}

No tocante à importância do idioma para o exercício da profissão, os dizeres desses alunos apontam para o aprendizado da língua inglesa como uma necessidade profissional, haja vista as qualificações exigidas, marcadas dentro de uma verdade de mercado globalizado e competitivo, implicando, pois, num reconhecimento da presença da ideologia na língua. Concebem, portanto, que:

Para o profissional de Comércio Exterior, o idioma é de grande importância. (Aluno A)

$O$ inglês é um idioma que influencia no desenvolvimento e no aprimoramento profissional de todo e qualquer profissional, principalmente de uma secretária executiva. (Aluno B) 
O domínio de outro idioma para o profissional de secretariado executivo ou para o profissional de comércio exterior é de fundamental importância para o sucesso profissional do mesmo. (Aluno C)

O inglês, a língua considerada "universal", tem grande importância para ser praticada na vida profissional. (Aluno D)

Vimos que o mercado de trabalho exige o domínio do inglês, principalmente em minha área (Comex). (Aluno E)

O domínio da língua inglesa, sob tais óticas, acaba por definir ideologicamente as posições dos sujeitos nas cadeias discursivas, nas quais os discursos veiculam o saber como gerador de poder. Esses dizeres são entendidos como algo que caracteriza a relação que Foucault denomina de "saber-poder", por considerar o discurso como o ponto de articulação entre ambos. Como diz Veiga-Neto (2005, p.141), ao estudar articulações entre poder e saber, Foucault descobriu que os saberes se engendram e se organizam para "atender" a uma vontade de poder. Em seu livro Vigiar e Punir, Foucault diz que temos de admitir que:

[...] poder e saber estão diretamente implicados; que não há relação de poder sem constituição correlata de um campo de saber, nem saber que não suponha e não constitua ao mesmo tempo relações de poder. [...] não é a atividade do sujeito de conhecimento que produziria um saber, útil ou arredio ao poder, mas o poder-saber, os processos e as lutas que o atravessam e que o constituem, que determinam as formas e os campos possíveis do conhecimento. (FOUCAULT, 2007a, p.270)

Nesse sentido, o domínio do idioma representa posições mais privilegiadas no mercado de trabalho, gerando efeitos de sentidos produzidos pelas práticas discursivas. Práticas essas que perpassam pelas academias institucionais construindo um sistema de significados, os quais capturam o pensamento e a reflexão sobre a realidade profissional de que quem tem o domínio da Língua Inglesa tem maior poder para a empregabilidade. Para Foucault (2008), as práticas discursivas funcionam como um processo que produz transformações constantes, de forma que um discurso, decorrente de uma dada formação discursiva, é constituído a partir de regras de aparecimento de suas condições de apropriação e utilização. Entendem, assim, que:

O profissional que tem essa ferramenta a seu favor tem mais oportunidades de emprego. (Aluno $\mathrm{C}$ )

Em virtude das exigências do trabalho, o idioma é mister no nosso dia a dia, considerando ser fator preponderante para a avaliação de perfil profissional. (Aluno D) 
Os discursos desses sujeitos revelam o domínio de idioma como elemento transformador, pois está posicionado dentro de uma concepção de que um profissional qualificado tem "garantia de estabilidade empregatícia, de sucesso profissional, de completude", assumindo um caráter cada vez mais informacional e significativas mudanças sobre o perfil do emprego e provocando, também, modificações nas relações, forma e conteúdo do trabalho. Por outro lado, o não domínio do idioma os colocam em uma posição de incompletude. Segundo Orlandi (2007, p.52), "nem sujeitos nem sentidos estão completos, já feitos, constituídos definitivamente. Constitui-se e funcionam sob o modo do entremeio, da relação, da falta, do movimento. Essa incompletude atesta a abertura do simbólico, pois a falta também é lugar do possível".

Assim, ao dizer que "é excluído do processo e do mercado de trabalho", as marcas discursivas revelam um sujeito que, no momento em que não atesta o domínio do idioma, se vê fora desse mercado e, portanto, distanciado de ocupar um lugar institucionalizado pelas exigências do mercado globalizado. No segundo momento, a conjunção "mas" formula uma verdade de habilidades exigidas que reforça o sentido dessa exclusão, constituindo um assujeitamento do sujeito com as demandas do mercado. Em outros termos, o assujeitamento do sujeito está relacionado ao espaço ocupado em um determinado grupo ou formação social sem que o mesmo tenha consciência disso. Nas palavras dos informantes:

O profissional que não tem nenhum domínio do idioma é excluído do processo e mercado de trabalho. (Aluno D)

Inclusive surgiu vaga para atuar no comércio exterior mas na época não havia profissional com os pré-requisitos exigidos, ou seja, domínio do idioma inglês. (Aluno E)

Em relação às exigências do mercado de trabalho, os sujeitos-alunos revelam um discurso advindo do processo de globalização, visto que, por meio dos estudos de Pêcheux, sabemos que um discurso nasce a partir de outro discurso. Nesse contexto, verificamos que esses dizeres apontam um mundo tal como nos fazem crer, onde a globalização se apresenta como meio de homogeneização, legitimada e regulada pelas regras do mercado profissional, as quais, normalmente, são acompanhadas de conflitos e de ideologias. Acreditamos, também, que o domínio de um outro idioma enquadra-se nesse sistema de regulação, visto que é apontado como "necessidade de comunicação para como os outros países", o que gera uma representação identitária do próprio e do alheio cultural. Conforme revelam os dizeres dos enunciadores: 
Com o mundo globalizado o mercado praticamente se torna um só, havendo uma necessidade de comunicação para com outros países, sendo assim, o Inglês, uma língua ou idioma praticamente falado em quase todos os países, se torna essencial para a inclusão do profissional da área de Comex. (Aluno A)

[...] as exigências do mercado globalizado, requer cada vez mais um profissional capacitado, com habilidade para falar e escrever um idioma fluente. (Aluno B)

No tocante ao processo ensino-aprendizagem, os sujeitos expõem, em seus dizeres, uma não satisfação na forma como a Instituição de ensino aplica a disciplina de Língua Inglesa no programa curricular dos referidos cursos. Revela, também, um sujeito preocupado com o fator tempo de duração das disciplinas. Tais discursos nos remetem ao que Orlandi denomina de incompletude. Segundo a autora (2007, p. 52), "essa incompletude atesta a abertura do simbólico, pois a falta também é lugar do possível". Vejamos:

\footnotetext{
A faculdade nos oferece noções do inglês instrumental para a secretária executiva, o que não nos prepara para o mercado de trabalho. (Aluno C)

$\mathrm{Na}$ minha opinião, sugiro que a faculdade possa dar um apoio maior a esses alunos, pois esses levam o nome da instituição, o que pode ser bom ou ruim para a mesma. (Aluno E)

Penso que na grade curricular da FACAPE o ensino da língua inglesa deveria ser ministrado em todos os períodos. (Aluno D)
}

\subsection{Sujeito-professor}

O ponto inicial dos nossos questionamentos estava relacionado à metodologia usada pelos docentes em sala de aula. E nos dizeres dos três professores, percebemos certa homogeneidade. Por outro lado, a modalização desse discurso mobiliza uma memória discursiva de que o termo abordagem comunicacional é defendida como referencial teórico para o ensino-aprendizagem de Língua Estrangeira uma vez que centraliza o ensino na comunicação. Essa abordagem, diz Almeida Filho (2007), mostrase preocupada com o próprio aluno, enquanto sujeito e agente, no processo de formação através de uma nova língua e que tem menor ênfase no ensino e mais força no que o faz crescer como pessoa e cidadão. Nesse sentido, os sujeitos-professores constituem uma identidade profissional.

Percebemos, também, o discurso de sedução usado pelos três docentes, interpelando o sujeito-aluno por meio da ideologia, pelo uso das palavras "dinâmicas 
diversificadas", "estímulo à curiosidade do aluno", "cativo o aprendizado participativo". Discursos esses, que podem ser entendidos como uma verdade, que pode estimular a subjetividade do aluno em sua aprendizagem. Verdade essa que, na perspectiva teórica adotada nesta pesquisa, não pode ser entendida como única, fixa e estável, mas como verdades que são constantemente construídas e postuladas para certos momentos, em dados lugares (FOUCAULT, 2008). Assim, os professores revelam suas práticas de ensino:

Estudo orientado, leitura crítica dos termos geradores acompanhados de textos, aulas expositivas, trabalhos individuais e em grupo utilizando dinâmicas diversificadas, construção de textos individuais e coletivos. (Professor A)

Depende do enfoque que se quer dar à aprendizagem do idioma:

Inglês Instrumental - avaliação da condição do aluno/nivelamento; estratégias de leitura; textos apropriados à área; estímulo à curiosidade do aluno; outras leituras de mundo (visual / auditiva / contextual). Inglês para comunicação - aplico as metodologias comunicativas (abordagem) seguindo todos os passos (warm up, previous review, words in action, predicting, explanation, internalization, practice, etc). (Professor B)

No contexto geral procuro abordar (trabalhar) os três fundamentos básicos da Língua, ou seja: o som, vocabulário e estrutura nas diferentes realidades profissionais. Inglês Instrumental para Turismo, Comex e Secretariado Executivo. O enfoque principal é abordar a língua no âmbito comunicacional empresarial capacitando assim o discente a ter subsídios necessários para a comunicação em seus locais de trabalho. Cativo o aprendizado participativo onde os alunos estudam as teorias e as colocam em seguida em prática. (Professor $\mathrm{C}$ )

A interação com os alunos foi o questionamento para esta sequência discursiva, visto que, ocupando posições diferentes no discurso pedagógico, professor e aluno são interpretantes. O professor significa a sua posição regulado pelo contexto histórico e social de que é legitimado para ensinar; ao mesmo tempo, seus dizeres, como qualquer outra produção discursiva, é atravessado por vários outros dizeres, que circulam dentro e fora da sala de aula. Nessa perspectiva, Orlandi (2002, p. 249) afirma que:

As relações entre os homens são relações de sentidos, e a análise de discurso procura compreender como isso funciona produzindo efeitos de tal modo que, ao significar, os sujeitos se significam. $O$ aluno, ou o professor, já têm sentidos pelo fato mesmo de, ao entrarem na Escola, esta se apresenta como um lugar de significação (de interpretação) em que os sentidos já estão postos e funcionando antes mesmo que $x$ ou $y$ entrem nela (posições-sujeito).

Partindo desse ponto de vista, tais trechos revelam um sujeito que se sente responsável pela subjetividade do aluno, centrada no indivíduo enquanto um ser social, o 
que implica em um efeito de sentido de que o professor é completo no que se refere à metodologia da sala de aula. Revela a crença de um sujeito consciente do processo de aprendizagem, das estratégias, do controle sobre o processo de ensino-aprendizagem.

Consideramos necessidades básicas para a interação com os alunos: estímulo oferecido durante as aulas; método do trabalho e segurança com que as informações são passadas, além disso, olhar o aluno como um ser humano em desenvolvimento constante no campo social e cultural. As interações são importantes e precisam ser levadas em consideração. (Professor A)

Como já disse: gosto de fazer um ensino-aprendizagem participativo, motivando todos os alunos a se engajarem nesse processo junto com o professor. (Professor C)

Já na sequência discursiva abaixo, o sujeito-enunciador define o ato de ensinar língua inglesa no contexto escolar como algo que "causa alegria"; com isso, assume uma conduta de amante da profissão. Podemos observar, também, que é um sujeito que se aceita, satisfeito com a sua profissão, vê o seu trabalho como sua identidade.

Sou apaixonada pelo que faço! Ensinar línguas é a razão da minha vida! Realizo-me ao sentir que "conquistei" algum aprendiz para o "encantamento" que o domínio de qualquer idioma favorece [...] "Meus alunos", acaso possa considerá-los assim, são meus parceiros quando está envolvida a realização, o cumprimento de objetivos que traçamos para cada etapa de aprendizagem.(Professor B)

Sobre a relação teoria e prática do idioma para o mercado de trabalho, temos enunciadores que revelam um discurso pedagógico de que a aprendizagem de um idioma estrangeiro pode gerar oportunidades no mercado de trabalho, discurso que se entrecruza com o do processo de globalização que diz que o mesmo tem provocado, no ser humano, uma emergência na aquisição de novos conhecimentos. Nessa relação dialógica, os sujeitos-professores enunciam que teoria e prática da língua inglesa não se limitam apenas à transmissão de signos e estruturas, mas uma relação interacional com 0 mercado de trabalho, efeitos de uma ideologia do professor quanto ao resultado do seu trabalho em sala de aula. No ponto de vista de Orlandi (2007, p.46), "a ideologia faz parte, ou melhor, é a condição para a constituição do sujeito e dos sentidos". Os seguintes segmentos delineiam os dizeres desses professores:

É de suma importância o embricamento entre a teoria e a prática na aquisição do conhecimento técnico e científico para que o aprendiz possa enfrentar o mercado de trabalho com segurança e competência linguística. (Professor A) 
A teoria é aquilo que nós abordamos em tese em sala de aula. É a instrução formal. A prática é a consequência do aprendizado teórico no qual o aluno aplicará em prática e experimentos aquilo que ele aprendeu. (Professor C)

Por outro lado, na sequência discursiva abaixo, um outro enunciador revela um dizer marcado por uma dualidade entre sentimento e razão, por uma ausência, por um desejo recalcado, por uma negação na relação teoria / prática, causas do suposto insucesso do ensino da língua inglesa no contexto escolar. Dizer que corrobora com o sentimento do aluno de uma não satisfação no tocante ao papel institucional da Faculdade em relação ao ensino-aprendizagem da língua estrangeira. Essas contradições vividas por esses enunciadores mostram uma relação que o sujeito mantém com as discursividades que o constituem, o que comprova a complexidade de sua subjetividade. Podemos, ainda, dizer que a parte prática do ensino aprendizagem da Língua Inglesa nesses cursos é a que abafa a completude do desejo desse enunciador, o que gera a distinção entre o real do discurso e o imaginário. Nas palavras de Orlandi (2007), o real do discurso é a descontinuidade, a dispersão, a incompletude, a falta, o equívoco, a contradição, constitutivos tanto do sujeito como do sentido. Já o imaginário está no nível da completude, da coerência, da não contradição. Entretanto, no real do discurso, o idioma é apresentado de forma segmentada, onde o aluno não tem meios de encaixar estes fragmentos em seu dia a dia.

Essa é a realidade mais triste da profissão. Alunos que devem ter certa proficiência nos idiomas requisitados em suas grades curriculares, saem do curso com um conhecimento exíguo dos mesmos. Há cursos em que o contato dos alunos com idioma chega a 2 anos (4 semestres)e ele sai dos mesmos com um parco conhecimento das língua envolvidas.(Professor B)

O seguinte segmento revela a prática de uma verdade que mostra algo que demanda condições especiais não presentes na instituição de ensino, a do pleno domínio do idioma no período referente às aulas na graduação. Esse dizer coloca alunos e professores numa posição de imobilidade em relação ao ensino de língua inglesa. Negase o potencial das escolas para ensinar o idioma e idealiza-se os cursos livres como o lugar privilegiado para a aquisição do mesmo. A busca por cursos livres representa, pelo viés desse dizer, uma forma de superação da desigualdade de oportunidades, certa aquisição de competência para a disputa de acesso ao mercado de trabalho cada vez mais exigente e competitivo. Nesse sentido, o sujeito-aluno torna-se um assujeitado dos 
efeitos desse interdiscurso de aquisição de uma segunda língua, pois o processo de aprendizagem na instituição universitária é lento e fragmentado.

Podemos observar, também, que o uso do termo "exige", entre aspas, contribui para reforçar o sentido de que a língua inglesa é um instrumento essencial para operar nesse mercado de trabalho, do seu poder que vem da história e da memória. Logo em seguida, o enunciador usa também o termo "abandonado" também entre aspas para revelar situações de desigualdade (econômica, por exemplo), uma realidade excludente, que deixa grande parcela da população estudantil à margem do mercado de trabalho em virtude de uma outra verdade, que é a não qualificação profissional. Esse imbricamento, que anuncia e denuncia a heterogeneidade educacional, nos faz retomar o pensamento de Foucault em relação à educação (2007, p.44) onde diz que "todo o sistema de educação é uma maneira política de manter ou de modificar a apropriação dos discursos, com os saberes e os poderes que esses trazem consigo". Vejamos, então, esse dizer:

É notório que o aluno necessita desembolsar dinheiro para estudar idiomas em cursos especializados. Isso, quando dispõem desses recursos. Por onde tenho lecionado, é raríssimo encontrar algum aluno que detenha conhecimento prévio dos idiomas vivenciados. Tampouco saem com um domínio mínimo que o requisito merece. Considere-se, acima de tudo, que o mercado de trabalho "exige" profissionais com níveis de proficiência em línguas para atender às demandas sempre recorrentes.

O aluno sabe dessa necessidade premente, porém, sente-se "abandonado" e sem base para lutar por uma chance de concorrer, em nível de igualdade, com tantos profissionais mais bem preparados no requisito "domínio de idiomas". (Professor B)

\subsection{Sujeito-empresa}

Relativo aos critérios usados para a contratação de um Secretário Executivo e/ou um bacharel em Comércio Exterior, vemos um discurso, que corrobora tanto com o do sujeito-aluno como com o do sujeito-professor no sentido da necessidade de conhecimentos não só nas mais diversas áreas, como também do conhecimento linguístico para a atuação no mercado de trabalho. Nesse fragmento, a língua inglesa é vista como uma qualificação básica do indivíduo, algo que contribui, sobremaneira, para a obtenção de um cargo nessa empresa. Um discurso que reflete ideias da memória discursiva da idealização da língua inglesa. Retomando esse pensamento, Paiva (1996, p.26) diz que "a língua inglesa circula entre nós como uma mercadoria de alta cotação no mercado". 
Ao usar a palavra "trunfo", o enunciador revela uma comparação que retoma o discurso que advém dos jogos de cartas, onde o trunfo é uma carta superior às demais em determinados jogos e que é usado, muitas vezes, para vencer a partida. Por outro lado, perpassa, também, a ideia de re-significação em um momento decisório, podendo provocar deslocamentos na constituição do papel subjetivo da competência profissional. Para Coracini (2003 p.153), inscrever-se numa língua estrangeira é re-significar e resignificar-se nas condições de produção de uma outra língua, ou seja, é ser falado por ela. A autora diz, ainda, que essa inscrição será portadora de novas vozes, novos questionamentos, alterando a constituição da subjetividade, modificando o sujeito, sem gerar o apagamento da discursividade da língua materna que o constitui. Esse dizer aponta que:

Além dos critérios básicos que identificam a postura e nível profissional, principalmente o domínio do idioma da língua inglesa que é também um critério básico na seleção. O domínio da língua se tornou um trunfo na empresa para os que o possuem, além do fator determinante no valor da mão-de-obra desse profissional.

Em se tratando de remuneração, verificamos que o discurso da diferença salarial, em virtude da proficiência na língua, é revelado pelo enunciador como uma recompensa. Esse dizer está sedimentado por uma verdade historicamente constituída sobre as exigências do mundo moderno, onde se supõe um efeito de assujeitamento do funcionário em sua carreira profissional uma vez que há diferenças salariais incorporadas diante do domínio de um outro idioma em seu currículo.

Por esse viés, torna-se claro que a competitividade se legitima não apenas pela experiência profissional, mas também pelo conhecimento linguístico, discurso que se articula mais uma vez com o que Foucault chama de saber-poder. Foucault (2008, p.205) pontua que "o saber não está contido somente em demonstrações; pode estar também em ficções, narrativas, regulamentos institucionais, decisões políticas". Partindo desse ponto de vista, podemos afirmar que a dimensão polifônica do domínio da língua inglesa reflete na hierarquização de lugares sociais, bem como na forma de enunciação desse sujeito.

Sim, principalmente porque a colaboração do funcionário e a sua atuação se tornam mais abrangentes no exercício da sua função, por esse motivo se é aplicado uma diferença salarial significativa sobre o salário do profissional bilíngue (preferencialmente língua inglesa). 
Quanto à proporção, é aplicado por níveis. Na Diretoria, existe uma diferença para aqueles que falam fluentemente inglês para aqueles que não falam, cuja média é em torno de $45 \%$.

No tocante à relação teoria e prática da Língua Inglesa de um Secretário Executivo e/ou de um bacharel em Comércio Exterior com o mercado de trabalho, esse sujeitoempresa percebe o idioma como fundamental para a comunicação empresarial, corroborando, mais uma vez, com as concepções dos alunos e dos professores em relação ao discurso da eficiência trabalhista.

$\mathrm{Na}$ ótica do sujeito-empresa, o saber do funcionário perpassa, também, como um elemento disseminador e/ou transformador de imagem empresarial. Nesse contexto, convém ressaltar o poder do conhecimento linguístico ao acesso a diversos níveis de situações sociais e empresariais. Segundo Foucault (2008, p.205), "um saber é, também, o espaço em que o sujeito pode tomar posição para falar dos objetos que se ocupa em seu discurso".

No dizer "Se o fazemos de forma incorreta ou ineficaz, corremos o risco de estar deixando lacunas e passando uma imagem deficiente da nossa organização", podemos conferir uma visão implícita das práticas de gestão desenvolvidas pelas organizações empresariais referente à inclusão ou exclusão do indivíduo numa determinada esfera empresarial relativo ao conhecimento profissional acadêmico, bem como do aprimoramento da capacidade comunicativa, uma vez que, nas palavras de Orlandi (2007, p.82), "há sempre no dizer um não dizer necessário".

Outro ponto que observamos foi a preocupação que esse sujeito revela com relação ao processo de comunicação com outras instituições, com a competitividade. Competitividade definida, aqui, como a capacidade da empresa formular e implementar estratégias concorrenciais, que the permitam ampliar ou conservar, de forma duradoura, uma posição sustentável no mercado (HAGUENAUER, L.; FERRAZ, J. C.; KUPFER, D. S., 1996 p.196). Assim, o sujeito-empresa enuncia:

Existe uma relação direta entre a teoria e prática. A comunicação eficaz depende de uma comunicação escrita e verbal construída com estruturas corretas. Exemplifico com o próprio português, nossa língua nativa. Quando nos comunicamos, estamos propagando uma imagem da empresa. Se o fazemos de forma incorreta ou ineficaz, corremos o risco de estar deixando lacunas e passando uma imagem deficiente da nossa organização. Afinal, a comunicação nos dá um alcance com associados, fornecedores, instituições brasileiras e estrangeiras, parceiros, embaixadas, etc. 
As análises apreendidas revelaram que os alunos têm consciência da necessidade de saber um idioma estrangeiro. Em função disso, são influenciados por diversos fatores internos e externos, como o intelectual e o profissional. Passam, também, por um processo de transformação sócio-histórico-cultural onde o conhecimento não é apenas a acumulação de teorias vividas em sala de aula, mas o domínio pleno sobre tudo o que é abrangido pela tarefa que se encontra sob a responsabilidade direta do indivíduo no mercado de trabalho, onde a maximização desses conhecimentos é aspecto importante a ser considerado para a perfeita harmonia e integração da funcionalidade do ensinoaprendizagem da Língua Inglesa, os quais são necessários para o desenvolvimento profissional e social.

Mostraram, ainda, que, ao se inserirem na discursividade da língua estrangeira, os sujeitos-alunos estão, na verdade, em confronto com a sua própria discursividade, visto que, fazem deslocamentos consideráveis em suas filiações sócio-históricas-ideológicas de identificação, o que caracteriza a complexidade da subjetividade de quem estuda outro idioma, uma vez que as contradições com outras formações discursivas puderam ser percebidas em seus discursos. O discurso é o lugar em que se pode observar essa relação entre língua e ideologia, compreendendo-se como a língua produz sentidos por/para os sujeitos (ORLANDI, 2007, P.17).

Partindo desse pressuposto, podemos afirmar que esses sujeitos-alunos não estão preparados para encarar esse mercado de crescente necessidade linguística e que os mesmos têm de se preparar para o desafio da exigência desse mercado, que faz da Língua Inglesa o idioma preferencial na maioria dos negócios realizados, uma vez que essa interação depende de uma construção conjunta em um contexto sócio-históricocultural. Conforme Meksenas (1994), "a relação existente entre compreensão e ação no mundo é mediada pelo uso da linguagem. Assim, a linguagem pode ser considerada como um suporte para o desenvolvimento do conhecimento".

A prática pedagógica revela um certo contraponto ao projeto pedagógico proposto, visto que muitos aprendizes, mesmo com o aprimoramento de métodos, abordagens e técnicas, não conseguem estabelecer uma relação de identificação com a língua estrangeira, fato que leva a apresentar uma visão da realidade escolar brasileira, não apenas em relação à Língua Inglesa, mas acerca do sistema escolar.

Ainda no tocante ao enfoque interacional do ensino da língua inglesa com a prática profissional, as análises demonstraram que fatores como o não domínio do idioma, o não conhecimento e não acompanhamento do processo de globalização, bem como a não 
conscientização da diversidade cultural contribuem para a exclusão, não total, mas parcial, dos sujeitos-alunos na prática profissional, principalmente nas empresas de exportação, visto que a necessidade comunicacional é apontada pelo sujeito-empresa como primordial. Essa lacuna exprime uma realidade profissional da não qualificação do indivíduo, geradas, a nosso ver, não somente pela instituição de ensino, mas por questões econômicas, sociais, culturais, motivacionais, que se opõem ao desenvolvimento e à constituição do saber-poder do sujeito profissional, uma vez que o aperfeiçoamento da aprendizagem modifica o pensar, transforma o sujeito

Em função disso, sugerimos que os professores de idiomas envolvam mais os alunos desses cursos em atividades contextulaizadas com suas profissões, a fim de que os mesmos se sintam contribuindo com o próprio processo de ensino-aprendizagem. Assim, poderão visualizar as aulas de Língua Inglesa como um momento de interação intelectual e humana, de dialogismo, de inclusão profissional, tornando o processo de ensino-aprendizado mais próximo, confiante e eficaz, visto que o processo de ensinoaprendizagem representa mais que uma marca cultural; refere-se, pois, a algo da ordem de uma inscrição de sujeitos e sentidos no discurso do ensino-aprendizagem da Língua Inglesa e da prática profissional, que estão além da aprendizagem.

Diante do exposto, esperamos que a nossa pesquisa possa contribuir para uma reflexão crítica sobre os problemas abordados, bem como sobre a relação saber-poder. Assim, a partir do momento que os sujeitos-alunos compreenderem melhor a dinâmica da sociedade em que vivem, poderão perceber-se como elementos ativos de força política e capacidade de transformar e, até mesmo, viabilizar mudanças estruturais que apontem para um modelo mais justo de sociedade e de empregabilidade uma vez que uma língua estrangeira é muito mais que um instrumento de comunicação, de garantia de um emprego melhor em um mercado de trabalho cada vez mais competitivo, pois, mesmo que seja aprendida com um fim meramente utilitarista, ela traz consigo consequências para a constituição de sujeitos e sentidos.

\section{Referências}

ALMEIDA FILHO, José Carlos Paes de. Linguística Aplicada: Ensino de Línguas e Comunicação. Campinas, SP: Pontes Editores e ArteLíngua, 2 ed. 2007.

ALTHUSSER, Louis. Aparelhos ideológicos de Estado. 8 ed. Rio de Janeiro: Graal, 2007. CHAUI, Marilena. O que é ideologia. São Paulo: Brasiliense, 2006.

CORACINI, Maria José R. Faria. Língua estrangeira e língua materna uma questão de sujeito e identidade. In: . (org.). Identidade e Discurso: (des)construindo subjetividades. Campinas: Editora da UNICAMP; Chapecó: Argos Editora Universitária, 2003.p.139-159. 
FOUCAULT, Michel. A arqueologia do saber. 7 ed. Tradução: Luiz Felipe Baeta Neves. Rio de Janeiro: Forense Universitária, 2008.

A ordem do discurso. Tradução Laura Fraga de Almeida Sampaio. 15 ed. São Paulo: Edições Loyola, 2007. (Coleção Leituras Filosóficas)

Vigiar e punir: nascimento da prisão. 33 ed. Tradução de Raquel Ramalhete.

Petrópolis: Vozes, 2007a

HAGUENAUER, L.; FERRAZ, J. C.; KUPFER, D. S. Competição e Internacionalização na Indústria Brasileira. In: BAUMAN, Renato (org.). O Brasil e a economia Global. Rio de Janeiro: Elsevier: SOBEET, 1996.

ORLANDI, Eni P. Língua e Conhecimento Lingüístico: para uma história das ideias no Brasil. São Paulo: Cortez, 2002.

. Análise de discurso: princípios e procedimentos. 7 ed., Campinas, SP: Pontes, 2007.

PAIVA, Vera Lúcia Menezes de Oliveira (org.). Ensino da Língua Inglesa: reflexões e experiências. Campinas, SP: Pontes; Minas Gerais: Departamento de Letras Anglo Germânicas. UFMG, 1996.

PÊCHEUX, Michel. Semântica e Discurso: uma crítica a afirmação do óbvio. Campinas:

Editora da Unicamp, 1995.

SANTOS, José Luiz dos. O que é Cultura. São Paulo: Brasiliense, 2004.

VEIGA-NETO, Alfredo. Focault e a Educação. 2 ed., Belo Horizonte: Autêntica, 2005.

O PAPEL DO CURRÍCULO DO CURSO DE FORMAÇÃO DE PROFESSORES DE LÍNGUA INGLESA NAS CRENÇAS DOS LICENCIANDOS DA UNIVERSIDADE DE PERNAMBUCO

THE FUNCTION OF THE CURRICULUM IN THE ENGLISH TEACHERS TRAINNING BASED IN THE UNDERGRADUATES' BELIEFS AT UNIVERSITY OF PERNAMBUCO

Relma Lúcia Passos de Castro Mudo relmacastro@gmail.com

Roberta Guimarães de Godoy e Vasconcelos 
RESUMO: A ideia deste artigo nasceu com base na prática docente das autoras no curso de Letras- Licenciatura em língua inglesa e suas literaturas na Universidade de Pernambuco, campus Petrolina. A partir do constante contato com alunos de diferentes períodos nas disciplinas ministradas bem como nos encontros para orientação monográfica, percebeu-se determinadas crenças a respeito do papel do curso superior na formação do professor de língua estrangeira, no caso, a língua inglesa. Diante desse pressuposto, objetivou-se investigar, através do currículo do curso e de questionários aplicados aos discentes, se os mesmos estão conscientes de suas competências e do papel das disciplinas que formam o projeto político-pedagógico do curso na referida instituição. Após a investigação, buscou-se refletir sobre as mudanças necessárias em relação ao discurso dos docentes, materiais e leituras adotados e mesmo uma necessária mudança de algumas disciplinas que fazem parte do currículo. Por meio dos resultados, foi possível considerar que, a maioria dos alunos não tem consciência da importância da elaboração de projetos e que o olhar crítico do pesquisador também faz parte do exercício docente.

PALAVRAS-CHAVE: Formação dos professores; Licenciatura em Língua Inglesa; Crenças dos licenciandos.

ABSTRACT: The idea of this article was based on the authors' teaching practice in the course of Bachelor of Arts in English language and literatures at the University of Pernambuco, Petrolina campus. From constant contact with students from different periods in the subjects taught and in meetings for monographic orientation, it was noticed certain beliefs about the role of higher education in the training of foreign language teacher, in this case, the English language. Given this assumption, this paper was aimed to investigate, through the course curriculum and through questionnaires to students, whether they are aware of their responsibilities and the role of the disciplines politicalpedagogic area in that institution. After investigation, we sought to reflect on the chan ges needed in relation to the speech of teachers, materials and readings adopted a needed change in some disciplines that are part of the curriculum. Through the results it was possible to consider that most students are unaware of the importance of project design and that the critical gaze of the researcher is also part of the teaching exercise.

KEYWORDS: Teachers training; English Language graduation; Students' beliefs. 


\section{Introdução}

Investigações sobre a linguagem e a prática pedagógica têm se tornado interesse de diversas áreas de conhecimento visto que buscam entender a sala de aula, seus participantes e seus discursos como práticas sociais. Por serem elementos participantes de uma prática social, os mesmos são estabelecidos, influenciados e transformados a partir dos discursos que norteiam esse contexto.

Dentro dessa área de interesse, a ideia da pesquisa aqui proposta nasceu a partir da prática docente das autoras no curso de Letras-Licenciatura em língua inglesa e suas literaturas na Universidade de Pernambuco, campus Petrolina, localizada no sertão pernambucano. A partir do constante contato com alunos de diferentes períodos nas disciplinas ministradas bem como nos encontros para orientação monográfica, foi possível perceber determinadas crenças, muitas vezes equivocadas, a respeito do papel do curso superior na formação do professor de língua estrangeira, no nosso caso, a língua inglesa.

Cientes da importância do curso de Letras na formação de profissionais conscientes e competentes a respeito do seu papel formador na sociedade contemporânea, o currículo do curso propõe capacitar os discentes não somente melhorando seu nível linguístico da LE, mas oferecendo também uma formação teóricoprática para outras competências essenciais ao trabalho docente. Diante da necessidade dessas competências, visamos refletir discursivamente sobre os dizeres dos discentes do departamento sobre satisfação, conhecimento e acesso à matriz curricular, relação teoria e prática profissional, como também dizeres sobre uma possível reformulação no projeto pedagógico do curso.

Para tanto, temos como sujeitos da pesquisa, alunos de diferentes períodos do curso citado acima. A coleta e análise dos dados foram feitas a partir de questionários semi estruturados aplicados aos mesmos com o intuito de atingir os objetivos do nosso estudo, preconizando-os com teóricos abordados.

A metodologia foi realizada de forma qualitativa e descritiva levando em consideração as subjetividades dos alunos envolvidos. O resultado da pesquisa aponta que, a maioria dos alunos, não tem consciência da importância de determinadas disciplinas que não fazem parte do grupo de desenvolvimento da competência linguísticocomunicativa, considerando como mudanças necessárias, a reestruturação de algumas disciplinas e ampliação da carga horária de disciplinas diretamente voltadas para a Língua Inglesa. 


\section{O professor em formação enquanto sujeito de uma prática social}

Ao pensarmos o aluno em formação, como participante de uma prática social, é imprescindível considerarmos os discursos que os rodeiam como formadores de sua crenças sobre o que é ser um professor de inglês e que conhecimentos e competências são necessários ao exercício docente. Esse ciclo gera uma interligação na qual a teoria gera a prática e vice-versa, dando-se suporte e significado mutuamente. Partindo desse nosso pressuposto, propomos um breve olhar discursivo que articule linguagem e ideologia, entremeadas pelo contexto social, conduzidos pelas contribuições da Análise do Discurso.

No ponto de vista de Brandão (2004, p.46) o discurso é uma das instâncias em que a materialidade ideológica se concretiza, isto é, é um dos aspectos materiais da "existência material" das ideologias. É o porta-voz dos acontecimentos sócio-histórico ideológico porque ele é veiculado pela linguagem. A autora (2004 p. 10) afirma ainda que:

a linguagem enquanto discurso não constitui um universo de signos que serve apenas como instrumento de comunicação ou suporte de pensamento; a linguagem enquanto discurso é interação, e um modo de produção social; ela não é neutra, inocente e nem natural, por isso o lugar privilegiado de manifestação da ideologia.

No ponto de vista de Vygotsky (1998) a construção da competência de ensino do professor de inglês é entendida como um processo que se forma no interior das relações sociais, através da mediação social das atividades do indivíduo, o que possibilita a construção partilhada de instrumentos e de processos de significação. Essa mediação social se constitui a partir da participação de "outros" no processo, ou seja, por meio de uma interdisciplinaridade onde professores e alunos discutem, ampliam, e (re)constroem processos de significação, viabilizando a ocorrência das interações sociais, e, principalmente, mediando as operações abstratas do pensamento.

Partindo desse ponto de vista, os sujeitos-alunos têm de se preparar para o desafio da exigência do mercado. A necessidade do domínio de uma língua estrangeira faz também com que esses sujeitos-alunos tenham uma visão da linguagem. Brandão (2004, p.8) diz que essa visão da linguagem como interação social, em que o Outro desempenha papel fundamental na constituição do significado integra todo ato de enunciação individual num contexto mais amplo, revelando as relações intrínsecas entre o linguístico e o social. A autora (ibid) também assegura que "através de cada ato de enunciação, se realiza a intersubjetividade humana, o processo de interação verbal passa a constituir, no bojo de 
sua teoria, uma realidade fundamental da língua". Entendemos, então, que, à medida que as vozes dos sujeitos entram em contato com outras vozes, nas situações de comunicação de que participam, esses futuros profissionais constroem e reconstroem seus conhecimentos, suas concepções sobre a natureza social da linguagem e da aprendizagem e, em última análise, constroem e reconstroem a si próprios como profissionais.

Nesse sentido, podemos dizer que a unidade básica de análise linguística é o enunciado, ou seja, elementos linguísticos produzidos em contextos sociais reais e concretos como participantes de uma dinâmica comunicativa, onde o sujeito se constitui ouvindo e assimilando os discursos do outro, fazendo com que esses discursos sejam processados de forma que se tornem, parcialmente, as palavras do sujeito e, parcialmente, as palavras do outro. Esse fenômeno Bakhtin (2006) chama de dialogismo. Por outro lado, o que acontece com o indivíduo enquanto ser social acontece também com a comunidade; ou seja, assim como um indivíduo, a comunidade também se constitui em arena de conflito de discursos concorrentes, e esse fenômeno, o autor chama de polifonia. Segundo esses conceitos, cada língua e cada indivíduo são formados por variantes conflitantes sujeitas à questão do poder.

Vale ressaltar que a aprendizagem de uma língua estrangeira não é um sistema vazio de sentido, visto que ela traz consigo, à revelia do aprendiz, uma carga ideológica que o coloca em conflito permanente com a ideologia da língua materna. Nesse processo, estão em jogo valores, símbolos e imagens da língua materna onde as representações que habitam o imaginário do sujeito são reveladoras de identidade. É pela enunciação que o sentido novo pode surgir, uma vez que representa interpretação historicizada pelo sujeito da linguagem. E esses sujeitos críticos e conscientes das suas escolhas, constroem suas identidades a partir das escolhas linguísticas que fazem organizar seus discursos, os quais estão relacionados com suas origens sociais, gêneros, classes, atitudes e crenças, construídos a partir de outros discursos relacionados àqueles produzidos pelos sujeitos.

Assim, a educação escolar atua historicamente na vida do indivíduo, constituindose não só como necessária para sua sobrevivência, mas também como base de informação e cultura para enfrentar o mercado de trabalho e, principalmente, como formadora de agente criador e transformador da sociedade. 


\subsection{Crenças e conhecimentos participantes da formação do professor de línguas}

Seguindo a breve perspectiva acima apresentada, é difícil dissociar as vozes existentes dentro do aluno que agora se vê como futuro professor ( ou já como tal), e as vozes daqueles que junto a ele participam da sua formação como colegas de classe, textos, professores, currículo, ementas de disciplinas, pois, conforme a perspectiva bakhtiniana

as vozes dos integrantes de cada situação de comunicação verbal entram em contato e controem, reconstroem ou traduzem em sentidos os significados que estão sendo negociados, sua consciência, seu conhecimento do mundo, e, em última análise, eles próprios se contemplam e se constroem continuamente nas suas práticas discursivas e nas dos outros." (BAKTHIN 1992 apud CASTRO, 2003 p. 12)

É importante pensarmos então, como o currículo participa no diálogo entre essas vozes. O mesmo é peça central na organização dessas vozes, visto que é o documento que organiza e até certo ponto, molda, todos os outros elementos participantes de um curso de formação de professores.

Assim, quando pensamos em uma análise de currículo dentro do curso de Letras, devemos considerar as três dimensões formadoras do mesmo, segundo Almeida Filho (2000, p.23). São elas: a competência linguístico-comunicativa (incluindo as subcompetências sócio-cultural, estratégica, metalinguística, lúdica e estética); a competência aplicada (abarcando a subcompetência teórica e emergindo do diálogo entre a teoria sabida e a prática implícita que se vive); e uma competência formativoprofissional ( para a compreensão da própria história de ensino de línguas, do valor, do potencial e dos deveres do professor de línguas). A partir desse ponto de vista, podemos afirmar que quando visamos à formação de nos cursos de Letras, a tarefa de propor mudanças curriculares com fundamentação teórica a partir de dados reais do contexto de um curso $\mathrm{X}$, implica sistematicamente prover experiências em disciplinas ou nos seus interstícios que cubram tais dimensões de competências do professor:

No entanto, nem sempre, o currículo abrange de forma equilibrada essas competências necessárias ou, quando o faz, as crenças que os alunos têm a respeito do que é esperado dele quando enfrentando o mercado de trabalho, acabam por gerar uma desvalorização de algumas disciplinas. Muitos deles esperam, no contexto de formação de professores de língua estrangeira, adquirir o conhecimento de técnicas, típicas de um determinado método ou mesmo em aprimorar suas competências linguístico- 
comunicativas, valorizando-as (e muitas vezes só dando importância a estas competências) em detrimento de outras.

De acordo com Moita-Lopes (2005), a sala de aula acaba sendo um lugar de aplicação de técnicas e o conhecimento já é dado como algo pronto por um professor ou pesquisador, não havendo o desenvolvimento de um senso crítico, do olhar de pesquisador desse aluno-professor que, muitas vezes, não sabe o contexto de ensino que esse conhecimento será usado. Diante das dificuldades apresentadas em aplicar essas técnicas de um determinado método, aprendido por ele como o certo, o aluno-professor acaba por sentir-se frustrado ou por culpar seu aluno que não se adaptou àquelas técnicas para o aprendizado da Língua Estrangeira, ou ainda, desenvolvendo a crença, na maioria das vezes pautadas pela sua experiência como aluno, de que ensinar língua é ensinar regras gramaticais.

Diante da formação dessas crenças definidas por componentes afetivos e avaliativos, sua base é o julgamento. No que diz respeito às crenças, Pajares (1992, p. 313), diz que as antigas experiências vão interferir no julgamento final das novas experiências e quando as mesmas se transformam em teorias, são altamente resistentes às mudanças e influenciam o processamento de nova informação. Ainda sobre a importância das crenças na formação desse professor, Pirovano (2006 p. 18) citando Richards (1998) afirma que o sistema de crenças do professor é a principal fonte em prática de sala de aula e que o sistema é composto de informações, atitudes, valores, expectativas, teorias e suposições sobre o ensino e a aprendizagem. Desse modo, os instrumentos e processos de significação são construídos através de relações sociais mediadas por suas atividades.

$\mathrm{Na}$ visão de Castro (2003), os mediadores (a professora da disciplina língua inglesa, colegas de classe, bem como professores de outras disciplinas, supervisores etc.), que atribuem, restringem, discutem, ampliam, constroem processos de significação, e da utilização dos signos linguísticos, não apenas viabilizam a ocorrência das interações sociais, mas, medeiam as operações abstratas do pensamento. Conforme essa abordagem, podemos dizer que os futuros professores de inglês devem não somente aprender os conteúdos teóricos, mas devem também estar preparados para reconhecer, a apreciar e a produzir ações eficazes de ensino, desenvolvendo desse modo, um olhar crítico.

Sobre o criticismo, Castro (2003) ressalta que o aluno aprende, mais especificamente, as formas de atuação pelas quais esses significados são negociados que os processos que contribuem para a apropriação desse conhecimento, assim como o 
próprio instrumento que medeia a construção desses significados. Diante do exposto, salientamos a importância de verificar o olhar dos alunos do curso de Letras ( Língua Inglesa e suas Literaturas) a respeito do currículo do curso a fim de averiguar seu entendimento a respeito das disciplinas e sua importância e, a partir disso, analisarmos que crenças subjazem esse entendimento.

\section{Percurso metodológico}

Para uma melhor precisão das informações coletadas, temos como sujeitos da nossa pesquisa, 9 alunos do curso de Letras Inglês da Universidade de Pernambuco Campus Petrolina. O grupo é composto de sete participantes que encontram-se na faixa etária de 18 a 25 anos, um na faixa de 26 a 35 e um acima de 35 de variados períodos e turnos, o que permite uma visão mais abrangente a respeito dos seus dizeres.A escolha desse curso foi norteada pelas relações profissionais das pesquisadoras e os alunos foram selecionados através de uma amostragem aleatória.

Nessa perspectiva, os dados coletados foram analisados a partir da matriz curricular do curso e de questionários semi estruturados, com indagações quanto a opção pelo curso e instituição, conhecimento, acessibilidade e satisfação com a matriz curricular, a importância do conhecimento teórico para a prática profissional e sugestões de mudanças ou alterações nas disciplinas do curso. Tal processo ocorreu sem a presença das pesquisadoras visando a espontaneidade necessária dos sujeitos para o processo investigatório.

Com base nas informações, o processo de análise dos dados foi feito de forma qualitativa tendo como referência os objetivos deste estudo, visto que a mesma recai sobre a compreensão dos dados reais, levando em conta as subjetividades dos sujeitos envolvidos na investigação e o contexto social no qual estão inseridos. Além disso, os dados coletados são descritivos, incluindo opiniões e transcrições das respostas dos questionários dos sujeitos envolvidos.

Os resultados desse estudo serão apresentados subsequentemente, levando em consideração que o objetivo não foi apenas em responder tais questionamentos, mas compreender o papel do currículo na formação dos alunos do curso em estudo, bem como identificar as diferentes perspectivas dos mesmos com relação à formação teóricoprática para outras competências essenciais ao trabalho docente. 


\section{O desvelar das crenças dos sujeitos-alunos}

Conforme explicitado na seção anterior, o questionário foi composto de perguntas semi estruturadas cujos dizeres serão analisados a seguir.

O primeiro questionamento estava relacionado à opção pelo curso de Letras-Inglês na UPE. Sete deles responderam que era, principalmente, pela afinidade com a língua inglesa. Destes, dois acrescentaram que era também pelo desejo de ser professor e apenas um pelo fato de não poder cursar sua primeira opção, não especificada na resposta. Vale destacar o dizer de uma aluna concluinte que apresenta uma consciência a respeito do papel do professor como transformador, demonstrando um olhar mais crítico sobre o exercer da profissão. A formação dessa identidade profissional aponta o professor de inglês não como transmissor de conhecimentos sobre a língua, mas como sujeito ideológico, com suas maneiras próprias de pensar e ver o mundo e que produz sentido e cuja subjetividade é constituída e alterada conforme a história de cada um, a partir das vozes com que tem contato. Essa noção de sujeito polifônico formado por várias vozes perpassa sua identidade enquanto sujeito professor, pois a partir do momento que se declara como agente transformador do meio, o mesmo admite que seu aluno também o é, pois esse aluno é passível de mudança. Conforme Coracini (2003 p.153), "Inscrever-se numa segunda língua é re-significar e resignificar-se nas condições de produção de uma outra língua, o que significa, em última instância, "saber" essa língua, isto é, ser falado por ela".

No segundo ponto do seu dizer, verificamos a questão ideológica de conhecimento da língua inglesa como instrumento de poder visto que esta pode trazer mais oportunidades profissionais. Veiga-Neto (2005) referenda o saber-poder, termo de domínio Foucaultiano, como elemento capaz de explicar como os saberes são produzidos e como nos constituímos na relação entre eles. Vejamos:

\footnotetext{
"Primeiramente por ver o professor em geral como um agente transformador do meio e, segundo, pelo fato de que eu veja na língua inglesa um leque de oportunidades no campo profissional tanto dentro quanto fora do país." ( Aluna concluinte)
}

A segunda questão foi direcionada sobre a concepção a respeito do curso. Todos os dizeres revelam uma satisfação, mas expressam um desejo por uma maior carga horária do inglês, corroborando com a crença de que o conhecimento linguístico ainda é o mais importante para o exercício da profissão. Nas palavras do informante: 


\begin{abstract}
"Seria interessante aumentar ou extender do início ao fim do curso as disciplinas de conversação, produção de texto, gramática, pois nos daria a oportunidade de ter uma bagagem consistente para a aplicação da teoria na prática." (concluinte)
\end{abstract}

Na sequência abaixo, destacamos dois dizeres que se inter-relacionam. Nesses fragmentos, podemos notar a presença de discursos atravessados por outros discursos, uma vez que vislumbram possíveis caminhos para um ensino de qualidade, que não beire a repetição, a falta, mas que promova a construção de conhecimentos, a não passividade dos mesmos em sala de aula.

Nesse caso, suas crenças apontam que o professor deve estar em mudança contínua e que deve trazer algo de inovador à sua prática pedagógica. Certos métodos e abordagens são esperados por esses alunos como ideais existindo a não-aceitação de métodos ditos "tradicionais", termo que carrega em si toda uma carga pejorativa quando se pensa no discurso pedagógico. Tais relatos retomam um dito quanto ao padrão discursivo tradicional da metodologia do professor em sala de aula. São eles:

"O curso em si é satisfatório, contudo, precisa-se se pensar como ele está sendo abordado pelos professores do mesmo, uma vez que a prática pedagógica se confronta com o modo como está sendo aplicada pelos professores" (Aluno iniciante)

\footnotetext{
"Acho que poderia renovar a abordagem pedagógica, uma vez que aprendemos que temos que inovar na sala de aula mas não vivemos essa realidade na própria universidade. No que diz respeito ao ensino de língua propriamente dito, observa-se uma certa anacronia de técnicas induzindo uma volta ao Grammar translation." (Aluno iniciante)
}

A sequência seguinte aborda o conhecimento da matriz curricular do curso. Quatro sujeitos declararam conhecê-la parcialmente e quatro disseram que a conhecem na sua totalidade, todos por meio do SIGA (sistema de acesso e registros da universidade via internet). Apenas um disse que não a conhece. No entanto, o sistema não permite que os alunos visualizem as ementas ou os conteúdos programáticos das disciplinas, o que gera uma incompletude do conhecimento sobre o currículo proposto.

A respeito da satisfação dos licenciandos sobre a matriz atual, oito deles declararam estar satisfeitos apenas parcialmente, e uma aluna disse estar satisfeita. Essa insatisfação parcial, da maioria dos alunos, foi revelada em dizeres anteriores, retomando um dito desses alunos sobre a insuficiência da carga horária para um aprendizado eficiente da língua inglesa. 
O seguinte segmento discursivo versou sobre os saberes teóricos que influenciam na prática docente dos participantes, futura ou atual. Nele, os dizeres reforçam maior destaque às disciplinas que visam desenvolvimento da competência linguísticocomunicativo e da competência pedagógica retomando o discurso de que de que o saber inglês é ainda o mais importante para esses alunos. Nesse sentido, é importante considerar que os alunos devem ter a consciência de que o saber linguístico por si só não é suficiente para o professor de idiomas, estando relacionado e sendo dependente de duas outras competências citada por Almeida Filho (2000). Retomando o seu pensamento, podemos dizer que a competência aplicada permite que o professor justifique porque utiliza determinada metodologia e explique ainda como essa forma de ensinar influencia nos resultados que obtém, e a competência profissional, que é desenvolvida quando o professor toma consciência de sua importância social como profissional do ensino de línguas, engajando-se em atividades de formação continuada.

Em relação à disciplina de Didática do Ensino de Língua Inglesa podemos perceber duas visões distintas nos dizeres dos alunos: $O$ primeiro se coloca, através do seu discurso, como um sujeito transformador, que tem consciência de que seu aluno é um indivíduo distinto dos outros, ou seja, respeita a noção de subjetividade pela qual o sujeito busca sua individualidade, e o bom professor é aquele que leva esse fator individual em consideração. Ao mesmo tempo, admite que esse desejo de individualidade acaba deparando-se com a presença do outro, que terão influência na sua formação, através das crenças, atitudes e valores, o que Bakhtin (2006) chama de polifonia, ou seja, a pluralidade de vozes constitutivas da linguagem e do sujeito. Essa pluralidade se dá pelo papel da disciplina na formação identitária do sujeito professor, ao mesmo tempo que, este futuro professor admite sua própria influência na formação do seu aluno.

Nas palavras de Brandão (2004 p.46), o discurso é uma das instâncias em que a materialidade ideológica se concretiza, isto é, é um dos aspectos materiais da "existência material" das ideologias. Assim, um segundo aluno, concebe a disciplina como "voz da verdade" se preocupando com o conteúdo mais prescritivo da disciplina, que vai lhe dar a "receita" para uma boa aula de inglês. O que dizem:

"Os conhecimentos da disciplina didática colaboram na compreensão do aluno como indivíduo distinto, dotado de sentimentos, sonhos capaz de ser motivado ou não por um professor, o que pode ser muito útil na prática de sala de aula."

(aluno em período intermediário) 
"As aulas de didática contribui para o aprendizado de técnicas importantes, como a preparação de um plano de aula, formas de lidar com o público de diversas idades." (aluno concluinte)

Logo abaixo, revelamos o dizer de um aluno concluinte. No seu ponto de vista, a teoria consiste no conhecimento da língua estrangeira, de modo que, para este participante, ensinar uma língua estrangeira limita-se a transmitir conhecimentos sobre a mesma, seus signos e suas estruturas. Nas palavras do aluno falta essa percepção de mundo e o papel da linguagem na construção dessa percepção. Falta a visão de que a língua é um construto sócio-histórico e não somente estrutura. Esse dizer entra em contradição com a concepção de Fiorin (1990) pela qual o mesmo afirma que a linguagem cria a imagem do mundo, mas é também produto social e histórico e que à medida que os sistemas linguísticos se vão constituindo vão ganhando certa autonomia em relação às formações ideológicas. Vejamos esse dito:

"Seria interessante aumentar ou extender do início ao fim do curso as disciplinas de conversação, produção de texto, gramática, pois nos daria a oportunidade de ter uma bagagem consistente para a aplicação da teoria na prática." (concluinte)

A falta de consciência da importância da Sociologia e da Filosofia também se encontra no dizer de alguns alunos que sugerem a retirada destas disciplinas. Essas falas revelam uma falta de maturidade acadêmica destes alunos para compreenderem que teorias que permitem um melhor entendimento da noção do sujeito e de como as relações sociais são estabelecidas numa dada sociedade, interferem sim, na formação do sujeito professor. A falta de um maior aprofundamento destas disciplinas gera uma sensação de incompletude neste sujeito que sente que tais conhecimentos não serão utilizados na sua prática docente, revelando uma visão de sistema de ensino:

[...] com tendência à especialização, limitado, portanto, à transmissão de conhecimentos científicos, formais, básicos, pouco preocupado em interessar, de fato, os alunos, forçando-os a aceitarem o que lhes é transmitido- acaba por constituir um obstáculo à aprendizagem da ciência, construindo um bloqueio que se manifesta, nos alunos, como "ausência de curiosidade", contra a qual a divulgação científica precisa lutar. ( Coracini, 2003,p..327)

Os dizeres dos alunos seguem abaixo:

"Substituir Filosofia e Sociologia porque Inglês é mais importante. Saber mais da língua que escolhemos."(aluno iniciante) 
"Filosofia e Sociologia são disciplinas que não têm uma profundidade no curso, ao menos como estão sendo aplicadas atualmente. As idéias significativas das mesmas são facilmente desenvolvidas em disciplinas como prática e didática, seja direta ou indiretamente" (aluno intermediário)

Baseados na concepção bakhtiniana da linguagem como processo dialógico da comunicação, acreditamos que os dizeres desses alunos estão marcados por diferentes vozes que os constituem e que somente é possível compreender a construção linguística, tomando por referência os elementos associados à condição de produção, à sua formação social, momento sócio-histórico, bem como valores ideológicos. Ressaltamos a incompletude das nossas análises em virtude dos diversos olhares discursivos.

\section{Considerações finais}

Após as reflexões apresentadas a partir dos discursos dos alunos podemos considerar que as crenças dos licenciados em relação ao currículo do curso de língua inglesa e suas literaturas da Universidade de Pernambuco, campus Petrolina são formadas a partir do imaginário de que a proposta pedagógica e os objetivos a serem alcançados nas disciplinas do curso relativos à contemplação dos ementários das disciplinas já mencionadas anteriormente revelam uma plena aquisição dos conhecimentos linguísticos. Entretanto, no real do discurso, o idioma e seus diversos aspectos relacionados ao lado linguístico-comunicativo, teórico-prático e profissional é apresentado de forma segmentada. Desse modo, o aluno, não consegue ter a compreensão de como encaixar esses conhecimentos no seu fazer docente.

As sequências analisadas revelam, também, que os sujeitos-alunos, nas suas subjetividades, apontam os docentes como responsáveis pela aprendizagem, o que implica na crença de que o professor deve ser completo no que se refere à metodologia da sala de aula. Assim como revela a crença de um sujeito-aluno consciente do processo de aprendizagem, das estratégias, do controle sobre o processo de ensino-aprendizagem, mas que ainda é incompleto no sentido da aplicabilidade do saber teórico.

Sobre a relação teoria e prática do idioma para o mercado de trabalho, temos enunciadores que revelam um discurso de que a aprendizagem de um idioma estrangeiro é essencial ao profissional de línguas, discurso que se entrecruza com o das exigências do mercado de trabalho que diz que o mesmo tem provocado, no ser humano, uma 
emergência na aquisição de novos conhecimentos, dessa forma, o ser professor perpassa o saber da língua.

Ainda em relação ao processo de ensino-aprendizagem de uma LE pelo viés da história e da memória, podemos dizer que a aprendizagem instrumentaliza, ao menos teoricamente, o sujeito a se posicionar dentro de uma história e de uma cultura do outro. Nesse sentido, o professor, enquanto portador da memória, influencia saberes e domínios de técnicas capazes de produzir uma verdade ou revelação, influencia na imposição de normas. Para os alunos, o ser professor, exige o reconhecimento dos desejos e subjetividades uma vez que a memória opera com liberdade selecionando acontecimentos no espaço e no tempo, não arbitrariamente, mas porque se relacionam através de expectativas comuns.

Assim, a partir do nosso olhar, esperamos que o registro discursivo feito neste trabalho permita a compreensão do encontro e do arranjo de múltiplas crenças e remeta a práticas e situações privilegiadas que se recusam a morrer ou a serem esquecidas, que insistem em produzir e atribuir sentidos e, na medida em que os sentidos se constituem por meio da materialização nas formas linguísticas, o caráter discursivo da Língua Inglesa e daquele que irá ensiná-la.

Isso posto, esperamos, também, contribuir para uma melhor compreensão da dinâmica do futuro professor de Língua Inglesa, visto que, como participante da sociedade em que vive, é elemento ativo com capacidade de transformar e até mesmo de viabilizar mudanças na sua formação linguístico-comunicativa e profissional.

\section{Referências}

ALMEIDA FILHO, José Filho. Crise, transições e Mudanças no currículo de formação de professores de línguas. In: Fortkamp, Mailce \& Tomich, Lêda (ORGs.) Aspectos de Linguística Aplicada. Estudos em homenagem ao professor Hilário Inácio Bohn.

Florianópolis: Insular, 2000

BAKHTIN, Mikhail. Marxismo e Filosofia da Linguagem. 12 ed., São Paulo: Hucitec, 2006. BRANDÃO, Helena H. Nagamine. Introdução à Análise do Discurso. Campinas: Editora da UNICAMP, 2004.

CASTRO, S. A construção da competência docente do futuro professor de língua estrangeira: um estudo com alunos de inglês de um curso de letras. In: LEILA, Barbara \& RAMOS, Rosinda (ORGs). Reflexão e ações no ensino-aprendizagem de línguas. São Paulo: Mercado das Letras, 2003. pp. 35-49.

CORACINI. Maria José. As representações do saber científico na constituição da identidade do sujeito-professor e do discurso de sala de aula. In: CORACINI, Maria José (ORG). Identidade e Discurso. Campinas: Ed. Unicamp, 2003. pp. 319-336

FIORIN, José Luiz. Linguagem e Ideologia. 2 ed. São Paulo: Ática, 1990.

MOITA LOPES, Luiz . Oficina de lingüística Aplicada. Mercado das Letras: São Paulo, 2005 
PAJARES,M.F. Teacher's beliefs and educational research: cleaning up a messy construct. Review of Educational Research, Washington, DC, v.62, n.3, p.307-332, 1992. PIROVANO, Maria. Professores de língua inglesa da rede pública estadual de ensino e suas crenças sobre o evento-aula. In: FONTANA, Niura \& LIMA, Marilia (ORGs). Língua estrangeira e segunda língua: aspectos pedagógicos. Caxias do Sul: EDUCS. 2006 pp.1362.

VEIGA-NETO, Alfredo. Focault e a Educação. 2 ed., Belo Horizonte: Autêntica, 2005. VYGOTSKY, Lev S. Pensamentos e Linguagem. São Paulo: Martins Fontes, 1998. 


\title{
O PAPEL DA AVALIAÇÃO POR PORTFÓLIOS NO PROCESSO DE ESCRITA E REESCRITA DE ALUNOS DE LÍNGUA INGLESA
}

\section{THE ROLE OF PORTFOLIO EVALUATION IN THE WRITING AND REWRITING PROCESS OF STUDENTS OF ENGLISH AS FOREIGN LANGUAGE}

\author{
Roberta Guimarães de Godoy e Vasconcelos \\ Universidade de Pernambuco - UPE \\ robertaggv@gmail.com
}

\begin{abstract}
RESUMO: Pela importância social que a escrita assume na nossa sociedade faz-se necessário que o ensino-aprendizagem desta habilidade seja feito de forma efetiva e consciente. Desse modo, a avaliação no ensino de línguas deve voltar-se para um processo reflexivo que considere as dificuldades individuais dos alunos, promovendo assim, uma revisão e refacção das produções a fim de levar a uma aprendizagem mais efetiva. Um processo avaliativo condizente com essa proposta é o de avaliar através de portfólios, processo que permite avaliação como processo de acordo com objetivos e critérios pré-definidos. Através de uma experiência com alunos adultos de inglês de nível intermediário pudemos perceber que esse tipo de verificação da aprendizagem levou a resultados consistentes no que diz respeito à conscientização dos alunos do porquê estavam cometendo os mesmos erros. Ao buscarem pesquisar sobre os erros cometidos e assim, refletir e refazer seus trabalhos, os sujeitos participantes desse estudo demonstraram melhorar a proficiência na língua-alvo.
\end{abstract}

PALAVRAS-CHAVE: ensino-aprendizagem de LE; avaliação; portfólio; escrita.

ABSTRACT: Because of the importance that writing has in our society, it is necessary that teaching this ability is made in an effective and conscious way. Thus, the evaluation of writing of the foreign language must be based on a reflexive approach which will consider specific students'difficulties, giving them the opportunity to review and rewrite the texts produced, leading to a more effective learning process. The portfolios (collection and reflective) make it possible to evaluate based on pre-defined objectives and criteria. Through an experience with adult learners of an intermediate level we concluded that this process of evaluation led to consistent results about the awareness of students related to the reasons they were making the same mistakes and presenting the same problems in their writings. Once they were asked to reflect about their mistakes and through some hints research about them and try to correct and rewrite their texts, students presented an improvement on their fluency.

KEYWORDS: English teaching, evaluation, portfolio, writing. 


\section{Introdução}

O ensino/ aprendizagem de uma língua estrangeira, particularmente da língua inglesa, por fatores políticos, históricos e culturais, possibilita o envolvimento do aprendiz enquanto ser humano e cidadão. Deve, para tanto, focalizar-se na percepção discursiva e sócio-interacionista da linguagem, enquanto capacidade de se engajar e engajar outros no discurso de modo a poder agir no mundo social.

O aluno, enquanto ser discursivo, tem consciência do seu envolvimento com os processos sociais de criar significados por intermédio da utilização de uma língua estrangeira. Apesar de ser um conhecimento de alto prestígio social, as línguas estrangeiras, enquanto disciplinas do ensino obrigatório, encontram-se deslocadas da escola pois seu ensino é visto como elemento secundário na formação do aluno.

Dentro da perspectiva de relevância social do ensino/aprendizagem, existe nas instituições de ensino escola, um maior enfoque nas habilidades de leitura e escrita, visto que são destas que o aluno faz uso no seu contexto social imediato, considerando-se que o suo da LE vincula-se à leitura de textos técnicos ou de lazer, ou ainda aos exames formais (vestibular ou admissão em cursos de Mestrado e Doutorado) que requerem a habilidade de leitura.

Outro objetivo daqueles que estudam inglês como Le no Brasil é o de comunicar-se através de e-mails, mensagens instantâneas (MSN), seja por razões profissionais ou de diversão, como também escrever artigos na língua estrangeira ou fazer provas de envolvidas no que se refere ao ensino-aprendizagem de línguas.

\section{Referencial Teórico}

\subsection{Perspectiva tradicionalista x Perspectiva sócio-interacionista}

A maior parte das pesquisas sobre leitura e escrita é delineada por três elementos:

a) a interação entre o leitor e o texto (processos cognitivos);

b) os papéis do autor ao escrever um texto (seus valores, conceitos e experiências);

c) c) as característica físicas do texto (mecanismos linguísticos, ortografia,pontuação, sintaxe e estilo, aliados à sua forma e função).

Apesar das pesquisas levarem em conta os mecanismos que fazem parte do processo de compreensão, é comum o enfoque no produto da leitura, apresentando, portanto, uma menor preocupação com o ensino voltado para textos, formulação de 
hipóteses, confirmação ou rejeição de informações implícitas e explícitas, elaboração de sumários e avaliação crítica.

$\mathrm{Na}$ abordagem tradicional, a língua é vista como algo fechado e imutável. Dentro dessa perspectiva, compreender um texto seria apenas decodificá-lo, buscando informações objetivas ou o significado de cada palavra, operando apenas com o material linguístico e sem a influência do outro ou do contexto.

Uma mudança ocorre a partir da perspectiva cognitivista, que se preocupa com os processos mentais do leitor, como: planejamento, monitoração, inferência, auto-avaliação, introspecção, etapas de leitura-escrita e as relações que interferem no processo de compreensão e de produção de textos com o intuito de promover uma maior conscientização e controle desses processos.

Esta abordagem cede lugar, posteriormente, às reflexões sócio-interacionistas, que visto não considera as características históricas, sociais e interacionais dos textos, assim como sua diversidade numa determinada sociedade.

Nesta perspectiva, os processos inferenciais e de interação têm um papel fundamental na aprendizagem. Para Marcuschi (2001,p. 34) esta perspectiva "preocupase com os processos de produção de sentido tomando-os como situados em contextos marcados por atividades de negociação ou por processos inferenciais." Dentro dessa visão o desenvolvimento passa pelos processos de mediação, internalização e controle. Por mediação, entende-se o conhecimento partilhado sobre o qual o outro ou o próprio aprendiz irá decidir se é ou não relevante para determinada situação. Esse lento se junta com o que é internalizado pelo indivíduo, aumentando, assim, o controle da linguagem e ampliando, seu conhecimento sobre as estratégias textuais.

Dessa forma, pratica-se a língua dentro de um contexto social e não apenas como conhecimento de palavras isoladas e de frases gramaticalmente corretas e memorizadas. Sendo assim, as atividades devem abordar situações que façam parte do interesse dos alunos enquanto usuários da língua.

Assim, a produção/compreensão dentro desta perspectiva sócio- interacionista volta-se para os mais diversos gêneros textuais visto que tudo aquilo que queremos comunicar $p$ fazemos por meio de um gênero textual.

\subsection{Gêneros textuais e ensino}

De acordo com Bronckart (1999, p.137), os textos são produtos de atividades sociais, visto que surgem por causa de interesses, objetivos e questões específicas. Tais 
atividades fazem surgir diferentes espécies de texto que apresentam características estáveis.

Assim, o contato com os gêneros textuais faz com que os alunos reflitam sobre os mecanismos linguísticos e extralinguísticos que os constituem, ampliando sua capacidade de interagir como seres sociais.

Marcuschi (2004) fazendo uso das palavras de Dolz \& Schneuwly (2004) afirma que nesta abordagem dos gêneros na prática escolar, vale ressaltar os modelos das didáticas, definidas como um conjunto de atividades escolares organizadas, de sistemática, em torno de um gênero textual oral ou escrito.

Este modelo visa trabalhar situações reais permitindo o entendimento dos alunos sobre o processo de relação entre produtores e receptores. Dessa forma, ao lidar com esse processo, o professor proporciona ao aprendiz uma forma de realizar todas as etapas para a de um gênero, articulando a produção textual com outros aspectos do domínio da como sintaxe, ortografia e estilística. Ainda segundo Marcuschi (2004), duas são as perspectivas desta abordagem: a indutiva, de Dolz \& Schneuwly (2004) e a dedutiva, de Bronckart (2000). A diferença entre as perspectivas são apresentadas na tabela abaixo.

\section{MODELOS DAS SEQUÊNCIAS DIDÁTICAS}

\begin{tabular}{|c|c|}
\hline Modelo intuitivo (Dolz \& Schneuwly: 2004) & Modelo Dedutivo (Bronckart: 2000) \\
\hline $\begin{array}{l}\text { 1) Apresentação da situação: Apresenta-se a } \\
\text { tarefa, decide-se o gênero, a audiência, a } \\
\text { Modalidade(oral ou escrita), e a forma. } \\
\text { Refere-se também aos conteúdos } \\
\text { promovendo pesquisas sobre o tema e a } \\
\text { apresentação do gênero a ser produzido. }\end{array}$ & $\begin{array}{l}\text { 1) Elaborar um modelo didático: Possui três } \\
\text { objetivos de ensino: analisar as atividades } \\
\text { discursivas, operar com os tipos textuais } \\
\text { coerentes ao gênero, dominar os } \\
\text { mecanismos linguísticos de organização } \\
\text { textual(os aspectos gramaticais, léxicos e a } \\
\text { escolha de registros e estilos. }\end{array}$ \\
\hline $\begin{array}{l}\text { 2) Produção: Primeiro esboço do texto que } \\
\text { pode ser produzido coletivamente ou } \\
\text { iodividualmente. O texto irá ser revisado e } \\
\text { avaliado quantas vezes forem necessárias } \\
\text { na próxima fase. }\end{array}$ & $\begin{array}{l}\text { 2) Identificar as capacidades adquiridas: } \\
\text { Testar quanto os alunos foram capazes de } \\
\text { adquirir ou perceber os três aspectos } \\
\text { trabalhados. }\end{array}$ \\
\hline $\begin{array}{l}\text { 3) Módulos:Trabalham-se os problemas da } \\
\text { produção inicial, através de observações e } \\
\text { análises em cima do texto, comparando-o }\end{array}$ & $\begin{array}{l}\text { 3) Elaborar e conduzir atividades de } \\
\text { produção: Os alunos produzem os gêneros. } \\
\text { Cabe ao professor deixar claro as condições }\end{array}$ \\
\hline
\end{tabular}




\begin{tabular}{|c|c|}
\hline com outras produções, reescrevendo & $\begin{array}{l}\text { específicas e as situações determinadas do } \\
\text { gênero em questão, dando continuidade ao } \\
\text { trabalho das etapas anteriores }\end{array}$ \\
\hline $\begin{array}{l}\text { Produção Final: O aluno se utiliza } \\
\text { de tudo o que aprendeu durante os } \\
\text { processos para produzir o gênero em } \\
\text { questão, sabendo o que fez, porque fez } \\
\text { e fez. O professor deve considerar os } \\
\text { progressos dos alunos como também as } \\
\text { habilidades não atingidas para, } \\
\text { posteriormente chegar a uma produção } \\
\text { efetiva dos textos segundo o gênero } \\
\text { lido. }\end{array}$ & $\begin{array}{l}\text { 4) Avaliar as novas capacidades adquiridas: } \\
\text { O docente analisa os textos dando, em } \\
\text { seguida, um retorno aos alunos para que } \\
\text { esses possam prosseguir na produção de } \\
\text { gêneros similares ou de outros. }\end{array}$ \\
\hline
\end{tabular}

Fonte: Marcuschi (2004)

Ambas as perspectivas trabalham a produção textual de forma significativa, pois os aprendizes têm consciência da finalidade das atividades. Promovem ainda uma reflexão contínua por parte de alunos e professores visto que a avaliação é constante.

Não se limitam às redações escolares descontextualizadas, apenas para a obtenção de nota, formando-se, desse modo, alunos capazes de se comunicar nas situações concretas com as quais se deparam no dia-a-dia.

\subsection{Avaliação}

De acordo com a proposta de sequências didáticas, é possível percebermos que a avaliação, conforme exposto anteriormente, é parte essencial do processo e deve ser contínua a fim de atingir os objetivos da aprendizagem.

A noção de avaliação que subjaz este trabalho é o de avaliação formativa que de acordo com Hadji (2001. p. 20) "torna-se formativa na medida em que se inscreve em um projeto educativo específico, (ode favorecer o desenvolvimento daquele que aprende, deixando de lado qualquer outra preocupação."

Outra característica, essencial que torna uma avaliação formativa é, ainda conforme Hadji (op cit), a de informar os participantes principais do processo: professor e aluno. Estes, através desse formato de avaliação poderão guiar seu trabalho e planejar estratégias para futuras ações de forma mais consciente. 
Desse modo, a terceira e mais importante característica, segundo o autor, é a função de regulação. A partir dos resultados do processo formativo, "o professor, assim o aluno, deve poder corrigir sua ação, modificando, se necessário, seu dispositivo pedagógico com o objetivo de obter melhores efeitos por meio de uma maior habilidade didática" (HADJI, 2001,p. 21)

Outra concepção de avaliação participante desta pesquisa é o de avaliação autêntica de desempenho. Exemplos desse tipo são os portfólios e a auto-avaliação. "Na avaliação de desempenho, o aluno pode construir uma resposta a um problema real, oralmente ou por escrito utilizando recursos múltiplos que incluem seminários, trabalhos escritos, individuais ou em grupo, demonstrações, entrevistas, resumos de leituras e várias formas de atividades escritas que refletem as exigências da vida real. " (Campbell, 2004,p. 16)

Em relação à avaliação em língua estrangeira, Brindley (2001 apud CAMPBELL (2004)) afirma que os propósitos da avaliação são:

1. Seleção: decidir se o aluno tem a proficiência de língua para ser promovido para próximo nível,

2. Certificação: oferecer ao aluno uma declaração de habilidade,

3. Responsabilidade: prover evidências às autoridades de financiamento que os resultados desejados da aprendizagem estão sendo alcançados,

4. Diagnóstico: identificar os pontos fortes e fracos dos alunos,

5. Tomada de decisões instrucionais: decidir quais os materiais devem ser apresentados e revisados;

6. Motivação: estimular o estudo.

O objetivo da avaliação não é só medir resultados, mas também melhorar a qualidade do aprendizado e do ensino. O melhoramento visa ajustar o ensino de acordo com as necessidades dos alunos, estimular ensino reflexivo que informa a prática e reconhece o ensino. De acordo com Campbell (2004, p.21) "para aprender independentemente, é preciso dar ao aluno mais controle sobre o seu próprio processo de aprendizagem.

Alguns problemas se apresentam na aplicação desse modo de verificação da aprendizagem e consequente resistência por parte de alunos e professores. Primeiramente, a exigência de mais tempo do professor na elaboração de atividades e projetos que devem ter critérios e objetivos bem definidos e explícitos e também na que precisa ser constante e refeita de modo a modificar a prática quando necessário. A resistência por parte dos alunos se dá também na necessidade de se gastar mais tempo na realização das tarefas, visto que precisam ser refeitas. 
Outra característica essencial desse tipo de avaliação é a reflexão das atividades a fim de tornar os aprendizes mais conscientes de como aprendem e quais as suas dificuldades. Kallick (2000 apud CAMPBELL (2004) sugere que o professor que quer implementar um programa de reflexão na avaliação do aluno deve se perguntar sobre:

1. A auto-avaliação: como podem os alunos criticar o seu próprio trabalho? Como podem criticar o trabalho dos seus companheiros?

2. A autodireção: como podem os alunos planejarem e organizarem a sua aprendizagem? Como podem formular metas pessoais?

3. A auto-adaptação: como podem os alunos modificarem o seu trabalho baseado no retorno que recebem?

\subsection{0 processo de escrita e reescrita no ensino de línguas}

O ensino da escrita em língua estrangeira, doravante LE, pode ser orientado de duas formas que dependerão da concepção de língua do professor: a escrita como produto ou como processo. A noção de escrita como produto vem da herança das "escolas de gramática" do século XVI, XVII e XVIII que segundo Quaresma (2001), tinham por objetivo ensinar regras gramaticais do latim clássico. Era através do estudo da gramática e do auxílio de dicionários que os alunos aprendiam a ler e interpretar os textos lidos em latim clássico. Essa mesma abordagem, de acordo com o autor, fundamentou o estudo de línguas estrangeiras baseado em gramática e tradução. Ensinava-se, portanto, a LE por meio de regras gramaticais detalhadas e da tradução de sentenças da língua materna para a língua-alvo. A escrita era, portanto, a forma de se avaliar esse conhecimento gramatical.

Nos anos 50, o ensino de língua estrangeira sofre forte influência do chamado método audiolingual, de base behaviorista. Neste método, a escrita passa a servir como apoio para a habilidade. "A concepção behaviorista típica era de que língua é fala, e a escrita "um: registrar a língua" (Silva, 1990; Gass e Magnan, 1995 apud Quaresma, 2001, p. 37).

O objetivo maior de ensinar escrita por esse método era portanto, reforçar regras a fim de contribuir para a proficiência oral. Com o intuito de atingir tal objetivo, a escrita era praticada sob a forma de repetitivos drills, ou seja exercícios de substituição, preenchimento de espaços em branco.

Outra prática que influenciou o ensino de línguas foi a de uso de combinações de sentenças. Essa se deu nos anos 60 e 70, permitindo aos alunos explorar o aspecto sintático. O objetivo dessa forma de ensino de escrita tão controlada era fazer que os 
alunos cometessem o menor número de erros possível. (COOPER, 1973; DAIKER et al., 1978)

Apesar de Chomsky (1959) citado por Quaresma (2001) ter criticado a teoria behaviorista a língua não se adquire por repetição, a idéia de imitação de um modelo persistiu no ensino de LE como prática mais comum a fim de adquirir a escrita na LE. Ainda conforme Quaresma, estudos posteriores mostram que apesar de ambas as práticas contribuírem para o ensino da escrita, elas devem ser usadas como mais um recurso e não como a forma ideal de ensino desta habilidade.

Já a escrita como processo valoriza as idéias, o conteúdo para então se preocupar com a forma. Nessa perspectiva; Hayes e Flower(1980) em Hayes (2004) apresentaram um modelo de escrita que considerava as etapas de planejamento, tradução e revisão como interactantes juntamente com a memória. De acordo com esse modelo, eram três os componentes principais do processo de escrita:

1) Ambiente da tarefa; incluem todos os fatores externos que influenciam a atividade da escrita, (fatores sociais e físicos)

2) Processos Cognitivos; dos quais fazem parte o planejamento (a decisão do que dizer e como dizer), tradução (que se refere à geração do texto) e revisão (que visa à melhora do texto já existente.)

3) Memória de longo prazo; que incluem conhecimento sobre o tópico, público-alvo e gênero textual).

Hayes (2004) aperfeiçoou esse modelo de 1980 e passou a agrupar cognição, afetividade e memória como aspectos do indivíduo e fatores sociais e físicos como formadores do ambiente da tarefa. Portanto, o novo modelo pode ser considerado, segundo o autor, como um modelo do indivíduo e do ambiente ao invés de um modelo social-cognitivo conforme a proposta de 1980.

Conforme exposto acima, diversos são os fatores que participam do processo de escrita. Desse modo, os professores devem levá-los em conta no momento de ensinoaprendizagem desta habilidade, bem como na correção e avaliação das produções dos alunos.

A escrita é um processo de geração e integração de idéias em que o escritor pensa. escreve, apaga, reescreve, revisa conforme Quaresma (2001).De acordo com esse modelo, a geração de idéias refere-se aos momentos que o autor recorre à memória ou a outros textos para obter idéias sobre o assunto que vai escrever. À medida que a produção ocorre, novas idéias surgem e podem modificar idéias anteriores, o que torna necessário uma revisão por parte do autor. Este deve se preocupar ainda com a 
delimitação do tópico, sendo preciso focalizar o assunto do texto. Precisa também decidir a ordem das idéias e como agrupá-las no seu texto, ou seja, a etapa de estruturação das idéias. Ao passar suas idéias para o papel. inicia o processo de rascunho, sendo este o início do texto, envolvendo portanto escolhas de palavras, estruturas, etc. A avaliação consiste na etapa que o escritor se como auto-crítico da sua obra. Parte então, novamente para a revisão, checando a forma e o conteúdo.

Estes sub-processos se relacionam e complementam então de forma não-linear.A revisão é um exemplo da recursividade do processo de escrita, podendo o autor,fazê-las durante o processo de escrita em si como também após o término dos textos. Dada a importância e complexidade desse sub-processo dentro do processo cognitivo maior da escrita foi criado um modelo de revisão. (DELLAGNELO, 2000)

De acordo com a autora, este modelo apresenta 3 tipos diferentes de avaliações que ocorrem durante o processo de revisão: a avaliação da gramática, ortografia e clareza; reflexão sobre planos e, quando necessário o descarte dos mesmos e a avaliação de intenção versus execução.

Esta avaliação pode gerar novos problemas, sendo necessário descartar grande parte do texto, se a quantidade de problemas for muito grande ou se o revisor não conseguir revertê-los. Assim, a idéia global é mantida, mas grande parte do texto é retrabalhada.

A revisão ocorre quando os autores solucionam os problemas e preservam as idéias originais. No entanto, muitas vezes durante esse processo, novos problemas são gerados.

Tendo em vista a complexidade que circunda o processo de escrita é preciso termos nas atividades que propomos aos nossos alunos: metas e competências a desenvolver muito bem estabelecidas a fim de facilitar o planejamento da produção por parte dos alunos. São importante também critérios de avaliação claros e objetivos para guiar essa produção visto que o aprendiz saberá o que dele se espera e poderá assim selecionar e organizar melhor as idéias que colocará no texto.

\section{Consequências da avaliação no processo de escrita: uma experiência.}

É comum que os professores tenham a expectativa que os alunos produzam textos livres de erros e ao mesmo tempo, os alunos se preocupem com os erros que cometem esperando que professores corrijam todos os problemas. 
Vários estudos, no entanto, comprovam a ineficácia de somente corrigir os erros ou de processos de destacar os erros estruturais nos textos dos alunos, ao invés de focarem no conteúdo e na reflexão. O uso dessas formas de correção não impedem que os alunos continuem apresentando os mesmos problemas em seus textos.

\subsection{Percurso metodlógico}

Com esse problema em mente conduzimos um estudo com um grupo de 7 alunos de nível intermediário de inglês a fim de verificarmos quais eram os reais efeitos da avaliação na aprendizagem da escrita em LE.

Desde o início do segundo semestre letivo de 2010, as correções eram feitas através de códigos e comentários. O objetivo dos códigos de correção era que os alunos refletissem sobre erros estruturais como gramática, ortografia, preposições bem como erros de colocação referentes a vocabulário, expressões idiomáticas, geralmente confundidas com as expressões e palavras da língua materna.

A tabela abaixo apresenta os códigos:

\begin{tabular}{|c|c|}
\hline Códigos & Descrição \\
\hline Ww & $\begin{array}{l}\text { Wrong Word: refere-se ao uso de uma palavra empregada } \\
\text { equivocadamente por conta da influência do português. Ex.: "...he } \\
\text { wanted to find out that sickness I had" quando o uso correto deveria } \\
\text { ser "....which sickness I had". "That"pode ser usado como "que", mas } \\
\text { não em todos os casos. }\end{array}$ \\
\hline Wsp & Wrong spelling: erro de ortografia \\
\hline Wp & Wrong preposition: preposição empregada equivocadamente \\
\hline Wv & $\begin{array}{l}\text { Wrong verb: uso incorreto de verbos devido á influência da língua } \\
\text { materna. Por exemplo: "I have } 27 \text { years old"ao invés de "I am } 27 \\
\text { years old" }\end{array}$ \\
\hline $\mathrm{Cp}$ & $\begin{array}{l}\text { Collocation problem: tradução literal de expressões idiomáticas do } \\
\text { português para o inglês. }\end{array}$ \\
\hline$\wedge$ & Missing Word: ausência de palavras ao longo dos períodos. \\
\hline Wo & Equívoco na ordem. \\
\hline $\mathrm{Gr}$ & $\begin{array}{l}\text { Grammar: erros de gramática referentes à tempos verbais, formas de } \\
\text { adjetivos/advérbios, uso de superlativos/comparativos, uso de } \\
\text { pronomes pessoais/objetos. }\end{array}$ \\
\hline
\end{tabular}


Além dos códigos ao longo do texto, eram feitos também comentários em relação ao desenvolvimento das idéias e sugestões para melhora do texto, quando necessário. Por se tratar de uma turma de adultos, provavelmente acostumados com um ensino tradicional da língua materna no qual o professor é um transmissor de idéias, houve resistência por parte de alguns, ao saberem que teriam que descobrir os problemas, de acordo com as dicas, e reescreverem seus textos à medida que fossem descobrindo-os. Muitos alegaram não ter tempo para fazê-lo, mas foram aos poucos se acostumando com o processo.

Por ser uma turma semestral e cujos encontros só aconteciam duas vezes por semana a cada I h e 15 minutos, a proposta foi diminuir a quantidade de textos e focalizar no processo de reescrita a fim obter uma aprendizagem mais significativa.

Antes de produzirem os textos, os alunos tinham critérios de avaliação bem estabelecidos em relação ao conteúdo que se esperava deles em suas produções através de normas e instruções que deveriam responder e seguir na escritura dos textos.

\subsection{Análise dos resultados}

Traremos para a análise de resultados deste artigo dois textos produzidos: uma narrativa sobre um evento passado e um pequeno artigo de opinião sobre a importância de se ter hábitos saudáveis.

As duas atividades eram referentes à primeira unidade estudada no semestre cujo tema era 'Vida saudável". Nesta unidade os alunos aprenderam nomes de doenças e os e possíveis tratamentos e sugestões a serem dadas a alguém que estava doente. Após discutirmos sobre os problemas de saúde em sala, começamos a falar sobre o que fazer para prevenir esses problemas termos uma vida mais saudável. Foram debates e leituras em que refletimos sobre a importância da alimentação, fatores afetivos no controle e combate de doenças e na aquisição de uma vida saudável. Foi explicado que eles deveriam trazer exemplos e dar argumentos e contra-argumentos visto que a importância de cada fator na aquisição de uma vida saudável foi um fator que gerou discordâncias no grupo. Após a discussão do tópico foram dadas as duas opções de produção para os alunos (narrativa- baseada em uma sequência de figuras ou artigo- a partir de pontos discutidos em sala) e estes deveriam escolher uma delas.

Os problemas apresentados nas produções dos alunos podem ser vistos na tabela abaixo. 


\begin{tabular}{|c|c|c|}
\hline Aluno & $\begin{array}{l}\text { Problemas apresentados na } \\
\text { versão } 1\end{array}$ & $\begin{array}{c}\text { Problemas apresentados na } \\
\text { versão } 2\end{array}$ \\
\hline A1 & $\mathrm{Wv}(5), w w(3), \operatorname{gr}(3) X(4)$ & Wv(2);gr(I) \\
\hline A2 & $W v(3), w c(2), g r(4), s p(2)$ & $\operatorname{Gr}(2), w v(I)$ \\
\hline A3 & $\operatorname{Gr}(3), w c(1), s p(2), w v(1)$ & $\operatorname{Gr}(I), w v(2)$ \\
\hline A4 & $W v(3) X(I), w w(2)$ & --------------------- \\
\hline A5 & $W p(2), \operatorname{gr}(4), \mathrm{sp}(\mathrm{I})$ & $\operatorname{Gr}(2)$ \\
\hline A6 & $\operatorname{Gr}(4), w w(1), \wedge(2), \operatorname{sp}(5), c p(I)$, & $\operatorname{Gr}(I) X(I)$ \\
\hline A7 & $\operatorname{Gr}(2), w w(3) X(I)$ & $\mathrm{Ww}(\mathrm{I})$ \\
\hline
\end{tabular}

Apesar de os problemas relacionados à estrutura e à confusão em relação aos vocábulos, eles se repetiam ao longo dos textos de diferentes formas, já que os códigos bem gerais. O que guiou os alunos na revisão e reescritura de seus textos foram as pcreuntas relacionadas a estes códigos.

Podemos ver na tabela acima que apesar de termos feito apenas uma revisão do primeiro rascunho devido ao pouco tempo disponível para terminarmos o tópico, foi possível percerbemos uma melhora significativa em relação aos erros apresentados nas produções.

Veremos adiante alguns exemplos das primeiras versões dos textos dos alunos com as correções e comentários e posteriormente, as versões reescritas.

\section{A3- Versão 1}

The woman was the doctor because she had the flu. The doctor examined the woman and he done one prescription to she can by some aspirine and vitamin $\mathrm{C}$.

The doctor recommend that the woman should go to bed early because was important to cure her flu.

The woman was visit the chemist prepared some strong pils to help her flu.

Os problemas foram marcados e os códigos usados. Foi feita a pergunta: 
“And? What happened after that?" ( E? O que aconteceu depois?)

Em seguida, foram feitos os seguintes comentários:

"Cheque os problemas de acordo com os códigos e veja se você consegue descobrir quais são. Senti que sua história Não teve um final. Por favor, adicione mais detalhes e diga se o que ela fez ajudou ou não."

Vejamos agora o exemplo de outro aluno:

\section{A4- Versão 1}

Going to the doctor's.

When I got up I was feeling ill. I had a headache and felt dizzy too. As I feel too bad I made an appointment with the doctor. He asked how I was and I told him about my problems. He said I had the flu. Then, he passed a prescription for I take medicine for the flu. He said I should rest too. I stayed at home for 3 days, took the medicine and got well. After that I go back to work.

\section{Comentários do texto de A4:}

"Suas idéias estão muito claras e organizadas. No entanto, é preciso que você revise as palavras sublinhas de acordo com os códigos e reescreva seu texto."

Os alunos, ao devolverem seus textos reescritos conseguiram descobrir vários dos problemas estruturais e melhorar as idéias.

Nossa intenção era trabalhar com a sequência didática seguindo o modelo intuitivo, conforme apresentado por Dolz \& Schneuwly ( 2004 apud Marcuschi, 2004) por permitir que 0 aluno analise, revise e reavalie seu texto, permitindo ao professor considerar os progressos dos alunos, levando em conta todo o processo da produção escrita e não somente a produção final.

A avaliação por portfólio permite essa reflexão, visto que os alunos têm acesso aos critérios previamente e devem escolher para o seu conjunto as atividades mais 
representativas, bem como justificar o porquê da escolha daquela atividade e como a mesma o ajudou no desenvolvimento de uma determinada habilidade.

\section{Versão 2 do texto de $\mathbf{A 3}$}

The woman went to the doctor because she had the flu. The doctor examined her and did one prescription for she to buy some aspirins and vitamin C.

The doctor recommended that the woman should go to bed early because it was very important to cure the flu.

The woman visited the chemist's and he prepared some strong pills to help her. Then, she went home and her husband made a very delicious chicken soup. She slept and on the next day she feel better and go to work.

Comentários feitos ao texto da aluna:

"Você conseguiu encontrar e consertar alguns dos problemas referentes à estrutura, mas ainda teve alguns problemas em relação ao uso do pronome e tempos verbais. Qual é a forma do pronome que usamos após preposições e quanto aos verbos? Você estava contando a situação no passado. O que muda então?

Sua história agora tem um final e você conseguiu usar todas as figuras, no entanto, sinto que você poderia ter usado mais as expressões que estudamos e acrescentando mais detalhes, deixando sua história mais criativa."

\section{Versão final do texto 2:}

Going to the doctor's.

When I got up I was feeling ill. I had a headache and felt dizzy too. As I felt too bad I scheduled an appointment with the doctor. He asked how I was and I told him about my problems. He said I had the flu. Then, he did a prescription for some flu medicine. He said I should rest too. I stayed at home for 3 days, took the medicine and got well. After that I went back to work.

Foi então feita a seguinte observação:

"ótimo trabalho! Você revisou seu rascunho e sua história acabou ficando perfeitamente escrita bem como criativa! Continue com o bom trabalho! 
Além dos códigos e comentários, os alunos recebiam também na avaliação dos seus portfólios, critérios de avaliações (rubrics) específicos para cada habilidade (oral, compreensão auditiva, leitura, escrita e gramática) das atividades que incluíam e sobre as quais refletiam no seu conjunto de atividades. Os critérios eram apresentados de modo que eles pudessem saber o que era esperado deles e assim, poderem refletir melhor sobre seus textos. Essa forma de escrita e reescrita, bem como o uso de critérios bem estabelecidos de avaliação condizem com a proposta de avaliação formativa, conforme exposto anteriormente por Hadji (2001) permite ao aluno e professor, guiarem seu trabalho e planejar estratégias para futuras ações de forma mais consciente.

\section{Considerações Finais}

Através das reflexões feitas pelos alunos em seus portfólios, bem como na melhora de seus textos podemos concluir que é importante sabermos primeiramente, como professores, os objetivos que temos ao corrigirmos os erros dos nossos alunos.

Um outro ponto importante é sermos conscientes de que devemos incorporar na nossa prática avaliativa os seguintes elementos: resolução de problemas, para que os alunos tornem-se mais idependentes, feedback individualizado, possibilitando que cada um busque soluções para suas dificuldades sendo a aprendizagem, assim, mais eficiente, usar métodos variados como: códigos, comentários, rubrics para levar em conta também fatores como criatividade e afetividade como partes importantes no processo de aquisição de uma língua estrangeira.

Ter em mente que apesar de erros e inadequações fazerem parte do processo natural de aprendizagem, eles não se corrigem por si só, e cabe a nós, professores, encontrar a melhor forma de corrigi-lo.

No entanto, é importante, revermos as abordagens de correção que temos a fim de tornar os aprendizes conscientes do processo e sua melhora ao final de um ano letivo ou semestre, melhorando também a auto-estima do aluno, fator importante na caminhada do aprender.

\section{Referências bibliográficas}

BRONCKART, Jean Paul. Atividades de linguagem, textos e discursos. Educ: São Paulo, 1999.

CAMPBELL, Courtney. Avaliação Autêntica: avaliando portfólios para medir o progresso do aluno adolescente no inglês do Brasil. Especialização em História das Artes e Religiões. UFRPE, 2004. 
DELLAGMELO, Adriana. O papel da resposta do professor no processo de revisão de textos escritos em inglês como língua estrangeira. In: Fortkamp, Mailce \& Tomitch, Leda (ORGs). Aspectos de Linguística Aplicada: estudos em homenagem ao professor Hilário Inácio Bohn. Insular: Florianópolis. p. 73-92, 2000

HADJI, Charles. Avaliação Desmistificada. Artmed: Porto Alegre, 2001.

HAYES, John. A new framework for understanding cognition and affect in writing. In:

Ruddel, Robert and Singer, Harry (eds). Theoretical Models and Processes of Reading. $5^{\text {th }}$ Edition. Newark: International Reading Association. P. 1399-1430, 2004

MARCUSCHI, Luiz Antônio. Propostas para um trabalho com gêneros textuais no formato de sequências didáticas (mímeo). 2004 QUARESMA, Francisco José. Correção com os pares. Os efeitos da correção dialogada na aprendizagem da escrita em língua inglesa. Doutorado. UFMG, 2001. 


\title{
LEITURA DE TEXTOS DE INFORMÁTICA E PRODUÇÃO DE UM GLOSSÁRIO DE VERBOS DE MOVIMENTO POLISSÊMICOS
}

\author{
READING OF COMPUTING TEXTS AND PRODUCTION OF A GLOSSARY OF \\ POLYSEMOUS MOTION VERBS
}

\author{
Rosana Ferrareto Lourenço Rodrigues ${ }^{63}$ \\ rosanaferrareto@yahoo.com.br
}

Leonardo de Melo João ${ }^{64}$

leomelo16@gmail.com

\begin{abstract}
RESUMO: Em todas as línguas, os verbos de movimento são utilizados polissemicamente para expressar situações diversas de seus sentidos originais. Conhecer alguns dos principais usos é importante para se aprender inglês com eficiência. Desse modo, acreditamos que uma descrição dos principais sentidos dos verbos de movimento, a partir de textos de informática, pode consistir em importante recurso metacognitivo para ampliar a competência de leitura do aprendiz de inglês como língua estrangeira. Um exemplo, em português, seria o emprego do verbo rodar em seu sentido original de fazer mover à volta, na frase "O ventilador rodou o dia todo". É bastante comum, porém, vê-lo empregado em frases como: "Caminhões não rodam aqui" (percorrer); "Esse namoro rodou faz tempo" (não dar certo); "O programa roda em qualquer PC" (funciona). Em inglês, ao estudar o verbo run, verificamos, também, uma profusão de sentidos, além do original em "I ran to catch the bus" (correr). Alguns exemplos: "The software runs on any PC (rodar); He runs that company (gerenciar); Jackson is running for president (concorrer)". Considerando que o domínio desses sentidos normalmente é aprendido assistematicamente, pretendemos desenvolver uma ferramenta que auxilie o aprendiz de inglês na leitura. Para tanto, propomos produzir um glossário virtual inglês/português.
\end{abstract}

PALAVRAS-CHAVE: glossário virtual; polissemia; verbos de movimento em inglês.

ABSTRACT: In every language, verbs of motion are used to express polysemous meanings differently from its original meaning. Getting to know the most important uses can mean to learn English effectively. Thus, we believe that a description of the main meanings of verbs of motion may consist of an important metacognitive resource to expand the reading skill of the learner of English as a foreign language. One example, in Portuguese, would be the use of the verb rodar (run, rotate) in its original sense move around in the sentence "The fan ran all day". It is quite common, however, to see it used in sentences like: "Trucks do not run here" (drive); The program runs on any PC (work)". In English, we have also found in the verb run a profusion of meanings, beyond the original "I ran to catch the bus (move quickly with legs). Some examples: "The software runs on any PC (work); He runs that company (manage), Jackson is running for president (compete)". Since the domain of these senses is usually learned unsystematically, we intend to

\footnotetext{
${ }^{63}$ (UNESP/Araraquara; IFSP, campus SJBV)

${ }^{64}$ (IFSP, campus SJBV; CNPq)
} 
develop a tool which helps the learner of English in reading. To this end, we propose to produce an English/Portuguese virtual glossary.

KEYWORDS: virtual glossary; polysemy; verbs of motion in English.

\section{Introdução}

Em todas as línguas do mundo, os verbos de movimento são utilizados polissemicamente para expressar situações diversas de seus sentidos originais.

Ao consultarmos um dicionário inglês/português, por exemplo, verificamos as várias ocorrências do verbo run: o primeiro sentido acionado é o de movimento - a partir de algumas de suas significações, como correr (em I had to run to catch the bus); passar (em She ran her eye around the room); estender-se (em $A$ fence runs around the field); e levar (em Can I run you to the station?), o leitor certifica-se de que seu sentido está integrado ao conceito de veículo. Contudo, ao acessar suas demais acepções, torna-se perceptível sua integração a outros conceitos, de outros domínios discursivos, tais como o da informática, a partir da noção de máquina; o dos negócios, por meio do contexto situacional da administração; o da política, aliado à ideia de competição; e o do jornalismo, como veículo de informações. É em virtude desses usos metafóricos, explicados pelo princípio da integração conceptual, que temos enunciados tais como The software will run on any PC (O programa funciona/“roda” em qualquer computador); He is the man who runs that company (Ele é o homem que gerencia aquela empresa); Jackson announced his intention to run for president (Jack anunciou sua intenção em concorrer ao cargo de presidente); e The local newspaper is running an article about the threats of global warming ( $\mathrm{O}$ jornal local está publicando um artigo sobre as ameaças do aquecimento global).

Considerando que o domínio desses sentidos normalmente é ensinado/aprendido assistematicamente, pretendemos desenvolver uma ferramenta que auxilie o aprendiz de inglês como língua estrangeira na leitura. Para tanto, propomos a produção de um glossário virtual inglês/português em formato de hipertexto que esteja disponível para consulta.

A produção desse glossário virtual faz parte de um projeto de iniciação científica da modalidade PIBIC-EM em que estão trabalhando os dois autores desse artigo como professora orientadora e aluno-pesquisador de Ensino Médio de um Curso Técnico Integrado à Informática. O arcabouço teórico proposto para o tratamento linguístico dos dados faz parte do projeto de doutorado da professora-orientadora. 
A relevância de disponibilizar essa ferramenta, o glossário virtual, está baseada na proposta de apresentação de uma nova abordagem de ensino do vocabulário do inglês como língua estrangeira para fins do desenvolvimento da competência da leitura. Sabemos que o ensino/aprendizagem de inglês nos Cursos Técnicos Integrados ao Ensino Médio dos Institutos Federais focaliza, principalmente, o desenvolvimento da habilidade da leitura, uma vez que o objetivo principal dessa disciplina nos planos de curso é preparar o aluno para o mercado profissional e para o ingresso na universidade. Devido à demanda atual desses dois segmentos, estamos convencidos de que este projeto de iniciação científica irá contribuir para o aprimoramento da leitura em língua estrangeira por parte do aprendiz brasileiro.

Muitas vezes, a dificuldade de compreensão do que se lê em inglês ocorre por causa da significativa recorrência dos verbos de movimento em projeções metafóricas nos vários tipos de textos, inclusive os de informática, requeridos no vestibular e no mercado de trabalho. Isso acontece porque, ao ler em inglês, o falante nativo de português acaba acionando os mesmos modelos cognitivos e/ou representações mentais que aciona para entender português. Essa mobilização/processo não funciona porque cada língua está ligada à uma cultura, história e usos diferentes.

Ao ler, fazemos projeções equivocadas do uso de nossa língua de origem, o português, para a língua-alvo, o inglês. Para entender o diferente funcionamento dos usos metafóricos de cada língua, pressupomos ser preciso estudar integração conceptual (cf. Fauconnier e Turner, 2002 e Bache, 2005) e esquemas de imagem ligados aos verbos (cf. Hampe, 2005, Peña, 2008). A partir dessa proposta teórica, o professor, assim, consegue assegurar a seus alunos a oportunidade de aprender a pensar por meio da "concretização" do pensamento abstrato em favor do desenvolvimento da competência da leitura. Acreditamos que um estudo bibliográfico desses autores sustenta essa proposta e amplia as possibilidades para o professor adotar uma abordagem cognitiva no ensino da leitura em inglês e realizar a tarefa de ensinar os alunos a pensar.

Sabemos que vem sendo enfatizada pelos educadores a importância das estratégias metacognitivas para otimizar a aprendizagem. Segundo Winn, W \& Snyder, D. (1996), "metacognição é a capacidade de o aprendiz criar estratégias próprias para aprender o que lhe é ensinado, o que envolve reflexão, auto-responsabilidade e iniciativa”. Infelizmente, a escola tem uma larga tradição de passar conteúdos, achando que os alunos já possuem, por si próprios, a capacidade de trabalhar com eles.

Além disso, como diz Ribeiro (2003, p. 110), 
a metacognição pode exercer influência sobre a motivação, pois sabemos que um aluno que sabe como aprender é sempre mais motivado a pôr empenho em seus estudos do que aquele que repete várias vezes a leitura de uma mesma página para entender um mínimo.

Sendo assim, faz-se necessário repensar os processos metacognitivos tradicionais, como o de ensinar os alunos a decorar todas as possíveis traduções dos verbos, para que não tenham apenas uma estratégia metacognitiva superficial, mas sejam capazes de aprofundar outras mais motivadas.

Resumindo, as justificativas para que se realize esta pesquisa, do ponto de vista pedagógico, é o de que a abordagem teórica adotada serve como recurso metacognitivo, o que confere ao leitor de inglês como língua estrangeira maior autonomia para desenvolver o conhecimento do vocabulário dessa língua e a competência da leitura.

Finalmente, cabe ainda salientar a relevância social desta pesquisa: seu produto, o glossário, será de grande utilidade para todos os alunos dos Institutos Federais, que poderão acessar e utilizar essa ferramenta na internet e divulgá-las a outros alunos/escolas.

\section{Descrição das etapas da produção do glossário}

Como foco central da proposta de obter como resultado dessa pesquisa um glossário virtual Inglês/Português dos verbos de movimento polissêmicos, está a de promover uma aplicação didática dos dados coletados na pesquisa na produção de uma ferramenta que auxiliará o aluno do IFSP a ler melhor em inglês.

O glossário, produto desta pesquisa, uma vez disponibilizado no site do IFSP-SJBV (www.ifsp.edu.br/saojoaodaboavista), irá não só facilitar a leitura, mas também possibilitará ao aluno-pesquisador utilizar seus conhecimentos técnicos da área de informática. Caberá a ele, depois dos estudos da polissemia de verbos de movimento em inglês e sua interface com o português (sob orientação das leituras e da professoraorientadora), produzir o glossário em forma de hipertexto e disponibilizá-lo na internet.

O projeto, que começou a ser desenvolvido em fevereiro de 2011, tem demandado o levantamento de dados necessários para a construção do corpus, a partir do uso de dicionários monolíngues e bilíngues e de textos utilizados na prática pedagógica diária no IFSP, campus São João da Boa Vista. A coleta consiste em pesquisar as acepções e os usos de verbos de movimento em inglês. 
Até o presente momento, três verbos foram selecionados para o estudo: os verbos run (correr), go (ir) e walk (andar). Os gêneros textuais utilizados para verificar o uso dos verbos, a partir da coleta de pequenos enunciados, são do domínio discursivo da informática: artigos científicos, artigos de opinião, tutoriais e capítulos de livros. Após a coleta dos enunciados, os verbos são descritos de acordo com os esquemas de imagem e com o princípio da integração conceptual e, então, traduzidos de acordo com seu emprego metafórico no enunciado em que está inserido. Esse material será, posteriormente, utilizado para compor o glossário. O aluno-pesquisador criará o hipertexto para disponibilizar o produto final na internet.

\begin{tabular}{|c|l|}
\hline Atividade & \multicolumn{1}{|c|}{ Descrição } \\
\hline $\mathbf{1}$ & $\begin{array}{l}\text { Construir um corpus de alguns verbos de movimento a partir da leitura de } \\
\text { textos de informática utilizados nas disciplinas técnicas da grade do Curso } \\
\text { de Informática integrado ao Ensino Médio e na disciplina de Inglês. Essa } \\
\text { construção parte do levantamento de alguns verbos com o auxílio de } \\
\text { dicionários monolíngues e bilíngues e da coleta de pequenas } \\
\text { frases/enunciados dos textos escolhidos em que esses verbos aparecem. }\end{array}$ \\
\hline $\mathbf{2}$ & $\begin{array}{l}\text { Descrever os verbos de movimento dos textos de informática a partir de } \\
\text { das teorias dos esquemas de imagem e da integração conceptual. }\end{array}$ \\
\hline $\mathbf{3}$ & $\begin{array}{l}\text { Elaborar um glossário em formato de hipertexto, para a consulta não-linear, } \\
\text { que registre os empregos metafóricos dos verbos de movimento nos textos } \\
\text { de informática. }\end{array}$ \\
\hline $\mathbf{4}$ & \begin{tabular}{l} 
Disponibilizar o glossário na internet. \\
\hline
\end{tabular}
\end{tabular}

Tabela 1. Descrição das atividades

\section{Tratamento Linguístico dos Dados}

Esta pesquisa assume os princípios da Linguística Cognitiva, uma abordagem baseada na ideia de que o significado é corporificado e no fato de explicar fatos linguísticos em termos de propriedade e mecanismos da mente humana. Sob a ótica da integração conceptual, por exemplo, a língua é um sistema de representação em que a projeção do ponto de vista do usuário ocorre para a construção do significado.

A escolha desse modelo teórico foi motivada pelas seguintes hipóteses: (1) Os falantes de todas as línguas parecem preferir empregar uma construção metafórica com verbos de movimento a utilizar uma construção literal. (2) A linguística cognitiva tem muito 
a oferecer ao ensino de inglês como língua estrangeira porque fornece uma aprendizagem significativa, promovendo uma percepção dos princípios conceituais que dão suporte ao trabalho com o vocabulário a partir de uma abordagem semântica. (3) O conhecimento dos esquemas de imagem e dos processos de integração conceptual facilita 0 entendimento do uso polissêmico dos verbos de movimento e, consequentemente, contribui para o aprendizado das diferentes acepções desses verbos. Tal abordagem teórica serve como recurso metacognitivo, o que confere ao leitor de inglês como língua estrangeira maior autonomia para desenvolver o conhecimento do vocabulário dessa língua e a competência da leitura.

Desse modo, os principais objetivos do tratamento linguístico dos dados desta pesquisa são: (1) Apresentar uma descrição dos principais sentidos dos verbos de movimento em inglês, a partir da teoria da integração conceptual e dos esquemas de imagem, vinculados ao modelo da linguística cognitiva. (2) Entender como e porque os falantes da língua inglesa utilizam, metaforicamente, verbos de movimento ou expressões idiomáticas construídas com esses verbos, no lugar de verbos de sentido conceptual. (3) Fornecer subsídios para o trabalho com a Língua Inglesa em sala de aula, utilizando essa abordagem como importante recurso metacognitivo para ampliar, por exemplo, a competência de leitura do aprendiz de inglês como língua estrangeira.

Tendo em vista a importância de se entender que "a polissemia parece ser norma em vez de exceção na língua", como consideram Evans \& Green (2006), pretendeu-se estudar três verbos de movimento polissêmicos: go, run e walk a partir do referencial teórico dos esquemas de imagem e da metáfora, vista modernamente como ancorada na experiência corporal. Os dados apresentados descrevem algumas projeções metafóricas que acontecem devido ao mecanismo da integração conceptual. De acordo com esse ponto de vista, "a polissemia aparece porque as palavras estão ligadas à uma rede de conceitos lexicais em vez de estarem ligadas a um conceito individual" (EVANS \& GREEN, 2006, p. 169).

Nesta pesquisa, coletamos dados em textos do domínio discursivo da informática pertencentes aos seguintes gêneros - capítulos de livros, tutoriais, artigos científicos e artigos de opinião. Nesses textos, encontramos ocorrências dos verbos run e go com as seguintes acepções, respectivamente: criar, hospedar, rodar, administrar, executar, funcionar, utilizar, circular e avançar; e avançar, estender, deixar e ir. Não houve ocorrência do verbo walk, que também pretendíamos descrever inicialmente. Neste artigo, optamos por apresentar os dados referentes ao emprego metafórico de run, a partir das 
ocorrências em dois gêneros textuais pesquisados, o que constitui um pequeno corpus de nove enunciados.

\subsection{Esquemas de imagem ligados aos verbos e emprego metafórico}

A discussão sobre o emprego metafórico de verbos de movimento em inglês apóiase, principalmente, nos estudos de Fauconnier \& Turner (2002), que abordam o princípio da integração conceptual por meio da criação de conceitos (denominado princípio de identidade), da projeção entre domínios de origem e domínios-alvo (denominada metáfora), da projeção da parte em um todo (chamada metonímia) e da compressão do tempo ou do espaço; e também nos de Lakoff \& Johnson (1999) e Peña (2008), que propõem a teoria dos esquemas de imagem, a partir da ideia da linguagem corporificada.

"Os esquemas de imagem tem fornecido material conceptual para a construção de muitas expressões linguísticas" e, além disso, constituem "relações naturais que motivam a polissemia" (PEÑA, 2008, p. 1041, 1042). Esses esquemas são padrões estruturais recorrentes em nossa experiência sensório-motora que, quase sempre, servem para estruturar conceitos complexos. Sua origem está ligada à nossa estrutura física. Utilizando nosso próprio corpo como ponto de observação, criamos conceitos como direita, esquerda, frente, atrás, acima, abaixo. Como somos seres dotados de movimento, criamos conceitos como origem, caminho, destino, obstáculos. Como somos confrontados com forças que nos puxam ou empurram (vento, animais, outros seres humanos), criamos um conceito chamado de FORÇA DINÂMICA. Os principais esquemas de imagem são: PERCURSO (com início, meio e fim, dirigido à frente, ao alto ou para baixo); CONTAINER (com suas partes: fora, dentro e limites); LIGAÇÃO (entre partes, entre unidades etc.); FORÇA DINÂMICA (resultado do contato dinâmico entre partes); EQUILÍBRIO (de força, de massa, de luz etc.); PARTE-TODO (tanto no sentido parte-todo quando no sentido todo-parte) (cf. LAKOFF \& JOHNSON, 1999). Como exemplo, podemos citar o verbo andar. Em português, é possível empregá-lo com o sentido de "ter relações carnais": "Soube-se que ele andava com a empregada". O esquema de imagem é o de percurso (SOURCE-PATH-GOAL ou INÍCIO-MEIO-FIM) com foco no aspecto durativo do percurso, vinculado ao frame de estar acompanhado, relacionar-se com outra pessoa. $\mathrm{O}$ traço de "movimentar-se dando passos" é desintegrado durante o processo de blend (mesclagem). Em inglês, não verificamos esse emprego de walk e, portanto, o enunciado equivalente seria "He's having an affair with the maid" (tendo um caso com).

Nessa descrição, é possível verificar o princípio da integração conceptual, aliado 
aos esquemas de imagem, aplicado ao estudo da polissemia dos verbos de movimento promovendo o entendimento do emprego metafórico dos verbos analisados.

\subsubsection{Enunciados de capítulos de livros}

(1) The language wasn't originally intended to run enterprise-class web sites (GILMORE, 2010, p. 38).

Não se tinha a intenção que a linguagem criasse sites de classe empresarial.

Aqui, temos o esquema de percurso com foco no movimento. Nessa frase, o autor poderia ter empregado o verbo create. Para expressar o sentido de "fazer algo novo ou original que não existia antes", preferiu utilizar uma projeção metafórica por meio do verbo correr (run) que, conceptualmente, significa "deslocar-se no espaço velozmente". percurso (PATH) corresponde ao ato de criação e o existir do algo novo consiste na diferença entre a origem (SOURCE) e o fim (GOAL) do percurso. Verificamos, também, a personificação de "linguagem" como ator da ação de "criar". Além disso, as projeções denominadas por Turner (1996, p. 39) como EVENTS ARE ACTIONS (eventos são ações) e ACTORS ARE MOVERS (atores são coisas que se movem) estão presentes nessa construção. Essas projeções consistem em projeções de estórias de ação corporificada em outras estórias de ação e de estórias de movimento corporificados em histórias de ação, respectivamente. Assim, a linguagem (ATORES SÃO COISAS QUE SE MOVEM) cria sites (EVENTOS SÃO AÇÕES).

(2) If you'd like to run PHP with IIS, I recommend following the instructions in the "Installing IIS and PHP on Windows" section (GILMORE, 2010, p.46).

Se você deseja hospedar sites em PHP pelo IIS, eu recomendo que você siga as instruções na seção "Installing IIS and PHP on Windows".

O verbo hospedar ou to host, conceptualmente, designa "oferecer ou receber abrigo; alojar(-se), abrigar(-se)". Na informática, é usado para expressar "fornecer a infraestrutura necessária para que um site possa ser utilizado". O "host computer" é o principal computador de uma rede que controla certos processos ou arquivos. Verificamos, assim, que a tradução para o português emprega "hospedar" 
metaforicamente a partir dos esquemas de imagem de CONTAINER e PARTE-TODO. Em inglês, o emprego de run, a partir do esquema DINÂMICA DE FORÇAS integra conceptualmente ao verbo correr, o frame de "controle de processos e movimento, funcionamento".

(3) The computer actually does not run them all simultaneously. Rather, it runs a small portion of one user's job, then moves on the service the next user, perhaps providing service to each user several times per second (DEITEL, 2004, p. 5).

O computador na verdade não roda todos eles simultaneamente. Ao invés disso, ele roda uma pequena porção da tarefa de cada usuário, e então transfere o serviço para o próximo usuário, desse modo provê serviços a todos os usuários muitas vezes por segundo.

"Fazer movimentos circulares" é o que significam os verbos turn e rodar. O computador e seus programas ou tarefas necessariamente não correm e nem giram para funcionar, mas esse emprego metafórico está baseado na compreensão de que run (correr) ou rodar (fazer girar) é fazer executar. O esquema de imagem é o de DINÂMICA DE FORÇAS, ou seja, o resultado do contato dinâmico entre partes da máquina contribui para o funcionamento do sistema.

(4) Software business is said to be run by this "returns law"; this is especially important to the packaged software producers who are more able to gain economies of scale and enjoy low marginal costs (TYRVÄINE, P.; JANSEN, S.; CUSUMANO, M. A., 2010, p. 78).

É dito que esse negócio de software é administrado por essa "lei de retorno", isto é especialmente importante para os produtores de pacotes de software que são mais capazes de ganhar economias de escala e aproveitar os baixos custos marginais.

A partir de uma projeção metafórica que indica movimento à frente, os verbos run e administrar estão empregados sob os esquemas de PERCURSO e DINÂMICA DE FORÇAS. Nessa construção, temos o esquema de PERCURSO com foco no caminho, mas com o esquema DINÂMICA DE FORÇAS agregado a ele. A ideia de dirigir está integrada conceptualmente a esses esquemas: os produtores de pacotes de software 
atuam como administradores da "lei do retorno" que, por sua vez, comanda os negócios, fazendo-os progredir para o negociador ganhar. $O$ traço de velocidade no frame do verbo run (correr) é integrado à ideia da competição econômica e concorre para realizar o almejado: chegar primeiro, antes. Temos também, aqui, a metáfora primária CHEGAR AO FIM É BOM (cf. LAKOFF \& JOHNSON, 1980) e uma projeção do espaço (percurso físico realizado na corrida) no tempo (chegar primeiro consiste em chegar antes, mais rapidamente).

(5) Prior to running cluster analyses, we inspected the data and found that the variables were right-skewed (TYRVÄINE, P.; JANSEN, S.; CUSUMANO, M. A., 2010, p. 5).

Antes de executar a análise de agrupamentos, nós vistoriamos os dados e descobrimos que as variáveis foram bem apurados.

Similar ao emprego de run com o sentido de rodar, o emprego de executar que, na informática, quer dizer processar as instruções de um programa ou algoritmo está sob o esquema de DINÂMICA DE FORÇAS. Desempenhar um movimento, que seria expresso conceptualmente pelo verbo execute, encontra no verbo run o traço de movimento integrado à ideia de funcionar, fazer acontecer.

(6) Most of the data come from the five working groups running in parallel and engaging approximately 70 participants, of whom most are senior executives of software firms (TYRVÄINE, P.; JANSEN, S.; CUSUMANO, M. A., 2010, p.171).

A maioria dos dados provenientes dos cinco grupos de trabalho funciona em paralelo e envolve cerca de 70 participantes, sendo a maioria deles grandes executivos de empresas de software.

Os "dados funcionam" é um emprego comum em português. Em contrapartida, os "dados correm" é estranho ao falante nativo dessa língua. Em inglês, function cumpriria o propósito de expressar a ideia de "estar em atividade ou operar". Nesse emprego, temos run como metáfora, agregando o frame de movimento ao funcionamento e à noção primária de que algo que funciona é algo que dá certo, dá bom resultado. Temos, novamente, uma associação dos esquemas DINÂMICA DE FORÇAS e PERCURSO com foco no fim. Correr até o final consiste em movimentar-se para realizar uma operação bem 
sucedida.

\subsubsection{Enunciados de Tutoriais}

(7) It is supported by all computers running Windows, and by all the most popular web browsers (except Google Chrome) (Disponivel em http://www.w3schools.com/media/media_soundformats.asp. Acesso em 12 Mar 2011).

Há suporte para todos os computadores que utilizam Windows, e todos os navegadores mais populares (exceto Google Chrome).

O uso de uma máquina é sempre um uso por meio do qual se pretende obter um resultado. O verbo conceptual "usar" exprimiria a ideia de "lançar mão de, fazer uso de, aplicar, empregar (algo) em ou para determinado fim". Novamente, o esquema de PERCURSO com foco no fim é utilizado aqui para designar o funcionamento do computador via sistema operacional Windows.

(8) The ASF format (Advanced Streaming Format) is specially designed to run over the Internet (Disponivel em http://www.w3schools.com/media/media_windowsformats.asp. Acesso em $12 \mathrm{Mar}$ 2011).

O formato ASF é especialmente designado para circular na internet.

Nessa tradução, mais uma vez, encontramos um emprego metafórico em português. "Circular" aqui não designa "mover-se ao redor de". Entendemos "circular na internet" desta forma: informações ou ideias, quando circulam, é porque uma pessoa fala ou escreve sobre elas a outro alguém para que mais pessoas passem a saber sobre o assunto. Em inglês, circulate ou move around poderiam ser empregados para denotar esse sentido. Contudo, o verbo run foi empregado metaforicamente com o auxílio do esquema DINÂMICA DE FORÇAS, cuja existência está inextricavelmente ligada ao esquema de PERCURSO. O traço do percurso "estar em algum espaço em movimento" é o responsável pelo emprego de run com a ideia de circular. Afinal, "mover-se ao redor de" promove a manutenção do sentido de "estar em movimento". Esse traço está integrado à 
ideia de divulgação (do formato ASF) para as pessoas que coexistem nesse mesmo lugar ou espaço, nesse caso, a internet.

(9) Use break to prevent the code from running into the next case automatically (Disponivel em http://www.w3schools.com/php/php_switch.asp. Acesso em $12 \mathrm{Mar}$ 2011).

Use o comando break para impedir o código de avançar para o próximo caso automaticamente.

Novamente, "fazer mover para frente, avançar, progredir" são conceitos presentes no emprego metafórico de run a partir do esquema PERCURSO. Aqui, temos a projeção do espaço no tempo. O elemento do frame de SOURCE-PATH-GOAL em foco é o de que progredir no caminho é positivo, pois, quando se faz isso, o destino fica mais próximo. No enunciado analisado, a mudança automática de um caso para outro, que consistiria nesse avanço, deve ser impedida. Por isso, verificamos também o esquema DINÂMICA DE FORÇAS, do tipo BLOCKAGE (bloqueio), uma vez que o avanço não pode ocorrer quando se utiliza o comando break. Assim, a "corrida" para o caso seguinte seria interrompida (prevent the code from "running") e não se atingiria o fim previsto em qualquer avanço ou progresso.

A descrição das diversas acepções de run nos nove enunciados pode ser feita com o auxílio de quaisquer dicionários monolíngues e/ou bilíngues. Contudo, a adoção dessa abordagem cognitiva pode ser utilizada na prática pedagógica do professor de inglês na aula de leitura. Além disso, o aluno de um curso de tecnologia na área de informática pode traduzir as várias acepções do verbo run sem precisar recorrer ao dicionário, mas baseado no uso já sistematizado desses comandos em português. Esses fatos são justificativas suficientes para modelar todas essas informações na criação de um produto tecnológico, o glossário, que pode facilitar a aprendizagem desse vocabulário para alunos iniciantes nessa área técnica. A descrição da última prática proposta está apresentada a seguir.

\section{Tratamento Computacional}

Para melhor entender o resultado do glossário, é necessário apresentar a descrição de como está ele sendo programado e algumas informações sobre a linguagem na qual está sendo escrito. 
Tendo como ideia final do projeto uma página que possa ser aberta em qualquer navegador (para melhor atender aos usuários), utilizaremos, para sua criação, a linguagem HTML (Hypertext Markup Language) com padrões para validação na W3C (World Wide Web Consortium), consórcio que visa desenvolver padrões para a criação e interpretação de conteúdos para a web.

A linguagem HTML é uma linguagem de marcação, utilizada para produzir páginas na web. Utilizando apenas HTML seria possível obter uma página com um bom design rapidamente. Porém, como temos por objetivo obter uma página para execução precisa em qualquer navegador, necessitamos utilizar também uma linguagem adicional de estilo chamada CSS (cascading style sheets).

O CSS é uma linguagem que, em conjunto com o HTML, proporciona melhor manuseio da página, podendo alterar em uma simples linha todos os textos de um determinado formato.

Para melhor entender essa linguagem, observemos um exemplo de código CSS com uma breve explicação sobre seu conteúdo.

h3 \{

font-family: Arial

font-size: 18pt;

color: black

O código acima define qual será o tamanho, a cor e o tipo da fonte contida dentro de uma tag h3 $(<\mathrm{h} 3>\ldots</ \mathrm{h} 3>)$ em qualquer parte de um documento HTML.

Essa linguagem é também usada para fazer o alinhamento do site utilizando tags de divisões por pixels. Porém, alinhar o site por meio dessas tags demanda um pouco de tempo. Por isso, para a criação do esboço do site, que será apresentado a seguir, o alinhamento foi feito através de tabelas sem bordas. Olhando as figuras abaixo podemos entender melhor sobre esse alinhamento.

A Figura 1 mostra a divisão por tabelas, em que cada quadrante representa uma linha ou coluna. 


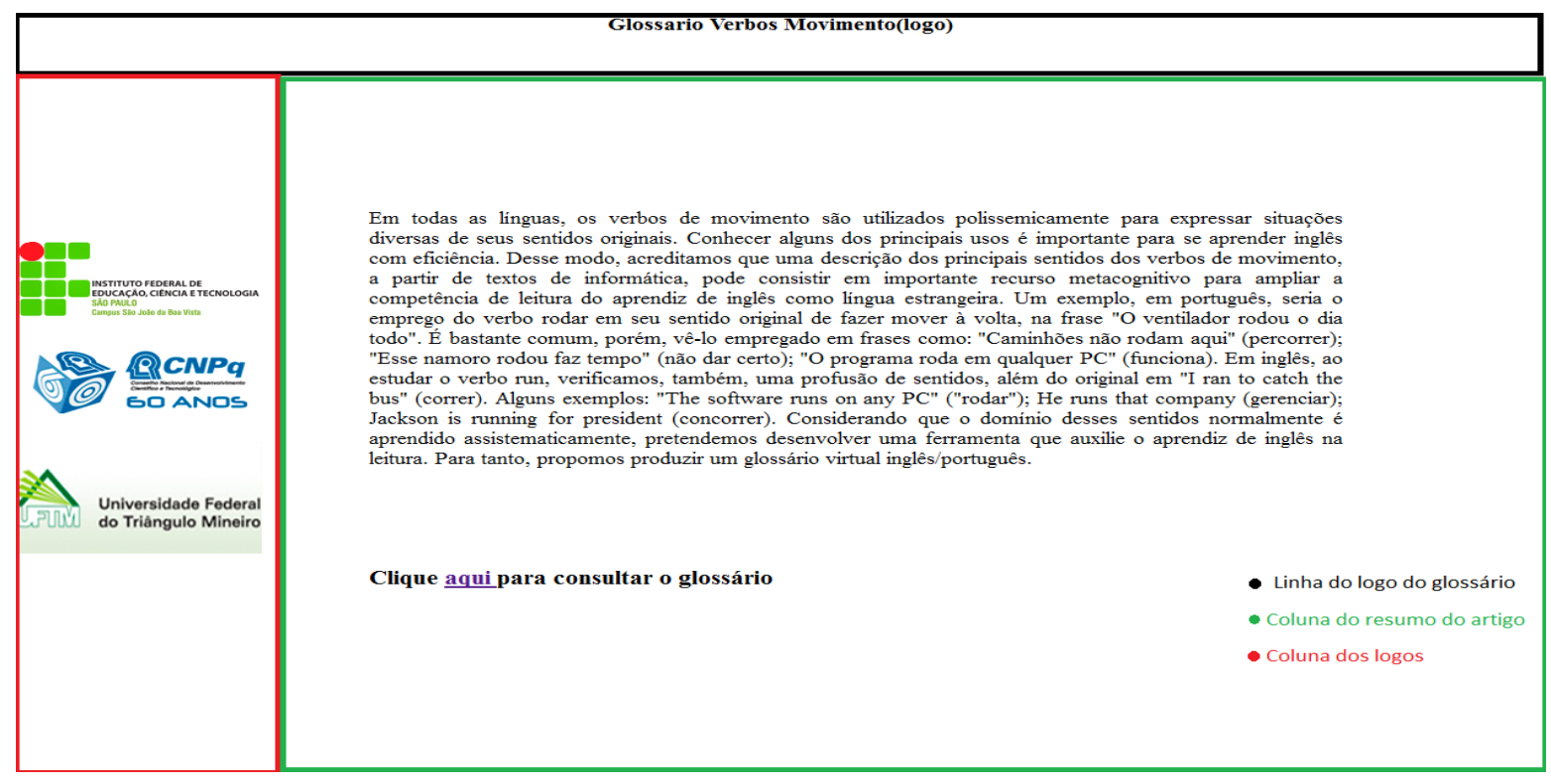

Figura 1. Divisão por tabelas

Tendo conhecido o que era preciso para entender a linguagem e sabendo que o glossário como produto acabado será a última etapa do projeto, serão exibidas a seguir fotos e explicações sobre o esboço do glossário, com resultados parciais. Até este ponto da pesquisa, o glossário foi criado a partir de tabelas para a obtenção de uma visualização prévia do conteúdo de navegação.

Na página inicial, apresentada na figura 2, há um espaço para o logo do glossário (que ainda será idealizado e programado); os logos das instituições relacionadas a esta pesquisa; o resumo do projeto, localizado no centro da página; e um link, que será substituído por um botão de acesso para a página da tabela dos verbos.

Glossario Verbos Movimento(logo)

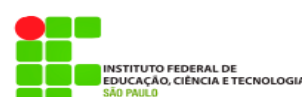

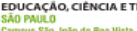

Em todas as linguas, os verbos de movimento são utilizados polissemicamente para expressar situações diversas de seus sentidos originais. Conhecer alguns dos principais usos é importante para se aprender inglês com eficiência. Desse modo, acreditamos que uma descrição dos principais sentidos dos verbos de movimento, a partir de textos de informática, pode consistir em importante recurso metacognitivo para ampliar a a partir de textos de informática, pode consistir em importante recurso metacognitivo para ampliar a emprego do verbo rodar em seu sentido original de fazer mover à volta, na frase "O ventilador rodou o dia todo". E bastante comum, porém, vê-lo empregado em frases como: "Caminhões não rodam aqui" (percorrer); "Esse namoro rodou faz tempo" (não dar certo); "O programa roda em qualquer PC" (funciona). Em inglês, ao estudar o verbo run, verificamos, também, uma profusão de sentidos, além do original em "I ran to catch the bus" (correr). Alguns exemplos: "The software runs on any PC" ("rodar"); He runs that company (gerenciar); Jackson is running for president (concorrer). Considerando que o dominio desses sentidos normalmente aprendido assistematicamente, pretendemos desenvolver uma ferramenta que auxilie o aprendiz de inglês na leitura. Para tanto, propomos produzir um glossário virtual inglês/português.

Clique aqui para consultar o glossário 
Na página das tabelas dos verbos, na figura 3, é possível observar duas tabelas com os verbos que possivelmente serão estudados.

A primeira tabela destina-se ao aprendiz-escritor, que precisa do significado do português para o inglês.

A segunda tabela destina-se ao aprendiz-leitor, que necessita saber o significado do verbo em uma frase em inglês.

Ao clicar sobre um verbo, a página do verbo selecionado será aberta, como podemos observar nas figuras 3 e 4 .

Glossario Verbos Movimento(logo)

Escolha um verbo na tabela abaixo

Choose a verb in the table below
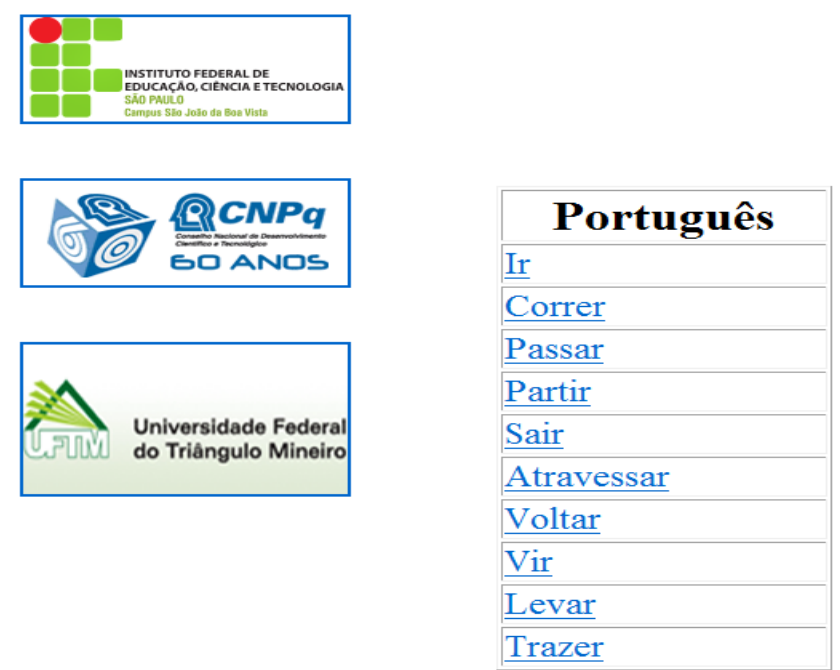

\begin{tabular}{|l|}
\hline \multicolumn{1}{|c|}{ English } \\
\hline Go \\
\hline$\underline{\text { Run }}$ \\
\hline Pass \\
\hline$\underline{\text { Spend }}$ \\
\hline Leave \\
\hline Cross \\
\hline Return \\
\hline Come \\
\hline Take \\
\hline Bring \\
\hline
\end{tabular}

Figura 3. Tabelas de verbos

Nesse exemplo, a página do verbo run foi aberta. Nela, é possível observar significados e seus respectivos exemplos de aplicação em frases. Ao clicar no significado desejado, automaticamente o local da página onde estão os exemplos será aberto. 


\section{Machine: work \\ 2. control/organize}
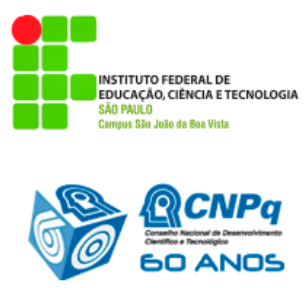

1. 1. - [intransitive/transitive] computing to start or to use a computer program.

The computer actually does not run them all simultaneously. Rather, it runs a small portion of one user's job, then moves on the service the next user, perhaps providing service to each user several times per second.(Java How to Program Sixth Edition, H. M. Deitel, Chapter 1 Setion 4)

Software business is said to be run by this "returns law"; this is especially important to the packaged software producers who are more able to gain economies of scale and enjoy low marginal costs. (Software Business, First International Conference, ICSOB 2010 Jyväskylä, Finland, June 2010 page 78)

Figura 4. Verbo run

\section{Considerações finais}

A descrição dos dados desta pesquisa confirma o que as pesquisas atuais em linguística cognitiva enfatizam: os esquemas de imagem fornecem material conceptual para a construção de muitas expressões linguísticas (PEÑA, 2008, p. 1042) e um importante fator motivador das extensões de significado e, portanto, da existência da polissemia, é a metáfora (EVANS \& GREEN, 2066, p. 39 apud LAKOFF, 1987).

Devido à significativa recorrência dos verbos de movimento em projeções metafóricas nas leituras requeridas nos meios técnico-profissional, acadêmico-científico e/ou para fins de realização de provas dos vestibulares brasileiros, por exemplo, é preciso que o professor promova uma reflexão sobre a funcionalidade atual e diária dessas projeções, assegurando a seus alunos a oportunidade de aprender a pensar por meio da "concretização" do pensamento abstrato em favor do desenvolvimento da competência da leitura.

Neste projeto, especificamente, a interação do aluno do técnico integrado ao ensino médio, via criação de um produto tecnológico - o glossário, proporcionou uma realização dessa estratégia metacognitiva na esfera didática da pesquisa. Afinal, este trabalho resultou em uma ferramenta que pode ser utilizada nessa esfera tanto pelo 
professor, em sua prática pedagógica como material didático, quanto para o aluno, no desenvolvimento da habilidade de leitura de modo mais significativo e autônomo.

Podemos concluir que os princípios dos esquemas de imagem e da integração conceptual, aplicados ao estudo da polissemia dos verbos de movimento em seus empregos metafóricos, pode auxiliar a desenvolver a competência da leitura do aprendiz de inglês como LE por lhe oferecer uma estratégia de aprendizagem mais motivada.

\section{Referências teóricas}

BACHE, Carl.Constraining conceptual integration theory: Levels of blending and disintegration. Journal of Pragmatics, 37, 1615-1635, 2005.

DAVIS, Claudia, NUNES, Marina M. R. e NUNES, Cesar A. A. Metacognição e Sucesso Escolar: Articulando Teoria e Prática, Cadernos de Pesquisa, v. 35 n 125, Caxambu: ANPED, 2005.

EVANS, Vyvyan \& GREEN, Melanie. Cognitive Linguistics: an introduction, New Jersey, London: Lawrence Erlbaum Associates, Publishers, 2006.

FAUCONNIER, Gilles \& TURNER, Mark. The way we think: conceptual blending and the mind's hidden complexities, New York: Basic Books, 2002.

HAMPE, Beate. From Perception to Meaning: Image Schemas in Cognitive Linguistics, New York, Mouton de Gruyter.

LAKOFF, George \& JOHNSON, Mark. Philosopy in the flesh: the embodied mind and its challenge to western thought. New York: Basic Books, 1999.

LAKOFF, George \& JOHNSON, Mark. Metaphors We Live By, Chicago: The University of Chicago Press, 1980.

PEÑA, M. S. Dependency systems for image-schematic patterns in a usage-based approach to language, Journal of Pragmatics 40, 1041-1066, 2008.

RIBEIRO, Célia. Metacognição: Um apoio ao Processo de Aprendizagem. Psicologia: Reflexão e Crítica, (16 (1), pp. 109-116, Viseu PT: Universidade Católica Portuguesa, 2003.

TURNER, Mark. The Literary mind: the origins of thought and language, Oxford: Oxford University Press, 1996.

WINN, W. \& SNYDER D. Cognitive perspectives in psychology. Ind D. H. Honassen, ed. Hand book of research for educational communications and technology, 112-142 New York: Simon \& Schuster Macmillan, 1996.

\section{Referências do corpus}

DEITEL, H. M. Java ${ }^{\mathrm{TM}}$ how to program. Sixth Edition. New Jersey: Prentice Hall, 2004. GILMORE, W. J. Beginning PHP and MySQL: from novice to professional. Fourth edition. New York: Apress, 2010.

HTML tutorials. Disponível em: <http://www.w3schools.com/default.asp> Acesso em: 12 mar. 2011.

TYRVÄINE, P.; JANSEN, S.; CUSUMANO, M. A. (eds.). Software business: first international conference, ICSOB 2010 Jyväskylä, Finland, June 21-23 2010 proceedings. Jyväskylä: Springer, 2010. 


\title{
WORKING WITH WIKI IN THE ENGLISH CLASSES FOR ELEMENTARY EDUCATION
}

\author{
Viviane Cabral Bengezen - GPNEP \\ vbengezen@gmail.com
}

RESUMO: Meu principal objetivo nesse trabalho é apresentar e discutir os resultados de uma pesquisa narrativa desenvolvida com meus alunos. Minha questão de pesquisa é: Como alunos e professora do ensino fundamental II podem trabalhar com o Wiki nas aulas de inglês? A metodologia que utilizei foi a pesquisa narrativa conforme Clandinin e Connelly. A pesquisa foi realizada durante três meses, quando eu e meus alunos do $6^{\circ} \mathrm{e}$ $7^{\circ}$ ano de uma escola municipal de Uberlândia criamos um Wiki nas aulas de inglês. Fiz a composição dos textos de campo a partir dos e-mails enviados a mim, as atividades realizadas em sala e os textos produzidos pelos alunos. Para escrever o texto de pesquisa, parti dos pressupostos teóricos de Ely, Vinz, Downing e Anzul (1991), sobre a composição de sentidos. Como base teórica, fundamento-me nas discussões sobre novos letramentos, conforme Lankshear e Knobel (2005) e sobre sequências didáticas baseadas em gêneros, conforme Cristóvão e Szundy (2008). As histórias construídas durante essa pesquisa podem contribuir para os estudos sobre o ensino de línguas e as novas tecnologias, já que relatam experiências de ensinar e aprender inglês a partir de uma perspectiva que utiliza os gêneros digitais e as linguagens multimodais.

PALAVRAS-CHAVE: wiki; aprendizagem de inglês; pesquisa narrativa.

ABSTRACT: My main goal with this work is to present and discuss the results of a narrative inquiry developed with my students in the English classes. My research question is: How can students and teacher of Elementary Education work with wiki in the English classes? The methodology I used was narrative inquiry, according to Clandinin and Connelly. The research was developed during three months, when my 6th and 7th grade elementary students and I, teacher of a municipal school of Uberlândia, created a wiki. I composed the field texts from the e-mails sent to me, the activities developed in class and the texts produced by the students. These documents were viewed with the lens of Ely, Vinz, Downing and Anzul's (2001) interpretative perspective, who sustain possibilities for composing meanings in the research. The theoretical background used to discuss new literacies stories includes Lankshear and Knobel (2005) and to discuss the didactic sequences based on genres includes Cristóvão and Szundy (2008). The stories contructed during this research can contribute for the studies about language teaching and the new technologies, as they relate experiences of teaching and learning English from a perspective that uses digital genres and multimodal language.

KEYWORDS: wiki; English learning; narrative inquiry. 


\section{Introdução}

Este trabalho é o resultado de uma pesquisa narrativa que desenvolvi juntamente com meus alunos do ensino fundamental II em uma escola pública de Uberlândia, Minas Gerais. Durante o primeiro semestre, minha proposta foi construir um wiki (site de escrita colaborativa) para ser utilizado por mim e por meus alunos de inglês do $6^{\circ}$ e $7^{\circ}$ ano do ensino fundamental.

Como minha intenção era compreender o processo de construção e a utilização do wiki, escolhi seguir o caminho teórico e metodológico da pesquisa narrativa (CLANDININ; CONNELLY, 2000), por acreditar que as histórias contadas sobre as experiências vividas poderiam me ajudar a refletir acerca de questões como interação, papel do professor, trocas de informações e produção coletiva de conhecimento.

Dividi este artigo em três partes, além de introdução e referências. Considerando os quatro movimentos da pesquisa narrativa (CLANDININ; CONNELLY, 2000), cujos termos são retrospectivo, prospectivo, introspectivo e extrospectivo, inicio o texto de pesquisa pela história Vamos criar um wiki? - a história inicial, na qual faço um movimento retrospectivo e conto minha história de quando eu era aluna do $6^{\circ}$ ano e tive contato com a língua inglesa pela primeira vez. Narro, também, minha experiência como professora do $6^{\circ}$ e $7^{\circ}$ ano buscando criar um espaço de produção de textos em inglês e formulando a questão de pesquisa. A partir da narrativa inicial, eu reconto a experiência vivida com meus alunos, com o olhar de pesquisadora e construo duas histórias principais: Quem sou eu? - Criando nosso perfil e O lugar onde moro - Criando as vídeo narrativas.

A segunda parte do artigo é dedicada à história Fazendo pesquisa narrativa - eu e meus 280 alunos..., cujo foco é a metodologia de pesquisa que utilizo para desenvolver esta pesquisa. Por meio dessa história, descrevo o contexto de pesquisa, os participantes, a composição dos textos de campo (coleta de material documentário), a composição de sentidos, conforme Ely, Vinz, Downing e Anzul (1991) e a escrita do texto de pesquisa, que resultou nesse texto de pesquisa.

A terceira parte desse trabalho contém as histórias criadas a partir da análise dos textos de campo. São elas: Aprender fazendo vs. pedagogização da internet e Trabalho em duplas (interações - papel do professor). 


\section{Vamos criar um wiki? - a história inicial}

Tive contato com a língua inglesa pela primeira vez na quinta série (atual 6ํano). Minha professora era uma mulher séria, brava e autoritária. Eu tinha medo dela. Eu era uma menina de 11 anos comunicativa, esforçada, obediente e responsável. As aulas de inglês eram marcadas por exercícios repetitivos e chamadas orais.

Eu queria muito aprender inglês, mas sentia que era impossível, pois a maioria das minhas colegas de sala estudavam inglês em escolas de idiomas e viajavam para o exterior. Eu vibrava quando uma delas me dava uma letra de música em inglês, traduzida, que elas ganhavam dos cursos de inglês. Era um prazer poder conhecer as letras das músicas (lembro que naquela época, anos 80, não havia computador) que eu ouvia no rádio e na televisão.

Não quero ser a professora que tive no $6^{\circ}$ ano. Sinto a necessidade de criar, para meus alunos, espaços de aprendizagem de língua inglesa que possibilitem trocas de informações, diversidade cultural, reflexão sobre nossa constituição identitária, entre outros.

Sou professora de inglês de uma escola municipal de Uberlândia, no estado de Minas Gerais. No início do ano de 2011, eu estava pensando em criar algum espaço onde os alunos do $6^{\circ}$ e $7^{\circ}$ ano do ensino fundamental pudessem expor seus trabalhos para alunos de outras partes do mundo. As novas tecnologias da informação e da comunicação fazem parte da vida de grande parte dos alunos e no ano passado eu tinha trabalhado com blogs, por isso a ideia de criar um wiki, já que o blog era editado somente por mim e os alunos só podiam postar comentários e seguir os links.

Com a esperança de que os alunos editassem os textos em língua inglesa e tivessem mais iniciativa em produzir textos em língua inglesa, em vez de apenas postar comentários sobre os textos, fiz a proposta da criação de um wiki. Senti, inicialmente, que alguns dos meus alunos lançaram-me olhares desconfiados, outros entusiasmados, e eu fiquei ansiosa por trabalhar com essa ferramenta pela primeira vez, envolvendo tantos alunos (eram cinco turmas de $6^{\circ}$ ano e quatro turmas de $7^{\circ}$ ano, com 33 alunos cada turma, aproximadamente).

A partir dessa história, refleti sobre minha questão de pesquisa, que é a seguinte:

- Como alunos e professora do ensino fundamental II podem trabalhar com o Wiki nas aulas de inglês?

Para responder à minha pergunta de pesquisa, passo agora a recontar minhas experiências com os alunos participantes desta pesquisa, a partir de duas histórias 
principais, intituladas Quem sou eu? - Criando nosso perfil e O lugar onde moro Criando as vídeo narrativas. Essas histórias são de experiências que vivenciei com meus alunos durante as aulas de língua inglesa nas quais trabalhamos com sequências didáticas (CRISTÓVÃO; SZUNDY, 2008) baseadas nos gêneros perfil e vídeo narrativa. Durante $\mathrm{o}$ ano letivo anterior à construção do wiki, esses foram alguns dos gêneros estudados pelos alunos do $6^{\circ}$ e $7^{\circ}$ ano. Ao criar o wiki, propus aos alunos do ano de 2011 a leitura dos textos produzidos por seus colegas no ano anterior e a possibilidade de criar seu próprios textos para serem postados no wiki.

\section{Quem sou eu? - Criando nosso perfil}

O gênero perfil é o primeiro gênero com o qual os alunos do $6^{\circ}$ ano têm contato nas aulas de inglês ministradas por mim. Para grande parte desses alunos, no 6 o ano é a primeira vez que eles realizam atividades de aprendizagem de língua inglesa de forma sistemática. Por isso, acredito que o trabalho com o gênero perfil possa ser um caminho para despertar o interesse dos alunos pela língua inglesa, já que eles podem ler perfis em língua inglesa de alunos da mesma faixa etária, de diversas partes do mundo e muitos já estão familiarizados com perfis escritos na língua materna, graças à utilização das redes sociais.

A sequência didática com base no gênero perfil foi desenvolvida durante um bimestre, ou seja, aproximadamente vinte aulas de língua inglesa, de cinquenta minutos cada, que aconteceram duas vezes por semana, incluindo o período de avaliações. A figura 01 é um exemplo do gênero perfil, que foi analisado pelos alunos e discutido em sala de aula. 


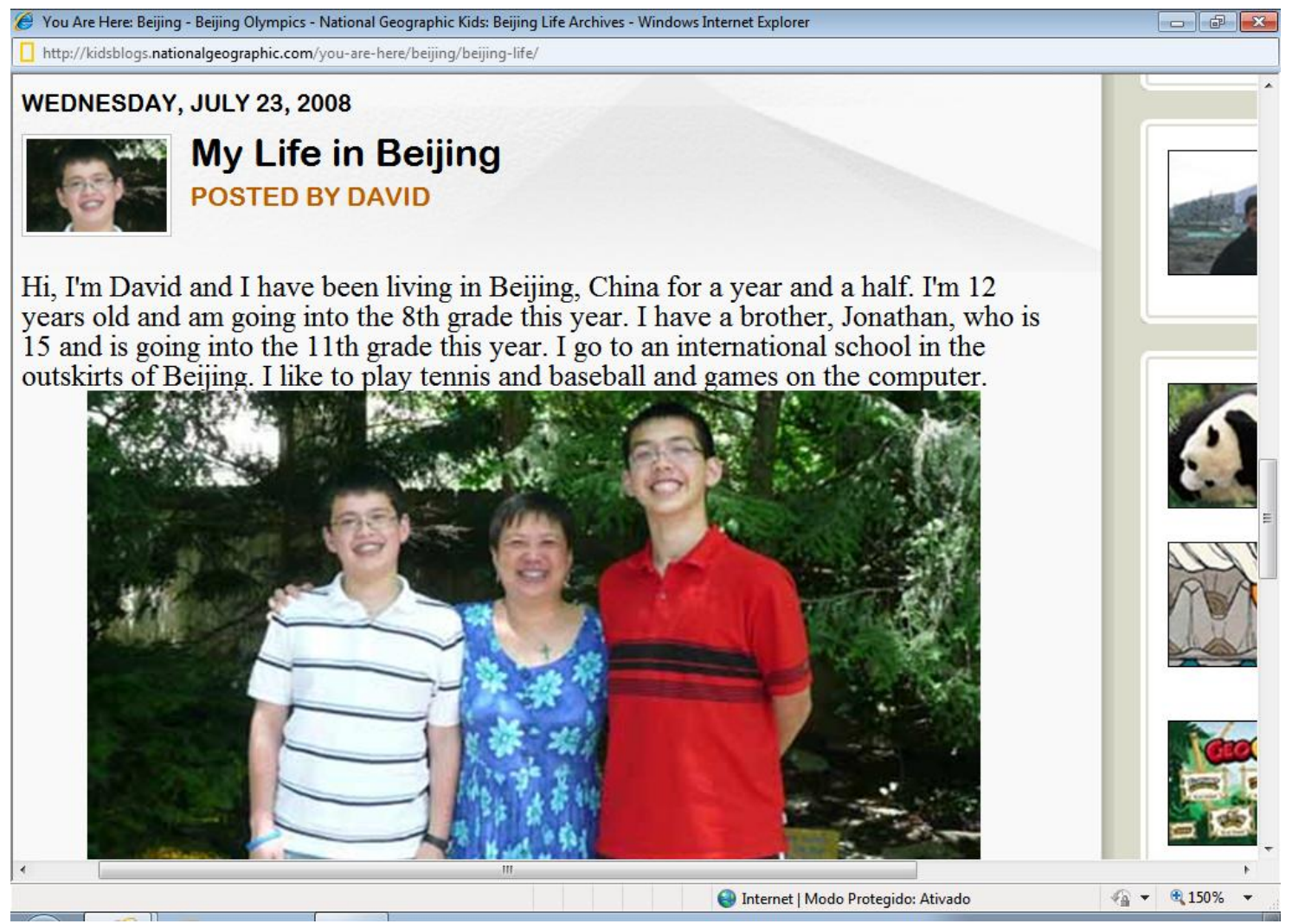

Figura 1. Gênero perfil

Uma das atividades desenvolvidas pelos alunos foi a que está representada no quadro 01. As questões foram digitadas e coladas no caderno, e os alunos destacaram os cognatos e responderam às questões sobre o gênero perfil. Além disso, discutimos, em sala de aula, sobre os moves (SWALES, 1990) do gênero. Os alunos concluíram que, de modo geral, o gênero perfil começa com a apresentação do nome da pessoa que posta seu perfil na internet, do lugar onde mora e onde nasceu, seguido de informações sobre a família, gostos pessoais e o lugar onde estuda ou trabalha.

\begin{tabular}{|c|c|}
\hline \multicolumn{2}{|c|}{ ATIVIDADE 6 ANO - GÊNERO PERFIL } \\
\hline 1. Utilizando uma caneta "destaca-texto" ou & e) Ouantos anos ele tem? \\
\hline um lápis colorido, destaque, no texto, 5 & f) Quem é Jonathan? \\
\hline cognatos. & g) Quantos anos Jonathan tem? \\
\hline & h) O que David gosta de fazer? \\
\hline 2. Responda, em português, conforme o & i) De onde este texto foi tirado? \\
\hline texto: & j) Dê outro título para o texto. \\
\hline a) Que tipo de texto é este? & k) Com base nas informações do texto, o \\
\hline
\end{tabular}


b) Em que dia, mês e ano este texto foi

que você gosta de fazer? escrito?

c) Quem é o narrador?

d) De onde ele é?

Quadro 1 - atividade sobre o gênero perfil

Depois de trabalhar com a leitura e a análise de vários exemplos do gênero perfil, os alunos do $6^{\circ}$ ano produziram seu próprio perfil, escrito, em língua inglesa, e tiveram a oportunidade de postar no wiki. Criei uma página intitulada Profiles e sugeri que os alunos postassem seus perfis, para que qualquer visitante do wiki pudesse conhecer um pouco da vida dos alunos uberlandenses, como onde nasceram, do que gostam, onde estudam, sua idade ou outras informações. A figura 2 representa a página dos perfis postados.

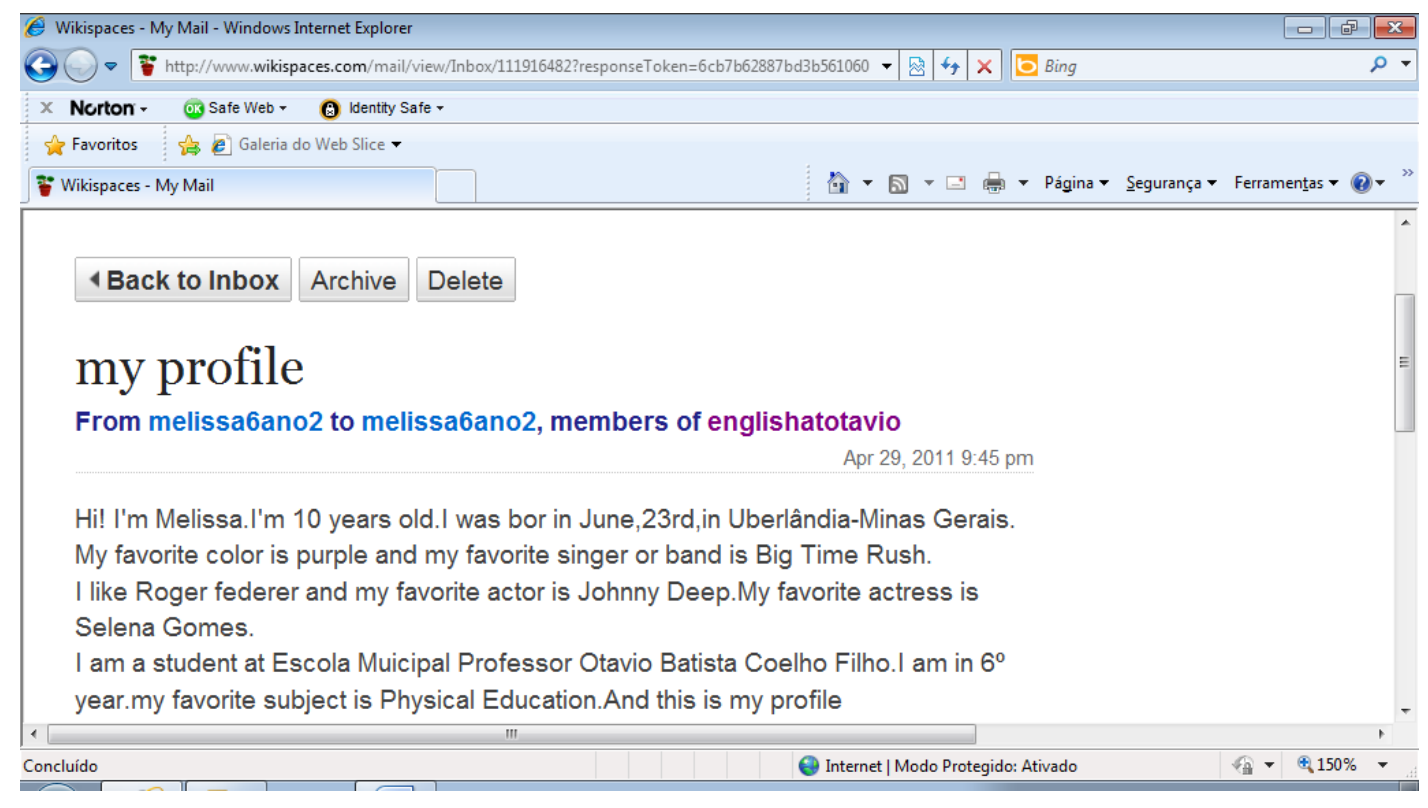

Quadro 2 - perfil de Melissa

A aluna Melissa postou seu perfil como mensagem, pois eu ainda não tinha criado uma página específica para os perfis. Depois de criada, enviei uma mensagem de volta para a aluna, sugerindo que ela postasse seu perfil novamente, mas na página Profiles, para que todos pudessem visualizar o texto produzido por ela.

Há muitas outras histórias envolvendo a experiência com o trabalho do gênero perfil, mas não é possível relatá-las aqui. Meu foco, nesse trabalho, é apresentar como foi o trabalho com o wiki de forma mais geral, sem me limitar a analisar mais profundamente a sequência didática baseada em um único gênero. Conto, a seguir, a história da sequência didática baseada no gênero vídeo narrativa. 


\section{O lugar onde moro - Criando as vídeo narrativas}

A sequência didática baseada no gênero vídeo narrativa foi desenvolvida com os alunos do $7^{\circ}$ ano, em catorze aulas de cinquenta minutos cada, que aconteciam duas vezes por semana, ao longo de um bimestre. Meus objetivos, ao propor esse trabalho, eram:

1. criar espaços de discussão sobre a diversidade cultural (família, lugar onde mora e cotidiano, origens);

2. estudar a organização textual dos gêneros vídeo narrativa, apresentação pessoal e relatos de experiências;

3. estudar a compreensão oral e os moves dos gêneros;

4. pensar sobre a percepção da cidade de Uberlândia;

5. estudar parte da estrutura gramatical presente nos gêneros trabalhados.

Trabalhando com esse gênero, os alunos tiveram a oportunidade de aprender os cumprimentos (hello, ladies and gentlemen.../ hi); a ordem das sentenças (SUJEITOVERBO-COMPLEMENTO); os pronomes possessivos e pessoais; as preposições (in/ from); algumas noções sobre tempos verbais (presente, passado, infinitivo) e a reconhecer os cognatos (morfologia).

Algumas vídeo narrativas foram postadas no wiki em formato de vídeo e poderão ser vistas pelos alunos do $6^{\circ}$ ano, como uma forma de valorizar a cultura e a produção dos alunos da escola pública da cidade de Uberlândia. Podem ser vistas, também, por alunos ou pessoas de qualquer parte do mundo, possibilitando um trabalho intercultural.

\section{Fazendo pesquisa narrativa - eu e meus 280 alunos...}

O caminho teórico-metodológico que escolhi para desenvolver este trabalho foi a pesquisa narrativa baseada nos pressupostos teóricos de Clandinin e Connelly (1995, 2000). A experiência é o foco deste paradigma de pesquisa. Segundo Dewey (1976), a experiência é pessoal e social. As pessoas vivem a experiência, sempre em interação, em um contexto social. Dewey imaginava a pesquisa como o estudo da experiência (CLANDININ; CONNELLY, 2000).

A pesquisa narrativa é permeada por quatro movimentos realizados pelo pesquisador narrativo. Esses movimentos criam o que Clandinin e Connelly (2000) chamam de espaço tridimensional da pesquisa narrativa, composto pela temporalidade, pela sociabilidade e pelo espaço. Isso significa que, durante todo o processo de pesquisa, 
o pesquisador precisa considerar os movimentos da temporalidade, que são o backward (retrospectivo) e o forward (prospectivo), e os movimentos da sociabilidade, que são o inward (introspectivo) e o outward (extrospectivo ), além do espaço.

Compreender os movimentos, do ponto de vista de um pesquisador narrativo e segundo Clandinin e Connelly (2000), é ter sempre a ideia de ambiguidade, complexidade, dilemas e incertezas presentes durante o processo de investigação. É nesse sentido que não são as afirmações nem as respostas que movem a investigação narrativa, mas os questionamentos. Quando um pesquisador narrativo interpreta seus textos de campo, isto é, quando compõe sentidos para seu material documentário, é o seu olhar que está sendo lançado sobre determinada questão. Não há verdades préestabelecidas, mas há sentidos compostos e histórias construídas e reconstruídas sobre algo que o inquieta e que ele se propôs a investigar.

Os trabalhos de Telles (1996, 1998, 2002, 2004) e de Mello (1999, 2004, 2007) são exemplos de estudos realizados conforme a pesquisa narrativa de Clandinin e Connelly (2000) e contribuem para que essa perspectiva teórico-metodológica seja difundida no Brasil.

Entre os trabalhos mais recentes, no campo da Linguística Aplicada, sob a perspectiva da pesquisa narrativa conforme Clandinin e Connelly (2000), está o trabalho de Almeida (2008), que teve como objetivo relatar e analisar uma experiência de ensino aprendizagem para alunos com deficiência visual nas aulas de leitura, a pesquisa com base em artes desenvolvida por Arantes (2009) e o trabalho realizado por Dias (2009), que relata experiências vivenciadas em um contexto de prática de tandem, via MSN Messenger, buscando analisar como essas experiências podem contribuir para a formação do professor de língua inglesa.

Em relação à análise, na pesquisa narrativa, chamamos o material documentário, ou o que são considerados "dados" em outros paradigmas de pesquisa, de textos de campo (CLANDININ; CONNELLY, 2000, p. 92), que são compostos a partir do olhar do pesquisador, diferentemente de "dados" que são "coletados". Os textos de campo não são coletados, mas sim compostos e criados, para que então seja possível uma composição de sentidos e a escrita dos textos de pesquisa (CLANDININ; CONNELLY, 2000). Composição, conforme Ely, Vinz, Downing e Anzul (2001), é um processo que envolve fazer escolhas, interpretar e dar forma aos textos de campo. Como a pesquisa narrativa é o estudo da experiência, os textos de campo, nesse caso, possuem o papel de ajudar o pesquisador a recobrar a experiência, as histórias vividas e a paisagem pesquisada. 
Meus textos de campo foram compostos a partir dos e-mails enviados a mim, pelos alunos, as atividades realizadas em sala e os textos produzidos por eles e postados no wiki. Os participantes dessa pesquisa foram alunos do $6^{\circ}$ e $7^{\circ}$ ano do Ensino Fundamental de uma escola municipal de Uberlândia, Minas Gerais. A idade deles varia entre dez e catorze anos.

A análise dos textos de campo foi feita por meio de uma composição de sentidos, com base nos estudos de Ely, Vinz, Anzul e Downing (2001). Para essas autoras,

ao invés de tentar encontrar ou ver sentido "nos dados", é mais produtivo compor os sentidos que os dados nos conduzem a compreender. Na vida, nós criamos nossa própria realidade em relação às pessoas ou situações; não é que a pessoa ou a situação é, de fato, a realidade (ELY, VINZ, DOWNING, ANZUL, 2001, p. 20).

Uma das partes do processo de composição de sentidos é fazer escolhas. As autoras chamam a atenção para o fato de que as posições filosóficas, ideológicas, políticas e morais do pesquisador influenciam a forma como ele analisa e apresenta seus dados. O que conta não é tanto o que vemos, mas como vemos os textos de campo (ELY, VINZ, DOWNING, ANZUL, 2001).

Passo agora a recontar as histórias vividas durante a construção do wiki, analisando as histórias iniciais e compondo sentidos.

\section{Aprender fazendo vs. pedagogização da internet}

Certa vez, pedi para que os alunos do $6^{\circ}$ ano escrevessem uma história sobre a experiência deles com as novas tecnologias e as aulas de língua inglesa. Em uma das histórias, uma aluna (que chamarei de Lara) contou que na sua antiga escola os alunos só iam para o computador jogar, mas que nessa atual escola as atividades no laboratório de informática eram muito bem organizadas e os professores utilizavam a internet para ensinar a matéria. A história de Lara me chamou a atenção porque toca em dois aspectos importantes em relação ao uso das novas tecnologias na educação: o aprender fazendo e a pedagogização da internet.

Quando planejo uma atividade para ser desenvolvida com meus alunos, preocupome em criar oportunidades de aprendizagem crítico reflexiva (BENGEZEN, 2010; IFA, 2006; ROJO, CORDEIRO, 2004; CELANI, 2003) de língua inglesa. Ao utilizar a internet nas aulas de inglês, faço uma reflexão sobre a apropriação de ferramentas que não foram criadas para a escola e para o ensino, justamente para o ambiente escolar. Pergunto-me 
quais seriam os riscos trazidos por essa pedagogização da internet. Gomes (2010) considera a utilização das redes sociais um movimento anárquico e contra cultural, pois não obedece aos "imperativos da escola, como centralização do poder e hierarquia".

Seguindo essa mesma perspectiva, Freire (2009) aponta para as diferenças entre a escola e a sociedade. Segundo a autora, elas caminham em direções opostas e não falam a mesma língua, estando a escola, estática e previsível, de um lado, e a sociedade, dinâmica e imprevisível, do outro. Concordo com os autores e considero necessário rever o processo de educação que temos conduzido nas escolas. A meu ver, seria produtivo levar a sala de aula para os ambientes extraescolares, ao invés de levar a internet para a sala de aula.

O que quero dizer com isso é que não faz sentido utilizar o wiki, por exemplo, para fazer um aluno copiar determinado texto e passar as frases para a negativa ou para a interrogativa. Trabalhar com o wiki é mais do que isso - é uma chance de incluir os alunos na sociedade digital e proporcionar a eles uma aprendizagem de leitura e produção de gêneros digitais.

\section{Trabalho em duplas (interações - papel do professor)}

No laboratório de informática da escola, há um computador para cada dupla de alunos. Geralmente, costumo deixar que os alunos escolham, sem a minha intervenção, com quem desejam trabalhar. Entretanto, essa permissão me faz viver um dilema, por várias questões.

Um dos pontos que me levam a refletir sobre a formação das duplas é quanto aos alunos que "sobram" e ninguém quer trabalhar com eles, que ficam excluídos e parecem ficar constrangidos por serem deixados por último a tomar seus lugares. Às vezes eu tento contornar a situação impondo onde cada um vai se sentar.

Outra questão é em relação ao par mais experiente, numa visão sociointeracionista da aprendizagem (VYGOTSKY, 1986). Nas vezes em que coloquei um aluno com mais facilidade (tanto com a língua inglesa como com a internet) junto com um aluno que tem dificuldades de aprendizagem, na esperança de ver o par mais experiente ajudando o outro a aprender, o resultado não foi satisfatório. Geralmente, o aluno com facilidade trabalha sozinho enquanto o outro é deixado sem fazer atividade alguma, e muitas vezes causando tumulto na sala pois, desmotivado, conversa com outros colegas.

Em busca de resolver essa situação, tenho colocado os alunos com mais facilidade juntos, e quando eles terminam a atividade, peço que circulem pelo laboratório para 
monitorar as outras duplas. Isso tem ajudado os alunos que demoram um pouco mais para realizar certas tarefas.

\section{Considerações finais}

No início desse artigo, coloquei minha questão de pesquisa, que retomo agora:

- Como alunos e professora do ensino fundamental II podem trabalhar com o Wiki nas aulas de inglês?

Para responder a essa questão, contei histórias relacionadas às atividades desenvolvidas com meus alunos, cujos temas eram constituição identitária, pedagogização da internet, papel do professor e interação. Ao reler essas histórias, percebo que, ao trabalhar com o wiki, os alunos do $6^{\circ}$ e $7^{\circ}$ ano tiveram oportunidades de ler e produzir gêneros digitais.

Em relação à aprendizagem da língua inglesa, por meio da história das vídeo narrativas, eu destaco qual o conhecimento sistêmico trabalhado durante a realização da sequência didática. Ao ler os textos do wiki e produzir novos textos e postar informações no wiki, os alunos tiveram espaços nos quais podiam utilizar a língua inglesa e aprender de forma colaborativa, já que qualquer aluno tinha permissão e era incentivado a editar ou criar textos em inglês.

Um dos maiores problemas que encontrei durante esse trabalho foi o tempo. A escola teve problemas com a internet e minhas aulas no laboratório foram canceladas. Para conseguir marcar novas datas, foi preciso esperar mais de um mês. Como o bimestre estava no fim, os pais e responsáveis começaram a se preocupar e a procurar a supervisão em busca de um posicionamento. A solução que encontrei foi propor outro trabalho valendo a nota que seria atribuída ao wiki e deixar a utilização do wiki livre, ou seja, somente os alunos que quisessem utilizariam o wiki.

Termino esse artigo com palavras de incentivo e esperança para os professores, educadores, pais ou qualquer pessoa interessada no processo de ensino e aprendizagem. Na sala de aula, hoje, os alunos me perguntam se este ou aquele texto "vai para o wiki", e eu sinto que essa ferramenta está, aos poucos, motivando-os a aprender inglês. Alguns chegam a perceber a relevância de ter seus textos publicados na internet e a dimensão de transitarem de um ambiente passivo para uma oportunidade de utilização da web 2.0, produzindo textos, som e imagem. 


\section{Referências}

ALMEIDA, J. A leitura do mundo por meio dos sentidos: histórias de ensino, aprendizagem e deficiência visual. 2008. 201 f. Dissertação (Mestrado em Estudos Linguísticos)-Instituto de Letras e Linguística, Universidade Federal de Uberlândia, Uberlândia, 2008.

BENGEZEN, V. C. Histórias de aprendizagem de língua inglesa e de formação de professores. 2010. $173 \mathrm{f}$. Dissertação (Mestrado em Estudos Linguísticos)-Instituto de Letras e Linguística, Universidade Federal de Uberlândia, Uberlândia, 2010.

CELANI, M. A. A. (Org.). Professores e formadores em mudança: relato de um processo de reflexão e transformação da prática docente. São Paulo: Mercado de Letras, 2003. 223 p. CLANDININ, D.J.; CONNELLY, F.M. Narrative Inquiry: Experience and Story in Qualitative Research. San Francisco: Jossey Bass, 2000, 211 p.

CRISTÓVÃO, V. L. L.; SZUNDY, P. T. C. Projetos de formação pré-serviço do professor de língua inglesa: sequências didáticas como instrumento no ensino-aprendizagem. Revista Brasileira de Linguística Aplicada, Belo Horizonte, v. 8, n. 1, p. 115-137, jan./jul. 2008.

DEWEY, J. Experiência e educação. São Paulo: Nacional, 1976, 101 p.

ELY, M.; VINZ, R.; ANZUL, M.; DOWNING, M. On writing qualitative research: living by words. London and Philadelphia: Routledge Falmer, 2001, $411 \mathrm{p}$.

GOMES, L. F. Redes sociais e contracultura: a escola fora da escola. Anais eletrônicos. Universidade Federal de Pernambuco - Núcleo de Estudos de Hipertexto e Tecnologias na Educação. 2010. Disponível em: <http://www.ufpe.br/nehte/simposio/anais/AnaisHipertexto-2010/Mesa-Redonda\%20_Luiz\%20-Fernando-Gomes.pdf> Acesso em 21 mar 2011.

IFA, S. A Formação Pré-Serviço de Professores de Língua Inglesa em uma Sociedade em Processo de Digitalização. 2006. 274 f. Tese (Doutorado em Linguística)-LAEL, Pontifícia Universidade Católica de São Paulo, São Paulo, 2006.

MELLO, D. Histórias de subversão do currículo, conflitos e resistências: buscando espaço para a formação do professor na aula de língua inglesa do curso de Letras. 2004. $225 \mathrm{f}$. Tese (Doutorado em Linguística)-LAEL, Pontifícia Universidade Católica de São Paulo, São Paulo, 2004.

ROJO, R.; CORDEIRO, G. S. Apresentação: gêneros orais e escritos como objetos de ensino: modo de pensar, modo de fazer. In: SCHNEUWLY, B.; DOLZ, J. Gêneros orais e escritos na escola. Tradução e organização de Roxane Rojo e Glaís Sales Cordeiro.

Campinas, SP: Mercado de Letras, 2004. p. 7-18.

SWALES, J. M. Genre analysis: English in academic and research settings. Cambridge: Cambridge University Press, 1990. $260 \mathrm{p}$.

TELLES, J. A. É pesquisa, é? Ah, não quero, não, bem! Sobre pesquisa acadêmica e sua relação com a prática do professor de línguas. Linguagem \& Ensino (UCPel), Pelotas, RS, v. 5, n. 2, p. 91-116, jul./dez. 2002.

VYGOTSKY, L. Pensamento e linguagem. Tradução: Jeferson Luiz Camargo. 3. ed. São Paulo: Martins Fontes, 1986. 135 p. 


\title{
AS RELAÇÕES ENTRE TECNOLOGIAS E PRÁTICAS PEDAGÓGICAS: NECESSIDADE DE ENFRENTAMENTO DO SUJEITO PROFESSOR
}

\section{RELATIONS BETWEEN TECHNOLOGY AND PEDAGOGICAL PRACTICES: THE NEED TO CONFRONTATION THE SUBJECT TEACHER}

\author{
Walleska Bernardino Silva (UFU/Eseba) ${ }^{65}$
}

walleskabs@yahoo.com.br

\begin{abstract}
RESUMO: O objetivo desse trabalho é problematizar os discursos que circulam sobre as TICs e sua relação com o ensino a partir do escopo teórico da Análise do Discurso. Para tanto, partimos de depoimentos de professores que participaram de um curso sobre o uso de novas tecnologias oferecido pelo MEC/SEED. Evidenciamos que os discursos apresentam caráter positivista com relação às tecnologias e as práticas pedagógicas relação sustentada pelos professores como sinônimo de sucesso. Todavia apontamos que a sedução, a inovação ou a efetivação de práticas pedagógicas via TICs se dá pelo enfrentamento do sujeito e seus processos de (des)identificação que possibilitam o novo e não, simplesmente, o efeito de novidade.
\end{abstract}

PALAVRAS-CHAVE: Tecnologias; Ensino; Sujeito; Discurso.

ABSTRACT: The aim of this paper is to question the discourses that circulate about the relationship between TICs and education from the theoretical scope of Discourse Analysis. The starting point was the testimony of teachers who attended a course on the use of new technologies offered by MEC/SEED. These discourses show a positive character with respect to technology and pedagogical practices - the relationship sustained by teachers as synonymous with success. However, we point out that seduction, innovation or accomplishment of pedagogical practices through TICs may be brought by the confrontation of the subject and its processes of (dis)identification that enable the novelty and not simply the effect of innovation.

KEYWORDS: Technology; Teaching; Subject; Discourse.

\section{Introdução}

Novas maneiras de lidar com o tempo-espaço redimensionam as interações, especialmente as realizadas no processo de ensino-aprendizagem. Eis uma nova sociedade configurada pelo desafio da Era do Conhecimento Tecnológico mediada pelas Tecnologias da Informação e Comunicação (doravante TICs).

Diante dessa demanda e tendo em vista nosso interesse acerca dos estudos que envolvem as TICs e o ensino, propomos neste trabalho uma reflexão sobre os discursos

65 Doutoranda pelo Curso de Pós-Graduação em Estudos Linguísticos da Universidade Federal de Uberlândia e professora da Escola de Educação Básica da UFU. 
que contemplam o uso das tecnologias e o ensino, tendo em vista que "o discurso é o lugar em que se pode observar a relação entre língua e ideologia" (ORLANDI, 2009, p. 17). Isso será feito por um viés discursivo e terá como mote para a discussão relatos de experiência de um grupo de professores que participaram do curso "Tecnologias na Educação: ensinando e aprendendo com as TICs", oferecido pelo MEC/SEED, no ano de 2010, e disponíveis publicamente no blog de uma professora ministrante do curso.

Buscaremos mostrar a emergência de discursos em que predomina a recorrência do caráter de novidade e o tom otimista atribuído às práticas pedagógicas que utilizam as TICs para polemizar: até que ponto são realmente novas as práticas que se utilizam da TICs? Basta a utilização de TICs para que as práticas pedagógicas sejam consideradas eficazes? Qual o lugar das TICs? O que fazer com elas? As TICs configuram-se, então, como uma estratégia de poder? O que emerge dos discursos sobre as TICs? Qual o imaginário desses professores depoentes? Qual o lugar social que ocupam?

Esses questionamentos provocaram as discussões ainda iniciais que por ora apresentamos embasadas pelo escopo teórico da Análise do Discurso. O nosso propósito não será responder delimitadamente a cada uma das inquietações acima, mas tratá-las de modo geral.

Iniciaremos nossa exposição apresentando um breve panorama da condição pósmoderna e sua relação com a educação para traçar alguns contrapontos entre TICs e ensino. Depois trataremos do caráter ufano atribuído ao uso das tecnologias para engendrar uma possibilidade de "desconstrução" desse tipo de discurso. Por fim, discutiremos sobre o binômio novo/novidade para polemizar as relações entre as TICs e as práticas pedagógicas nos depoimentos analisados, apresentando o poder unilateral das tecnologias no mundo pós-moderno, especialmente no ensino.

\section{Pós-modernidade e implicações na e para a educação}

O Pós-modernismo ${ }^{66}$ surge de uma postura contrária ao Modernismo. Instaura-se a partir do declínio de um sujeito unificado, portador de uma estrutura e tradição social estáveis. Há uma descentralização do sujeito e, por conseguinte, de identidades. Não há mais um sujeito racional com identidade fixa e estável, mas um sujeito subjetivo, uma "figura discursiva", que se caracteriza por rupturas, fragmentações, deslocamentos,

\footnotetext{
${ }^{66}$ Não é consensual a definição e a eleição de termos para tratar do momento pós-moderno devido à sua complexidade e possibilidades de inserção em vários campos de saber. Assim, neste trabalho, entendemos as noções pós-moderno, pós-modernismo como se tratando do movimento de descentramento do sujeito, como rompimento com a modernidade.
} 
descontinuidades e cuja identidade é, conforme Hall (1987 apud HALL, 2006, p. 13), "'celebração móvel': formada e transformada continuamente em relação às formas pelas quais somos representados ou interpelados nos sistemas culturais que nos rodeiam".

Para falar do descentramento do sujeito na modernidade tardia em oposição ao sujeito cartesiano - fundado por Descartes -, e ao sujeito sociológico - emergido das correntes interacionistas -, Hall (2006) nos apresenta cinco grandes motivações, a saber: i) as tradições do pensamento marxista que deslocava o homem como autor de sua história para privilegiar as condições históricas; ii) a descoberta do inconsciente por Freud e as releituras freudianas psicanalíticas feitas por Lacan; iii) a formalização de Saussure quanto ao caráter social e não individual da língua; iv) a produção da "genealogia do sujeito moderno", destacando o poder disciplinar por Foucault, e v) o impacto do movimento feminista.

Desses descentramentos, um nos interessa mais: as tradições do pensamento marxista. Esse descentramento e suas reinterpretações, especialmente as feitas por Pêcheux e seus estudiosos, admitem o pensamento de que os efeitos de sentidos se criam a partir de condições de produção específicas, portanto, os aspectos históricos, sociais e ideológicos são decisivos para o desvelamento da posição ideológica da enunciação. O homem será considerado na sua história. Essa ideia coloca em xeque a noção de sujeito racional, conhecedor e intencional, dono do seu dizer, e nos interessa porque a discussão em torno da polêmica que pretendemos fazer ecoar recai justamente na necessidade de problematizar os discursos de sujeitos que ocupam um lugar social professor - e que começam a absorver como verdade a ideologia "da moda"; no caso a ideologia de que usar as TICs no ensino significa ter sucesso na aprendizagem. Uma vez absorvida essa ideologia, seus desdobramentos terão consequências um tanto desastrosas para um ensino que almeja a possibilidade de "fazer a diferença".

Com isso, o que propomos é uma reflexão para (re)dimensionar o lugar das tecnologias nas práticas pedagógicas e, para tanto, é imprescindível que haja enfrentamento do sujeito a fim de que ele seja interpelado por discursos outros que o façam deslocar da condição, por vezes submissa, que se porta com relação às TICs.

Mas qual a relação, então, da pós-modernidade que dissemina a noção de descentramento do sujeito com a educação? E o que nos interessa disso para as reflexões que faremos?

Conforme Usher e Edwards (1996), a educação é fruto de um pensamento moderno, pensamento este que circunda em torno do individualismo, da razão, da rigidez das relações. Como o movimento pós-moderno valoriza, ao contrário do individualismo, o 
subjetivismo, o descentramento do sujeito - especialmente um sujeito que não é "transparente", mas que muito não sabe de si - cabe então (re)discutir os conflitos e mudanças pelas quais a educação passa sob prisma pós-moderno, sob condições singulares em que impera a necessidade de um sujeito que leve em consideração as condições histórico-sociais em que se encontra para (re)criar sua prática pedagógica. A justificativa para que essa discussão ocorra, em conformidade com os autores supracitados, revela-se pela nossa crença de que a "A educação é talvez a mais importante forma como nos relacionamos com o mundo, a forma como vivemos, entendemos e tentamos mudar o mundo e as maneiras pelas quais entendemos a nós mesmos e nossas relações com os outros" (USHER; EDWARDS,1996, p. 4) ${ }^{67}$.

E é justamente sob esse prisma pós-moderno, em conformidade com a ideia de que a educação hoje apresenta mudanças advindas de um outro momento social, de uma nova época, especialmente de uma conjuntura sócio-histórica em que as mudanças produzidas pelas TICs em nível mundial/global aceleram e modificam as maneiras de relacionarmos com o mundo e conosco mesmos, é que nos propomos analisar os discursos de professores que se veem diante da necessidade de adequar-se à pósmodernidade e ao uso das TICs em suas práticas pedagógicas para problematizar o lugar das tecnologias na educação.

Para o entendimento dessa condição pós-moderna na educação, o essencial é compreender que não somente a maneira de aquisição do conhecimento, mas a forma e a concepção mudaram. Se antes o professor era aquele que detinha o saber - por consequência, o poder, e cuja principal função era a de transmissor desse conhecimento $^{68}$, hoje não é mais. A grande responsável pela guinada das relações pedagógicas são as TICs, em especial, a internet. E é por isso que as TICs são tidas como elemento base de um novo discurso pedagógico que precisa ser (re)visitado. Um discurso marcado pela crença de que as tecnologias e, às vezes, somente elas, resolvem todos os problemas, ou que somente levar a tecnologia para a sala, no sentido tecnicista do termo, bastasse para o aprendizado. Enfim, um discurso de uma época marcada pelo poder legitimado da expressão "sociedade da informação". Nisso, conforme Barreto (2004, p. 1184), o que está em jogo é o "paradigma tecnoinformacional que, articulado à

\footnotetext{
${ }^{67}$ Nossa tradução do original: "Education is perhaps the most important way we relate to the world, to the way we experience, understand and attempt to change the world and to the ways we in which we understand ourselves and our relations with others"

${ }^{68}$ Uma ressalva: se o professor era a única fonte de dizer, o conhecimento aos alunos chegava apenas por uma via. Outros dizeres eram transformados no dizer do professor, o que, por via de regra, traz implicações inúmeras à constituição do sujeito aluno e sua formação.
} 
globalização, permite a referência à sociedade planetária, a partir da suposição ${ }^{69}$ da ausência de um centro identificável, de fronteiras e, ainda, de líderes".

À guisa de confirmação acerca da ideia da pós-modernidade como difusora de discursos que colocam as TICs como detentoras de um papel privilegiado no ensino, Coracini destaca:

o discurso da pós-modernidade estaria ancorado, de um lado, na concepção de sujeito fragmentado, inefável, múltiplo, disperso, atravessado pelo inconsciente, e, de outro, comprometido com a globalização, que, por sua vez, se insere numa situação política capitalista, contribuindo fortemente para a proliferação de verdades com base em interesses - econômicos e mercantilistas - que fazem ver as novas tecnologias, resultantes das pesquisas científicas e por elas legitimadas, como a única alternativa para a construção de uma sociedade eficiente, "para além" da modernidade [grifo nosso] (CORACINI, 2006, p. 9).

Na contramão desse interesse mercantilista, é preciso compreender que o papel da escola vai além meramente do uso de uma tecnologia, além de um paradigma tecnoinformacional, é preciso politizar o aluno, apresentar-lhe condições éticas mínimas para tomar decisões frente às escolhas que deve operar não somente no contexto educacional e tecnológico, mas na vida. Qual a conduta que se espera, por exemplo, de um professor ao trabalhar com a World Wide Web? Espera-se que ele apenas ensine os alunos a navegar pelos sites e a dominar as funções das ferramentas disponíveis? Muito mais do que isso deve ser considerado na relação das práticas pedagógicas e o uso das TICs. Como trabalhar a conduta ética com e (d)esse aluno para que muito mais do que navegar, ele aprenda a interagir de forma produtiva conforme suas necessidades e/ou identificações? Eis o que se coloca, TICs e ensino: por quê? Para quê? Como?

Entendendo, então, essa época pós-moderna na educação como um período em que conflitos são gerados devido às várias maneiras de subjetivar o mundo, em que não existe um único centro, ou pelo menos se supõe isso ${ }^{70}$, uma única ordem ou uma única forma de aquisição do conhecimento, um tempo que dilui a homogeneização e opta pela pluralidade e pela multiculturalidade, resolvemos trazer inquietações pertinentes à forma como os professores têm tratado as TICs nas e para as práticas pedagógicas.

\footnotetext{
${ }^{69} \mathrm{O}$ destaque da palavra suposição é nosso. Será mesmo que não existe um centro identificável? Não existem fronteiras? Não existem líderes? As pessoas tendem, na Era Tecnológica, a pensar o mundo de uma forma mais libertária... mas será mesmo? O que de liberdade nos é dado? Como essa liberdade é oferecida? Até que ponto temos, de fato, liberdade? Esses questionamentos merecem discussão que, por ora, não nos cabe empreender aqui.

${ }^{70}$ Ver nota 4.
} 


\section{0 corpus}

O Programa Nacional de Formação Continuada em Tecnologia Educacional (PROINFO) é oferecido pelo MEC/SEED e tem como um de seus objetivos "promover o uso pedagógico das tecnologias da informação e da comunicação nas redes públicas da educação básica." ${ }^{\prime 11}$. Assim, são oferecidos cursos aos professores da rede pública para capacitá-los à utilização das TICs em propostas pedagógicas.

Os quatro depoimentos recolhidos nesse trabalho são de professores que realizaram o curso oferecido pelo MEC/SEED e tais relatos foram disponibilizados publicamente no blog $^{72}$ de uma professora ministrante do curso. Essa professora coloca que o blog "tem por finalidade apresentar e divulgar as experiências vivenciadas por grupos de professores que procuram ampliar seus conhecimentos em busca de uma nova postura ${ }^{73}$ (grifo nosso) frente às tecnologias".

Os professores depoentes e seus respectivos relatos, transcritos ipsis litteris, em anexo ao trabalho, serão identificados por letras. Para a discussão que por ora empreenderemos, escolhemos trabalhar a partir da materialidade linguística, por meio de marcas que denunciam ou deflagram efeitos de sentidos que competem à nossa empreitada.

\section{Do caráter ufano dos discursos envolvendo as TICs e as práticas pedagógicas}

Nossas considerações quanto aos discursos recolhidos se colocam na tentativa de "desconstruir", no sentido derridiano do termo, o tom ufano com que as TICs são tratadas nas práticas educacionais. Desconstruir porque não é destruição ${ }^{74}$, mas um desvendamento de sentidos outros que se mostram camuflados no fio discursivo, porque as palavras não comunicam necessariamente o que prometem e, não comunicando o que prometem, provocam um devir. Conforme afirma o próprio Derrida (apud SKLIAR, 2008, p. 18), "Indiscutivelmente, a desconstrução é um gesto de afirmação, um sim originário que não é crédulo, dogmático ou de consentimento cego, otimista, confiado, positivo".

71 Objetivo retirado do Decreto $\mathrm{n}^{\circ} 6.300$, de 12 de dezembro de 2007. Disponível em: <http://www.planalto.gov.br/ccivil 03/ Ato2007-2010/2007/Decreto/D6300.htm>. Acesso em 20 dez. 2010.

72 Endereço do blog: <http://janeteczs.blogspot.com/2010/11/depoiementos-dos-concludentes-do-curso.html>. Acesso em 20 dez. 2010.

${ }^{73}$ Para problematizar: até que ponto essa "nova postura", colocada pela professora do curso, foi de fato nova, ou seja, até que ponto os professores após o curso conseguiram deslocar-se, gerar novos discursos frente ao uso das TCls em sala? Ou ainda: até que ponto o curso foi capaz de possibilitar nova inscrição ideológica desses professores com relação ao uso da TCls?

${ }^{74}$ Não é destruição porque sempre se coloca alguma coisa no lugar; sempre há uma outra tomada de posição, uma outra inscrição ideológica. 
A ufania, termo pelo qual resolvemos nomear os discursos otimistas dos professores com relação ao uso das TICs em sala, estabelece-se justamente na condição de não enfrentamento do professor em relação ao que está posto. Esse não enfrentamento inicia-se nos cursos de formação de licenciados que, em sua maioria, não contemplam um currículo para tratar das especificidades político-pedagógicas relativas às TICs. Se os professores formadores não tratam disso, se não se tem uma discussão em torno de ações pedagógicas voltadas essencialmente para o uso das tecnologias em sala numa dimensão complexa, não há como evitar lacunas incrustadas no exercício da prática docente. Falamos em uma dimensão complexa porque não basta ensinar aos alunos licenciandos o uso tecnicista ou instrumental dos recursos tecnológicos, por exemplo: como criar um blog para postar textos ou ainda como utilizar provedores para trabalhar o gênero e-mail. É preciso trabalhar com esses alunos questões de outras naturezas, como a postura ética que compete os usos virtuais, a questão da autoria, os processos que envolvem a identificação ou não com as TICs, as posições ideológicas assumidas nos dizeres e arranjos virtuais, dentre outras possibilidades.

E justamente dessa formação lacunar ${ }^{75}$ é que os professores hoje desconhecem o potencial $^{76}$ dos recursos das TICs na educação. Potencial que pode deflagrar positiva ou negativamente práticas pedagógicas. E desconhecendo sua potencialidade, discursos que valorizam simplesmente o uso de tecnologias em sala de aula, sem mesmo saber suas consequências, são cada vez mais disseminados entre os professores. Nesse sentido, nos discursos analisados há um tom ufanista quando os professores se postam na perspectiva de uso das TICs como garantia de sucesso em sala de aula. Garantia que advém apenas da utilização das tecnologias, sem um uso problematizado delas, sem uma perspectiva derridiana da desconstrução: quais as consequências das TICs para o ensino, para a sociedade? Em outras palavras, o que advém ou o que advém como impossível do uso das TICs? Quais as inscrições ideológicas produzidas?

Seguem alguns trechos para reflexão:

(A)

(...) tive a oportunidade de aprender a lidar com as pesquisas e inovar as aulas utilizando os meios tecnológicos, como também desenvolver aulas atraentes com a utilização de áudios,vídeos e animações, na qual os alunos respondiam atentamente

\footnotetext{
${ }^{75}$ Em conformidade com essa ideia, Stahl (1997) também questiona: "O professor está sendo efetivamente preparado para usar as novas tecnologias? Novas e diferentes tarefas docentes não exigirão algo mais em sua formação? Está sendo desenvolvida uma consciência do impacto das novas tecnologias na sociedade?

${ }^{76}$ Potencial no sentido de prover condições para uma identificação ou não dos usos dos recursos tecnológicos numa sociedade pós-moderna.
} 
ao meio utilizado (computador), e assim ficavam motivados a executar suas tarefas (...) todo profissional precisa incrementar na sua prática, pois essa ferramenta precisa estar a nosso dispor no processo de ensino - aprendizagem, pois nos trás resultados surpreendentes e eficazes.

(B)

Além do mais, podemos perceber a necessidade que há de trabalhar com as mesmas [tecnologias] juntamente com os alunos, pois facilita a assimilação dos conteúdos através de diversas fontes de pesquisas e buscas de novas informações (...) Quero ainda agradecer o autor dessa ferramenta tão importante no âmbito educacional para que a educação possa cada vez mais evoluir.

(D)

(...) a própria escola deve reconhecer que é necessária a adesão de novas práticas metodológicas em sala de aula, para que haja assim, evolução (...)verdadeiro aprendizado.

Se não se tem preparo para lidar com a tecnologia numa perspectiva problematizadora em sala de aula, não se tem conhecimento para implementar ou relativizar esse uso. E, obviamente, o que "sobra" nos discursos é uma supervalorização da tecnologia (vejamos, por exemplo, o uso da palavra "evoluir" no depoimento B e "evolução" no depoimento D) em detrimento ao que a escola tem de oferecer essencialmente: o conhecimento. É por isso que hoje a predominância tende à difusão de dados e informações e não a conhecimentos; tende predominar o "saber instrumental" ao "saber desconstruir derridianamente"; daí a nossa insistência na afirmação de que as TICs estão postas e não retrocederão, mas os professores ainda não sabem o que fazer com elas.

Vejamos abaixo, em destaque, como se configura o "domínio das tecnologias" para o depoente $\mathrm{C}$. Esse trecho confirma a nossa premissa de que falta conhecimento para saber o que e como fazer com as TICs, isto é, temos o ensino tecnicista e instrumental sobrepujando o ensino que resolvemos chamar de problematizador: 
(C)

Precisei superar aquela fase de ansiedade para dominar o uso das tecnologias (...)sinto-me capaz de pesquisar nos sites educativos, planejar atividades e proporcionar aos educandos a utilização de práticas inovadoras [grifo nosso] (...).

Ainda, o discurso das TICs evidenciado como o discurso contemporâneo educacional do que dá certo, da garantia de sucesso em sala deixa emergir a ideia de que ensinar na contemporaneidade é possível apenas por meio das TICs, ou, ainda, que se se propõe o ensino atualmente, é preciso que o concilie com as tecnologias. É o que pode ser percebido no depoimento a seguir:

(A)

pois essa ferramenta [computador] precisa estar a nosso dispor no processo de ensino - aprendizagem, pois nos trás resultados surpreendentes e eficazes [grifo nosso].

Esses dizeres produzem efeitos no processo enunciativo que marcam fronteiras claras entre o antes e depois das TICs, especialmente pelo uso da expressão "resultados surpreendentes e eficazes". É como se todo o ensino anterior à introdução das tecnologias tivesse apresentado resultado, entretanto, um resultado pouco surpreendente, não eficaz. É o resultado da anterioridade atravessando o acontecimento discursivo, como em (D):

(D)

E é através desse processo de troca de informações, e construção de conhecimento que se dá o verdadeiro aprendizado [grifo nosso].

Mais uma ocorrência em que o discurso aponta para dizeres outros que otimizam em tom imponderado o ensino "eficaz" e "produtivo" atrelado ao uso das TICs. Nessa sequência discursiva, a palavra "verdadeiro" é forte o suficiente para réplicas sobre o ensino anterior ao "processo de troca de informações e construção do conhecimento". 0 ensino antes das TICs e seus desdobramentos consistia em pseudo-aprendizado? O que se aprende a partir do uso das TICs é mais verdadeiro do que se aprendia antes delas? Qual o parâmetro para classificar aprendizado como verdadeiro ou não? 
Claro que em nenhum momento nossa pretensão é confirmar esses questionamentos, mas o fazemos para problematizar a forma como as tecnologias em sala têm sido encaradas pelos professores e revelada em seus discursos. Problematizar, pensando derridianamente, é, como já pudemos perceber, a chave de leitura dessa proposta.

Assim, no imaginário dos professores depoentes a prática pedagógica atual sem considerar as tecnologias está fadada ao insucesso, porque conforme $(A)$, a prática docente precisa inovar, ou, como coloca (B), é preciso dinamizar as aulas, ou, de acordo com o que diz $(\mathrm{C})$, é necessário proporcionar aos alunos práticas inovadoras, ou, segundo (D), a prática deve ser revista.

É por isso que precisamos problematizar e buscar meios de enfrentar as TICs para que discursemos sim de tecnologias na educação, mas circunstanciando um lugar para elas, argumentando sobre a importância que têm numa sociedade pós-moderna, num momento globalizado e multicultural, e, ao mesmo tempo, impondo seus limites, uma vez que falar da importância das TICs na e para a educação é falar de seus limites. Já nos inspirava Derrida quanto à posição da desconstrução como um gesto que se afasta do conhecimento para conhecê-lo. É como "Um impulso que comina para outra interpretação da experiência, para outra experiência da alteridade que aquela que se rege por um pensar entronizado, governado pelo entendimento" (GABILONDO, 2001 apud SKLIAR, 2008, p. 22).

Como pôde ser observado pelos depoimentos, o uso das TICs é revestido por um caráter de verdade única quando se observa o discurso ufano com relação às tecnologias e as práticas pedagógicas: sinônimo de sucesso. E essa premissa choca-se com a condição pós-moderna no sentido de que no momento pós-moderno não se tem a verdade, mas uma multiplicidade de verdades, porque como já dizia Derrida (apud USCHER; EDWARDS, 1996, p. 120), "É impossível chegar a uma verdade porque há sempre uma interpretação" 77 . Ademais, conforme a linha teórica discursiva que perseguimos neste trabalho, não é possível chegar à verdade completa, porque a língua é sujeita a equívocos, a linguagem não é transparente; "a condição da linguagem é a incompletude" (ORLANDI, 2009, p. 52).

Assim é preciso cautela com os discursos que propagam as TICs como a solução dos problemas, a verdade, ou como sinônimo de práticas sedutoras, inovadoras e efetivas. Temos apontado que a sedução, a inovação ou a efetivação de práticas

\footnotetext{
77 Nossa tradução do original: "It is impossible to arrive at the one truth because there is always interpretation"
} 
pedagógicas via TICs se dá pelo enfrentamento do sujeito. É disso especificamente que tratará o tópico a seguir.

\section{TICs e o ensino: novo ou novidade? Do poder invisibilizado}

Começamos este tópico apresentando sua justificativa a partir do corpus. Chamou nossa atenção a ocorrência em todos os depoimentos do morfema nov(i/o) ${ }^{78}$ compondo o determinante de um nome (p.ex.: "novos conhecimentos"), ou formando um nome (p.ex.: "inovação"), ou um verbo (p. ex.: "inovar"). Todavia, mais do que compor morficamente um sintagma, o interesse recaiu sobre o uso do morfema na composição de palavras que se referiam, de forma direta ou indireta, ao uso de práticas pedagógicas envolvendo as TICs. Vejamos o levantamento, em negrito, das ocorrências no corpus:

(A)

(...) tive a oportunidade de refletir sobre o uso das tecnologias no contexto educacional, mais especificamente na sala de aula, no que diz respeito a inovação que a prática docente precisa efetivar. Assim sendo, tive a oportunidade de aprender a lidar com as pesquisas e inovar as aulas utilizando os meios tecnológicos (...).

(B)

Portanto, vale enfatizar que a escola atual precisa urgentemente estar adaptada com as novas formas de realizar os conhecimentos de ensino na escola. $E$ para isso, o professor também deve estar preparado e capacitado para lidar com essa nova forma de executar o ensino no sistema escolar (...)aplicando esses novos conhecimentos.

\footnotetext{
${ }^{78}$ Conforme o Dicionário Eletrônico Houaiss 3.0, nov(i/o) apresenta o verbete:

"elemento de composição: antepositivo, do lat. nòvus, a,um 'novo', conexo com o gr. néos - ver ne(o)-; der. e comp. latinos: novitas,átis 'novidade, qualidade do que é novo', novo,as,ávi,átum,áre 'renovar', novátus, a,um 'feito há pouco, inventado', novátus, us 'mudança, transformação', innovo, as 'inovar; renovar', innovatìo,ónis 'renovação', renovo,as 'renovar, reparar', renovatio,ónis 'renovação', renovátor,óris 'reparador, restaurador', novella, ae 'vinha plantada de novo', novello, as 'plantar bacelos, renovar', novicius ou novitius, a,um 'que é escravo há pouco tempo, que não está acostumado (a uma coisa), noviço'; ocorre em voc. já orign. latinos, já em outros introduzidos desde as orig. do vern.: inovar, inovação; nova, novação, novador, noval, novar, novato, novedio, novel, novela, noviciado, noviciar, noviclassicismo, noviço, novidade, novidadeiro, novidão, novídeo, novilatino, novo, novobiocina, novocaína; renova, renovação, renovar, renovo"
} 
(C)

(...) sinto-me capaz de pesquisar nos sites educativos, planejar atividades e proporcionar aos educandos a utilização de práticas inovadoras(...).

(D)

(...) a própria escola deve reconhecer que é necessária a adesão de novas práticas metodológicas em sala de aula, para que haja assim, evolução. A introdução de novas linguagens, de novos modelos de ensino (...) Essa foi uma experiência que abriu-me portas rumo a novos conhecimentos (...).

Isso nos direcionou para tratar especificamente da condição do caráter de novo atribuído ao uso das TICs em sala de aula, entendida essa relação ou como "prática inovadora", ou como proponente de "novos conhecimentos" ou ainda como "nova forma de realizar o ensino". Assim, nossa discussão neste tópico persegue a ideia de uma (re)elaboração acerca do que podemos entender como novo e o que se configura como efeito de novidade.

Como foi pontuado no tópico anterior, é preciso reconhecer a importância das TICs na e para o ensino. É uma questão posta e não há retrocessos. As tecnologias estão disseminadas no cotidiano e não há como pensarmos em vida sem atrelarmo-na às TICs. Desde um simples "alô" em um longínquo lugar às movimentações financeiras empreendidas num serviço de autoatendimento de um banco, as tecnologias dominam nossas interações e são úteis à nossa vida. Todavia a questão central é entender que as tecnologias têm seu lugar, têm seus limites, primordialmente quando se referem ao âmbito educacional. Mas como o professor entenderá esse limite e como ele fará a diferença no uso das TICs?

Para isso, ele precisa deslocar-se frente ao que está posto, aos já-ditos, à condição histórica presentificada. Ele precisa, a partir do posto, propor uma "desconstrução" para alcançar uma outra dimensão acerca do uso das TICs em suas práticas pedagógicas. Uma dimensão que consiga trazer o novo para a sala de aula e não apenas o efeito de novidade que as TICs causam.

O novo só pode ser novo se o professor conseguir criar (des)identificações, se de alguma forma ele for interpelado. É na tentativa de desconstrução que o sujeito constrói uma discursividade para esse "novo", na tentativa de identificar que ele se desidentifica e proporciona outros olhares sobre o "objeto" e, por conseguinte, outros olhares para sua prática educacional. Já dizia Pêcheux que "(...) todo enunciado é intrinsecamente 
suscetível de tornar-se outro, diferente de si mesmo, se deslocar discursivamente de seu sentido para derivar outro" (1988 apud TRIFANOVAS, 2009, p. 83).

Logo cabe propor um retorno do sujeito professor à questão das tecnologias para, por meio de outros olhares, considerá-las de uma maneira diferente e singular com relação aos discursos e práticas existentes.

O retorno proposto só pode acontecer pela via do sujeito inscrito na história, porque somente ele tem a possibilidade de marcar a diferença via contexto sócio-histórico ideológico. Pela via de um sujeito desejante, pela via da singularidade, admitindo a possibilidade de um devir. Ser capaz de deslocar-se requer desse sujeito uma postura outra a partir de uma tensão que é justamente o enfretamento do sujeito com as TICs: seria para ele uma necessidade ou uma questão de (des)identificação? Ou ainda o entremeio disso?

Questionando sua posição é que será possível o sujeito professor empreender o novo. O novo é o devir - resultado de um movimento singular no plano simbólico estabelecido por uma relação de alteridade. Surge da falta, da necessidade de desconstrução. E justamente nesta perspectiva é que o professor ao utilizar as TICs pode trabalhar com o aluno: possibilitando que este crie identificações e/ou desidentificações. Este é o acesso que a escola deveria preconizar: fazer emergir no sujeito essa tensão. $\mathrm{Na}$ tensão, o sujeito de fato "inova". É preciso que haja algum tipo de identificação, de interpelação, que o simbólico aconteça para o sujeito ter uma relação diferenciada com as TICs. O oposto disso é o efeito de novidade que não surge do processo de singularização no coletivo. É apenas repetição impensada... é posição irrefletida. É apenas efeito... não ressoa.

E esse efeito de novidade, entendido pelo professor como a verdade, tem sido apontado em outros estudos, como o de Coracini (2006, p. 8) que diz "o desenvolvimento tecnológico assume, no imaginário de professores, valor de verdade e, como decorrência, a partir de um processo de naturalização, ganha o status de necessidade".

Assim, ao ganhar "status de necessidade", as TICs no ensino deixam de provocar interpelações no sujeito professor para que ele (re)crie vínculos, (des)identificações. Ao contrário, o processo de naturalização faz com que o professor se veja numa situação em que não há como refletir ou problematizar o uso das TICs, ele apenas se vê na necessidade de incorporá-las. Isso desperta nele inquietações que se instauram na alteridade: desejo de domínio versus dificuldade do domínio.

Tudo isso culmina no poder das TICs sobre o professor. Poder que "é exercido por meio de micropráticas que, em decorrência de sua constante repetição, são naturalizadas 
e passam despercebidas pelos sujeitos submetidos, tornando-se, por isso, "invisíveis" (TRIFANOVAS, 2009, p. 86)".

Ou como asseverava Foucault:

o que faz com que o poder se mantenha e que seja aceito é simplesmente que ele não pesa só como a força que diz não, mas que de fato ele permeia, produz coisas, induz ao prazer, forma saber, produz discurso" (FOUCAULT, 1979aㅗ apud MAIA, 1995)

Nessa perspectiva foucaultiana, somos levados a admitir pelos depoimentos analisados que grande é o poder exercido pelas TICs, especialmente, na esfera educacional. Poder legitimado: i) pela produção de discursos que privilegiam a ideologia do conhecimento via tecnologia; ii) pelos rituais de verdade que se originam da relação TICs e o ensino; iii) pelo não enfrentamento do professor, sua não interpelação; iv) pela não delimitação das TICs e o não reconhecimento de um papel/uma função dentre inúmeras outras que a escola pode propiciar.

Assim é que "o poder produz realidade, produz campos de objetos e rituais da verdade. O indivíduo e o conhecimento que dele se pode ter se originam nessa produção" (Foucault, 1977 apud MAIA, 1995).

\section{Considerações finais}

O objetivo desse trabalho foi problematizar algumas questões que merecem consideração posterior em análises mais detidas. O que buscávamos era evidenciar que os discursos que circulam sobre as TICs e sua relação com o ensino devem ser problematizados, devem ser (re)pensados a partir de uma noção de sujeito discursivo, inserido numa conjuntura sócio-histórica ideológica, que cria, que inova pela falta, pelo desejo, enfim, pela singularidade construída na relação com a história, com os discursos outros que coexistem, com as alteridades, operando deslocamentos, criando (des)identificações.

Acreditamos que o professor deve buscar interpelar o já-dito, provocando deslocamentos. A partir disso, será possível ao professor redimensionar, articular os sentidos do que está posto sobre o uso das TICs no ensino e ser capaz, dessa forma, de romper com os discursos que resolvemos chamar de ufânicos, fazendo emergir não apenas uma nova discursividade, mas uma nova prática, uma outra prática, uma prática diferente, produzindo (trans)formações na história. 
Estejamos comprometidos com o novo, que é da ordem do movimento do sujeito buscando singularizar-se na historicidade, e não com a novidade. Insistamos na possibilidade da diferença. Façamos o movimento de resistência, da "desconstrução derridiana" com os sentidos e discursos já dados assim como demanda o momento pósmoderno. Dispamos o poder que as TICs exercem no ensino; um poder que embora se apresente por discursos de transparência e democratizantes, aliena e transforma.

\section{Referências bibliográficas}

BARRETO, Raquel Goulart. Tecnologia e Educação: trabalho e formação docente. In: Educ. Soc. Campinas, vol. 25, n. 89, p. 1181-1201, Set./Dez. 2004. Disponível em: $<$ www.scielo.br/pdf/es/v25n89/22617.pdf>. Acesso em: 12 dez. 2010.

CORACINI, M. J. R. F. Pós-modernidade e novas tecnologias no discurso do professor de língua. In: Alfa, São Paulo, 50 (1): 7-21, 2006. Disponível em: $<$ http://seer.fclar.unesp.br/alfa/article/view/1392/1092>. Acesso em 20 jan. 2011. DERRIDA, Jacques; ROUDINESCO, Elizabeth. De que amanhã. In: SKLIAR, Carlos. A escrita na escrita: Derrida e a educação. In: SKLIAR, Carlos (Org.). Derrida e a Educação. Belo Horizonte: Autêntica, 2008.

GABILONDO, Angel. La vuelta del outro. Diferencia, identidad, alteridad. In: SKLIAR, Carlos. A escrita na escrita: Derrida e a educação. In: SKLIAR, Carlos (Org.). Derrida e a Educação. Belo Horizonte: Autêntica, 2008.

HALL, Stuart. A identidade cultural na pós-modernidade. Tradução de Tomaz Tadeu da Silva e Guaracira Lopes Louro. 11 ed. Rio de Janeiro: DP\&A, 2006.

MAIA, Antônio C. Sobre a analítica do poder de Foucault. Tempo Social; Rev. Sociol. USP, S. Paulo, 7(1-2): 83-103, outubro de 1995. Disponível em:

$<$ http://www.fflch.usp.br/sociologia/temposocial/site/images/stories/edicoes/v0712/analise1 .pdf>. Acesso em 20 jan. 2011.

ORLANDI, Eni. P. Análise do discurso: princípios e procedimentos. 8.ed. Campinas, SP: Pontes, 2009.

STAHL, Marimar M. Formação de professores para uso das novas tecnologias de comunicação e informação. In: ANDAU, V. M. (Org.). Magistério: Construção Cotidiana. Petrópolis: Vozes, 1997. Disponível em:

$<$ http://www.mvirtual.com.br/pedagogia/tecnologia/prof nitcs.doc $>$. Acesso em 20 jan. 2011.

TRIFANOVAS, T. E-mail: dispositivo sinóptico de legitimação de poder. In: Letras e Letras, v. 25, n. 2, jul./dez. 2009 - Uberlândia, Universidade Federal de Uberlândia, Instituto de Letras e Linguística.

USHER, Robin; EDWARDS, Richard. Postmodernism and education. Canada/USA: Routledge, 1996. 


\section{Anexo}

(A)

"Para mim foi um prazer participar do Curso TIC (100 HS), pois aqui tive a oportunidade de refletir sobre o uso das tecnologias no contexto educacional, mais especificamente na sala de aula, no que diz respeito a inovação que a prática docente precisa efetivar.Assim sendo, tive a oportunidade de aprender a lidar com as pesquisas e inovar as aulas utilizando os meios tecnológicos, como também desenvolver aulas atraentes com a utilização de áudios,vídeos e animações, na qual os alunos respondiam atentamente ao meio utilizado (computador), e assim ficavam motivados a executar suas tarefas. Dessa forma, cresci como profissional e acredito que hoje possuo um olhar diferente no que se refere aos meios tecnológicos e acredito que todo profissional precisa incrementar na sua prática, pois essa ferramenta precisa estar a nosso dispor no processo de ensino - aprendizagem, pois nos trás resultados surpreendentes e eficazes. Assim sendo, gostaria de agradecer a formadora do curso professora Janete Lopes que sempre esteve a nos incentivar com suas mensagens, como também aos colegas do curso."

(B)

"O curso TICs para mim, foi bastante proveitoso, pois a partir de então pode refletir sobre a minha prática pedagógica e entender a infinidade de recursos tecnológicos que temos à nossa disposição para podermos dinamizar a nossa aula. Nossa! é o máximo!!!Também foi possível compreender a importância das tecnologias no currículo escolar, ou seja, em todo o processo de ensino e aprendizagem. Além do mais, podemos perceber a necessidade que há de trabalhar com as mesmas juntamente com os alunos, pois facilita a assimilação dos conteúdos através de diversas fontes de pesquisas e buscas de novas informações. Portanto, vale enfatizar que a escola atual precisa urgentemente estar adaptada com as novas formas de realizar os conhecimentos de ensino na escola. E para isso, o professor também deve estar preparado e capacitado para lidar com essa nova forma de executar o ensino no sistema escolar. Quero ainda agradecer o autor dessa ferramenta tão importante no âmbito educacional para que a educação possa cada vez mais evoluir. Agradeço a prof. formadora Janete pelo empenho nessa formação e pela paciência que teve com nós cursista em estar tirando as nossas dúvidas e 
aplicando esses novos conhecimentos. Valeu pela força e a coragem. É dessa forma que se faz educação. "Ensinando e aprendendo".

(C)

“'Precisei superar aquela fase de ansiedade para dominar o uso das tecnologias, pois era algo que me assustava bastante. Ao término deste curso, com o apoio dos colegas da turma e da orientadora, sinto-me capaz de pesquisar nos sites educativos, planejar atividades e proporcionar aos educandos a utilização de práticas inovadoras onde a Tecnologia da Informação vai ao encontro da integração entre as pessoas, em busca do acesso e da criação do conhecimento."

(D)

"Esse curso foi de extrema importância para mim e certamente terá grande influência em minha carreira como educadora. Fez-me rever minha prática pedagógica. Através dele compreendi que a tecnologia pode ser aliada, e importante instrumento de ensino que, quando utilizado de forma correta, buscando o aprimoramento do rendimento escolar, pode gerar bons resultados no âmbito educacional. Além disso, a própria escola deve reconhecer que é necessária a adesão de novas práticas metodológicas em sala de aula, para que haja assim, evolução. A introdução de novas linguagens, de novos modelos de ensino, permite ampliar visões quanto à forma de lecionar. E é através desse processo de troca de informações, e construção de conhecimento que se dá o verdadeiro aprendizado. Essa foi uma experiência que abriu-me portas rumo a novos conhecimentos, os quais irei buscar colocar em prática." 